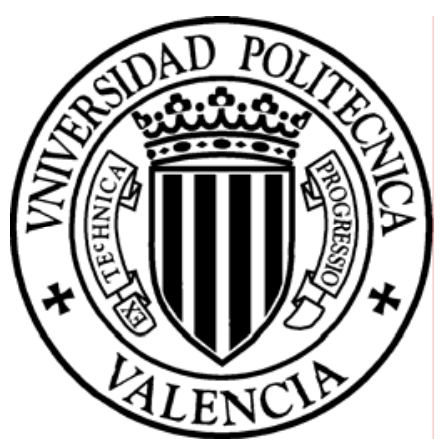

CONTRIBUCIÓN A LA CARACTERIZACIÓN EXPERIMENTAL Y AL MODELADO DE TURBINAS DE GEOMETRÍA VARIABLE EN GRUPOS DE SOBREALIMENTACIÓN

\author{
Presentada por \\ CARMEN CERVELLÓ ROMERO
}

En el

DEPARTAMENTO DE MÁQUINAS Y MOTORES TÉRMICOS de la UNIVERSIDAD POLITÉCNICA DE VALENCIA

Para la obtención del grado de

DOCTOR

Valencia, Noviembre 2004 

TESIS DOCTORAL

\section{CONTRIBUCIÓN A LA CARACTERIZACIÓN EXPERIMENTAL Y AL MODELADO DE TURBINAS DEGEOMETRÍA VARIABLE EN GRUPOS DE SOBREALIMENTACIÓN}

Realizada por: $\quad D^{\mathrm{a}}$. Carmen Cervelló Romero

Dirigida por: Dr. D. José Ramón Serrano Cruz

TRIBUNAL CALIFICADOR

Presidente: $\quad$ Dr. D. Francisco Payri González

Secretario: $\quad$ Dr. D. José Manuel Luján Martínez

Vocales: Dr. D. Ricardo Martínez-Botas

Dr. D. Octavio Armas Vergel

Dr. D. Francisco V. Tinaut Fluixá

Vocales Suplentes:

Dr. D. Magín Lapuerta Amigo

Dr. D. Andrés Melgar Bachiller

Dr. D. Jose Galindo Lucas

Dr. D. Jose $\mathrm{M}^{\mathrm{a}}$ Desantes Fernández

Dr. D. Francisco Castro Ruiz 



\section{Resumen}

La incorporación generalizada de los sistemas de sobrealimentación a los motores diesel de automoción está haciendo imprescindible desarrollar un nivel de investigación capaz de profundizar en los factores que influyen en el funcionamiento y rendimiento de los turbogrupos acoplados a los motores de combustión interna alternativos.

En esta tesis se presentan dos herramientas que van a permitir progresar en el estudio de los turbogrupos y en especial en las turbinas de geometría variable. En primer lugar se muestra como se ha diseñado y construido un banco de ensayo de turbogrupos, que permite un conocimiento más amplio, a partir de medidas experimentales, sobre los fenómenos físicos que ocurren en una turbina tanto en condiciones de diseño como fuera de ellas. Este conocimiento del comportamiento fluidodinámico de la turbina va a ser de gran ayuda en el desarrollo de modelos.

En la segunda parte de la tesis se presenta un modelo unidimensional fluidodinámico para turbinas radiales de geometria variable. Este modelo ha sido implementado en un modelo de acción de ondas, que reproduce el comportamiento fluidodinámico de motores de combustión interna alternativos. El modelo ha sido validado en el banco de ensayo descrito en la primera parte de la tesis y para turbinas acopladas a un grupo de sobrealimentación de motores diesel tanto en comportamiento estacionario como transitorio del motor.

\section{Resum}

La incorporació generalitzada dels sistemes de sobrealimentació als motors dièsel d'automoció està fent imprescindible desenvolupar un nivell d'investigació capaç de profunditzar en aquells factors que influeixen en el funcionament $i$ el rendiment dels turbogrups acoblats als motors de combustió interna alternatius.

En esta tesis es presenten dos ferramentes que van a permetre progressar en l'estudi dels turbogrups i en especial de les turbines de geometria variable. En primer lloc es mostra com s'ha dissenyat i construït un banc d'assajos de turbogrups, que permet un coneixement més ampli, a parti de mesures experimentals, d'aquells fenomens fisics que ocorren en una turbina en condicions de treball de disseny o fora d'elles. Este coneixement del comportament fluidodinàmic de la turbina va a ser de gran ajuda a l'hora de desenvolupar models teòrics.

En la segona part de la tesis es presenta un model unidimensional fluidodinàmic per a turbines radials de geometria variable. Este model ha sigut implementat en un model d'acció d'ones, que reprodueix el comportament fluidodinàmic de motors de combustió interna alternatius. E1 model ha sigut validat en el banc d'assajos descrit en la primera part de la tesis i per a turbines acoblades a grups de sobrealimentació de motors dièsel, tan en comportament estacionari com transitori del motor. 


\section{Abstract}

The generalized incorporation of the turbocharging to the automotive diesel engines makes essential to develop an investigation level able to deepen in the parameters that influence the performance and the efficiency of the turbochargers fitted to internal combustion engines.

In this thesis are presented two different tools, which allow the improvement of the knowledge about turbochargers, and specifically variable geometric turbines. Firstly, the thesis shows the design and the construction of a turbocharger test bench which allows a wider knowledge, as much theoretical as experimental, about the physical phenomena that happen in design conditions or other conditions. This knowledge about the fluiddynamic behaviour will held the model development.

In the second part of this thesis, a uni-dimensional fluid-dynamic model to calculate radial variable geometric turbines is presented. This model has been set up in a wave action model which reproduces the fluid-dynamic behaviour of reciprocating internal combustion engines. The model has been checked with experimental data obtained in the test bench developed in the first part of this work and in steady and transient engine conditions. 
A Salva i Mari....

A Jose...

Als meus germans....

A la meua família

-iii- 
-iv- 


\section{Agradecimientos}

Quiero agradecer el apoyo, la ayuda y la paciencia que mi director de tesis José Ramón Serrano Cruz me ha brindado en todos estos años de labor investigadora en el departamento de Máquinas y Motores Térmicos.

También me gustaria extender estos agradecimientos José Galindo y José Manuel Luján, los otros jefes de Renova, así como a los responsables de este departamento que me han permitido presentar la tesis que se recoge en este documento.

Muy especialmente me gustaria dar las gracias a Fran, con quien compartí mi primer despacho y un par de turbos; a Anabelis, por ser una amiga y no solo una compañera; a Paco y Vicente, con los que he compartido mis otros despachos, millones de horas de música y más de uno y de dos informes, gracias chicos por haberme tratado siempre tan bien. A javidom por todos esos programillas que tenemos a medias, a Antonio por echarme una mano, o las dos, con los cálculos 3D. Al Pibe y a Tania, por a ayudarme a medir en el labo. A Héctor, por modelar conmigo el compresor de tornillo, gracias y a Josevi, por ayudarme a modelar la turbina con matlab, gracias puñales, no creas que no me acuerdo. A Litos, por ayudarme con las FFTs y a Benjamín, a Jose Manuel, a Ali, a Xemari, a Leo, a Elena, a David, a Inma..... a todos, muchas gracias por todo!

No quisiera olvidarme de todos los proyectandos que han trabajado conmigo ni de todos aquellos con los que he compartido despacho, gracias chic@s, esto también es un poquito cosa vuestra.

Muy especialmente quiero dar las gracias a mis chicos del Halcón Milenario, ;), Papa Miguel, Valentín, Eusebio, Paco, Miguel C, Fito, Berni, Danilo, Teo, Juanjo y todos los panchos que por alli han pasado, por todos los buenos ratos, porque sin vosotros medir no hubiera sido lo mismo, gracias! 
-vi- 


\section{INDICE}

CAPÍTULO 1: INTRODUCCIÓN .................................................. 1

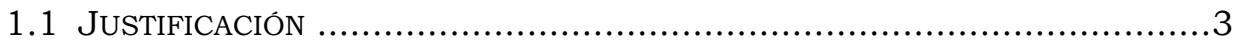

1.1.1 Ventajas e inconvenientes de la turbosobrealimentación.........3

1.1.2 Necesidad del modelado de turbinas centripetas .................. 5

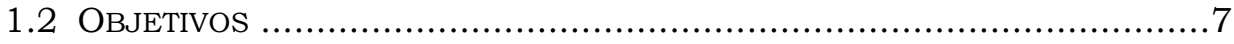

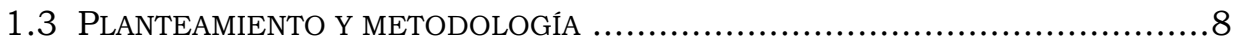

\section{CAPÍTULO 2: DISEÑO Y PUESTA A PUNTO DE UN BANCO ESPECÍfICO}

PARA EL ENSAYO DE TURBOGRUPOS..................................... 11

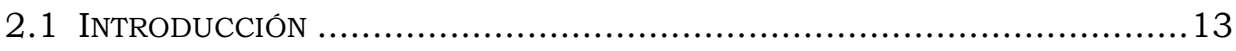

2.2 INSTALACIONES EXISTENTES EN LA BIBLIOGRAFÍA ............................. 15

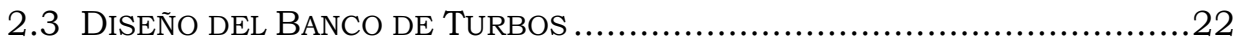

2.3.1 Objetivos ..................................................................... 22

2.3.2 Descripción del diseño ....................................................23

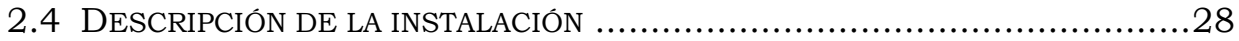

2.4.1 Elementos que controlan el flujo de gas por la turbina..........28 
2.4.2 Elementos que controlan el flujo de aire por el compresor .... 41

2.4.3 Linea de potencia de la instalación ....................................... 43

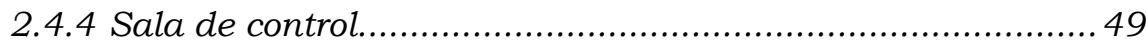

2.5 VARIABLES OPERATIVAS DE LA INSTALACIÓN ..................................... 51

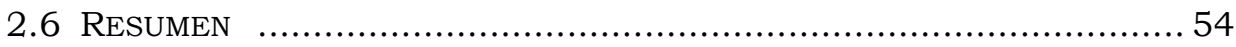

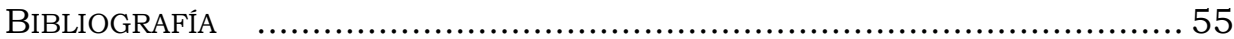

CAPÍTULO 3: DISEÑO Y PUESTA A PUNTO DE UN PROCEDIMIENTO DE MEDIDA PARA LA CARACTERIZACIÓN DE TURBOGRUPOS.................57

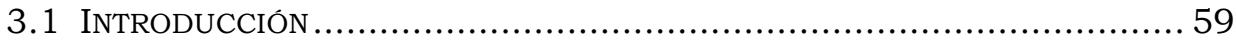

3.2 OBTENCIÓN DE LAS VARIABLES FUNDAMENTALES DEL TURBOGRUPO ......... 60

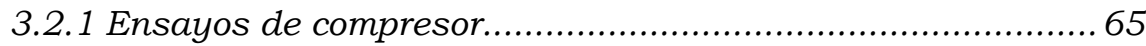

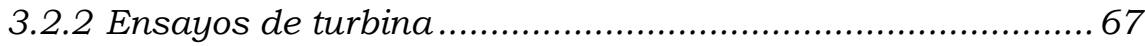

3.3 MEdidA DE LAS VARIABLES FUNDAMENTALES DEL TURBOGRUPO .............. 70

3.3.1 Análisis de la normativa existente ..................................... 70

3.3.2 Descripción de elementos y transductores usados en el procedimiento de medida................................................. 74

3.3.3 Descripción del sistema de adquisición de datos y control de la instalación: SAMARUC................................................... 91

3.4 OBTENCIÓN DEL MAPA DE FUNCIONAMIENTO DEL TURBOGRUPO …........... 95

3.4.1 Análisis de la normativa existente ..................................... 95

3.4.2 Estudio de estabilización de las variables ........................... 97

3.4.3 Mapa de un compresor .................................................. 102

3.4.4 Criterio para discriminar los puntos de bombeo .................. 106

3.4.5 Mapa de una turbina: Análisis y elaboración del mapa de funcionamiento de una turbina....................................... 121

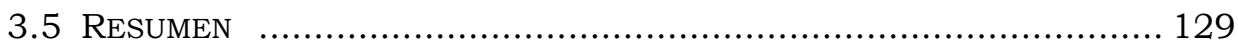

ANEXo 1: CÁlCULO DE LAS INCERTIDUMBRES DE LAS MEDIDAS. ................. 131

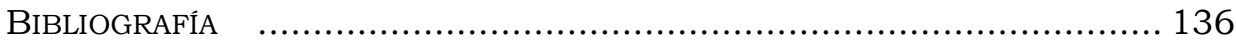




\section{CAPÍTULO 4: MODELADO UNIDIMENSIONAL DE TURBINAS DE GEOMETRÍA VARIABLE (TGV)}

4.1 INTRODUCCIÓN 141

4.2 REVISIÓN DE LOS MODELOS UNIDIMENSIONALES EXISTENTES DE TURBINAS

RADIALES 142

4.2.1 Modelado de turbinas radiales de geometria fija 142

4.2.2 Modelado de turbinas radiales de geometría variable 148

4.3 MEJORA DE Un MODELO EXISTENTE DE TURBINA RADIAL DE GEOMETRÍA FIJA 152

4.4 NuEVO MOdElo PARA TURBINAS DE GEOMETRÍA VARIABLE (TGV) 156

4.4.1 Descripción de las TGV.......................................... 156

4.4.2 Cálculo del grado de reacción de una TGV.......................158

4.4.3 Cálculo de la presión a la salida del estator ....................161

4.5 RESUMEN ....................................................... 174

BIBLIOGRAFÍA $\quad$........................................................... 176

\section{CAPÍTULO 5: VALIDACIÓN DEL MODELO DE TURBINAS DE GEOMETRÍA}

5.1 INTRODUCCIÓN

5.1.1 Descripción del modelo de acción de ondas utilizado 181

5.2 VALIDACIÓN DEL MODELO CON ENSAYOS DE FLUJO NO ESTACIONARIO EN EL BANCO DE TURBOS 186

5.2.1 Modelado de la instalación en condiciones de flujo estacionario 186

5.2.2 Interacción medido-modelado para el modelado bajo condiciones de flujo no estacionario.

5.3 VALIDACIÓN DEL MODELO CON ENSAYOS EN BANCO MOTOR 207

5.3.1 Validación del modelo para TGV de álabes fijos. 207

5.3.2 Validación del modelo para TGV de álabes móviles. 217

ANEXO 1: TABLAS DE MEDIDAS 243

BIBLIOGRAFÍA 253 


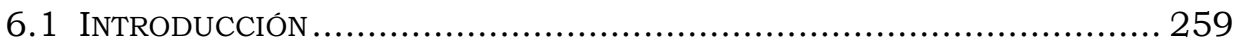

6.2 NUEVA INSTALACIÓN PARA LA CARACTERIZACIÓN DE TURBOGRUPOS....... 260

6.2.1 Conclusiones acerca del ensayo de un turbogrupo ..............261

6.2.2 Comportamiento del compresor en bombeo........................263

6.3 NUEVO MODELO UNIDIMENSIONAL PARA TURBINAS DE GEOMETRÍA VARIABLE

6.3.1 Modelado de la instalación..................................................266

6.3.2 Validación del modelo en ensayos de motor ......................267

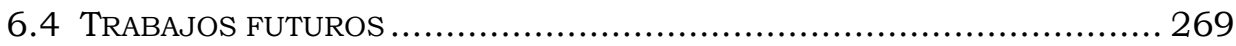




\section{LISTA DE SÍMBOLOS}

Latinos

$\begin{array}{cl}\text { a } & \text { Velocidad del sonido } \\ \mathrm{a}_{\mathrm{n}} & \text { Amplitud de las funciones armónicas de la transformada de } \\ & \text { Fourier } \\ \mathrm{A} & \text { Area } \\ \mathrm{A}_{\mathrm{n}} & \text { Amplitud de las funciones armónicas de la transformada de } \\ & \text { Fourier } \\ \mathrm{A} / \mathrm{F} & \text { Relación aire combustible } \\ \mathrm{b}_{\mathrm{n}} & \text { Amplitud de las funciones armónicas de la transformada de } \\ & \text { Fourier } \\ \mathrm{c} & \text { Velocidad } \\ \mathrm{Cp} & \text { Calor específico, para un proceso a presión constante } \\ \mathrm{D} & \text { Diámetro } \\ \mathrm{F} & \text { Fuel } \\ \mathrm{Fp} & \text { Factor de pulsación } \\ \mathrm{f}_{\mathrm{S}} & \text { Frecuencia de muestreo de una señal instantánea. } \\ \mathrm{h} & \text { Entalpía } \\ \dot{m} & \text { Gasto másico } \\ \mathrm{N} & \text { Régimen de giro del turbogrupo } \\ \mathrm{n} & \text { Régimen de giro del motor } \\ \mathrm{p} & \text { Presión } \\ \mathrm{R} & \text { Constante universal de los gases } \\ \mathrm{R} & \text { Grado de reacción }\end{array}$




$\begin{array}{cl}\mathrm{r}_{\mathrm{c}} & \text { Relación de compresión } \\ \mathrm{r}_{\mathrm{exp}} & \text { Relación de expansión } \\ \mathrm{rtc} & \text { Régimen de giro del turbogrupo } \\ \mathrm{T} & \text { Temperatura } \\ \mathrm{T} & \text { Par } \\ \mathrm{T} & \text { Periodo de muestreo de una señal instantánea } \\ \mathrm{u} & \text { Velocidad } \\ \mathrm{W} & \text { Trabajo } \\ \mathrm{Z} & \text { Numero de cilindros }\end{array}$

Griegos

$\gamma \quad$ Relación de calores específicos $\left(c_{p} / c_{v}\right)$

$\alpha \quad \%$ de acelerador o Throtle

$\eta \quad$ Rendimiento

$\varphi_{\mathrm{n}} \quad$ En las series de Fourier indica la fase.

$\omega \quad$ En las series de Fourier indica frecuencia.

Subíndices y superindices

$0 \quad$ Indica condiciones de parada

adm Admisión

ef Efectiva

est Estator

BB Blow by

C Compresor

E Entrada

f Combustible

int Indica valor instantáneo

max Indica valor máximo de una variable

med Indica valor medio de una variable

min Indica valor mínimo de una variable

REF Indica variable de referencia

rod Rodete

rot Rotor

s Salida

s Indica evolución isoentrópica

T Turbina

* Indica variable corregida

Siglas

ECU

ELR

Unidad de control electrónica (Electronic Control Unit)

PID Proporcional Integral Derivativo

TGV Turbina de geometría variable

CGV Compresor de geometría variable 


\section{Capitulo 1: Introducción}

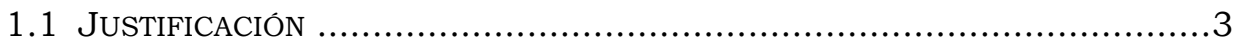

1.1.1 Ventajas e inconvenientes de la turbosobrealimentación............................3

1.1.2 Necesidad del modelado de turbinas centrípetas ......................................5

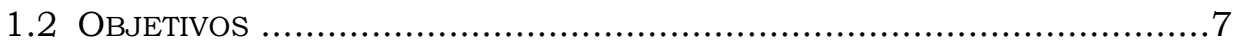

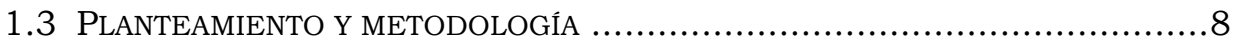





\subsection{Justificación}

Los motores diesel están teniendo en los últimos años un gran protagonismo en el sector de automoción tanto de vehículos ligeros como pesados, siendo posible afirmar que nos encontramos ante un cambio drástico en los patrones de uso de los motores de combustión interna, equiparándose el uso de motores de ciclo Diese y de ciclo Otto en vehículos ligeros, originado como consecuencia de la legislación vigente, cada vez más restrictiva en cuanto a los niveles de emisiones contaminantes. Los avances técnicos logrados gracias a las nuevas técnicas experimentales y teóricas hacen que sea posible cumplir la legislación y los requerimientos del usuario, cada vez más exigente en términos de prestaciones, manejo agradable y confort.

Prácticamente la totalidad de los motores diesel de automoción desarrollados en la actualidad son sobrealimentados y para el correcto funcionamiento de los turbogrupos, éstos deben de estar bien acoplados con el motor. Es por ello que se hace necesario el desarrollo de instalaciones experimentales, impulsadas con el fin de profundizar en el estudio de los factores que influyen en el funcionamiento y rendimiento de los turbogrupos utilizados para la sobrealimentación de motores de encendido por compresión. Estas instalaciones han de ser versátiles y fiables, capaces de proporcionar información útil y muy amplia de las turbinas y los compresores ensayados, de manera que permitan profundizar en el conocimiento de los procesos físicos que ocurren con el flujo en el interior de las turbomáquinas.

El desarrollo de modelos simples capaces de reproducir el comportamiento de los motores de combustión interna alternativos sobrealimentados se hace cada día más necesario, ya que son una ayuda imprescindible para el diseño de motores y complementaria a los ensayos, que está permitiendo acelerar de forma muy importante el desarrollo de los motores. Éstos siguen evolucionando a medida que comprendemos mejor los fenómenos físicos involucrados durante los procesos que se dan en el motor y es previsible que sigan siendo cada vez más una herramienta importante que sirva como ayuda al diseño de motores. Así pues, el correcto modelado físico tanto de la fluidodinámica como del comportamiento energético de los sistemas de sobrealimentación se hace necesario para completar los modelos globales de motor y se convierte en una poderosa herramienta para el diseño de estrategias de control, que pueden ser implementadas electrónicamente con el fin de obtener mejoras considerables en el comportamiento del motor.

\subsubsection{Ventajas e inconvenientes de la turbosobrealimentación}

La sobrealimentación de motores de combustión interna alternativos consiste en el aumento de la densidad del aire de admisión por medio de un aumento de presión. Este aumento de densidad a la entrada del motor 
permite aumentar el gasto másico de aire o mezcla a través del motor para una cilindrada determinada. El aumento de la presión en el colector de admisión se consigue mediante un compresor.

Este aumento de gasto de aire se puede acompañar de un aumento del gasto de combustible que quema el motor. Si consideramos que el rendimiento efectivo del motor no se ve afectado, en primera aproximación es cierto, esto va a conducir a un aumento proporcional de la potencia del motor.

En los últimos años la evolución de la presión de sobrealimentación, en los motores destinados a la automoción, ha sido muy rápida. Poder aumentar la presión de sobrealimentación también favorece los procesos de mezcla y combustión, con lo que cuanto más alta es la presión de sobrealimentación mayor puede ser el dosado límite.

También presenta ventajas en puntos de muy baja carga para reducir las emisiones de $\mathrm{HC}$ y $\mathrm{CO}$, puesto que un aumento de la densidad del aire de admisión permite reducir el choque combustible-pared, lo que favorece la evaporación y el encendido.

Además hay que tener en cuenta que los valores limites de emisiones contaminantes permitidos por la legislación vigente se evalúan en $\mathrm{g} / \mathrm{kWh}$ para los motores diesel de transporte pesado, de modo que toda técnica que permita elevar la potencia del motor en un determinado grado sin aumentar la cantidad de sustancias contaminantes, hará disminuir el nivel de emisiones expresado en las unidades antes mencionadas.

En concreto, la sobrealimentación por turbina de escape presenta las ventajas de su reducido peso y tamaño, por la elevada potencia específica de las máquinas empleadas, y además, como la turbina de escape aprovecha una energía que de otra manera se habría enviado a la atmósfera, se va a producir casi en todos los casos un aumento del rendimiento efectivo del motor.

En motores de automoción, para bajo régimen de giro del motor se necesita una turbina que para un gasto másico pequeño tenga una elevada relación de expansión (sección efectiva de paso de los gases de escape pequeña), para que dé la suficiente potencia como para satisfacer los requerimientos del compresor. En cambio, a alto régimen una turbina con mayor sección efectiva ya da la suficiente potencia. Por tanto una turbina no se adapta correctamente a todas las condiciones de funcionamiento del motor. Para solucionar este problema se pueden utilizar turbinas de geometría variable que pueden variar la sección efectiva de paso del flujo de gases o turbinas de geometría fija con válvula de wastegate. Este segundo tipo de turbinas se adaptan a las necesidades del motor a bajo régimen y cuando la presión de admisión alcanza un determinado valor actúa una 
válvula que desvía los gases de escape hacia el exterior sin pasar por la turbina.

Sin embargo, la turbosobrealimentación introduce una serie de inconvenientes que es necesario tener en cuenta, en primer lugar el acoplamiento fluidodinámico entre el motor y el grupo de sobrealimentación no es fácil ya que son dos máquinas muy diferentes. La principal diferencia es que las turbomáquinas están diseñadas para trabajar en condiciones estacionarias con flujo continuo, mientras que el motor alternativo opera en una amplia gama de gastos másicos y relaciones de presiones, en flujo esencialmente discontinuo.

Además, la energía disponible en los gases de escape es menor a bajo régimen y baja carga, por lo que la curva de par será creciente con el régimen de giro, lo cual no es favorable para los vehículos de tracción.

Hay que tener en cuenta también que durante los transitorios de aceleración o de aumento rápido de la carga del motor, el grupo de sobrealimentación va a tener un retraso relacionado con la inercia del grupo de sobrealimentación y con la llegada de la energía necesaria a la turbina.

La energía en los gases de escape de un motor de combustión interna alternativo se va a presentar en dos formas, energía térmica (presión y temperatura) y energía cinética, así pues el diseño del sistema de escape va a ser fundamental para obtener el mayor aprovechamiento de la energía de escape.

La potencia generada por la turbina de escape vendrá dada por el salto de presiones entre las condiciones aguas arriba y aguas abajo de la turbina. Esto se traduce en un aumento de contrapresión de escape y, por lo tanto, en una disminución del rendimiento efectivo del motor. Sin embargo, la presión de admisión también se eleva por efecto del compresor de manera que, en el caso de los motores utilizados en los vehículos de transporte pesado (salvo a baja carga y bajo régimen), la presión de admisión va a ser superior a la de escape, por lo que el trabajo de bombeo será positivo.

Por último, la aplicación de la sobrealimentación por turbina de escape conduce en los motores de encendido provocado a un mayor riesgo de detonación.

\subsubsection{Necesidad del modelado de turbinas centripetas}

De los diferentes modelos desarrollados para el cálculo de los procesos de intercambio de gases en motores de combustión interna los modelos de acción de ondas, basados en la hipótesis de flujo unidimensional, han sido y son ampliamente utilizados para predecir el comportamiento de motores, teniendo en cuenta los sistemas de admisión y escape. 
Estos modelos unidimensionales integran las ecuaciones diferenciales que describen el comportamiento del flujo a través de los tubos y tienen en cuenta fenómenos que afectan al flujo tales como la fricción, la transferencia de calor, cambios en la sección, interacciones entre diferentes ondas de presión, etc. Por lo tanto estos esquemas de cálculo son muy precisos en regiones de los sistemas de admisión y escape, pero también han de hacer frente a elementos complejos donde la hipótesis de flujo unidimensional no es válida y donde se dan comportamientos del flujo claramente no unidimensionales.

Es por ello que es necesario introducir submodelos específicos para calcular el comportamiento del flujo en y a través de estos elementos. En algunos casos el submodelo puede ser tan simple como una condición de contorno impuesta por el valor de una determinada variable. En otros casos el comportamiento puede ser más complejo y debe establecerse un submodelo completo, basado en hipótesis específicas y en valores experimentales.

Un importante caso entre estos elementos es el turbogrupo en un motor sobrealimentado, que está formado por una turbina, un compresor y, en alguna ocasiones, por un mecanismo regulador de ambos (válvula de wastegate, TGV, CGV...). El primer elemento que es necesario modelar es la turbina, puesto que el cálculo del trabajo mecánico que produce es un dato de entrada para calcular el comportamiento del compresor.

El correcto modelado de la turbina de un grupo de sobrealimentación de un motor de combustión interna es una parte importante y compleja del modelo, necesaria para desarrollar un modelo global del motor.

El cálculo y modelado del comportamiento global de la turbina debe tener en cuenta dos características fundamentarles:

- El comportamiento fluidodinámico de los gases, esto es, el establecimiento de la condición de contorno en el extremo del colector de escape, que tendrá que calcular la correcta interacción dinámica entre los cilindros y la turbina y también la evolución del flujo aguas abajo de la turbina hacia el resto del sistema de escape.

- La conversión de la energía, esto es, la producción del trabajo mecánico a partir de la expansión del gas a través del estator y del rotor de la turbina. Este trabajo será el que el compresor tendrá disponible y habrá que hacer un balance entre el trabajo producido por la turbina y el que absorba el compresor. El punto de funcionamiento puede ser establecido entonces, y por lo tanto se fijan las condiciones de contorno del flujo a la entrada del motor. 


\subsection{Objetivos}

El objetivo principal que justifica la realización de este trabajo es el desarrollo de un modelo unidimensional para turbinas de geometría variable, que pueda ser acoplado a un modelo general de motor, con el fin de completarlo. Para que este modelo sea útil, ha de ser capaz de reproducir el comportamiento fluido-energético de la turbina.

El correcto modelado físico de la fluidodinámica y el comportamiento energético de la turbina de geometría variable es una poderosa herramienta para el correcto diseño de estrategias de control, las cuales pueden ser implementadas electrónicamente con el fin de obtener mejoras tanto en el comportamiento en transitorio como en el comportamiento en estacionario del motor.

De un modo más general, el modelado de una turbina de geometría variable proporciona un mejor conocimiento de los fenómenos físicos que aparecen en la interacción entre turbocompresores y motores de combustión interna alternativos.

Con el fin de obtener las medidas necesarias para el desarrollo y la validación del modelo hace necesario diseñar y construir una nueva instalación experimental. Es por ello que tanto la puesta en funcionamiento del sistema de medida como la validación de la metodología propuesta se convierten en un objetivo en sí mismo del trabajo.

Se ha pretendido construir un banco de ensayo de turbogrupos de tal modo que se disponga de una herramienta experimental capaz de reproducir las condiciones del flujo a la entrada de la turbina y el compresor lo más cercanas posible a las existentes cuando el turbogrupo trabaja acoplado a un motor de combustión interna alternativo, pero en condiciones de funcionamiento controladas, para obtener medidas que sean útiles a la hora de desarrollar el modelado unidimensional de turbinas radiales.

Así pues, el principal objetivo experimental del presente trabajo es diseñar, montar y explotar científico-técnicamente una instalación versátil y fiable, capaz de proporcionar información útil y lo más amplia posible de las turbinas y los compresores ensayados, tanto para los fabricantes de motores como para aquellos que se dedican a la investigación y mejora de motores de combustión interna alternativos, turbogrupos y de su funcionamiento cuando ambos están acoplados. 


\subsection{Planteamiento y metodologia}

La metodología seguida hasta finalizar el trabajo que ahora se presenta ha sido la que se describe a continuación.

En una primera etapa se diseña y monta una instalación experimental destinada exclusivamente al ensayo y a la caracterización fluidodinámica de turbogrupos destinados a la sobrealimentación de motores de combustión interna alternativos, herramienta fundamental para la caracterización de turbinas y para obtener medidas que faciliten el estudio y modelado de las mismas. Esta instalación se describe en el capítulo 2, en el que se realiza una exhaustiva descripción de todos y cada uno de los elementos que forman el banco específico para el ensayo de turbogrupos o Banco de Turbos.

A continuación, en el capítulo 3 , se diseña y pone a punto un procedimiento de medida para la caracterización en el banco de ensayo de los turbogrupos. En este capítulo se describe cómo alcanzar un determinado punto de funcionamiento, esto es, el proceso para llegar al punto de medida deseado. Para ello se distinguen dos casos, las medidas de los puntos de funcionamiento del compresor y las medidas de los puntos de funcionamiento de la turbina. En este capítulo también se realiza una revisión sobre la normativa existente para la realización de medidas para la caracterización de turbogrupos y se describen tanto la elección y la situación de los puntos de medida como la instrumentación utilizada para la realización de dichas medidas.

Al final del capítulo se realizará una revisión del tratamiento de las medidas para poder obtener los mapas de funcionamiento del turbogrupo, la normalización de las medidas a partir de la normativa existente, la obtención de la variables termodinámicas de funcionamiento del turbogrupo, así como el desarrollo de un método para discriminar los puntos de bombeo del compresor frente a los puntos de funcionamiento estable.

Una vez que se dispone de una potente herramienta capaz de proporcionar medidas experimentales precisas se desarrolla un modelo unidimensional para turbinas de geometría variable.

En primer lugar se realiza una revisión bibliográfica de los modelos de turbinas radiales existentes, distinguiendo entre los modelos aplicables a turbinas radiales de geometría fija y los aplicables a turbinas radiales de geometría variable. Esta revisión bibliográfica se desarrolla al inicio del capítulo 4 .

A continuación se lleva a cabo la ampliación de un modelo de turbina de geometría fija existente y el desarrollo de un nuevo modelo de turbinas de 
geometría variable, tanto de álabes fijos como móviles en el estator. Estos modelos, se presentan en el capítulo 4.

En el capítulo 5, se valida el modelo presentado en el capítulo anterior. Esta validación se realiza de tres formas distintas. En primer lugar se realiza un modelado completo de la instalación descrita en el capítulo 2, en el que se incluye el modelo de turbina de geometría variable presentado. La validación de este modelado permite obtener información de variables termodinámicas que no es posible medir en la instalación, como son las temperaturas instantáneas.

Al final del capítulo se presentan resultados del modelado completo de dos motores de combustión interna alternativos con turbogrupos movidos por una turbina de geometría variable. En primer lugar se modela el comportamiento estacionario de una turbina de geometría variable con posición angular fija en los álabes del estator, la cual está acoplada a un turbogrupo de un motor diesel extrarápido de pequeña cilindrada (2.2 1.). En segundo lugar se modela el transitorio de carga de un gran motor diesel destinado al transporte pesado (11 1.), sobrealimentado con un turbogrupo con turbina de álabes móviles en el estator. 
Contribución a la caracterización experimental y modelado de TGV en grupos de sobrealimentación 


\section{Capitulo 2: Diseño y puesta a punto de un banco especifico para el ensayo de turbogrupos}

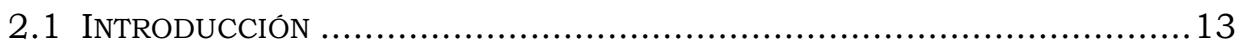

2.2 InSTALACIONES EXISTENTES EN LA BIBLIOGRAFÍA ............................... 15

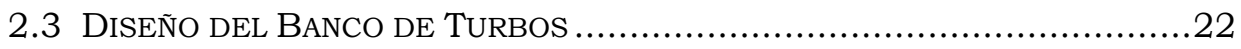

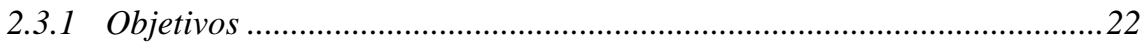

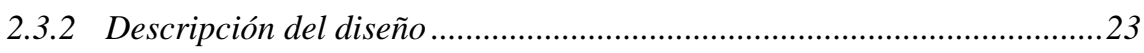

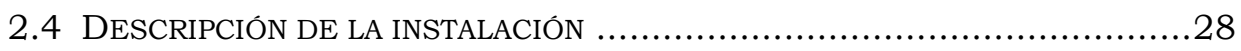

2.4.1 Elementos que controlan el flujo de gas por la turbina ..............................28

2.4.2 Elementos que controlan el flujo de aire por el compresor .......................41

2.4.3 Línea de potencia de la instalación.............................................................43

2.4.4 Sala de control .........................................................................................49

2.5 VARIABLES OPERATIVAS DE LA INSTALACIÓN.......................................51

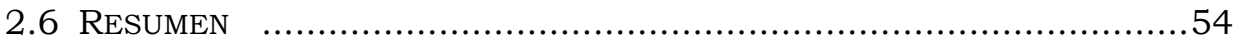

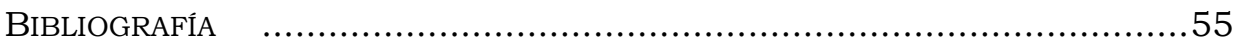





\subsection{Introducción}

En la segunda parte de esta tesis se describirá un modelo unidimensional capaz de reproducir el comportamiento fluidodinámico de una turbina radial trabajando acoplada a un motor de combustión interna alternativo. Al presentar este modelo y el resto de los modelos existentes en la bibliografia quedará constancia de la necesidad de tener datos experimentales para validarlos. En algunos casos, incluso será posible observar cómo algunos investigadores [7][8] no pueden validar los modelos que presentan por falta de información experimental y, sobre todo, se verá la necesidad de medidas para que los modelos existentes puedan seguir evolucionando conforme se conozca más y mejor los procesos físicos que ocurren con el flujo en el interior de las turbomáquinas.

La tradición aeronáutica asociada a los turbogrupos hace que los fabricantes los diseñen, y ensayen de forma diferente a las condiciones de trabajo de estas turbomáquinas cuando están acopladas a un motor de combustión interna alternativo. Se limitan a ensayar sus turbinas con flujo continuo, cuando el flujo que las alimenta al estar acopladas al motor es de carácter pulsante, o ensayan los compresores a partir de regímenes de giro en los que el rendimiento es elevado, no ofreciendo información del comportamiento del compresor para bajos regímenes de giro, información que es absolutamente necesaria en el estudio de motores sobrealimentados para modelar y desarrollar los mismos, especialmente en comportamiento transitorio. Como conclusión se desprende que la información proporcionada por los fabricantes de turbogrupos requiere ser completada cuando éstos trabajan acoplados a un motor.

En este capítulo se presenta una instalación experimental desarrollada con el fin de profundizar en el estudio de los factores que influyen en el funcionamiento y rendimiento de los turbogrupos utilizados para la sobrealimentación de motores de encendido por compresión. Esta instalación es versátil y fiable, capaz de proporcionar información útil y muy amplia de las turbinas y los compresores ensayados, tanto para los fabricantes de motores como para aquellos que se dedican a la investigación y mejora de motores de combustión interna alternativos, de turbogrupos y de su funcionamiento cuando ambos están acoplados.

La instalación es capaz de generar flujo para poder ensayar turbogrupos en las mismas condiciones en las que trabajarian cuando están acoplados a un motor. Está preparada para medir mapas de funcionamiento de la turbina, tanto en condiciones de flujo continuo como de flujo pulsante y para completar los mapas de compresor proporcionados por los fabricantes, sobre todo en las zonas de menores regímenes de giro de turbogrupo. 
La instalación está dotada de todos los elementos de medida necesarios, instrumentación y técnicas de adquisición de datos de última generación para la realización de las medidas adecuadas para obtener los puntos de funcionamiento de las turbinas y compresores que en ella se ensayan. De este modo posibilitará un conocimiento más amplio, tanto teórico como experimental, sobre los fenómenos fisicos que ocurren en una turbina o en un compresor de un grupo de sobrealimentación, tanto en condiciones de diseño como fuera de ellas. Este conocimiento del comportamiento fluidodinámico del turbogrupo va a ser de gran ayuda en el desarrollo de modelos de turbinas y compresores y en el diseño de estrategias de control y acoplamiento del turbogrupo en los motores de combustión interna alternativos. 


\subsection{Instalaciones existentes en la bibliografia}

Desde 1986 se encuentran en la bibliografia al menos seis instalaciones con objetivos similares a los que se plantean a lo largo de este trabajo. Para la instalación que se ha desarrollado se ha intentado aprovechar los aspectos positivos que en ellas se presentan y solucionar los problemas e inconvenientes de estas instalaciones precedentes.

Una de las primeras instalaciones (figura 2. 1) la presentan Dale y Watson en 1986 [2] En ella se utiliza un compresor de tornillo eléctrico (0.5 $\mathrm{kg} / \mathrm{s}$, 4 bar) cuyo caudal másico se hace pasar por un calentador eléctrico (60 $\mathrm{kW}$ ) para que el flujo de aire que llega a la entrada de la turbina alcance temperaturas de hasta $400 \mathrm{~K}$ y evitar que el vapor de agua existente pueda condensar en su expansión a través de la turbina. En esta instalación, para controlar el régimen de giro de la turbina, se utiliza un dinamómetro no comercial desarrollado para el proyecto que se describe en el artículo. Este dinamómetro es capaz de absorber $24 \mathrm{~kW}$, lo que limita el rango de ensayos de la turbina, ya que la elección del máximo régimen de giro del eje de la turbina está dada por un compromiso entre las consideraciones dinámicas del rotor del dinamómetro y la necesidad de medir a regímenes de giro equivalentes a los de máximo par del motor térmico al que va acoplado la turbina que se está ensayando.

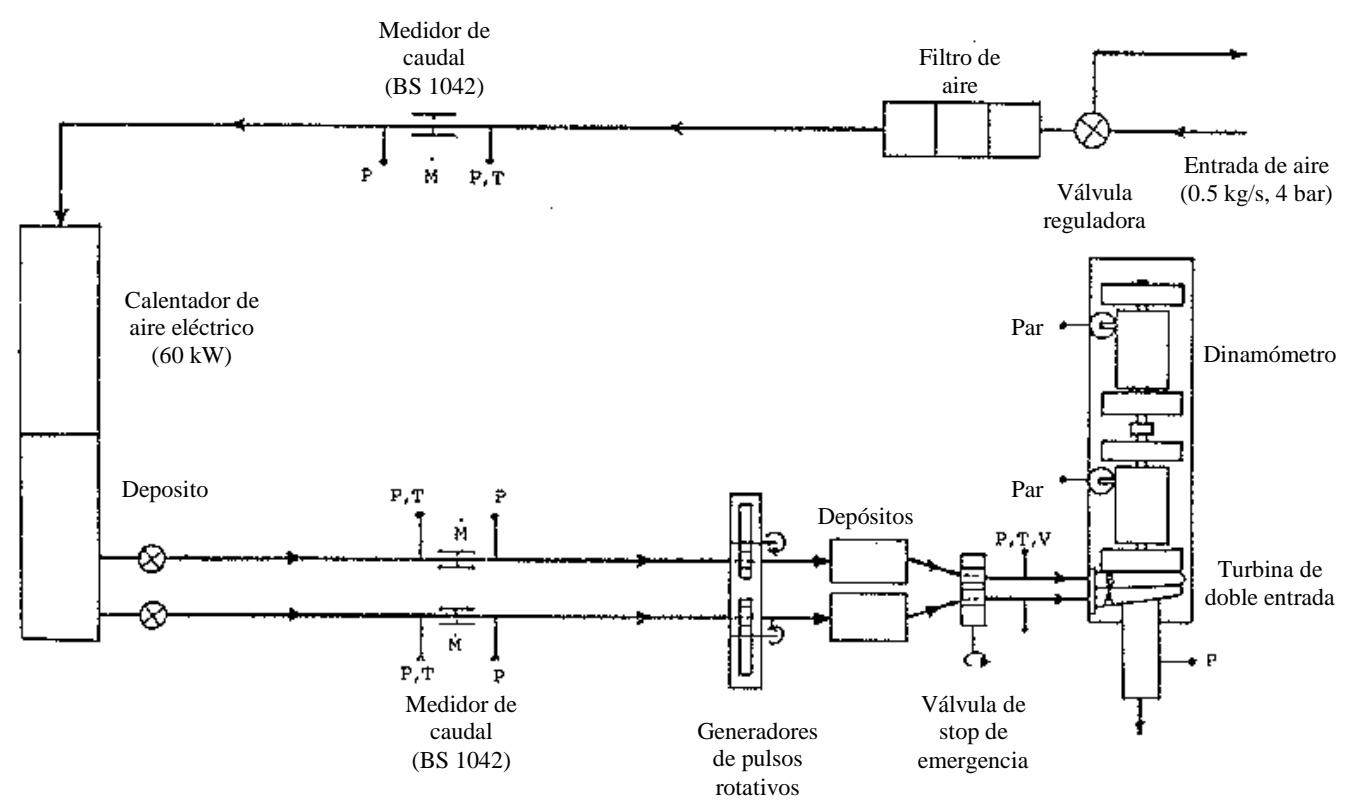

Figura 2. 1: Banco de ensayo de turbinas diseñado por Dale y Watson [2] en 1986. 
Por otro lado, para generar flujo pulsante a la entrada de la turbina se utilizan válvulas rotativas movidas por un motor eléctrico.

Las principales desventajas de esta instalación son el alto consumo de energía eléctrica necesario para realizar los ensayos, las bajas temperaturas de ensayo, en comparación con la temperatura de los gases de escape de los motores, así como fugas en las válvulas rotativas. Además las propiedades termodinámicas de los gases utilizados en esta instalación (calor específico, coeficiente adiabático...) difieren de forma considerable de las propiedades termodinámicas de los gases de escape de los motores de combustión interna alternativos.

En 1993, Furukawa, Yamaguchi, Takagi y Okita [4] presentan una instalación similar desarrollada para ensayar turbinas en condiciones cercanas a las que trabajan éstas cuando están acopladas a un motor diesel de automoción, con la finalidad de estudiar comportamientos anormales de las mismas y estudiar sus causas.

La instalación se muestra en la figura 2. 2. En este caso se utiliza una fuente de aire que alimenta una cámara donde se produce una combustión para elevar la temperatura del flujo másico que atravesará la turbina. Entre esta cámara y la turbina a ensayar se colocan un depósito y una válvula rotativa para crear los pulsos de presión a la entrada de la turbina, que se mantiene acoplada al compresor. La salida de la turbina se estrangula para aumentar la presión de trabajo, simulando el tubo de escape.

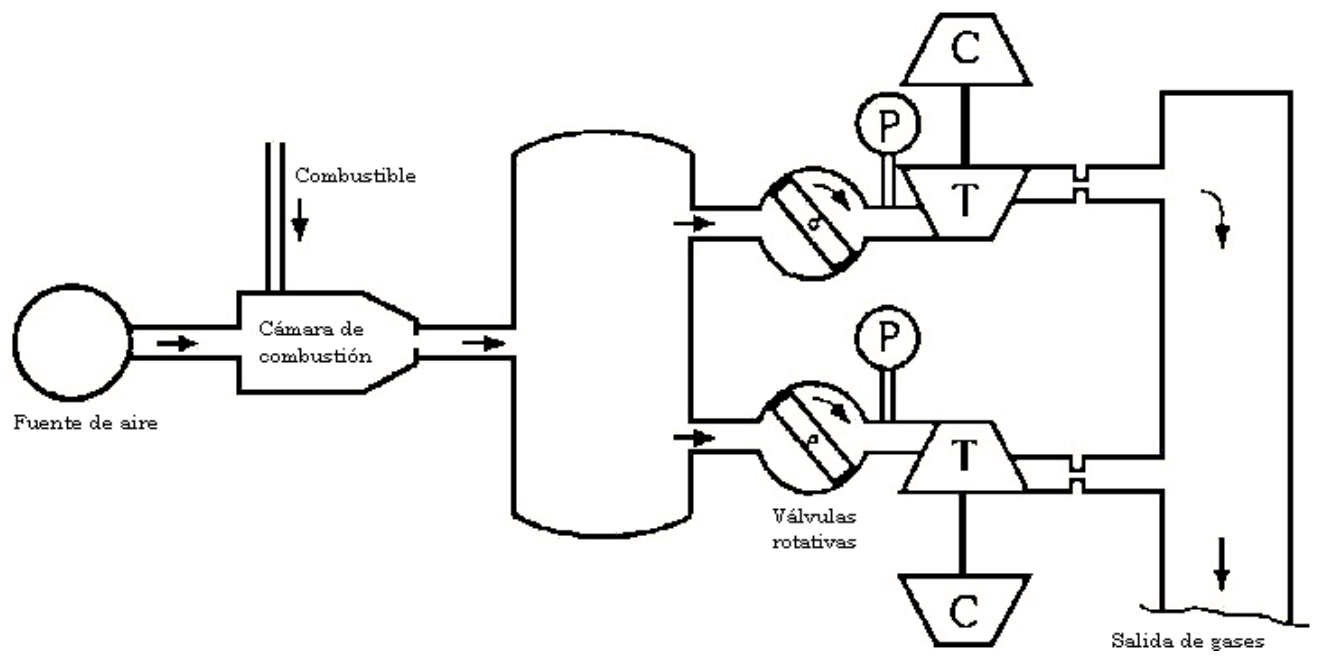

Figura 2. 2: Banco de ensayos de turbinas bajo condiciones de flujo pulsante propuesto por Furukawa, Yamaguchi, Takagi y Okita [4] en 1993.

Para analizar en profundidad esta instalación se debería tener más información, que no se refleja en el artículo mencionado. Sin embargo, cabe 
destacar el cambio básico que se produce respecto a la primera, ya que en ésta ya no se calienta con energía eléctrica el aire proveniente de una fuente sino que mediante una combustión se aumentan la temperatura del flujo de gases que va a trasegar la turbina, lo que hace que los ensayos sean a temperaturas más elevadas con el único coste del combustible inyectado.

Por otro lado no se tiene información ni de la toma de las medidas ni de las limitaciones básicas de la fuente de aire (potencia máxima de trabajo) ni del resto de los componentes de este banco de ensayos y, a priori, las fugas de aire en las válvulas rotativas parece su principal limitación, puesto que la medida del aire se realiza antes del quemador.

En 1996, Chen, Hakeem y Matínez-Botas [1] presentan una nueva instalación para ensayar turbinas con flujo pulsante (figura 2. 3). Esta instalación se construyó en el departamento de Energía Mecánica del Imperial College of Science, en Londres y es heredera de la presentada por Dale y Watson en 1986.

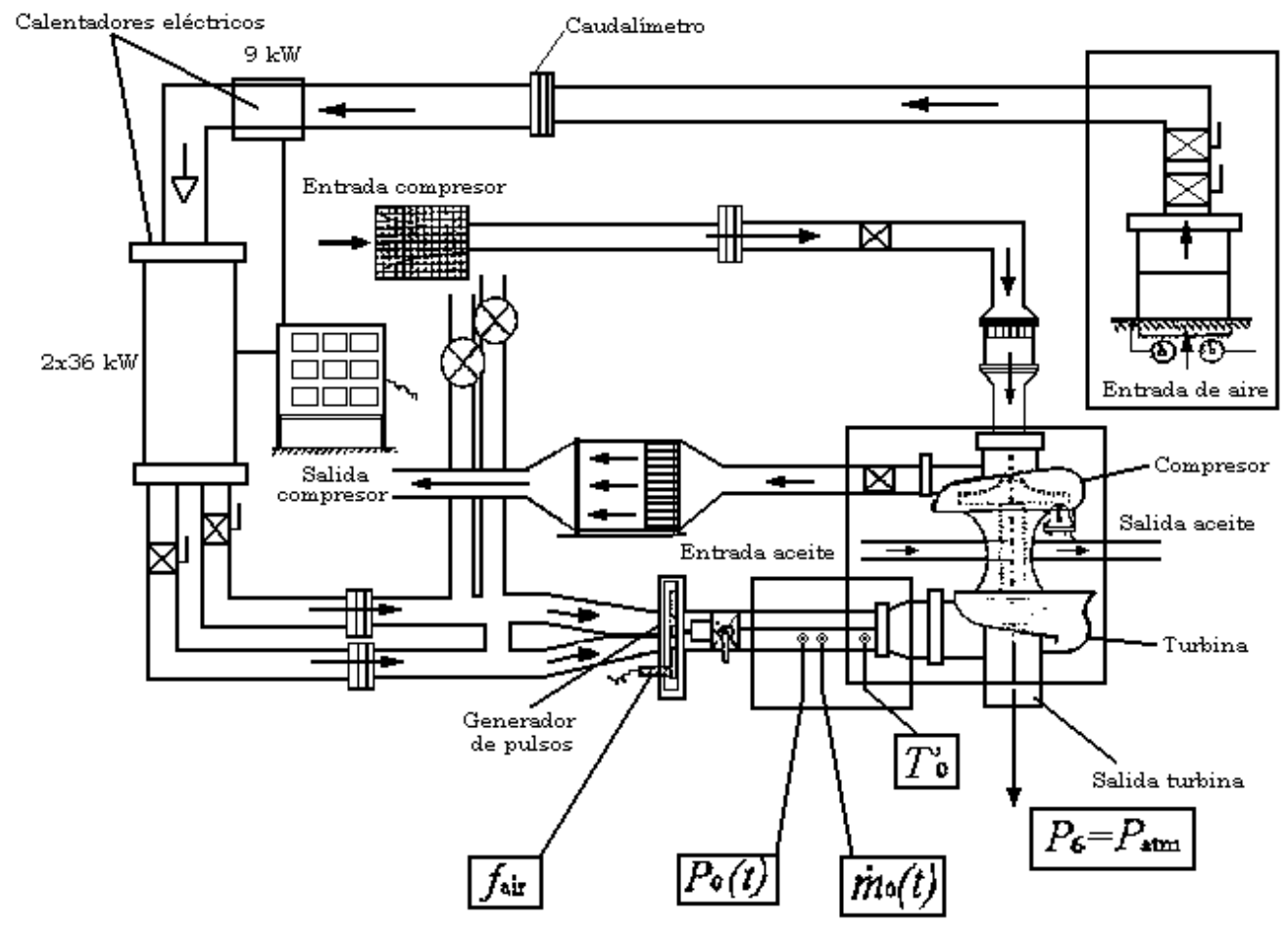

Figura 2. 3: Banco de ensayo de turbinas construido en el Imperial College of Science de Londres [1]. 
Igual que en el primer montaje descrito se utilizan calentadores eléctricos para aumentar la temperatura del aire que entra a la turbina, pero a diferencia de éste ahora el calentamiento se produce en dos etapas y se utiliza el compresor del turbogrupo para absorber la potencia generada por la turbina. Los pulsos de presión se siguen produciendo con válvulas rotativas y la turbina descarga directamente a la atmósfera, asimilándose la presión atmosférica a la presión a la salida de la turbina. En este caso se mide la masa de aire tras las válvulas rotativas, de modo que se soluciona el posible problema de las fugas que se ha visto en el caso anterior.

Debido a la gran potencia necesaria en los calentadores eléctricos para calentar el aire, la temperatura a la entrada de la turbina que se alcanza con esta instalación es muy inferior a la que alcanzan los gases de escape de los motores de combustión interna, con lo que no se reproducen exactamente las condiciones de trabajo de la turbina cuando se encuentra acoplada a un motor.

Además el aire comprimido es suministrado por un compresor movido por un motor eléctrico, con lo que también por este lado se tiene una importante fuente de consumo. Esta es una característica común a todas las instalaciones analizadas hasta el momento.

Al año siguiente Stemler y Lawless [14] diseñaron un banco de ensayos para analizar el comportamiento de los turbogrupos bajo condiciones de flujo pulsante en los motores de combustión interna a los que se encuentran acoplados. Este banco de ensayos fue diseñado específicamente para simular el flujo no estacionario de un motor y estudiar el comportamiento del turbogrupo bajo dichas condiciones.

En esta instalación el flujo caliente se obtiene mediante un quemador al que le llega el aire proporcionado por un compresor que en este caso es movido por un motor diesel de camión, ya que las limitaciones del lugar donde está instalado no permiten que el compresor sea movido eléctricamente. Utilizar un motor diesel de camión soluciona de forma económica estas limitaciones. La gran desventaja de esta instalación es que aparte de emplear un quemador se necesita incorporar un motor para accionar el compresor cuyo caudal de aire va a ser el que se utilice para ensayar el turbogrupo.

Por otro lado cabe destacar que este banco de ensayos está diseñado para turbogrupos de sobrealimentación de motores de gran cilindrada, siendo muy dificil poder ensayar turbogrupos de sobrealimentación de motores de turismos por las especificaciones con las que se ha construido. Además, no existe la posibilidad de que el flujo másico que llegue a la turbina sea pulsante, sólo es posible ensayar con pulsos en el compresor. 
Desde 2001 KRATZER AUTOMATION AG y BORG-Warner Turbosystems GmbH [11] comercializan distintos bancos de ensayo de turbogrupos que utilizan quemadores de gas natural para proporcionar aire caliente a la turbina.

La estructura básica de estos bancos de ensayo es siempre la misma y como puede observarse en la figura 2. 4, lo único que cambia de unos a otros, dependiendo del caudal de aire que se quiera calentar, es el modelo de calentador utilizado, lo que pone en evidencia su reducida versatilidad.

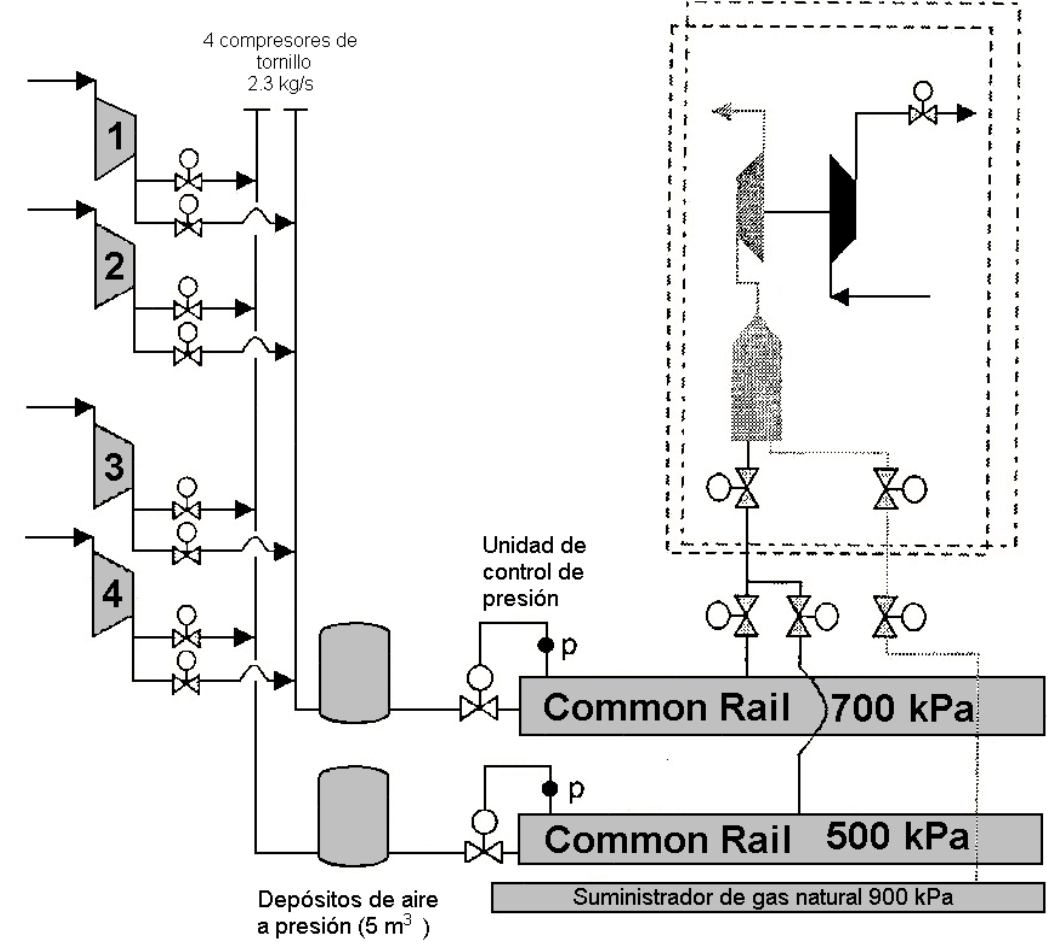

Figura 2. 4: Esquema de la instalación necesaria para poder realizar ensayos de turbogrupos con el banco de ensayos que comercializan KRATZER AUTOMATION AG y BORG-Warner Turbosystems GMBH [11].

Para poder realizar ensayos con estos bancos es necesario disponer de una red de compresores (figura 2. 4) para alimentar el quemador de gas natural. La principal ventaja es la capacidad que tienen de mantener constante tanto el flujo másico de entrada a la turbina como la temperatura del mismo, de modo que se garantizan condiciones fijas a la entrada de la turbina en el caso de que ello sea deseable.

Por otro lado no es posible ensayar turbogrupos con flujo pulsante ni obtener rangos de medida en gasto amplios. 
Finalmente se comentará el banco de turbos desarrollado en la Technical University de Berlín, presentado por Pucher [13] en 2003. La parte principal de esta instalación es una cámara de combustión capaz de proporcionar gas entre 400 y $1450^{\circ} \mathrm{C}$. Una de sus principales características es aumentar la presión del aire a la entrada del compresor de estudio, de tal forma que aumenta el caudal trasegado por éste. En consecuencia aumenta el trabajo consumido por el compresor y por tanto se puede aumentar la energía de los gases que alimentan la turbina sin que ésta se acelere.

Para que el sistema sea eficaz, el trabajo que induce en el aire el compresor de ensayo ha de evacuarse del sistema a través de un enfriador de aire. En resumen el compresor de ensayo queda presurizado para aumentar la densidad del aire a la entrada del mismo y el caudal que es capaz de trasegar (figura 2. 5).
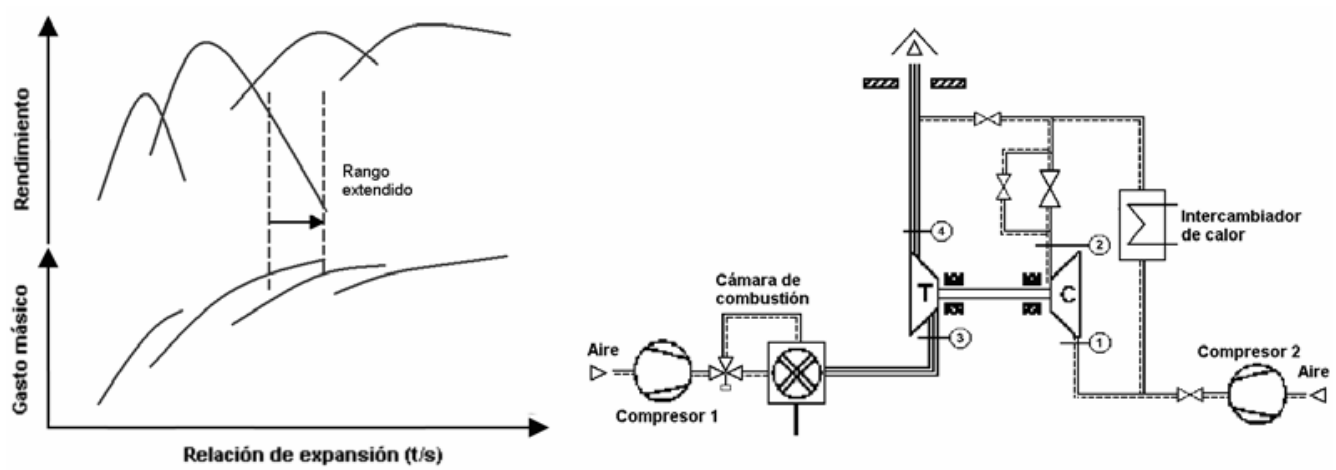

Figura 2. 5: Ampliación del rango de trabajo de la turbina a régimen de giro constante. Esquema de la instalación experimental[13] de la Technical University de Berlín.

Otra utilidad interesante que aporta esta instalación es la de poder medir las curvas de isorégimen del compresor en zonas de relación de compresión menor que la unidad. Esta situación se produce en los motores turboalimentados durante el comienzo de la aceleración, cuando el gasto aguas abajo del compresor disminuye bruscamente y éste se encuentra trabajando con relaciones de compresión inversas; también es una situación frecuente en los actuales motores biturbo con sobrealimentación en doble etapa, ya que en el momento de bypasear el compresor de alta presión, éste queda trabajando en zonas del mapa de alto gasto y muy baja relación de compresión. La técnica consiste en aumentar fuertemente la presión aguas abajo del compresor de ensayo con el caudal proporcionado por un compresor auxiliar para convertir al compresor en una fuerte pérdida de carga y de esta forma conseguir dicha diferencia de presiones inversa. Una descripción gráfica de la instalación puede verse en la figura 2. 6. 
Capitulo 2 Diseñoy puesta a punto de un banco específico para el ensayo de turbogrupos

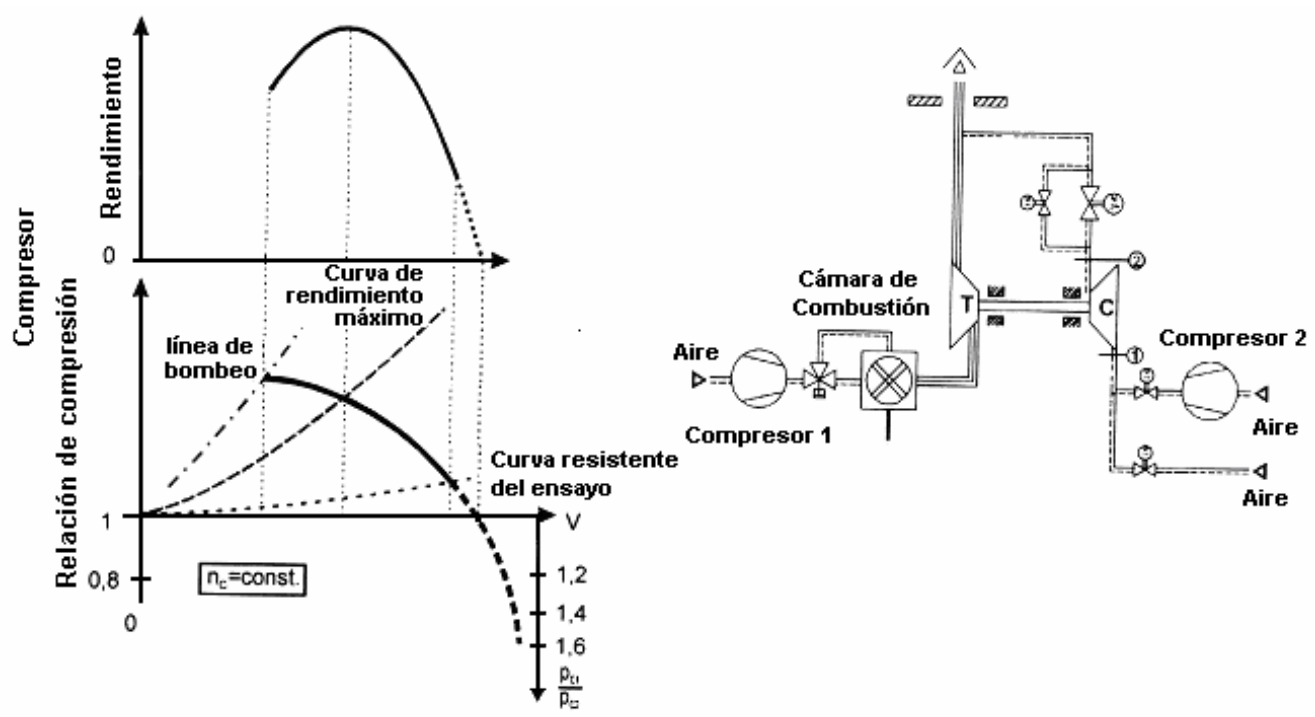

Figura 2. 6: Curvas de isorégimen para relaciones de compresión $<1$. 


\subsection{Diseño del Banco de Turbos}

\subsubsection{Objetivos}

Como ya se ha comentado, los fabricantes de turbogrupos proporcionan poca información sobre el comportamiento de los mismos cuando trabajan acoplados a motores de combustión interna alternativos. La información que se proporciona sobre las turbinas se ciñe a las zonas en que trabaja con máximo rendimiento, ocurriendo lo mismo en el caso de la información proporcionada sobre los compresores, ya que los fabricantes no proporcionan información sobre el comportamiento de los mismos para zonas de bajo régimen de giro. Además toda esta información se obtiene a partir de ensayos del turbogrupo en flujo continuo, casi nunca se ofrecen medidas del comportamiento del turbogrupo bajo condiciones de flujo pulsante a la entrada de la turbina.

En definitiva, la finalidad de diseñar y construir este banco de ensayo de turbogrupos es obtener una herramienta experimental capaz de reproducir las condiciones del flujo a la entrada de la turbina y el compresor lo más cercanas posible a las existentes cuando el turbogrupo trabaja acoplado a un motor de combustión interna alternativo.

La instalación ha de permitir medir la presión y la temperatura a la entrada y a la salida del compresor y de la turbina, la velocidad de giro del eje del turbogrupo y el gasto trasegado por el compresor y la turbina. De este modo será posible elaborar los mapas de funcionamiento de ambos elementos, incluyendo información sobre el rendimiento de las dos máquinas en todo el rango de funcionamiento del turbogrupo.

Además la instalación experimental diseñada debe ser capaz de realizar ensayos tanto con turbogrupos para turismos como con turbogrupos que funcionen acoplados a motores de camión, lo que implica que los requerimientos de la instalación han de ser muy amplios. Estos requerimientos pueden verse en la tabla 2.1 .

Las premisas que se establecen para el desarrollo de la instalación son que ésta sea versátil, energéticamente eficiente y sobre todo fiable. La instalación ha de ser capaz de generar flujo caliente, tanto continuo como pulsante. Ha de ser capaz de proporcionar mapas de rendimiento de la turbina, y de completar los mapas de compresor proporcionados por los fabricantes, sobre todo en las zonas de menores regimenes de giro de turbogrupo. 


\begin{tabular}{|c|c|}
\hline Temperatura máxima a la entrada de la turbina & $1000 \mathrm{~K}$ \\
\hline $\begin{array}{l}\text { Presión absoluta máxima de sobrealimentación } \\
\text { del generador de calor }\end{array}$ & 4 bar \\
\hline Flujo másico de gases calientes (máximo) & $0.6 \mathrm{~kg} / \mathrm{s}$ \\
\hline $\begin{array}{l}\text { Potencia mecánica estimada para la } \\
\text { sobrealimentación del generador de calor } \\
\left(\eta_{\text {compresor } \simeq 0.6)}\right.\end{array}$ & $150 \mathrm{~kW}$ \\
\hline $\begin{array}{l}\text { Potencia térmica estimada para la turbina } \\
\left(\eta_{\text {turbina }} \cong 0.75\right)\end{array}$ & $200 \mathrm{~kW}$ \\
\hline
\end{tabular}

Tabla 2. 1: Requerimientos máximos de la instalación.

El hecho de emplear un MCIA de gran cilindrada, como se verá en los siguientes apartados, para generar el flujo caliente le confiere la versatilidad requerida, y el hecho de no recurrir a motores eléctricos y generadores de calor independientes, hará que sea una instalación energéticamente eficiente. Finalmente, la disposición de los sistemas de medida y la tecnología aplicada, concluirán en una instalación fiable.

En resumen, una instalación del tipo de la que se pretende desarrollar permitirá un conocimiento más amplio, tanto teórico como experimental, sobre los fenómenos físicos que ocurren en una turbina o en un compresor de un grupo de sobrealimentación. Este conocimiento del comportamiento fluidodinámico del turbogrupo va a ser de gran ayuda en el desarrollo del modelo expuesto en esta tesis, en el desarrollo del diseño de estrategias de control y en el estudio del acoplamiento de turbogrupos en los motores de combustión interna alternativos.

\subsubsection{Descripción del diseño}

El banco de ensayos que se ha desarrollado está basado en un motor de encendido por compresión de 101 de cilindrada, capaz de proporcionar suficiente caudal como para poder ensayar turbogrupos destinados a sobrealimentar motores de transporte pesado. Este motor ha sido desprovisto de su turbogrupo original y se sobrealimenta con un compresor volumétrico acoplado mecánicamente a dicho motor, con lo que el motor se utiliza para proporcionar flujo caliente y pulsante para mover la turbina y a su vez la potencia mecánica que desarrolla se utiliza para mover el compresor volumétrico que lo sobrealimenta. 
Entre el motor y el compresor volumétrico se ha acoplado un freno de corrientes de Foucault, que se encarga de absorber la potencia sobrante entre el que proporciona el motor y lo que consume el compresor volumétrico, con lo que regula el régimen de giro del conjunto. Además ha sido necesario acoplar una caja multiplicadora entre el freno y el compresor volumétrico, pues el régimen máximo del motor es la mitad del régimen máximo del compresor volumétrico.

La unión física entre estos elementos está encargada a dos tipos de transmisiones. Entre el motor y el freno, y entre el freno y la caja multiplicadora se han colocado transmisiones de tipo CARDAN, y entre la caja multiplicadora y el compresor, las transmisión es de tipo elástico.

Todo el conjunto se encuentra fijado a una bancada antisísmica de 7 Tm. de masa que flota sobre cuatro muelles, cuya misión es aislar y filtrar las vibraciones producidas por el motor y demás dispositivos.

Se realizará a continuación una breve descripción general del circuito principal que es el que efectúa el fluido de trabajo desde que entra en la instalación hasta que la abandona. Un esquema de la instalación, en el que se muestra este circuito, puede observarse en la figura 2.7.

En primer lugar, el aire atmosférico es introducido en la sala de ensayos mediante un sistema de impulsión forzada desde la azotea del edificio. Una vez dentro de la sala es absorbido por el compresor volumétrico que aumenta su presión en un rango que va desde 1.5 a 4 bares, como se verá más adelante al hablar de las especificaciones del compresor volumétrico. Cuando sale del compresor, se le hace pasar por un intercambiador aire-agua, que disminuye su temperatura y hace que el rendimiento volumétrico del sistema mejore considerablemente. A la salida del intercambiador hay sensores de presión y temperatura para controlar el estado del aire en ese punto. 


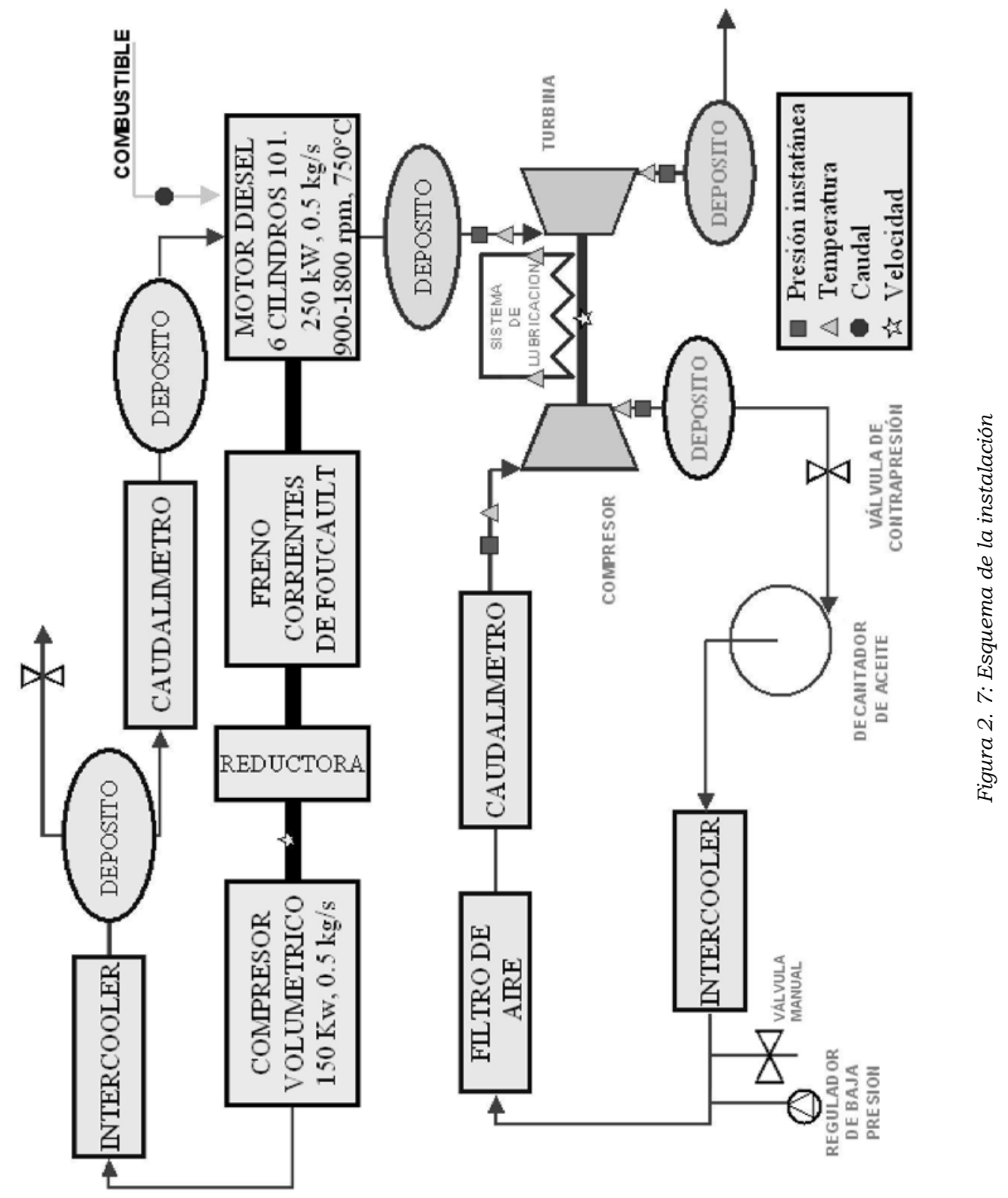


El siguiente elemento con el que se encuentra el aire es un depósito cilíndrico de acero de 150 litros de capacidad. Este depósito permite que el flujo se estabilice antes de entrar al motor y se encuentra suspendido de una estructura metálica, justo encima del compresor volumétrico y su eje corre paralelo a la línea trazada por los elementos de la bancada.

De él parten tres ramales, dos de los cuales se utilizan para llevar el aire desde el intercooler al motor, pero solo uno de ellos tiene acoplado un medidor del caudal de aire. Dependiendo de si se va a alimentar a la turbina con los gases de escape de 1, 3 ó 6 cilindros la configuración de estos dos ramales se adecua para que el aire que va a entrar a la turbina pase por el ramal en el que se encuentra colocado el medidor de gasto másico de aire. El tercer ramal descarga a la atmósfera el flujo sobrante de manera que se puedan regular de forma independiente la presión y el caudal proporcionado por el compresor volumétrico. Esto último se consigue con una válvula motorizada, controlada y monitorizada desde la sala de control. Además, este ramal cuenta con un silenciador aguas abajo de la válvula para mantener unas condiciones acústicas aceptables dentro de la sala.

Una vez se ha producido la combustión en el motor, los gases de escape se destinan a alimentar la turbina. En el caso de querer realizar ensayos de turbina bajo condiciones de flujo continuo se hacen pasar los gases de escape del motor por un depósito, donde se amortiguan los pulsos, antes de llegar a la turbina.

En el caso de que se ensaye con 3 ó 5 cilindros descargando a la atmósfera, los gases de escape que no van a ser trasegados por la turbina se envian directamente a la linea de escape, donde se ha situado una electroválvula que hace que la contrapresión de escape se mantenga constante para todos los cilindros. Esta válvula se regula desde la sala de control de la instalación.

Por su parte, el aire que pasa por el compresor del turbogrupo a ensayar cuenta con un circuito independiente. El compresor centrífugo sólo estará unido mecánicamente al circuito anterior a través del eje que une el rodete del compresor con el rodete de la turbina. Este circuito comienza con un filtro de aire y un caudalímetro que desemboca en el propio compresor. A la salida del compresor se ha colocado un pequeño depósito, que descarga a dos electroválvulas, con las que se regula la relación de compresión. Una vez el aire ha atravesado las electroválvulas se le hace pasar por dos decantadores de aceite (uno a la salida de cada electroválvula), para que quede limpio de restos de aceite de posibles fugas antes de entrar en el intercambiador de calor aire-agua situado a continuación de los decantadores. A la salida del intercooler se ha situado una válvula manual que permite dejar el circuito abierto a la atmósfera o cerrar el circuito del aire que trasiega el compresor. En este ramal se ha situado también un regulador de presión, que permite modificar la presión del aire a la entrada del 
compresor, con lo que es posible trabajar aumentando la presión a la entrada del compresor por encima de la atmosférica o disminuyéndola por debajo de ésta. 


\subsection{Descripción de la instalación}

A continuación se va a describir con detalle los elementos de la instalación desarrollada, dividiéndola en cuatro grandes partes. En primer lugar el recorrido del gas que llega a la entrada de la turbina. A continuación se describirán los elementos del circuito que recorre el aire que trasiega el compresor. Una vez descritas las principales lineas fluidodinámicas de la instalación se describirá la línea de potencia de la misma, formada por el motor de combustión interna alternativo, el freno, la caja multiplicadora y el compresor volumétrico. Poro último se describirá la sala de control desde la que se realizan las medias.

\subsubsection{Elementos que controlan el flujo de gas por la turbina}

Este recorrido es el que se ha descrito en el apartado 2.3.2 y los principales elementos que lo componen se describen a continuación.

\section{- $\quad$ Compresor volumétrico}

Uno de los elementos más importantes del sistema de admisión es el compresor volumétrico utilizado para la sobrealimentación del motor.

Para estudiar el comportamiento de cualquier turbogrupo en todo su rango de funcionamiento es necesario que funcione como un sistema independiente del resto de los elementos de la instalación, de modo que los puntos de funcionamiento del compresor centrífugo del turbogrupo no queden limitados por las condiciones operativas del motor, sino que puedan ser regulados libremente. Es por ello que, para independizar el comportamiento del compresor a ensayar de los requerimientos en la admisión del motor, se va sobrealimentar el motor con un compresor diferente, de modo que sea posible llegar a cualquier punto de funcionamiento del compresor que se desee ensayar.

Los compresores volumétricos generalmente proporcionan una elevada relación de compresión pero no un elevado caudal de aire, siendo necesario un compresor muy grande para sobrealimentar el motor debido a su gran cilindrada (10 litros).

El gran volumen y peso de los compresores de estas características no supone un inconveniente en una instalación fija, como este banco de turbos. Sin embargo, si es una ventaja su bajo régimen de giro, próximo al del motor. Este último factor hace que el sistema de sobrealimentación mecánica con un compresor volumétrico sea el óptimo para el motor del banco de turbos. En concreto el motor se sobrealimenta con un compresor volumétrico del tipo compresor de tornillo. 
Capitulo 2 Diseño y puesta a punto de un banco específico para el ensayo de turbogrupos

El compresor es del tipo con engranajes exteriores para transmitir el movimiento entre ambos rotores. En este caso puede existir juego entre los rotores, lo que evita el desgaste y hace innecesaria la lubricación.

El compresor de tornillo instalado es de una etapa de compresión, exento de aceite y está embridado a una caja de engranajes. Se trata del modelo Atlas Copco ZA 110-3.5 cuyas características se especifican en la tabla 2. 2.

\begin{tabular}{|l|c|}
\hline Caudal $(\mathrm{l} / \mathrm{s})$ & $223-507$ \\
\hline Potencia $(\mathrm{kW})$ & $60-130$ \\
\hline Temperatura salida aire $\left({ }^{\circ} \mathrm{C}\right)$ & 195 \\
\hline Velocidad eje accionamiento $(\mathrm{rpm})$ & $1800-3600$ \\
\hline
\end{tabular}

Tabla 2. 2: Características básicas del compresor escogido para la instalación. (Atlas Copco ZA 110-3.5)

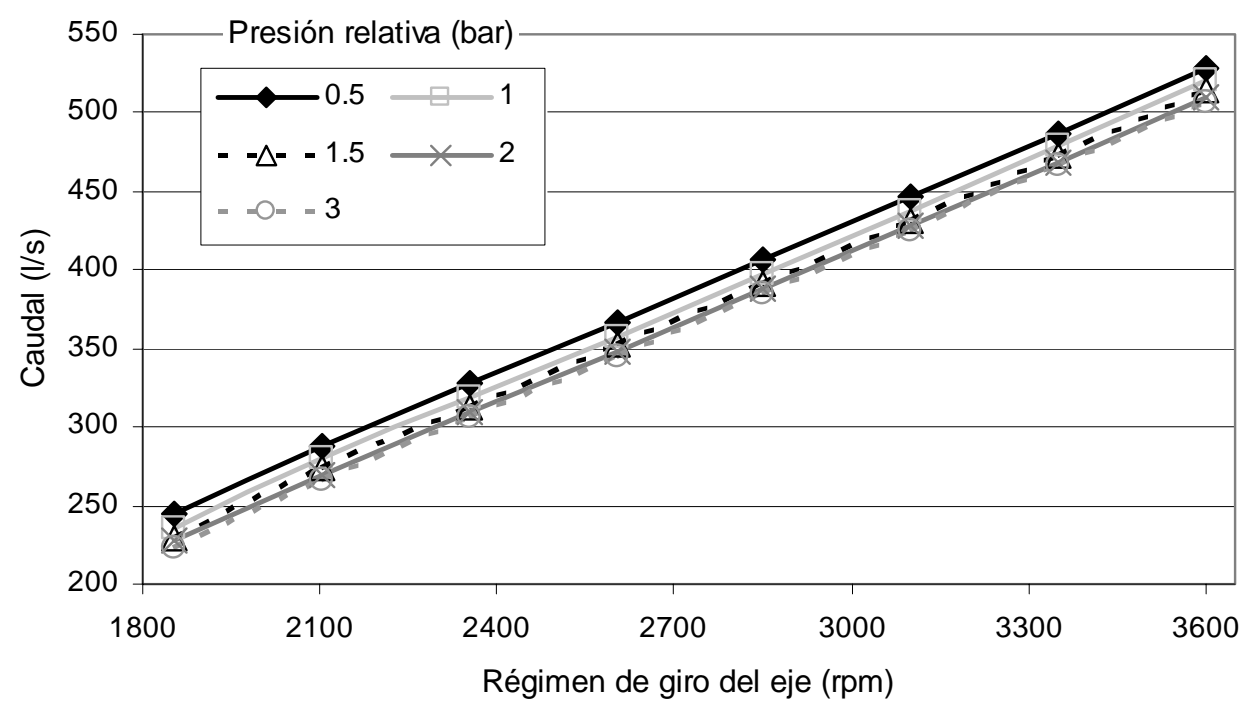

Figura 2. 8: Caudal impulsado por el compresor en función del régimen de giro para diferentes presiones.

Las curvas que muestran las características fluidodinámicas del compresor proporcionadas por el fabricante son las representadas en la figura 2. 8, en la que se grafica la relación entre la velocidad de giro y el caudal de aire que entra en el compresor para cada relación de compresión. Puede 
Contribución a la caracterización experimental y modelado de TGV en grupos de sobrealimentación

observarse como el caudal es prácticamente independiente de la relación de compresión.

\section{- $\quad$ Línea de admisión}

El sistema de admisión comprende los elementos y conducciones encargados de suministrar aire al motor en las condiciones adecuadas o impuestas por el ensayo a realizar.

Este sistema cuenta con un intercambiador agua-aire, dos remansos, dos caudalímetros, una válvula de descarga y el propio colector de admisión. Las conducciones empleadas para conectar dichos elementos son de acero con un diámetro interno de $72 \mathrm{~mm}$ y $2 \mathrm{~mm}$ de espesor y de PVC con un diámetro interno de $89 \mathrm{~mm}$ y un espesor de $8 \mathrm{~mm}$. Parte de este sistema, en concreto el remanso, el caudalímetro y la válvula, están situados en una estructura de perfiles metálicos que pende de tres pórticos. Para transmitir un nivel de vibraciones lo más bajo posible a esta estructura, se han usado manguitos flexibles en el intercooler, y el colector de admisión. De esta forma, no hay ningún elemento rígido entre la bancada y la estructura colgante. El sistema escogido para unir tubos entre sí es el de utilizar una pareja de bridas, una fija y otra móvil de $200 \mathrm{~mm}$ de diámetro y ocho taladros para tornillos de métrica 16, sellándolas con juntas especiales y silicona.

Se describe a continuación los elementos más relevantes del sistema de admisión.

\section{o Intercambiador aire-agua: Intercooler}

El intercooler es un intercambiador de calor aire-agua que enfria el aire de sobrealimentación proporcionado por el compresor de tornillo antes de su admisión al motor. Para evitar que el aire entre a temperaturas demasiado altas a los cilindros. El agua proviene del circuito de refrigeración de la sala, de modo que variando el caudal de agua mediante una válvula motorizada se regula la temperatura del aire a la entrada del motor.

La eficiencia del intercooler, definida como la relación entre el enfriamiento que se produce en el aire de sobrealimentación y el máximo que se podría producir habida cuenta de la temperatura ambiente, aumenta con la temperatura del aire de sobrealimentación, es decir, cuanto mayor es la relación de compresión, si se considera adiabática, mayor eficiencia presenta el intercooler.

La figura 2. 9 muestra el efecto del enfriamiento posterior a la compresión sobre la relación entre las densidades a la entrada del motor y a la entrada del compresor, en función de la relación de compresión y de la eficiencia del intercooler. Se aprecia como al aumentar la relación de compresión resulta más beneficioso el enfriamiento, ya que aumenta la 
relación entre densidades, y, a igual presión de entrada al compresor (generalmente la atmosférica), aumenta la densidad del aire de entrada al motor y reduce la carga térmica del motor.

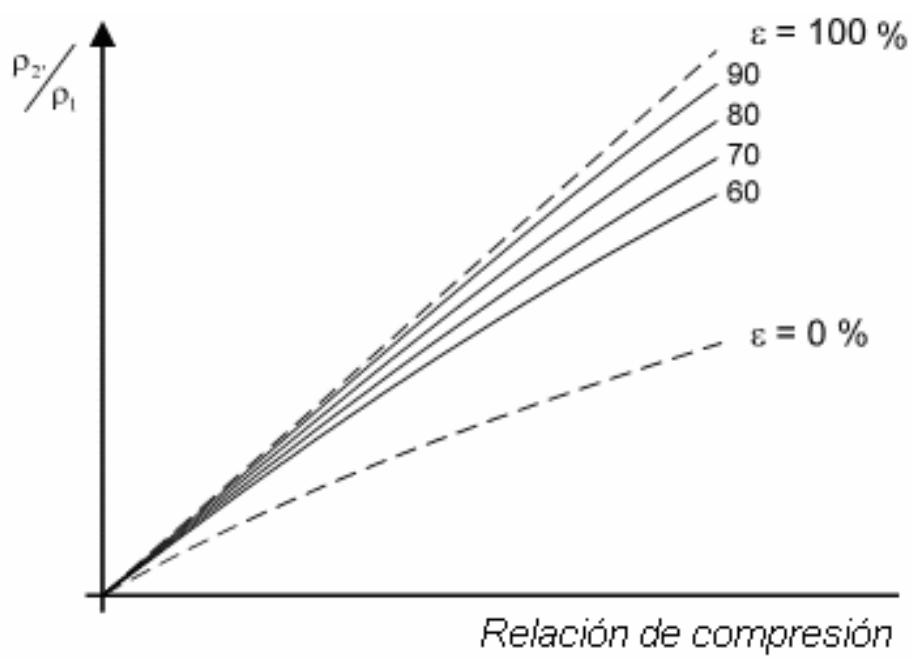

Figura 2. 9: Efecto del enfriamiento del aire de sobrealimentación sobre la densidad de entrada al motor.

\section{o Válvula de alivio}

Esta válvula está situada en la rama que descarga el aire sobrante a la atmósfera del depósito de remanso que se encuentra entre el intercooler y el motor, tiene la misión de regular la presión de admisión que se va a suministrar al motor, ya que en determinadas situaciones el compresor de tornillo suministrará más caudal del necesario (figura 2. 10). De esta forma se puede independizar el régimen de giro del compresor del caudal másico proporcionado al motor.

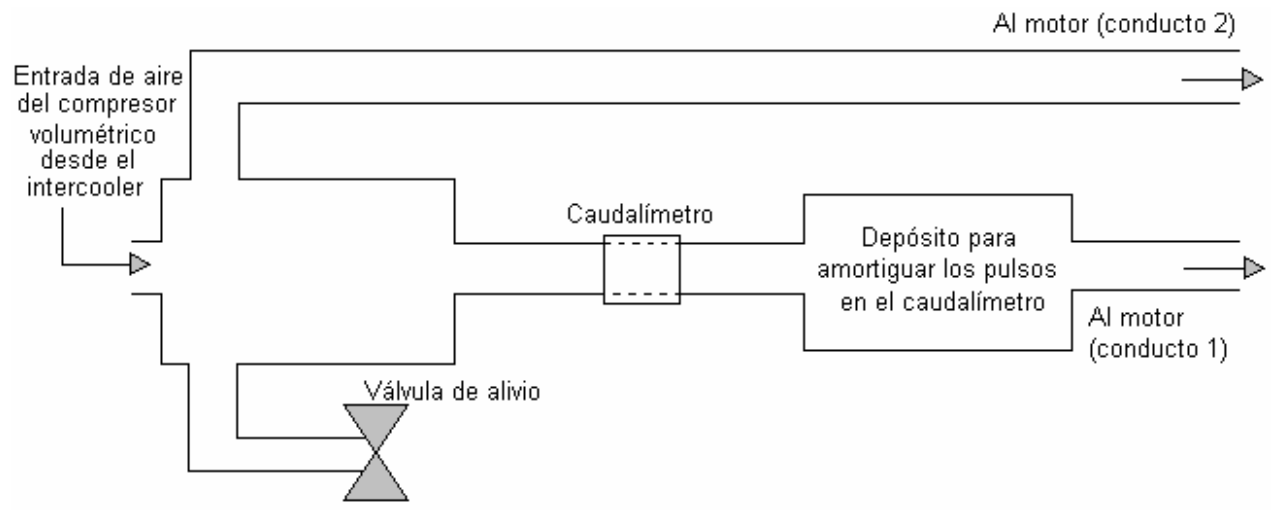

Figura 2. 10: Esquema de parte de la linea de admisión. 
Si no estuviera dicha válvula el caudal y el régimen estarían directamente relacionados, como se ve en la figura 2. 8, lo que reduciría la versatilidad global del banco, pues recordemos que el régimen del compresor es directamente proporcional al del motor.

Las válvulas empleadas en la instalación son de compuerta deslizante que controlan y regulan precisa, rápida y económicamente el paso del gas. Son válvulas de acero, alimentadas a $24 \mathrm{~V}$ y $50 \mathrm{~Hz}$, que disponen de un actuador electroneumático para el accionamiento de la válvula. Para controlar la posición de la ésta se dispone de unos interruptores de final de carrera y un posicionador electrónico (4-20mA).

En la figura 2. 11 aparece un esquema de las válvulas en dos posiciones diferentes: a la izquierda cerrada y a la derecha medio-abierta. A continuación se realiza una breve descripción de la figura utilizando los números que aparecen en ella.
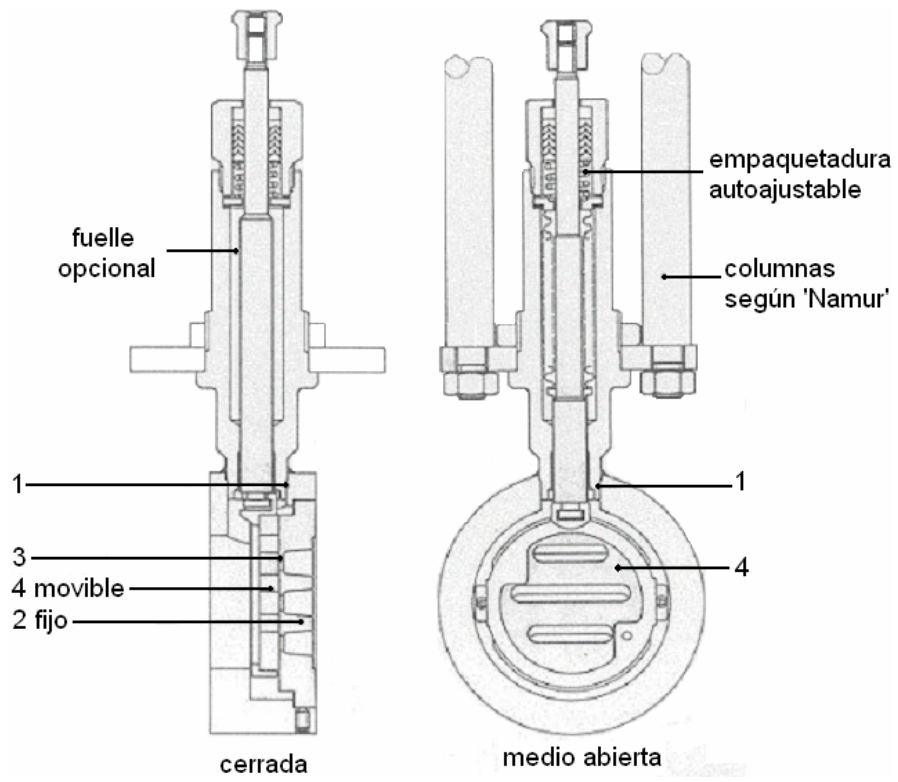

Figura 2. 11: Esquema de una válvula de compuerta deslizante.

Se posiciona, metido dentro de un cuerpo Wafer (1), perpendicularmente a la dirección del fluido, un disco fijo (que hace de asiento) (2) y tiene un número de orificios rectangulares (3) de diferente longitud, pero igual anchura.

Un disco deslizante (4) (que hace de obturador), tiene orificios de idéntica configuración al fijo, el cual se desliza perpendicularmente a la dirección de paso del fluido, con el fin de cambiar la sección de paso de los 
Capitulo 2 Diseñoy puesta a punto de un banco específico para el ensayo de turbogrupos orificios. Independientemente de la presión existente en línea, el disco deslizante está constantemente presionado contra el fijo (2).

Las ventajas de este tipo de válvulas son las siguientes:

- Diseño compacto: Debido a la construcción entre bridas según DIN 3202/K1.

- Alta versatilidad: La misma válvula cubre 3 rangos de presión. La misma válvula puede funcionar como normalmente abierta y cerrada únicamente girando el disco deslizante $180^{\circ} \mathrm{y}$ dispone de una válvula de control e interrupción en la misma válvula.

- Alta respuesta en la acción de control: Debido a su corta carrera la cual representa sólo una fracción de la carrera correspondiente a las válvulas de control tradicionales. (Por ejemplo: válvula DN 150 tiene 8,5 mm).

- Muy poco consumo de energía: Debido a los cortos movimientos de control que tienen que realizar para estabilizar un proceso, por lo que con poco consumo de energía eléctrica o neumática se consiguen los mismos.

- Pequeños actuadores cierran contra altas presiones diferenciales: Debido a que el disco no cierra contra el fluido, sino que lo corta.

- Alta estanqueidad: El margen de fuga es menor que el $0.0001 \%$ del valor del $\mathrm{K}_{\mathrm{vs}}$.[3], incluso en temperaturas superiores a $200{ }^{\circ} \mathrm{C}$.

- Muy fácil instalación: Debido a su diseño compacto y poco peso (por ejemplo: válvula de control DN 150 con actuador neumático pesa $14.2 \mathrm{~kg})$.

- Elementos de estrangulación libres de mantenimiento: Debido a la combinación de la alta calidad de los materiales usados en el disco deslizante y el fijo.

- Efecto autolimpiante: Debido al efecto cizalla del disco deslizante.

- Operación silenciosa: Debido a la efectiva reducción de turbulencias.

- Alta relación de regulación: 40:1 lineal o isoporcentual. 
Contribución a la caracterización experimental y modelado de TGV en grupos de sobrealimentación

- Precio asequible: En comparación con sus prestaciones.

\section{- Colector de admisión}

Entre las funciones elementales del sistema de admisión de un motor se encuentran:

- Mejorar la capacidad de "respiración" del motor.

- Mantener al mínimo las pérdidas de presión en los conductos y la cámara.

- Distribuir equitativamente el flujo másico en todos los cilindros. Esto se logra imponiendo leyes de simetría fluidodinámica al sistema.

No obstante, en la instalación que nos ocupa con la finalidad de darle mayor versatilidad, se ha rediseñado el sistema de admisión acorde con las necesidades de los ensayos que realizaremos. El sistema de admisión está formado por una serie de tubos y válvulas manuales que llevan el aire desde el depósito situado aguas abajo del caudalímetro (figura 2. 10) al colector de admisión y el esquema puede verse en la figura 2. 12. El colector de admisión se ha divido en tres piezas (figura 2. 13), de modo que no es necesario cambiarlo cada vez que se quiere cambiar el número de cilindros que van a descargar a la turbina.

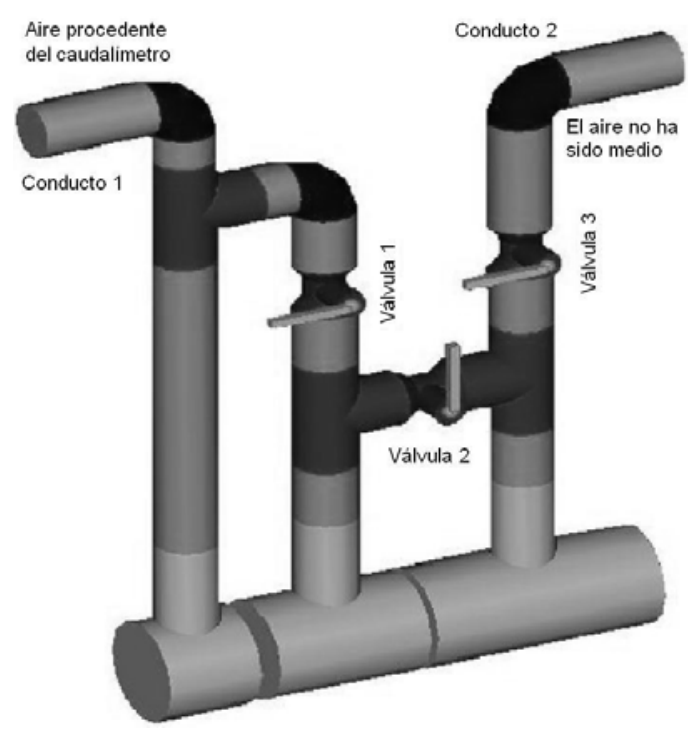

Figura 2. 12: Sistema de válvulas en la admisión del motor construido para dar versatilidad a la instalación.

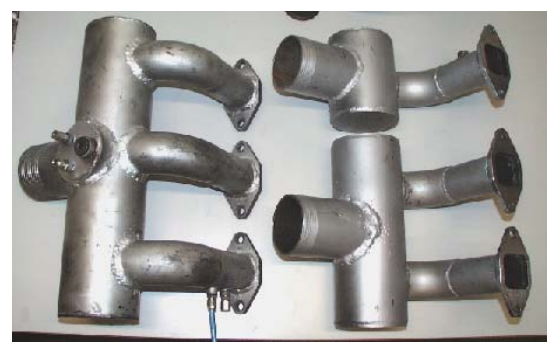

Figura 2. 13: Piezas utilizadas para el colector de admisión utilizado para ensayar turbogrupos. 
Con esta línea de admisión solo es necesario cambiar la apertura de las válvulas para modificar en los ensayos el número de cilindros que descargan sus gases de escape a la turbina. Así pues, dependiendo de si se quiere ensayar el turbo con los gases de escape provenientes de 1, 3 ó 6 cilindros, se abrirán o cerrarán las válvulas teniendo en cuenta que el aire que va por el conducto 1 ha sido medido en el caudalimetro y el que va por el conducto 2 no, pues viene directamente desde el depósito situado a la salida del intercooler, como puede verse en la figura 2. 10.

De una configuración a otra varía la apertura de las válvulas 1,2 y 3. Si se quiere ensayar alimentando la turbina con los gases de escape de 6 cilindros se dejarán abiertas las válvulas 1 y 2 y se cerrará la válvula 3 . Si se quiere ensayar alimentando la turbina con los gases de escape de 3 cilindros se dejarán abiertas las válvulas 1 y 3 y se cerrará la válvula 2 . Y si se quiere ensayar alimentando la turbina con los gases de escape de 1 cilindro se dejarán abiertas las válvulas 2 y 3 y se cerrará la válvula 1. La tabla 2 . 3 resume la posición de las válvulas para cada una de las diferentes posibilidades de ensayo.

\begin{tabular}{|c|c|c|c|}
\hline Configuración & Válvula 1 & Válvula 2 & Válvula 3 \\
\hline 1 cilindro & 0 & 0 & 0 \\
\hline 3 cilindros & 0 & 0 & 0 \\
\hline 6 cilindros & 0 & 0 & 0 \\
\hline
\end{tabular}

Tabla 2. 3: Posición de las válvulas en función del tipo de ensayo que se desee realizar (•: válvula

$$
\text { cerrada, o: válvula abierta). }
$$

- $\quad$ Generador de flujo caliente y pulsante. Motor de combustión interna alternativo, características fluidodinámicas

Como se ha comentado en el apartado 2.3.2 el banco de ensayos que se ha desarrollado está basado en un motor de encendido por compresión de 101 de cilindrada, capaz de proporcionar suficiente caudal como para poder ensayar desde turbogrupos destinados a sobrealimentar motores de turismo como turbogrupos destinados a sobrealimentar motores de transporte pesado.

E1 motor en cuestión es un motor diesel, un RVI-MIDR 06-20-45. Este motor es capaz de proporcionar $0.6 \mathrm{~kg} / \mathrm{s}$ con una temperatura máxima de los gases de escape de $750{ }^{\circ} \mathrm{C}$. La máxima presión de sobrealimentación en funcionamiento en vehículo es de 3.5 bar. Se describirá con más detalle cuando se comenten los elementos de la instalación de la línea de potencia de la instalación. 
- $\quad$ Linea de escape

Los principales elementos del sistema de escape son el colector de escape, una válvula de contrapresión, para simular el efecto de la turbina en los cilindros que no descarguen en ella, un remanso, cuya función es amortiguar los pulsos de los gases de escape a la salida del motor para poder ensayar la turbina bajo condiciones de flujo continuo, y el silencioso final.

Se le ha dado tal disposición a estos elementos que es posible alimentar el turbogrupo a ensayar directamente desde el colector de escape, con lo que el flujo seria pulsante, o a través del remanso, en el cual se atenúan de tal forma los pulsos provenientes del motor que se puede considerar el flujo como continuo.

Además, para favorecer la versatilidad de la instalación se utilizan dos colectores de escape y varias piezas de acople que permiten que la turbina sólo trasiegue los gases de escape provenientes de 1, 3 ó 6 cilindros, de forma equivalente a como se ha visto al explicar el colector de admisión. Con esta configuración es posible hacer que la turbina trasiegue muy poco gasto, para ensayar las líneas de isorégimen más bajas de un turbogrupo con muy baja relación de expansión en la turbina o hacer que trasiegue mucho gasto, para ensayar, por ejemplo, las líneas de isorégimen más altas y con elevada relación de expansión de turbogrupos que se utilicen para sobrealimentar motores de vehículos pesados de similar cilindrada.

\section{O El colector de escape}

El colector de escape que se va a utilizar en la instalación es el colector original de este motor, que está dividido en dos ramas, de manera que a cada una de ellas descargan tres cilindros, como se observa en la figura 2. 14. Este colector es útil tanto para ensayar el turbogrupo con 6 cilindros descargando a la turbina como para ensayar con 3 cilindros descargando a la turbina y los otros 3 a la válvula de contrapresión.

Si se pretende ensayar con 6 cilindros descargando a la turbina se acopla a la salida del colector una pieza realizada y diseñada en el departamento, que une el flujo proveniente de las dos ramas del colector. Si se pretende ensayar con 3 cilindros descargando a la turbina se cambia esta pieza por otra, también diseñada y realizada en el departamento, que mantiene separados los flujos provenientes de los cilindros que trasegarán la turbina y los que descargan por la otra rama, que irán a parar al sistema de extracción de gases de la sala.

Por otro lado, a partir de un colector de escape como original, se ha obtenido otro colector que es posible utilizar en el caso que se pretenda ensayar con un solo cilindro descargando en la turbina. Para ello se ha cortado el colector de escape original por uno de sus extremos, como puede 
verse en la figura 2. 15. En este caso la disposición de las válvulas manuales de la admisión debe ser la que se ha indicado en el apartado anterior para un solo silindro y que así sea posible medir el caudal trasegado por la turbina.

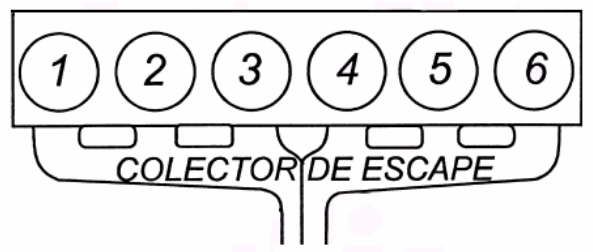

Figura 2. 14: Colector de escape utilizado para ensayar con 3 ó 6 cilindros descargando a la turbina.

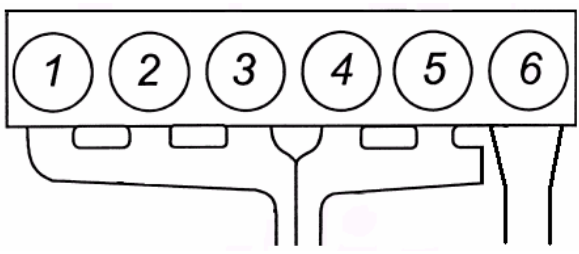

Figura 2. 15: Colector de escape utilizado para ensaya con 1 cilindro descargando a la turbina.

\section{- Válvula de contrapresión de los cilindros que descargan al ambiente}

Recordemos que en el caso de que no todos los gases de escape del motor sean necesarios para mover la turbina, los gases de escape de tres $o$ cinco cilindros se eliminan de la sala por el sistema de extracción, pero no se eliminan directamente, puesto que se ha colocado una electroválvula, del mismo tipo que la de alivio de la admisión.

Esta válvula permite ajustar la presión en esa parte de la línea de escape a un nivel similar a la parte de la línea de escape en la que se encuentra la turbina. La necesidad de tener presiones similares en ambas partes de la línea se debe a que como las presiones de admisión son iguales para los seis cilindros, el buen funcionamiento del motor exige que las presiones a la salida de los cilindros que descargan al ambiente sean del mismo orden que las de salida de los otros tres, que alimentan a la turbina. En caso contrario podría llegarse a la situación de que la diferencia de presión entre la admisión del motor y el escape en los tres o cinco cilindros de esta rama llegara a vencer los muelles de retorno de las válvulas, con la consiguiente apertura inadecuada de las válvulas de admisión.

\section{- Depósito amortiguador de las ondas de presión del escape}

El motor funciona como generador de flujo caliente y pulsado, de modo que es posible ensayar la turbina en las condiciones en las que funciona acoplada a un motor de combustión interna alternativo e incluso es posible hacer estudios sobre la influencia del nivel de pulsación en el comportamiento de la turbina, ya que es posible variarlo.

Para poder ensayar en condiciones de flujo no pulsado a la entrada a la turbina, se interpone un depósito entre le escape y la turbina. Este volumen es suficiente para que las ondas de presión del escape queden amortiguadas y la turbina sea alimentada con flujo continuo. 
Este remanso está soportado por una estructura regulable de perfiles de acero, es cilíndrico, de acero inoxidable y con 150 litros de capacidad. Se le ha dotado con tres orificios acabados en bridas de $220 \mathrm{~mm}$ a diferentes alturas y posiciones para poder modificar los puntos de entrada y salida al mismo.

El depósito puede estar aislado térmicamente de modo que la energía disponible en los gases de escape llegue a la turbina sin grandes pérdidas de calor, aunque esto será deseable o no dependiendo del tipo de ensayo que se pretenda realizar.

Para la elección del volumen se usó un modelo de acción de ondas de la instalación del que se hablará más ampliamente en el capítulo 5. Se realizaron distintas simulaciones con tamaños diferentes para el remanso y se compararon los resultados. Los resultados obtenidos se muestran en la figura 2. 16.

Se realizó el estudio paramétrico para la configuración de 6 cilindros descargando a la turbina y para la de 3 cilindros descargando a la turbina. Obtenidas las presiones instantáneas en el interior del depósito y la entrada y salida de la turbina se puede observar cómo afecta el volumen de este depósito en ambos casos.

Se denomina, por comodidad, configuración pulsante a la configuración en que se alimenta la turbina con los gases de escape del motor directamente, y configuración continua a la configuración en que se coloca este remanso entre el colector de escape y la turbina, con el fin de amortiguar los pulsos.

Observamos que, para ambas configuraciones, la presión en los tubos a la entrada y a la salida de la turbina es bastante continua a partir de un volumen superior a 50 litros.

Para comparar el nivel de las pulsaciones a la entrada de la turbina se ha utilizado el factor de pulsación, definido mediante siguiente expresión:

$$
F p=\frac{p_{\text {máx }}-p_{\text {mín }}}{p_{\text {med }}} \cdot \frac{60 \cdot 2}{n \cdot z}
$$

Donde $\mathrm{p}_{\text {máx }}, \mathrm{p}_{\text {min }} \mathrm{y} \mathrm{p}_{\text {med }}$ representan las presiones máximas, mínimas y medias respectivamente calculadas por el modelo a la entrada de la turbina, $\mathrm{n}$ es el régimen de giro del motor (en revoluciones por minuto) y $z$ es el número de cilindros que descargan a la turbina.

Definiciones similares del factor de pulsación se encuentran en la bibliografia [6]. 
Configuración 6 cilindros

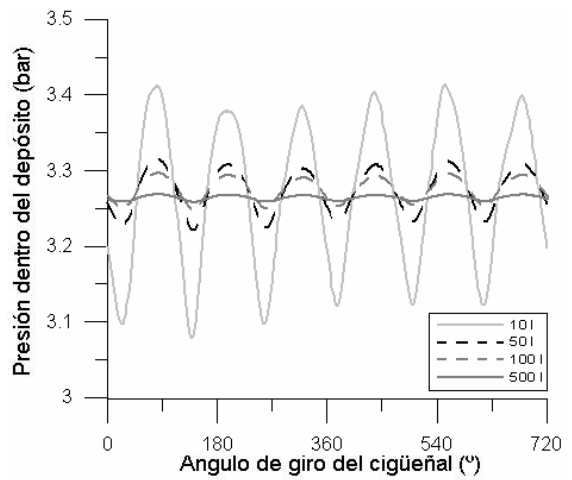

Configuración 3cilindros

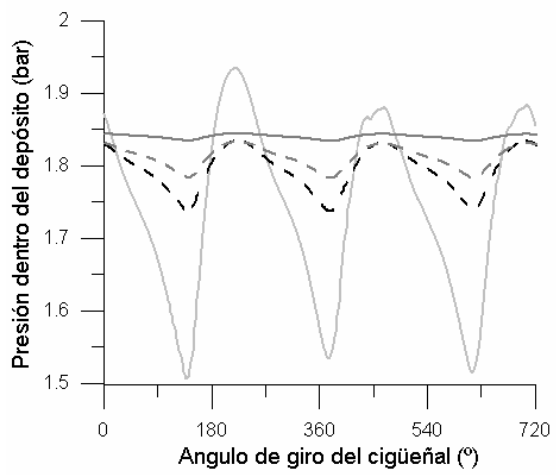

a) Presión instantánea durante un ciclo en el interior del depósito.
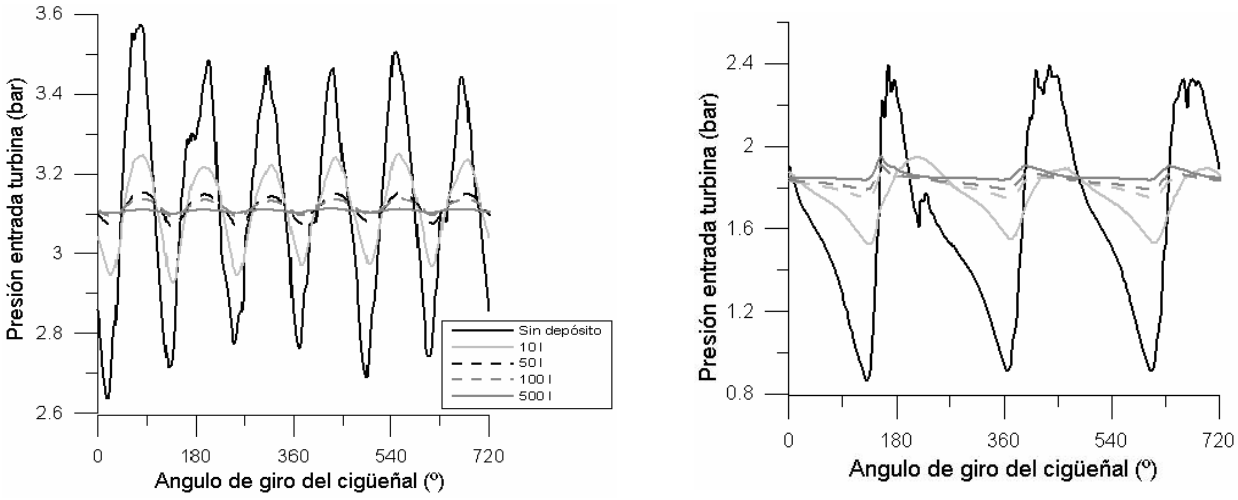

b) Presión a la entrada de la turbina.
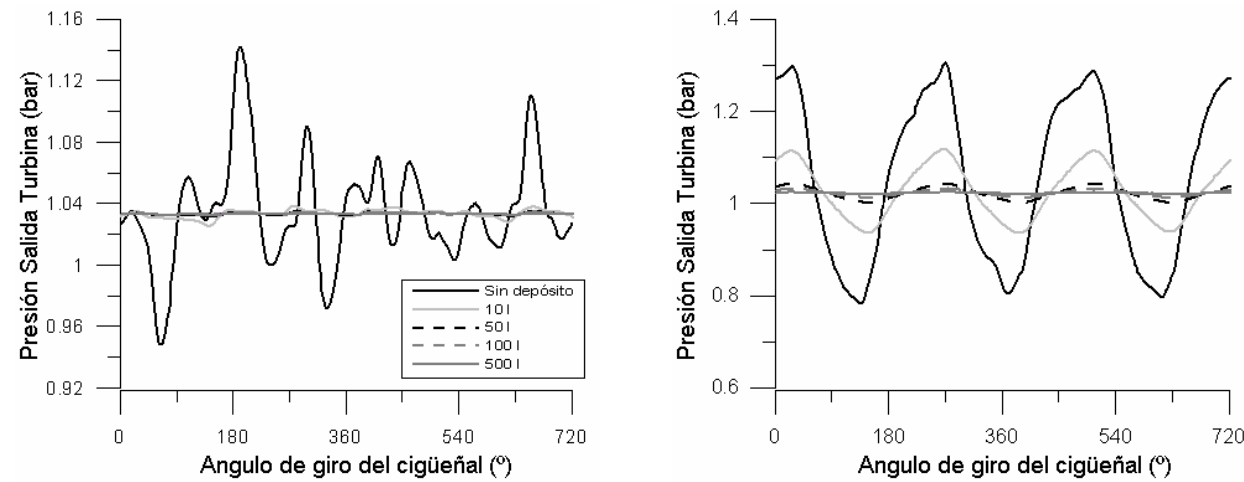

c)Presión a la salida de la turbina

Figura 2. 16: Valores instantáneos obtenidos mediante modelado del banco de ensayos en diferentes puntos del mismo y para distintos tamaños del depósito situado entre el colector de escape y la entrada de la turbina. 
Según el volumen del depósito anterior a la entrada de la turbina se obtienen los siguientes valores para la relación de presiones del factor de pulsación (el régimen de giro se ha mantenido fijo en $1200 \mathrm{rpm}$ ):

\begin{tabular}{|c|c|c|c|c|c|}
\hline Configuración & Pulsante & 101 & 501 & 1001 & 5001 \\
\hline $\begin{array}{c}\text { Fp } \cdot 10^{4} \\
\text { (6 cilindros) }\end{array}$ & 50.08 & 17.26 & 4.76 & 2.56 & 0.70 \\
\hline $\begin{array}{c}\text { Fp10 } \\
\text { (3 cilindros) }\end{array}$ & 314.4 & 80.4 & 17.6 & 9.0 & 2.4 \\
\hline
\end{tabular}

Tabla 2. 4: Variación del factor de pulsación a la entrada de la turbina en función del tamaño del depósito de remanso, para 6 y 3 cilindros.

Cuanto más bajo es el factor de pulsación calculado más amortiguados son los pulsos que le llegan a la turbina. Se observan muy pocas diferencias en el valor obtenido para un volumen de 100 litros y uno de 500. Para el primero, el factor de pulsación es $94.9 \%$ veces menor que el resultante para la configuración de pulsante y para el depósito más grande es $98.6 \%$ inferior.

La disminución de este parámetro con respecto al coste que supone colocar un depósito de 5001 en la instalación justifica la elección de un depósito inferior a 5001 y superior a 100 1. Por lo tanto, se comprueba que la elección de un volumen de 1501 es adecuada para amortiguar los pulsos de escape del motor a la entrada de la turbina.

\section{o El silencioso}

El silencioso que se ha instalado en la sala es el que equipa en origen el motor. Se ha montado en una estructura de perfiles de acero y malla metálica perforada para proteger a los operarios de posibles quemaduras. Este silencioso no filtra los gases provenientes de la turbina del turbogrupo que se este ensayando, para evitar eventuales perturbaciones en la medición de los pulsos de presión en la turbina se decidió bypasear el silencioso con dicho flujo.

A la salida del silencioso se ha acoplado una conducción flexible de tela ignifuga de la cual aspira un ventilador para favorecer la evacuación de los gases quemados y su expulsión al exterior. 


\subsubsection{Elementos que controlan el flujo de aire por el compresor}

El banco de ensayos diseñado es capaz de llegar a cualquier punto de funcionamiento de cualquier compresor centrífugo de los que habitualmente forman un turbogrupo destinado a la sobrealimentación de motores de encendido por compresión. Sin embargo, para el caso de las turbinas existen algunas limitaciones, debido a que para el ensayo de éstas se utiliza el compresor del turbogrupo como freno y el rango de ensayos de la turbina queda limitado por la zona de comportamiento estable del compresor, esto es, entre las zonas de choque y bombeo del mismo.

Existe una forma de aumentar el rango de ensayo de la turbina cuando se encuentra acoplada a un compresor que consiste en aumentar o disminuir la cantidad de aire que éste trasiega aumentando o disminuyendo su densidad.

Si la presión a la entrada del compresor aumenta, la densidad del aire aumenta y el gasto de aire que trasiega el compresor aumenta, aumentando también el trabajo realizado por él para mantener una determinada relación de compresión, de modo que el régimen de giro del turbogrupo disminuye, siendo posible de esta forma aumentar el caudal de gases de escape que trasiega la turbina para recuperar el régimen de giro del turbogrupo y de este modo aumentar la relación de expansión en la turbina.

$\mathrm{Si}$, por el contrario, se disminuye la presión a la entrada del compresor, el gasto de aire que éste trasiega disminuye, disminuyendo también el trabajo realizado por el compresor para mantener una relación de compresión dada, de modo que el régimen de giro del turbogrupo aumenta. Entonces, para recuperar el régimen de giro inicial es posible disminuir el caudal de gases que trasiega la turbina, de modo que se disminuye también la relación de expansión.

En resumen, teniendo en cuenta que el punto de mínima potencia consumida por el compresor a un determinado régimen coincide con el punto límite de bombeo y el de máxima potencia (al mismo régimen) está muy cercano a las condiciones de choque. Es posible, posicionando al compresor en los limites de bombeo a un determinado régimen, conseguir con esta técnica que éste consuma menos potencia (bajándole la presión a la entrada) y por tanto que la turbina, a la cual frena, trabaje con una relación de expansión menor (ampliando su rango de ensayo) sin que se frene el conjunto. De igual forma, posicionando al compresor en las cercanias del punto choque, es posible conseguir que éste consuma más potencia que la máxima consumida a presión atmosférica (subiéndole la presión a la entrada) $\mathrm{y}$, por tanto, que la turbina pueda trabajar con una relación de expansión mayor sin que se acelere el conjunto (ampliando a su vez su rango de ensayo a ese régimen). 
Con este fin se ha presurizado el circuito de aire del compresor, como muestra la figura 2. 17. Se observa como, el recorrido del aire que trasiega el compresor en los ensayos de turbogrupos es totalmente independiente del recorrido del aire que trasiega la turbina, que ha sido descrito en el apartado anterior. La figura 2. 17 muestra, esquemáticamente, los elementos del circuito del aire que trasiega el compresor, que está formado por un caudalímetro con su correspondiente filtro de aire, un depósito situado a la salida del compresor, dos electroválvulas que permiten variar la relación de compresión, dos decantadores de aceite (para limpiar el aire de posibles residuos), un intercambiado de calor, una válvula manual y un regulador de presión.

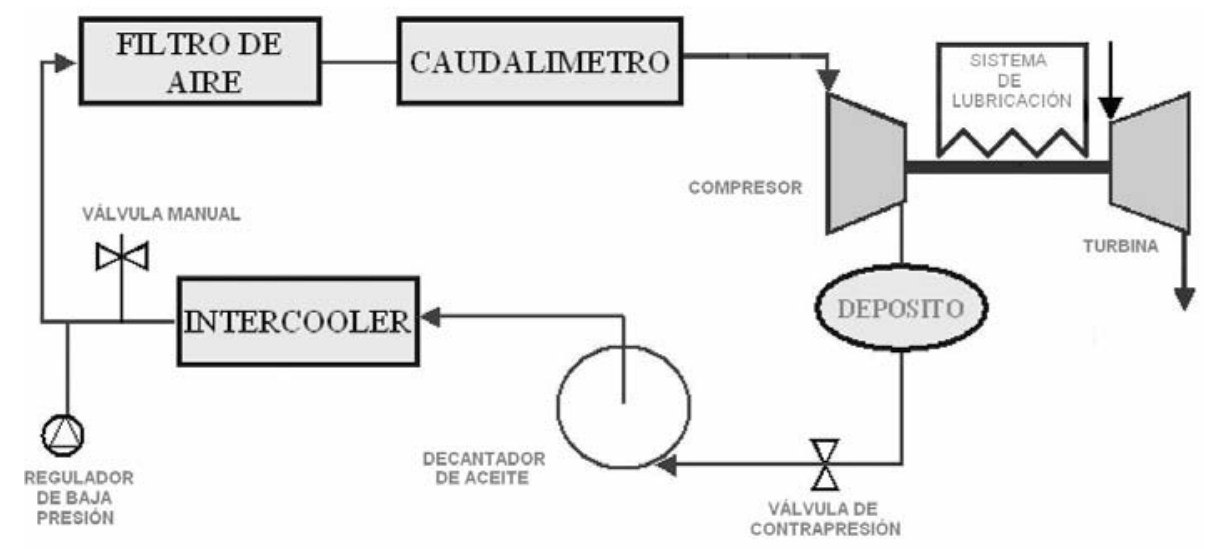

Figura 2. 17: Esquema circuito del aire que trasiega el compresor

Si la válvula manual está abierta y el regulador de presión está desconectado el sistema trabaja como un circuito abierto y el compresor trabaja con presión atmosférica a la entrada. Si la válvula manual se cierra el circuito es un circuito cerrado y el regulador de presión controla la presión a la entrada del compresor.

De los elementos que forman este sistema de sobrepresión sólo se van a describir en este apartado los decantadores, puesto que el intercambiador de calor empleado es igual al descrito en el apartado 2.4.1, el caudalímetro se verá en profundidad en el apartado destinado a la instrumentación y las electroválvulas son iguales a la también descrita en 2.4.1.

\section{- Decantadores}

Los decantadores utilizados en la instalación han sido diseñados y construidos en el Instituto CMT-Motores Térmicos de la Universidad Politécnica de Valencia. Un esquema de los mismos puede verse en la figura 2. 18. Como se observa, el aire, que entra tangencial, tiene que realizar un circuito por el que va perdiendo, por gravedad y por fuerzas centrífugas, las 
gotas de aceite que lleve en suspensión. La base de los decantadores está agujerada para sacar el aceite que se deposita y eliminarlo del circuito.

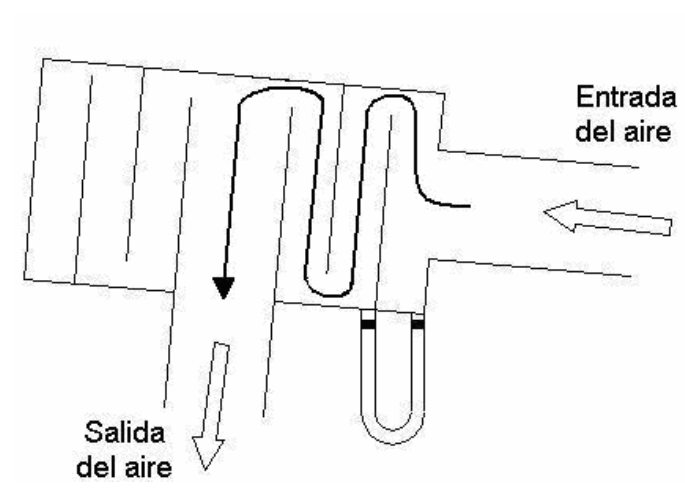

Vista lateral

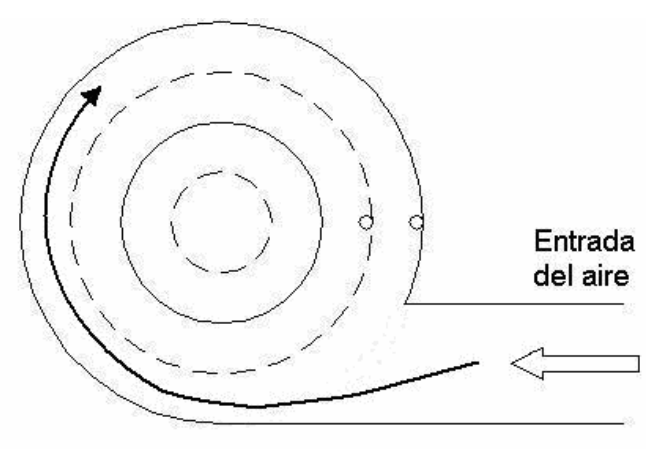

Vista superior

Figura 2. 18: Esquema de los decantadores utilizados para limpiar el circuito de sobrepresión de restos de aceite.

La salida del aire se construyó hacia abajo pues, por razones de espacio en la sala de ensayo, los decantadores se diseñaron para ser colocados en el techo.

\subsubsection{Linea de potencia de la instalación}

Se describirá a continuación la línea de potencia de la instalación, formada por el motor de combustión interna alternativo, sobrealimentado por el compresor volumétrico de tornillo, un freno, que absorbe el par sobrante entre el producido por el motor y el utilizado por el compresor, la caja multiplicadora que permite acoplar el freno y el compresor volumétrico, y finalmente las transmisiones necesarias para que el conjunto mecánico funcione correctamente.

\section{- $\quad$ Compresor Volumétrico. Características mecánicas}

Las curvas de funcionamiento del compresor volumétrico proporcionadas por el fabricante son las representadas en la figura 2.8 y la figura 2. 19, en la que se muestra la evolución de la potencia en el eje del compresor, para diferentes presiones, en función del régimen de giro para el que funciona.

Se aprecia que así como el caudal sí es prácticamente independiente de la presión del circuito, lógicamente no ocurre lo mismo con la potencia. 


\section{Contribución a la caracterización experimental y modelado de TGV en grupos de sobrealimentación}

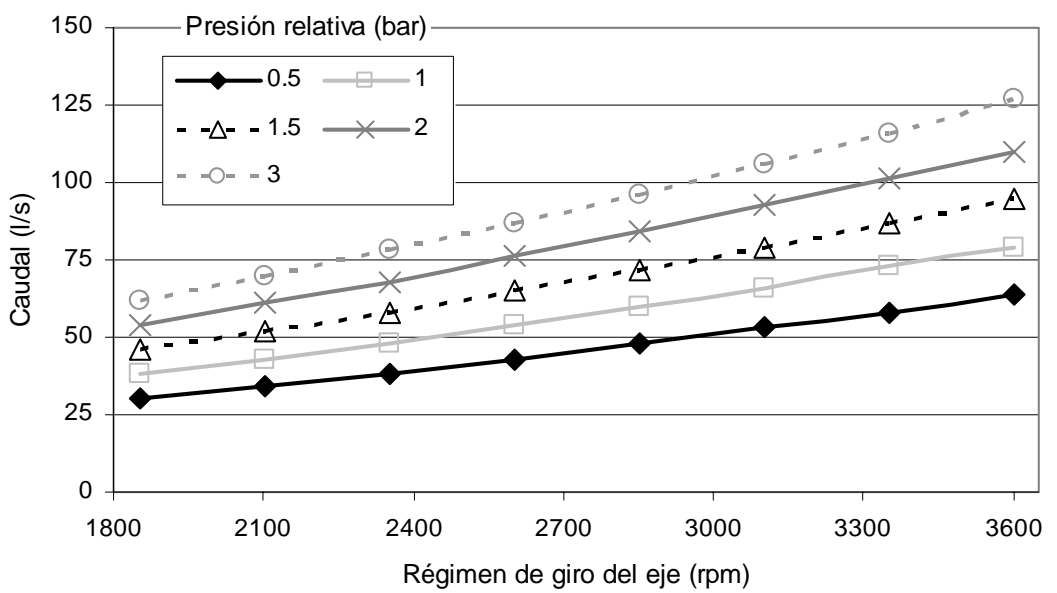

Figura 2. 19: Potencia al eje en función del régimen de giro para diferentes presiones.

- $\quad$ Transmisiones y caja multiplicadora

Son necesarias tres transmisiones, más una caja multiplicadora de régimen de giro, para el correcto funcionamiento de la instalación. El objetivo de la máquina multiplicadora dispuesta entre el motor y el compresor es compensar la diferencia de regímenes de giro a los que se mueven el compresor de tornillo y el motor.

El régimen de giro del compresor va desde 1800 a 3600 rpm para un correcto funcionamiento del mismo. Por otro lado el régimen de giro del motor va de 800 a $2000 \mathrm{rpm}$. La caja multiplicadora es necesaria para que estas dos máquinas puedan trabajar acopladas entre sí. Sus características más relevantes son: relación de velocidad entrada/salida $i=2.04$ y una potencia nominal de $500 \mathrm{~kW}$. Incorpora un sistema de lubricación a presión, con un depósito separado de aceite que tiene dos bombas, una para suministrar el aceite a la caja y otra para hacer circular éste interiormente y a través de un pequeño intercambiador agua-aceite que se encarga de mantenerlo a una temperatura adecuada de funcionamiento.

La primera transmisión es la que une la caja multiplicadora y el compresor. Esta transmisión es un amortiguador de par que cuenta con una corona almenada que se introduce en un tambor. En el interior del tambor se encuentran fijados unos tacos de goma de forma que no hay contacto metalmetal entre la corona y el tambor, cumpliendo así el cometido amortiguador.

La segunda transmisión es la que une el freno con la caja multiplicadora. Es también un amortiguador de par pero, a diferencia de la que une el compresor con la caja multiplicadora, ésta cuenta con elementos elásticos para ejercer tal misión. Su estructura son dos tambores 
concéntricos atravesados por pasadores, siendo el exterior el que está fijado a la caja multiplicadora. Unos tacos de caucho con dos taladros son los que unen el tambor exterior y el interior, atenuando golpes y cambios bruscos de régimen.

Por último, la transmisión que conecta el motor y el freno, es de tipo cardan. En la parte del motor hubo que diseñar y montar un disco de acople de $455 \mathrm{~mm}$ de diámetro sobre el volante de inercia. La transmisión tiene un diámetro medio de $110 \mathrm{~mm}$, una longitud máxima de $450 \mathrm{~mm}$ y $30 \mathrm{~mm}$ de juego telescópico. Los platos son de $180 \mathrm{~mm}$ de diámetro y ocho taladros. Se han utilizado tornillos M14 de dureza 12.9 y además se han bloqueado con un producto específico que mejora la seguridad.

Esta transmisión cuenta con una protección anclada al freno para que en caso de rotura se minimice el riesgo de daños colaterales a personas o a la instalación.

\section{- $\quad \underline{\text { Freno }}$}

El freno con el que se ha dotado a la instalación es un freno electromagnético (de corrientes de Foucault) y con las siguientes características técnicas:

- Potencia máxima: $230 \mathrm{~kW}$.

- Par de giro: $350 \mathrm{Nm}$.

- Momento de inercia: $0.014 \mathrm{Kp} \mathrm{ms}^{2}$

- Régimen máximo de giro. $10.000 \mathrm{rpm}$.

- Peso: 500 Kp.

El freno dinamométrico de corrientes de Foucault es un freno de potencia que transforma en calor la energía mecánica del motor a ensayar por medio de corrientes parásitas de Foucault. El calor se disipa mediante un circuito de refrigeración.

Consta principalmente de 4 partes: la carcasa basculante, el sistema dinamométrico, el bastidor de la máquina y el sistema de mando. La carcasa y el sistema dinamométrico están sujetos al bastidor de la máquina, que en su interior también contiene las conducciones para el agua de refrigeración.

Consta de un rotor de elevada permeabilidad con aspecto de engranaje recto de dientes anchos y paso elevado. El estator contiene una bobina de campo que es excitada mediante una pequeña corriente continua. La 
aplicación de esta corriente produce un campo magnético paralelo al eje del rotor cuyo giro produce cambios de flujo del campo magnético en las paredes de la cámara de agua de refrigeración del estator, dando lugar a la circulación de corrientes de Foucault cerca de la periferia interna del estator y a la disipación de energía en forma de calor al agua de refrigeración del estator. La potencia disipada se controla con la intensidad de corriente suministrada a las bobinas de campo, con lo que se consigue una rápida variación del par resistente. Es un freno simple y robusto, capaz de desarrollar un par de frenado elevado a velocidades relativamente bajas.

Para determinar la potencia absorbida se necesita además el número de revoluciones por minuto. Para ello se encuentra provisto de una polea dentada, por medio de la cual se transmiten sus revoluciones a un generador taquimétrico. La tensión de salida es proporcional a las revoluciones por minuto.

El freno está unido rígidamente a la bancada y está dispuesto encima de cuatro perfiles UPN 100 a modo de raíles que permiten su desplazamiento longitudinal y transversal para permitir su alineación respecto del motor.Su eje lleva acoplados en ambos extremos dos platos de transmisión. Para poder conectar dichos platos a las transmisiones escogidas, se tuvieron que mecanizar unos acoples en el propio departamento.

Hay dos modos básicos de regulación del régimen de giro del motor en función de tres variables, que son el par (T), el régimen de giro (n) y el tanto por ciento de acelerador o Throttle $(\alpha)$. El modo que más se utiliza es el de fijar o actuar sobre el régimen de giro y el Throttle $(n / \alpha)$ y dejar que el par se convierta en parámetro función de las otras dos variables. El otro modo (T/ $\alpha)$ no tiene sentido utilizarlo en esta instalación, ya que se dejaría el régimen de giro del motor como parámetro libre, cosa que comprometería la integridad de la instalación si se llegara a salir del rango de utilización del compresor.

- $\quad$ Motor de combustión interna alternativo. Características mecánicas

El motor utilizado en la instalación tiene dos misiones, por una parte ser el generador de flujo caliente y pulsante utilizado para ensayar la turbina $\mathrm{y}$, por otra, es el encargado de mover el compresor de tornillo que le dará el caudal de aire adecuado para ensayar las turbinas.

El modelo de motor en cuestión es un RVI-MIDR 06-20-45 (Renault Vehículos Industriales) destinado normalmente a su uso en vehículos de transporte público e industrial Originalmente se sobrealimentaba con un turbocompresor Schwitzer modelo 0.98-ZD2. 
Las principales características técnicas se muestran en la tabla 2. 5.

\begin{tabular}{|l|c|}
\hline Configuración & 6 cilindros en línea \\
\hline Diámetro/carrera & $120 \mathrm{~mm} / 145 \mathrm{~mm}$ \\
\hline Cilindrada & $9840 \mathrm{cc}$ \\
\hline Orden de encendido & $1-5-3-6-2-4$ \\
\hline Potencia máxima & $249 \mathrm{~kW}(338 \mathrm{cv})$ \\
\hline Par máximo & $1472 \mathrm{Nm}$ \\
\hline Régimen potencia máxima & $2000 \mathrm{rpm}$ \\
\hline Régimen par máximo & $1200 \mathrm{rpm}$ \\
\hline Consumo específico \\
Potencia máxima
\end{tabular}

Tabla 2. 5: Datos generales del motor. 
Contribución a la caracterización experimental y modelado de TGV en grupos de sobrealimentación tablas:

Otros parámetros geométricos del motor se detallan en las siguientes

\begin{tabular}{|c|c|}
\hline $\begin{array}{l}\text { Diámetro máximo del } \\
\text { Bowl }\end{array}$ & $0.075 \mathrm{~m}$ \\
\hline $\begin{array}{l}\text { Profundidad máxima del } \\
\text { Bowl }\end{array}$ & $0.025 \mathrm{~m}$ \\
\hline Volumen del Bowl & $98.37 \mathrm{~cm}^{3}$ \\
\hline Masa del pistón & $1.48797 \mathrm{~kg}$ \\
\hline $\begin{array}{l}\text { Superficie mojada cabeza } \\
\text { pistón }\end{array}$ & $0.01594 \mathrm{~m}^{2}$ \\
\hline Altura cabeza pistón & $0.06 \mathrm{~m}$ \\
\hline Relación de compresión & 16.97 \\
\hline
\end{tabular}

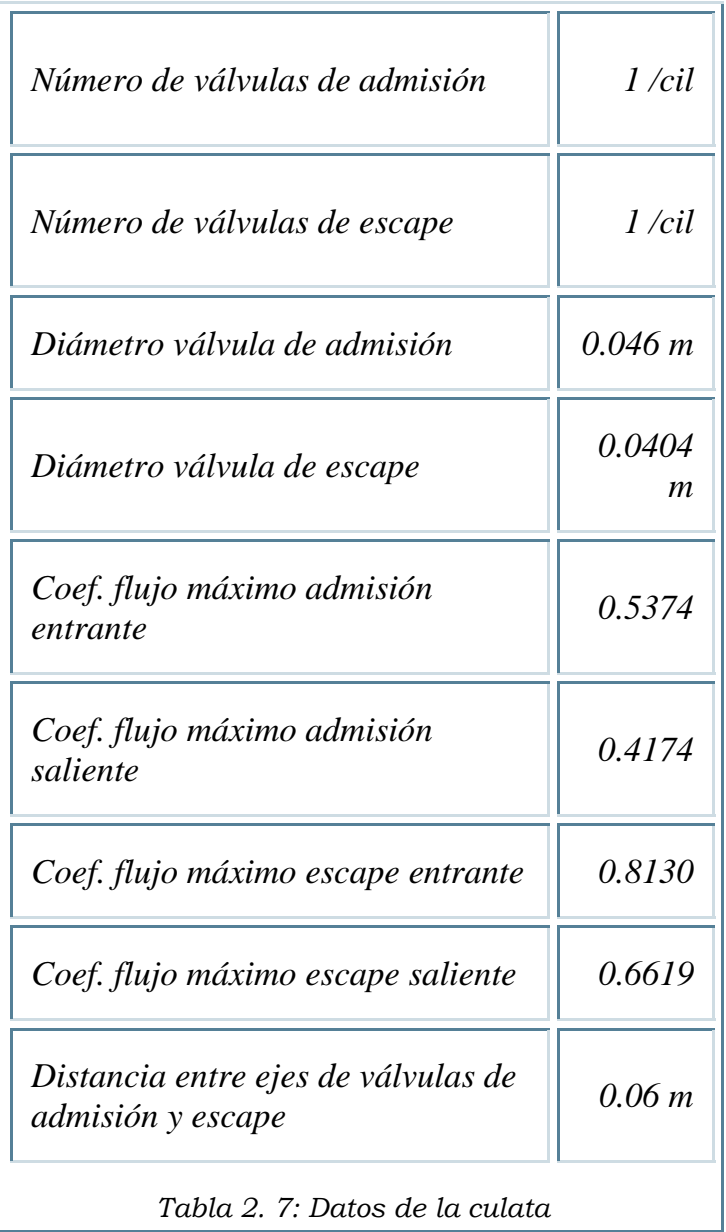

Tabla 2. 6: Datos del pistón

\begin{tabular}{|c|c|}
\hline Avance a la apertura de la admisión & $16^{\circ}$ \\
\hline Retraso al cierre de la admisión & $36^{\circ}$ \\
\hline Avance a la apertura del escape & $60^{\circ}$ \\
\hline Retraso al cierre del escape & $16^{\circ}$ \\
\hline
\end{tabular}

Tabla 2. 8: Datos del diagrama de distribución. 
El motor está fijado longitudinalmente a una bancada en forma de prisma rectangular mediante silent-bloks y es soportado por cuatro torretas regulables en altura.

Para su refrigeración se le ha dotado de un intercambiador de carcasatubos construido en acero y cobre, dispuesto para su funcionamiento en contracorriente. El propio circuito de refrigeración del motor cede la energía térmica excedente al sistema de refrigeración de las salas mediante este intercambiador, regulado por una válvula motorizada.

Para el control del motor, puesto que el sistema de alimentación de combustible es mediante bomba mecánica, se ha montado un servomotor eléctrico que acciona la palanca reguladora de la cantidad de combustible a inyectar, cuya precisión es óptima para el control de la instalación, más en concreto, del motor. Este servomotor se ha montado sobre un pie y éste a su vez sobre la bancada, a fin de que no haya un movimiento relativo entre el motor y su sistema de acelerador, de esta forma el control del motor es exacto en todo momento. Posee una varilla empujadora metálica que va montada por dentro de una funda que permanece estática. La varilla está conectada por un lado a la palanca de la bomba lineal de combustible del motor, y por el otro lado al servomotor, el cual la comanda. Este sistema se controla desde el programa de control y adquisición de datos que se encuentra en el PC de control de la instalación. Para apagar el motor se ha dispuesto un pistón neumático que actúa sobre la bomba de alimentación de combustible del motor y que es accionado por una electroválvula. Ambos sistemas accionan sus respectivos elementos mediante poleas y cables de acero.

El sistema eléctrico es básicamente el original, contando con dos baterías de $85 \mathrm{Ah}$. $12 \mathrm{~V}$. conectadas en serie y que son las encargadas de alimentar el motor de arranque. Este último es lo suficientemente potente como para arrastrar todo el sistema mecánico y vencer su inercia en los primeros momentos del arranque, es decir, mueve el motor, el freno, la caja multiplicadora y el compresor de tornillo. Por esta razón se desestimó la incorporación de un embrague que aislara al motor del resto de los elementos en el inicio de la puesta en marcha.

\subsubsection{Sala de control}

La sala de control es un recinto contiguo a la sala de ensayos desde donde se controla y regula la instalación. Existe un control visual de la sala de ensayos a través de una ventana de doble cristal mallado y un acceso a través de dos puertas blindadas.

En la sala de control se encuentra ubicado el puesto de trabajo del técnico que realiza los ensayos. En ella están instalados el PC de control y el rack que contiene los PID’s de las válvulas que controlan la temperatura del aire de admisión a la salida del intercooler, la temperatura del agua de 
Contribución a la caracterización experimental y modelado de TGV en grupos de sobrealimentación refrigeración de la sala, el módulo de regulación del freno y la electrónica de los caudalímetros, como se observa en la figura 2. 20 , en ella puede verse, en primer plano, el ordenador con el que se realizan las medidas instantáneas. En segundo plano se encuentra el ordenador desde el que se controla la instalación y se realizan las medidas.

También se encuentra en el interior de la sala de control un panel o sinóptico donde están centralizadas todas las funciones de ventilación, el sistema de bombas de refrigeración y el sistema de suministro de combustible. La centralita del sistema de vigilancia y alerta de atmósfera peligrosa también se halla ubicada en este recinto.

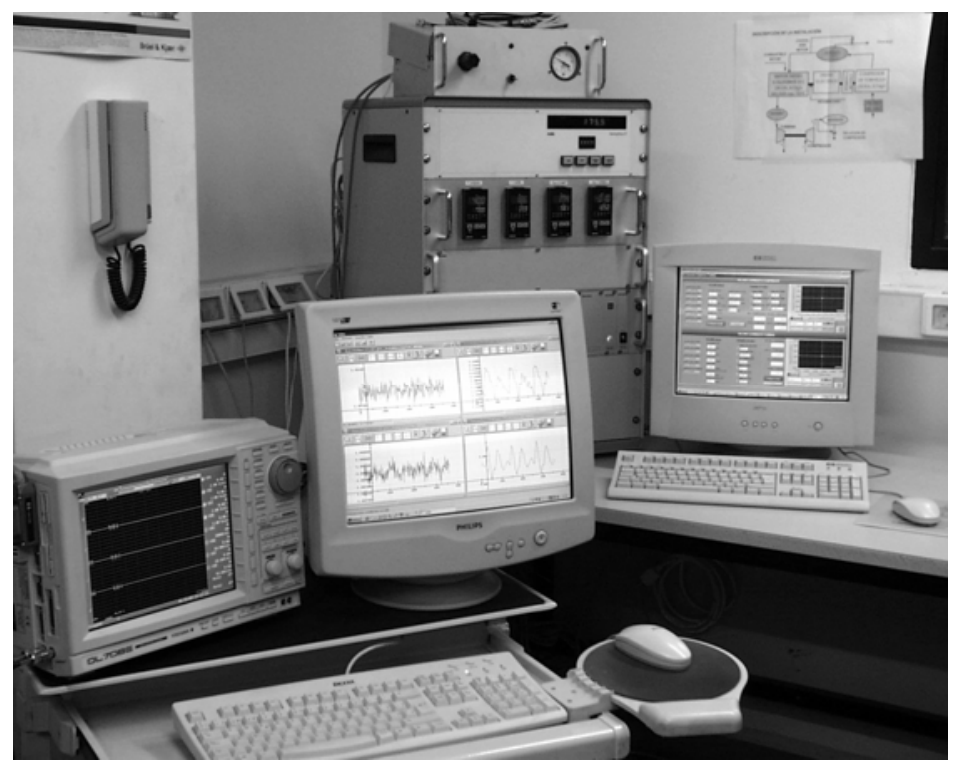

Figura 2. 20: Vista de la sala de control de la instalación. 


\subsection{Variables operativas de la instalación}

Antes de finalizar este capitulo se van a describir las variables operativas de la instalación, que se entienden como aquellas variables sobre las que se puede actuar directamente para variar las condiciones de funcionamiento del turbogrupo. Estas son:

- El número de cilindros que descargan a la turbina.

o El régimen de giro del motor.

- La masa de combustible inyectada al motor o el dosado, cuando se mantiene constante la masa de aire en la admisión.

o La apertura de la válvula de alivio de la admisión.

- La apertura de la válvula situada a la salida del compresor centrifugo.

- Número de cilindros que descargan a la turbina

Como se ha visto en el apartado 2.4 al describir las líneas de admisión y escape del motor se ha diseñado la instalación para que sea posible realizar ensayos con seis configuraciones diferentes, tres configuraciones cuando se alimenta la turbina directamente con flujo pulsante y estas mismas para el caso en que se sitúa el depósito entre el colector de escape y la turbina, de modo que el flujo que le llega es continuo. En cada uno de estos dos casos es posible alimentar la turbina con el aire proveniente de 1 cilindro, 3 cilindros o 6 cilindros.

El número de cilindros influirá directamente en el rango de caudales que podremos ensayar, así pues, es necesario tener en cuenta el tamaño del turbogrupo a ensayar antes de decidir la configuración que se va a utilizar para realizar los ensayos. En caso de duda es posible utilizar el modelado de la instalación para orientar en la toma de una decisión adecuada.

- Régimen de giro del motor.

El régimen de giro del motor está relacionado con la cantidad de aire que éste descargará a la turbina cuando se trabaje con una configuración determinada. Si la válvula de alivio de la admisión permanece fija en una posición, al variar el régimen de giro del motor se varía el caudal de gases de escape que trasegará la turbina, luego una vez fijado el rango de caudales con el número de cilindros se puede usar el régimen de giro del motor para regularlos. 
Puesto que el motor y el compresor volumétrico están acoplados mecánicamente por la caja multiplicadora que tiene una relación de 2:1 y el régimen de giro de trabajo del compresor volumétrico comprende el rango entre 1800 y $3600 \mathrm{rpm}$, el rango de regímenes de giro del motor queda reducido a 900-1800 rpm, rango en el cual el motor puede trabajar sin ninguna dificultad, como se vio en el apartado 2.4.3.

\section{- $\quad$ Combustible inyectado}

Por un lado, existe un combustible mínimo necesario para que la instalación funcione correctamente, puesto que el motor tiene que ofrecer una potencia superior a la que necesita el compresor de tornillo para trabajar a un régimen de giro determinado, de modo que se cumpla para cada ensayo la inecuación (2. 2):

$$
\dot{W} \text { motor } \geq \dot{W} \text { compresor tornillo+ }+\dot{W} \text { pérdidas mecánicas en la línea }
$$

Y teniendo en cuenta que la potencia del motor depende directamente de la masa del combustible, según la expresión (2. 3):

$$
\dot{\mathrm{W}}_{\mathrm{e}}=\eta_{\mathrm{e}} \cdot \dot{\mathrm{m}}_{\mathrm{f}} \cdot \mathrm{H}_{\mathrm{c}}
$$

Siendo $\eta_{\mathrm{e}}$ el rendimiento efectivo del motor, que será función del régimen de giro y del grado de carga del motor, $\mathrm{y}_{\mathrm{c}}$ el poder calorífico del combustible.

En el caso de que el motor proporcione más potencia de la que necesita el compresor, el freno absorberá la sobrante.

Por otro lado, la máxima cantidad de combustible inyectada será limitada atendiendo al dosado, de modo que va a estar muy relacionada con la posición de la válvula de alivio del compresor de tornillo.

Al establecer los límites que puede alcanzar el dosado lo habitual es referirse al dosado relativo [9]. Este valor de dosado relativo, para los ensayos habituales, suele estar alrededor de 0.2, como valor mínimo. En cuanto al límite superior, el dosado relativo, para motores de encendido por compresión (MEC), debe mantenerse por debajo de un cierto valor (entre 0.7 y 0.8) para evitar, en primer lugar, una opacidad en los humos excesiva y en segundo lugar que la temperatura de los gases a la entrada de la turbina supere un limite dado de $750{ }^{\circ} \mathrm{C}$ (la temperatura de los gases de escape en este tipo de motores aumenta casi linealmente con el dosado). Además, no es conveniente trabajar con dosados excesivamente altos para no dañar al motor, por la carbonilla que podría generarse dentro de los cilindros. También se debe cumplir que la presión máxima alcanzada en el interior de los cilindros sea 
menor que 170 bares. Esta presión depende tanto de la masa de combustible inyectado como de la presión del aire admitido por el motor.

Finalmente, la potencia máxima que el freno eléctrico puede disipar también será un condicionante $(230 \mathrm{~kW})$.

\section{- $\quad$ Apertura de la válvula de alivio}

La apertura de la válvula de alivio, del compresor de tornillo, está relacionada directamente con la presión en la admisión del motor y con la cantidad de aire que trasiega el motor. Si esta válvula se cierra aumentan tanto la presión de admisión como el aire que entra al motor. Así pues, estos parámetros serán los que marquen los límites en la apertura de la misma.

Para un régimen de motor dado, la máxima apertura vendrá determinada por la cantidad mínima de aire que necesita el motor para funcionar correctamente y la mínima presión de sobrealimentación requerida por el motor. La mínima apertura de la válvula estará determinada por el valor máximo de la presión de sobrealimentación, que variará en función del régimen de giro máximo del turbogrupo que se esté ensayando y que influye directamente en la presión máxima dentro del cilindro (170 bar). De tal forma que la válvula será un elemento más de regulación del caudal que junto con el régimen del motor y el número de cilindros confieren gran versatilidad a la instalación.

- $\quad$ Apertura de la válvula de contrapresión del compresor centrífugo

Esta válvula es la que controla la sección de paso del aire a la salida del compresor centrífugo. Con ella es posible regular el régimen de giro del turbogrupo, en el caso que se esté ensayando la turbina o la relación de compresión del compresor centrífugo en el caso que se esté ensayando éste. Efectivamente, es posible regular el régimen de giro en los ensayos de turbina con esta válvula puesto que éste varía a medida que cambia la relación de compresión.

Va a ser la relación de compresión máxima que puede alcanzar el compresor antes de entrar en bombeo o el mínimo gasto que pueda trasegar a un régimen de giro determinado lo que determine la mínima apertura de esta válvula. La máxima apertura está limitada por las condiciones de choque en el compresor, en este caso se obtendrá la mínima relación de compresión o el máximo gasto másico trasegado a un determinado régimen de giro. 


\subsection{Resumen}

A lo largo de este capítulo ha sido ampliamente descrita la instalación que se ha diseñado y puesto en marcha para el ensayo de turbogrupos destinados a la sobrealimentación de motores de encendido por compresión de automoción y de transporte pesado.

El capítulo comienza con una revisión de las instalaciones destinadas al ensayo de turbogrupos presentes en la bibliografia. Se vio que ninguna de ellas utiliza gases de escape reales de un motor alternativo para la obtención del flujo caliente necesario en el ensayo de turbinas, sino que utilizan quemadores o calentadores eléctricos para calentar el aire que trasiega la turbina y para la obtención de flujo pulsante utilizan válvulas rotativas. Además, muchas de ellas usan compresores movidos por motores eléctricos, lo que reduce enormemente la eficiencia energética de los ensayos.

En los dos siguientes apartados del capitulo se describe la instalación experimental diseñada, dividiendo esta descripción en cinco bloques. En primer lugar se realiza una descripción global de la instalación, en la que se nombran los principales elementos que la componen y se describe el recorrido de los gases que va a trasegar la turbina y del aire que va a trasegar el compresor.

A continuación se describe con detalle el circuito fluidodinámico del aire desde que entra en la sala hasta que es enviado después de haberse producido la combustión en el motor desde la turbina al tubo de escape.

En tercer lugar se describe en detalle el circuito fluidodinámico del aire que trasiega el compresor y se explica la posibilidad que existe de trabajar como un circuito cerrado con el fin de variar la densidad del aire a la entrada del compresor y de esta forma extender el rango de ensayo de la turbina.

En cuarto lugar se dan a conocer las características de los elementos que forman la línea de potencia de la instalación, formada por el motor, el freno, la caja multiplicadora, el compresor volumétrico y las transmisiones que unen entre sí estos cuatro elementos. En quinto lugar se describe brevemente la sala desde la que se controla el buen funcionamiento de la instalación y los ensayos.

Para finalizar el capítulo se hace un análisis principales variables operativas de la instalación que influyen en las prestaciones del turbogrupo a ensayar. Este análisis se hace tanto desde el punto de vista de límites de la turbomáquina (choque, bombeo, temperatura de los gases a la entrada de la turbina....) como de límites de la propia instalación (presión máxima en el cilindro, dosado máximo y mínimo.....) 


\section{Bibliografia}

[1] Chen, H., Hakeem, I. and Martinez-Botas, R. (1996). Modelling of a turbocharger turbine under pulsating inlet conditions. Proceedings of the Institution of. Mechanical Engineers, Vol 210, pp 397-407.

[2] Dale, A. and Watson, N. (1986). Vaneless diffuser turbocharger turbine performance. Proceedings of the Institution of. Mechanical Engineers, Part C. C110/86. pp 65-76.

[3] Creus, A. (1982) Instrumentros industriales. Su ajuste y calibración. Marcombo S.A. Barcelona. ISBN: 84-267-0452-2

[4] Furukawa, H., Yamaguchi, H., Takagi, K. and Okita, A. (1993) Reliability on Variable Geometry Turbine Turbocharger. SAE Technical Paper 930194.

[5] Hendricks, E., Chevalier, A., Jensen, M., Sorenson, S., Trumpy, D. and Asik, J. (1996) Modelling of the Intake Manifold Filling Dynamics. SAE Technical Paper. 960037.

[6] Lujan, J.M. Galindo, J. y Serrano, J.R. (2001) Efficiency characterization of centripetal turbines under pulsating flow conditions. SAE paper 2001-01-0272.

[7] Kessel, J.A., Schaffnit, J. and Schmidt, M. (1998) Modelling and realtime simulation of a turbocharger with variable turbine geometry (VTG). SAE Technical Paper 980770.

[8] Macek, J., Vávra, J. and Vítek, O. (2002) 1-D Model of radial turbocharger turbine calibrated by experiments. SAE Technical Paper 2002-01-0377.

[9] Muñoz, M., Payri, F. (1989) Motores de combustión interna alternativos. Sección de Publicaciones de la ETSII Fundación General UPM. ISBN 8486451019. Madrid

[10] Nasser, S.H. and Playfoot, B.B. (1999) A turbocharger selection computer model. SAE Technical Paper 1999-01-0559.

[11] Naundorf, D., Bolz, H. and Mandel, M. (2001). Design and Implementation of a New Generation of Turbo Charger Test Benches Using Hot Gas Technology. SAE Technical Paper 2001-01-0279. 
[12] Plint, M. and Martyr, A (1999) Engine Testing. Theory and practice. SAE Inc, $2^{a}$ ed. Isbn 0768003148

[13] Pucher, H. (2002) Overall engine process simulation - an important tool for the development of supercharged engines. ImechE Conference Transactions, C602/045/2002, pp. 155-166.

[14] Stemler, E. and Lawless, P. (1997) The Design and Operation of a Turbocharger Test Facility Designed for Transient Simulation. SAE Technical Paper 970344. 


\section{Capitulo 3: Diseño y puesta a punto de un procedimiento de medida para la caracterización de turbogrupos}

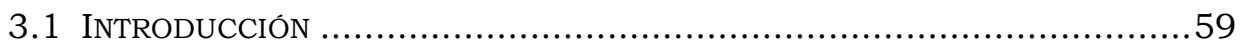

3.2 OBTENCIÓN DE LAS VARIABLES FUNDAMENTALES DEL TURBOGRUPO ........60

3.2.1 Ensayos de compresor ……………………………………………......65

3.2.2 Ensayos de turbina .............................................................................67

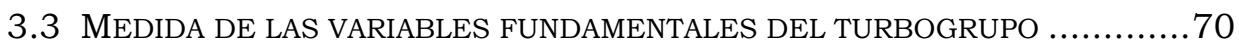

3.3.1 Análisis de la normativa existente ...........................................................70

3.3.2 Descripción de elementos y transductores usados en el procedimiento de

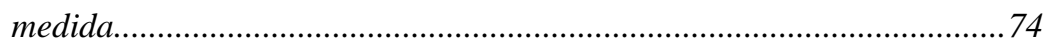

3.3.3 Descripción del sistema de adquisición de datos y control de la

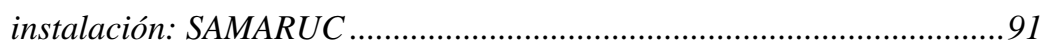

3.4 OBTENCIÓN DEL MAPA DE FUNCIONAMIENTO DEL TURBOGRUPO...............95

3.4.1 Análisis de la normativa existente .............................................................95

3.4.2 Estudio de estabilización de las variables..................................................97

3.4.3 Mapa de un compresor .........................................................................102

3.4.4 Criterio para discriminar los puntos de bombeo ....................................106

3.4.5 Mapa de una turbina: Análisis y elaboración del mapa de funcionamiento

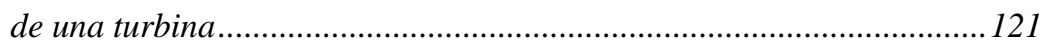

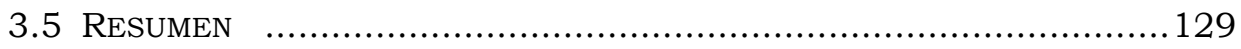

ANEXo 1: CÁlCULO DE LAS INCERTIDUMBRES DE LAS MEDIDAS..................131

Bibliografia................................................................... 136 



\subsection{Introducción}

En el capítulo anterior se ha realizado una exhaustiva descripción de todos y cada uno de los elementos que forman el banco específico para el ensayo de turbogrupos o Banco de Turbos. En este capítulo se va a revisar como es posible obtener los mapas de funcionamiento de los turbogrupos en dicha instalación.

El capítulo se ha divido en tres grandes apartados, en primer lugar se van a analizar las variables operativas del turbogrupo. Además se realizará una revisión en la que se relacionaran las variables operativas de la instalación, vistas en el capítulo anterior, con las variables operativas del turbogrupo, de forma que se verá como las primeras afectan al punto de funcionamiento en el mapa de la turbomáquina.

A continuación se describirá como alcanzar un determinado punto de funcionamiento, esto es, el proceso para llegar al punto de medida deseado. Para ello distinguiremos dos casos, las medidas de los puntos de funcionamiento del compresor y las medidas de los puntos de funcionamiento de la turbina.

Una vez alcanzado el punto de operación deseado, el siguiente paso es el de realizar la medida, y este paso es el que se describirá en el apartado 3.3, en el que revisará la normativa existente sobre la realización de medidas en turbomáquinas y se describirán tanto el procedimiento como la instrumentación utilizada para la realización de dichas medidas.

Seguidamente se realizará una revisión del tratamiento a realizar sobre las medidas para poder obtener los mapas de funcionamiento del turbogrupo: la normalización de las medidas, la elaboración de los mapas de funcionamiento del turbogrupo, así como un método para discriminar los puntos de bombeo del compresor frente a los puntos de funcionamiento estable.

Finalmente se realizará un estudio sobre la incertidumbre en la elaboración de los mapas de funcionamiento del turbogrupo atendiendo al error de los aparatos de medida y a la teoria de errores interpretada con criterios estadísticos. 


\subsection{Obtención de las variables fundamentales del turbogrupo}

Recordemos que un punto de funcionamiento de la turbina está definido por el gasto que trasiega la turbina, la relación de expansión que se produce y el régimen de giro del turbogrupo. Del mismo modo, el punto de funcionamiento de un compresor está definido por el gasto que trasiega el compresor, la relación de compresión que produce y el régimen de giro del turbogrupo. Las principales variables que determinan estos puntos de funcionamiento se describen a continuación, después la tabla 3. 1 muestra como están relacionadas las variables operativas de la instalación y las variables fundamentales del turbogrupo que se describen en este apartado.

- $\quad$ Temperatura de entrada a la turbina (TET)

Una de las variables más importantes en el ensayo de turbinas es la entalpía específica disponible en los gases de escape a la entrada de la turbina, ya que va a ser ésta, junto con el gasto másico, la que dé la disponibilidad energética de la turbina para realizar un determinado trabajo.

Es necesario recordar que la potencia suministrada por una turbina viene dada por la expresión:

$$
N_{T}=\dot{W}_{T}=\dot{m}_{E T} C_{p} T_{E T} \eta_{T} \eta_{m T}\left(1-\frac{1}{\left(\frac{p_{E T}}{p_{S T}}\right)^{\frac{\gamma-1}{\gamma}}}\right)
$$

Es posible modificar dicha entalpía influyendo en la temperatura de los gases a la entrada de la turbina modificando el dosado del motor de combustión interna alternativo. El dosado varía actuando de dos formas distintas, fijando la presión de admisión y actuando en la masa de combustible que se está inyectando, o viceversa.

Cuando se procede de la primera manera, lo que se hace es establecer un grado de apertura en la válvula de descarga de la admisión y actuar sobre el acelerador de la bomba de combustible. Para ello se ha dispuesto un sistema compuesto por un servomotor eléctrico para actuar sobre la cremallera de la bomba. El servomotor dispone de dos finales de carrera colocados en las proximidades de la leva de accionamiento de la cremallera de la bomba para conocer cuando alcanza una de sus posiciones extremas.

Por otro lado, si actuamos sobre la válvula de descarga, lo que sucede es que se modifica la presión en el colector de admisión y la masa de aire que 
Capitulo 3 Diseñoy puesta a punto de un procedimiento de medida para la caracterización de turbogrupos

trasiega el motor. Esta válvula puede ser controlada por el operario a través de un sistema electrónico desde la sala de control fijando un determinado valor porcentual que se traduce en una apertura de la válvula determinada. Sin embargo, no es la temperatura a la entrada de la turbina la principal variable a controlar por esta válvula, pues la regulación de la misma normalmente se lleva a cabo de manera automatizada mediante un PID fijando como valores de consigna determinadas variables del turbogrupo, como el régimen de giro o la relación de expansión.

\section{- $\quad$ Caudal de gases de escape}

Como muestra la expresión (3. 1) el gasto que trasiega la turbina influye, al igual que la temperatura de los gases a la entrada de la turbina, directamente sobre la potencia que ésta realiza.

Recordemos que el caudal de gases se escape, debido a su naturaleza de flujo caliente y con partículas no puede ser medido a la entrada de la turbina y, por lo tanto, se define como:

$$
\dot{m}_{E T}=\dot{m}_{a d m}+\dot{m}_{f}-\dot{m}_{B B}
$$

De los tres sumando que nos proporcionan el caudal de gases de escape el de mayor importancia es el primero, el aire que entra al motor que, como se verá, se mide con un caudalímetro a la entrada de éste. Teniendo en cuenta que este sumando es alrededor de un 95\% del total asumiremos las variaciones en él como las variaciones fundamentales en el caudal de los gases de escape a los efectos de control de la instalación.

En consecuencia, para una configuración determinada, basta regular el aire que admite el motor para regular el gasto por la turbina, este gasto se puede regular mediante el régimen de giro del motor, que, por estar acoplado al compresor volumétrico determina el gasto que llega al depósito de remanso de la admisión. Posteriormente, mediante la válvula de alivio en este depósito, se determina la fracción del gasto total que es conducida hacia el motor.

La regulación del régimen de giro del motor se realiza mediante el freno de corrientes de Foucault instalado y su electrónica de control, como se vió en el capítulo anterior.

A su vez el gasto másico de aire influirá directamente en la relación de expansión de la turbina para una posición dada de la misma (en el caso de una $\mathrm{TGV}$ ) o para un régimen de giro dado, de ahí que al cambiar el gasto másico de aire también se estará cambiando la otra variable que influye en la potencia de la turbina, la relación de expansión. 
- $\quad$ Régimen de giro del turbogrupo

El turbogrupo no produce potencia neta, sino que aumenta o disminuye su régimen de giro hasta igualar el trabajo producido en la turbina y el absorbido por el compresor [9].

Por ello el régimen de giro del turbogrupo depende tanto de las condiciones a la entrada de la turbina, que determinan el trabajo que ésta produce, como de las condiciones a la salida del compresor, que determinan la resistencia que éste ofrece al giro libre de la turbina debido al trabajo que invierte en comprimir el aire que trasiega.

En definitiva, que el régimen de giro del turbogrupo depende tanto del caudal de gases de escape y la entalpía de éstos, ya que son los que definen la potencia que produce la turbina, como de la apertura de las válvulas de contrapresión del compresor centrífugo, que regulan la potencia absorbida por el compresor.

Para unas condiciones dadas a la salida del compresor, conforme aumenta el caudal trasegado por la turbina, aumenta el trabajo producido, aumenta el régimen de giro, que también aumenta en el caso de que el caudal se mantenga constante y se aumente la temperatura de los gases de escape.

Por otro lado, para unas condiciones dadas a la entrada de la turbina, conforme disminuye la masa que trasiega el compresor aumentan la relación de compresión y el régimen de giro del turbogrupo. Esto implica que si se cierra la válvula de contrapresión del turbocompresor se produce un aumento de la relación de compresión y una disminución de la masa de aire por el compresor; el hecho adicional de que crezca el régimen de giro significa que, por lo general, a la turbina le cuesta menos trabajo mover un compresor que entrega altas relaciones de compresión que mover un compresor que entrega altos caudales másicos.

- Relación de compresión del compresor centrífugo

Este parámetro relaciona la presión de entrada al compresor, que es la presión ambiente, con la de salida. Por tanto, para modificar la relación de compresión se debe actuar sobre la presión a la salida del compresor, lo cual se consigue mediante las válvulas que se encuentran a la salida de un pequeño depósito de remanso situado en la descarga del compresor. Cerrando estas válvulas restringiremos el paso de aire y aumentará la presión a la salida del compresor, aumentando la relación de compresión.

El control de estas válvulas es el igual que el de la válvula de alivio de la admisión, es decir, puede ser regulada directamente por el operario a través de un sistema electrónico o bien mediante un controlador PID 
Capitulo 3 Diseñoy puesta a punto de un procedimiento de medida para la caracterización de turbogrupos estableciendo un valor de consigna para una determinada variable del turbocompresor.

Normalmente si se ensaya la turbina la válvula de contrapresión del compresor regula el régimen de giro del turbogrupo y si se ensaya el compresor, esta válvula regula la relación de compresión para un régimen de giro dado.

- $\quad$ Factor de pulsación

El factor de pulsación se ha definido en el capítulo anterior como:

$$
F p=\frac{p_{\text {máx }}-p_{\text {mín }}}{p_{\text {med }}} \cdot \frac{60 \cdot 2}{n \cdot z}
$$

Evidentemente, especialmente importante para variar la frecuencia de la pulsación es variar el número de cilindros que descargan a la turbina o el régimen de giro del motor, como se ve en la fórmula, pero también puede variarse este factor variando el combustible inyectado y/o el caudal másico por la instalación, que hace que cambie la amplitud de los pulsos de presión a la salida del motor, variando así la relación de presiones del factor de pulsación.

No obstante será conveniente distinguir entre frecuencia de los pulsos, definida por el régimen de giro del motor (n) y el número de cilindros que descargan a la turbina (z) y la amplitud de los mismos.

- Regulación y control de la instalación

El resumen de todo lo expuesto anteriormente se refleja en la siguiente tabla, donde las flechas indican el sentido en el que tienen que cambiar las variables de operación de la instalación para que aumenten las variables fundamentales del turbogrupo.

El subíndice $\mathrm{T}$ indica ensayo de turbina y el subíndice $\mathrm{C}$ indica ensayo de compresor. 


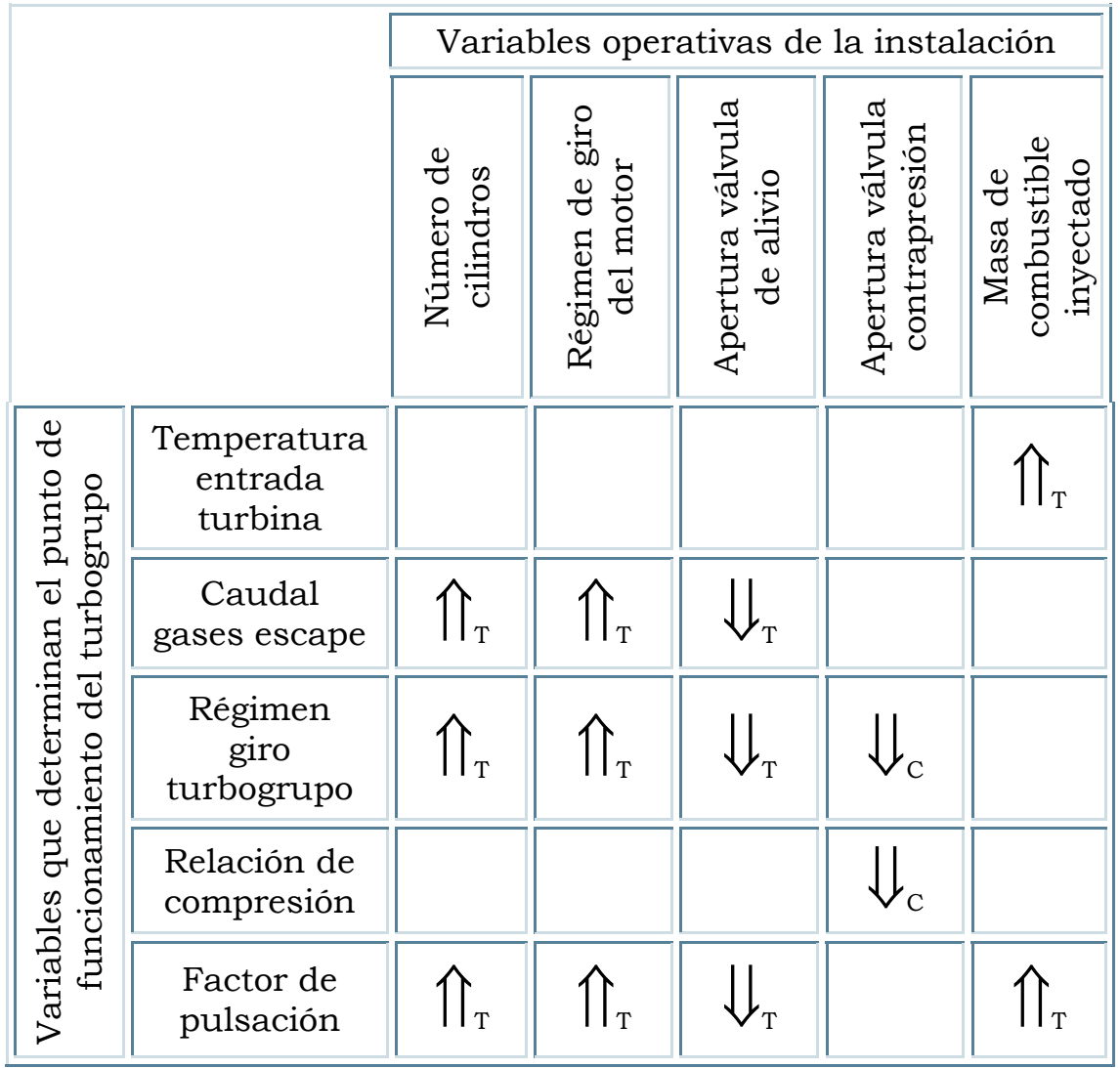

Tabla 3. 1: Relación entre las variables que es posible modificar en la instalación y las que determinan el punto de funcionamiento del turbogrupo.

- Regulación automática de las variables de funcionamiento del turbogrupo

El banco de turbos dispone de un sistema de control mediante PID que permite regular los puntos de funcionamiento a ensayar introduciendo valores de consigna para la variables que definen el funcionamiento del turbogrupo.

Uno de los PID se utiliza para controlar la válvula de alivio que regula la presión de admisión del motor y el otro regula la válvula de contrapresión del turbocompresor.

Para la regulación de los puntos de ensayo de la turbina se fijan el régimen de giro de la turbina y el gasto por la misma o la relación de expansión, ya que una vez fijadas dos de estas variables, la tercera de ellas estará definida. En este caso un PID actúa sobre la válvula de alivio de la 
Capitulo 3 Diseñoy puesta a punto de un procedimiento de medida para la caracterización de turbogrupos

línea de admisión para ajustar el valor del gasto que atraviesa la turbina o la relación de expansión. El régimen de giro se regula con el otro PID actuando sobre la válvula situada tras el compresor. De este modo se varía la resistencia que ofrece el compresor al giro del eje que lo une a la turbina y se regula, por tanto, el régimen de giro que puede alcanzar el turbogrupo. Por lo tanto, en el caso del ensayo de una turbina se utiliza el compresor como freno.

Para la regulación de los puntos de ensayo del compresor se fijan dos de las tres variables que caracterizan un punto de funcionamiento. Como lo habitual es ensayar líneas de isorégimen, una de las variables que se fijan es el régimen del compresor. Para regular esta variable un PID actúa sobre la válvula de alivio de la línea de admisión, que, al regular el gasto por la turbina, permite regular el régimen de giro para unas determinadas condiciones de salida, es decir, una determinada resistencia, del compresor. Para regular las condiciones de salida del compresor se fija como consigna bien la relación de compresión o bien el gasto con el otro PID actúa sobre la válvula de descarga situada tras el compresor hasta conseguir que la variable seleccionada se ajuste al valor de consigna. Así, estableciendo un régimen de giro del compresor y diferentes relaciones de compresión o gastos como consignas se pueden alcanzar de manera rápida y precisa los diferentes puntos de funcionamiento de cada línea isorégimen.

Con este sistema de control de regulación automática de las válvulas de alivio de la línea de admisión y de la válvula de descarga de la salida del compresor se acortan considerablemente los tiempos de ensayo, ya que el técnico al mando introduce las consignas deseadas y los PID se encargan de llevar el sistema al punto requerido para su posterior medición.

No obstante es necesario recalibrar las constantes de los PID cada vez que se cambia el turbogrupo a ensayar o se varía el número de cilindros del motor que están operativos en el ensayo.

\subsubsection{Ensayos de compresor}

Como se ha visto, cada punto de funcionamiento de un compresor está determinado por su régimen de giro, el gasto de aire que trasiega y la relación de compresión que está produciendo. También se ha visto que en la instalación es posible fijar dos de las tres variables, ya que entonces la tercera vendrá dada por el propio compresor.

Es importante señalar que antes de empezar los ensayos y en función del tamaño del compresor se tiene que decidir el número de cilindros del motor que descargarán gases de escape a la turbina, con lo que se determina la energía máxima que se va a proporcionar a la turbina, fijando así el régimen de giro máximo que será posible que alcance el compresor. Es 
posible que en algunos casos sea necesario realizar los ensayos para un solo mapa de compresor con varias configuraciones de la instalación.

Las medidas para elaborar el mapa del compresor se realizan siguiendo las líneas de isorégimen del compresor. La elección del régimen de giro por el que se comenzará a ensayar no es importante, puesto que se ha comprobado la repetitividad de las medidas. Ahora bien, generalmente, se empiezan los ensayos por el mínimo régimen de giro y se va aumentando la energía proporcionada a la turbina para ir aumentando poco a poco el régimen de giro del eje del turbogrupo. De modo que lo que se hace es ir aumentando poco a poco la cantidad de gases de escape que trasiega la turbina o la temperatura de los mismos, lo que hace que se vaya aumentando poco a poco la potencia de la turbina dentro de una de línea de isorégimen del compresor, e ir midiendo desde la linea de menor hasta las de mayor isorégimen. Se ha decidido proceder asi puesto que como se empieza por potencias bajas, las temperaturas que se alcanzan en la instalación son menores que las que se alcanzan al ir aumentando el régimen de giro y de este modo se estabiliza mejor cada punto, puesto que las temperaturas son la variables que más tiempo cuesta estabilizar en la instalación. Es posible así ahorrar tiempo de ensayo frente a comenzar por condiciones de ensayo de altas temperaturas y esperar a que se estabilice térmicamente la instalación para luego ir disminuyendo las temperaturas.

Dentro de una línea de isorégimen de giro del compresor se empieza a medir por el punto de mayor gasto trasegado por el compresor y menor relación de compresión producida. Este punto es en el que menos resistencia se opone a la salida del compresor, esto es, el punto en el que las dos válvulas que se encuentran a la salida del compresor están completamente abiertas. En este punto el comportamiento del compresor puede ser inestable y su rendimiento es muy bajo. Para seguir midiendo a lo largo de la línea de isorégimen, se van cerrando las electroválvulas, de modo que disminuye la cantidad de aire trasegado por el compresor y aumenta la relación de compresión producida. Los puntos sucesivos de deciden fijando el gasto que trasiega el compresor o la relación de compresión producida hasta llegar a la zona de comportamiento inestable del compresor, esto es, la zona de bombeo.

Como para mantener constante el régimen de giro del compresor se utiliza un controlador PID que regula la apertura de la válvula de alivio que se encuentra en el depósito de admisión (figura 2. 10). Si se llegara el caso en el que se cerrara esta válvula completamente y la cantidad de gases que trasiega la turbina no fuera suficiente para generar la potencia requerida para alcanzar el régimen de giro objetivo es posible aumentar el régimen de giro del motor, de modo que se aumenta este gasto de gases. Por otro lado es posible variar el régimen de giro del turbogrupo variando la temperatura de los gases de escape, lo que se consigue variando el dosado, esta opción todavía no está automatizada, pero sí se utiliza en caso de que sea necesario, por el operario que controla la instalación. 
Una vez recorrida toda la curva de isorégimen se modifica el control PID que regula el régimen de giro, dándole como consigna el régimen de la siguiente curva que se pretende medir. Es posible en este caso que no sea suficiente con que el PID cierre la válvula de alivio de la admisión y sea necesario que el operario aumente la temperatura de los gases de escape, aumentando el dosado, o que se tenga que aumentar el régimen de giro del motor.

Este proceso se repite tantas veces como lineas de isorégimen se pretenda medir para elaborar el mapa del compresor.

\subsubsection{Ensayos de turbina}

El mapa de una turbina representa para diferentes regímenes de giro el gasto másico corregido que atraviesa la turbina, frente a la relación de expansión que se produce en la misma. Para el caso de las turbinas de geometría variable (TGV) se presenta uno de estos mapas de funcionamiento para cada una de las diferentes posiciones de la turbina, siguiéndose la misma metodología de ensayo para cada una de ellas.

Así pues, una vez fijada la posición, en el caso de una TGV, lo que corresponde a una determinada apertura del estator, se ensaya a lo largo de diferentes líneas de isorégimen de giro. Los puntos de funcionamiento están limitados por los puntos de funcionamiento correspondientes del compresor, usado como freno en este caso, es decir, desde el correspondiente punto de bombeo del compresor (mínima potencia producida por la turbina) hasta el de máxima potencia consumida por el compresor a un determinado régimen de giro (punto próximo al punto de choque).

Al igual que ocurre en el caso del compresor es indiferente comenzar por una línea de isorégimen u otra. Se seguirá el mismo criterio de iniciar los ensayos por los puntos fríos para posteriormente ir elevando las temperaturas y medir los puntos calientes, de modo que se irá estabilizando térmicamente la instalación, por lo que se comienzan los ensayos por las líneas de mínimo régimen de giro.

Para el control del gasto trasegado por la turbina, fijado un régimen de giro del motor, se emplea la válvula de alivio de la admisión, que regula el gasto de admisión a los cilindros y con él el gasto trasegado por la turbina. Es evidente que antes de comenzar los ensayos y de acuerdo con el tamaño de la turbina que se vaya a ensayar se habrá montado la configuración del sistema de admisión más adecuada, como se vio en el capítulo anterior.

El régimen de giro del turbogrupo se regula con las válvulas de descarga situadas aguas abajo del depósito a la salida del compresor centrifugo. Como ya se ha comentado, estas válvulas actúan sobre las condiciones de salida, presión aguas abajo y gasto trasegado por el 
compresor, y, por tanto, sobre la resistencia ofrecida por éste al giro de la turbina, por lo que permite controlar el régimen de giro del turbogrupo.

Los ensayos de cada línea de isorégimen de la turbina pueden realizarse de varias formas diferentes, obteniéndose la misma curva con distintas metodologías de ensayo, a continuación se describe una de ellas, que nos asegura llegar a los limites de la instalación en cada curva, de forma que se ensaya el mayor rango posible. Además, la metodología se ha diseñado con el objetivo futuro de que sea automatizable.

Una vez elegido el número de cilindros que descargan a la turbina, adecuado al tamaño de la misma, se decide el régimen de giro a ensayar. Posteriormente se reposicionarán las válvulas aguas abajo del compresor de modo que la potencia que absorba el compresor sea máxima. Para que el caudal trasegado por la turbina sea máximo, a un régimen de giro determinado, la válvula que controla la descarga de la admisión deberá estar cerrada, de manera que todo el aire que salga del compresor volumétrico entre en la turbina. Si no es posible que está válvula esté completamente cerrada es porque el régimen de giro del motor no se puede disminuir más (recordemos que tenemos el régimen de giro del motor minimo limitado a 900 rpm), en este caso el régimen de giro se mantendrá en el mínimo posible y la válvula se abrirá hasta conseguir el régimen del turbogrupo deseado

Una vez alcanzado este punto, se puede seguir aumentando el caudal de gases de escape que trasiega la turbina, sin aumentar el régimen de giro, cerrando el circuito de sobrepresión del compresor. Si se aumenta la densidad del aire a la entrada del compresor el trabajo que éste absorbe también aumenta, de forma que frena a la turbina disminuyendo el régimen de giro del turbogrupo. Para recuperar el régimen de giro deseado se aumentará el régimen de giro del motor (si la válvula de la admisión estaba ya cerrada) o se cerrará la válvula de la admisión, si todavía estaba parcialmente abierta, aumentando posteriormente el régimen de giro del motor si fuera necesario. Esto es, se repite la misma operación que hemos descrito para alcanzar el primer punto.

Por el lado contrario, es decir, para minimos gastos trasegados por la turbina y mínimas relaciones de expansión lo que se requiere es que el compresor frene lo menos posible a la turbina, de modo que con muy poca energía disponible sea capaz de alcanzar el régimen de giro deseado. Con lo que habrá que llevar el compresor cerca de la zona de bombeo, puesto que es en este punto donde menos trabajo absorbe.

En este caso la válvula de la admisión deberá estar completamente abierta y se trabajará al mínimo régimen de giro del motor posible para alcanzar el régimen de giro del turbogrupo deseado con el mínimo gasto másico posible. Para aumentar el rango de ensayo, disminuyendo aún más el gasto trasegado y la relación de expansión es necesario entonces disminuir la 
Capitulo 3 Diseñoy puesta a punto de un procedimiento de medida para la caracterización de turbogrupos

densidad del aire a la entrada del compresor, de forma que éste disminuya todavía más el trabajo absorbido, de modo que es posible frenar menos la turbina, así que al disminuir la densidad del aire a la entrada del compresor el régimen de giro del turbogrupo aumenta, y de este modo es posible disminuir todavía más el gasto trasegado por la turbina. rutina.

Para cada grado de apertura que se desee estudiar se debe repetir esta

La automatización del control de las dos variables, régimen de giro de la turbina y gasto por la misma, permite ensayar la turbina en poco tiempo y con gran facilidad con diferentes grados de apertura.

Antes de aumentar o disminuir la presión a la entrada del compresor es aconsejable consultar las especificaciones del turbogrupo, para saber en que rango pueden realizarse estas variaciones de presión a la entrada del compresor, sin que ello pueda afectar al correcto equilibrado del eje del turbogrupo y a su sistema de lubricación. No se aconsejan variaciones de presión superiores a 0.5 bar con respecto a la ambiente.

Una vez conocidas estas especificaciones es pues posible ampliar el rango de funcionamiento de la turbina trabajando acoplada al compresor, sin necesidad de desmontar el turbogrupo ni utilizar dinamómetros [16] como se ha descrito anteriormente. 


\subsection{Medida de las variables fundamentales del turbogrupo}

Después de analizar con detenimiento las variables fundamentales del turbogrupo y ver cuales son los pasos que es necesario seguir para alcanzar los puntos de funcionamiento en los que se pretende medir, se describe ahora como se realiza la medida de estas variables.

En primer lugar se revisará la normativa existente relacionada con la instalación y la toma de medidas, a continuación se describirán los tubos de medida diseñados para colocar los captadores necesarios para realizar las medidas a la entrada y salida del turbogrupo y se describirán los captadores utilizados para la realización de las medidas en la instalación, finalmente se describirá el sistema de adquisición de datos.

\subsubsection{Análisis de la normativa existente}

Existe poca normativa en torno a la realización de ensayos de turbogrupos. La información útil, más adecuada a la instalación que en esta tesis se describe es la recogida por la Society of Automotive Engineers en su Supercharger Testing Standard [12] y en Turbocharger Gas Stand Test Code [14].

Dentro de esta normativa pueden encontrarse las definiciones básicas que es importante conocer a la hora de trabajar en el ensayo de turbogrupos, así como las condiciones de los ensayos y las correcciones necesarias en cada caso.

También puede encontrarse la siguiente información sobre el equipamiento que debe utilizarse en un banco de ensayo de turbogrupos.

Sobre las lineas de entrada y salida de los componentes del turbogrupo se especifica que:

- La linea de entrada empieza donde está situada la fuente que suministra el aire (que puede ser la atmósfera) y termina a la entrada de la turbomáquina. Esta línea debe ser diseñada con la menor cantidad de restricciones posibles. En el caso de que se quiera ensayar con restricciones de paso a la entrada de la máquina (debidas por ejemplo a la instalación de caudalimetros (figura 3. 1, figura 3. 2)) debe anotarse en los datos el diámetro de la restricción. El diámetro recomendado para los tubos de esta línea de entrada es el que se muestra en la tabla 3. 2.

Sobre la longitud de los tubos se especifica que deben tener por lo menos seis diámetros de largo antes de la transición 
Capitulo 3 Diseñoy puesta a punto de un procedimiento de medida para la caracterización de turbogrupos

a la entrada de la turbomáquina y debe contener los sensores de medida de presión y temperatura. La transición de entrada no debe exceder en longitud de 1.5 diámetros.

\begin{tabular}{|c|c|}
\hline Gasto de aire máximo & Diámetro del tubo \\
\hline Por debajo de $100001 / \mathrm{min}$ & $7.62 \mathrm{~cm}$ \\
De 10000 a $200001 / \mathrm{min}$ & $8.89 \mathrm{~cm}$ \\
De 20000 a $300001 / \mathrm{min}$ & $10.16 \mathrm{~cm}$ \\
Por encima de $300001 / \mathrm{min}$ & $12.7 \mathrm{~cm}$ \\
\hline
\end{tabular}

Tabla 3. 2: Especificaciones de los diámetros de los tubos.

- La linea de salida comienza a la salida de la turbomáquina y termina en la salida del aire a la atmósfera. En el caso del compresor, el sistema de salida deberá incluir una válvula para regular la relación de presiones.

El diámetro del tubo de salida deber ser igual al diámetro del tubo de entrada y, en cuanto a la longitud, se requieren 6 diámetros de largo, inmediatamente después de la transición de salida de la turbomáquina y este tubo debe contener, como en el caso del sistema de entrada, los sensores de medida de presión y temperatura. La transición a la salida de la turbomáquina no debe exceder de 1.5 diámetros. La línea entera debe ser lo menos restrictiva posible con la válvula completamente abierta de modo que cumpla que la caída de presión entre la salida de la turbomáquina y la atmósfera sea menor de $20 \mathrm{kPa}$ para el máximo régimen de giro del turbogrupo.

En cuanto a la instrumentación se destaca que la precisión requerida para los instrumentos de medida es:

- Régimen de giro: $\pm 0.2 \%$ del valor medido.

- Temperaturas: $\pm 1^{\circ} \mathrm{C}$ ó $0.5 \%$ del valor medido.

- Presiones: $\pm 0.5 \mathrm{kPa}$ ó $0.5 \%$ del valor medido.

- Gasto de aire: $\pm 1 \%$ del valor medido. 
Sobre la medida de la presión y temperatura se destaca que deben medirse para poder calcular el rendimiento de la turbomáquina y corregirlas con la presión y temperatura normales o de referencia.

Las turbomáquinas están afectadas por la densidad del aire, para tener una base común de comparación se hace necesario aplicar factores de corrección para tener en cuenta las diferencias entre las condiciones de referencia y las condiciones ambiente en las que se realizan las medidas.

\begin{tabular}{|c|c|c|}
\hline & $\begin{array}{c}\text { Condiciones } \\
\text { normales }\end{array}$ & $\begin{array}{l}\text { Rango de límites } \\
\text { recomendados en } \\
\text { los ensayos }\end{array}$ \\
\hline $\begin{array}{l}\text { Presión del aire a la entrada (Absoluta) } \\
\text { Presión Aire Seco (Absoluta) } \\
\text { Temperatura del aire a la entrada }\end{array}$ & $\begin{array}{l}100 \mathrm{kPa} \\
99 \mathrm{kPa} \\
25^{\circ} \mathrm{C}\end{array}$ & $\begin{array}{l}-- \\
90 \text { to } 105 \mathrm{kPa} \\
15 \text { to } 35^{\circ} \mathrm{C}\end{array}$ \\
\hline
\end{tabular}

Tabla 3. 3: Condiciones atmosféricas de referencia según "Supercharger Testing Standard" [12] para las que son válidos los procedimientos de corrección.

Los procedimientos de medida de la presión y la temperatura del gas a la entrada y salida de la turbomáquina que se presentan en la normativa son los que se muestran a continuación.

- Medida de la presión del gas a la entrada: La medida de la presión a la entrada deberá ser el valor medio de dos medidas de presión absoluta realizadas a una distancia de entre 1 y 2 diámetros antes de la transición de la entrada de la turbomáquina. Los transductores deben situarse perpendiculares a las paredes del tubo de medida, separados 180 grados entre ellos y cada uno a 90 grados relativos a la posición de los captadores de temperatura.

- Medida de la presión del gas a la salida: La medida de la presión a la salida deberá ser el valor medio de dos medidas de presión absoluta realizada a una distancia de entre 1 y 2 diámetros después de la transición de salida de la turbomáquina. Los transductores deben situarse perpendiculares a las paredes del tubo y a 45 grados relativos a la posición de los captadores de temperatura y, por lo menos, separados 90 grados entre ellos.

- Medida de la temperatura del gas a la entrada: Deberá realizarse al menos dos medidas de la temperatura a la entrada de la turbomáquina, situando los captadores a una distancia de entre 2 y 3 diámetros de la transición a la entrada de la turbomáquina. Los captadores deberán situarse perpendiculares a las paredes del tubo y a 180 grados uno del otro, además deben estar insertados a 1 / 3 del diámetro del tubo. 
- Medida de la temperatura del gas a la salida: Igual que la medida de la temperatura del gas a la entrada de la turbomáquina, deberá realizarse a una distancia de entre 2 y 3 diámetros desde la transición, evidentemente, en este caso de la transición de salida de la turbomáquina. En este caso deben situarse cuatro sensores a separados 90 grados entre ellos. Deben insertarse en el tubo de forma perpendicular a las paredes de éste, los captadores situados a 0 y 180 grados deben situarse a $1 / 3$ del diámetro del tubo, el captador situado a 90 grados debe insertarse hasta $1 / 2$ del diámetro del tubo y el captador situado a 270 grados debe insertarse hasta $1 / 4$ del diámetro del tubo. El valor medio de estos cuatro captadores es lo que se denominará temperatura del gas a la salida de la turbomáquina $\mathrm{y}$, por supuesto, no deben utilizarse ningún mecanismo o ventilador para reducir la temperatura del gas en la linea de salida antes de la medida de la temperatura.

Tal como se formulan estos procedimientos son aplicables al compresor y para la turbina se modificarán las disposiciones en la entrada y en la salida.

Sobre el proceso de medida se señala que el turbogrupo debe estar montado de acuerdo con las especificaciones del fabricante, teniendo en cuenta las especificaciones en cuanto a la lubricación y, en caso de ser necesario, las especificaciones sobre la refrigeración, vigilando la temperatura, presión y caudal del liquido refrigerante. Deberá aislarse, al menos, la voluta del compresor, y las líneas de salida, por lo menos hasta un diámetro después del punto donde se ha situado la instrumentación de medida de la temperatura.

Por otro lado, a la hora de decir el número de medidas a realizar ha de tenerse en cuenta qué líneas de isorégimen deben medirse y los puntos que han de medirse en cada linea deben estar suficientemente próximos entre si como para que no sea necesario realizar interpolaciones severas. Una práctica común es empezar a medir por los regímenes de giro más bajos, desde gasto másico máximo a mínimo, manteniendo el régimen de giro constante.

Como criterio de estabilización se impone que el régimen de giro del turbogrupo no debe variar más del $0.2 \%$ ó $\pm 10 \mathrm{rpm}$, eligiéndose el criterio mayor en cada caso.

Además, se define el cambio de temperatura adimensional [3], para un instante $\mathrm{t}$, como:

$$
\text { o Compresor } \quad \zeta_{t}=\frac{T_{S C, t}-T_{E C, t}}{T_{E C, t}}
$$




$$
0 \text { Turbina } \quad \zeta_{t}=\frac{T_{E T, t}-T_{S T, t}}{T_{S T, t}}
$$

Como ejemplo de criterio de estabilización se sugiere utilizar que la variación relativa entre dos cambios de temperatura adimensionales tomados en instantes sucesivos, (3. 6), sea menor de un 0.5\%[3][14]; cuando eso ocurra se habrá alcanzando una situación estable y la medida realizada será valida.

$$
\xi=\frac{\zeta_{t 2}-\zeta_{t 1}}{\zeta_{t 1}}<0.005
$$

Además, antes de comenzar los ensayos de un turbogrupo debe realizarse el rodaje del mismo, siguiendo las directivas del fabricante. En caso de que no se tenga esta información el rodaje que debe realizarse es el que se muestra en la tabla 3. 4.

\begin{tabular}{|c|c|c|c|}
\hline \multicolumn{1}{|l|}{} & Tiempo (min) & Régimen de giro & Relación de compresión \\
\hline 1 & 10 & $1 / 3$ del máximo & Mínima \\
2 & 5 & $2 / 3$ del máximo & $1 / 2$ de la máxima \\
3 & 3 & Máximo & Máxima \\
4 & 5 & $2 /{ }_{3}$ del máximo & $1 / 2$ de la máxima \\
5 & 5 & $1 / 3$ del máximo & Mínima \\
\hline
\end{tabular}

Tabla 3. 4: Especificaciones para el rodaje de un turbogrupo.

\subsubsection{Descripción de elementos y transductores usados en el procedimiento de medida.}

A partir de la normativa revisada [12][14] y atendiendo a los caudales que cada turbogrupo va a ser capaz de trasegar se han construido las líneas de entrada y salida al compresor y a la turbina siguiendo el esquema de la figura 3. 1 y de la figura 3. 2 . 
Capitulo 3 Diseñoy puesta a punto de un procedimiento de medida para la caracterización de turbogrupos
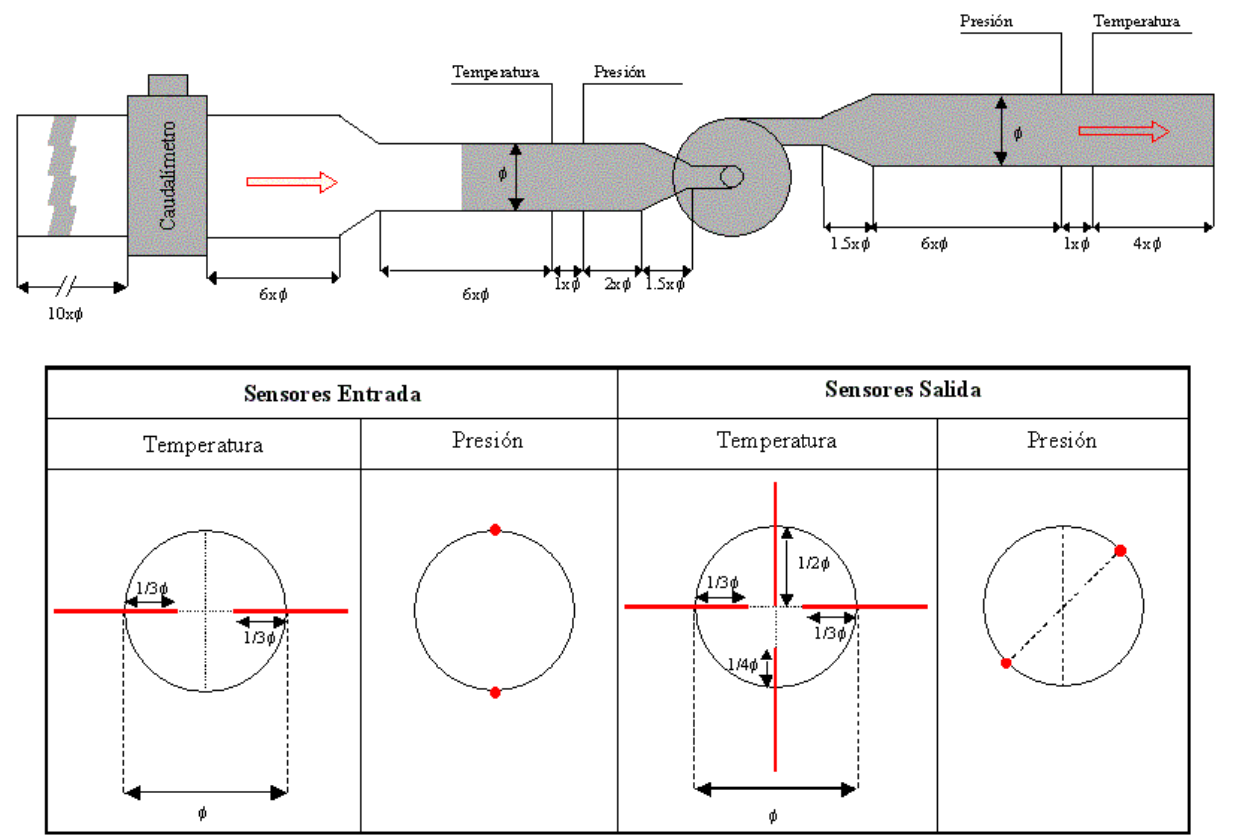

Figura 3. 1: Esquema de las líneas de entrada y salida del compresor, de la situación y posición de los captadores de presión y temperatura.

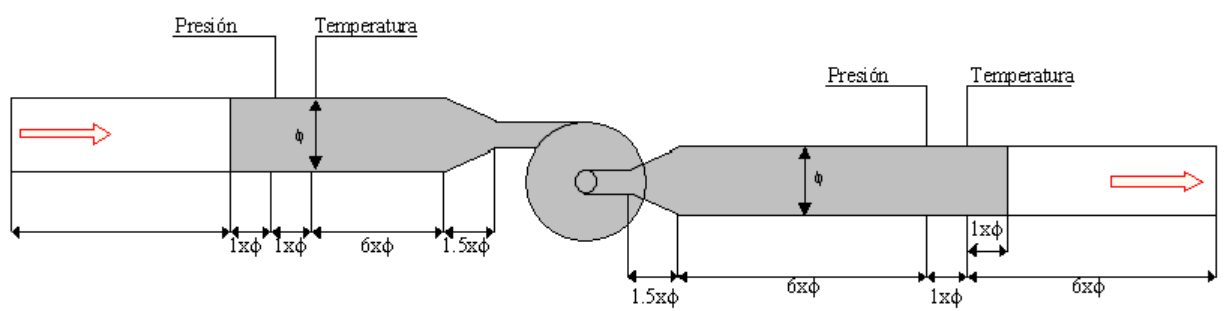

\begin{tabular}{|c|c|c|c|}
\hline \multicolumn{2}{|c|}{ Sensores Entrada } & \multicolumn{2}{c|}{ Sensores Salida } \\
\hline Temperatura & Presión & Temperatura & Presión \\
\hline
\end{tabular}

Figura 3. 2: Esquema de las líneas de entrada y salida de la turbina, de la situación y posición de los captadores de presión y temperatura. 
Como se observa en las figuras no se ha seguido de forma estricta la normativa vista a lo largo del apartado sino que se ha completado atendiendo a la experiencia adquirida en la medida de presión y temperatura en los conductos de los MCIA. A la salida de la turbina se han colocado cuatro termopares, ya que es una de las medidas más importantes de la instalación y una de las más dificiles de realizar, debido a la naturaleza del flujo en ese punto. La zona que se representa en las figuras de color gris está aislada térmicamente del ambiente con lana de roca.

Teniendo en cuenta los rangos de medida que cubren los turbogrupos que van a ensayarse en este banco de ensayo se han construido dos grupos de tubos de medidas, un conjunto de diámetro $51 \mathrm{~mm}$ y el otro conjunto con tubo de diámetro $81 \mathrm{~mm}$. El primer conjunto está destinado a los ensayos de los turbogrupos para la sobrealimentación de motores de vehículos ligeros y el segundo conjunto se construyó para el ensayo de turbogrupos destinados a la sobrealimentación de motores de vehículos de transporte pesado.

Se pasa ahora a describir la instrumentación que se utiliza en la sala de ensayos, con el fin de realizar los ensayos de forma rigurosa, eficiente y repetitiva. Se distinguirá según la magnitud física que se desea medir y se comenzará describiendo las medidas de presión que se realizan en la instalación.

\section{- Medida de presión}

La medida de presión tiene una importancia notable en los ensayos de turbogrupos. Es una de las variables básicas que define el comportamiento de la turbina y el compresor, es por ello que es necesario medir muy bien la presión a la entrada y a la salida de la turbina y el compresor del turbogrupo ensayado, para poder calcular correctamente la relación de expansión y compresión, así como las variables que dependen de esta magnitud.

Los dispositivos generalmente utilizados para registrar la presión instantánea, son los transductores eléctricos, ya que son de respuesta rápida, monitorizables, y sobre todo, muy adecuados para fenómenos de alta frecuencia.

La señal que proporcionan estos captadores es necesario acondicionarla, para ello se utilizan unos amplificadores que se encargan de convertir, transformar y amplificar la señal proveniente del captador, a una señal del orden de voltios fácilmente registrable por un sistema oscilográfico.

Entre los medidores de presión instantánea aplicables en nuestra instalación podemos destacar: los piezoeléctricos y los piezorresistivos.

Los transductores piezoeléctricos están basados en la propiedad de algunos cristales, generalmente cuarzo, aunque también se utilizan de sal de 
Capitulo 3 Diseñoy puesta a punto de un procedimiento de medida para la caracterización de turbogrupos

Rochelle y de titanio de bario, que son capaces de generar una carga eléctrica cuando se les somete a una cierta presión. Es por ello que son llamados captadores activos, ya que no necesitan ser excitados exteriormente.

Las principales ventajas que presentan son la casi linealidad de su respuesta, el alto rango dinámico, las altas frecuencias naturales, su elevada resistencia térmica (con temperaturas máximas de hasta $300{ }^{\circ} \mathrm{C}$, sin refrigerar), además de poseer un tamaño reducido y elevada robustez.

El mayor inconveniente que encontramos en ellos es la falta de presión de referencia con un nivel de cero variable, que lo imposibilita para realizar mediciones absolutas. De igual modo, son muy sensibles a los cambios bruscos de temperatura, y precisan ajuste de impedancias en caso de fuertes aceleraciones.

La señal de salida es muy débil, del orden de picoculombios, por lo que necesitan de un amplificador/acondicionador que transforme una señal analógica en voltios.

También hay que destacar que son muy sensibles al ruido externo y a los parásitos eléctricos. Por ello, es muy importante una adecuada elección de los cables conductores y de sus longitudes, además de mantener en perfecto estado todas las conexiones.

Por otro lado se encuentran los captadores piezorresistivos, que a diferencia de los anteriores son indirectos, es decir, necesitan de alimentación exterior para su funcionamiento, y es precisamente de esa alimentación exterior de la que nos servimos para cuantificar la presión a la que están sometidos, puesto que se basan en la propiedad de los semiconductores de modificar su resistencia cuando son deformados.

Son adecuados tanto para medir presiones medias como instantáneas, además de presentar una elevada sensibilidad y rango de frecuencias muy amplio.

Por el contrario, son muy sensibles a la temperatura, y su resistencia eléctrica varia con ella. Necesitan refrigeración para no sobrepasar la temperatura máxima de trabajo, que es de $100{ }^{\circ} \mathrm{C}$.

Estos captadores son más baratos que los piezoeléctricos, aunque también necesitan de un acondicionador de señal.

Los captadores finalmente utilizados en la instalación son del tipo piezorresistivo, fundamentalmente debido a que son capaces de medir presiones medias y no solo variaciones de presión. Para realizar medidas de presión instantánea se utilizan captadores de la marca Kistler modelo 4045 A 
Contribución a la caracterización experimental y modelado de TGV en grupos de sobrealimentación

5, con amplificadores Kistler también, modelo 4603. Su rango de medida de presiones es 0-5 bar, su sensibilidad $100 \mathrm{mV} /$ bar y su precisión es del $0.1 \%$.

Además de los amplificadores, estos captadores necesitan otro complemento para su correcto funcionamiento. Para protegerlos de las altas temperaturas que soportan en los conductos de escape, es necesario montarlos sobre mini-refrigeradores. La experiencia adquirida en el Instituto CMT-Motores Térmicos aconseja una doble refrigeración de estos dispositivos para asegurar su integridad bajo cualquier condición de trabajo. Debido a esto, además de los refrigeradores originales se ensamblan coaxialmente otros diseñados y construidos expresamente.

Captadores de este tipo son los que se encuentran situados en las líneas de entrada y salida tanto de la turbina como del compresor del turbogrupo a ensayar. Su situación y colocación es las que se muestra en la figura 3. 1 y en la figura 3. 2 y con ellos es posible medir presiones medias y obtener medidas de los pulsos de presión a frecuencias suficientemente elevadas.

Además se ha colocado otro captador de presión piezorresistivo en el colector de escape, para tener medidas de los pulsos de presión instantánea a la salida del motor.

Para realizar medidas de presiones medias en otros puntos de la instalación se utilizan también captadores piezorresistivos, de la marca Philips, modelo PMA 9407 242, estos captadores no necesitan amplificador. $\mathrm{Su}$ rango de medida de presiones es de 0-1.6, de 0-6 y de 0-10 bar. Su precisión es del $0.3 \%$

Se utilizan estos captadores para realizar medidas de presión en diferentes puntos de la instalación, como los colectores de admisión y escape, el aceite de lubricación del turbogrupo y del motor, a la salida del intercambiador de calor.

Las principales características de los captadores de presión utilizados en la instalación se resumen en la tabla 3. 5 . 
Capitulo 3 Diseñoy puesta a punto de un procedimiento de medida para la caracterización de turbogrupos

\begin{tabular}{|c|c|c|c|c|}
\hline \multicolumn{5}{|c|}{ Captadores de presión piezorresistivos } \\
\hline & Presiones & \multicolumn{3}{|c|}{ Presiones medias } \\
\hline Modelo del captador & $\begin{array}{c}\text { Kistler } 4045 \\
\text { A5 }\end{array}$ & $\begin{array}{c}\text { PMA } \\
9407242 \\
03311\end{array}$ & $\begin{array}{c}\text { PMA } \\
9407242 \\
03341\end{array}$ & $\begin{array}{c}\text { PMA } \\
9407242 \\
03351\end{array}$ \\
\hline $\begin{array}{l}\text { Modelo del } \\
\text { amplificador }\end{array}$ & Kistler 4603 & -- & -- & -- \\
\hline $\begin{array}{l}\text { Rango de medida } \\
\text { (bar) }\end{array}$ & $0-5$ & $0-1.6$ & $0-6$ & $0-10$ \\
\hline $\begin{array}{l}\text { Sensibilidad } \\
\text { (mV/bar) }\end{array}$ & 100 & -- & -- & -- \\
\hline Precisión (\%) & 0.1 & 0.3 & 0.3 & 0.3 \\
\hline Punto de aplicación & $\begin{array}{l}\text {-Salida } \\
\text { compresor } \\
\text {-Entrada } \\
\text { turbina } \\
\text {-Salida turbina } \\
\text {-Colector de } \\
\text { escape del } \\
\text { motor }\end{array}$ & $\begin{array}{l}\text {-Ambiente } \\
\text {-Entrada } \\
\text { compresor }\end{array}$ & $\begin{array}{l}\text {-Aceite del } \\
\text { turbogrupo } \\
\text {-Colector } \\
\text { de } \\
\text { admisión } \\
\text {-Salida del } \\
\text { intercooler }\end{array}$ & $\begin{array}{l}\text {-Aceite del } \\
\text { motor }\end{array}$ \\
\hline
\end{tabular}

Tabla 3. 5: Principales características de los captadores de presión piezorresistivos, utilizados para realizar las medidas en la instalación.

- $\quad$ Medidas de temperatura

La medida de temperatura de los fluidos que circulan por la instalación de una sala de ensayos es una de las pautas más comunes a la par que importantes. Además, con ella se pueden obtener otros parámetros asociados, como la densidad del fluido, en un determinado punto.

La temperatura es una magnitud fisica intensiva que no se puede medir directamente, sino a través de otra magnitud relacionada con ella misma.

Por ello, hay que tener en cuenta que para todos los sistemas de medida conocidos, su principal inconveniente es el elevado tiempo de respuesta, ya que una correcta medición se produce al alcanzarse el 
equilibrio entre el aparato de medida y el fluido a medir, lo que dificulta, por el momento, la medida de temperaturas instantáneas de los gases de escape.

Sin embargo, como la medida de la temperatura es fundamental en el estudio de los procesos asociados al funcionamiento del motor y del turbogrupo, se ha adoptado casi universalmente el uso de termómetros eléctricos para la obtención de valores medios de esta variable. Entre los termómetros más empleados en los ensayos del tipo de los que vamos a realizar en la instalación se pueden citar las termorresistencias y los termopares, ya que presentan una alta sensibilidad y precisión, aunque su mayor inconveniente es que son lentos en la respuesta.

Las termorresistencias son resistencias de metal cuyo valor varía linealmente con la temperatura. Esta variación será mas o menos acentuada en función del material empleado es lo que se conoce como coeficiente de temperatura $(\mathrm{dR} / \mathrm{dT})$ que indica la variación, en ohms, de la resistencia por cada grado de temperatura.

Los metales más utilizados son: el platino, el cobre, el níquel y el wolframio. De los cuales, el platino es que más linealidad presenta aunque también es el más caro. La variación de la resistencia de estos metales se suele medir mediante un puente de Wheastone. Estos materiales presentan características tales como:

- Alta resistividad.

- Alto coeficiente de temperatura de la resistencia.

- Relación lineal resistencia-temperatura.

- Tenacidad y ductilidad.

- Estabilidad de sus características durante su vida útil.

De todos los termómetros eléctricos, las termorresistencias son las que mejor linealidad, precisión y estabilidad presentan. Por el contrario, su sensibilidad es baja, ya que la variación de la resistencia con la temperatura es pequeña y su respuesta lenta. Además requieren de alimentación exterior y son de precio elevado.

Por todo lo expuesto anteriormente, son adecuadas para medir en sistemas donde la temperatura no es muy alta y no evoluciona rápidamente, como por ejemplo el turbocompresor.

Por su funcionamiento simple, los termopares son los más utilizados. Su principio de funcionamiento está basado en la propiedad de ciertos metales por la que acoplados mediante dos uniones a distinta temperatura, 
Capitulo 3 Diseñoy puesta a punto de un procedimiento de medida para la caracterización de turbogrupos generan una fuerza electromotriz (diferencia de potencial). El montaje consiste en una unión caliente que está en contacto con el medio que se quiere medir y una unión fría sometida a una temperatura de referencia. La fuerza electromotriz generada depende de los materiales que forman ambas uniones. Normalmente la unión fría se encuentra en el sistema de adquisición a temperatura ambiente, tomándose ésta como referencia para corregir el valor de temperatura asociado a la fuerza electromotriz generada por la unión caliente.

Dependiendo de los metales que intervienen en las uniones, existen diferentes termopares. Su elección vendrá determinada por el rango de temperaturas a medir y por la atmósfera existente, aunque las uniones pueden ir recubiertas por una vaina que asegura la protección mecánica y química del termopar.

Como muestra la tabla 3. 6 dependiendo de los elementos que formen el termopar su rango de medida varía.

Las principales ventajas de estos termómetros son su moderado coste, su funcionamiento simple, su bajo tiempo de respuesta, la gran variedad de configuración y el amplio rango de temperaturas dónde pueden medir, además de no necesitar alimentación exterior.

Por otro lado, sus mayores inconvenientes son la falta de linealidad, la baja tensión de salida, que son poco estables y sensibles y la necesidad de una unión de referencia.

\begin{tabular}{|c|c|c|}
\hline \multicolumn{1}{|c|}{ Tipo } & Conductores & Rango de medida $\left({ }^{\circ} \mathrm{C}\right)$ \\
\hline $\mathrm{B}$ & Platino 30\%- Rodio o Platino 6\% -Rodio & 870 a 1700 \\
$\mathrm{E}$ & Cromel-Constantán & 0 a 870 \\
$\mathrm{~J}$ & Hierro-Constantán & 0 a 750 \\
$\mathrm{~K}$ & Cromel-Alumel & 0 a 1260 \\
$\mathrm{R}$ & Platino $13 \%$ - Rodio o Platino puro & 0 a 1480 \\
$\mathrm{~S}$ & Platino 10\%-Rodio o Platino puro & 0 a 1480 \\
$\mathrm{~T}$ & Cobre-Constantán & -180 a 370 \\
\hline
\end{tabular}

Tabla 3. 6: Tipos de termopares existentes en el mercado, con lo elementos que los componen y el rango de utilización de cada uno de ellos. 
Contribución a la caracterización experimental y modelado de TGV en grupos de sobrealimentación

En las salas de ensayo para motores, los termopares más utilizados son de tipo T (Crómel-Constantán), los de tipo J (Hierro-Constantán) y los de tipo K (Crómel-Alumen), siendo estos últimos los de respuesta más lineal.

Vistas las características y el rango de trabajo de los diferentes termómetros, para realizar las medidas de temperatura en la instalación se ha optado por:

- Termorresistencias Pt100, en la línea del compresor, para el sistema de admisión y el sistema de refrigeración del motor. También para la medida de la temperatura del combustible y del aceite de lubricación del motor y del turbo.Para la medida de las temperaturas del aire aguas abajo y aguas arriba del compresor se utilizan termorresistencias descubiertas y en este caso la unión de medida está rodeada por el gas cuya temperatura se quiere medir.

- Termopares tipo K: Es el termopar más utilizado por su amplio rango. Es muy adecuado para atmósferas oxidantes. En la instalación se ha utilizados para medir temperaturas en el colector de escape, en el depósito de remanso para amortiguar los pulsos a la entrada de la turbina y en los tubos de las líneas de entrada y salida de la turbina.

Las principales características de estos captadores se resumen en la tabla 3. 7 .

\begin{tabular}{|l|c|c|}
\hline \multicolumn{2}{|c|}{ Captadores de temperatura } \\
\hline & Termorresistencias & Termopares \\
\hline Tipo & Pt 100 & $\mathrm{~K}$ \\
\hline Rango de medida $\left({ }^{\circ} \mathrm{C}\right)$ & $-200 \sim 390$ & $0 \sim 1260$ \\
\hline Sensibilidad & $0.63\left(\Omega /{ }^{\circ} \mathrm{C}\right)$ & $0.04\left(\mathrm{mV} /{ }^{\circ} \mathrm{C}\right)$ \\
\hline Precisión $(\%)$ & 0.033 a $0^{\circ} \mathrm{C}$ & 0.3 \\
\hline
\end{tabular}

Tabla 3. 7: Principales características de los captadores de temperatura, utilizados para realizar las medidas en la instalación. 
Capitulo 3 Diseñoy puesta a punto de un procedimiento de medida para la caracterización de turbogrupos

- $\quad$ Medida del gasto másico de aire

Una de las magnitudes que es necesario medir con más precisión en esta instalación es el gasto másico que trasiegan la turbina y el compresor del turbogrupo que se desea ensayar.

Por otra parte, también es necesario conocer este dato en relación con el funcionamiento del generador del flujo, el motor. El gasto másico de aire está vinculado directamente con el dosado, que es un parámetro fundamental en el control de la instalación.

El mayor riesgo de cometer imprecisiones en la medida del gasto másico de aire se encuentra en las fugas que pueden existir en la instalación, por lo que es necesario revisarlas con regularidad, para asegurar, en la medida de lo posible, la ausencia de las mismas.

Para medir el gasto másico de aire que discurre por un conducto existen varias opciones. Las más conocidas son los medidores de presión diferencial, los medidores de gasto turbulento, los viscosos o de flujo laminar y los de hilo caliente [7].

Los primeros, medidores de presión diferencial, son los más antiguos y de construcción sencilla, pero su precisión es baja, siendo necesario conocer la presión y temperatura del fluido para obtener los resultados en las unidades que nos interesan en la instalación.

De los medidores de gasto turbulento podemos destacar los diafragmas y las toberas. El primer tipo tiene el inconveniente de producir grandes pérdidas de carga y además no sirve para flujos no estacionarios, lo que lo inhabilita para el ensayo en motores. Las toberas en cambio, son ampliamente utilizadas.

Las toberas son conductos de geometria variable, en los que a la entrada el fluido de encuentra a presión atmosférica y en la salida a una presión diferente, debido al cambio de sección entre la entrada y la salida. Si se conocen las temperaturas de entrada y salida, tomando el aire como un gas ideal y sabiendo que el proceso es adiabático, se puede conocer el caudal que pasa por la tobera, en función del salto de presión que se produce entre la entrada y la salida.

Los medidores viscosos son aquellos que transforman un flujo turbulento en otro con régimen laminar. Esto se consigue haciendo pasar el fluido por orificios de diámetro muy reducido hasta alcanzar un número de Reynolds inferior a 2000.

Aunque este sistema permite medir flujos no estacionarios, resulta muy susceptible a partículas de suciedad y polvo, lo que obliga a revisarlos 
con mucha asiduidad. Otra cuestión a tener en cuenta es que la viscosidad del aire influirá en la medida, siendo necesario realizar correcciones calculando en varios puntos la densidad del aire. Por todo ello, el rango de medida de este sistema es menor que el de las toberas.

Los medidores volumétricos son aquellos que atrapan el fluido a medir en un volumen fijo y cuentan el número de volúmenes trasegados por unidad de tiempo. El proceso seguido para discretizar el flujo en volúmenes definidos varia de unos caudalimetros a otros, engranajes con dos rótores o con ruedas ovaladas son muy utilizados. El volumen desplazado en una revolución del medidor es prácticamente constante dentro del rango de caudal, viscosidad, presión y temperatura, de manera que midiendo el número de revoluciones del medidor se obtiene el volumen de gas trasegado. Es necesario determinar la densidad del fluido para conocer el caudal másico.

Los medidores de hilo caliente están constituidos por un hilo eléctrico que atraviesa un conducto por el que circula el caudal del gas a medir. Este hilo forma parte de un circuito eléctrico con una determinada relación de tensión. Al aumentar el caudal de gas, el hilo se enfría, con lo que disminuye su temperatura y consecuentemente, su resistencia.

El medidor dispone de un sistema de regulación que eleva la corriente de tal forma que el hilo recupere su temperatura inicial. Lo cual se consigue en milésimas de segundo gracias a la pequeña masa del hilo, manteniendo así casi constante la temperatura. El incremento de intensidad será por tanto proporcional al caudal másico trasegado, de tal modo que midiendo este incremento es posible conocer el caudal.

Estos son los medidores más adecuados para la instalación, el problema que surge para medir el caudal que trasiega la turbina es que no es fácil encontrar medidores de flujo que se adapten a las características de los gases de escape, de modo que se va a medir este caudal como la suma del aire que entra al motor y el combustible inyectado, menos el caudal de gases que se pierde en el motor por el fenómeno de blow-by[8].

Para los ensayos de turbina se han instalado dos caudalimetros en la línea de admisión del motor, que como se vio en el apartado anterior, solo miden el caudal de aire que entra en motor y va a ser trasegado por la turbina.

Se han instalado dos caudalimetros debido que para gastos másicos bajos se utiliza, por su precisión y rapidez de lectura, un caudalímetro de hilo caliente, el modelo elegido para medir el aire ha sido el Sensyflow $\mathrm{P}$ DN80 de la marca Sensycom, cuyas características son las que se muestran en la tabla 3. 8. Sin embargo, para gastos altos es muy caro y dificil encontrar un medidor de hilo caliente que aguante la suficiente presión, por 
Capitulo 3 Diseñoy puesta a punto de un procedimiento de medida para la caracterización de turbogrupos

lo que se ha optado por un medidor volumétrico, capaz de medir hasta caudales de $2500 \mathrm{~m}^{3} / \mathrm{h}$, usado generalmente para medir caudales de gas natural, cuyas características también aparecen en la tabla 3. 8.

El hecho de tener dos caudalimetros en serie aumenta la precisión de la medida para caudales inferiores a $720 \mathrm{~kg} / \mathrm{h}$ que es cuando ambos están operativos

Se ha colocado este caudalímetro puesto que resulta muy caro y complicado encontrar medidores de caudal de hilo caliente con un rango de funcionamiento adecuado para medidas de más de $720 \mathrm{~kg} / \mathrm{h}$ que sea capaz de medir en condiciones de presión elevada.

\begin{tabular}{|c|c|c|}
\hline \multicolumn{2}{|c|}{ Caudalímetros para medir el aire trasegado por la turbina } \\
\hline \multicolumn{1}{|c|}{ Tipo } & Sensyflow P DN 80 & $\begin{array}{c}\text { Elster TRZ-IFS } \\
\text { G1600 }\end{array}$ \\
\hline Rango de medida & $20-720 \mathrm{~kg} / \mathrm{h}$ & $0(80)-2500 \mathrm{~m}^{3} / \mathrm{h}$ \\
\hline Precisión (\% FE) & 1.5 & 0.3 \\
\hline $\begin{array}{c}\text { Perdida de carga } \\
\text { máxima }\end{array}$ & $40 \mathrm{mBar}$ & \\
\hline \begin{tabular}{|c|} 
Presión máxima de \\
trabajo (bar)
\end{tabular} & 5 & 11 \\
\hline $\begin{array}{c}\text { Diámetro nominal } \\
\text { tubo (mm) }\end{array}$ & 80 & 200 \\
\hline $\begin{array}{c}\text { Material del tubo y } \\
\text { carcasa }\end{array}$ & Aluminio GFK & \\
\hline
\end{tabular}

Tabla 3. 8: Principales características de los caudalimetros, utilizados para realizar las medidas de gasto másico de aire que trasiega la turbina..

Al medidor de hilo caliente le acompaña un sistema electrónico montado en el armario de racks, que se encuentra en el exterior de la sala. Este elemento se encarga de gestionar la señal que le llega del caudalimetro, registrando en un lector digital el gasto horario de aire, así como la temperatura del aire que circula por ese punto de la instalación. De esta electrónica obtenemos una señal analógica que permite registrar la medida del gasto de aire directamente en el ordenador de control de la sala.

El montaje del sistema consta de un filtro, un tubo de sección circular calibrado, y el propio aparato de medida. El filtro se encuentra situado en el interior del remanso-distribuidor de admisión para hacer más compacto el conjunto. A continuación de este caudalímetro de hilo caliente se ha colocado el caudalímetro volumétrico.

Por otro lado, también es necesario medir el aire que trasiega el compresor centrífugo. Se van a utilizar dos medidores diferentes de hilo 
caliente dependiendo del rango de caudales en el que se quiera medir. Para compresores que trasieguen caudales menores de $720 \mathrm{~kg} / \mathrm{h}$ se utilizará un caudalimetro Siemens 5WK9 628 PBT-GF30, para el caso de caudales mayores se utiliza el Sensyflow P DN150 el modelo elegido para medir el aire ha sido el Sensyflow P DN150, también de la marca Sensycom, cuyas características son las que se muestran en la tabla 3. 9. En este caso ha sido posible usar un caudalimetro de hilo caliente puesto que las condiciones de baja presión de trabajo si que lo permiten.

Igual que ocurre en el la medida de gasto de aire que trasiega la turbina, se tendrá una medida redundante para gastos inferiores a $720 \mathrm{~kg} / \mathrm{h}$.

\begin{tabular}{|c|c|c|}
\hline \multicolumn{2}{|c|}{ Caudalimetros para medir el aire trasegado por el compresor } \\
\hline \multicolumn{1}{|c|}{} & $\begin{array}{r}\text { Siemens 5WK9 628 } \\
P B T-G F 30\end{array}$ & Sensyflow P DN 150 \\
\hline Tipo & Hilo caliente & Hilo caliente \\
\hline Rango de medida (kg/h) & $20-720$ & $0(80)-2400$ \\
\hline Precisión (\% FE) & - & 1.5 \\
\hline $\begin{array}{c}\text { Presión máxima de } \\
\text { trabajo (bar) }\end{array}$ & 2 & 150 \\
\hline $\begin{array}{c}\text { Diámetro nominal } \\
\text { tubo(mm) }\end{array}$ & 65 & Aluminio GFK \\
\hline $\begin{array}{c}\text { Material del tubo y } \\
\text { carcasa }\end{array}$ & PVC & 2 \\
\hline
\end{tabular}

Tabla 3. 9: Principales características de los caudalimetros, utilizados para realizar las medidas de gasto másico de aire que trasiega el compresor.

- Medida del régimen de giro del turbogrupo

Para registrar el régimen de giro del turbogrupo se ha instalado un sistema de tipo inductivo que consiste en un sensor que transmite las alteraciones generadas por el paso de las palas del compresor a una bobina donde varía la impedancia, este cambio de impedancia produce una señal eléctrica que es la que se registra.

El sensor se coloca en la carcasa del compresor, ya que en él las condiciones de presión, temperatura y composición del caudal son mucho menos severas que en la turbina. Se practica un agujero roscado y se sitúa el sensor de tal forma que su superficie sensible y las palas del compresor estén a una distancia de entre $0.1 \mathrm{~mm}$ y $0.5 \mathrm{~mm}$.

Las sensibilidad del equipo depende fuertemente de la posición relativa entre las palas y el sensor. En la carcasa del controlador hay dispuesto un led para indicar cuando se detectan los pulsos provenientes del sensor y verificar que esta distancia está dentro de los márgenes correctos de funcionamiento. 
Capitulo 3 Diseñoy puesta a punto de un procedimiento de medida para la caracterización de turbogrupos

Las características más destacables de los sensores utilizados se muestran en la tabla 3. 10.

\begin{tabular}{|c|c|c|}
\hline \multicolumn{3}{|c|}{ Sensores de régimen de giro del eje del turbogrupo } \\
\hline Nombre & $\begin{array}{l}\text { Micro-epsilon } \\
\text { DS05(04) }\end{array}$ & $\begin{array}{l}\text { Picoturn } \\
\text { V3-V4 }\end{array}$ \\
\hline Rango de medida (rpm) & $0-400000$ & $200-400000$ \\
\hline Frecuencia de excitación & $3.2768 \mathrm{MHz}$ & \\
\hline Rango de palas registrable & De 2 a 15 & $1-15 / 16-31$ \\
\hline Output & $\begin{array}{c}1 \text { pulso / pala (duración del } \\
\text { pulso } 7 \mathrm{mseg} \text { ) } \\
1 \text { pulso / revolución } \\
\text { (duración del pulso } 100 \mathrm{mseg} \text { ) }\end{array}$ & \\
\hline Voltaje de salida (V) & $0 a+10$ & 0.5 a 4.5 \\
\hline $\begin{array}{l}\text { Rango de temperatura de } \\
\text { funcionamiento }\left({ }^{\circ} \mathrm{C}\right)\end{array}$ & -40 a 150 & -40 a 180 \\
\hline Diámetro del sensor (mm) & 3 & 3 \\
\hline
\end{tabular}

Tabla 3. 10: Caracteristicas de los sensores de régimen de giro del turbogrupo utilizados en la instalación.

- Medida del ángulo de giro del cigüeñal

Una de las medidas más importantes dentro de los ensayos de motores de combustión interna es el ángulo girado por el cigüeñal. Este dato es fundamental para poder referenciar cualquier medida instantánea en los ensayos de motores, es decir, para conocer como evolucionan los parámetros medidos en cada instante del ciclo termodinámico del motor.

En nuestro caso será fundamental cuando deseemos modelar el flujo pulsante a la salida de los cilindros del motor y compararlo con una medida de referencia. Este modelado será muy útil para el análisis del funcionamiento de la turbina y para el diseño de mejoras en la instalación.

Para realizar tales medidas se recurre a una serie de dispositivos que son capaces de capturar la posición del cigüeñal con respecto al PMS o al PMI, estos dispositivos son denominados codificadores angulares. Para poder obtener una serie de datos coherentes, el codificador se engloba en un sistema compuesto por un captador de presión instantánea, una cadena de medida, y un ordenador para relacionar y representar las medidas realizadas.

Básicamente existen dos tipos de codificadores angulares, los electromagnéticos y los ópticos, que a continuación describiremos brevemente.

Los captadores electromagnéticos utilizan una serie de discontinuidades en forma de dientes, mecanizadas en el volante de inercia 
del motor. Se coloca un transductor en las proximidades del volante que detecta alteraciones de campo magnético. El sensor se compone de un material conductor en forma de espiras, por el cual pasa una intensidad de corriente determinada. Esto da lugar a un flujo magnético que saldrá por el extremo del sensor haciendo que este detecte las discontinuidades.

Por otro lado, los captadores ópticos poseen un disco de poca inercia que se une solidariamente a la polea del cigüeñal. Este disco se compone de sectores opacos y sectores transparentes, situados de manera equidistante y alternativa. El material empleado en ellos suele ser cromo sobre vidrio o metal ranurado.

Aunque los captadores angulares ópticos presentan algunos problemas derivados de la posible inclusión de polvo, vibraciones o variaciones térmicas, hemos escogido un captador de este tipo ya que son los que disponen de una mayor resolución.

En el motor se ha instalado un codificador angular de tipo óptico de la marca AVL del modelo 354. Sus características más importantes son las que se muestran en la siguiente tabla.

\begin{tabular}{|c|c|}
\hline & Codificador angular: AVL-345 \\
\hline Tipo & Óptico \\
\hline Rango de medida (rpm) & $10-15000$ \\
\hline $\begin{array}{l}\text { Aceleración radial } \\
\text { máxima }\end{array}$ & $100 \times 9.81 \mathrm{~m} / \mathrm{s}^{2}$ \\
\hline Ángulo de salida máximo & $\begin{array}{l}720 \text { pulsaciones (20 pulsaciones de onda } \\
\text { cuadrática asimétrica por revolución, con la } \\
\text { posibilidad de multiplicarse por } 5 \text { ) }\end{array}$ \\
\hline Peso (gr) & 450 \\
\hline $\begin{array}{l}\text { Rango de temperatura de } \\
\text { funcionamiento }\left({ }^{\circ} \mathrm{C}\right)\end{array}$ & $30-70$ \\
\hline Vida útil & $\begin{array}{l}\text { Un mínimo de } 10 \text { millones de revoluciones } \\
\text { con las máximas vibraciones permitidas. }\end{array}$ \\
\hline
\end{tabular}

Tabla 3. 11: Principales características del codificador angular AVL-345, utilizado en la instalación.

Desde el módulo electrónico salen dos señales, una de Trigger y otra de muestreo. La primera es la señal de disparo, es decir, es la que sirve de origen a la escala angular dando un impulso por vuelta de cigüeñal (1 x v). Mientras que la segunda es la que establece dicha escala, dando $n$ señales por vuela (n x v). 
Capitulo 3 Diseñoy puesta a punto de un procedimiento de medida para la caracterización de turbogrupos

- $\quad$ Medida del gasto másico de combustible

La medida de gasto de combustible es de interés tanto para conocer el consumo de combustible, que formará parte del caudal de gases de escape, como para determinar el dosado, dato necesario para el control de la sala.

Para obtener una buena precisión en las medidas hay que asegurarse de que el sistema está perfectamente calibrado, de que no hay burbujas de aire en el circuito de alimentación, de que el combustible no está contaminado ni contiene partículas en suspensión. Además, y como resulta obvio, hay que cerciorarse de que no existen fugas en ningún punto de la instalación.

Los métodos más importantes y comúnmente utilizados para cuantificar el gasto de combustible son:

- Método volumétrico: Este es el sistema más simple y barato de todos. El equipo utilizado se reduce a un cronómetro y una probeta graduada. La probeta está conectada en paralelo al circuito deposito-motor mediante una válvula de tres vías, cuando se necesita hacer la medición se restringe el paso de combustible del deposito y el motor consume el de la probeta, que es de volumen conocido.

El principal inconveniente de este método es que la densidad del combustible depende de la temperatura del mismo, y por tanto, para conocer el gasto de combustible es necesario medir la temperatura de este.

- Método gravimétrico: Este método, en contrapartida al anterior, consiste en determinar el tiempo empleado por el motor en consumir una masa determinada de combustible ubicada en una balanza de precisión.

Su mayor inconveniente es su elevado precio y complejidad, pero por otra parte es un procedimiento muy preciso y puede introducirse en sistema altamente automatizados. Además, su medida no depende de la densidad o temperatura del combustible.

- Método Flo-Tron:_Este es un sistema de medida lineal de flujo en el que el medidor consta de agujeros calibrados y de una bomba que hace circular el flujo de referencia, la salida del fluido por los agujeros, esta a diferente presión de la que entrada, siendo esta lineal y proporcional al flujo de circulación. 
Este sistema no es sensible a cambios de viscosidad, temperatura del fluido y densidad del flujo, y además posee un gran rango de medida, pero es de dificil adquisición y es él más caro de todos los sistemas.

El método seleccionado para realizar la medida de combustible inyectado al motor de la instalación es el método gravimétrico, debido a su versatilidad, su gran precisión y una fácil automatización que permite controlarlo y regularlo a través del sistema de control de la sala.

Este sistema de medida indica el consumo instantáneo del motor en $\mathrm{kg} / \mathrm{h}$, así como el consumo medio durante un tiempo de medida seleccionado por el usuario, controlados directamente y en tiempo real en la pantalla del ordenador de control de la sala, además puede ofrecer el consumo acumulado sobre un período de medida seleccionado.

El control de llenado de la balanza se realiza de forma automática en función del vaciado de combustible y mediante control remoto desde el ordenador de control de la sala.

El medidor dinámico empleado en la instalación es un AVL 733S, y cuenta con 5 funciones básicas, que se describen a continuación.

- Control de precisión o Accuracy check: Este control indica el grado de error existente en la masa de combustible medida. Se realiza añadiendo una pesa con una masa conocida y obteniendo un valor de la masa total. El error debe estar situado en un intervalo del -2 al $2 \%$, si no es así, se deberá proceder a una calibración de la balanza y subsanar el posible error.

Este chequeo dura aproximadamente 2 minutos y puede realizarse con el motor en marcha, gracias a la válvula de by-pass que permite que el motor consuma combustible sin tener que pasar por la balanza.

- Calibración: Mediante la calibración se eliminan todos los errores, prevaleciendo la linealidad. Al igual que el Accuracy check se activa desde el PC de control.

Para trazar una nueva recta de calibración, primero se vacía la balanza y coloca una pesa de 90 gr., adoptando entonces el cero, luego se empieza a llenarla y se añade la pesa de 90 gr. cada vez que se alcanza una masa de combustible predeterminada.

- Reset: El reset es un dispositivo que reinicia la electrónica de la balanza, se encuentra en la parte superior derecha del interior de la balanza, mediante este se limpian los errores existentes en ese 
Capitulo 3 Diseñoy puesta a punto de un procedimiento de medida para la caracterización de turbogrupos

momento y carga los parámetros necesarios desde la EPROM en el estado manual, para luego poder pasar a la calibración o al Accuracy check.

- Indicadores de error: Junto al reset existen 7 leds que indican los posibles errores, la falta de estos o estado de funcionamiento, según sea el estado de la luz, encendida o apagada. Para conocer su significado acudir bien al apartado correspondiente del manual del aparato.

- Control de la válvula de llenado: La válvula de llenado esta controlada por un control remoto desde el ordenador de control y su apertura dependerá del nivel máximo de la balanza. Exceptuando cuando el sistema contiene errores, se realiza un Accuracy check, o se produce un sobrellenado, la válvula estará siempre cerrada, además no habrá acceso a ella cuando se calibre, y estará abierta cuando el nivel de combustible sea cero.

Para la instalación del sistema de medida, se realiza un by-pass con llaves de paso de media pulgada unidas por tubo de cobre o latiguillos metálicos para gasoil, bien para poder desmontar la balanza y seguir trabajando o bien para ensayar sin la necesidad de esa medida.

Por recomendaciones del fabricante recogidas en el manual de operaciones, se le adjunta un sistema de detección de sobrellenado de la balanza, Overflow, en la salida de aireación, que consiste en un vaso de decantación, en el que al llenarse, una boya transmite una señal eléctrica que activa en el ordenador de control una alarma, este vaso tiene dos salidas, una para el vaciado, mediante una llave de paso y la otra que lleva el aire hasta el silenciador de extracción de la sala.

Además de la entrada y las dos salidas (motor y aireación), el AVL733S tiene otra entrada para el retorno de combustible del motor, pero como interesa que ese retorno no se vuelva a medir en la balanza, sino que sea devuelto al motor para así tener una medida correcta de lo que consume y más fiel a la realidad, esa entrada sirve de vaciado del sistema de medida gravimétrico.

\subsubsection{Descripción del sistema de adquisición de datos y control de la instalación: SAMARUC}

El sistema Samaruc es una herramienta desarrollada en el Instituto CMT-Motores Térmicos para el control de salas de ensayo de motores de combustión interna alternativos. Su gran flexibilidad y adaptabilidad lo convierten en una solución idónea para el control de la sala de ensayo de turbogrupos. 
La tarea principal del sistema es el control del banco de ensayos y la adquisición de datos procedentes de los diferentes elementos de medida instalados en la sala. Además también se asume parte de la tarea de procesado y evaluación de resultados del ensayo, siendo una característica importante del sistema la parametrización flexible que ofrece al usuario, lo que garantiza la implementación de las tareas en un tiempo breve con una mínima planificación previa de lo que se desea hacer a lo largo del ensayo.

El elemento de control central del sistema Samaruc es el PC, el cual se destina exclusivamente al banco de ensayo. La interface gráfica del operador que rueda bajo MS Windows garantiza la versátil pero sencilla operación del sistema.

La interfaz del operador consiste en el programa SamarucFP, que permite controlar y visualizar el ensayo; el programa EditorFP, que se utiliza para la parametrización del sistema y finalmente el programa FieldPoint Explorer, que se utiliza para la configuración del hardware del sistema.

\section{- $\quad$ SamarucFP}

Todas las acciones operativas en el banco de ensayo (control, monitorización, vigilancia, adquisición de datos, etc...) son ejecutadas y visualizadas por medio del programa SamarucFP.

El sistema SamarucFP distinguirá entre todas estas acciones, un único estado de operación desde el cual se efectuaran las siguientes tareas:

-Inicialización y carga de parámetros específicos de todo el sistema.

-Carga de parámetros del ensayo y de la unidad del ensayo.

-Activación de las funciones de vigilancia de limites y seguridades del banco.

-Medida, almacenamiento y presentación de valores medidos.

Todos los valores medidos y calculados así como todos los parámetros necesarios para el control de la instalación son visualizados en la pantalla del PC. Las variables a visualizar pueden ser seleccionadas libremente por el operador de acuerdo a sus necesidades particulares, lo que ofrece una gran libertad a la hora de diseñar los ensayos. opciones:

El menú principal del programa permite esencialmente las siguientes

- Menú principal para operar con el sistema. 
Capitulo 3 Diseñoy puesta a punto de un procedimiento de medida para la caracterización de turbogrupos

- Linea de estado para indicar el estado del sistema y el del motor de la instalación. Samaruc.

- Lineas de mensaje para indicar eventos ocurridos en el sistema

- Ventanas con displays alfanuméricos, gráficos y botones de acción.

En las pantallas de trabajo se muestran las variables de interés para el correcto control de la sala, las variables de interés para el ensayo de compresores y turbinas, los menús que permiten otras acciones, como la adquisición de datos en un instante determinado o el control de las variables que controlan los limites de la instalación.

El hardware usado en la adquisición de valores y control del sistema Samaruc es suministrado por la firma National Instruments.

Todos los datos necesarios para la evaluación del ensayo son almacenados en los archivos de resultados de ensayo, compatibles con hojas de cálculo y procesadores de texto comerciales, tales como MS EXCEL, y WORD.

Las variables a almacenar durante el ensayo son seleccionadas por el usuario en una tabla de datos específica, y pueden ser declaradas diferentes tablas en función del ensayo que se desee.

Adicionalmente a los datos medidos, se almacena también datos como la fecha y la hora del comienzo del ensayo, la hora a la que se toma cada medida, los mensajes importantes del Samaruc y mensajes o comentarios realizados por el técnico que ha realizado el ensayo.

Todas las variables adquiridas o calculadas por el sistema Samaruc pueden ser vigiladas dentro de unos limites (inferior y superior) establecidos por el usuario. La violación de uno de los límites provocará que el sistema ejecute una reacción de emergencia. Las posibles reacciones de emergencia son el paro de emergencia, el paro del motor, una rutina de enfriamiento o un mensaje de aviso.

\section{- Editor Fp: Parametrización del sistema}

La preparación del ensayo y de otros parámetros del ensayo necesarios se efectúa mediante el programa EditorFP.

Además, como parámetros propios del ensayo, se configuran los siguientes tipos de canales desde la misma aplicación: 
- Canales especiales para la medida con el equipo AVL, para medir el consumo de combustible.

- Canales a almacenar durante el ensayo. Son aquellos canales cuyas variables se desea guardar.

- Canales a calcular a partir de expresiones matemáticas y de las medidas de otros canales. Se utilizan para calcular online valores como el gasto corregido, el régimen de giro del turbogrupo corregido, la relación de compresión y la de expansión, el rendimiento de la turbina y el compresor....

- Canales de medida manual para guardar la presión, temperatura y humedad ambiente, así como el nombre y la descripción de los puntos ensayados.

- Datos específicos del ensayo a realizar, como los diámetros de los tubos de medida, el número de álabes de los rodetes de la turbina y el compresor y las presiones y temperaturas ambientales. 
rendimiento puede ser expresado como función de variables independientes, que pueden agruparse formando grupos adimensionales [2][3][15]. Para una determinada turbomáquina, teniendo en cuenta que $R$ y $\gamma$ son constantes y que el número de Reynolds del gas tiene poco efecto sobre el comportamiento de la turbomáquina, se tiene que:

$$
\frac{\dot{m} \sqrt{T_{E 0}}}{p_{E 0}} \text { y } \eta \text { son exclusivamente } \mathrm{f}=\left(\frac{\mathrm{N}}{\sqrt{T_{E 0}}}, \frac{p_{S 0}}{p_{E 0}}\right)
$$

Dónde $\frac{\mathrm{N}}{\sqrt{T_{E 0}}}$ representa el número de Mach en la punta del álabe del rotor como se muestra en la expresión (3. 8):

$$
M=\frac{u}{a}=\frac{\pi N D_{r o d}}{\sqrt{\gamma R T_{E 0}}}=k \frac{\mathrm{N}}{\sqrt{T_{E 0}}} \quad \mathrm{k}=\frac{\pi D_{\text {rod }}}{\sqrt{\gamma R}}
$$

Por otro lado, $\frac{\dot{m} \sqrt{T_{E 0}}}{p_{E 0}}$ está relacionado con la relación de presiones, $\frac{p_{S 0}}{p_{E 0}}$, a través de la ecuación de la tobera (ecuaciones (4. 1)(4. 2)).

Se utilizan las temperaturas y presiones de referencia ( $\mathrm{T}_{\mathrm{REF}}$ y $\left.\mathrm{p}_{\mathrm{REF}}\right)$ para adimensionalizar el efecto de la corrección en las variables, de modo que el gasto corregido $y$ el régimen de giro corregido mantienen dimensiones de gasto y régimen respectivamente.

Un resumen de lo que muestra la normativa en cuanto al tratamiento de las variables medidas para calcular las variables fundamentales que describen el comportamiento del turbogrupo puede verse en la tabla 3.13 . 
Capitulo 3 Diseñoy puesta a punto de un procedimiento de medida para la caracterización de turbogrupos

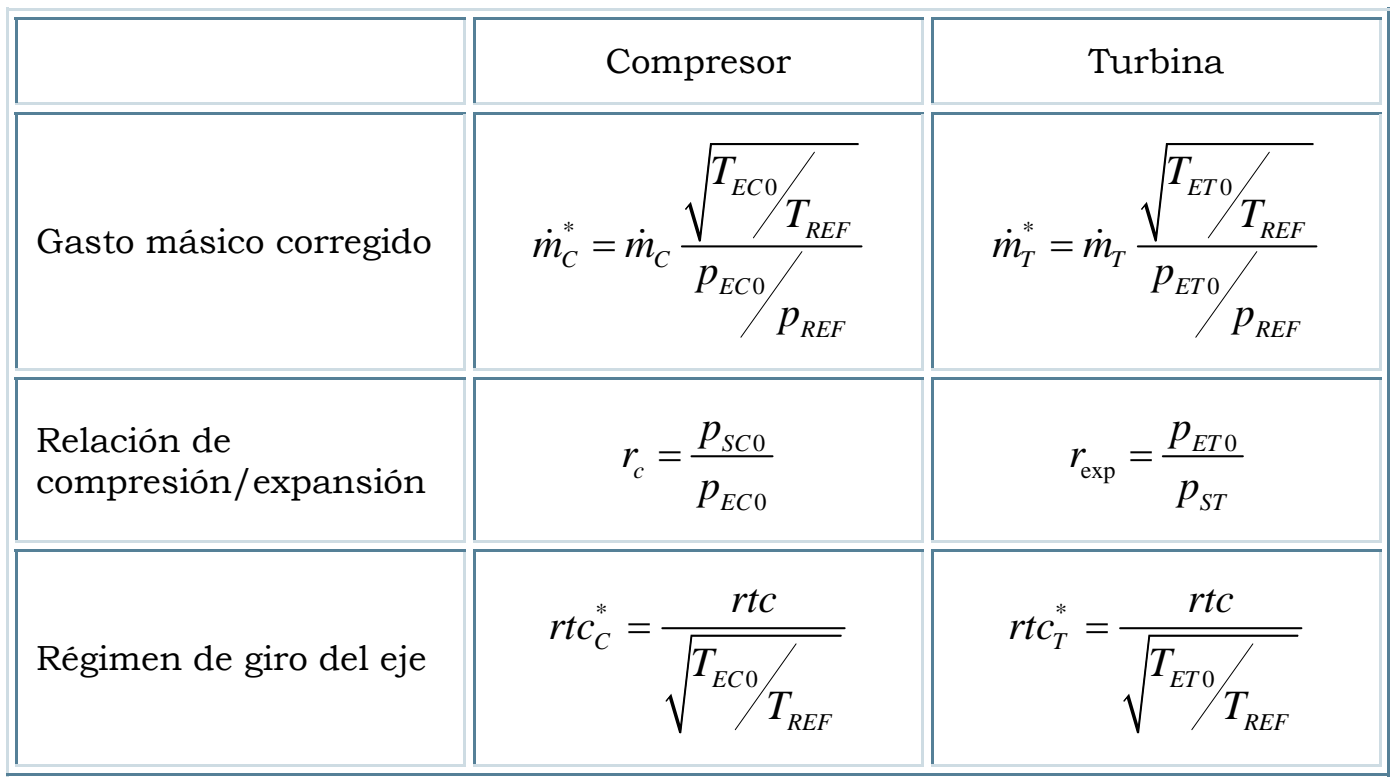

Tabla 3. 13: Corrección de las variables medidas para la representación de los mapas de compresor y turbina.

\subsubsection{Estudio de estabilización de las variables}

Se realizaron una serie de medidas en la instalación para estudiar el tiempo que necesita la misma para estabilizarse y que la medida realizada pueda considerarse como un punto de funcionamiento estable del turbogrupo y sea, por lo tanto, correcta. Como variables de control de estabilidad se han tomado el rendimiento de la turbina y del compresor.

Tras cambiar el punto de funcionamiento y una vez se dejaron constantes las variables que controlan la instalación se comenzó a tomar medidas durante 10 segundos a intervalos de un minuto, durante unos 45 minutos.

Las medidas obtenidas son las que se muestran en la figura 3. 3. Se observa que la presión a la entrada y salida de la turbina estabilizan rápidamente, obteniéndose diferencias entre la primera y la última medida menores del $1.5 \%$, sin embargo las temperaturas tardan mucho más en estabilizar, las variaciones de la temperatura en el compresor se encuentran alrededor del 10\% entre la primera y la última media, para el caso de la turbina estas diferencias todavia son mayores, obteniéndose para este caso más de un $20 \%$ de diferencia. 
Otra de las variables medidas directamente es el gasto que trasiegan el compresor y la turbina, en el caso del compresor las variaciones entre el instante inicial y el final son de entorno al 7\%, para el caudal de gases que trasiega la turbina esta diferencia está entorno al $2 \%$. Es debido a que la variación de la temperatura a la entrada de la turbina influye en la potencia del compresor y por tanto en el gasto trasegado por éste, más que en las variaciones de la densidad del aire a la entrada de la misma.

A partir de las medidas directas realizas se obtuvo la variación temporal de las variables que caracterizan el comportamiento del turbogrupo. Esta evolución se muestra en la figura 3. 4.

El régimen de giro corregido de ambos tarda en estabilizarse alrededor de la mitad del tiempo, pero la diferencia entre el valor inicial y el final es del $5 \%$, y durante el $20 \%$ inicial del tiempo total considerado varia un $80 \%$ de lo que lo hace en total.

Se observa que aunque los valores de las temperaturas tarden más del $60 \%$ del tiempo total en estabilizar, sin embargo transcurrido el $40 \%$ del tiempo total (960 s) el comportamiento de la turbina es prácticamente estacionario y es posible realizar la medida con totales garantías.

Las dos últimas gráficas de la figura 3. 4 muestran la evolución de la medida en el mapa de la turbina y del compresor y en la figura 3 . 5 se muestra la evolución del rendimiento de la turbina en función de la relación cinemática, en dos escalas distintas. Se observa en ambos casos que a partir de la octava medida (aproximadamente la cuarta parte del tiempo total) el punto del mapa ya no varía, por lo que solo es necesario esperar que estabilice el rendimiento de la turbina, el rendimiento del compresor y la relación cinemática para no cometer errores importantes. 
Capitulo 3 Diseñoy puestaa punto de un procedimiento de medida para la caracterización de turbogrupos

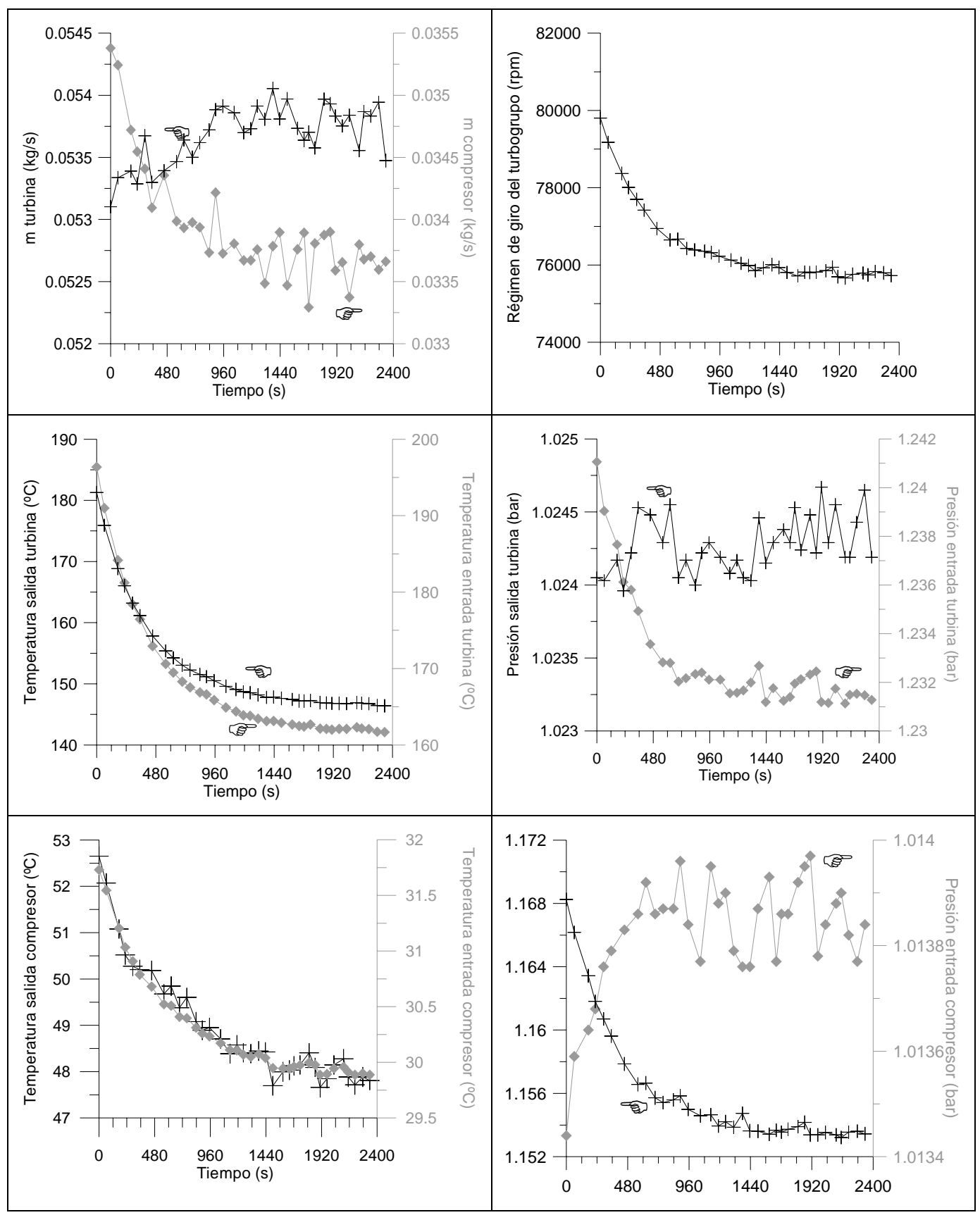

Figura 3. 3: Evolución temporal de las medidas realizadas en la instalación. 


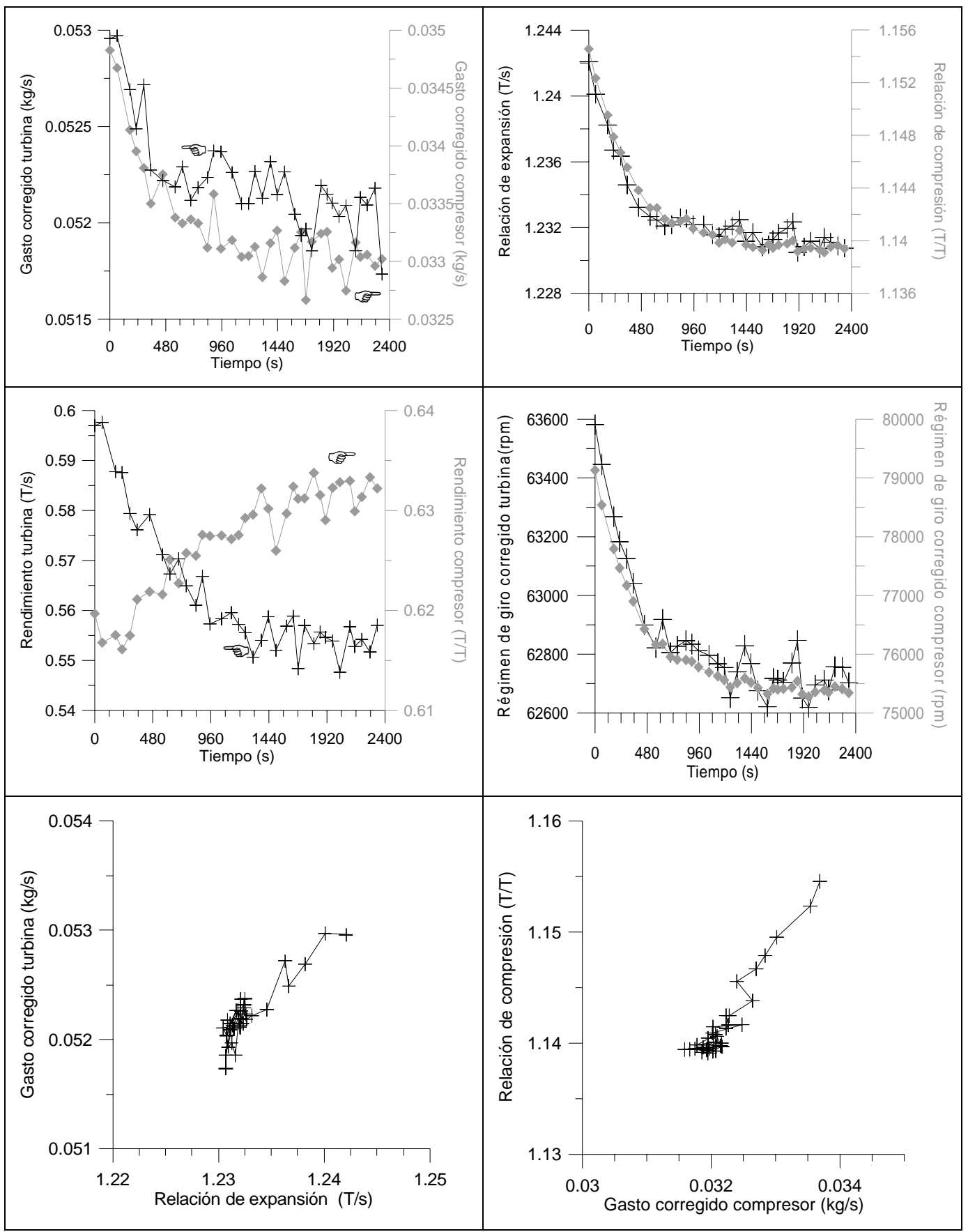

Figura 3. 4: Evolución temporal de las principales que determinan el funcionamiento del turbogrupo. 
Capitulo 3 Diseñoy puesta a punto de un procedimiento de medida para la caracterización de turbogrupos
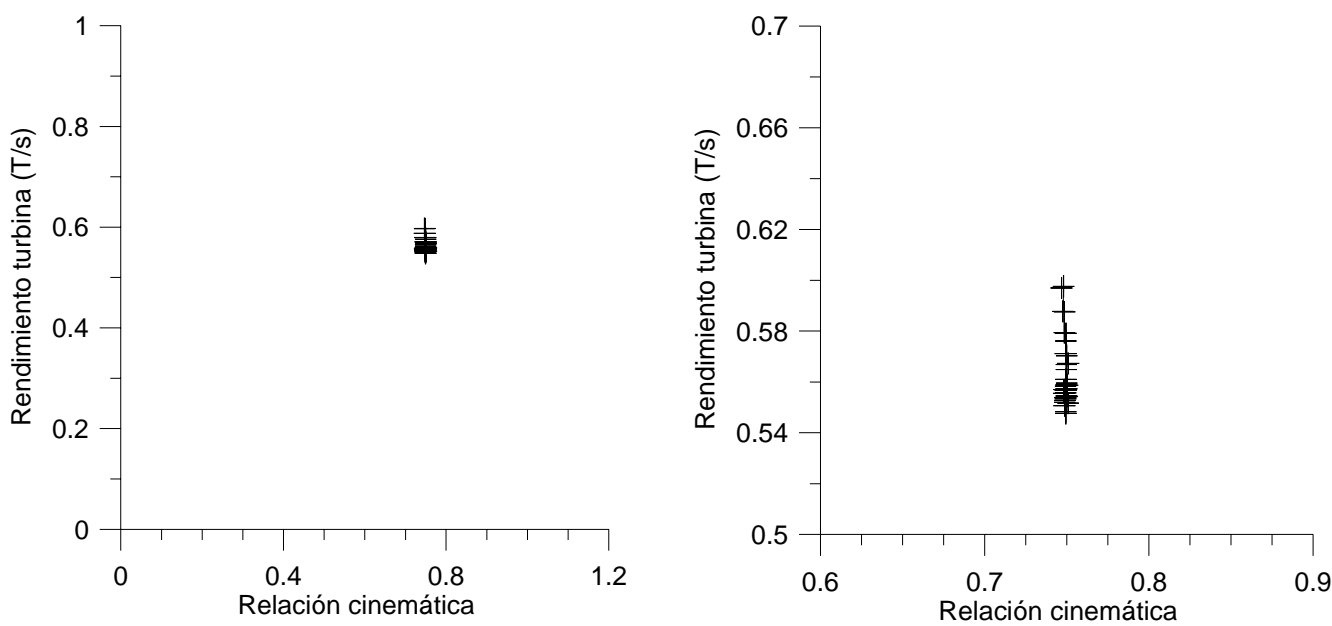

Figura 3. 5: Evolución del rendimiento de la turbina frente a la relación cinemática, en dos escalas distintas.

Si se aplica el criterio de estabilización de medida expuesto en el apartado 3.3.1, calculando (3. 6), sería necesario esperar casi 40 minutos para poder medir en el caso de la turbina, como se observa en la figura 3. 6, puesto q no se alcanza la consigna de $\zeta_{\mathrm{t}}<0.005$ hasta entonces. En el caso del compresor sería posible medir antes, transcurridos unos 27 minutos desde que se deja estabilizar térmicamente la instalación.

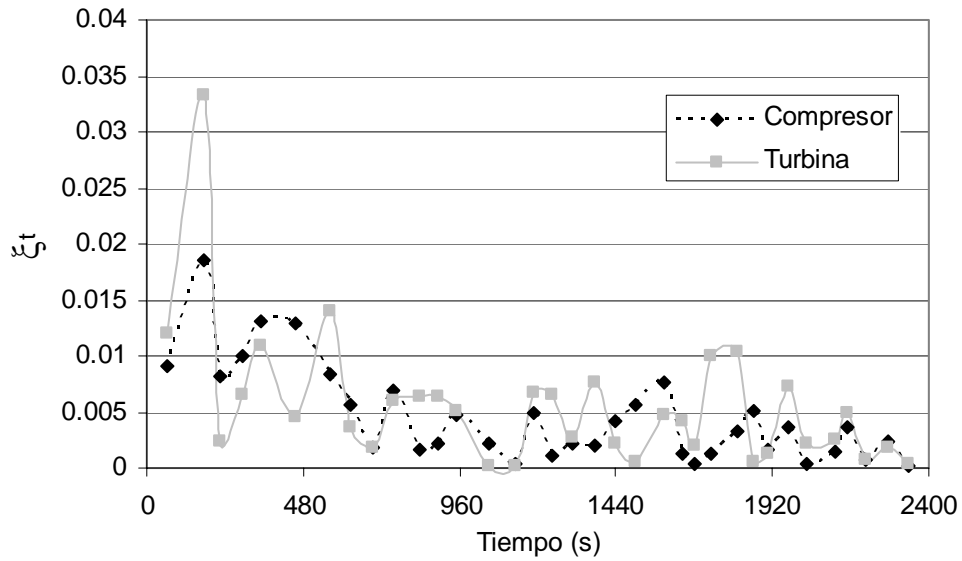

Figura 3. 6: Evolución de la variación relativa del parámetro adimensional de temperaturas para el compresor y la turbina.

Sin embargo, la variación del rendimiento de la turbina es menor de $1 \%$ cuando han transcurrido 960 segundos (16 min), es decir cuando $\zeta_{t}$ es siempre menor que 0.01 , con que se evidencia que para hacer una medida correcta no es necesario esperar has que $\zeta_{\mathrm{t}}<0.005$, sino que una vez las variaciones de 
temperatura dejan de ser significativas, esto es, cuando $\zeta_{\mathrm{t}}$ es siempre menor que 0.01 es posible realizar la medida con garantías.

\subsubsection{Mapa de un compresor}

El mapa de un compresor representa para cada línea de régimen de giro del turbogrupo la relación de compresión total a total, entendida como la relación entre las presiones de parada a la salida y a la entrada del compresor, frente al gasto másico trasegado por éste. Los rendimientos isoentrópicos se representan en forma de curvas de isorendimiento total a total, que unen los puntos de funcionamiento que presentan el mismo valor de rendimiento. Las variables corregidas se calculan como muestra la tabla 3. 13.

Siguiendo la nomenclatura de la figura 3. 7, donde se representa el diagrama h-s del proceso de compresión, marcando la entrada del rotor del compresor con el número 1, la salida del rotor y entrada del estator con el 2 y la salida del estator con el 3, la relación de compresión, según la tabla 3. 13:

$$
r_{c}=\frac{p_{30}}{p_{10}}
$$

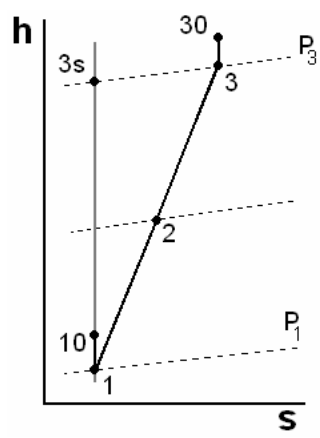

Figura 3. 7: Diagrama h-s de la compresión en un compresor centrífugo.

Dadas unas condiciones de presión $\left(\mathrm{p}_{1}\right)$ y temperatura $\left(\mathrm{T}_{1}\right)$, las condiciones de parada $\left(\mathrm{p}_{10}\right.$ y $\left.\mathrm{T}_{10}\right)$ son aquellas con energía cinética nula a las que se llega desde las condiciones dadas a través de una evolución isoentrópica. En las condiciones de parada toda la energía, que en condiciones dinámicas se reparte en energía térmica y energía cinética, es térmica. Por tanto la temperatura de parada de un punto 1, en una compresión como la de la figura 3. 7 , se obtiene despejando de la ecuación de conservación de la energía:

$$
h_{10}=C_{p} \cdot T_{10}=h_{1}+\frac{c_{1}^{2}}{2}=C_{p} \cdot T_{1}+\frac{c_{1}^{2}}{2}
$$


Capitulo 3 Diseñoy puesta a punto de un procedimiento de medida para la caracterización de turbogrupos

Donde $\mathrm{T}_{1}$ es la temperatura del punto $1, \mathrm{~T}_{10}$ la temperatura de parada correspondiente $\mathrm{y}_{1}$ la velocidad del fluido en el punto 1.

Despejando se obtiene la temperatura de parada:

$$
T_{10}=T_{1}+\frac{c_{1}^{2}}{2 \cdot C_{p}}
$$

La presión de parada se calcula teniendo en cuenta la definición de condiciones de parada. Para una evolución isoentrópica se cumple que:

$$
p_{10}=p_{1} \cdot\left(\frac{T_{10}}{T_{1}}\right)^{\frac{\gamma}{\gamma-1}}
$$

siendo $\gamma$ el coeficiente adiabático, igual al cociente entre calores específicos, que se calcula como muestra la tabla 3. 12.

Obteniendo las presiones de parada para las condiciones de entrada y salida del compresor se puede calcular la relación de compresión como indica la expresión (3. 9).

El rendimiento del compresor en un punto de funcionamiento dado se calcula como el cociente entre el trabajo específico isoentrópico $\mathrm{W}_{\mathrm{s}}$, que es el mínimo necesario para una compresión adiabática ideal, y el que se produce en la evolución real entre la entrada y la salida del compresor $\mathrm{W}_{\mathrm{u}}$, esto es el trabajo real necesario para alcanzar la misma relación de compresión [9]. Debido a las irreversibilidades del proceso el trabajo necesario para la compresión es mayor que el correspondiente al salto entálpico ideal, por lo que el cociente entre ambos indica el rendimiento en el proceso de compresión.

Los trabajos específicos $\mathrm{W}_{\mathrm{s}} \mathrm{y} \mathrm{W}_{\mathrm{u}}$ son iguales a la diferencia de entalpías de parada de los puntos que marcan la evolución correspondiente, según la ecuación de conservación de la energía y bajo la suposición de que el proceso de compresión es adiabático, suposición válida en el caso de turbocompresores [17]:

$$
W_{s}=h_{30 s}-h_{00}=h_{30 s}-h_{10}
$$

El rendimiento isoentrópico del compresor es, por tanto:

$$
\eta_{C}=\frac{h_{30 s}-h_{10}}{h_{30}-h_{10}}
$$


Contribución a la caracterización experimental y modelado de TGV en grupos de sobrealimentación

Calculándose las entalpías de parada a partir de las diferentes temperaturas de parada y de la expresión propuesta por la normativa internacional [12][14], que se muestra en la tabla 3. 13, para el cálculo de la entalpía del aire, en función de su temperatura.

Teniendo en cuenta que el calor específico del aire a presión constante es función de la temperatura de este, la aproximación

$$
T_{3 s}=T_{1}\left(\frac{p_{3 s}}{p_{1}}\right)^{\frac{\gamma-1}{\gamma}}
$$

no es válida, puesto que para llegar a ella se realiza la hipótesis de que es constante.

Para calcular la temperatura de salida isoentrópica hay que remontarse a la definición de proceso isoentrópico. La variación de entropía en un proceso real viene dada por la siguiente expresión:

$$
d s=\frac{d\left(c_{p} \cdot T\right)}{T}-\frac{d(R \cdot p)}{p}
$$

En este caso se cumple que:

$$
\begin{aligned}
& R=c t e \\
& c_{p}=f(T)
\end{aligned}
$$

Si el proceso es isoentrópico;

$$
\left.\begin{array}{l}
d s=0 \\
R=c t e
\end{array}\right] \Rightarrow 0=\frac{d\left(c_{p} \cdot T\right)}{T}-R \frac{d p}{p} \Rightarrow 0=d c_{p}+c_{p} \frac{d T}{T}-R \frac{d p}{p}
$$

donde, como se ha visto en la tabla 3. 13

$$
c_{p}=R \frac{a-b T}{a-b T-1} \text { donde } a=1.42592 \quad \text { y } \quad b=8.03974 \cdot 10^{-5} K^{-1}
$$

Integrando a partir de la expresión (3. 18) se obtiene:

$$
\int_{1}^{3 s}\left(\frac{d c_{p}}{d T}+\frac{c_{p}}{T}\right) d T=R \int_{1}^{3 s} \frac{1}{p} d p
$$


Capitulo 3 Diseñoy puesta a punto de un procedimiento de medida para la caracterización de turbogrupos

$$
\left.\left.\left.\left.\frac{b}{(a-1)-b^{2} T}\right]_{1}^{3 s}+\frac{1}{2} \ln \left((a-1) T-b T^{2}\right)\right]_{1}^{3 s}-\frac{a+1}{2(a-1)} \ln \frac{(a-1)-b T}{T}\right]_{1}^{3 s}=\ln p\right]_{1}^{3 s}
$$

Al despejar $\mathrm{T}_{3 \mathrm{~s}}$ se obtiene una ecuación implícita que es posible resolver iterando (la convergencia se alcanza normalmente tras 5 ó 6 iteraciones):

$$
T_{3 s}=\left[\frac{T_{1}^{a}}{(a-1)-b T_{1}}\left(\frac{p_{3}}{p_{1}}\right)^{(a-1)}\left((a-1)-b T_{3 s}\right)\right]^{1 / a}
$$

En el caso de realizar los ensayos de compresor en condiciones de presión y temperatura ambiente, el cálculo de la temperatura de salida del compresor teniendo en cuenta que $c_{p}$ y $\gamma$ varian con la temperatura del gas carece de sentido, puesto que las diferencias obtenidas entre utilizar la ecuación (3. 22) y la aproximación (3. 15) son despreciables, sin embargo, si se decide ensayar el compresor con temperaturas del gas a la entrada de más de $100^{\circ} \mathrm{C}$ (para reproducir, por ejemplo, las condiciones de un compresor de un sistema de sobrealimentación doble etapa) las diferencias obtenidas alcanzan el $2 \%$. Se ha decidido implementar este cálculo en el proceso desarrollado para el tratamiento de las medidas realizadas en la instalación y evitar este error al realizar ensayos de compresor a elevadas temperaturas de entrada.

El rendimiento que expresa la ecuación (3. 14) es el rendimiento total a total, que tiene en cuenta la energía cinética disponible en las condiciones de salida, considerando la entalpía de parada $h_{30 \text { s }}$ en lugar $h_{3 s}$, que es la considerada en el cálculo del rendimiento total a estático. La razón de calcular el rendimiento total a total para el compresor es que en la sobrealimentación el flujo comprimido es conducido al motor, donde se aprovecha tanto su energía térmica como su energía cinética. Por tanto, las condiciones de energía cinética alcanzadas en la salida también constituyen trabajo útil y deben ser consideradas en la evaluación del rendimiento. Esto se realiza a través de las entalpias de parada que, como ya se ha explicado, comprenden tanto la energía térmica como la cinética del flujo.

En caso de no ser útil la energía cinética de salida, el trabajo específico mínimo sería aquél que llevara el flujo desde las condiciones de parada a la entrada, 10, a las condiciones de salida isoentrópicas, 3s, con energía cinética de salida nula (es decir $30 \mathrm{~s}=3 \mathrm{~s}$ ), que serian las condiciones óptimas de salida en este caso. Sin embargo, al ser útil, se consideran óptimas unas condiciones de salida con velocidad no nula, de modo que el trabajo específico mínimo invertido es el que lleva el flujo hasta las condiciones $3 \mathrm{~s}$ con una determinada velocidad, es decir, con condiciones de parada 30 s. 
Una vez realizadas estas operaciones sobre las variables medidas se obtiene el mapa del compresor representando para cada línea de régimen de giro corregido constante la relación de compresión frente al gasto corregido.

Los rendimientos se calculan también para cada punto de funcionamiento ensayado. Puesto que los puntos ensayados presentan valores muy diversos que no permiten el trazado de las curvas isorendimiento para obtenerlas se ha de realizar una interpolación entre los puntos medidos.

\subsubsection{Criterio para discriminar los puntos de bombeo}

El fenómeno de bombeo consiste en un comportamiento inestable del compresor que aparece para gastos bajos, para los que el flujo no se adapta a la geometría del compresor generando desprendimientos de las líneas de flujo que provocan reflujos y, por tanto, oscilaciones de gasto y presión[1][15].

Históricamente, el bombeo de un turbocompresor ha estado asociado con inestabilidades en las variables operativas del mismo (presión, gasto de aire y régimen de giro) y con efectos claramente audibles. Durante los ensayos, la detección del bombeo ha estado confiada a operadores expertos quienes decidian cuando el compresor entraba en la zona de bombeo. Este procedimiento clásico, evidentemente, tiene muchas desventajas: el comportamiento del compresor se clasifica de acuerdo a criterios subjetivos y no es posible una completa automatización de los ensayos de compresores. En este apartado se muestra un criterio objetivo desarrollado para discriminar los puntos de bombeo de un compresor de los puntos de funcionamiento estable. Ningún criterio similar ha sido encontrado en la bibliografia, aunque existen monografias completas destinadas al estudio del bombeo de los compresores $[4][5][17]$.

Es bien sabido que cuando el compresor entra en la zona de bombeo aparecen variaciones significativas en las variables operativas del compresor (presión, gasto de aire, régimen de giro)[11][13][15][17]. Esta característica puede ser utilizada para detectar la existencia de bombeo. Un algoritmo simple, basado en el análisis en frecuencia de las variables instantáneas parece suficiente para terminar la zona de comportamiento inestable del compresor.

Con objeto de encontrar criterios de identificación del fenómeno de bombeo se estudia la evolución de las variables instantáneas del compresor medidas en puntos de funcionamiento dentro de la zona de bombeo y puntos fuera de la zona de bombeo. Para ello se analiza la señal en el dominio frecuencial utilizando la transformada de Fourier de la variable considerada, a fin de encontrar las frecuencias que predominan en las oscilaciones de esta variable. 
Capitulo 3 Diseñoy puesta a punto de un procedimiento de medida para la caracterización de turbogrupos

\section{- Análisis de señales mediante la transformada de Fourier}

La representación de una señal compuesta por una suma de funciones armónicas de distintas frecuencias en el dominio frecuencial, o espectro de la señal, se obtiene graficando la amplitud y el ángulo de fase en función de la frecuencia. Este tipo de representación permite el análisis individual de las componentes frecuenciales que constituyen la señal.

Para poder representar una señal temporal, como las variables instantáneas medidas, en el dominio frecuencial es necesario por tanto conocer cómo se descompone en suma de funciones armónicas, lo cual se consigue mediante el análisis de Fourier.

Una función periódica puede representarse por una suma, generalmente de un número infinito de términos, de funciones armónicas de distintas frecuencias, lo que se conoce como desarrollo en serie de Fourier. Así, la función periódica $\mathrm{f}(\mathrm{t})$ puede expresarse del siguiente modo:

$$
f(t)=A_{0}+A_{1} \cdot \operatorname{sen}\left(\omega t+\varphi_{1}\right)+A_{2} \cdot \operatorname{sen}\left(2 \omega t+\varphi_{2}\right)+\ldots+A_{n} \cdot \operatorname{sen}\left(n \varpi t+\varphi_{n}\right)
$$

El término $A_{1} \cdot \operatorname{sen}\left(\omega t+\varphi_{1}\right)$ se denomina fundamental o $1^{\text {er }}$ armónico.

Como $\operatorname{sen}\left(n \omega t+\varphi_{n}\right)=\operatorname{sen}(n \omega t) \cdot \cos \varphi_{n}+\cos (n \omega t) \operatorname{sen} \varphi_{n}$ las series pueden escribirse de la siguiente forma:

$$
f(t)=a_{0}+a_{1} \operatorname{sen}(\omega t)+. .+a_{n} \operatorname{sen}(n \omega t)+. .+b_{0}+b_{1} \cos (\omega t)+\ldots+b_{n} \cos (n \omega t)
$$

Los términos $a_{n}$ y $b_{n}$ se calculan como sigue:

$$
\begin{aligned}
& a_{n}=\frac{\omega}{\pi} \cdot \int_{0}^{2 \pi / \omega} f(t) \cdot \operatorname{sen}(n \omega t) \cdot d t \\
& b_{n}=\frac{\omega}{\pi} \cdot \int_{0}^{2 \pi / \omega} f(t) \cdot \cos (n \omega t) \cdot d t
\end{aligned}
$$

y para la serie en términos de senos y $\varphi$ :

$$
A_{n}^{2}=a_{n}^{2}+b_{n}^{2} \quad \mathrm{y} \quad \tan \varphi_{n}=\frac{b_{n}}{a_{n}}
$$

En el caso en que $f(t)$ sea una función impar $(f(t)=-f(-t))$ los $b_{n}$ serán nulos y si la $\mathrm{f}(\mathrm{t})$ es par $(\mathrm{f}(\mathrm{t})=\mathrm{f}(-\mathrm{t}))$, los $a_{\mathrm{n}}$ serán nulos. 
Cualquier función temporal, que pueda ser representada de forma matemáticamente exacta, puede descomponerse en sus diferentes componentes armónicas mediante la aplicación de fórmulas que permiten obtener de manera exacta las expresiones que generan todos los elementos de la serie de Fourier. Sin embargo, las señales medidas no permiten realizar este estudio de la manera clásica ya que no son susceptibles de ser representadas por una fórmula matemática.

Con el avance de las técnicas de computación se han desarrollado programas que permiten obtener el espectro de una señal a partir de los datos almacenados en un registro temporal. Estos programas encuentran las componentes armónicas de la señal numéricamente sin necesidad de que la misma sea representable por una función matemática exacta. Existen dos algoritmos para tal fin: el de la Transformada Discreta de Fourier, DFT (Discrete Fourier Transform), y el algoritmo más usualmente utilizado, denominado Transformada Rápida de Fourier, FFT (Fast Fourier Transform)[10]. El segundo no es más que la derivación del algoritmo de análisis espectral DFT pero mucho más rápido.

Así, cualquier señal podrá ser representada como la suma de señales sinusoidales de amplitud, frecuencia y fase apropiada a partir de la señal temporal medida. Cada una de las señales en las que hemos descompuesto la señal original se puede representar en el dominio frecuencia (en el cual se representa la amplitud frente a la frecuencia) obteniendo así el espectro de la señal.

La trasformada Discreta de Fourier (DFT) está definida como:

$$
X\left(e^{i \omega}\right)=\sum_{n=-\infty}^{n=\infty} x(n) e^{-i n \omega}
$$

donde:

$$
\omega=2 \pi f T=2 \pi f / f_{s}
$$

donde $\mathrm{T}$ es el periodo de muestreo y $\mathrm{f}_{\mathrm{s}}$ es la frecuencia de muestreo.

La trasformación inversa se define como:

$$
x(n)=\frac{1}{2 \pi} \int_{-\pi}^{\pi} X\left(e^{i \omega}\right) e^{i n \omega} d \omega
$$

Las ecuaciones (3. 28) y (3. 29) forman conjuntamente la representación de Fourier de la secuencia de entrada. La ecuación (3. 30), o trasformada 
Capitulo 3 Diseñoy puesta a punto de un procedimiento de medida para la caracterización de turbogrupos

inversa de Fourier, es una ecuación de síntesis. Es decir, representa x(n) como una superposición de sinusoides complejas infinitesimalmente pequeñas de la forma:

$$
\frac{1}{2 \pi} X\left(e^{i \omega}\right) e^{i n \omega} d \omega
$$

con $\omega$ en un intervalo de longitud $2 \pi . X\left(e^{i \omega}\right)$ representa la cantidad relativa de cada componente sinusoidal compleja. Aunque al escribir la ecuación (3. 30) ha sido escogido el intervalo de valores de $\omega$ entre $-\pi$ y $\pi$, se puede utilizar cualquier intervalo de longitud $2 \pi$. La TDF (ecuación (3. 28)), es una expresión para calcular $X\left(e^{i \omega}\right)$ a partir de la secuencia $x(n)$, es decir, para analizar la secuencia $x(n)$ determinando que cantidad de cada componente en frecuencia es necesaria para sintetizar $x(n)$ utilizando la ecuación (3. 30).

En general, la TDF es una función compleja de $\theta$ y puede ser expresada en forma rectangular

$$
X\left(e^{i \omega}\right)=X_{R}\left(e^{i \omega}\right)+i X_{I}\left(e^{i \omega}\right)
$$

o en forma polar

$$
X\left(e^{i \omega}\right)=\left|X\left(e^{i \omega}\right)\right| e^{i \Phi\left(X\left(e^{i \omega}\right)\right)}
$$

Las cantidades $\left|X\left(e^{i \omega}\right)\right|$ y $\Phi\left(X\left(e^{i \omega}\right)\right)$ son, respectivamente, el módulo y la fase de la TDF. La fase no está determinada de forma única ya que se puede sumar a dicha fase cualquier múltiplo entero de $2 \pi$ sin afectar al resultado de la exponenciación compleja.

La condición que la secuencia sea absolutamente sumable es condición suficiente para la existencia de la representación de la TDF. Claramente, cualquier secuencia de longitud finita será absolutamente sumable y por lo tanto admitirá una representación mediante la TDF.

Las secuencias periódicas todavía no cumplen la condición anterior, ya que no se aproximan a cero cuando $n$ tiende a $\pm \infty$. Sin embargo, se puede considerar que las secuencias que se pueden expresar como suma de exponenciales complejas admiten una representación mediante la TDF como trenes de pulsos. Esto se puede hacer interpretando la TDF de una señal periódica como un tren de pulsos de periodo $2 \pi$ en el dominio de la frecuencia con valores proporcionales a los coeficientes del desarrollo en serie de Fourier de la secuencia. La expresión quedaría entonces: 


$$
X(k)=\left.\sum_{n=0}^{N-1} x(n) e^{-i \omega n}\right|_{\omega=2 \pi k / N}=\sum_{n=0}^{N-1} x(n) e^{-i(2 \pi / N) k n} \quad \text { con } 0 \leq k \leq N-1
$$

y la transformación inversa seria:

$$
x(n)=\left.\frac{1}{N} \sum_{k=0}^{N-1} X(k) e^{i \omega n}\right|_{\omega=2 \pi k / N}=\sum_{k=0}^{N-1} X(k) e^{i(2 \pi / N) k n} \quad \text { con } 0 \leq n \leq N-1
$$

Concretamente en este trabajo ha sido utilizada la función FFT del programa comercial Matlab, que utiliza un algoritmo rápido de resolución de la trasformada (Trasformada rápida de Fourier) sólo si el número de componentes del vector de la secuencia de datos es una potencia de 2 . En otro caso utiliza el método de resolución clásico.

Una sencilla transformación posterior permite calcular los coeficientes del desarrollo en serie de Fourier:

$$
a_{0}=X(0) / N \quad a(k)=2 \cdot \operatorname{Re}\{X(k)\} / N \quad b(k)=-2 \cdot \operatorname{Im}\{X(k)\} / N
$$

La fase y el ángulo de desfase serán:

$$
\left|f_{k}\right|=\sqrt{a_{k}^{2}+b_{k}^{2}} \quad \theta_{k}=\arctan \left\{b_{k} / a_{k}\right\}
$$

Tratando de este modo la señal temporal medida en el banco de ensayos se obtiene su espectro, es decir, la representación de las amplitudes $\left|\mathrm{f}_{\mathrm{k}}\right|$ de los armónicos en los que se descompone la señal en función de la frecuencia. El espectro permite reconocer las frecuencias que contribuyen más significativamente a la representación de la señal y, por tanto, las que definen mejor las oscilaciones que esta presenta.

\section{- Análisis del bombeo mediante la Transformada de Fourier}

Una vez vista cual es la rutina a seguir para realizar las medidas necesarias para poder elaborar un mapa de compresor y después de ver como se puede utilizar la Transformada de Fourier para realizar un análisis en frecuencia de una señal, vamos a ver ahora como podemos utilizar esta herramienta para discriminar los puntos de bombeo de los que no lo son y de este modo poder trazar la linea de bombeo cuando se elabore el mapa del compresor. 
Capitulo 3 Diseñoy puesta a punto de un procedimiento de medida para la caracterización de turbogrupos

Para mostrar esta herramienta se han utilizado medidas de en turbogrupo de la marca Holset HY40V formado por un compresor centrifugo y una turbina de geometría variable.

Las principales características geométricas del compresor son:

- Diámetro entrada compresor: $58.5 \mathrm{~mm}$

- Diámetro salida compresor: $52 \mathrm{~mm}$

- Número de álabes del rodete: 6 dobles

Se analizaron los espectros de las medidas de gasto trasegado, presión a la salida del compresor y régimen de giro del turbogrupo instantáneos para puntos de bombeo y puntos fuera de bombeo a diferentes regímenes de giro. En todos los regimenes se han tomado medidas de puntos en la zona de funcionamiento estable y de una serie de puntos en la zona de bombeo con la válvula a la salida del compresor centrífugo cada vez más cerrada, lo cual, en funcionamiento estable implicaría relaciones de compresión crecientes y gastos trasegados decrecientes.

A la hora de analizar el espectro de las variables hay que tener en cuenta que al calcular la transformada de Fourier el primer valor obtenido es la media de la variable instantánea, por lo que su valor queda fuera de la escala de amplitudes del resto del espectro y no debe ser considerado como un pico de amplitud que muestre la importancia de su correspondiente frecuencia en la transformada.

En la figura 3. 8 se muestra el mapa del compresor del turbogrupo HY40V, y se ha ampliado la zona donde se encuentran los puntos que determinan la linea de bombeo para la linea de $100000 \mathrm{rpm}$.

En la columna de la derecha se muestra para los puntos a, b y c la medida instantánea del gasto trasegado, la presión a la salida del compresor y el régimen de giro instantáneo.

El punto 'a' es el último punto de funcionamiento estable del compresor para este régimen de giro, se observa en las gráficas de la derecha de la figura 3. 8 como las variables medidas se mantienen constantes con el tiempo.

Si se disminuye el gasto que trasiega el compresor la presión a la salida del mismo aumenta, aumentando también la presión a la entrada debido a que disminuyen las pérdidas en el filtro de aire del caudalímetro. Una vez se alcanza el valor limite comienza a observarse un comportamiento oscilatorio en todas las variables, es entonces cuando el compresor entra en la zona de bombeo. El punto 'b', es el primer punto medido dentro de la llamada zona de bombeo. En las gráficas de la derecha de la figura 3.8 se observa como 
comienzan a aparecer inestabilidades de baja frecuencia en las variables instantáneas medidas.

El punto 'c', que no ha sido representado en el mapa del compresor, es otro punto medido dentro de la zona de bombeo, donde el comportamiento de las variables operativas del compresor (figura 3. 8) es claramente inestable.

Este punto no se ha representado en el mapa del compresor puesto que debido a las inestabilidades de las medidas los valores medios no son significativos y no tiene sentido representarlo.

Aunque todas las variables operativas del compresor se encuentran afectadas por el fenómeno de bombeo, es más evidente en algunas de ellas. Por ejemplo, cuando el compresor se encuentra en bombeo la variación del régimen de giro (medida como la amplitud pico-pico) solo representa un 6\% del valor medio, además es difícil de medir, debido al alto ruido inherente al principio de medida y a la influencia de las ondas de presión a la entrada de la turbina. Para el caso de la presión a la salida del compresor la variación es de entorno al 33\%, y mucho más significativa. En el caso del gasto de aire la variación puede llegar a ser del $100 \%$. A pesar de la gran variación relativa hay que tener en cuenta que la medida del gasto de aire se realiza con un anemómetro de hilo caliente y la frecuencia de respuesta del sensor es no tan buena como en el caso de la presión. Además el circuito de medida tiene un volumen importante entre el compresor y el sensor.

A la vista de estas circunstancias y con la experiencia obtenida del ensayo de otros compresores se decidió utilizar como variable de control del bombeo la presión a la salida del compresor. 
Capitulo 3 Diseñoy puesta a punto de un procedimiento de medida para la caracterización de turbogrupos

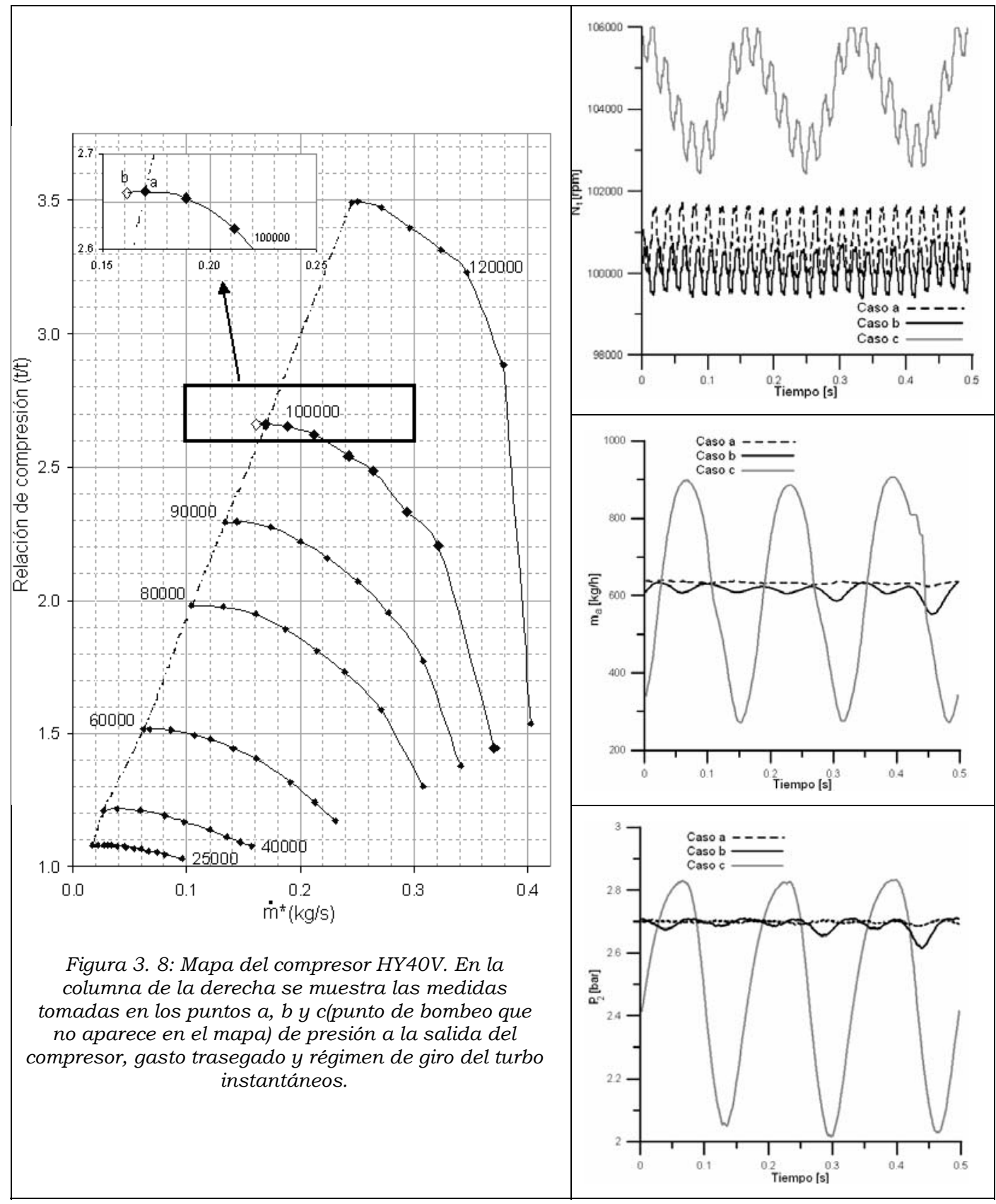

En la figura 3. 9 se muestra el espectro de la presión a la salida del compresor, $\left(\mathrm{P}_{\mathrm{SC}}\right)$, el gasto trasegado $(\dot{m})$, y el régimen de giro del turbogrupo $(\mathrm{n})$ para los puntos a, b y c, cuyas medidas se han mostrado anteriormente (figura 
3. 8). Se observa que en todos los casos aparece un pico claro en las zonas de bajas frecuencias para el punto que se encuentra en condiciones de bombeo, concretamente alrededor de $6 \mathrm{~Hz}$.
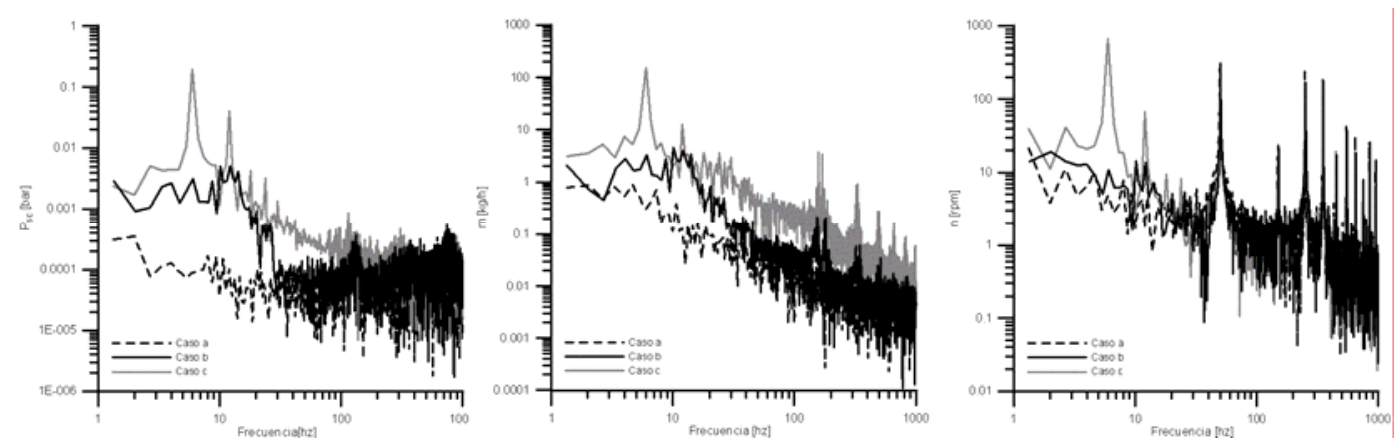

Figura 3. 9: Espectros obtenidos al analizar las señales de presión a la salida del compresor, gasto trasegado y régimen de giro del turbogrupo para los puntos $a, b$ y $c$.

Si tenemos el rango de frecuencias audibles por el oído humano está entre 20 y $20000 \mathrm{~Hz}$ es evidente que este armónico de $6 \mathrm{~Hz}$ no puede ser escuchado, pero si es posible oír todos los armónicos a partir del cuarto, que se encuentra, en este caso, alrededor de los $24 \mathrm{~Hz}$. Es por ello que este fenómeno resulta claramente audible.

En la figura 3. 10 se representan los espectros obtenidos para la presión a la salida del compresor de diferentes puntos de bombeo, medidos a distintos regimenes de giro. Los picos de bajas frecuencias lo marcan claramente y puede observarse como la frecuencia del armónico principal disminuye con el régimen de giro, encontrándose todos en un rango que va desde 5 a $10 \mathrm{~Hz}$.

En la figura 3. 11 se ha representado la frecuencia a la que aparece el principal armónico y el segundo, en función de la presión a la salida del compresor, puede observarse más claramente la disminución de la frecuencia del armónico principal con la presión a la salida del compresor. 
Capitulo 3 Diseñoy puesta a punto de un procedimiento de medida para la caracterización de turbogrupos

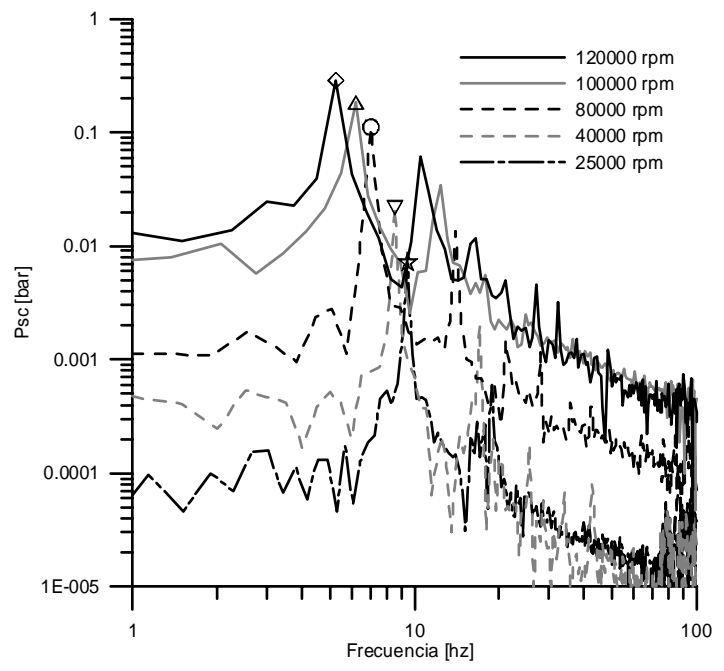

Figura 3. 10: Espectro de los puntos medidos en bombeo del compresor del turbogrupo HY4OV, para diferentes regimenes de giro del mapa.

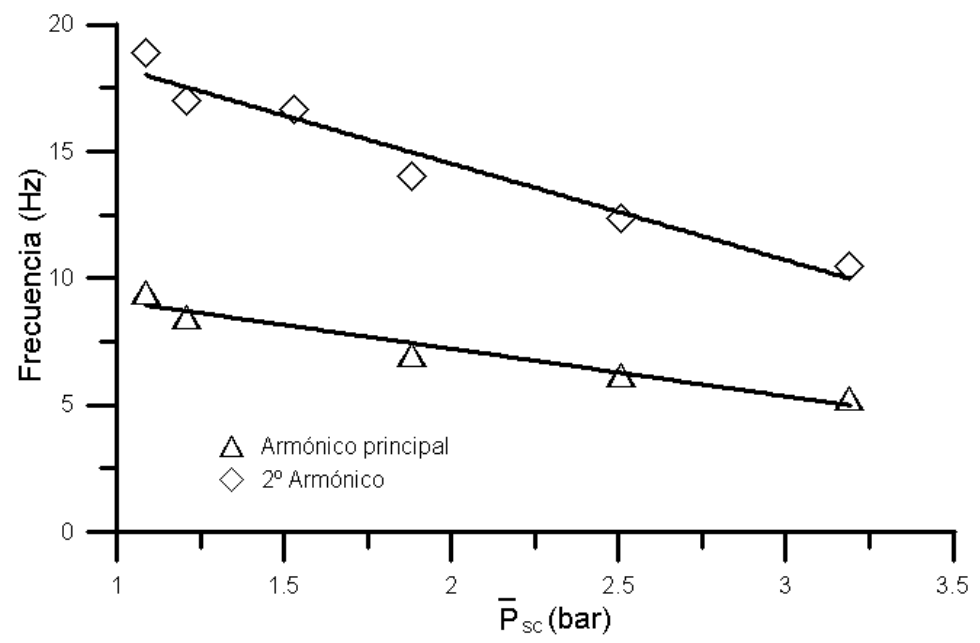

Figura 3. 11: Variación de la frecuencia de bombeo con la presión media a la salida del compresor.

Se ha comprobado en la instalación que la frecuencia a la que aparece el bombeo varia con el volumen que hay aguas abajo del compresor. Si este volumen se reduce, la frecuencia a la que aparece el bombeo aumenta. Se realizaron medidas con un compresor de un turbogrupo de sobrealimentación de un motor de 1.61 de cilindrada obteniéndole los resultados que se muestran en la siguiente tabla: 
Contribución a la caracterización experimental y modelado de TGV en grupos de sobrealimentación

\begin{tabular}{|c|c|c|c|}
\hline & Frecuencia principal $(\mathrm{Hz})$ & $2^{\circ}$ harmónico $(\mathrm{Hz})$ \\
\hline \multirow{2}{*}{ 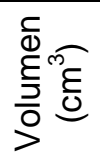 } & 1.000 & 47 & 95 \\
\hline & 20.000 & 4.1 & 8 \\
\hline
\end{tabular}

Tabla 3. 14: Variación de la frecuencia de bombeo principal y del segundo harmónico con el volumen aguas abajo del compresor.

Se concluye que el bombeo se manifiesta en unas oscilaciones de gran amplitud y baja frecuencia en las variables instantáneas medidas en el compresor. Por tanto, es posible detectar el bombeo realizando la transformada de Fourier de una de las variables instantáneas medidas y representando su espectro a bajas frecuencias durante los ensayos o en el tratamiento a posteriori de las medidas. Los puntos en los que dicho espectro presente un pico de una amplitud a una frecuencia baja serán considerados puntos de bombeo.

Aunque solo se han mostrado medidas realizadas con un compresor este proceso se ha repetido para todos los compresores que han sido ensayados ya en la instalación y los resultados obtenidos confirman el método aquí descrito.

Se concluye que la frecuencia es función del volumen aguas abajo del compresor y de la relación de relación de compresión, aunque es necesario un estudio más detallado del fenómeno para determinar mejor sus causas.

\section{- Ejemplos}

Para finalizar este apartado se van a mostrar dos mapas de dos compresores diferentes ensayados en la instalación. En los ensayos se ha procurado medir en las zonas de bajos regímenes de giro, esta zona es muy importante en la sobrealimentación de motores ya que durante el transitorio de carga el turbogrupo pasa por estos puntos de funcionamiento.

En ambos mapas se observa la típica forma de las curvas isorégimen, aplanadas en la zona próxima a bombeo, e incluso con ligeras pendientes positivas cerca de bombeo a altos regimenes, y fuertes pendientes negativas en la zona próxima a la línea de choque. La forma plana o con pendiente positiva de las curvas para bajos gastos marca la cercanía del funcionamiento inestable, es decir, bombeo.

En la tabla 3. 15 se muestran las características geométricas de los compresores ensayados y en la figura 3. 13 y la figura 3. 12 los mapas obtenidos. 
Capitulo 3 Diseñoy puesta a punto de un procedimiento de medida para la caracterización de turbogrupos

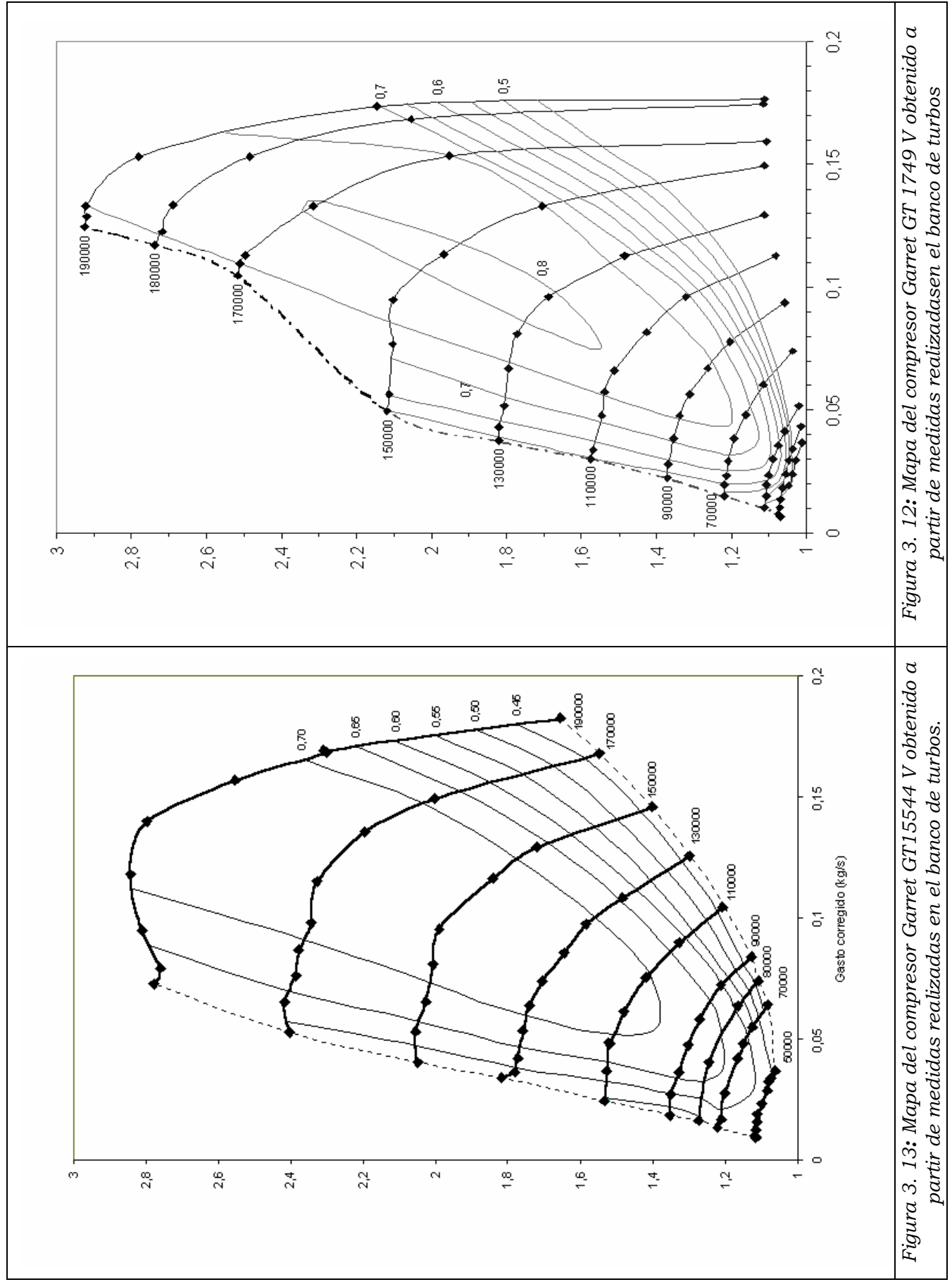


Contribución a la caracterización experimental y modelado de TGV en grupos de sobrealimentación

\begin{tabular}{|l|c|c|}
\hline \multicolumn{1}{|l|}{} & GT $1749 \mathrm{~V}$ & GT15544 V \\
\hline \hline TRIM & 53 & 50 \\
\hline \hline A/R & 0.42 & 0.33 \\
\hline Diámetro entrada & $39.4 \mathrm{~mm}$ & $41 \mathrm{~mm}$ \\
Diámetro salida & $37.6 \mathrm{~mm}$ & $35 \mathrm{~mm}$ \\
\hline Diámetro rodete máximo & $49 \mathrm{~mm}$ & $44 \mathrm{~mm}$ \\
Diámetro rodete mínimo & $35 \mathrm{~mm}$ & $31 \mathrm{~mm}$ \\
\hline \hline $\mathrm{N}^{\circ}$ álabes & 6 dobles & 6 dobles \\
\hline
\end{tabular}

Tabla 3. 15: Características geométricas de los compresores ensayados en la instalación.

Una forma de validar la calidad de las medidas de la instalación ha sido comprando el mapa de un compresor medido en la misma con las medidas obtenidas por el fabricante. Esta operación ha sido realizada con el compresor utilizado para describir el criterio para discriminar los puntos de bombeo. De la comparación de ambos mapas se ha obtenido la figura 3. 14, en la que se aprecia que el grado de acuerdo entre ambos mapas es prácticamente total, a excepción de una pequeña zona, en la que se obtiene discrepancias considerables, pero en la que el compresor no suele trabajar, puesto que es una zona de muy bajo rendimiento. 
Capítulo 3 Diseñoy puesta a punto de un procedimiento de medida para la caracterización de turbogrupos

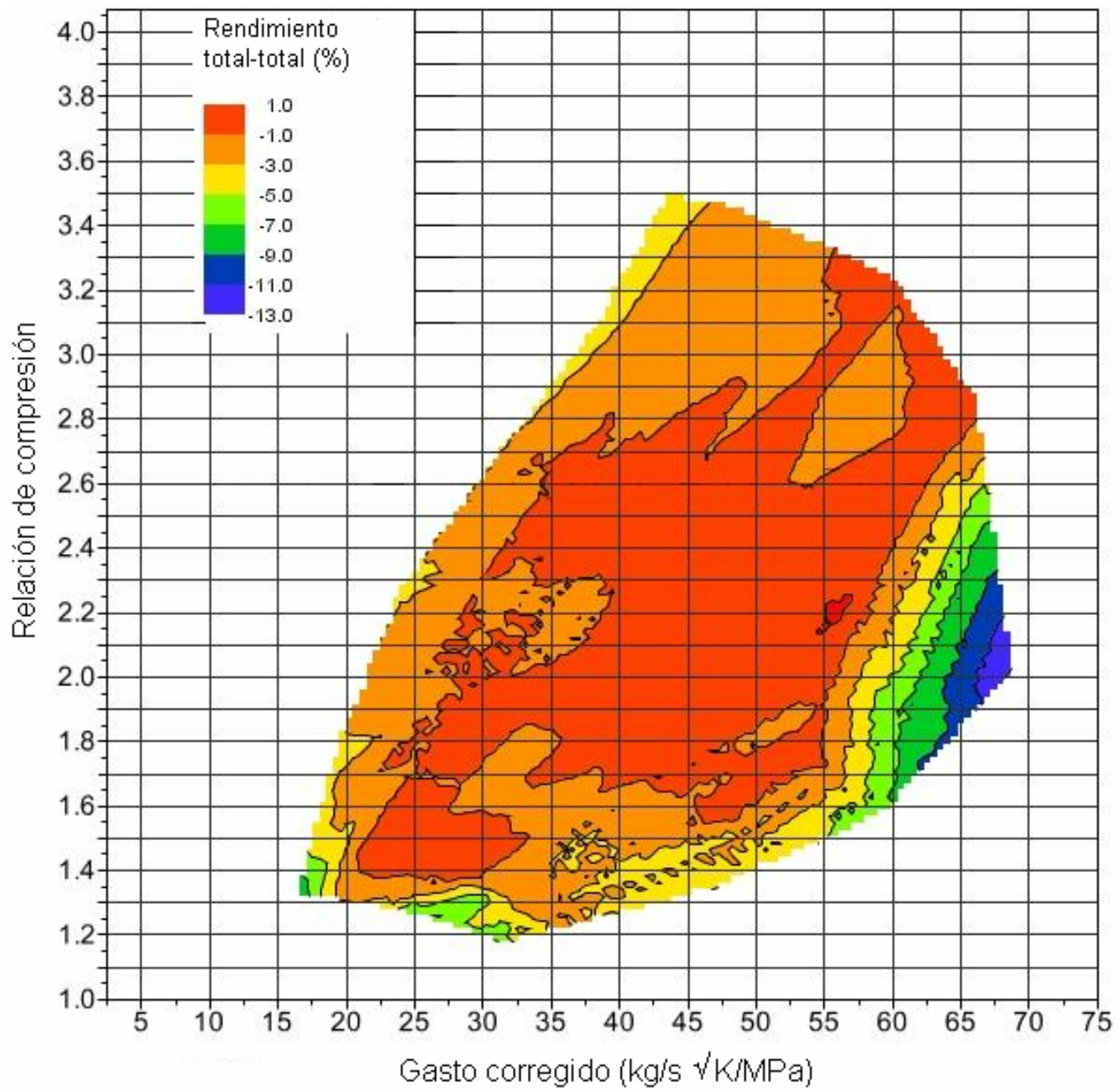

Figura 3. 14: Mapa comparativo del rendimiento de un compresor medido en la instalación descrita y medido por el fabricante.

Por otro lado, se ha realizado un estudio de las incertidumbres en las medidas que se realizan en la instalación, a partir de la teoría de errores [6]. Una descripción detallada del cálculo de la incertidumbre de las medidas se encuentra en el anexo I. Un ejemplo de los resultados que se obtiene se muestran en la siguiente figura, en la que se muestra el mapa y el rendimiento de un compresor GT1749 V de la marca Garret, en los que se han incluido los errores obtenidos a partir de las medidas realizadas.

Se observa en el mapa del compresor que la incertidumbre solo es significativa en una zona del mapa en la que el comportamiento del compresor es inestable, que es diferente del comportamiento de bombeo. Esta zona no es 


\section{Contribución a la caracterización experimental y modelado de TGV en grupos de sobrealimentación}

característica de todos los compresores como se puede observar comparando el mapa del compresor de la figura 3. 13 con el de la figura 3. 12. Esta zona de inestabilidades se debe a la pendiente positiva de las líneas de isorégimen, es una zona de grandes inestabilidades en el gasto másico que trasiega el compresor y se desaconseja el uso del mismo en dicha zona.

Se observa en las gráficas del rendimiento que los errores obtenidos para las lineas de menor isorégimen son más altos que para alto régimen, lo que es debido a que los saltos de presión y temperatura son menores y entonces las variaciones entalpía son menores, lo que hace que el error en el cálculo del rendimiento aumente.

Puede observarse también que dentro de una línea de isorégimen, los errores obtenidos aumentan al disminuir el gasto trasegado por el compresor, ya que en la zona de bombeo las desviaciones estándar de las medidas son mayores, lo que indica que el comportamiento del compresor es algo menos estable. Por otro lado en la zona cercana a la linea de bombeo (80000 y 160000 $\mathrm{rpm}$ ) también se observan algunos puntos con incertidumbres mayores que el resto de los puntos de su línea de isorégimen, cosa que refleja la proximidad de la zona de comportamiento inestable que es la zona de bombeo.

Se puede concluir entonces que la metodología y la instrumentación utilizadas en la instalación es la adecuada para realizar la caracterización de compresores de grupos de sobrealimentación. 
Capítulo 3 Diseñoy puesta a punto de un procedimiento de medida para la caracterización de turbogrupos

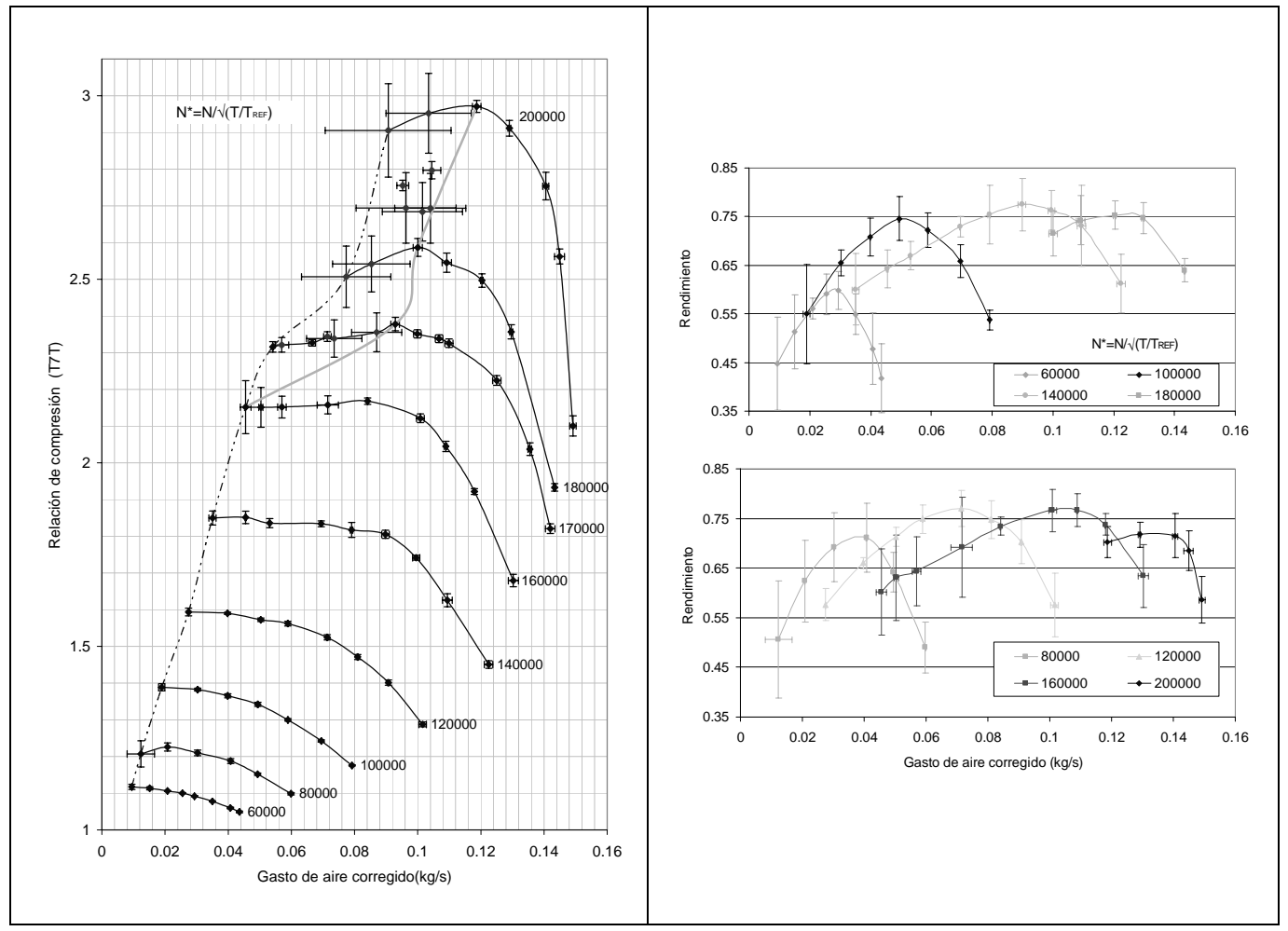

Figura 3. 15: Mapa y rendimiento del compresor GT1749V incluyendo el cálculo de errores.

\subsubsection{Mapa de una turbina: Análisis y elaboración del mapa de funcionamiento de una turbina}

El mapa de una turbina representa para diferentes regímenes de giro el gasto que atraviesa la turbina frente a la relación de expansión. Si se trata de una turbina de geometría variable se debe ensayar con distintos grados de apertura, obteniendo un mapa distinto para cada uno de ellos. Los rendimientos se representan en gráficas del mismo tipo que las de gasto, esto es. para cada régimen de giro se representa los rendimientos obtenidos frente a la relación de expansión.

Del mismo modo que en el caso del compresor las variables medidas utilizadas para la obtención del mapa de la turbina deben ser corregidas según lo visto en la tabla 3. 13 .

En la figura 3. 16 se muestra en un diagrama h-s la evolución del flujo en una turbina radial. A la derecha se muestra un esquema señalando los puntos considerados en el diagrama: a la sección de entrada al estator se le asigna el número 0 , a la sección de entrada al rotor el 1 y a la salida del rotor, el número 2. 


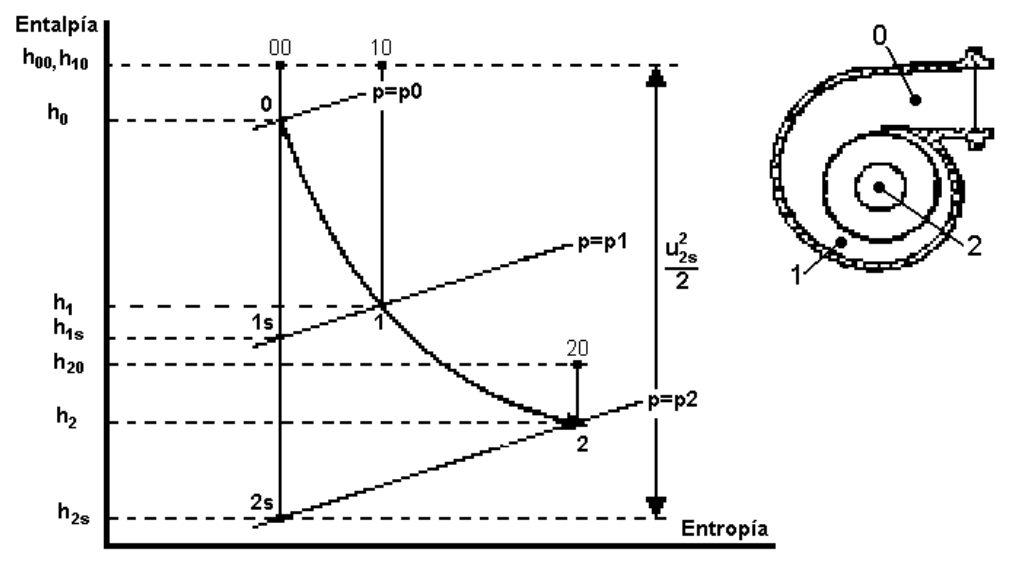

Figura 3. 16: Expansión en una turbina radial.

La relación de expansión se calcula como se ha visto en la tabla 3. 13 como $r_{\text {exp }}=\frac{p_{E T 0}}{p_{S T}}=\frac{p_{00}}{p_{2}}$. En la entrada se considera la presión de parada $\left(\mathrm{p}_{00}\right)$ puesto que también la energía cinética disponible a la entrada de la turbina es aprovechable en la turbina. En cambio a la salida la energía cinética de los gases de escape no se puede aprovechar, ya que son expulsados al ambiente, por lo que sólo se considera para evaluar el salto la presión dinámica, en lugar de la estática, como a la entrada de la turbina.

Las condiciones de parada se calculan exactamente igual que en el caso de las variables del compresor, con la salvedad de que en el caso de los gases de escape el cociente de calores específicos $\gamma$ toma un valor diferente, como se ha visto en el apartado 3.4.1.

El rendimiento isoentrópico de la turbina se define como el cociente entre el trabajo específico de la turbina una vez consideradas las irreversibilidades termodinámicas $\mathrm{W}_{\mathrm{u}}$ y el trabajo específico obtenido en la evolución isoentrópica, que aporta el trabajo máximo $\mathrm{W}_{\mathrm{s}}$.

$$
\eta_{T}=\frac{W_{u}}{W_{s}}
$$

Considerando la turbina adiabática el trabajo $\mathrm{W}_{\mathrm{u}}$ es, por la ecuación de conservación de la energía, igual al salto entálpico entre las condiciones de parada a la entrada y a la salida:

$$
W_{u}=h_{00}-h_{20}
$$


Capitulo 3 Diseñoy puesta a punto de un procedimiento de medida para la caracterización de turbogrupos

El trabajo obtenido en la evolución isoentrópica es:

$$
W_{s}=h_{00}-h_{2 s}
$$

En el cálculo del trabajo específico real obtenido se consideran condiciones de parada tanto a la entrada de la turbina como a la salida. En cambio en la evaluación del trabajo ideal se consideran condiciones dinámicas en la salida de la turbina. La razón es que la energía cinética del flujo de salida no se aprovecha, es decir, constituye una pérdida, puesto que los gases de escape son expulsados al ambiente. El rendimiento calculado bajo estas consideraciones recibe el nombre de rendimiento total a estático.

Según estas consideraciones el rendimiento de la turbina será:

$$
\eta_{T}=\frac{h_{00}-h_{20}}{h_{00}-h_{2 s}}
$$

Ocurre, igual que en el caso del compresor que el calor específico de los gases de escape a presión constante y la constate de los gases $\mathrm{R}$ son función de la temperatura de los gases de escape y del dosado de los mismos.

$$
\begin{aligned}
& R=f(A / F) \\
& c_{p}=f(A / F, T)
\end{aligned}
$$

La variación de entropía en un proceso real viene dada por la siguiente expresión:

$$
d s=\frac{d\left(c_{p} \cdot T\right)}{T}-\frac{d(R \cdot p)}{p}
$$

Para el caso de un proceso isoentrópico se obtiene que:

$$
\begin{aligned}
& \left.\begin{array}{l}
d s=0 \\
R=c t e
\end{array}\right] \Rightarrow 0=\frac{d\left(c_{p} \cdot T\right)}{T}-R \frac{d p}{p} \\
& A / F=c t e \Rightarrow c_{p}=K_{1} \cdot T^{B} / K_{1}=f(A / F)
\end{aligned}
$$

Despejando queda:

$$
0=\frac{d\left(K_{1} \cdot T^{B} \cdot T\right)}{T}-R \frac{d p}{p} \Rightarrow 0=\frac{K_{1} \cdot d\left(T^{B+1}\right)}{T}-R \frac{d p}{p}
$$


Teniendo en cuenta que para un determinado punto de funcionamiento la relación aire combustible permanece constante, de modo que la constante de los gases, R, no varía para cada punto:

$$
\frac{d\left(T^{B+1}\right)}{T}=\frac{R}{K_{1}} \frac{d p}{p} \Rightarrow \frac{(B+1) T^{B} d T}{T}=\frac{R}{K_{1}} \frac{d p}{p}
$$

Hay que integrar desde las condiciones iniciales a las condiciones de salida isoentrópicas:

$$
\int_{0}^{2 s}(B+1) T^{B-1} d T=\int_{0}^{2 s} \frac{R}{K_{1}} \frac{d p}{p}
$$

De donde se obtiene que la temperatura de salida isoentrópica viene dada por la siguiente expresión:

$$
T_{2 s}=\left(T_{0}^{B}+\frac{R \cdot B}{K_{1} \cdot(B+1)} \ln \left(\frac{p_{2 s}}{p_{0}}\right)\right)^{1 / B}
$$

Las diferencias obtenidas entre calcular la temperatura de salida isoentrópica con la expresión (3. 49) o calcularla suponiendo que $\mathrm{R}, \mathrm{c}_{\mathrm{p}} \mathrm{y} \gamma$ son constantes aumenta con la relación de expansión, el dosado y la temperatura del gas de escape, alcanzándose diferencias de $7 \%$ en los casos más extremos, con lo que se hace importante considerar la variación de $\mathrm{R}, \mathrm{c}_{\mathrm{p}} \mathrm{y} \gamma$ con el dosado y la temperatura del gas, para evitar introducir este error en el cálculo del rendimiento de la turbina.

Dado que en realidad la turbina no es adiabática como asume la expansión isoentrópica, pudiera ser que el coeficiente politrópico de la expansión, $\mathrm{k}$, fuera menor que $\gamma \mathrm{y}$ por tanto el rendimiento de la turbina definido según la expresión (3. 41) fuera mayor que uno. Para evitar esta situación el rendimiento se calcula como el cociente entre la potencia real consumida por el compresor y potencia isoentrópica de la turbina, teniendo así en cuenta en el rendimiento de la turbina las pérdidas mecánicas del acoplamiento con el compresor. Por tanto la expresión según la cual se calcula el rendimiento de la turbina por los fabricantes de turbogrupos es:

$$
\eta_{T}=\frac{\dot{W}_{C} \cdot \dot{m}_{C}}{\dot{W}_{T s} \cdot \dot{m}_{T}}
$$

Operando sobre las variables medidas de este modo se obtienen los mapas de la turbina para las diferentes aperturas ensayadas. 
Capitulo 3 Diseñoy puesta a punto de un procedimiento de medida para la caracterización de turbogrupos

A continuación, como ejemplo, se muestra un mapa de una turbina de geometría variable, cuyas características se muestran en la siguiente tabla:

\begin{tabular}{|l|c|}
\hline Características & GT $1749 \mathrm{~V}$ \\
\hline Diámetro entrada & $33 \mathrm{~mm}$ \\
Diámetro salida & $38.5 \mathrm{~mm}$ \\
Diámetro rodete & $42.5 \mathrm{~mm}$ \\
No álabes rodete & 9 \\
No álabes móviles en el estator & 11 \\
\hline
\end{tabular}

Tabla 3. 16: Características geométricas de la turbina de geometria variable, ensayada en la instalación.

El mapa de la turbina se muestra a continuación en la figura 3. 17. Los diferentes regímenes de giro se identifican en función del color y el símbolo de cada punto según indica la leyenda. Los desplazamientos asociados a cada posición de los álabes del estator están indicados junto al punto de mayor gasto de cada curva.

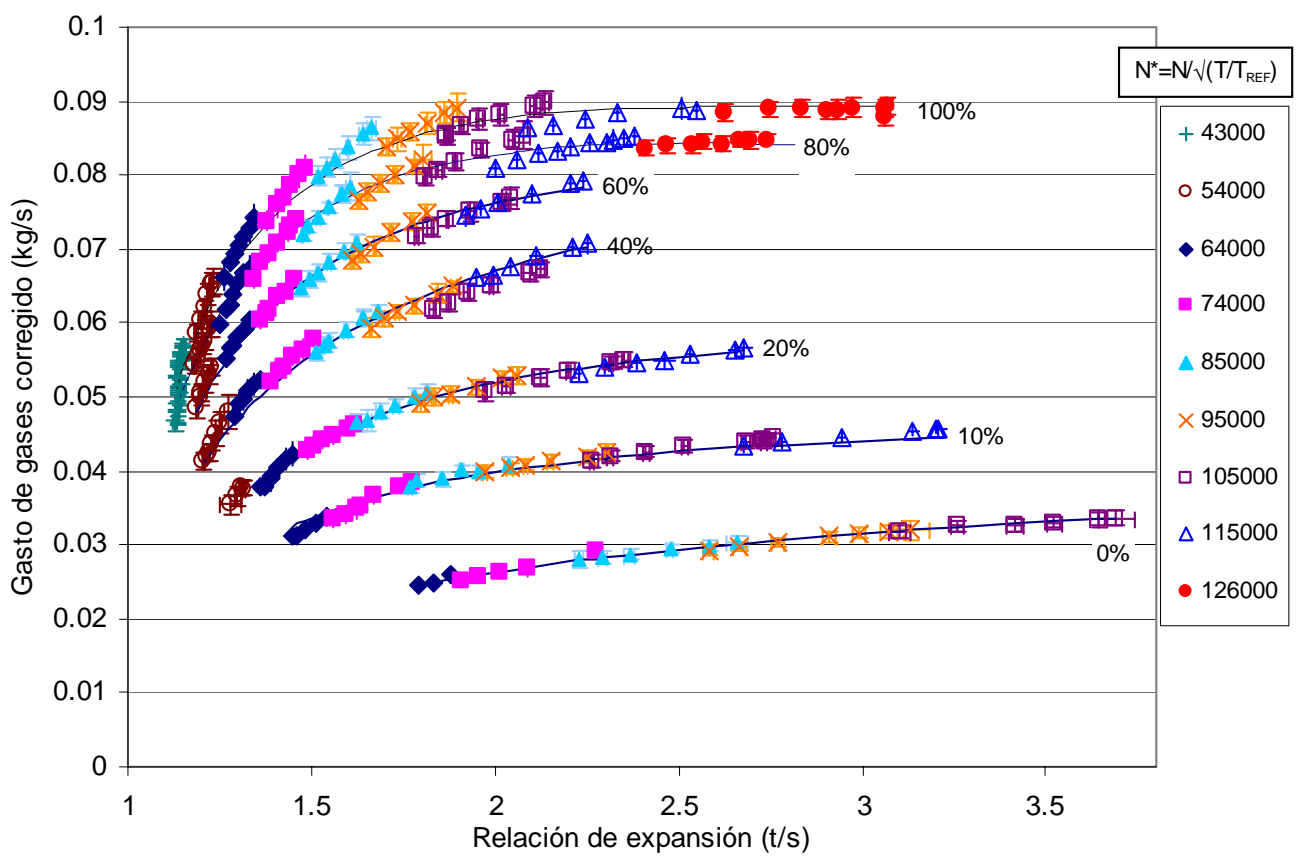

Figura 3. 17: Mapa de una turbina de geometria variable. 
El mapa muestra el comportamiento del flujo a través de la turbina, que sigue la forma de la ecuación de la tobera. Para cada apertura los menores regímenes de giro se alcanzan en la zona de menores relaciones de expansión y los regímenes de giro más altos aparecen con las relaciones de expansión más elevadas.

La curva gasto másico-relación de expansión, que presenta la misma forma para todas las aperturas, queda desplazada hacia menores relaciones de expansión y mayores gastos másicos a medida que aumenta la apertura de los álabes del estator. La variación del gasto con la relación de expansión es más significativa para regímenes de giro bajos. En cambio la variación de la apertura de la turbina tiene una gran influencia sobre la cantidad de gasto trasegado. El aumento de la relación de expansión influye muy significativamente, en todas las aperturas del estator, sobre el régimen de giro alcanzado.

También se observa en esta figura 3. 17 como las lineas de régimen de giro constante se desplazan hacia menores gastos a medida que aumenta el grado de apertura de la turbina.

A continuación, en la figura 3. 18, se muestran los mapas de los rendimientos de la turbina para los puntos de funcionamiento ensayados. En ellos se representa el rendimiento frente a la relación de expansión de la turbina para diferentes regímenes y aperturas del estator. Los colores y simbolos se han asignado según el mismo criterio utilizado en el mapa de la turbina (figura 3. 17).

Se comprueba que para todos los regímenes los rendimientos obtenidos con el estator de la turbina totalmente abierto son menores que con cualquier otro grado de apertura. Los rendimientos obtenidos para la turbina cerrada son los siguientes más bajos, aunque el nivel es más próximo al de las curvas correspondientes al resto de aperturas que al de las curvas del estator de la turbina totalmente abierto. Las aperturas intermedias presentan rendimientos similares entre sí, siendo los mayores rendimientos alcanzados los máximos de las curvas de apertura del $40 \%$.

Todos los rendimientos toman valores entre 0.6 y 0.75 , excepto en el caso de apertura total en el que los rendimientos quedan comprendidos entre $0.35 \mathrm{y}$ 0.5. Los valores obtenidos son razonables para una turbina como la ensayada. 
Capitulo 3 Diseñoy puesta a punto de un procedimiento de medida para la caracterización de turbogrupos
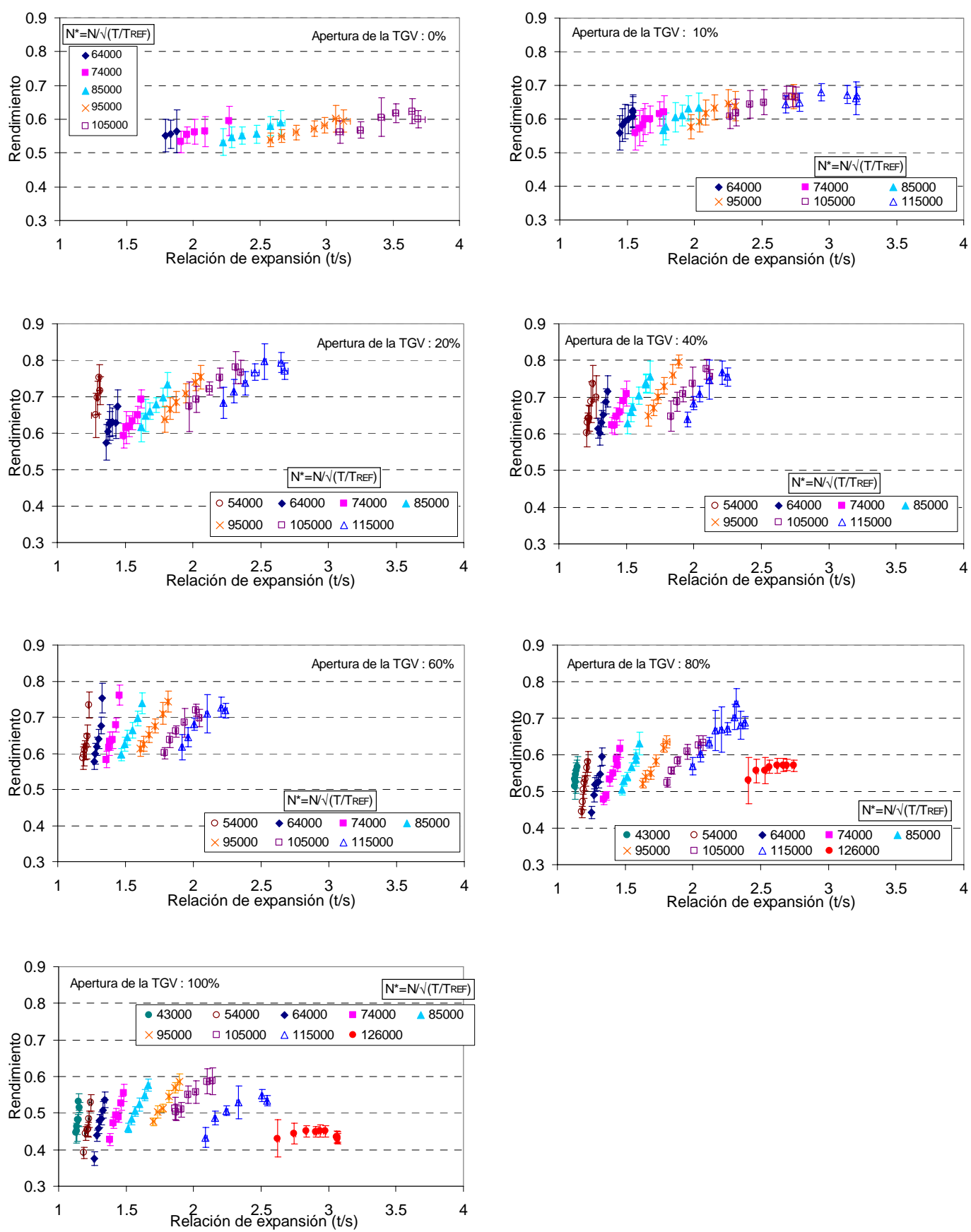

Figura 3. 18: Rendimiento de la turbina frente a gasto másico diferentes aperturas de la turbina. 
En cuanto a las incertidumbres obtenidas para el caso de la turbina hay que destacar el mismo comportamiento que en el caso del compresor, es decir, las incertidumbres aumentan cuando los saltos de presión y temperatura entre la entrada y la salida de la turbina disminuyen, lo que ocurre generalmente en el caso de regímenes de giro bajos.

Por otro lado, se observa que las incertidumbres obtenidas para el rendimiento de la turbina son elevadas, superando el $10 \%$ del valor de la medida en algunos casos.

Este resultado era de esperar en tanto que en el cálculo del rendimiento de la turbina intervienen la mayor parte de las medidas realizadas en la instalación, de manera que la acumulación de las incertidumbres hace que el resultado obtenido sea el que se muestra en la figura 3. 18. En el Anexo I se desarrolla de una forma detallada el cálculo de la incertidumbre del rendimiento de la turbina. 


\subsection{Resumen}

A lo largo de este capítulo se ha analizado la forma de realizar los ensayos de un turbocompresor, con la instalación descrita en el capítulo anterior.

El capítulo se ha divido en tres grandes apartados, en primer lugar se ha realizado una revisión en la que se relacionan las variaciones de las variables operativas de la instalación, esto es, aquellas variables de la instalación que al modificarse van a hacer que cambie a su vez el punto de funcionamiento de la turbina o el compresor que se esté ensayando con las variables fundamentales del turbogrupo, de forma que se ha obtenido una relación entre cada una de ellas y el punto de funcionamiento de la turbina y el compresor.

A continuación se ha descrito como alcanzar un determinado punto de funcionamiento, esto es, el proceso para llegar al punto de medida deseado. Para ello se han distinguido dos casos, las medidas de los puntos de funcionamiento del compresor y las medidas de los puntos de funcionamiento de la turbina.

Una vez alcanzado el punto de medida deseado, se ha revisado la metodología para realizar la medida, analizándose la normativa existente sobre la realización de medidas para la caracterización de turbogrupos. Se describen tanto la preparación de los puntos de medida donde se sitúan los captadores de presión y temperatura como la instrumentación utilizada para la realización de dichas medidas.

Se ha realizado un estudio para determinar el tiempo que tarda la instalación en estabilizarse y que las medidas realizadas sean correctas. De dicho estudio se concluye que aunque el comportamiento de la turbina y el compresor se hace estable rápidamente, es necesario esperar a que estabilicen las temperaturas de los gases en la instalación para que al realizar los cálculos necesarios los valores obtenidos para los rendimientos sean correctos.

Al final del capitulo ha realizado una revisión del tratamiento que se aplica sobre las medidas para poder obtener los mapas de funcionamiento del turbogrupo, la normalización de las medidas a partir de la normativa existente, la obtención de la variables termodinámicas de funcionamiento del turbogrupo, así como un método para discriminar los puntos de bombeo del compresor frente a los puntos de funcionamiento estable.

También se ha realizado una revisión sobre la incertidumbre en los resultados obtenidos, concluyéndose que la instrumentación y metodologías utilizadas para caracterizar turbogrupos son adecuadas, puesto que los 
Contribución a la caracterización experimental y modelado de TGV en grupos de sobrealimentación valores de las incertidumbres obtenidas son aceptables. Como era de esperar las mayores incertidumbres se obtienen para el rendimiento de la turbina, puesto que esta variable es función de un gran número de medidas de la instalación y la acumulación de las incertidumbres de todas estas medidas es la que hace que se alcancen, en algunos casos, valores de la incertidumbre del rendimiento de la turbina elevados. 


\section{Anexo 1: Cálculo de las incertidumbres de las medidas.}

El error del proceso de medida es un parámetro que caracteriza la dispersión de los valores que podrian ser razonablemente atribuidos al proceso de medida. El error de medida consta, en general, de varios componentes. Algunos de estos componentes pueden ser evaluados a partir de la distribución estadística de las series de medidas de los resultados y se puede caracterizar con la desviación estándar.

La desviación estándar experimental para una serie de $\mathrm{n}$ medidas de la misma medida viene dada por la ecuación (A.1) y caracteriza la dispersión de los resultados.

$$
\sigma=\sqrt{\frac{\sum_{i=1}^{n}\left(x_{i}-\bar{x}\right)^{2}}{n-1}}
$$

Siendo $\mathrm{x}_{\mathrm{i}}$ el resultado de la i-ésima medida $\mathrm{y}$ la media aritmética de las $\mathrm{n}$ medidas consideradas.

Si la variable ' $\mathrm{y}$ ', siendo $\mathrm{y}=\mathrm{f}\left(\mathrm{x}_{1}, \mathrm{x}_{2} \ldots \mathrm{x}_{\mathrm{k}}\right)$, representa una cierta variable que no puede ser medida y se calcula, necesariamente, a partir de otras variables que si son directamente medidas (como por ejemplo el rendimiento isoentrópico) la incertidumbre en el valor de yse obtiene combinando adecuadamente las incertidumbres de las variables medidas. Por lo tanto, la incertidumbre de la variable $\mathrm{y}, \mathrm{u}_{\mathrm{c}}(\mathrm{y})$, viene dada por la ecuación (A. 2)

$$
u_{c}(y)=\sqrt{\sum_{i=1}^{k}\left(\frac{\partial f}{\partial x_{i}}\right)^{2} \cdot u^{2}\left(x_{i}\right)}
$$

Donde cada $\mathrm{u}\left(\mathrm{x}_{\mathrm{i}}\right)$ is la desviación estándar obtenida de cada una de las medidas, calculada según la ecuación (A. 1).

Para hacer una medida, el sistema de adquisición de datos del banco de ensayo de turbogrupos realiza la adquisición de datos durante un tiempo determinado que elige el usuario, generalmente 30 segundos, tomando una medida cada $0.5 \mathrm{~s}$. De este modo para cada medida que se realiza se obtiene el valor medio y la desviación estándar de las 60 medidas realizadas para obtener el valor medio. Obtenidos todos los valores medios y todas las desviaciones estándar es posible obtener la incertidumbre para cualquier variable medida o calculada. 
Contribución a la caracterización experimental y modelado de TGV en grupos de sobrealimentación

A modo de ejemplo se muestra el desarrollo matemático seguido para el cálculo de la incertidumbre en el rendimiento de la turbina.

El rendimiento de la turbina se ha definido como:

$$
\eta_{T}=\frac{\dot{W}_{C} \cdot \dot{m}_{C}}{\dot{W}_{T s} \cdot \dot{m}_{T}}
$$

A partir de la definición de la incertidumbre se tiene que:

$$
u_{c}\left(\eta_{T}\right)=\sqrt{\left(\frac{\partial \eta_{T}}{\partial \dot{W}_{C}}\right)^{2} u^{2}\left(\dot{W}_{C}\right)+\left(\frac{\partial \eta_{T}}{\partial \dot{m}_{C}}\right)^{2} u^{2}\left(\dot{m}_{C}\right)+\left(\frac{\partial \eta_{T}}{\partial \dot{W}_{T s}}\right)^{2} u^{2}\left(\dot{W}_{T s}\right)+\left(\frac{\partial \eta_{T}}{\partial \dot{m}_{T}}\right)^{2} u^{2}\left(\dot{m}_{T}\right)}
$$

Derivando la expresión (A. 3)

$$
\begin{array}{cc}
\frac{\partial \eta_{T}}{\partial \dot{W}_{C}}=\frac{\eta_{T}}{\dot{W}_{C}} & \frac{\partial \eta_{T}}{\partial \dot{m}_{C}}=\frac{\eta_{T}}{\dot{m}_{C}} \\
\frac{\partial \eta_{T}}{\partial \dot{W}_{T}}=\frac{\eta_{T}}{\dot{W}_{T}} & \frac{\partial \eta_{T}}{\partial \dot{m}_{T}}=\frac{\eta_{T}}{\dot{m}_{T}}
\end{array}
$$

Hay que tener en cuenta también que:

$$
\begin{aligned}
& u\left(\dot{W}_{C}\right)=\sqrt{\left(\frac{\partial \dot{W}_{C}}{\partial \dot{m}_{C}}\right)^{2} \cdot u^{2}\left(\dot{m}_{C}\right)+\left(\frac{\partial \dot{W}_{C}}{\partial h_{E C 0}}\right)^{2} \cdot u^{2}\left(h_{E C 0}\right)+\left(\frac{\partial \dot{W}_{C}}{\partial h_{S C 0}}\right)^{2} \cdot u^{2}\left(h_{S C 0}\right)} \\
& u\left(\dot{m}_{C}\right)=\sigma\left(\dot{m}_{C}\right) \\
& u\left(\dot{W}_{T s}\right)=\sqrt{\left(\frac{\partial \dot{W}_{T s}}{\partial \dot{m}_{T}}\right)^{2} \cdot u^{2}\left(\dot{m}_{T}\right)+\left(\frac{\partial \dot{W}_{T s}}{\partial h_{E T 0}}\right)^{2} \cdot u^{2}\left(h_{E T 0}\right)+\left(\frac{\partial \dot{W}_{T s}}{\partial h_{S T s}}\right)^{2} \cdot u^{2}\left(h_{S T s}\right)} \\
& u\left(\dot{m}_{T}\right)=\sqrt{\left(\frac{\partial \dot{m}_{T}}{\partial \dot{m}_{a}}\right)^{2} \cdot u^{2}\left(\dot{m}_{a}\right)+\left(\frac{\partial \dot{m}_{T}}{\partial \dot{m}_{f}}\right)^{2} \cdot u^{2}\left(\dot{m}_{f}\right)+\left(\frac{\partial \dot{m}_{T}}{\partial \dot{m}_{b b}}\right)^{2} \cdot u^{2}\left(\dot{m}_{b b}\right)}
\end{aligned}
$$

(A. 6), (A. 8) y (A. 9) a su vez se descompone como se muestra a continuación. 
Capitulo 3 Diseñoy puesta a punto de un procedimiento de medida para la caracterización de turbogrupos

1. Para calcular $u\left(\dot{W}_{C}\right)$ :

$$
\begin{aligned}
& \left(\frac{\partial \dot{W}_{C}}{\partial \dot{m}_{C}}\right)=h_{S C 0}-h_{E C 0} \\
& \left(\frac{\partial \dot{W}_{C}}{\partial h_{E C 0}}\right)=\left(\frac{\partial \dot{W}_{C}}{\partial h_{S C 0}}\right)=\dot{m}_{C} \\
& u\left(h_{E C 0}\right)=\sqrt{\left(\frac{\partial h_{E C 0}}{\partial h_{E C}}\right)^{2} \cdot u^{2}\left(h_{E C}\right)+\left(\frac{\partial h_{E C 0}}{\partial v_{E C}}\right)^{2} \cdot u^{2}\left(v_{E C}\right)} \\
& u\left(h_{S C 0}\right)=\sqrt{\left(\frac{\partial h_{S C 0}}{\partial h_{S C}}\right)^{2} \cdot u^{2}\left(h_{S C}\right)+\left(\frac{\partial h_{S C 0}}{\partial v_{S C}}\right)^{2} \cdot u^{2}\left(v_{S C}\right)} \\
& \left(\frac{\partial h_{E C 0}}{\partial h_{E C}}\right)=\left(\frac{\partial h_{S C 0}}{\partial h_{S C}}\right)=1 \quad\left(\frac{\partial h_{E C 0}}{\partial v_{E C}}\right)=v_{E C} \quad\left(\frac{\partial h_{S C 0}}{\partial v_{S C}}\right)=v_{S C} \\
& u\left(h_{S C}\right)=\left(\frac{\partial h_{S C}}{\partial T_{S C}}\right) \cdot u\left(T_{S C}\right)=0.93325 T_{S C}^{0.1457} \cdot \sigma\left(T_{S C}\right)
\end{aligned}
$$

Teniendo en cuenta que $\mathrm{R}$ es constante y que el error de los valores de las áreas de entrada y de salida son despreciables frente al resto, para la velocidad se obtiene una incertidumbre que viene dada por:

$$
\begin{aligned}
& u(v)=\sqrt{\left(\frac{\partial v}{\partial T}\right)^{2} \cdot u^{2}(T)+\left(\frac{\partial v}{\partial P}\right)^{2} \cdot u^{2}(p)+\left(\frac{\partial v}{\partial \dot{m}_{C}}\right)^{2} \cdot u^{2}\left(\dot{m}_{C}\right)}= \\
& =\sqrt{\left(\frac{v}{T}\right)^{2} \cdot \sigma^{2}(T)+\left(\frac{v}{p}\right)^{2} \cdot \sigma^{2}(p)+\left(\frac{v}{\dot{m}_{C}}\right)^{2} \cdot \sigma^{2}\left(\dot{m}_{C}\right)}= \\
& =\sqrt{\left(\frac{\sigma(T)}{T}\right)^{2}+\left(\frac{\sigma(p)}{p}\right)^{2}+\left(\frac{\sigma\left(\dot{m}_{C}\right)}{\dot{m}_{C}}\right)^{2}}
\end{aligned}
$$


2. Para calcular $u\left(\dot{W}_{T s}\right)$ :

$$
\begin{aligned}
& \left(\frac{\partial \dot{W}_{T s}}{\partial \dot{m}_{T}}\right)=h_{S T s}-h_{E T 0} \\
& \left(\frac{\partial \dot{W}_{T S}}{\partial h_{E T 0}}\right)=\left(\frac{\partial \dot{W}_{T S}}{\partial h_{S T S}}\right)=\dot{m}_{T} \\
& u\left(h_{E T 0}\right)=\sqrt{\left(\frac{\partial h_{E T 0}}{\partial h_{E T}}\right)^{2} \cdot u^{2}\left(h_{E T}\right)+\left(\frac{\partial h_{E T 0}}{\partial v_{E T}}\right)^{2} \cdot u^{2}\left(v_{E T}\right)} \\
& \left(\frac{\partial h_{E T 0}}{\partial h_{E T}}\right)=1 ;\left(\frac{\partial h_{E T 0}}{\partial v_{E T}}\right)=v_{E T} \\
& u\left(h_{E T}\right)=\sqrt{\left(\frac{\partial h_{E T}}{\partial T_{E T}}\right)^{2} \cdot u^{2}\left(T_{E T}\right)+\left(\frac{\partial h_{E T}}{\partial A / F}\right)^{2} \cdot u^{2}(A / F)} \\
& \left(\frac{\partial h_{E T}}{\partial T_{E T}}\right)=2.3260 \cdot\left(0.1284+2.3 \cdot 10^{-4} \mathrm{~A} / F\right) \cdot\left(1.0954-2.967 \cdot 10^{-4} \mathrm{~A} / F\right) \cdot T_{E T}^{\left(1.0954-2068 \cdot 10^{-4} A F\right)-1} \\
& u(A / F)=\sqrt{\left(\frac{\partial A / F}{\partial \dot{m}_{a}}\right)^{2} \cdot \sigma^{2}\left(\dot{m}_{a}\right)+\left(\frac{\partial A / F}{\partial \dot{m}_{f}}\right)^{2} \cdot \sigma^{2}\left(\dot{m}_{f}\right)}= \\
& =\sqrt{\left(\frac{A / F}{\dot{m}_{a}}\right)^{2} \cdot \sigma^{2}\left(\dot{m}_{a}\right)+\left(\frac{A / F}{\dot{m}_{f}}\right)^{2} \cdot \sigma^{2}\left(\dot{m}_{f}\right)}=A / F \sqrt{\left(\frac{\sigma\left(\dot{m}_{a}\right)}{\dot{m}_{a}}\right)^{2}+\left(\frac{\sigma\left(\dot{m}_{f}\right)}{\dot{m}_{f}}\right)^{2}} \\
& u(v)=v \sqrt{\left(\frac{\sigma(T)}{T}\right)^{2}+\left(\frac{\sigma(p)}{p}\right)^{2}+\left(\frac{\sigma\left(\dot{m}_{C}\right)}{\dot{m}_{C}}\right)^{2}} \\
& u\left(h_{\text {STS }}\right)=\left(\frac{\partial h_{\text {STS }}}{\partial T_{\text {STS }}}\right) \cdot u\left(T_{\text {STs }}\right)
\end{aligned}
$$


Capitulo 3 Diseñoy puesta a punto de un procedimiento de medida para la caracterización de turbogrupos

3. Para calcular $u\left(\dot{m}_{T}\right)$ :

$$
\begin{aligned}
\left(\frac{\partial \dot{m}_{T}}{\partial \dot{m}_{a}}\right) & =\dot{m}_{f}+\dot{m}_{b b} \\
\left(\frac{\partial \dot{m}_{T}}{\partial \dot{m}_{f}}\right) & =\dot{m}_{a}+\dot{m}_{b b} \\
\left(\frac{\partial \dot{m}_{T}}{\partial \dot{m}_{b b}}\right) & =\dot{m}_{a}+\dot{m}_{f} \\
u\left(\dot{m}_{a}\right)=\sigma\left(\dot{m}_{a}\right) & =\sigma\left(\dot{m}_{f}\right) \quad u\left(\dot{m}_{b b}\right)=\sigma\left(\dot{m}_{b b}\right)
\end{aligned}
$$




\section{Bibliografia}

[1] Bathie, W.W., (1996) Fundamental of Gas turbines. John Wiley \& Sons, Inc.

[2] Chapman, K.S., Mohsen, O. "Real Time Performance of an Elliott HSeries Turbocharger" National Gas Machinery Laboratory. Kansas State University Laboratory.

[3] Chapman, K.S., Shultz, J. "Guidelines for Testing Large-Bore Engine Turbochargers" National Gas Machinery Laboratory. Kansas State University Laboratory.

[4] Gravdahl, J.T., Egeland, O.(1999) "Centrifugal Compressor Surge and Speed Control. IEEE Transctions on Control Systems Technology, Vol 7, No 5,.

[5] Gravdahl, J.T., Egeland, O., Vatland, S.O., (2001) Active Surge Control of Centrifugal Compressors Using Drive Torque. Proceedings of the 40th IEEE Conference on Decision and Control, pp 12861291.

[6] Guide to expression of uncertainty in measurement (1995) ISBN 9267-10188-9, developed by BIPM(Bureau international des piods et measures), IEC(International Electrotecnical Commision), IFCC(Internationa Federation of Clinical Chemistry), ISO(International Organization for Standadization), IUPAC(International Union of Pure and Applied Chemistry), IUPAP (International Union of Pure and Applied Physics) and OIML (International Organization of Legal Metrology)

[7] Hayward, A.T.J. (1983) Flowmeters. A basic guide and source-book for users. The MacMillan Press Ltd. ISBN 0-333-21920-1.

[8] Muñoz, M., Payri, F. (1989) Motores de combustión interna alternativos. Sección de Publicaciones de la ETSII Fundación General UPM. ISBN 8486451019. Madrid

[9] Muñoz, M., Payri, F. (1978) Turbomáquinas Térmicas. Sección de Publicaciones de la ETSII Fundación General UPM. ISBN 8474840023. Madrid.

[10] Proakis, J.G., Manolakis, D.G. (1996) "Digital Signal Processing" Prentice Hall Inc. 
Capitulo 3 Diseñoy puesta a punto de un procedimiento de medida para la caracterización de turbogrupos

[11] Skopil, M., Bulaty, T., (1998) Calculation of compressor surge with unsteady flow model". ImechE Conference Transactions, C554/018/98, pp. 219-225.

[12] Supercharger Testing Standard. SAE J1723 ISSUED AUG95. Society of Automotive Engineers, Inc. (1995)

[13] Theotokatos, G., Kyrtatos, N.P., (2001) Diesel Engine Transient Operation with Turbocharger Compressor Surging. SAE Paper 200101-1241.

[14] Turbocharger Gas Stand Test Code. SAE J1826 REAF. MAR95. Society of Automotive Engineers, Inc. (1995)

[15] Watson, N., Janota, M.S. Turbocharging the Internal Combustion Engine. MacMillan Publishers Ltd. ISBN 0333242904.

[16] Winterbone, D.E., Pearson, R.J. (1998) Turbocharger turbine performance under unsteady flow - a review of experimental results and proposed models. IMechE 6th International Conference on Turbocharging \& Air Management Systems. C554/031, pp.193-206, 3-5.

[17] Yano, T., Nagata, B., (1971) A Study on Surging Phenomena in Diesel Engine Air-Charging System. Bulletin of JSME, Vol 14, No. 70, pp 364-376. 
Contribución a la caracterización experimental y modelado de TGV en grupos de sobrealimentación 


\section{Capitulo 4: Modelado unidimensional de turbinas de geometria variable (TGV)}

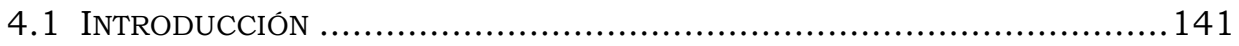

4.2 REVISIÓN DE LOS MODELOS UNIDIMENSIONALES EXISTENTES DE TURBINAS RADIALES

142

4.2.1 Modelado de turbinas radiales de geometría fija.....................................142

4.2.2 Modelado de turbinas radiales de geometría variable ...............................148

4.3 MEJORA DE UN MODELO EXISTENTE DE TURBINA RADIAL DE GEOMETRÍA FIJA 152

4.4 NuEVo MOdELO PARA TURBinaS DE GEOMETRÍA VARIABLE (TGV) .........156

4.4.1 Descripción de las TGV ......................................................................156

4.4.2 Cálculo del grado de reacción de una TGV ...........................................158

4.4.3 Cálculo de la presión a la salida del estator .............................................161

4.5 RESUMEN 174BIBLIOGRAFÍA 
Contribución a la caracterización experimental y modelado de TGV en grupos de sobrealimentación 


\subsection{Introducción}

En la actualidad muchos de los motores diesel de inyección directa vienen equipados con turbinas de geometría variable (TGV) debido a su amplio rango de operación. Este tipo de turbinas es capaz de mejorar la respuesta en transitorio de un motor turbodiesel, con un control adecuado, y reducir las perdidas de bombeo cuando el motor trabaja en condiciones estacionarias.

Aplicado a un modelo unidimensional, el correcto modelado físico tanto de la fluidodinámica como del comportamiento energético de la TGV es una poderosa herramienta para el diseño de estrategias de control, las cuales pueden ser implementadas electrónicamente con el fin de obtener mejoras tanto en el comportamiento en transitorio como en el comportamiento en estacionario del motor.

De un modo más general, el modelado unidimensional de una turbina de geometría variable proporciona un mejor conocimiento de los fenómenos físicos que aparecen en la interacción entre turbocompresores y motores de combustión interna alternativos.

Al inicio de este capítulo se realiza una revisión sobre los modelos unidimensionales de turbinas radiales para grupos de sobrealimentación de motores de combustión interna alternativos. Se comienza analizando los modelos de turbinas radiales de geometría fija, para describir a continuación los modelos encontrados en la bibliografia de turbinas radiales de geometría variable.

Posteriormente se desarrolla una mejora para el modelo de turbina unidimensional propuesto por Payri et al. [18], que se describe al inicio del capítulo, para pasar a continuación a proponer un modelo unidimensional para turbinas de geometria variable, aplicable a los distintos tipos de turbinas de geometría variable utilizados en la actualidad para la sobrealimentación de motores de combustión interna alternativos. 


\subsection{Revisión de los modelos unidimensionales existentes de turbinas $\underline{\text { radiales }}$}

El cálculo y modelado del comportamiento global de la turbina debe tener en cuenta dos características:

1. El comportamiento fluidodinámico de los gases, esto es, el establecimiento de la condición de contorno en el extremo del colector de escape, que tendrá que calcular la correcta interacción dinámica entre los cilindros y la turbina y también la evolución del flujo aguas abajo de la turbina hacia el resto del sistema de escape.

2. La conversión de la energía, esto es, la producción del trabajo mecánico a partir de la expansión del gas a través del estator y del rotor de la turbina, este trabajo será el que el compresor tendrá disponible y habrá que hacer un balance entre el trabajo producido por la turbina y el que absorba el compresor. El punto de funcionamiento puede ser establecido entonces, y por lo tanto se fijan las condiciones de contorno del flujo a la entrada del motor.

Quizás la forma más simple de alcanzar los objetivos propuestos sea introducir las curvas características de la turbina, como sugiere Benson [4] y como muestran algunos modelos publicados [14].

La principal diferencia entre estas simulaciones y los modelos en que la turbina es calculada como un conjunto de elementos sencillos. Es evidente que estas simulaciones necesitan de un amplio rango de medidas previas para caracterizar la turbina y teniendo en cuenta que hasta hace muy poco los fabricantes de turbinas no las ensayaban bajo condiciones de flujo pulsante, como las que van a encontrar al trabajar acopladas al motor, va a ser necesario relacionar las curvas características de funcionamiento de la turbina bajo flujo estacionario con el comportamiento de ésta al ser acoplada al motor. Esta diferencia en el comportamiento de la turbina bajo condiciones de flujo estacionario y flujo pulsante ha sido estudiada por varios autores durante los últimos años [5][10][25]. Además imponer las curvas características del funcionamiento de la turbina supone tener siempre que interpolar y no poder extrapolar y supone asumir un comportamiento totalmente cuasiestacionario en la turbina, siendo imposible tener en cuenta las acumulaciones de masa que se producen en la misma. El uso de funciones de interpolación también presenta el inconveniente de aumentar los tiempos de cálculo.

\subsubsection{Modelado de turbinas radiales de geometria fija}

El modelo más simple desarrollado para una turbina centrípeta de geometría variable fue desarrollado por Watson y Janota [23]. Este modelo se basa en reemplazar la turbina por una tobera situada en el escape que sea 
capaz de reproducir el salto de presiones que se produce en la turbina para un determinado gasto másico trasegado por la misma. Para el caso de turbinas radiales con grados de reacción elevados, dónde la expansión se produce en dos etapas, las condiciones de flujo criticas se alcanzan con una relación de expansión entorno a 3, mientras que una tobera alcanza condiciones de choque con una relación de expansión de 1.89. Por lo tanto este modelo tiene que proporcionar soluciones adicionales para las condiciones de choque del flujo. Otro inconveniente de este modelo es que la sección efectiva de la tobera es constante. Esta sección efectiva debería ser función de la expansión producida, para representar con precisión las características del comportamiento fluidodinámico de una turbina radial.

Una alternativa a este primer y sencillo modelo es la descrita por Payri et al.[20] y Winterbone [24], que consiste en la misma idealización de la turbina por una tobera simple, pero con un área efectiva tal que un determinado flujo másico produce la mitad del salto de presiones que se produce en la turbina. De este modo se resuelve el problema de la expansión crítica y del área de la tobera no constante. Sin embargo, la presión a la salida de la tobera corresponde a la presión entre el estator y el rotor, y necesita ser fijada como una función de la presión a la salida de la turbina, que tiene que ser conocida y se asume como constante. Esta circunstancia impide el cálculo de la evolución instantánea de la presión a la salida de la turbina y el cálculo de los efectos que esta variable puede tener sobre el comportamiento de la turbina.

Hribernik et al.[9] proponen un modelo más completo para turbinas de doble entrada, basado en las uniones entre tubos, en el que se introducen toberas de sección variable para simular la expansión del flujo en el estator, mientras que se utiliza un modelo predictivo para modelar el rotor. La evolución de la presión calculada a la salida del cilindro de un motor de seis cilindros concuerda con los resultados experimentales. Sin embargo, los resultados a la salida del rotor no se presentan en el artículo que describe el modelo.

En 1991, Payri et al.[17][18] presentan un modelo basado en dos toberas en serie, separadas por un volumen intermedio. Esta geometría combina las ventajas de los primeros modelos comentados y además supera con éxito el problema de las relaciones de expansión elevadas y el problema del cálculo de la presión instantánea aguas abajo de la turbina. Además permite acumular masa y tener en cuenta fenómenos no estacionarios.

Un modelo muy similar en lo que se refiere a la inclusión de un volumen intermedio aguas arriba del rotor, fue propuesto por Baines et al. [3], aunque no se tenía en cuenta la expansión del flujo en el estator de la turbina $\mathrm{y}$, por lo tanto, se consideraba que toda la expansión había de tener lugar en el rotor. 
Por ser uno de los modelos más completos vamos a detenernos en explicar con más detalle el modelo propuesto por Payri et al [18]. Como ya se ha comentado este modelo sustituye la turbina por dos toberas ideales (que reproducen las caídas de presión que se producen en el estator y en el rotor) que descargan a un volumen intermedio (que reproduce la acumulación de masa en el sistema) como muestra la Figura 4. 1.
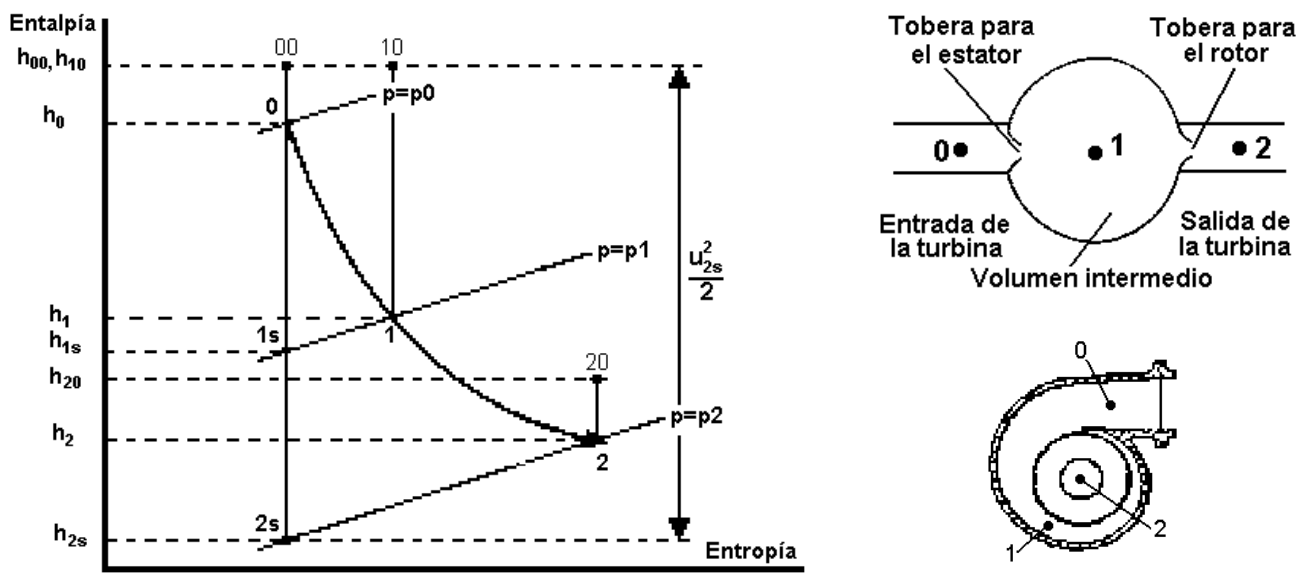

Figura 4. 1: Evolución termodinámica del flujo en una turbina radial y esquema geométrico del modelo de turbina.

Como se observa en la figura 4. 1 el flujo en una turbina real se expande en dos pasos, primero en el estator, donde los gases de escape son acelerados y dirigidos hacia las palas del rotor. Después, en el rotor, los gases de escape se expanden hasta las condiciones de salida.

Este modelo se presenta validado para una turbina de entrada simple $\mathrm{y}$ waste-gate en un motor de 4 cilindros en línea y para una turbina de doble entrada en un motor de 6 cilindros en línea, siendo posible obtenerse con el modelo la evolución temporal correcta de todas las variables instantáneas que describen el comportamiento de la turbina [18].

Las principales hipótesis de este modelo son suponer que el comportamiento de la turbina es cuasiestacionario a lo largo de las toberas que simulan la turbina, tanto desde el punto de vista fluidodinámico como energético, y que la caída de presión es la misma a través del estator y del rotor.

La primera hipótesis se utiliza comúnmente en el modelado de todas las condiciones de contorno existente en motores de combustión interna alternativos.

La segunda hipótesis permite calcular fácilmente los valores de las áreas efectivas de las toberas que representan al estator y al rotor de la 
turbina. Además, no se aleja mucho de lo ocurre en una turbina con grado de reacción 0.5, que son las turbinas sin álabes directores en el estator y con las paletas rectas o radiales que se utilizan en automoción, ya que es uno de los criterios de diseño de estas turbinas [23]. Watson [23] señala además que es dificil diseñar una turbina radial de paletas rectas y sin álabes directores cuyo grado de reacción se aleje de 0.5 , ya que en estas condiciones el flujo que entra al rotor es controlado por el ángulo de ataque del mismo y es cuando se puede alcanzar un mayor salto total en la turbina sin que se produzcan condiciones sónicas en el estator ni en el rotor.

Para el cálculo de las áreas efectivas equivalentes al estator y al rotor, se asume que el estator de la turbina se comporta como una tobera que trasiega el mismo flujo de masa que la turbina:

$$
\begin{gathered}
\dot{m}_{\text {est }} \cdot \frac{\sqrt{\gamma R T_{00}}}{p_{0}}=A_{\text {est }} \cdot F\left(\frac{p_{1}}{p_{00}}\right) \\
F\left(\frac{p_{1}}{p_{00}}\right)=\gamma \cdot\left(\frac{p_{1}}{p_{00}}\right)^{1 / \gamma} \cdot \sqrt{\frac{2}{\gamma-1} \cdot\left[1-\left(\frac{p_{1}}{p_{00}}\right)^{(\gamma-1) / \gamma}\right]}
\end{gathered}
$$

Si se conocen las condiciones de entrada del flujo másico, esto es, gasto, presión y temperatura a la entrada de la turbina, se necesita conocer el salto de presiones que se produce en el estator para determinar el área efectiva de la tobera.

$\mathrm{Al}$ igual que en el estator, el comportamiento de la tobera equivalente al rotor puede expresarse mediante las ecuaciones:

$$
\begin{gathered}
\dot{m}_{\text {rot }} \cdot \frac{\sqrt{\gamma R T_{10}}}{P_{1}}=A_{\text {rot }} \cdot F\left(\frac{p_{2}}{p_{1}}\right) \\
F\left(\frac{p_{2}}{p_{1}}\right)=\gamma \cdot\left(\frac{p_{2}}{p_{1}}\right)^{1 / \gamma} \cdot \sqrt{\frac{2}{\gamma-1} \cdot\left[1-\left(\frac{p_{2}}{p_{1}}\right)^{(\gamma-1) / \gamma}\right]}
\end{gathered}
$$

En este caso, si se conocen las condiciones de salida del flujo másico, para calcular el área efectiva de la tobera equivalente al rotor, se necesita conocer el salto de presiones que se produce en el mismo.

Teniendo en cuenta la segunda de las hipótesis, el valor de p1 se calcula imponiendo la condición de igual relación de expansión a través de estator y rotor, como se ve en la siguiente ecuación: 


$$
\frac{p_{1}}{p_{00}}=\frac{1}{2} \cdot\left[1+\frac{p_{2}}{p_{00}}\right]
$$

Este modelo es aplicable también a turbinas centripetas de geometría fija de doble entrada. En este caso la turbina se sustituye por tres toberas. Dos de las toberas se encuentran a la entrada del volumen y reproducen la caída de presión en el estator, la tercera tobera, como en el caso anterior, reproduce la caída de presión en el rotor.

En 1996 fue publicado el modelado de una turbina de flujo mixto bajo condiciones de flujo pulsante desarrollado por Chen et al. [5]. Este modelo es una evolución del modelo de turbina de geometría fija bajo condiciones de flujo estacionario y flujo pulsante presentado por Chen y Winterbone en 1990 [6].

En este modelo se simula la entrada de la turbina como un tubo que se estrecha. La parte espiral de la carcasa se simula como un tubo de cierta longitud, en función de la geometría de la turbina a modelar, desde el inicio de la voluta hasta un ángulo de $180^{\circ}$ en azimud. El volumen de la carcasa se puede mantener haciendo una definición apropiada para el área de flujo del conducto. Esta hipótesis da a la voluta una longitud que es muy importante en los estudios de flujo no estacionario. Y al mismo tiempo permite que el rotor sea simulado de manera cuasiestacionaria, según el análisis tradiconal del flujo estacionario unidimensional.

El rotor se simula por un modelo de flujo cuasiestacionario, esto es, se emplea un análisis de flujo unidimensional estacionario para cada intervalo de tiempo, como si para cada instante el rotor se comportara como si estuviera en condiciones de flujo estacionario. La justificación de utilizar esta hipótesis de flujo cuasiestacionario es que el número de Strouhal, que describe la importancia relativa de los efectos no estacionarios en los cuasiestacionarios, es mucho menor que uno para el rotor considerado en el estudio.

Hay que tener en cuenta que para la turbina de flujo mixto la velocidad radial utilizada en el método original debe ser interpretada como la velocidad meridional.

En este caso han añadido muchos modelos de pérdidas al modelo original, que muestran mejoras en las simulaciones de flujo estacionario en condiciones lejanas a las de diseño.

Según los autores la aplicación del modelo propuesto a cuatro casos de funcionamiento de la turbina bajo condiciones de flujo pulsante confirma su capacidad para predecir el flujo de masa instantáneo. También se demuestra un aumento en la capacidad de trasegar gasto bajo condiciones de 
flujo pulsante, que según los autores un modelado basado en interpolaciones en el mapa de la turbina no sería capaz de predecir.

En el artículo sólo se muestran resultados de flujo instantáneo trasegado, pero no de otras variables que definen el comportamiento de la turbina, como relación de expansión o rendimiento.

Otro modelo de turbinas centrípetas es el presentado recientemente por Macek et al. [13]. Este modelo es un modelo unidimensional, que consiste en sustituir el comportamiento del flujo real tridimensional al atravesar la turbina, en una serie de procesos unidimensionales. El esquema que sigue el modelo es el que se muestra en la siguiente figura:

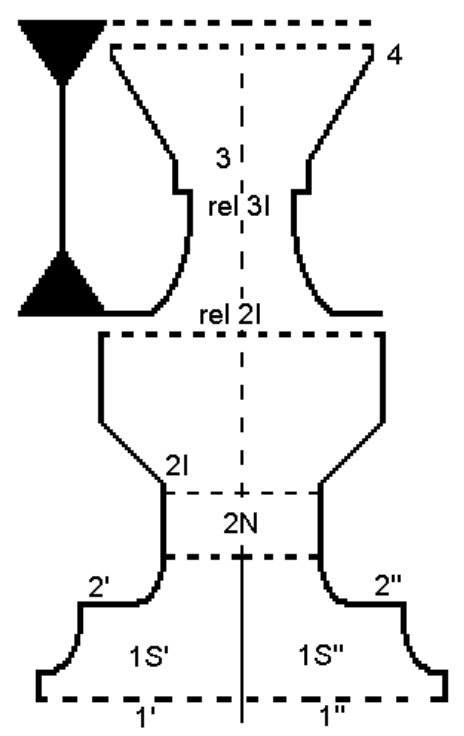

Figura 4. 2: Simplificación de una turbina en el modelo unidimensional de Macek et al. [13]

El modelo describe el paso del flujo másico a través de la turbina de siguiente modo:

1. Una aceleración inicial desde 1' a 1S' (en el caso de turbinas de doble entrada, como muestra la figura, también hay una aceleración de 1" a $1 \mathrm{~S} ")$.

2. Una aceleración en la voluta de la turbina, de 1S' a 2'.

3. Después se transforma la velocidad absoluta en velocidad relativa, teniendo en cuenta la velocidad del turbogrupo y las pérdidas por incidencia (2N-2I-rel 2I) 
Contribución a la caracterización experimental y modelado de TGV en grupos de sobrealimentación

4. A continuación se simula la expansión relativa bajo la influencia de una fuerza centrífuga (rel 2I- rel 3I).

5. Se vuelve a transformar la velocidad relativa al sistema de coordenadas fijo, teniendo en cuenta las pérdidas a la salida (rel 3I-3).

6. Finalmente se tiene en cuenta que a la salida de la turbina hay un difusor, que en este caso se representa por una deceleración del flujo a la salida (3-4).

Este modelo aporta el cambio a condiciones relativas con respecto a las existentes y aunque necesita muchos parámetros de ajuste ofrece una interesante vía de investigación.

En 2004 Plafreyman y Martínez -Botas [21] presentaron un modelado tridimensional realizado con el código comercial Star-CD para una turbina de flujo mixto bajo condiciones de flujo pulsante, demostrándose que es posible modelar tridimensionalmente el comportamiento de una turbina bajo condiciones de flujo pulsante, siendo capaces de medir y reproducir las principales características del flujo pulsante.

La principal desventaja que se presenta es la necesidad de recursos computacionales y los tiempos de cálculo que se necesitaron para realizar los cálculos que se muestran.

\subsubsection{Modelado de turbinas radiales de geometria variable}

La sobrealimentación es una técnica que aumenta la potencia de los motores de combustión interna y reduce el consumo específico, pero la aplicación de esta técnica plantea problemas de acoplamiento entre el motor y el turbogrupo, ya que no tiene siempre el tamaño óptimo para todas las condiciones de funcionamiento del motor. A bajo régimen de giro del motor se necesita una turbina que para un gasto másico pequeño tenga una elevada relación de expansión (sección efectiva de paso de los gases de escape pequeña) que dé la suficiente potencia para los requerimientos del compresor. En cambio, a alto régimen de giro del motor una turbina con mayor sección efectiva ya da la suficiente potencia al compresor. Por tanto una turbina no se adapta correctamente a todas las condiciones de funcionamiento del motor. Para solucionar este problema se pueden utilizar turbinas de geometría variable que pueden variar la sección efectiva de paso del flujo de gases, de modo que con la utilización de una de estas turbinas es posible mejorar las prestaciones de motor para distintos regímenes de giro y disminuir el consumo.

Para conseguir cambiar el área de paso de los gases de escape se puede actuar variando el ángulo de inclinación de los álabes directores que se encuentran en el estator de la turbina o variando la sección de la carcasa de 
la misma, mediante el desplazamiento de los álabes a lo largo de un eje paralelo al eje de giro del rotor. Generalmente es la primera solución la que se adopta, de forma que se hace pivotar a los álabes directores, variando así el ángulo de inclinación y la sección efectiva de paso con la que se encuentra el flujo.

La utilización de turbinas de geometría variable en la sobrealimentación de motores de combustión interna se ha incrementado en los últimos años, puesto que son muy adecuadas para los grupos de sobrealimentación de estos motores, tanto por las ventajas que ofrecen a nivel de prestaciones como de reducción de emisiones contaminantes (humos y $\mathrm{NO}$ x combinados con EGR) respecto a la sobrealimentación con turbinas de geometria fija. A pesar de las ventajas que ofrecen, su uso ha tardado en extenderse por las dificultades de realizar este tipo de turbinas con un costo razonable y con una fiabilidad adecuada del mecanismo de actuación de la geometría variable.

Sobre el modelado de turbinas centrípetas de geometría variable no se encuentran muchos artículos en la bibliografia y los que se encuentran están basados mayoritariamente en cálculos computacionales en tres dimensiones, así que son dificilmente acoplables a los modelos unidimensionales de motor. Un ejemplo de estos modelos de turbina radial con álabes directores en el es el presentado en 2002 por Lam et al. [12] basado en el código comercial CFD Fluent, que utilizan para resolver las ecuaciones diferenciales en derivadas parciales no lineales del flujo (ecuaciones de Navier-Stokes) y la transferencia de calor, teniendo en cuenta la geometría tridimensional de la turbina. Éste es un modelo tridimensional y el principal inconveniente de este modelo es la dificultad que se tiene hoy en día para acoplarlo a los modelos unidimensionales así como los tiempos de cálculo que necesita. Sin embargo cuenta con la ventaja de que es capaz de modelar el comportamiento de la turbina con un mínimo número de coeficientes de pérdidas. El artículo no muestra comparación de resultados medidos-modelados.

Entre los modelos fácilmente acoplables a un modelo de acción de ondas del motor completo destacamos los siguientes:

Kessel et al.[11] presentaron un modelo de turbina cuya finalidad era obtener datos para entrenar una red neuronal que simulara el comportamiento de una turbina de geometría variable.

El modelo que presentan está basado en la figura 4. 3, que muestra un diagrama $\mathrm{h}$-s describiendo los estados en el interior de una turbina radial. 

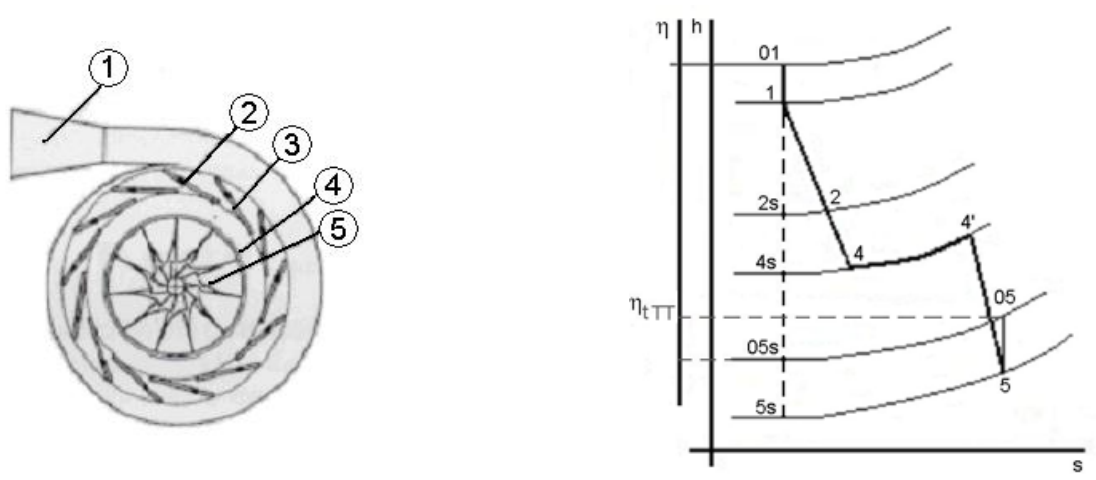

Figura 4. 3: Esquema de la turbina y diagrama de Mollier.

En este diagrama (Figura 4. 3) las posiciones caracteristicas están señaladas con números que van de 1 a 5 :

1. Entrada a la carcasa de la turbina

2. Mínima área de paso a través de los álabes de la turbina de geometría variable.

3. Salida al volumen anterior al rotor.

4. Inmediatamente antes de la entrada al rotor.

4'. Inmediatamente después de la entrada al rotor.

5'. Inmediatamente antes de la salida del rotor.

5. Inmediatamente después de la salida del rotor.

Cada transición se calcula para un determinado flujo másico. Primero se utiliza una solución numérica para encontrar el salto de presiones entre dos puntos incluyendo un parámetro que describe el rendimiento local, después se calcula el correspondiente salto de temperaturas y finalmente se calculan otras variables como la entalpia y los incrementos de entropía. Estos pasos se siguen con un tratamiento especial de geometria de toberas (transición 2-3), espacios sin álabes (transición 3-4) y entrada al rotor fuera de las condiciones de diseño (transición 4-4').

Recordemos que este modelo sólo se utiliza para calcular valores que se utilizan para entrenar la red neuronal, que será la que simule el comportamiento de la turbina. Los autores advierten que si pudieran medir todos los valores que son necesarios para entrenar la red no se utilizaría el modelo. 
Nasser y Playfoot [15] presentaron en 1999 un modelo de turbina centrípeta con álabes móviles. Este modelo es parte de un modelo completo de turbogrupo y está basado en un modelo anterior de una turbina de álabes fijos.

Este modelo está basado en las leyes de conservación de la masa, la energía y la cantidad de movimiento en una dimensión. A ello se le incorpora un submodelo de transferencia de calor para tener en cuenta las pérdidas en el colector de escape y no sobreestimar la temperatura a la entrada de la turbina, con lo que consiguen disminuir el error en el valor modelado de la temperatura a la entrada de la turbina de un $63 \%$ a un $14 \%$. Además el modelo asume que el flujo a través del compresor es no isentrópico y unidimensional, utilizándose un cálculo semiempírico de pérdidas para mejorar la precisión en el cálculo a la salida del compresor.

Los autores explican que no han comprobado las predicciones del modelo puesto que no disponían de datos experimentales, con lo que no es posible comprobar su validez. 


\subsection{Mejora de un modelo existente de turbina radial de geometria fija}

En este apartado se describe la mejora del modelo propuesto por Payri et al. [18] y expuesto en el apartado 4.2.

Este modelo, como se verá en el capítulo 5, fue implementado en un modelo completo de acción de ondas de motor de combustión interna alternativo sobrealimentado, formando parte del modelado completo del turbogrupo.

Los objetivos a alcanzar por este modelo son principalmente los de obtener valores de la presión, temperatura y velocidades del fluido antes y después de la turbina, así como obtener el trabajo proporcionado por la turbina durante un ciclo del motor.

Obteniendo estos valores es posible conocer el comportamiento fluidodinámico de la turbina, así como estudiar el acoplamiento entre esta y el compresor [16].

Recordemos que en el modelo de turbina de geometría fija se sustituye a la turbina por dos toberas ideales (que reproducen las caídas de presión que se producen en el estator y en el rotor) que descargan a un depósito intermedio (que reproduce la acumulación de masa en el sistema).

El modelo de turbina se introduce en el modelo completo de motor como un submodelo de llenado y vaciado. Este submodelo de depósito está formado por un volumen al que llegan un número cualquiera de conductos [7]. El depósito está caracterizado por su volumen (constante), su masa y su temperatura, estando la presión impuesta por la ecuación de estado. En el depósito se considera que no hay velocidad, es decir, el fluido está en reposo. No se considera transmisión de calor con el exterior ni pérdidas por fricción con las paredes.

La interacción del depósito con los conductos viene caracterizada por el gasto que se establece en las uniones tubo-depósito, entrante o saliente del depósito, a partir del salto de presiones existente entre el depósito y los extremos de los conductos y del área de paso, que puede ir afectada de un coeficiente de restricción o coeficiente de descarga [19]. Este coeficiente de descarga viene dado por la relación entre el gasto real entre conducto y depósito y viceversa, y el gasto teórico que habría si el proceso fuera isoentrópico.

En la resolución de un elemento del tipo depósito en un instante de tiempo determinado hay dos etapas bien diferenciadas. En la primera se calcula la interacción entre conducto y depósito, es decir, todos los gastos entrantes y salientes al depósito utilizando como datos los del instante 
anterior del depósito y la información de las características incidentes, los niveles de entropía de las ramas con flujo entrante al depósito y los coeficientes de descarga de las conexiones entre los tubos y el depósito.

En la segunda etapa, con la información de los gastos de cada uno de los conductos, se realiza un balance másico con el que se determina la nueva masa en el depósito y un balance energético para el cálculo de la nueva temperatura y presión en el depósito, conociendo de este modo las propiedades en el depósito en el instante posterior.

El balance de masa contabiliza la variación de la masa de gas en el depósito en función de las aportaciones de las diferentes ramas en el intervalo de integración.

$$
\Delta m_{d}=\sum_{i} \dot{m}_{i} d t
$$

Para la realización del balance de energía en el depósito se plantea el primer principio de la termodinámica para un sistema abierto en forma diferencial.

$$
d\left(m_{d} e_{d}\right)=\delta q_{d}+\delta w_{d}+\sum\left(h_{e}+\frac{u_{e}^{2}}{2}\right) d m_{e}-\sum\left(h_{s}+\frac{u_{s}^{2}}{2}\right) d m_{s}
$$

La variación de energía interna $\left(e_{d}\right)$ en el depósito se obtiene a partir del balance del calor transmitido $\left(\delta q_{d}\right)$, trabajo producido $\left(\delta w_{d}\right)$ y entalpías totales entrantes o salientes por las ramas del depósito.

Si se tiene en cuenta que el calor transmitido en el depósito y que el trabajo producido son nulos, la ecuación (4. 7) se simplifica. Además la entalpía total del fluido saliente del depósito es la del depósito:

$$
h_{s}+\frac{u_{s}^{2}}{2}=h_{d}
$$

De la misma manera, si se plantea el balance de masa en el depósito se cumple:

$$
d m_{d}=\sum d m_{e}-\sum d m_{s}
$$

Con lo que la expresión del primer principio queda:

$$
d\left(m_{d} e_{d}\right)=\sum\left(h_{e}+\frac{u_{e}^{2}}{2}\right) d m_{e}-h_{d}\left(\sum d m_{e}-d m_{d}\right)
$$


Diferenciando el primer término, considerando la definición de entalpía $(h=e+p v)$, la de calor específico a volumen constante $\left(\mathrm{e}=\mathrm{c}_{\mathrm{v}} \mathrm{T}\right) \mathrm{y}$ agrupando términos se obtiene:

$$
P_{d} v_{d} d m_{d}+m_{d} c_{v} d T_{d}=\sum\left(h_{e}+\frac{u_{e}^{2}}{2}-h_{d}\right) d m_{e}
$$

Dividiendo la ecuación (4.11) por el producto de presión por volumen específico $(p v)$, poniendo la entalpia en función del calor específico a presión constante y teniendo en cuenta las definiciones de $c_{v}$ y $c_{p}$, en función de $\gamma$ y R se obtiene:

$$
\frac{d m_{d}}{m_{d}}+\frac{1}{\gamma-1} \frac{d T_{d}}{T_{d}}=\frac{1}{p_{d} v_{d}} \sum\left(h_{e}+\frac{u_{e}^{2}}{2}-h_{d}\right) d m_{e}
$$

En donde el primer término se puede integrar directamente, no así el segundo término.

A partir de la variación de la masa y energía en el depósito se calculan las nuevas propiedades termodinámicas (presión y temperatura) que se utilizan en el siguiente paso de integración para el cálculo de los gastos a través de las ramas.

Si se introduce este modelo directamente en el modelo completo de motor sin tener en cuenta el trabajo que realiza la turbina, las condiciones del gas a la salida de la misma no van a ser correctas, puesto que en el depósito el gas pierde la energía cinética a presión constante pero no se le resta el trabajo realizado por la turbina, como puede verse en la figura 4. 4, en la que se muestra en un diagrama h-s la evolución real del gas en la turbina (línea negra) y la evolución del gas según el modelo, sin tener en cuenta el trabajo realizado por la turbina (línea gris), donde se ve la expansión en el estator (01), la evolución a presión constante (1-10') y la expansión en el rotor (10'-2').

Es por ello que en el caso de la condición de contorno turbina hay que tener en cuenta el trabajo que ésta realiza al plantear la ecuación del primer principio de la termodinámica (ecuación (4. 7)). De modo que al hacer el balance de energía en el depósito se le reste el trabajo que realiza la turbina:

$$
W_{T}=\dot{m}\left(h_{E T 0}-h_{S T s}\right) \eta_{t s} \Delta t
$$

Donde:

- $\dot{m}$ : Es el gasto másico de gases de escape que trasiega la turbina.

- $h_{\mathrm{ETO}}$ : Es la entalpía de parada a la entrada de la turbina. 
- $\mathrm{h}_{\mathrm{STs}}$ : Es la entalpía que tendrian los gases a la salida de la turbina, si la evolución fuese de tipo isoentrópico.

- $\eta_{\mathrm{ts}}$ : Es el rendimiento (total a estático) de la turbina, para las condiciones de funcionamiento en este determinado punto.

- $\Delta$ t: Es el incremento de tiempo de cálculo.

Al restar el trabajo producido en la turbina en el balance de energía de la condición de contorno depósito se consigue reproducir a la salida de la turbina las condiciones de presión y temperatura experimentales, como se muestra en la figura 4. 5, en la que se muestra en un diagrama h-s la evolución real del gas en la turbina (línea negra) y la evolución del gas según el modelo, teniendo en cuenta el trabajo realizado por la turbina (linea gris). En este caso en el depósito primero se pierde la energía cinética a presión constante (1-10”) y luego se le resta el trabajo de a turbina (10"-1").

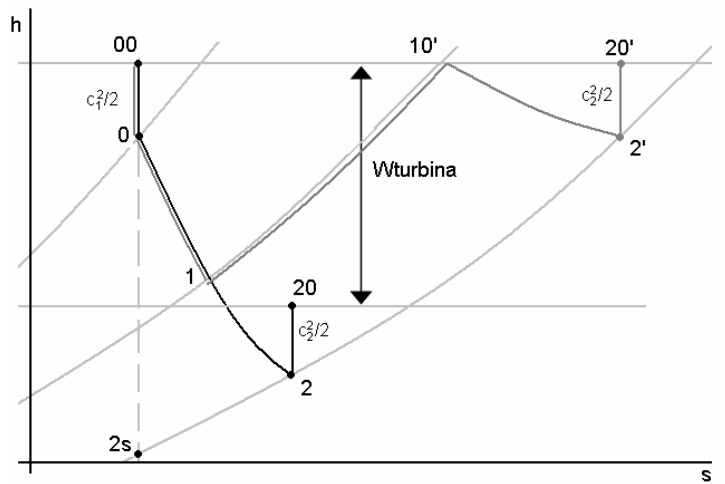

Figura 4. 4: Diagrama h-s de la evolución que sigue el gas en el depósito si no se tiene en cuenta el trabajo realizado por la turbina.

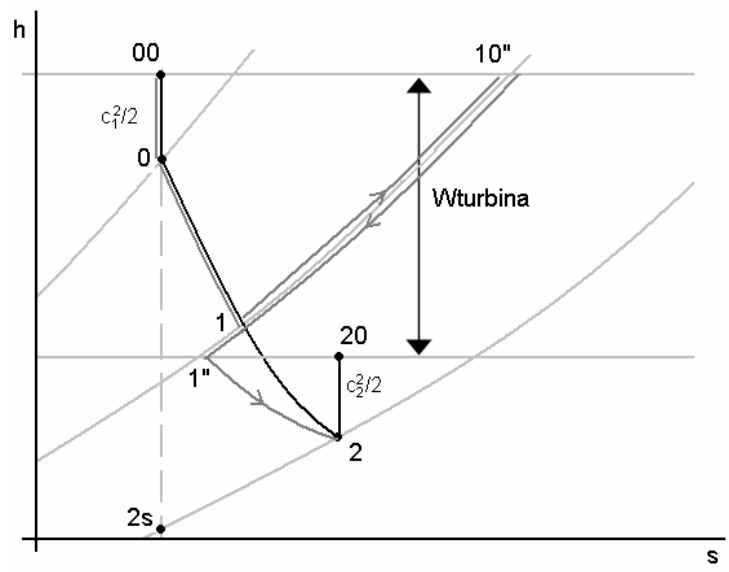

Figura 4. 5: Diagrama h-s de la evolución que sigue el gas en el depósito si se tiene en cuenta el trabajo realizado por la turbina. 


\subsection{Nuevo modelo para turbinas de geometria variable (TGV)}

\subsubsection{Descripción de las TGV}

Actualmente, cada vez más, los motores diesel de automoción ligeros se equipan con turbinas de geometría variable, puesto que es posible controlarlas para que adapten su forma de actuar a las condiciones de funcionamiento del motor, reduciendo las pérdidas de bombeo en estacionario y mejorando la respuesta dinámica del turbogrupo en transitorio. Ocurre que para las turbinas de geometria variable, que generalmente llevan álabes directores en el estator, la condición anterior no se cumple pues son los álabes del estator y no las paletas rectas del rotor los que dirigen el flujo, por lo tanto el triángulo de velocidades cambia y el grado de reacción ya no vale 0.5 , como se verá en este apartado.

Los turbinas de geometría variable se componen de los mismos elementos que un turbina normal pero incluyendo una corona de álabes móviles en el estator. La posición de estos álabes está controlada por la presión en el colector de admisión. La corona de álabes está unida a una cápsula neumática por una varilla. La cápsula neumática está dividida en dos cámaras por una membrana. La cámara superior está unida a una bomba de vacío. La cámara inferior se mantiene a la presión atmosférica y dispone de un muelle de retorno para mantener los álabes en la posición que haga que la sección de paso a través del estator sea máxima.

Los álabes directrices ajustables en el estator de la turbina permiten aumentar o reducir, cuando sea necesario, la relación de expansión. E1 resultado es un aumento controlable de la presión de admisión. Esto redunda en un mejor aprovechamiento de la energía de los gases de escape, una mejor respuesta del turbocompresor a los cambios de carga, un desarrollo más homogéneo de la potencia del motor, una disminución del consumo de combustible, un aumento más homogéneo de la presión de admisión, así como en una disminución de las emisiones contaminantes [1][2][8].

Se pretende que el modelo que se desarrolle sea lo más general posible y aplicable a todo tipo de turbinas de geometría variable. En la actualidad, para turbinas radiales destinadas a la sobrealimentación de motores de combustión interna alternativos, se utilizan fundamentalmente dos mecanismos diferentes para variar el área de paso de los gases en el estator de la turbina, como puede verse en la figura 4. 6 y en la figura 4. 7.

En los dos mecanismos de accionamiento de los álabes de una turbina de geometría variable existe un vástago móvil al que se unen los álabes del estator y una bomba de vacío que controla la posición del vástago, siendo el funcionamiento de la turbina relativo a una presión de referencia en la 
admisión, que define las condiciones de funcionamiento ideales para un régimen de giro y gasto de combustible inyectado en el motor dados.

El primero de los mecanismos mantiene el ángulo de los álabes del estator fijo y varia la sección de paso del estator al rotor al desplazarse la corona de álabes paralela al eje de giro del eje de la turbina (figura 4. 6). En este mecanismo los álabes del estator están unidos en una corona circular que está unida al mecanismo de control que hace que varie su posición.

El otro mecanismo utilizado con el mismo fin es el que se muestra en la figura 4. 7, en el que los álabes del estator están unidos con una corona que mediante el vástago está unida a un mecanismo de control que hace que la corona varie de posición, los álabes del estator pivotan alrededor de un punto y varían su posición relativa.

Se dice que la turbina está cerrada cuando el área de paso a través del estator es mínima y se dice que la turbina está abierta cuando el área de paso a través del estator es máxima.

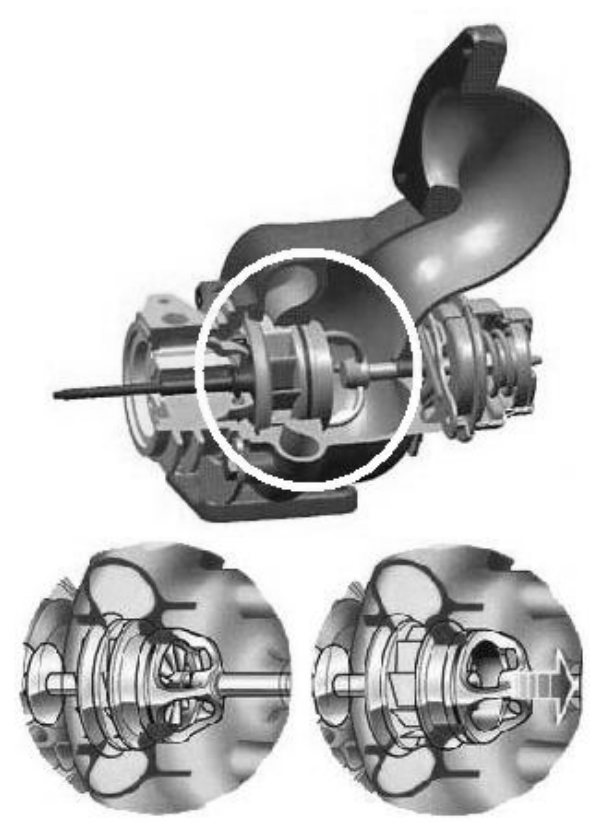

Figura 4. 6: Mecanismo de variación del área de paso de los gases en el estator manteniendo fija la posición de los álabes. En la parte de abajo se muestran dos posiciones diferentes, en la figura de la derecha la turbina está "cerrada" y en la figura de la izquierda está "abierta".

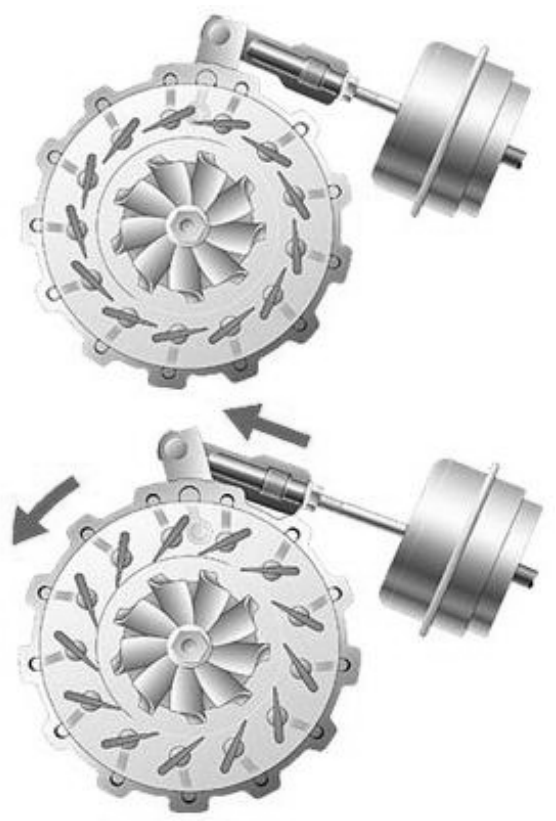

Figura 4. 7: Mecanismo de variación del área de paso de los gases en el estator variando la posición relativa de los álabes En la figura de arriba la turbina está "cerrada" y en la de abajo está "abierta". 
La diferencia entre el valor de la presión medida a la entrada del colector de admisión y una presión de consigna definida en la Unidad de Control Electrónico del motor (ECU) envía una señal que produce una depresión en el pulmón, desplazando el vástago, lo que permite abrir o cerrar el paso del estator. Las diferentes secciones de paso en el estator permiten modificar la potencia disponible del flujo que pasa por el rotor y por consiguiente variar la energía comunicada al compresor.

Cuando el motor gira a bajo régimen, el gasto másico y la velocidad de los gases de escape son reducidos. Para mover la turbina de escape es necesario que los gases dispongan de más velocidad y esto se consigue manteniendo la corona de álabes en la posición más cerrada. De esta forma, los gases tienen muy poca sección de paso y aumentan la velocidad para conseguir que pase todo el gasto. Los gases de escape llegan al rotor a mayor velocidad tangencial y consiguen hacerlo girar más rápido, aumentando la potencia en el compresor.

Para simplificar, en el resto del documento, se denominarán turbinas de geometría variable de álabes fijos a las que se varian el área de paso de los gases de escape por el estator utilizando un mecanismo del tipo del mostrado en la figura 4. 6 y se denominará turbina de geometría variable de álabes móviles a las que varían el área de paso de los gases de escape por el estator con un mecanismo del tipo del que se muestra en la figura 4. 7.

\subsubsection{Cálculo del grado de reacción de una TGV}

Hasta la aparición de las turbinas de geometría variable ha sido habitual utilizar la hipótesis de grado de reacción 0.5 para modelar el comportamiento de las turbinas radiales empleadas en sobrealimentación de motores de combustión interna alternativos, ya que al diseñarse sin álabes directores en el estator y con álabes radiales en el rotor cumplian tal condición [23].

El modelo propuesto por Payri et al. [18], expuesto en el apartado 4.2.1, podría ser válido para una turbina de geometría variable si se encontrara un método adecuado para calcular el grado de reacción de la turbina en función de las condiciones de operación de la misma y fuera posible calcular el salto de presiones que se produce en el estator y en el rotor de la turbina al cambiar las condiciones de funcionamiento de ésta.

Lo que este nuevo modelo propone es un método para calcular el grado de reacción y los saltos de presiones a partir de éste. Una vez conocidos es posible calcular el área efectiva de las toberas ideales equivalentes que reproducen las caídas de presión que ocurren en la turbina, utilizando la ecuación de la tobera, al igual que se hacía en el modelo anterior. 
En la figura 4. 8 se muestra un esquema de los triángulos de velocidades de una turbina radial a la entrada y a la salida del rotor, en la que puede verse como se han definido los ángulos que se van a utilizar a continuación.
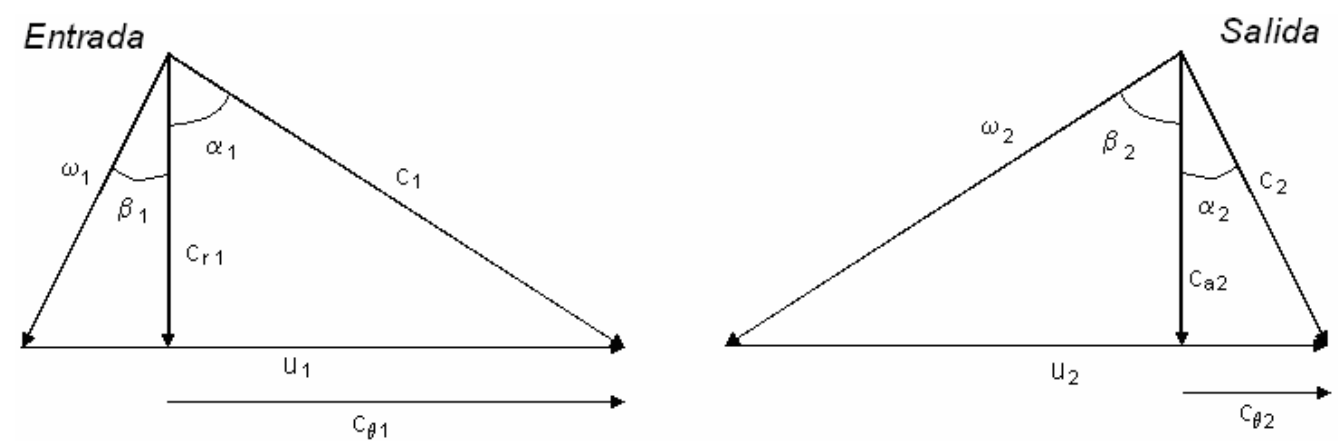

Figura 4. 8: Triángulos de velocidades de una turbina radial a la entrada y salida del rotor.

Es usual definir el grado de reacción basándose en la energía transferida, esto es, como el cociente entre la energía transferida debida al cambio en la presión en el rotor y la variación total de energía:

$$
R=\frac{h_{1}-h_{2}}{h_{00}-h_{02}}=\frac{\left(h_{01}-c_{1}^{2} / 2\right)-\left(h_{02}-c_{2}^{2} / 2\right)}{h_{00}-h_{02}}
$$

Puesto que en el estator no se realiza trabajo $h_{00}=h_{01}$ :

$$
R=1-\frac{c_{1}^{2}-c_{2}^{2}}{2 \cdot\left(h_{01}-h_{02}\right)}
$$

Si el fluido puede considerarse como un gas ideal, se puede escribir:

$$
\mathrm{h}_{01}-\mathrm{h}_{02}=\mathrm{c}_{\mathrm{p}} \cdot\left(\mathrm{T}_{01}-\mathrm{T}_{02}\right)
$$

Por otro lado la transferencia de energía en el rotor puede darse como el producto del par por la velocidad angular:

$$
\dot{W}=\omega \cdot M=\dot{m} \cdot\left(u_{1} c_{\theta 1}-u_{2} c_{\theta 2}\right)=\dot{m} \cdot c_{p} \cdot\left(T_{01}-T_{02}\right)
$$

Despejando de la ecuación anterior se obtiene: 


$$
T_{01}-T_{02}=\frac{\left(u_{1} c_{\theta 1}-u_{2} c_{\theta 2}\right)}{c_{p}}
$$

Si se desprecia el swirl a la salida como hipótesis de diseño $\left(\mathrm{c}_{\theta 2}=0 \rightarrow\right.$ $\mathrm{c}_{2}{ }^{2}=\mathrm{c}_{\mathrm{a} 2}{ }^{2}$ ) y la componente radial de la velocidad a la salida del estator (entrada del rotor) es igual a la componente axial de la velocidad a la salida del rotor, hipótesis de diseño si no hay variación de sección entre entrada y salida y se conserva el gasto másico $\left(c_{r 1}=c_{a 2}=c_{1} \cdot \cos \alpha_{1}\right)$, se puede escribir, a partir de la ecuación (4.15) y la (4.18) que:

$$
R=1-\frac{c_{1}^{2}-c_{2}^{2}}{2 u_{1} c_{\theta 1}}=1-\frac{c_{\theta 1}^{2}+c_{r 1}^{2}-c_{a 2}^{2}}{2 u_{1} c_{\theta 1}}
$$

$\mathrm{Si}$ se sigue operando, teniendo en cuenta las condiciones antes mencionadas y los triángulos de velocidades (figura 4. 8), se obtiene:

$$
R=1-\frac{c_{\theta 1}}{2 u_{1}}=1-\frac{c_{1} \cdot \operatorname{sen} \alpha_{1}}{2 u_{1}}=1-\frac{c_{a 2} \cdot \frac{\operatorname{sen} \alpha_{1}}{\cos \alpha_{1}}}{2 u_{1}}=1-\frac{\operatorname{tg} \alpha_{1}}{2} \cdot \frac{c_{a 2}}{u_{1}}
$$

Donde $\alpha_{1}$ es el ángulo de entrada de los gases al rotor, que vendrá determinado por los álabes directores del estator.

En el caso de rotor con álabes radiales, $\beta_{1}=0$ y sin álabes directores que dirijan el flujo, $c_{\theta 1}=u_{1}$, entonces en $(4$. 20) se cumple que el grado de reacción de la turbina es de 0.5 , como se ha afirmado para el caso de la turbina de geometría fija y sin álabes directores.

Además, si se tiene en cuenta la expresión del gasto másico a la salida del rotor, siendo $\mathrm{A}_{2}$ el área geométrica a salida del mismo:

$$
\dot{m}=\rho_{2} \cdot c_{a 2} \cdot A_{2}=\frac{p_{2}}{R T_{2}} \cdot c_{a 2} \cdot A_{2} \Rightarrow c_{a 2}=\frac{\dot{m} R T_{2}}{A_{2} p_{2}}
$$

Sustituyendo en la expresión (4. 21) en la (4. 20) se obtiene:

$$
R=1-\frac{\operatorname{tg} \alpha_{1}}{2 \cdot u_{1}} \cdot \frac{\dot{m} R T_{2}}{A_{2} p_{2}}
$$

Con lo que es posible calcular el grado de reacción con el que se comporta una turbina conociendo parámetros geométricos de la misma ( $\alpha_{1}$, 
$\mathrm{A}_{2}$ ), el gasto másico que la atraviesa $(m)$ y la presión y la temperatura de los gases de escape a la salida de la turbina $\left(\mathrm{p}_{2}, \mathrm{~T}_{2}\right)$.

\subsubsection{Cálculo de la presión a la salida del estator}

Al analizar y estudiar el modelo publicado por Payri et al. [18], presentado en el apartado4.2.1, se ha concluido que si se conoce la presión intermedia entre el estator y el rotor es posible conocer las áreas efectivas de las toberas equivalentes utilizadas para que el modelo sea válido y represente el comportamiento de una turbina radial.

En el caso de turbinas sin álabes directores se ha demostrado que el valor del grado de reacción en este caso es igual a 0.5, y, Payri et al [18] propusieron como hipótesis para el cálculo de la presión intermedia la ecuación (4. 5).

No obstante es posible calcular esta presión intermedia si se conoce el grado de reacción, puesto que ambas magnitudes están relacionadas. Esta relación, entre la presión $\mathrm{P}_{1}$ y el grado de reacción, $\mathrm{R}$, va a variar en función del tipo de turbina que se esté considerando y de las condiciones de trabajo de la misma, distinguiéndose varios casos diferentes, que se van a ir explicando a continuación.

Se pretende que el modelo planteado para la TGV sea lo más general posible y aplicable a los diferentes tipos de turbinas radiales de geometría variable existentes en el mercado, así pues se van a distinguir dos casos, en primer lugar se va a considerar el caso de una turbina de álabes fijos y a continuación se estudiará el caso de una turbina de álabes móviles.

- Turbina de geometria variable de álabes fijos: $\alpha_{1}$ constante

Una vez obtenido el grado de reacción de la turbina en función de las condiciones del gas a la salida de la misma y de parámetros geométricos fácilmente medibles sólo falta pues conocer como se relaciona con la presión intermedia entre el estator y el rotor de la turbina para poder aplicar el modelo de dos toberas con depósito intermedio.

El grado de reacción se define como el cociente entre la energía transferida debida al cambio en la presión en el rotor y la variación total de la energia, esto es:

$$
R=\frac{h_{1}-h_{2}}{h_{00}-h_{02}}
$$

Considerando el gas como un gas ideal en el que $\mathrm{h}=\mathrm{c}_{\mathrm{p}} \mathrm{T}$ y despejando: 


$$
\frac{T_{1}}{T_{0}}=(1-R) \cdot\left(\frac{T_{2}}{T_{0}}\right)+R
$$

Conociendo el tipo de evolución que tiene lugar en la turbina será posible relacionar la presión intermedia con el grado de reacción.

Una evolución ideal a lo largo de la turbina vendría dada por la relación: $\frac{p_{2}}{p_{0}}=\left(\frac{T_{2}}{T_{0}}\right)^{\gamma / \gamma-1}$. En el caso real es necesario analizar detenidamente las evoluciones del gas en la turbina (en diagramas h-s) y obtener el tipo de relación que existe entre presiones y temperaturas, distinguiendo varios casos.

Teniendo en cuenta que cualquier evolución termodinámica a la que es sometida un fluido que atraviesa la turbina parte de unas condiciones iniciales, $\left(P_{0}, T_{0}\right.$ (se continua manteniendo la nomenclatura establecida en la figura 4. 1)) y llega a unas condiciones finales $\left(p_{2}, T_{2}\right)$, tales que $\mathrm{p}_{0}<p_{2}$ y $T_{0}<T_{2}$, el exponente politrópico de la evolución puede tomar valores comprendidos entre 1 , en el caso extremo de que $T_{0}=T_{2}$, y 1.33, que tomaría en el caso de gases de escape y que la evolución fuera isoéntrópica. Asumiendo el proceso del gas en la turbina como adiabático pero irreversible, es físicamente imposible que el exponente politrópico tome valores menores que 1 , ya que esto implicaria un aumento de la temperatura, y mayores que 1.33, que implicaría una disminución de la entropía del estado final respecto del inicial.

Si la evolución que sigue el gas al atravesar la turbina fuera una evolución politrópica, con un determinado índice de politropía $n$, éste vendría dado por:

$$
\frac{p_{2}}{p_{0}}=\left(\frac{T_{2}}{T_{0}}\right)^{n / n-1} \Rightarrow \frac{n}{n-1}=\frac{\ln \left(p_{2} / p_{0}\right)}{\ln \left(T_{2} / T_{0}\right)}
$$

Ocurre sin embargo que cuando la turbina está muy cerrada la evolución que el gas sigue en el estator es mucho más irreversible (ya que al disminuir el área de paso aumentan las pérdidas por fricción) que la evolución que sigue en el rotor, de modo se cree conveniente analizar la hipótesis de que la evolución a lo largo del estator y la evolución a lo largo de rotor no son iguales, sino que al haber dos saltos de presión y temperatura es posible que las evoluciones sean con exponentes politrópicos distintos.

Para cada uno de los saltos de presiones se ha de cumplir la ecuación (4. 26) asumiendo la hipótesis de que $i$ es constante a lo largo del proceso: 


$$
\frac{p_{\text {salida }}}{p_{\text {entrada }}}=\left(\frac{T_{\text {salida }}}{T_{\text {entrada }}}\right)^{i / i-1}
$$

Y para la evolución total desde la entrada de la turbina hasta la salida se cumple que:

$$
\frac{p_{2}}{p_{0}}=\frac{p_{2}}{p_{1}} \cdot \frac{p_{1}}{p_{0}}=\left(\frac{T_{2}}{T_{1}}\right)^{g / g-1} \cdot\left(\frac{T_{1}}{T_{0}}\right)^{k / k-1}=\left(\frac{T_{2}}{T_{0}}\right)^{n / n-1}
$$

Como no es posible medir presiones y temperaturas en el punto 1 , que está situado entre el estator y el rotor de la turbina, no se puede obtener los exponentes politrópicos $\mathrm{k}$ y g directamente, pero es posible relacionarlos con $\mathrm{n}$, como se muestra en la ecuación (4. 28).

$$
\frac{k}{k-1}=\frac{g}{g-1}+\frac{\left(\frac{n}{n-1}-\frac{g}{g-1}\right) \cdot \ln \frac{T_{2}}{T_{0}}}{\ln \left[(1-R) \cdot \frac{T_{2}}{T_{0}}+R\right]}
$$

El problema que se presenta ahora es que se dispone de una sola ecuación, (4. 28), con dos incógnitas, $\mathrm{k}$ y g.

Debido a la imposibilidad de resolver este problema y a que el área física de entrada al rotor no varía al desplazarse el mecanismo de la TGV (sólo varía el área física de entrada al estator) se puede hacer la hipótesis de que la evolución que se produce en el rotor es isoentrópica, con lo que se está suponiendo que todas las irreversibilidades que ocurren se producen en el estator. Con esta hipótesis conocemos el índice $g=1.33$ y podemos calcular $\mathrm{k}$ de (4. 28), pues $n$ viene dado por la ecuación (4. 25).

Con el fin de tener medidas para conocer como varia el grado de reacción de una TGV de álabes fijos se realizaron ensayos, que se describen ampliamente en el apartado 5.3.1, y a partir de las medidas realizadas se obtuvo el grado de reacción. Las medidas se realizaron para siete posiciones de la TGV constantes (desplazamiento de $0 \mathrm{~mm}$ indica TGV cerrada y desplazamiento $10 \mathrm{~mm}$ indica TGV completamente abierta), en cada posición se ensayaron distintos regímenes de giro y relaciones de expansión. Los resultados obtenidos se muestran en la figura 4. 9, en la que se observa que el grado de reacción aumenta al cerrarse la TGV. A partir de estos resultados se plantearon las hipótesis que a continuación se describen. 


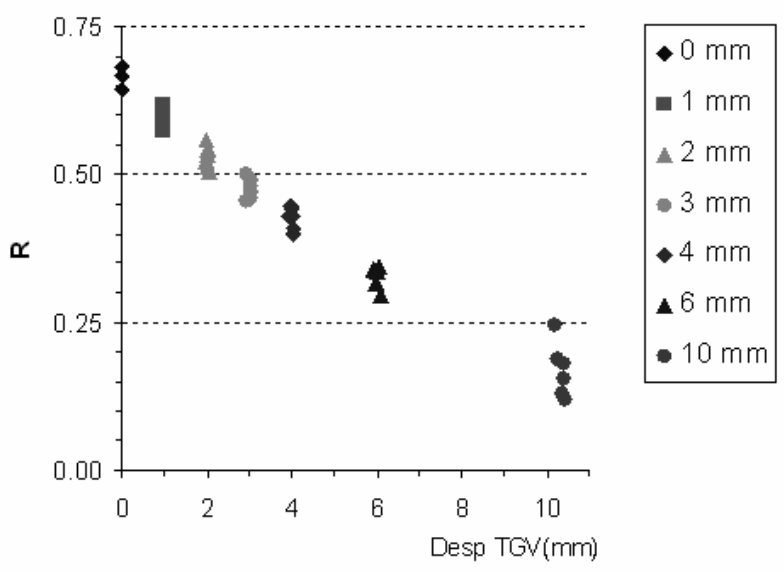

Figura 4. 9: Variación del grado de reacción obtenida a partir de datos experimentales para una TGV de álabes fijos.

En la figura 4. 10 puede observarse un esquema de lo que ocurre con estas hipótesis en el caso de la TGV abierta, en el que la evolución real es prácticamente equidistante entre la evolución con índice de politropía constante y la evolución con dos índices politrópicos diferentes (evolución isentrópica en el rotor y con un índice de politropia $k$, (dado por la ecuación (4. 28) en el estator). Puede observarse en el esquema de la figura 4.10 como una vez fijado el grado de reacción y un incremento de entropía pequeño, debido a la baja velocidad del flujo en el estator, las diferencias entre $\mathrm{P}_{1 k-g} \mathrm{y}$ $\mathrm{P}_{1 k^{\prime}-\gamma}$ es de las menores entre las evoluciones posibles y en cualquier caso la presión buscada queda contenida entre $\mathrm{P}_{1 n}$ y $\mathrm{P}_{1 k^{\prime}-\gamma}$.

Sin embargo, como se observa en la figura 4. 11, cuando la TGV está cerrada, y el área real de paso del estator es muy pequeña, el aumento de entropía en el estator es muy elevado por los mayores esfuerzos de fricción y la evolución que sigue es muy horizontal, lo que es equivalente a un exponente politrópico más cercano a la unidad. En el rotor no ocurre lo mismo, puesto que aunque se haya disminuido el área física de entrada a la turbina, una vez el flujo sale del estator sufre una expansión en el rotor similar al caso anterior (a igual régimen de giro) pues su área no ha variado. En este caso, vemos que la diferencia entre la hipótesis de un solo exponente ( $n=$ cte) y dos exponentes $(g=1.33$ y $1<k<1.33)$ es mayor. Siendo mejor hipótesis la segunda en que descomponemos la evolución real en dos partes.

En cualquier caso es necesario recordar que el objetivo final es calcular la presión intermedia $P_{1}$, tanto en la figura 4.10 como en la figura 4 . 11 se observa que las diferencias entre $P_{1 k-g}$ y $P_{1 k^{\prime}-\gamma}$ son las menores de todas y que la solución real siempre queda acotada entre las dos hipótesis realizadas. 


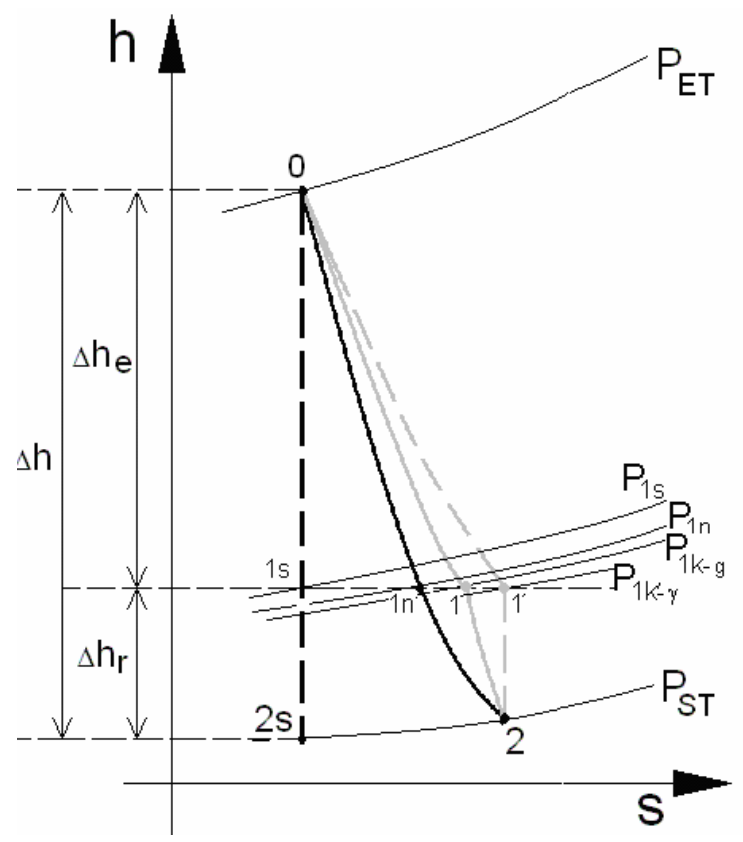

Procesos termodinámicos que se muestran en la figura:

- Línea negra a trazos: Proceso adiabático $\rightarrow n=c_{p} / c_{v}=\gamma$

- Linea negra continua: Proceso politrópico $\rightarrow n=$ cte

- Linea gris continua: Proceso real

Evolución en el estator: $k$

Evolución en el rotor: $g$

- Linea gris a trazos: Hipótesis del modelo

Evolución en el estator: $k$ '

Evolución en el rotor: $\gamma$

$$
\begin{gathered}
P_{1 s}>P_{1 n}>P_{1 k-g}>P_{1 k^{\prime}-\gamma} \\
P_{1 n} \approx P_{1 k-g} \approx P_{1 k^{\prime}-\gamma}
\end{gathered}
$$

Figura 4. 10: Diagrama $h$-s para una turbina de álabes fijos abierta $(R<0.5)$.

Procesos termodinámicos que se muestran en la figura:

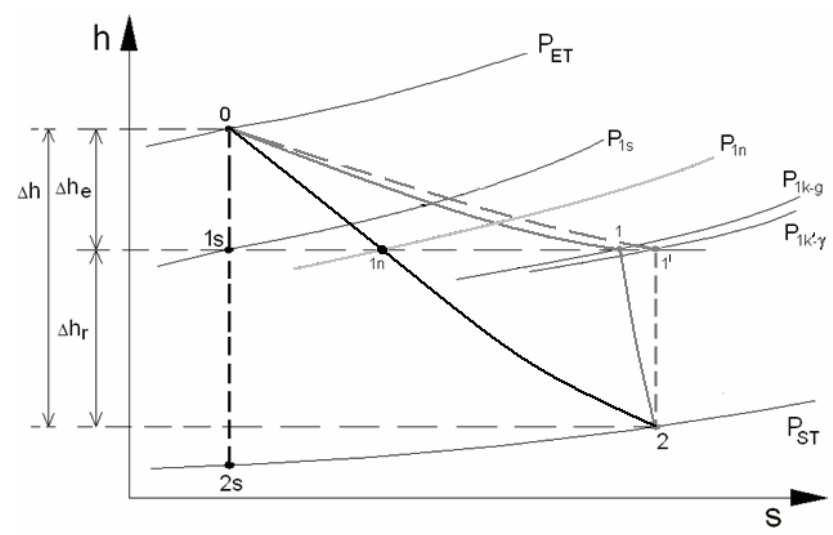

- Linea negra a trazos: Proceso adiabático $\rightarrow$ $n=c_{p} / c_{v}=\gamma$

- Línea negra continua: Proceso politrópico $\rightarrow n=$ cte

- Linea gris continua: Proceso real

Evolución en el estator: $k$ Evolución en el rotor: $g$

- Linea gris a trazos: Hipótesis del modelo

Evolución en el estator: $k$ ' Evolución en el rotor: $\gamma$

$$
\begin{gathered}
P_{1 s}>P_{1 n}>P_{1 k-g}>P_{1 k^{\prime}-\gamma} \\
P_{1 k-g} \approx P_{1 k^{\prime}-\gamma}
\end{gathered}
$$

Figura 4. 11: Diagrama $h$-s para una turbina de álabes fijos cerrada $(R>0.5)$.

En el caso de asumir la hipótesis de que las evolución en el estator sigue un exponente politrópico $\mathrm{k}$ (dado por la ecuación (4. 28) y la evolución en el rotor es isoentrópica, el cálculo de la presión intermedia viene dado por 


$$
\frac{p_{1}}{p_{0}}=\left((1-R) \cdot\left(\frac{T_{2}}{T_{0}}\right)+R\right)^{k / k-1}
$$

Donde $k$ se calcula con la ecuación (4. 28) asumiendo $g=\gamma$ y $n$ se calcula con la ecuación (4. 25).

Una vez obtenida la presión intermedia entre el estator y el rotor ya es posible obtener las áreas efectivas de las toberas equivalentes al estator y al rotor que reproducirán correctamente los saltos de presión que se producen en la turbina según las ecuaciones (4. 1) y (4. 3)del modelo presentado por Payri et al. [18]. El cálculo de las áreas efectivas de las toberas equivalentes se recuerda al final de este apartado.

\section{- $\quad$ Turbina de geometria variable de álabes móviles: $\alpha_{1}$ variable}

Ocurre en el caso de las turbinas de geometría variable de álabes móviles que llega una determinada posición de los álabes del estator en que éstos dejan de dirigir los gases de escape hacia el rotor, y se crea un pequeño volumen intermedio entre los álabes del estator y el rotor.

En la figura 4. 12 se observa un pequeño esquema, con uno de los álabes de la TGV y la circunferencia envolvente al rotor de la misma. En ese esquema se recuerda la definición del ángulo $\alpha_{1}$ y se observa como está relacionado con el ángulo $\phi$.

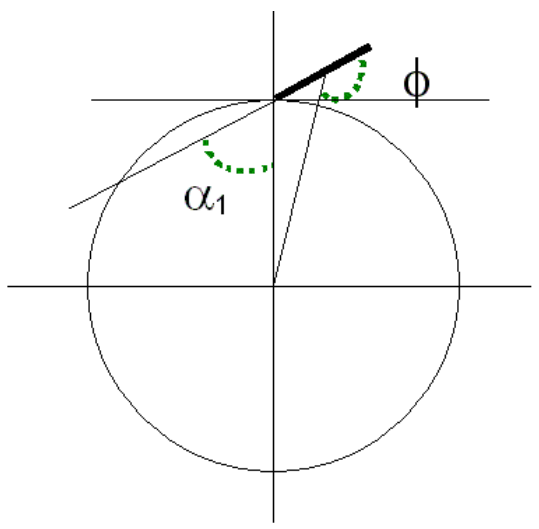

ENTRADA ROTOR

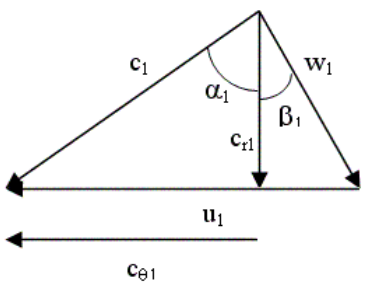

Figura 4. 12: Esquema geométrico y triángulo de velocidades a la entrada del rotor.

El caso de TGV de álabes móviles no es posible utilizar el razonamiento del apartado anterior para calcular el grado de reacción, en el momento en que el ángulo $\alpha_{1}$ deja de ser el ángulo de entrada al rotor. 
Observando la figura 4. 13 se aprecia que cuando $\phi$ es igual a un determinado valor $\left(\phi_{0} \approx 129^{\circ}\right)$ el eje de cada álabe es tangente al rotor de la turbina. Para valores de $\phi$ inferiores a este valor límite, el flujo saliente del estator ya no es dirigido hacia el rotor, sino hacia el volumen intermedio que se ha formado entre el estator y el rotor. Así, la dirección de la velocidad de entrada al rotor no depende del ángulo de los alabes del estator $\alpha_{1}$, dependiendo en este caso del ángulo de los alabes del rotor $\beta_{1}$. Entonces la turbina puede ser considerada como una turbina sin alabes direccionales en el estator y, asumiendo paletas rectas en el rotor y demás hipótesis de diseño, el grado de reacción se puede suponer 0.5 .

En la figura 4. 13 también se puede observar como cuando los álabes del estator se encuentran en la posición más cerrada dejan de dirigir el flujo hacia el rotor.

Una vez discriminados los diferentes casos es posible calcular el grado de reacción de cada uno y por tanto se pueden calcular las relaciones de expansión a través del estator y el rotor, y nuevamente estamos en disposición de obtener las áreas efectivas empleando la ecuación de la tobera. 


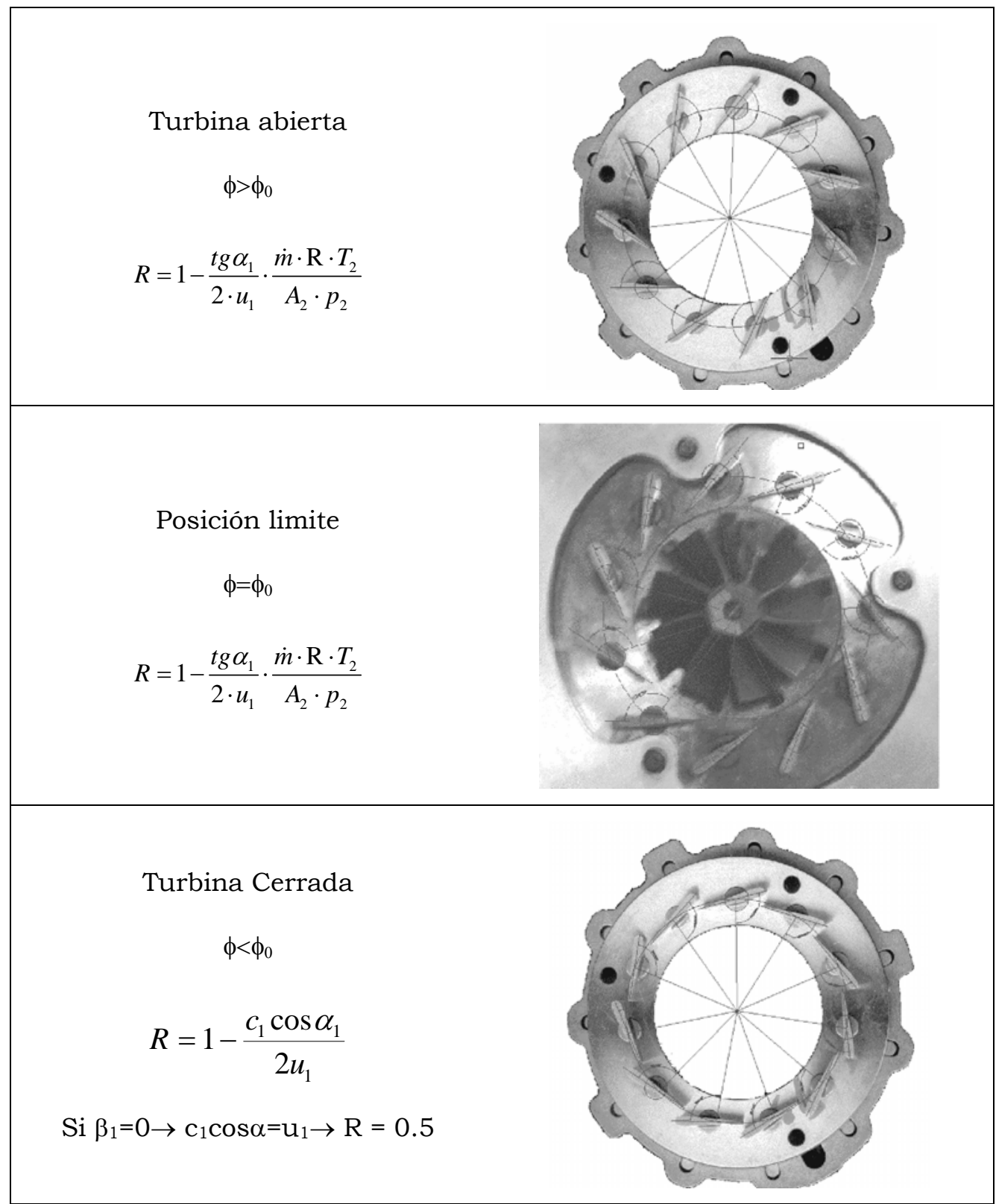

Figura 4. 13: Diferentes posiciones de los álabes de una turbina de geometría variable de álabes móviles. 
Con el fin de tener medidas para conocer a el grado de reacción de una TGV de álabes móviles, y teniendo en cuenta la hipótesis anterior de suponer grado de reacción 0.5 para valores de $\phi$ inferiores a este valor límite, se realizaron ensayos, que se describen ampliamente en el apartado 5.3.2, y a partir de las medidas realizadas se obtuvo el grado de reacción. Las medidas se realizaron para seis posiciones de la TGV constantes (ángulo de los álabes del estator de unos $85^{\circ}$, para la TGV cerrada y ángulo de los álabes del estator de unos $45^{\circ}$, para la TGV completamente abierta), en cada posición se ensayaron distintos regímenes de giro y relaciones de expansión. Los resultados obtenidos se muestran en la figura 4. 14, en la que se observa que el grado de reacción aumenta al abrirse la TGV. A partir de estos resultados se plantearon las hipótesis que a continuación se describen.

En este caso, como en el caso de las TGV de álabes fijos, es necesario distinguir también varios casos para relacionar el grado de reacción con la presión intermedia entre el estator y el rotor.

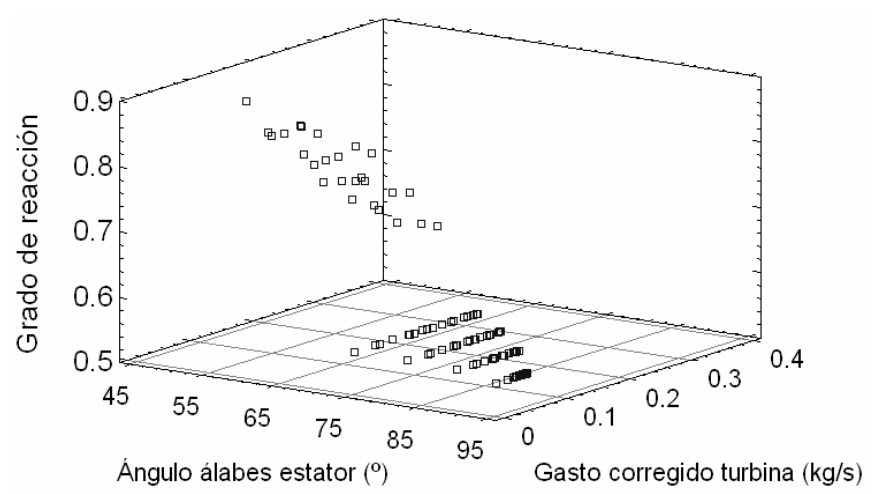

Figura 4. 14: Grado de reacción obtenido para los diferentes puntos de la TGV medidos, en función de la posición de los álabes del estator $\left(\alpha_{1}\right)$ y del gasto corregido trasegado por la misma.

Cuando la TGV está abierta el grado de reacción es mayor que 0.5, contrariamente a lo que sucedía con la TGV de álabes móviles, lo que implica en este caso hay poca expansión en el estator.

En el caso de que la turbina dirija el flujo al rotor la evolución termodinámica es similar al caso de una TGV de álabes fijos (en el que la $\mathrm{p}_{1}$ calculada con un índice de politropía constante está muy próxima a la $\mathrm{p}_{1}$ calculada con índices de politropía diferentes para el estator y el rotor), como se observa en la figura 4. 15. Pero en este caso, cuando la turbina está cerrada, y se tiene grado de reacción igual a 0.5 la evolución termodinámica sería parecida a la que se muestra en la figura 4. 16, debido a que la alta velocidad de flujo en el estator aumentará mucho el incremento de entropía. 
Se comprueba de nuevo que la hipótesis de suponer adiabática la evolución en el rotor y calcular $k$ en función de $n$ y $\gamma$ es la que proporciona un valor más adecuado de $\mathrm{p}_{1}$. Esto será más cierto cuanto más cerrado esté el estator.

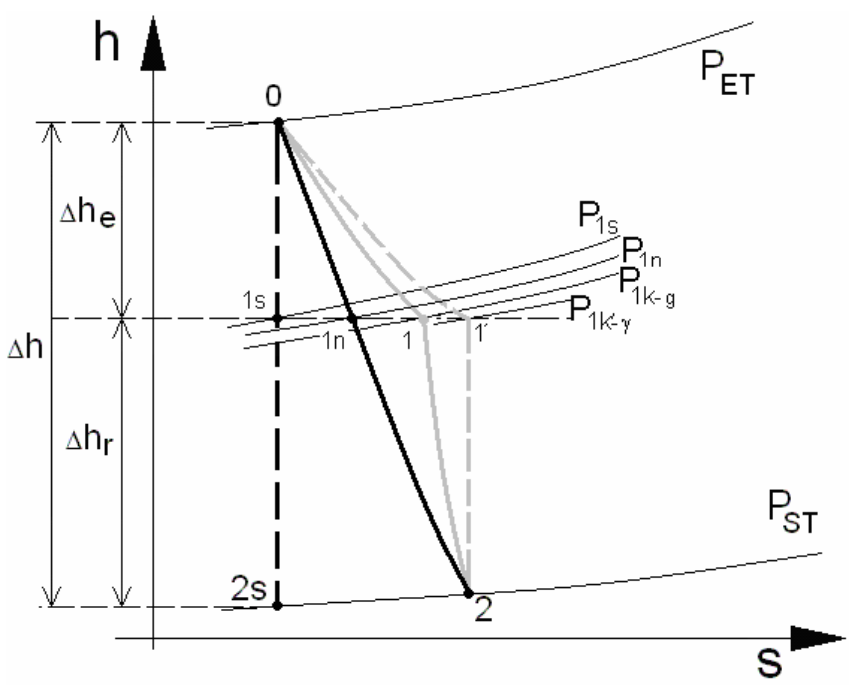

Procesos termodinámicos que se muestran en la figura:

- Linea negra a trazos: Proceso adiabático $\rightarrow n=c_{p} / c_{v}=\gamma$

- Linea negra continua:

Proceso politropico $\rightarrow n=c t e$

- Linea gris continua:

Evolución real Evolución en el estator: $k$ Evolución en el rotor: $g$

- $\quad$ Linea gris a trazos: Hipótesis del modelo

Evolución en el estator: $k$ ' Evolución en el rotor: $\gamma$

$$
\begin{gathered}
P_{1 n}>P_{1 k-g}>P_{1 k^{\prime}-\gamma} \\
P_{1 k-g} \approx P_{1 k^{\prime}-\gamma}
\end{gathered}
$$

Figura 4. 15: Diagrama h-s para una turbina de álabes móviles cerrada.

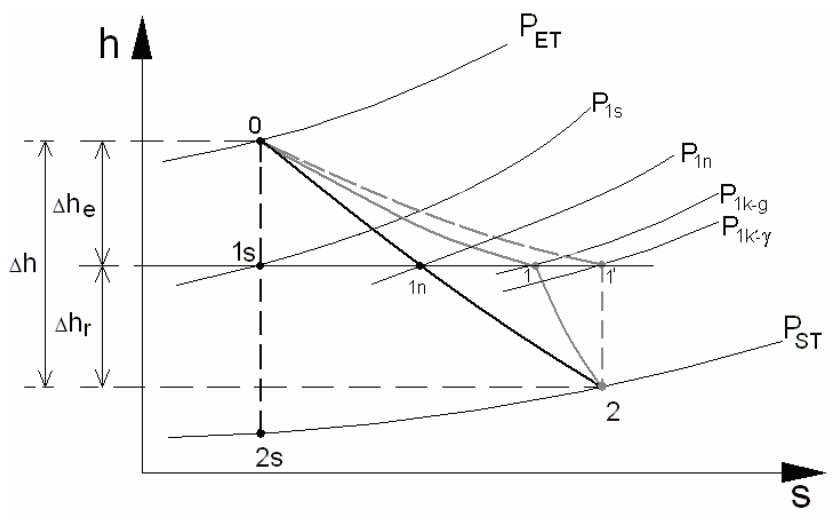

Procesos termodinámicos que se muestran en la figura:

- $\quad$ Linea negra a trazos: Proceso adiabático $\rightarrow n=c_{p} / c_{v}=\gamma$

- Linea negra continua: Proceso politropico $\rightarrow n=$ cte

- Linea gris continua:

Evolución real Evolución en el estator: $k$ Evolución en el rotor: $g$

- Linea gris a trazos: Hipótesis del modelo

Evolución en el estator: $k$ ' Evolución en el rotor: $\gamma$

$$
\begin{gathered}
P_{1 n}>>P_{1 k-g}>P_{1 k^{\prime}-\gamma} \\
P_{1 k-g} \approx P_{1 k^{\prime}-\gamma}
\end{gathered}
$$

Figura 4. 16: Diagrama h-s para una turbina de álabes móviles cerrada.

Efectivamente, cuando la TGV está cerrada, y el área real de paso del estator es muy pequeña, al igual que ocurre en las turbinas de álabes fijos las irreversibilidades por fricción son muy grandes y la evolución que sigue el gas en el estator debe tener un incremento de entalpía mayor que la evolución que siguen en el rotor, lo que es equivalente a un exponente politrópico más cercano a la unidad.

Repitiendo el razonamiento realizado en el caso de un TGV de álabes fijos, debido a que el área física de entrada al rotor no varía al desplazarse el eje de la TGV (sólo varía el área física de entrada al estator) se asume la 
hipótesis concentrar en el estator toda la variación de entropía. De modo que para calcular la presión intermedia entre el estator y el rotor se distinguirán dos casos y se asumirá también la hipótesis de índices politrópicos diferentes para la evolución en el estator y la evolución en el rotor.

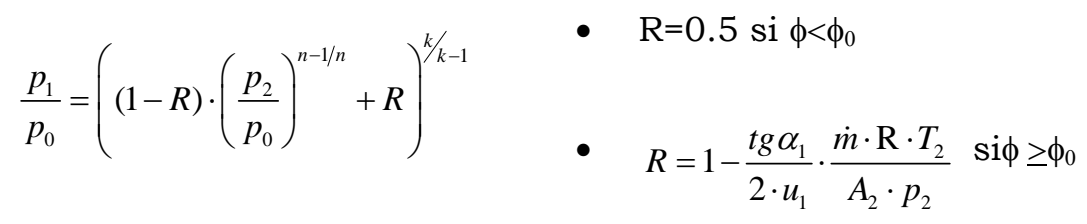

- Obtención de las áreas efectivas de las toberas equivalentes al estator y al rotor de la turbina

Una vez conocido el grado de reacción y sabiendo como se relaciona con el salto de presiones producido en el estator y el salto de presiones producido en el rotor el cálculo de las áreas efectivas de las toberas equivalentes al estator y al rotor se realiza a partir de la ecuación de la tobera[22], del mismo modo que se hacia en el modelo de Payri et al [18]:

$$
\begin{gathered}
\dot{m}_{T}=A_{\text {efESt }} \cdot \frac{p_{00}}{\sqrt{\gamma R T_{00}}} \cdot\left(\frac{p_{1}}{p_{00}}\right)^{1 / \gamma} \cdot \sqrt{\frac{2}{\gamma-1}\left[1-\left(\frac{p_{1}}{p_{00}}\right)^{(\gamma-1) / \gamma}\right]} \\
\dot{m}_{T}=A_{\text {efRot }} \cdot \frac{p_{1}}{\sqrt{\gamma R T_{10}}} \cdot\left(\frac{p_{2}}{p_{1}}\right)^{1 / \gamma} \cdot \sqrt{\frac{2}{\gamma-1}\left[1-\left(\frac{p_{2}}{p_{1}}\right)^{(\gamma-1) / \gamma}\right]}
\end{gathered}
$$

De donde se puede despejar las áreas efectivas para las toberas equivalentes, obteniéndose para el estator:

$$
A_{e f E s t}=\dot{m}_{T} \cdot \frac{\sqrt{\gamma R T_{00}}}{p_{00}} \cdot\left(\frac{p_{00}}{p_{1}}\right)^{1 / \gamma} \cdot\left(\sqrt{\frac{2}{\gamma-1}\left[1-\left(\frac{p_{1}}{p_{00}}\right)^{(\gamma-1) / \gamma}\right]}\right)^{-1}
$$

Y para el rotor:

$$
A_{\text {efRot }}=\dot{m}_{T} \cdot \frac{\sqrt{\gamma R T_{10}}}{p_{1}} \cdot\left(\frac{p_{1}}{p_{2}}\right)^{1 / \gamma} \cdot\left(\sqrt{\frac{2}{\gamma-1}\left[1-\left(\frac{p_{2}}{p_{1}}\right)^{(\gamma-1) / \gamma}\right]}\right)^{-1}
$$


Hay que destacar que todo lo expuesto anteriormente se puede aplicar a datos obtenidos de un mapa de turbina estándar sin necesidad de realizar ensayos para la caracterización de la misma, lo que facilita el modelado de la TGV a partir de la información que el fabricante proporciona. Efectivamente, asumiendo $\gamma$ y $c_{p}$ constantes, el grado de reacción (ecuación (4. 22)) puede escribirse en función de las variables corregidas.

Se ha obtenido en el apartado 4.4.2 que el grado de reacción puede escribirse como:

$$
R=1-\frac{\operatorname{tg} \alpha_{1}}{2 u_{1}} \cdot \frac{\dot{m} R T_{2}}{A_{2} p_{2}}
$$

La velocidad $\mathrm{u}_{1} \mathrm{y}$ el área de salida del rotor pueden escribirse como:

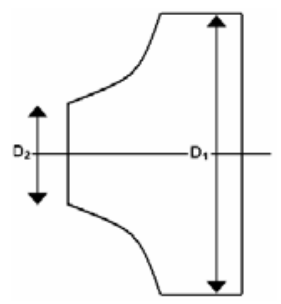

$$
\begin{aligned}
& u_{1}=\frac{2 \pi N D_{1}}{2}=\pi N D_{1} \\
& A_{2}=\frac{\pi D_{2}^{2}}{4}
\end{aligned}
$$

Figura 4. 17: Esquema del rotor de la TGV

Por otro lado, si asumimos $c_{p}$ como constante, el rendimiento isoentrópico de la TGV puede expresarse en función de las temperaturas como:

$$
\eta_{T s}=\frac{T_{00}-T_{2}}{T_{00}-T_{2 s}}
$$

Y despejando la temperatura de salida del gas y teniendo en cuenta que $T_{2 s}=T_{00} \cdot\left(\frac{p_{2}}{p_{00}}\right)^{(\gamma-1 / \gamma)}$ se obtiene que:

$$
T_{2}=T_{00}\left[1-\eta_{T s}\left(1-\left(\frac{p_{2}}{p_{00}}\right)^{(\gamma-1 / \gamma)}\right)\right]=T_{00} \cdot f^{\prime}\left(\frac{p_{2}}{p_{00}}\right)
$$

Sustituyendo las expresiones (4. 36), (4. 37) y(4. 39)en la (4. 35) se obtiene: 


$$
\begin{gathered}
R=1-\frac{\operatorname{tg} \alpha_{1}}{2 \pi D_{1} N} \cdot \frac{\dot{m}}{\frac{\pi D_{2}^{2}}{4}} \cdot \frac{R \cdot T_{00} \cdot f^{\prime}\left(\frac{p_{2}}{p_{00}}\right)}{p_{00} \frac{p_{2}}{p_{00}}}=1-\frac{2 \cdot \operatorname{tg} \alpha_{1} R}{\pi^{2} D_{1} D_{2}^{2}} \cdot \frac{\dot{m}^{*}}{N^{*}} \cdot f\left(\frac{p_{2}}{p_{00}}\right) \\
\text { donde } \quad f\left(\frac{p_{2}}{p_{00}}\right)=\left(\frac{p_{2}}{p_{00}}\right)^{-1}\left[1-\eta_{T_{s}}\left(1-\left(\frac{p_{2}}{p_{00}}\right)^{\gamma-1 / \gamma}\right)\right], \dot{m}^{*}=\frac{\dot{m} \sqrt{T_{00}}}{p_{00}} \quad \text { y } N^{*}=\frac{N}{\sqrt{T_{00}}}
\end{gathered}
$$

Y por lo tanto conocidos $\phi$ y $\alpha_{1}$ para cada posición de la TGV podemos calcular el grado de reacción para todos los puntos de funcionamiento y con la ecuación (4. 30) calcular el salto de presiones en el estator de la turbina $\left(\mathrm{p}_{1} / \mathrm{p}_{0}\right)$. Conocido el salto de presiones que se produce en el estator y conociendo la relación de expansión de la TGV es posible calcular el salto de presiones que se produce en el rotor $\left(\mathrm{p}_{1} / \mathrm{p}_{2}\right)$ y utilizando las ecuaciones (4. 33) y (4. 34) calcular las áreas efectivas de las toberas equivalentes al estator y al rotor. 


\subsection{Resumen}

A lo largo del capítulo que ahora se concluye se han mostrado los modelos para turbinas radiales presentes en la bibliografia. En primer lugar se han presentado los modelos para turbinas radiales de geometría fija presentes y entre ellos cabe destacar el modelo presentado por Payri et al. [18] en el que sustituye la turbina por dos toberas en serie con un volumen situado entre ambas, que permite que el modelo sea capaz de acumular masa.

En la segunda parte se analizan los modelos de turbina radiales de geometría variable presentes en la bibliografia.

Es destacable la escasez de modelos unidimensionales para turbinas de geometría variable [7][11], pero todavía es más destacable que algunos de los modelos que se encuentran presentes en la bibliografia no muestran validaciones de los mismos por la dificultad que han tenido los autores a la hora de realizar medidas experimentales.

Se ha observado la tendencia que existe en abandonar el modelado unidimensional de turbinas ya que con la potencia computacional actual es factible realizar modelados tridimensionales de turbinas [8], aunque eso si, si se pretende que el modelo de turbina forme parte de un modelo completo de motor resulta inviable acoplar estos modelos tridimensionales con los unidimensionales que se utilizan en el caso de motores.

En este cuarto capítulo se ha ampliado, en primer lugar, uno de los modelos de turbina radial de geometria fija más interesantes que se han encontrado en la bibliografia. Este modelo ha sido mejorado para predecir adecuadamente las condiciones termodinámicas de los gases de escape aguas abajo de la turbina.

A continuación se ha completado este modelo dotándolo de capacidad para predecir la evolución del flujo para que sea útil en el caso de turbinas de geometría variable, tanto de álabes fijos como de álabes móviles. estructura:

El modelo de turbinas de geometria variable sigue la siguiente

- En primer lugar se calcula el grado de reacción de la turbina en las condiciones de funcionamiento deseadas.

- A partir de ahí, y teniendo en cuenta el tipo de turbina que se esté modelando y las condiciones de trabajo, es posible calcular el salto de presiones que se produce en el estator y el salto de presiones que se produce en el rotor. 
- Una vez conocidos los saltos de presión que se producen en el estator y en el rotor es posible calcular las áreas efectivas de las toberas equivalentes que representan al estator y al rotor de la turbina. 


\section{Bibliografia}

[1] Aguilar Peris J. Curso de termodinámica. Ed. Alhambra; Madrid 1989.

[2] Arnold, S., Groskreutz, M., Shahed, S.M. and Slupski K. (2002) Advanced Variable Geometry Turbocharger for Diesel Engine Applications. SAE Technical Paper 2002-01-0161.

[3] Baines, N.C., Hajilouy-Benisi, A. and Yeo, J.H. (1994) The pulse flow performance and modelling of radial inflow turbines. Proceedings of the Institution of. Mechanical Engineers, C484(006), pp. 209-218.

[4] Benson, R.S. (1982) The Thermodynamics and Gas Dyamics of InternalCombustion Engines. Vol I. Oxford University Press, Oxford.

[5] Chen, H., Hakeem, I. and Martinez-Botas, R. (1996). Modelling of a turbocharger turbine under pulsating inlet conditions. Proceedings of the Institution of. Mechanical Engineers, 1996, Vol 210, pp 397-407.

[6] Chen, H. and Winterbone, D.E. (1990) A meted to predict performance of vaneless radial turbine under steady and unsteady flow conditions. Proceedings of ImechE International Conference on Turbochargers and turbocharging, pp 13-22.

[7] Galindo, J. (1998) Diseño de uniones de colectores de escape de motores alternativos. Tesis doctoral. Universidad Politécnica de Valencia. SPUPV-98.2141. ISBN: 84-7721-614-2.

[8] Hawley, J.G., Wallace, F.J., Cox, A., Horrocks, R.W., and Bird, G.L.(1999) Variable geometry turbocharging for lower emissions and improved torque characteristics. Proceedings of the Institution of. Mechanical Engineers, Vol 213, pp. 145-159.

[9] Hribernik, A., Dobovisek, Z. and Cernej, A. (1994) Application of rotor characteristics for one-dimensional turbine modelling. Proceedings of the Institution of. Mechanical Engineers, C484(034), pp. 239-249.

[10] Iwasaki, M., Nobuyuki, I., Marutani, Y. and Kitazawa, T. (1994) Comparison of Turbocharger Performance Between Steady Flow and Pulsating Flow on Engines. SAE Technical Paper 940839.

[11] Kessel, J.A., Schaffnit, J. And Schmidt, M. (1998) Modelling and realtime simulation of a turbocharger with variable turbine geometry (VTG). SAE Technical Paper 980770. 
[12] Lam, J.K-W., Roberts, Q.D.H. and Mcdonnell, G.T. (2002) Flow Modelling Of A Turbocharger Turbine Under Pulsating flow. Proceedings of the Institution of. Mechanical Engineers, C602/025/2002 , pp 181197.

[13] Macek, J., Vávra, J. And Vitek, O. (2002) 1-D Model of Radial Turbocharger Turbine Calibrated by Experiments. SAE Technical Paper 2002-01-0377.

[14] Moraal, P. and Kolmanovsky, I. (1999) Turbocharger Modeling for Automotive Control Applications. SAE Technical Paper 1999-01-0908.

[15] Nasser, S.H. and Playfoot, B.B. (1999) A turbocharger selection computer model. SAE Technical Paper 1999-01-0559.

[16] Payri, F. Predicción de las actuaciones de los grupos de sobrealimentación de motores diesel adaptados al vehículo de transporte por carretera. Tesis Doctoral. Universidad Politécnica de Madrid. 1983.

[17] Payri, F., Benajes, J., Jullien, J. and Duan, Q. (1991) Non-steady flow behaviour of supercharger turbine. Procedings of the Third EAEC International Conference, pp. 347-351, Strassbourg.

[18] Payri, F., Benajes, J. And Reyes, M. (1996) Modelling of Supercharger Turbines In Internal-Combustion Engines. International Journal of Mechanical Science, Nos 8-9, pp. 853-869.

[19] Payri, F., Corberán, J.M. Y Tinaut, F. (1984) Solución a la condición de contorno de la unión cilindro-conducto de los MCIA. Anales de Ingeniería Mecánica 3 (1), pp. 393-398.

[20] Payri, F., Desantes, J.M. and Boada, J. (1986) Prediction Method for the Operating Conditions of a Turbocharged Diesel Engine. Procedings of the Motor Sympo'86. Vol 2, pp. 8-16. Praga.

[21] Palfreyman, D. and Martínez-Botas, R. (2004) Turbocharger Turbine Under Computational Study. THIESEL 2004 Thermofluiddynamic Processes in Diesel Engines Conference Proceedings, pp 191-211.

[22] Shapiro, A.H. (1953) The dynamics and thermodynamics of compressible fluid flow. Wiley \& Sons, Inc.ISBN 0471066915.

[23] Watson, N. and Janota, S. (1982) Turbocharging the internal combustion engine. McMillan Publishers Ltd. ISBN 0333242904. London. 
Contribución a la caracterización experimental y modelado de grupos de sobrealimentación

[24] Winterbone, D.E. (1990) The theory of wave action approaches applied to reciprocating engines. J.H. Weaving Ed. in Internal Combustion Engineering: Science \& Technology, pp. 445-500, Elsevier Applied Science, London.

[25] Winterbone, D.E., Nikpour, B. And Frost, H. (1991) A contribution to understanding turbine performance in pulsating flow. Proceedings of the Institution of Mechanical Engineers, C433/011, pp 19-30. 


\section{Capitulo 5: Validación del modelo de turbinas de geometria variable propuesto}

5.1 INTRODUCCIÓN

5.1.1 Descripción del modelo de acción de ondas utilizado 181

5.2 VALIDACIÓN DEL MODELO CON ENSAYOS DE FLUJO NO ESTACIONARIO EN EL BANCO DE TURBOS 186

5.2.1 Modelado de la instalación en condiciones de flujo estacionario...........186

5.2.2 Interacción medido-modelado para el modelado bajo condiciones de flujo no estacionario 196

5.3 VALIDACIÓN DEL MODELO CON ENSAYOS EN BANCO MOTOR 207

5.3.1 Validación del modelo para TGV de álabes fijos ....................................207

5.3.2 Validación del modelo para TGV de álabes móviles...............................217

5.4 RESUMEN 241

ANEXO 1: TABLAS DE MEDIDAS ..... 243

BIBLIOGRAFÍA 253 



\subsection{Introducción}

A lo largo del documento se ha presentado un modelo unidimensional para turbinas de geometría variable y una instalación experimental en la que es posible caracterizar un amplio rango de turbogrupos de sobrealimentación de motor en todo su rango de funcionamiento. En este capítulo se va a validar el modelo de TGV propuesto y se van a combinar estas dos potentes herramientas, para obtener información sobre el comportamiento fluidodinámico de la turbina bajo condiciones de flujo no estacionario.

En primer lugar se va a mostrar detalladamente el modelo de acción de ondas en que se ha acoplado el submodelo de turbina de geometría variable presentado a lo largo del capítulo 4.

Seguidamente se modelará el banco de ensayos de turbogrupo para validar el modelo propuesto y una vez validado el modelado de la instalación, se utilizará éste para estudiar la influencia que tiene sobre el comportamiento fluidodinámico de la turbina el flujo no estacionario. Para ello se ha caracterizado una turbina distintos niveles de pulsación. A continuación se han modelado puntos de la turbina trabajando bajo condiciones de flujo estacionario y bajo condiciones de flujo no estacionario para analizar los resultados obtenidos.

Para completar el estudio, se realizará la validación del modelo de TGV propuesto a partir de datos obtenidos en ensayos en banco motor, para los dos tipos de turbinas de geometría variable presentados en el capítulo anterior y tanto para condiciones estacionarias de motor como para ensayos de transitorios de carga.

\subsubsection{Descripción del modelo de acción de ondas utilizado}

Como se ha comentado en la introducción y con el fin de aprovechar mejor la instalación para el estudio de turbinas y compresores se va ha hacer uso de un modelo de acción de ondas conocido como WAM (Wave Action Model), desarrollado en el Departamento de Máquinas y Motores Térmicos y que en general ha sido pensado para su uso en entornos de diseño en el ámbito de Universidades y departamentos I+D de empresas. En dicho modelo son aplicadas dos hipótesis para facilitar la obtención de soluciones. La primera es suponer que el flujo es unidimensional y la segunda que no es reactivo ni difusivo. Además resuelve el sistema formado por las ecuaciones de continuidad, de conservación de la cantidad de movimiento, de conservación de la energía y la ecuación de estado de los gases.

El WAM inicialmente fue concebido con el método de las características por Corberán [8] en 1984, como método de resolución del 
sistema de ecuaciones de conservación, basándose en una propuesta formulada por Benson [7].

Posteriormente, el método de las características fue modificado en 1984 por Payri, Corberán y Boada [21], mejorándose el algoritmo de generación y eliminación de las líneas características, especialmente para los casos en que el movimiento del fluido pasaba de ser nulo o saliente de los conductos a ser entrante en los mismos.

En 1991 Payri, Benajes y Chust [16] mejoraron, hasta el nivel que tiene actualmente, las condiciones de contorno de conexión con los conductos. En una siguiente etapa, se propuso sustituir el método de las características por otro basado en esquemas de diferencias finitas que mejoraban el tiempo de cálculo y eran menos difusivos.

Entre los diversos esquemas de posible utilización y después de realizarse en 1993 un estudio comparativo por Desantes, Chust y Llorens [11], se llegó a la conclusión de que los dos métodos más idóneos eran los esquemas de segundo orden y dos paso de Lax\&Wendroff y McCormack. Así pues, en 1993 se optó por la utilización del esquema numérico Lax\&Wendroff [25] siguiendo el mismo camino que otro autores [37][38] ya que en aquel entonces se trataba de un esquema de reconocidas ventajas. Desde la incorporación al modelo de dicho esquema, no se han realizado modificaciones en la forma de resolver las ecuaciones de conservación en los conductos hasta 2003, en el que Arnau [1] incorpora al modelo diferentes métodos numéricos como la combinación del método ya utilizado de Lax\&Wendroff combinado con FCT (Flux Corrected Transport), el método de McCormack y éste combinado con FCT, el esquema de cálculo CE-SE (Conservation Elements - Solution Elements) y un método TVD (Total Variation Diminishing) con limitador de flujo de Swedy.

A parte de la evolución llevada a cabo en los métodos de cálculo utilizados por el modelo, se han ido añadiendo submodelos para la resolución de los diferentes subsistemas de motor. Así, los cilindros y los depósitos se calculan desde los inicios del programa [8][22][23] como sistemas termodinámicos cero dimensionales mediante un modelo de llenado y vaciado.

En 1993 Payri, Benajes y Reyes [20] añadieron un submodelo para la resolución de la condición de contorno turbina, el cual ha sido posteriormente adaptado a la incorporación de turbinas de geometría variable con el modelo presentado en el capítulo 3 de la presente tesis, del cual se han publicado algunas versiones preliminares en distintos foros [24][33]. Reyes [29], en 1993, presentó su tesis sobre mejoras al modelado de la transferencia de calor en los conductos de escape del motor. En relación con la transmisión de calor en los conductos también se realizaron aportaciones en 1999 por Serrano [32] y en 2001 por Galindo, Serrano, Climent y Arnau [13]. También 
cabe destacar la mejora realizada en 1993 por Luján y Benajes [14] en el modelado del compresor, el cual, hasta la fecha, estaba basado en el trabajo de Requejo[28].

En 1994 Payri, Benajes y Luján [19] añaden un submodelo para el cálculo de la válvula waste-gate. Ese mismo año, se publica una mejora al modelado del intercooler por Benajes, Bermúdez y Galindo [2] y en 1995 se extiende al modelado de catalizadores por Payri, Benajes y Galindo [17]. Más tarde, en 2001 el submodelo de intercooler será substituido por Galindo, Serrano, Climent y Arnau [13].

Durante 1995 por parte de Desantes, Benajes y Luján [10] y durante 1996 por parte de Benajes, De los Reyes y Luján [6] se desarrolla el submodelo que permite el cálculo de sistemas, tanto internos como externos, de recirculación de gases de escape y que culmina en 1998 con la tesis de Luján [15].

Al mismo tiempo, durante los años 1996 y 1997 se dota al modelo de la capacidad de calcular el efecto direccional de las uniones de conductos en el escape [26] lo que permite mejorar las capacidades del modelo para el prediseño de colectores de admisión y de escape [4][5]. Con la tesis de Galindo [12] en 1998 se termina este trabajo y el modelo alcanza el nivel de desarrollo con el que comienza la adaptación del mismo al cálculo de transitorios de carga mediante una serie de trabajos tanto experimentales como teóricos [3][18][27][32].

Estos trabajos de transitorios fueron los que impulsaron la tesis de Arnau [1], con la que se resuelven lo problemas detectados en el nivel de conservación de ciertas propiedades, como la masa, durante el cálculo de las ecuaciones de flujo unidimensional en conductos, especialmente en los cónicos, lo que provocaba un desequilibrio entre la energía de la turbina y la del compresor que hacia que la evolución transitoria no se consiguiera de forma precisa.

Una de las últimas aportaciones a este modelo de acción de ondas ha sido la implementación de un modelo para el cálculo del transporte de diferentes especies químicas de forma desacoplada [34], es decir, se realiza de forma independiente a la resolución de las ecuaciones de conservación.

El actual modelo sigue evolucionando y creciendo con arreglo a las necesidades de los usuarios, las mejoras de conocimientos de los procesos involucrados en los motores de combustión interna alternativos, las mejoras en las capacidades de cálculo de los nuevos ordenadores y los nuevos métodos de cálculo.

De esta evolución continua surgió la necesidad de crear herramientas informáticas que ayudaran a una mejor y más rápida comprensión del 
modelo y al mismo tiempo permitieran al usuario una mayor versatilidad en el uso del programa, permitiendo la detección rápida de errores en el fichero de datos y la realización de forma automática de aquellos procesos que puedan ser repetitivos o rutinarios. Para la introducción rápida de datos en el modelo se desarrolló la herramienta informática de preproceso de datos Wamer con la que es posible crear ficheros de entrada de datos que utiliza el modelo para realizar los cálculos.

A continuación, figura 5. 1, se puede ver el aspecto general de la aplicación de pretratamiento con la configuración del banco de turbos modelado que se estudiará a lo largo del capítulo.

En la realización de la herramienta informática como interface de pretratamiento del fichero de datos Wamer se utilizó el programa informático Borland $\mathrm{C}++$, por ser un lenguaje de gran difusión y ampliamente utilizado, realizando éste de manera que en un futuro puedan ser fácilmente introducidas las sucesivas modificaciones a las que se someta el modelo.

El enfoque que se utilizó para el diseño de la aplicación es similar al utilizado en los programas de dibujo, es decir, con una barra de herramientas en la que se encuentran todos los elementos que pueden formar parte del modelo. Estos elementos pueden ir colocándose sobre la pantalla principal de la aplicación estableciendo la configuración deseada del motor modelado. Una vez establecida esta configuración mediante la barra de menús y mediante menús de tipo popup (menús desplegables que se activan al clickear sobre el elemento), se pueden introducir todos los parámetros que configurarán el fichero de datos de entrada del modelo. 


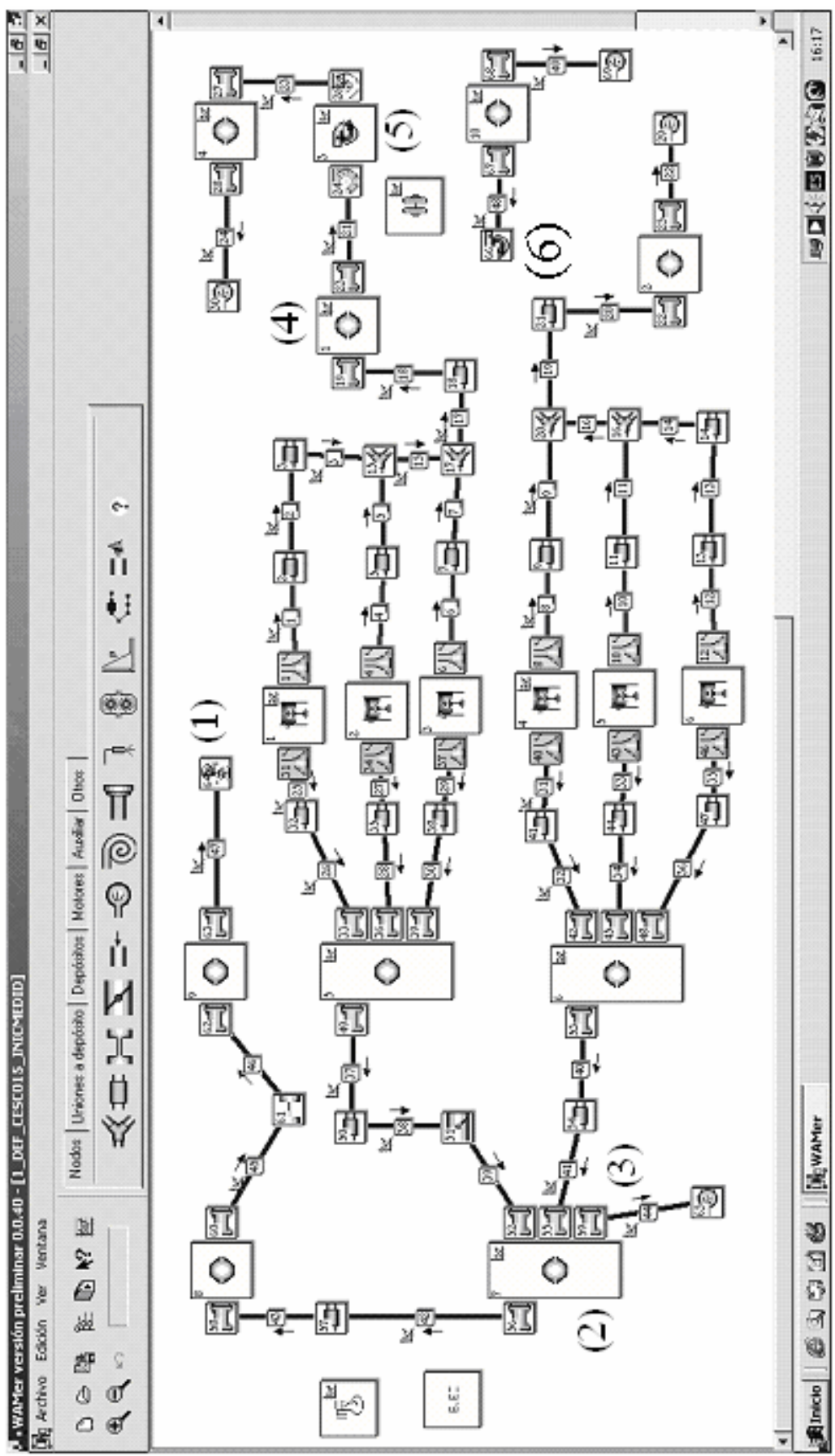

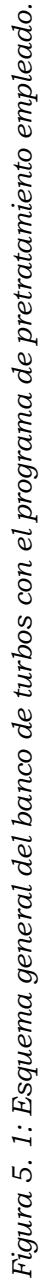




\subsection{Validación del modelo con ensayos de flujo no estacionario en el banco de turbos}

\subsubsection{Modelado de la instalación en condiciones de flujo estacionario}

La instalación del banco de turbos ha sido modelada mediante el programa WAM anteriormente descrito. Para ello se representa mediante los elementos disponibles en el programa de preprocesado Wamer el esquema del banco. La figura 5. 1 muestra el esquema del modelo de la instalación, con todos sus componentes. En ella se distinguen los elementos del banco real: la línea de admisión con el compresor volumétrico (1) y el depósito (2) de la válvula de alivio de este remanso (3), los seis cilindros, las dos líneas de escape, el remanso para eliminar los pulsos de escape (4), la turbina (5) y el compresor (6). En los extremos de los tubos que descargan al ambiente se dispone un nodo que impone la condición de descarga a condiciones ambientes, introducidas en el cuadro de datos generales de ejecución del modelo.

Puesto que el WAM sólo modela uniones fluidodinámicas entre elementos, la unión mecánica entre la turbina y el compresor del turbogrupo no queda reflejada en el esquema.

El programa es capaz de proporcionar valores medios e instantáneos de las variables termodinámicas en cualquier punto del motor, de un conducto o de un nodo.

La principal ventaja de la reproducción de los ensayos con el modelo radica en la posibilidad de obtener evoluciones instantáneas de determinadas variables, cuya medida resulta extremadamente dificil o imposible de obtener con fiabilidad, como es el caso de las temperaturas de entrada y salida de la turbina.

El banco de ensayos dispone de captadores de presión instantánea de elevada precisión. Sin embargo, hasta el momento no existen transductores de temperaturas fiables capaces de seguir los pulsos de temperatura generados por el proceso de escape del motor. Los termopares se utilizan únicamente para obtener un valor medio de la temperatura. En el caso de la temperatura de salida del compresor la diferencia no es significativa, pues la evolución instantánea no presenta pulsos importantes y la medida de temperatura media proporciona suficiente información. En cambio la variación de la temperatura instantánea de entrada a la turbina respecto a su valor medio es considerable $\mathrm{y}$, por tanto, la medida de temperatura media resulta insuficiente en los cálculos de variables instantáneas en los que intervenga la temperatura de entrada a la turbina. Así, si se pretende conocer la evolución instantánea del rendimiento de la turbina a lo largo de un ciclo para un determinado ensayo es necesario calcularlo considerando la 
temperatura instantánea de entrada a la turbina a lo largo del ciclo y, puesto que ésta no se puede medir, será necesario obtenerla por modelado. Lo mismo sucede a la hora de calcular el trabajo producido por la expansión del gas en la turbina, donde es necesario integrar el trabajo instantáneo en un determinado periodo de tiempo. El trabajo instantáneo a su vez se obtiene a partir de las evoluciones instantáneas de presión y temperatura a la entrada y salida de la turbina.

El ajuste de la onda de presión instantánea modelada a la medida, tanto en valor medio como en fase y amplitud, garantiza un correcto resultado de la temperatura del gas calculada, pues ésta influye en la velocidad de propagación de la onda de presión, que es la velocidad del sonido y depende de la temperatura según indica la expresión ¡Error! No se encuentra el origen de la referencia.), en la que $\gamma$ es el exponente adiabático, igual al cociente entre calores específicos, $\mathrm{R}$ la constante de los gases perfectos y $\mathrm{T}$ la temperatura del gas.

$$
a=\sqrt{\gamma \cdot R \cdot T}
$$

Por tanto, una vez aceptada la precisión del ajuste de la presión instantánea se asume que la temperatura instantánea modelada es correcta [29].

En este modelo se introducen, mediante el programa de preproceso, las condiciones que caracterizan el ensayo que se pretende modelar, tales como régimen de giro del motor, masa de combustible inyectado y temperatura y presión ambientes. Los grados de apertura de las válvulas se modelan a través de los coeficientes de descarga de los depósitos en cuya salida se encuentran. Éstos no están linealmente relacionados con el grado de apertura real, ya que las válvulas no son lineales, por lo que el ajuste de las variables se lleva a cabo probando diferentes valores de coeficientes de descarga hasta que el error cometido en el modelado se considera aceptable. Igual que éstos se dispone de una serie de parámetros, cuyo valor no queda determinado en el ensayo, que se utilizan para el ajuste de las variables modeladas. A continuación se explica cuales son estos parámetros y en que sentido actúan sobre el proceso de modelado.

\section{- $\quad$ Parámetros para el ajuste del punto modelado}

Se trata de parámetros cuyo valor, por no poder ser medido o no estar explícitamente relacionado con el correspondiente parámetro real medido, no queda determinado en el ensayo. Por tanto, su valor es aquél que consigue un ajuste preciso entre la variable modelada sobre la que influye y su correspondiente medida. 


\section{- Parámetros de ajuste en la admisión}

El gasto impulsado por el compresor volumétrico queda determinado por el mapa introducido en el programa para dicho compresor (figura 2. 8) y el régimen del motor establecido, cuya relación con el régimen del compresor volumétrico también se impone en el modelo.

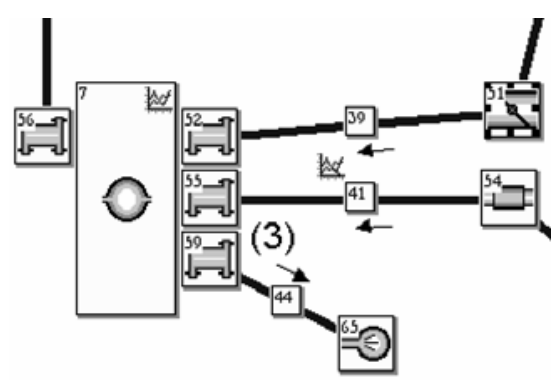

Figura 5. 2: Ampliación del esquema del modelado de la instalación. El nodo 59 (3) representa la válvula de descarga situada en el depósito de la admisión del motor.

El coeficiente de descarga del nodo de unión entre el depósito de la admisión y el conducto de descarga al ambiente (nodo 59 en la figura 5. 2), que representa el grado de apertura de la válvula de alivio de la línea de admisión, influye sobre la presión aguas arriba del mismo y, por tanto, sobre la presión de admisión, así como sobre el gasto expulsado al ambiente. Cuando el coeficiente de descarga de esta válvula no permite ajustar ambas variables a los valores medidos se puede modificar el coeficiente de ajuste de la transmisión de calor en la admisión a los cilindros para modelar con mayor precisión el gasto de admisión. Este coeficiente modifica el valor de calor transmitido al aire por el cilindro, caliente por las combustiones anteriores. Si la transmisión de calor es mayor la temperatura del aire de admisión aumenta, su densidad disminuye y, por tanto, el gasto se reduce. Del mismo modo, si la transmisión de calor es menor el gasto aumenta.

En conclusión, los dos parámetros para el ajuste de las variables en la admisión son el coeficiente de descarga del nodo de unión del depósito de la admisión al tubo de descarga al ambiente y el coeficiente de ajuste de la transmisión de calor en la admisión a los cilindros.

\section{- Parámetros de ajuste en el escape}

Aguas abajo del escape de tres de los seis cilindros se encuentra acoplada la turbina, cuyas áreas efectivas se determinan según el modelo expuesto en el capítulo 4.

En la línea de escape de los otros tres cilindros se dispone de un pequeño depósito cuyo nodo de salida se utiliza para simular la válvula de contrapresión del escape (figura 5. 3), de modo que el coeficiente de descarga 
de este nodo se utiliza para ajustar la presión de escape de esta línea. El ajuste de esta variable interesa fundamentalmente para garantizar un reparto del gasto de admisión similar al real.

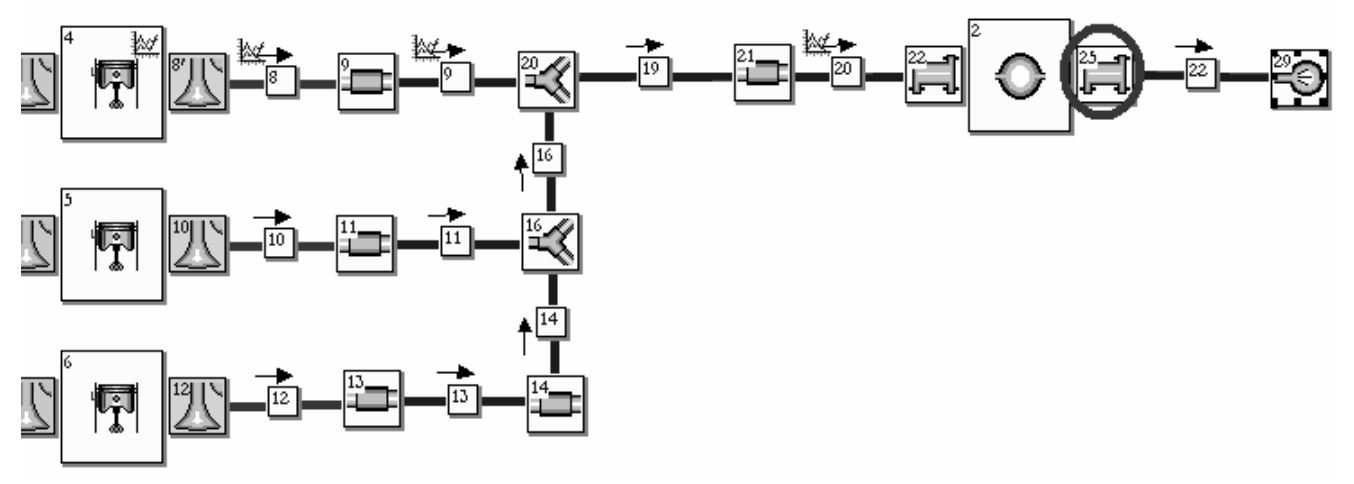

Figura 5. 3: Ampliación del esquema del modelado de la instalación. El nodo 25 representa la válvula de contrapresión de escape, situada en la rama del escape que descarga directamente a la atmósfera.

El rendimiento de la turbina se calcula en el modelo a partir de llos datos del fabricante y en función de la relación cinemática, como se verá en el apartado 5.3.2. Este rendimiento, junto con las condiciones de entrada y salida de la turbina, determina su trabajo útil. Como éste ha de ser igual al del compresor, una vez calculadas las variables de entrada y salida de la turbina, el rendimiento influirá directamente sobre el trabajo del compresor y, por tanto, sobre las condiciones de salida del mismo y el régimen de giro del turbogrupo. El coeficiente de ajuste del rendimiento de la turbina es un parámetro que se puede introducir en el modelo, de forma que el rendimiento de la turbina sea el producto del obtenido en función de la relación cinemática y este coeficiente. Modificando el rendimiento de la turbina se ajusta el trabajo de la turbina y, por tanto, del compresor. Así, junto con el mapa del compresor y las condiciones impuestas en la salida del mismo a través de los parámetros de ajuste de la línea de descarga del compresor, el coeficiente de ajuste del rendimiento de la turbina determina el régimen del turbogrupo, la presión de salida y el gasto del compresor.

\section{- Parámetros de ajuste en la línea de descarga del compresor del turbogrupo}

En esta línea se dispone del coeficiente de descarga del nodo de salida del depósito situado tras el compresor (figura 5. 4). Según el salto de presión que imponga este coeficiente entre el depósito y el ambiente, la presión a la salida del compresor y el gasto variarán. En función del mapa del compresor y del trabajo de la turbina, a un determinado coeficiente de descarga de este nodo corresponden unos valores de presión a la salida del compresor, gasto por el compresor y régimen del turbogrupo. 


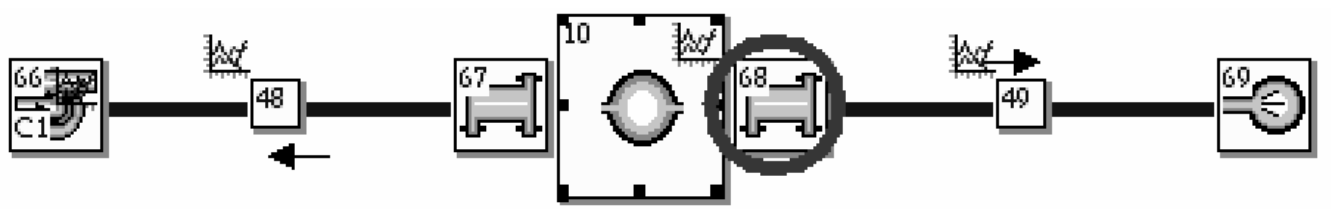

Figura 5. 4: Ampliación del esquema del modelado de la instalación. El nodo 68 representa la válvula de contrapresión, situada aguas abajo del compresor.

Se comprueba a lo largo de las ejecuciones que este coeficiente de descarga afecta con mayor intensidad a la presión aguas arriba que a los otros dos parámetros, por lo que se utiliza en primer lugar para ajustar esta variable, alcanzando los valores medidos para las otras modificando el coeficiente de ajuste del rendimiento de la turbina.

En realidad, como todas estas variables están tan estrechamente interrelacionadas el ajuste se consigue modificando tanto los parámetros de ajuste disponibles en la turbina como el coeficiente de descarga del depósito a la salida del compresor hasta que los errores cometidos en el cálculo de las variables modeladas se consideran aceptables.

- Comparación de los valores medidos y modelados en condiciones de flujo estacionario a la entrada de la turbina

En el presente trabajo se ha modelado, a modo de ejemplo, los ensayos realizados para la obtención de la línea de régimen de $130000 \mathrm{rpm}$ del mapa del compresor del turbogrupo GT1544 V, cuyas características principales se muestran en la tabla 5. 1. El objetivo de este modelado es comprobar la capacidad del modelo para ajustar con suficiente precisión los resultados a las correspondientes variables medidas. La configuración de la instalación para la realización de estos ensayos fue la de tres cilindros descargando a la turbina en flujo estacionario, que se muestra en la figura 5. 1 .

\begin{tabular}{|c|c|c|c|}
\hline \multicolumn{2}{|c|}{ GT1544V } & Compresor & Turbina \\
\hline \multirow{2}{*}{ Diámetros(mm) } & Entrada & 41 & 30 \\
\cline { 2 - 4 } & Salida & 35 & 38.3 \\
\hline Número álabes rodete & 6 & 11 \\
\hline Número de álabes estator & - & 11 \\
\hline
\end{tabular}

Tabla 5. 1: Características del turbogrupo utilizado para validar el modelado de la instalación.

\section{- Valores medios}

Los valores medios de las variables calculadas por el programa de modelado se han de ajustar a los de las variables medidas en la instalación para que el modelado del punto de ensayo sea correcto. 
Se han representado las variables medidas y modeladas para todos los puntos de ensayo modelados frente al gasto trasegado por el compresor, que es una de las variables que permite identificar fácilmente el punto ensayado dentro de una línea de régimen de giro constante. Los errores cometidos en el ajuste de cada una, calculados como la diferencia porcentual entre la variable medida y la modelada referida a la variable medida, se representan en la misma gráfica utilizando un eje secundario dispuesto en el lado derecho. El gasto por el compresor no se ha representado en ninguna gráfica. Su ajuste se comprueba en todas por la desviación en el eje de abscisas de los puntos representados en las gráficas, puesto que las variables modeladas se representan en función del gasto modelado y las medidas en función del correspondiente gasto medido. En las gráficas se constata que los gastos medidos y modelados son prácticamente iguales en todos los puntos. Se ha comprobado con los resultados obtenidos que los errores cometidos en el modelado de esta variable son muy pequeños.

En la figura 5. 5 se comprueba que los valores medios de las variables modeladas de la línea de admisión del motor del banco de ensayos se ajustan con precisión a las medidas. Los errores cometidos, mostrados en la gráfica referenciados al eje secundario, en la derecha, son para todos los puntos modelados menores al $5 \%$.
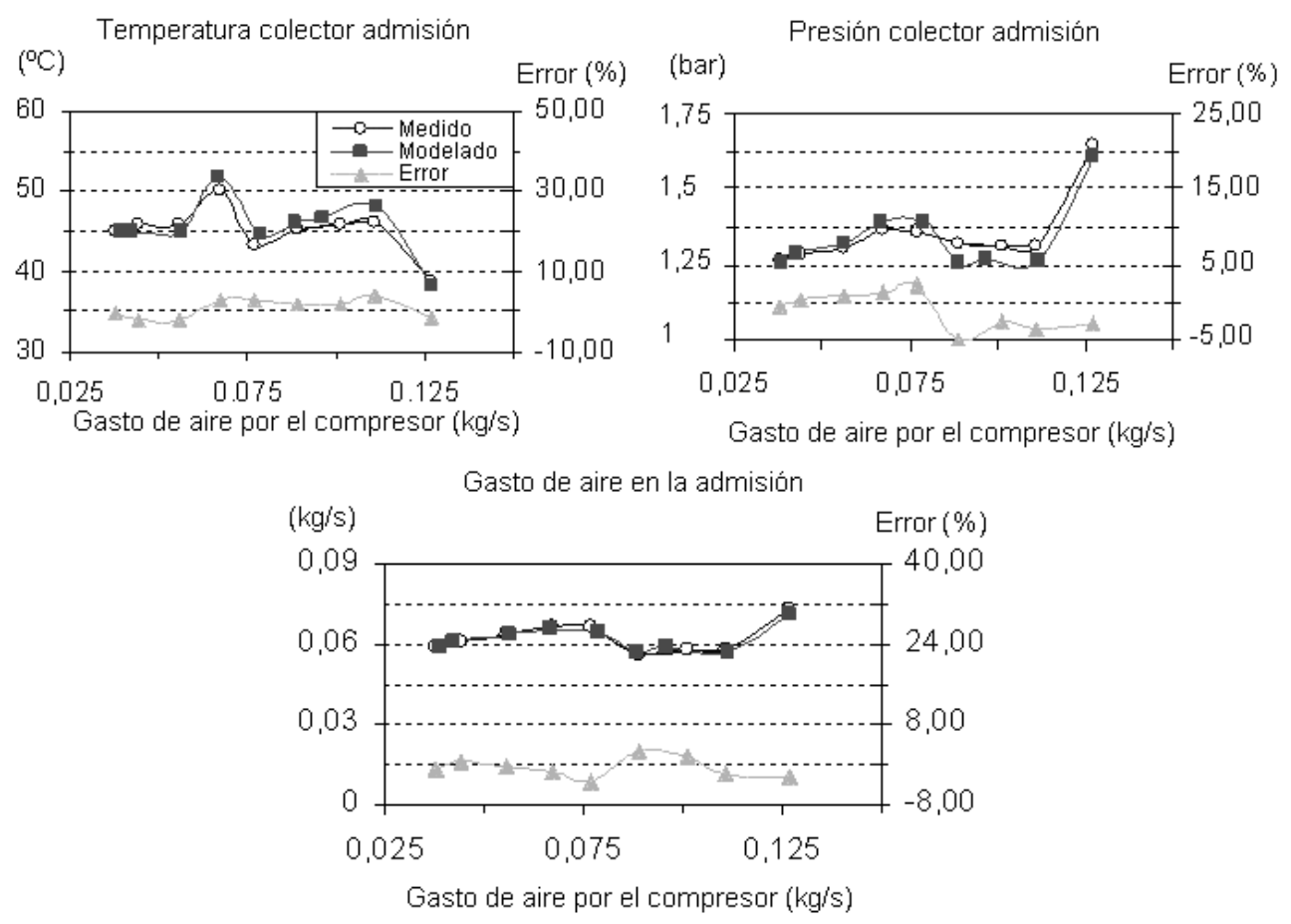

Figura 5. 5: Comparación de las variables medias medidas y modeladas en la línea de admisión del motor del banco de ensayos. 
La figura 5. 6 muestra la comparación de las variables medidas y modeladas de la línea de escape del motor, de los cilindros que alimentan la turbina: temperatura y presión del colector de escape, temperatura y presión de entrada a la turbina y temperatura y presión de salida de la turbina.

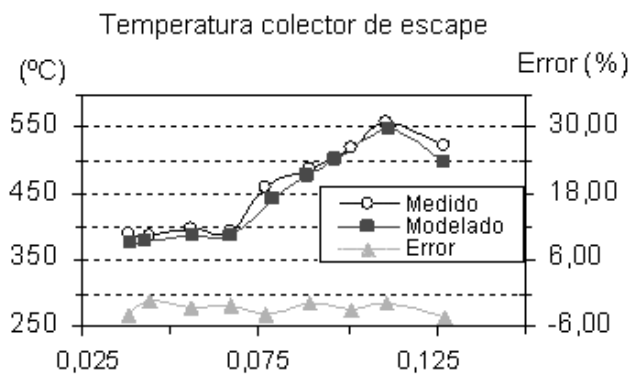

Gasto de aire por el compresor ( $\mathrm{kg} / \mathrm{s})$

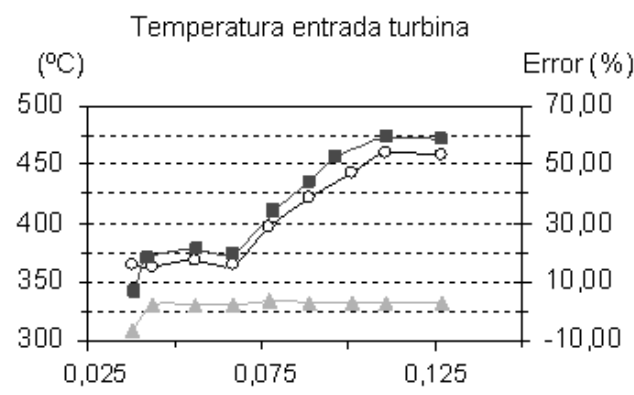

Gasto de aire por el compresor ( $\mathrm{kg} / \mathrm{s})$

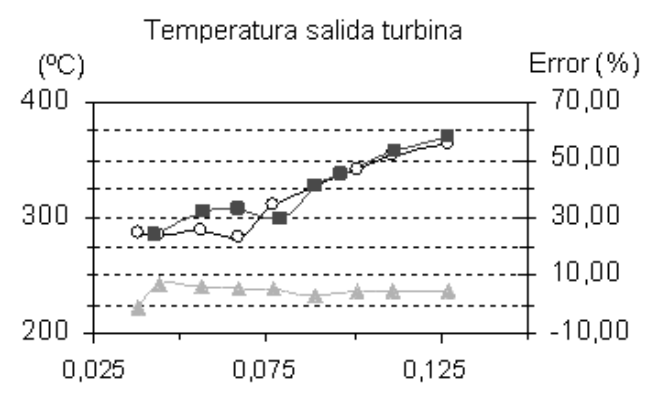

Gasto de aire por el compresor $(\mathrm{kg} / \mathrm{s})$

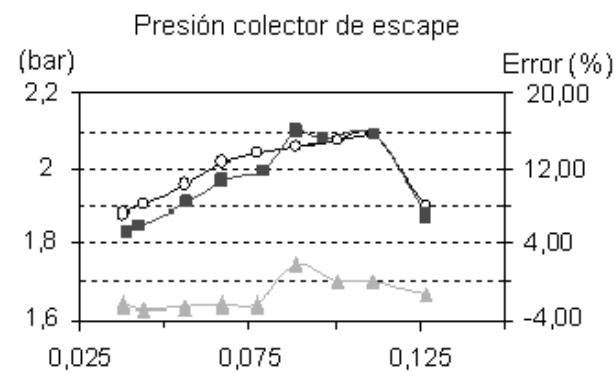

Gasto de aire por el compresor ( $\mathrm{kg} / \mathrm{s})$

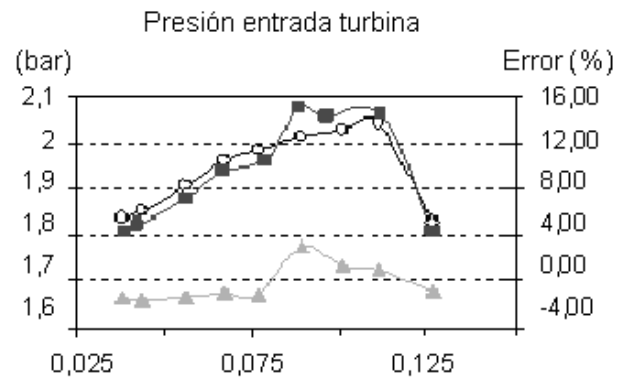

Gasto de aire por el compresor ( $\mathrm{kg} / \mathrm{s})$

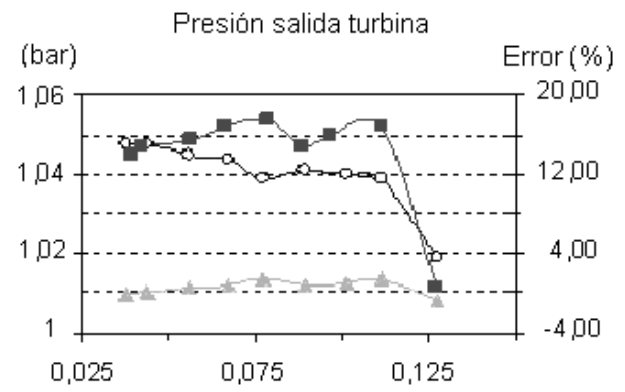

Gasto de aire por el compresor ( $\mathrm{kg} / \mathrm{s})$

Figura 5. 6: Comparación de las variables medias medidas y modeladas en la línea de escape del motor del banco de ensayos en la que se encuentra la turbina.

El ajuste es muy preciso, especialmente el de presión en los puntos de entrada y salida de la turbina cuyos correspondientes errores son menores al $3 \%$ en todos los casos. Esto indica que la energía disponible a la entrada y a la salida de la turbina queda bien modelada, por lo que el salto entálpico modelado representa adecuadamente el salto real. Se puede concluir 
entonces que si el trabajo calculado en el modelo coincide con el obtenido a partir de los ensayos, el rendimiento calculado para la turbina por el modelo es correcto. Puesto que el trabajo de la turbina y el del compresor se igualan en el funcionamiento estable de un turbogrupo, si el modelo calcula el trabajo del compresor correctamente y a la vez cumple la igualdad de los trabajos de los dos componentes del turbogrupo, se puede afirmar que el trabajo de la turbina calculado por el modelo es correcto. La figura 5. 7 muestra como el trabajo del compresor modelado se ajusta con errores menores al $5 \%$ en valor absoluto al calculado a partir de las medidas en el banco de ensayos según el salto entálpico entre las variables de parada a la entrada y a la salida del mismo. Además se comprueba que los trabajos de turbina y compresor modelados (gráfica de la derecha) coinciden con gran exactitud, por lo que se puede considerar que el turbogrupo modelado funciona en condiciones de equilibrio. Por tanto, dado que las condiciones de entrada y salida de la turbina son las medidas y el trabajo calculado en la turbina coincide con el supuesto real el rendimiento de la turbina calculado para cada punto se considera correcto.

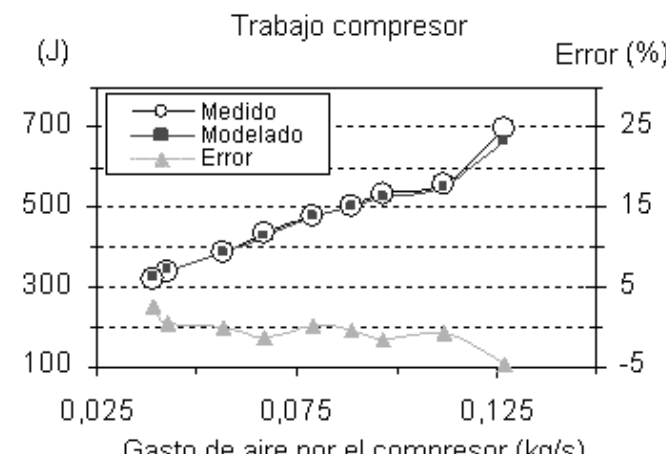

Gasto de aire por el compresor $(\mathrm{kg} / \mathrm{s})$
(J) Trabajo modelado

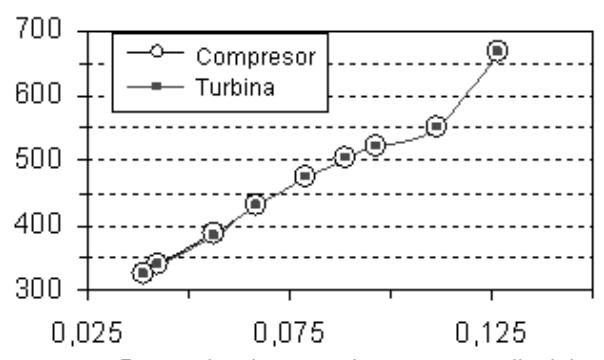

Gasto de aire por el compresor $(\mathrm{kg} / \mathrm{s})$

Figura 5. 7: Comparación de los trabajos del compresor medido y modelado y trabajos modelados de turbina y compresor.

En la figura 5. 8 pude verse la coincidencia de las variables del compresor, temperatura y presión a la salida, relación de compresión y régimen de giro del turbogrupo. Se observa que las variables modeladas coinciden, con errores muy bajos, con las medidas en el banco de turbos. E1 ajuste del gasto por el compresor es correcto, como se ha indicado al comienzo de este apartado. 


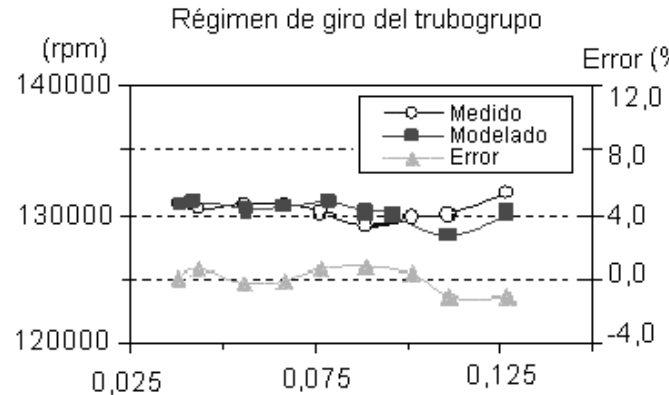

Gasto de aire por el compresor ( $\mathrm{kg} / \mathrm{s})$

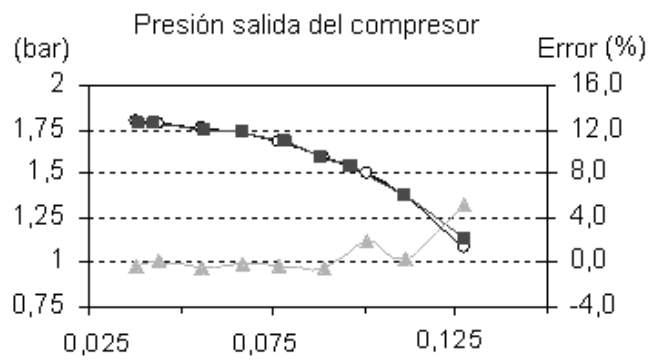

Gasto de aire por el compresor ( $\mathrm{kg} / \mathrm{s}$ )
Temperatura salida del compresor

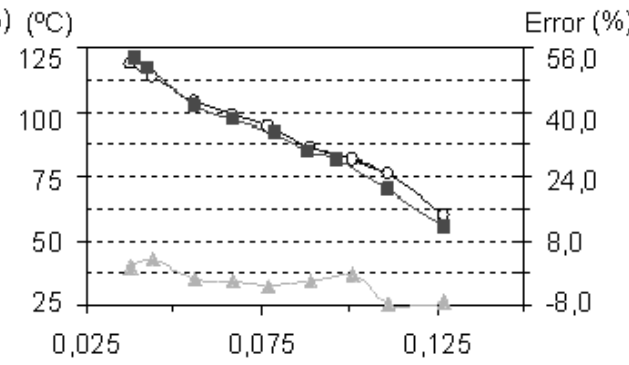

Gasto de aire por el compresor $(\mathrm{kg} / \mathrm{s})$

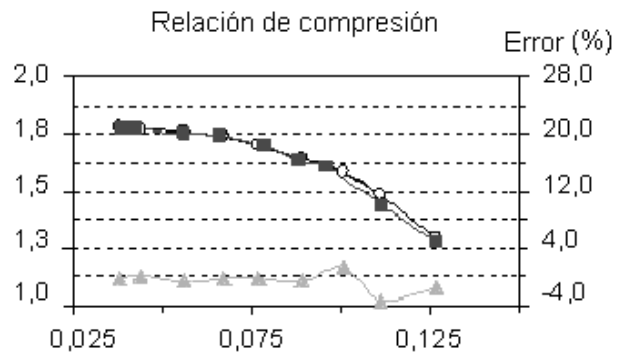

Gasto de aire por el compresor ( $\mathrm{kg} / \mathrm{s})$

Figura 5. 8: Comparación de las variables medias medidas y modeladas en el compresor del turbogrupo.

Finalmente, la figura 5. 9 muestra los rendimientos medios de la turbina y del compresor calculados para cada punto de ensayo, comparados con los valores obtenidos del modelo. Los rendimientos del compresor siguen la evolución esperada según los ensayos y vienen del mapa del compresor, con rendimientos máximos en la zona de gastos intermedios y menores en los extremos, tanto en la zona próxima a bombeo como en la próxima a choque. Los rendimientos de la turbina obtenidos del modelado se ajustan a los valores obtenidos a partir de las medidas, con diferencias máximas entre los valores medidos y modelados de un $6 \%$.
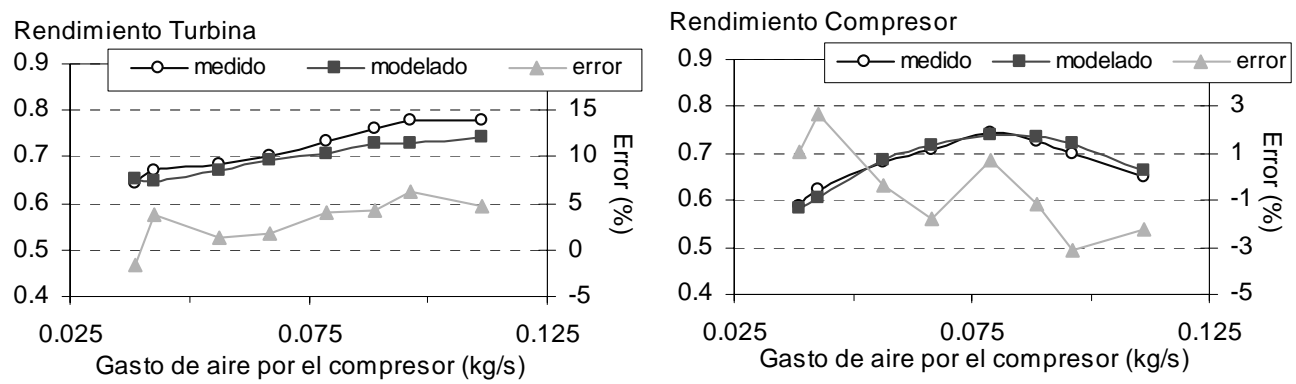

Figura 5. 9: Rendimientos del compresor y de la turbina obtenidos con los valores medidos $y$ modelados. 


\section{- Valores instantáneos}

Las variables instantáneas medidas en el banco de turbos son la presión en el colector de escape, a la entrada y salida de la turbina y a la salida del compresor. De ellas las más interesantes en cuanto a evolución instantánea son la presión del colector de escape y la de entrada a la turbina, pues nos permitirán en un futuro, calcular el rendimiento instantáneo de la turbina, bajo condiciones de flujo no estacionario y comparar con los valores proporcionados por el fabricante, o medidos en la instalación, en condiciones de flujo estacionario. La figura 5. 10 muestra la evolución instantánea medida y modelada de las presiones del colector de escape y de entrada a la turbina a lo largo de un ciclo de motor, para un determinado punto de ensayo, en el que el compresor trasiega $0.067 \mathrm{~kg} / \mathrm{s}$ y mantiene una relación de compresión de 1.74. No se ha representado la evolución instantánea de la presión de salida de la turbina ni las variables del compresor porque su variación alrededor del valor medio es tan pequeña que no resulta interesante.

En la figura se observa la onda de presión del colector de escape con seis picos, que son los tres debidos a los pulsos de escape de los tres cilindros con un valle producido por la interferencia de la onda de reflexión proveniente del depósito. La onda de presión de entrada a la turbina presenta una evolución muy amortiguada debido al efecto del depósito interpuesto entre el escape y la turbina, lo que se refleja en pulsos más bajos y anchos que los de la presión del colector de escape. Aquí se evidencia la efectividad del depósito en amortiguar los pulsos de presión.

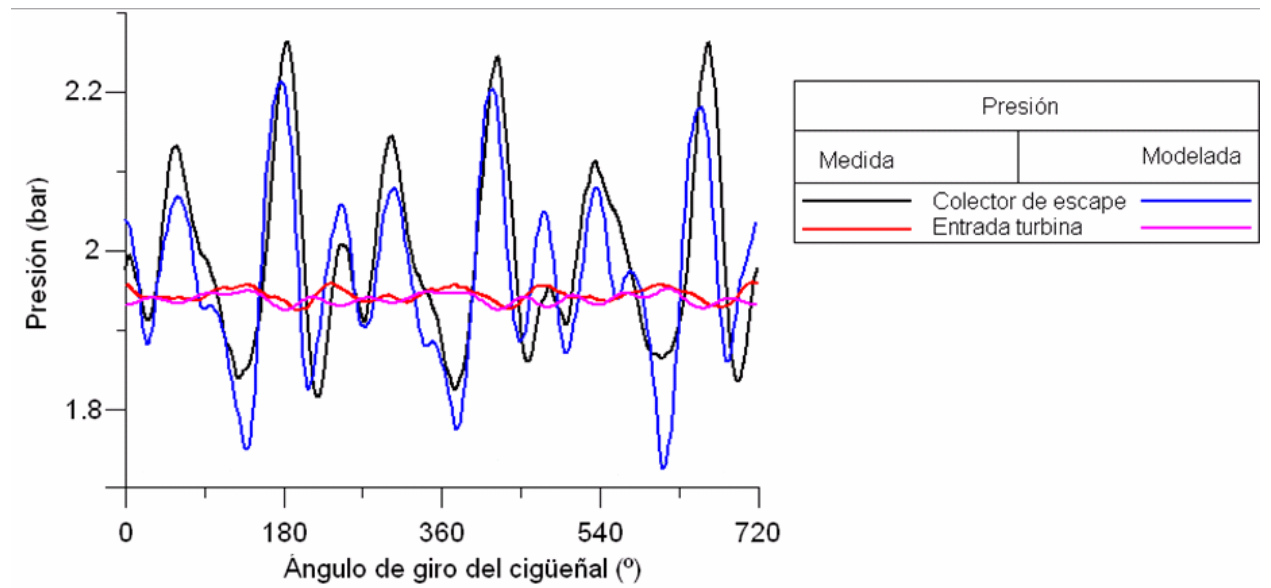

Figura 5. 10: Evolución instantánea medida y modelada de las presiones en el colector de escape a la, entrada a la turbina y a la salida del compresor a lo largo de un ciclo de motor.

Las ondas de presión modeladas reflejan satisfactoriamente este comportamiento. Aunque las evoluciones instantáneas del resto de puntos modelados no se incluyen se ha comprobado el ajuste adecuado de las ondas modeladas a las medidas en todos ellos. 
Puesto que las ondas de presión han sido correctamente modeladas y todos los valores medios están ajustados con una precisión suficiente se puede concluir que las evoluciones instantáneas modeladas del resto de variables, como temperatura en el escape y temperatura de entrada a turbina. Estas evoluciones se muestran en las figura 5. 11.

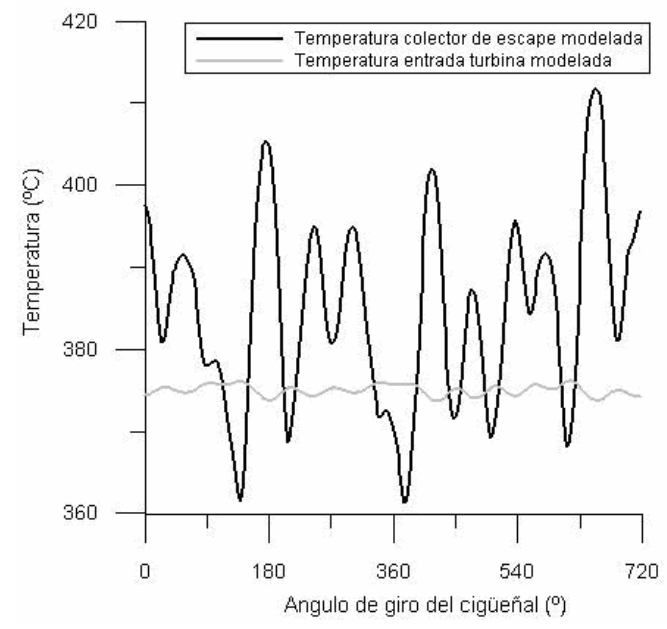

Figura 5. 11: Evolución instantánea modelada de las temperaturas del colector de escape y en la entrada a la turbina a lo largo de un ciclo de motor.

A la vista de estos resultados, es posible concluir que se ha conseguido combinar dos herramientas para obtener la máxima información posible del comportamiento fluidodinámico de la turbina.

Se ha validado la combinación de estas herramientas para condiciones de flujo estacionario a la entrada de la turbina, pero el verdadero potencial de todo esto se va a obtener al realizar y modelar ensayos bajo condiciones de flujo no estacionario, ya que el modelo nos va a proporcionar la información de las variables que no es posible medir.

\subsubsection{Interacción medido-modelado para el modelado bajo condiciones de flujo no estacionario}

La realización de medidas fiables para la caracterización de turbinas, y su correcto modelado, tanto bajo condiciones de flujo estacionario como bajo condiciones de flujo no estacionario, ha sido muy problemáticas durante la última década [36]. Las principales razones son:

- La dificultad de obtener medidas para la caracterización de la turbina en condiciones de flujo estacionario, a lo largo de todo el rango de funcionamiento de la misma. 
- Las turbinas de turbogrupos de sobrealimentación nunca trabajan bajo condiciones de flujo estacionario, incluso en el caso de los llamados sistemas de presión constante, y los efectos del flujo no estacionario en el comportamiento de la turbina deben tenerse en cuenta.

- El cálculo del rendimiento medio a partir de las variables medidas.

- La medida de la temperatura en condiciones de flujo no estacionario.

La posibilidad de contar con dos herramientas tan potentes como las que se han descrito a lo largo del documento permiten estudiar como afecta a una turbina de un grupo de sobrealimentación trabajar acoplada a un motor bajo condiciones de flujo no estacionario.

A lo largo de los capítulos 2 y 3 se han descrito las posibilidades y utilidades que nos ofrece la instalación a la hora de realizar medidas y estudios.

La utilidad del modelado de la instalación radica en la posibilidad de obtener valores de variables dificiles o imposibles de medir, como las temperaturas instantáneas. La temperatura de entrada a la turbina interesa para estimar las pérdidas de calor y el rendimiento de la turbina. Su evolución instantánea presenta importantes oscilaciones respecto al valor medio, especialmente en caso de ensayos con flujo no estacionario, que no pueden ser medidas. Sin embargo, modelando el ensayo con el modelo de acción de ondas se puede estimar esta evolución satisfactoriamente si el ajuste de las variables medidas de las que se dispone es correcto, tanto en valores medios como instantáneos.

Con los puntos modelados en el apartado anterior se ha comprobado que el modelo es capaz de reproducir correctamente los ensayos realizados. Las variables modeladas, medias e instantáneas, se ajustan con precisión a las medidas. En conclusión, el modelo reproduce bien los ensayos del banco de turbos y los resultados obtenidos en él son útiles para el análisis del turbogrupo, especialmente de la turbina, completando la información obtenida en los ensayos en el banco.

El funcionamiento de las turbinas bajo condiciones de flujo no estacionario ha sido estudiado por varios grupos de investigadores desde finales de los ochenta [9][35][36][39]. Está aceptado el hecho de que el rendimiento de la turbina se encuentra adversamente afectado cuando ésta se encuentra trabajando bajo condiciones de flujo no estacionario, como es el caso de las turbinas de los grupos de sobrealimentación de motores. 
Contribución a la caracterización experimental y modelado de TGV en grupos de sobrealimentación

El objetivo del estudio que se muestra a continuación es evidenciar el potencial de las herramientas desarrolladas para entender con más profundidad los efectos que tienen lugar en el interior de las turbinas, cuando estas trabajan en condiciones fuera de las de diseño. Para ello se utilizó un turbogrupo con una TGV de álabes móviles, cuyas características se muestran en la tabla 5. 2

\begin{tabular}{|c|c|c|c|}
\hline \multicolumn{1}{|c|}{} & Compresor & Turbina \\
\hline \multirow{2}{*}{ Diámetros $(\mathrm{mm})$} & Entrada & 41 & 30 \\
\cline { 2 - 4 } & Salida & 35 & 38 \\
\hline Número álabes rodete & 6 & 11 \\
\hline Número de álabes estator & - & 11 \\
\hline
\end{tabular}

Tabla 5. 2: Características del turbogrupo utilizado para validar el modelado de la instalación.

La caracterización de la turbina bajo condiciones de flujo estacionario dio lugar al mapa de la turbina que se muestra en la figura 5. 12. Los valores del rendimiento de la misma, en función de la apertura se muestran en la figura 5. 13. Para la caracterización de esta turbina se ensayaron distintas posiciones de la turbina y diferentes regímenes de giro para cada apertura. Las medidas realizadas en la instalación fueron tratadas como se ha explicado a lo largo del capítulo 3.

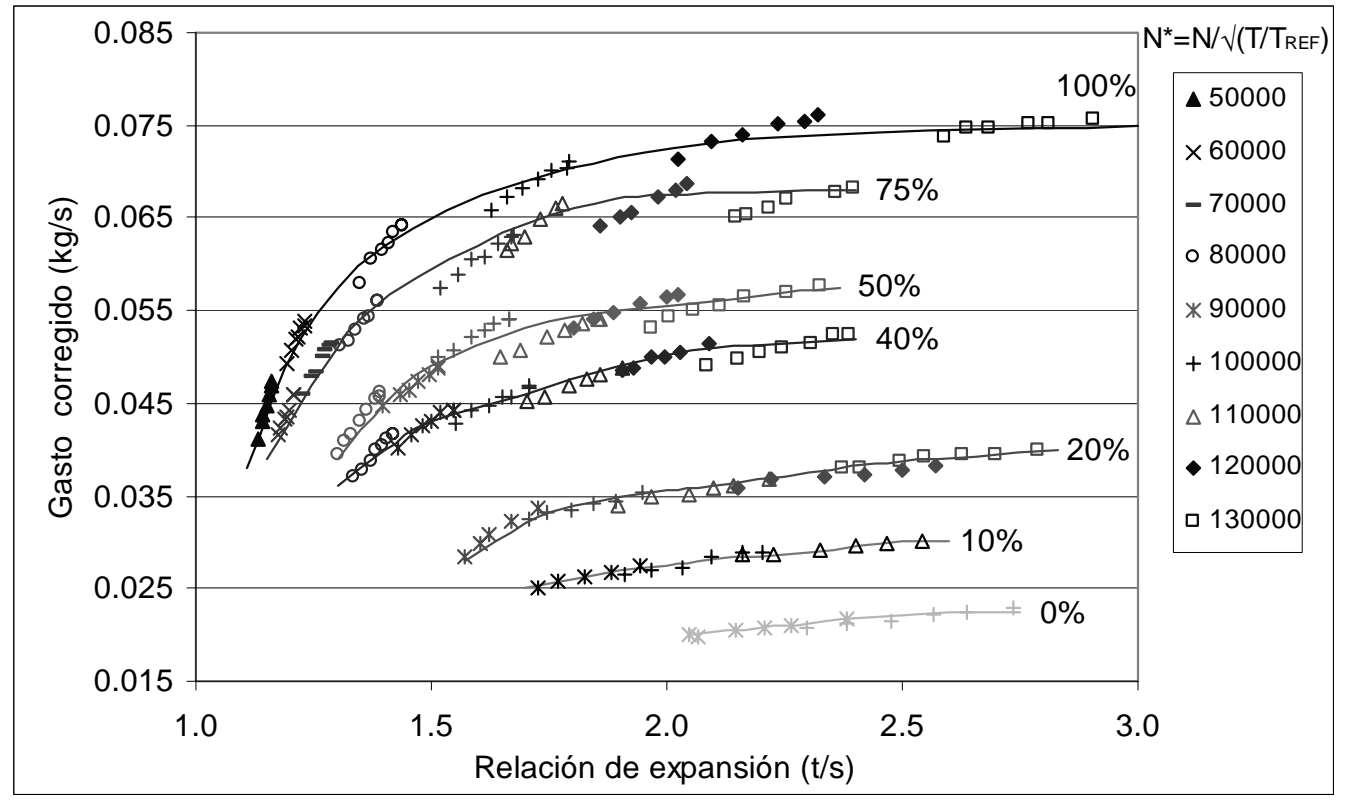

Figura 5. 12: Caracterización de la turbina GT1544 V bajo condiciones de flujo estacionario. 

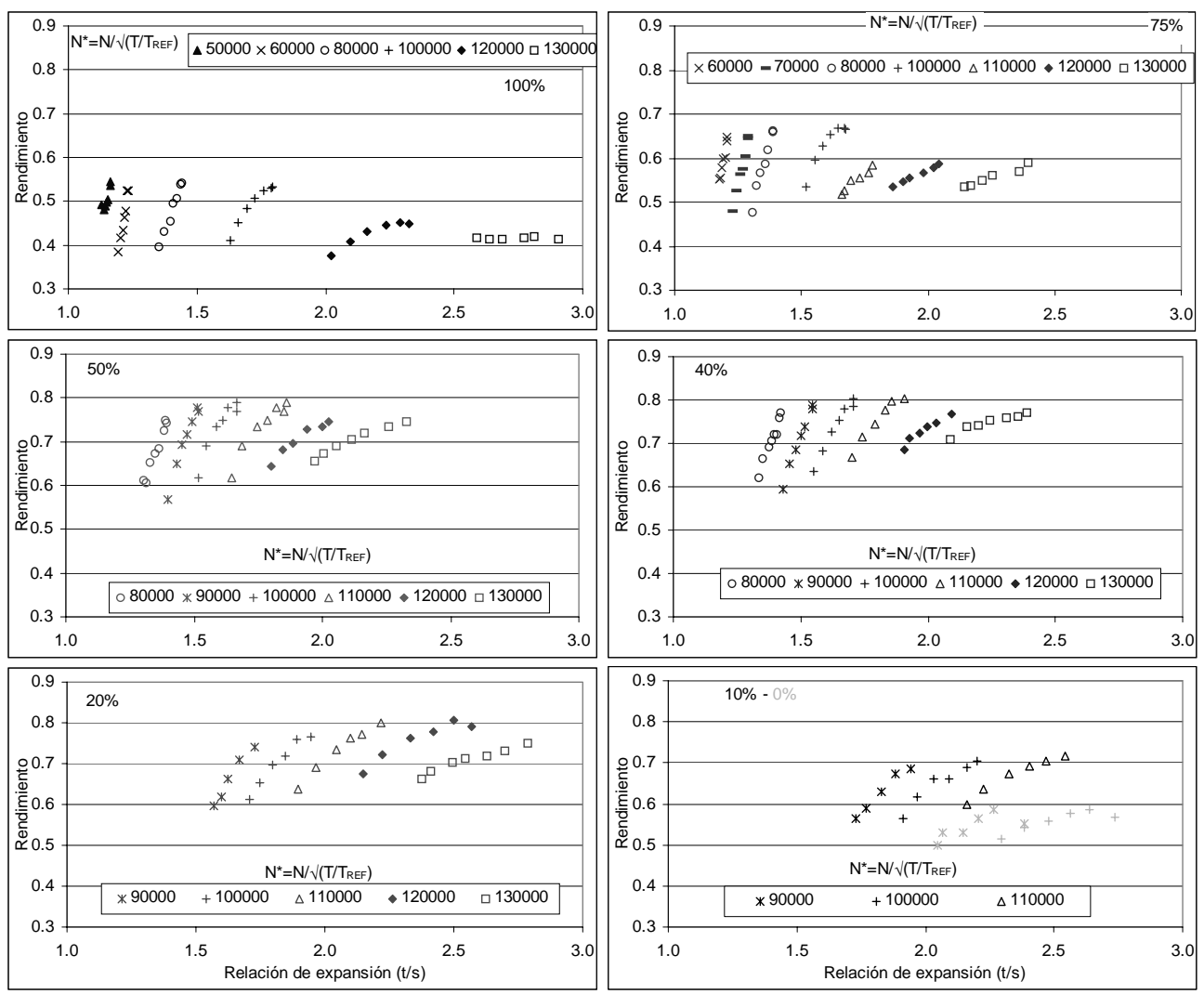

Figura 5. 13: Rendimiento de la turbina, en función de la relación de expansión, para las diferentes posiciones de la turbina ensayadas.

La realización de las medidas bajo condiciones de flujo estacionario se realizó tanto para comparar el comportamiento de la TGV bajo condiciones de flujo estacionario y bajo condiciones de flujo no estacionario, como para calcular las áreas efectivas de las toberas equivalentes al estator y al rotor del modelo de TGV presentado en el capítulo 4.

Una vez realizada la caracterización de la turbina descrita en la tabla 5. 2, bajo condiciones de flujo estacionario a la entrada de la misma (figura 5 . 12 y figura 5. 13), se realizaron medidas bajo condiciones de flujo no estacionario, para tres aperturas, distintos regimenes de giro y varios niveles de pulsación. Para la realización de estas medidas bajo condiciones de flujo no estacionario se mantuvo las variables operativas del banco de turbos en idéntica posición que para realizar la caracterización del turbogrupo bajo condiciones de flujo estacionario, excepto que el depósito que se utilizó para amortiguar los pulsos a la entrada de la turbina fue quitado y la turbina fue acoplada a 6 los cilindros del motor en uno de los casos y a solo 3 cilindros en los otros casos. El factor de pulsación se calcula según la expresión (3. 3). 
Contribución a la caracterización experimental y modelado de TGV en grupos de sobrealimentación

Tratando las medidas realizadas bajo condiciones de flujo no estacionario como se han tratado las medidas bajo flujo estacionario y asumiendo que el valor medio de las variables es el valor medido por los captadores, es posible representar los puntos medidos junto con el mapa de la turbina, como se muestra en la figura 5. 14.

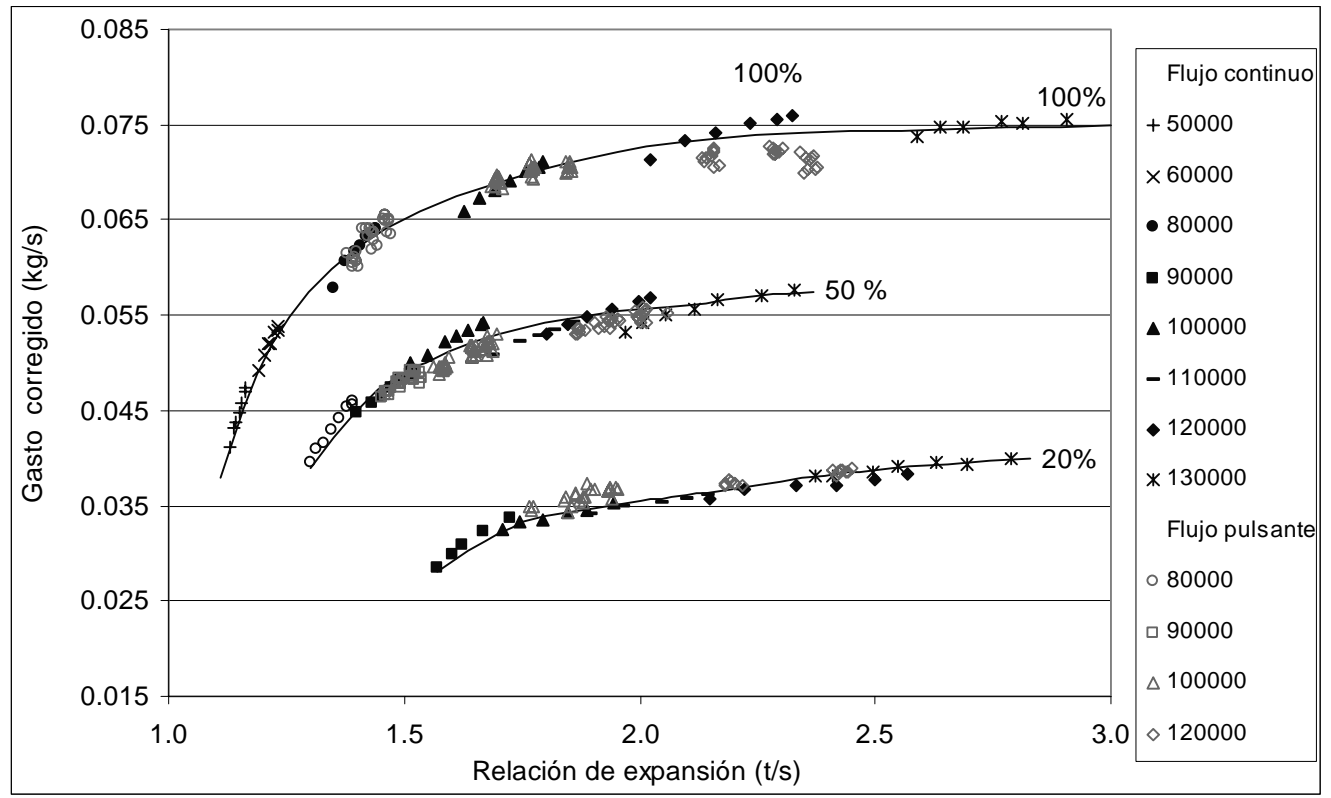

Figura 5. 14: Mapa de la turbina con los puntos medidos bajo condiciones de flujo no estacionario.

Del análisis de los valores rendimientos con flujo no estacionario no es posible obtener conclusiones válidas, puesto que la medida de las temperaturas del gas a la entrada y a la salida de la turbina se está realizando con termopares cuyo tiempo de respuesta es muy bajo y cuya capacidad de integración discutible, por lo que se decidió modelar algunos de los puntos medidos bajo condiciones de flujo no estacionario. En concreto se eligieron los 4 puntos de la tabla 5. 3 .

\begin{tabular}{|c|c|c|c|c|}
\hline \multicolumn{1}{|c|}{} & $\begin{array}{c}\text { Apertura de } \\
\text { Punto }\end{array}$ & $\begin{array}{c}\text { Régimen de } \\
\text { giro corregido } \\
\text { la Te la }\end{array}$ & $\begin{array}{c}\text { Relación de } \\
\text { expansión } \\
\text { TGV(rpm) }\end{array}$ & $\begin{array}{c}\text { Factor de } \\
\text { pulsación } \\
*\left(10^{3}\right)\end{array}$ \\
\hline 1 & 100 & 80000 & 1.40 & 48.74 \\
\hline 2 & 20 & 100000 & 1.86 & 44.83 \\
\hline 3 & 50 & 90000 & 1.47 & 29.46 \\
\hline 4 & 100 & 80000 & 1.45 & 4.25 \\
\hline
\end{tabular}

Tabla 5. 3: Puntos seleccionados para ser modelados. 
El resultado del modelado de los valores medios es el que se muestran en la figura 5. 15, en la figura 5. 16 y en la figura 5. 17.
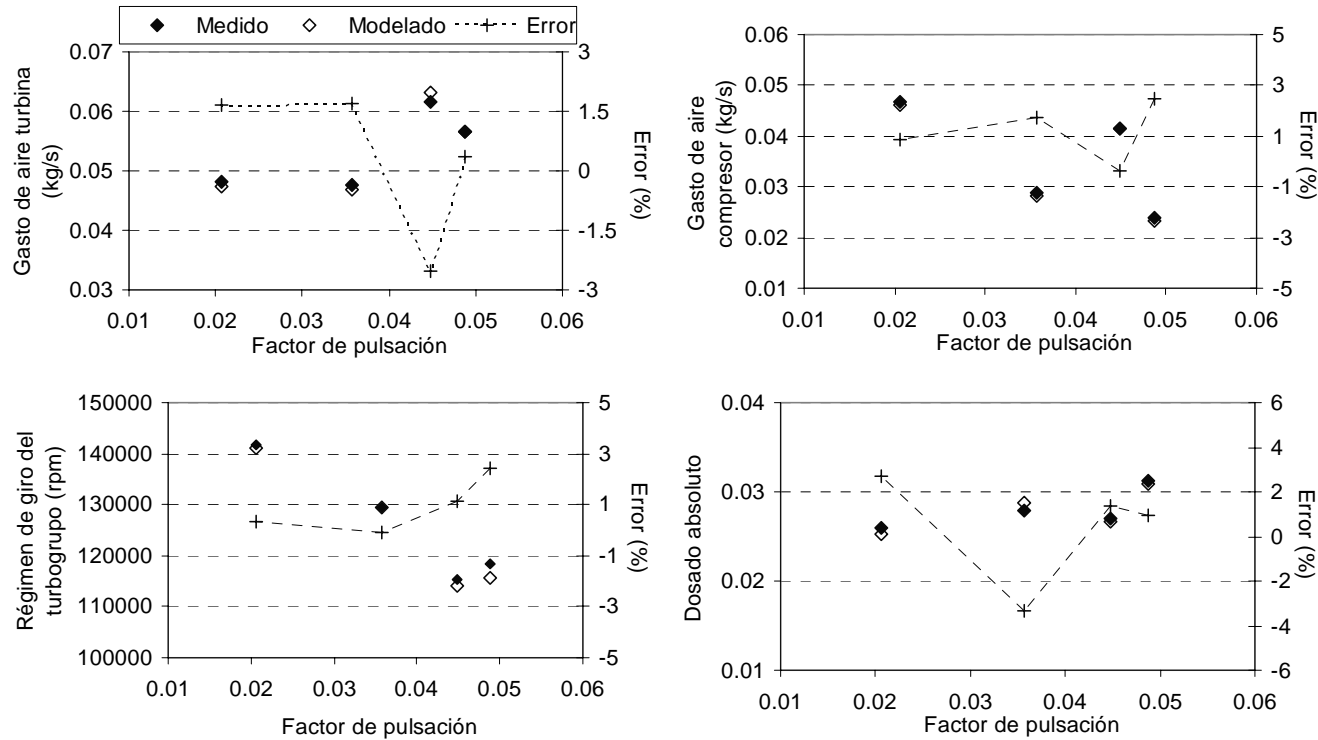

Figura 5. 15: Comparación medido-modelado del gasto de aire trasegado por la turbina, el gasto de aire trasegado por el compresor, el régimen de giro del turbogrupo y el dosado absoluto de los cuatro puntos de la tabla 5. 3.
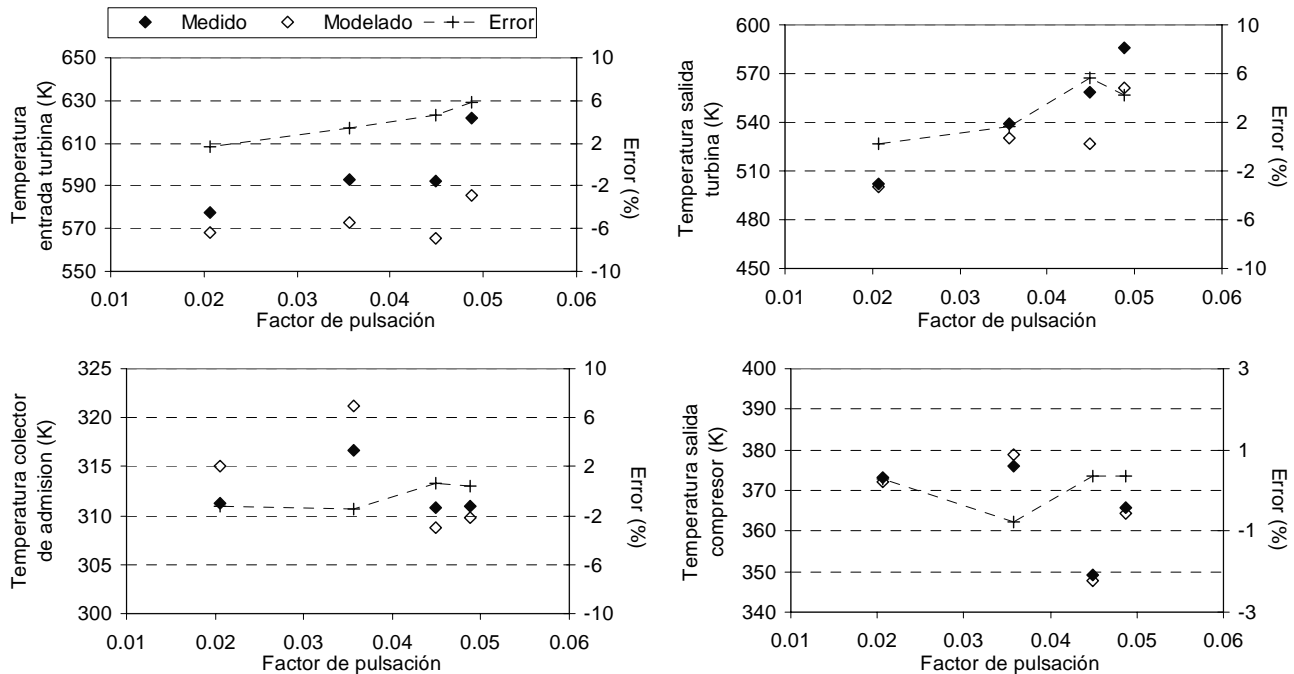

Figura 5. 16: Comparación medido-modelado de la temperatura del gas a la entrada y a la salida de la turbina y la temperatura del aire en el colector de admisión y a la salida del compresor de los cuatro puntos de la tabla 5. 3. 

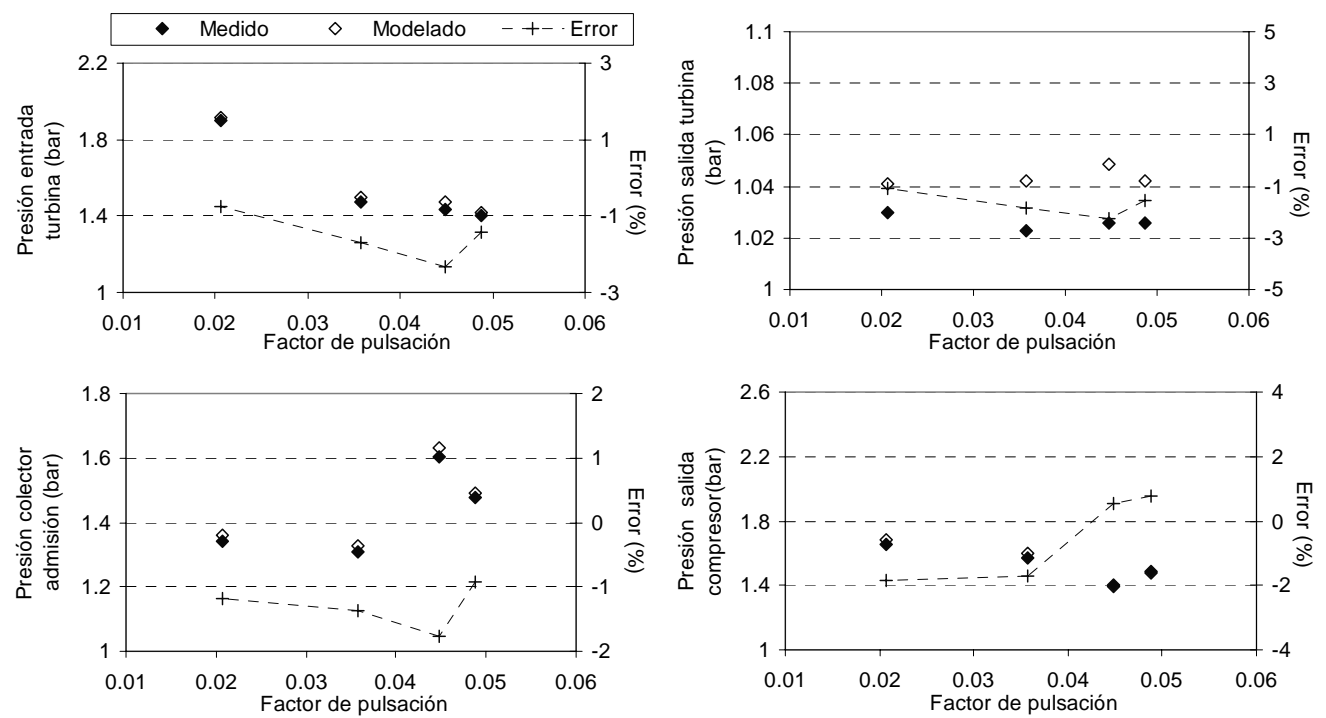

Figura 5. 17: Comparación medido-modelado de la presión del gas a la entrada y a la salida de la turbina y la presión del aire en el colector de admisión y a la salida del compresor de los cuatro puntos de la tabla 5. 3.

Como se observa existe un grado de acuerdo muy elevado entre las variables medidas y modeladas, excepto en el caso de las temperaturas, donde los errores son algo más elevados.

Las principales variables para la turbina calculadas con los valores medidos y con los modelados son las que se muestran en la figura 5. 18 

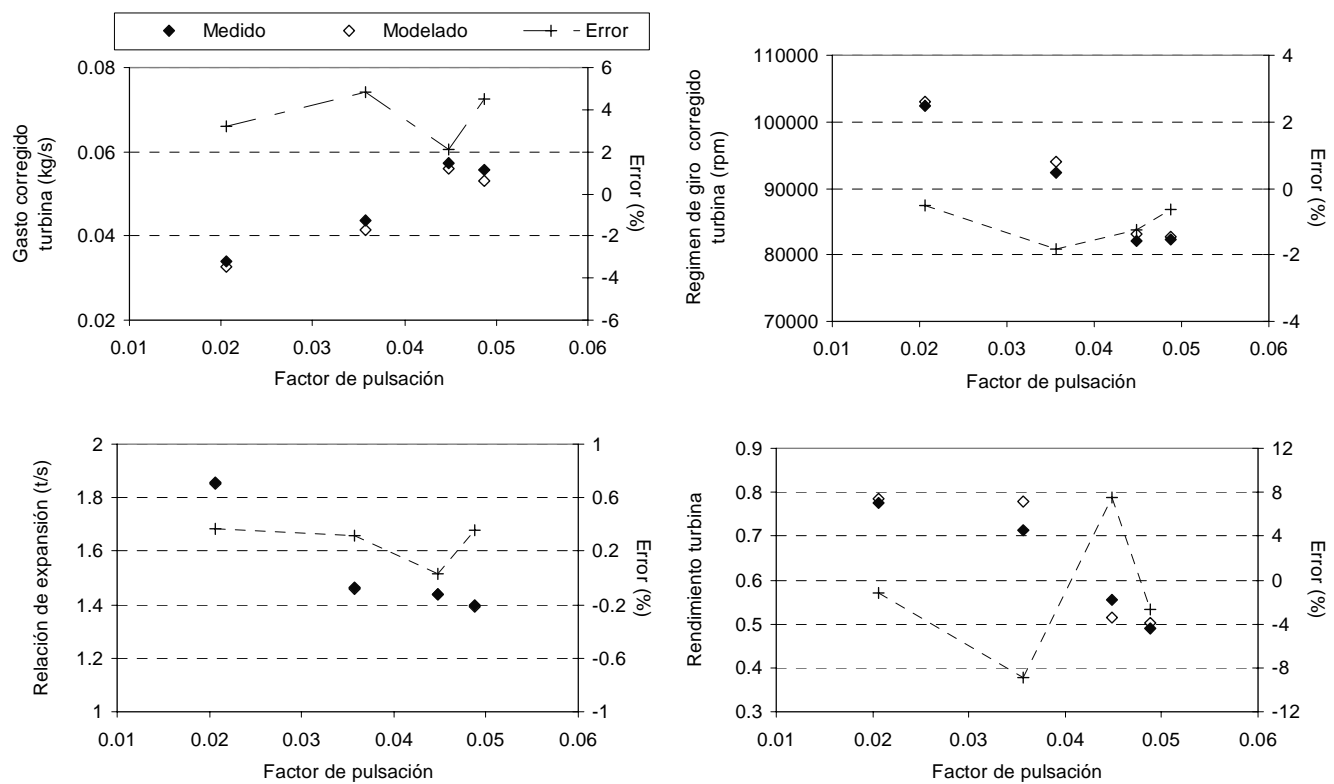

Figura 5. 18: Comparación medido-modelado de las variables básicas de la turbina, calculadas con los valores medidos y con los valores modelados de los siete puntos de la tabla 5. 3.

Una vez analizadas las variables medias, se analizaron también las presiones instantáneas a la entrada de la turbina. Los resultados obtenidos se muestran a continuación. 


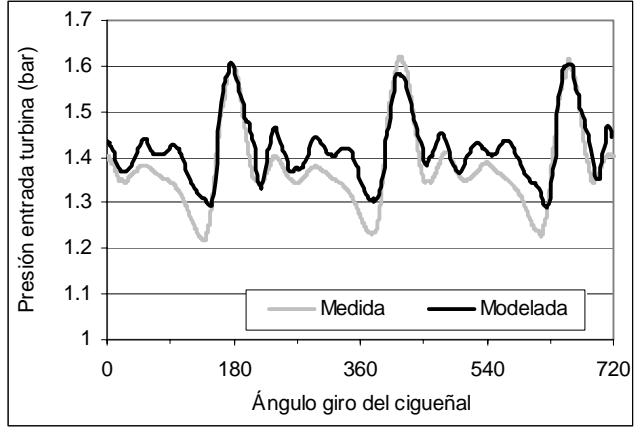

Punto 1: $100 \% 80000$ rpm, 900rpm

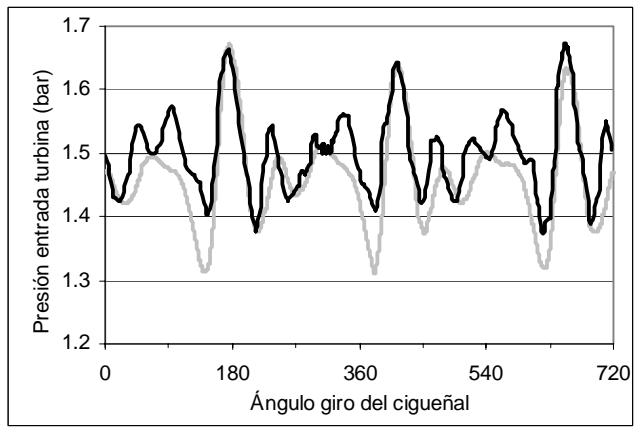

Punto 3: $50 \% 90000 \mathrm{rpm}, 900 \mathrm{rpm}$

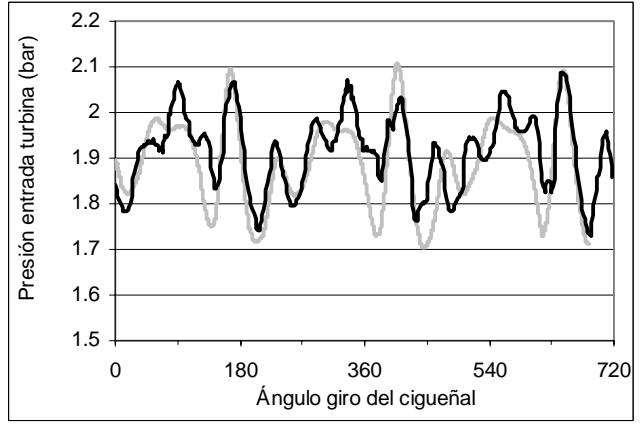

Punto 2: 20\% 100000 rpm,1150rpm

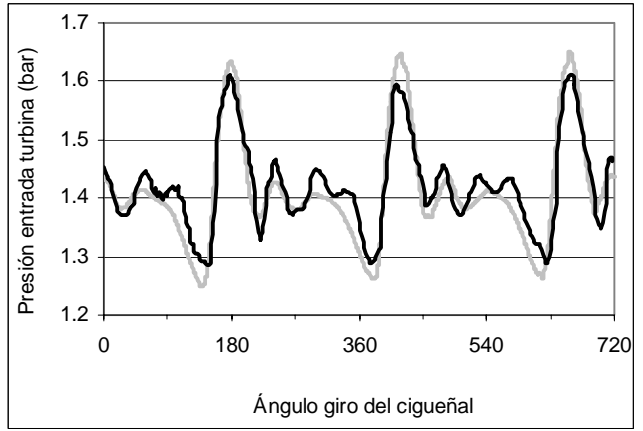

Punto 4: 100\% 80000 rpm,1100rpm

Figura 5. 19: Comparación medido-modelado de la presión a la entrada de la turbina.

Así pues, si asumimos las variables modeladas como correctas es posible obtener en todos los casos el rendimiento instantáneo de la turbina bajo condiciones de flujo no estacionario (figura 5. 20 y figura 5. 22).

En la figura 5. 22 se ha representado el rendimiento instantáneo obtenido en el modelado en función de la relación cinemática, así como los valores del rendimiento obtenidos a partir de los valores medidos, tanto bajo condiciones de flujo estacionario como bajo condiciones de flujo no estacionario. Se observa en todos los casos que el rendimiento medio medido bajo condiciones de flujo estacionario es mayor que los rendimientos obtenidos bajo condiciones de flujo no estacionario. 


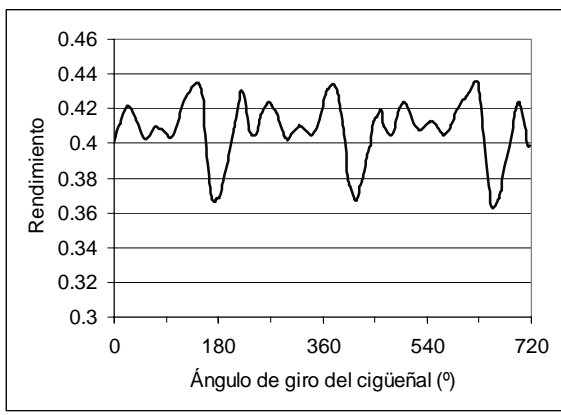

Punto 1: $100 \% 80000 \mathrm{rpm}$

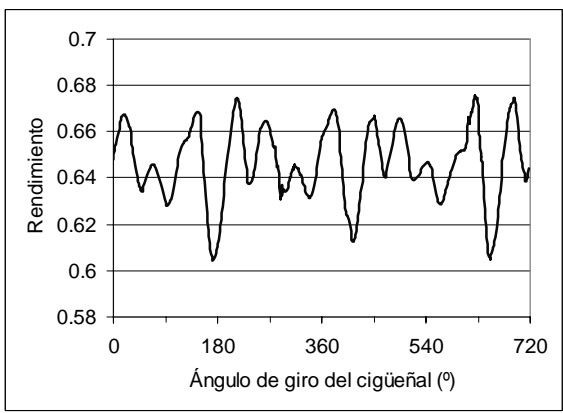

Punto 3: $50 \% 90000 \mathrm{rpm}$

Figura 5. 20: Rendimientos

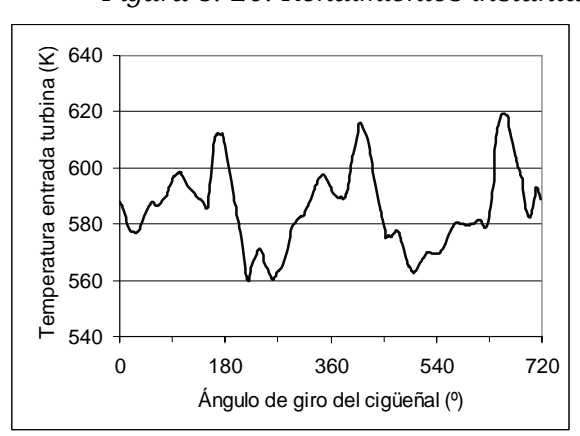

Punto 1: $100 \% 80000 \mathrm{rpm}$

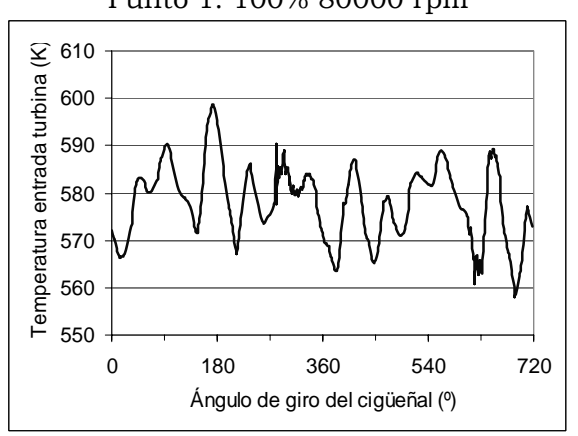

Punto 3: $50 \% 90000 \mathrm{rpm}$

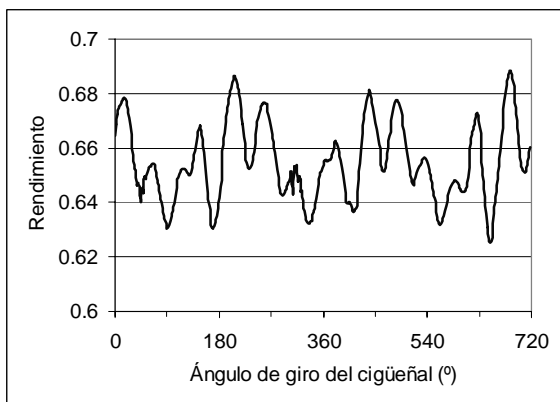

Punto 2: 20\% $100000 \mathrm{rpm}$

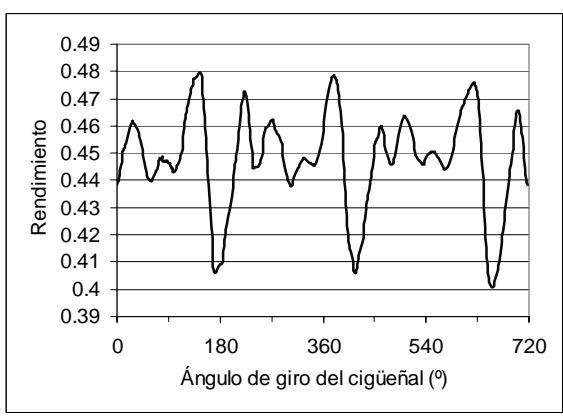

Punto 4: $100 \% 80000 \mathrm{rpm}$
Figura 5. 21: Temperaturas instantáneas del gas a la entrada de la turbina obtenidos para los puntos modelados

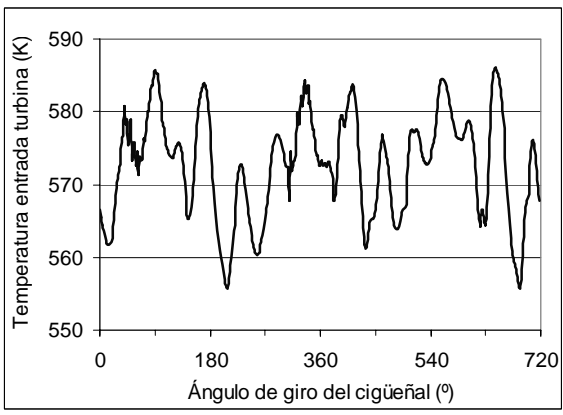

Punto 2: 20\% $100000 \mathrm{rpm}$

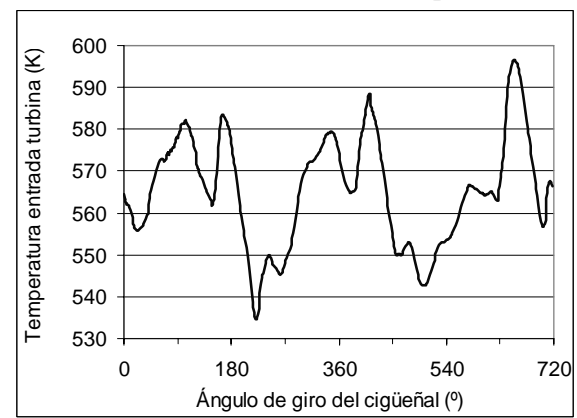

Punto 4: $100 \% 80000$ rpm 


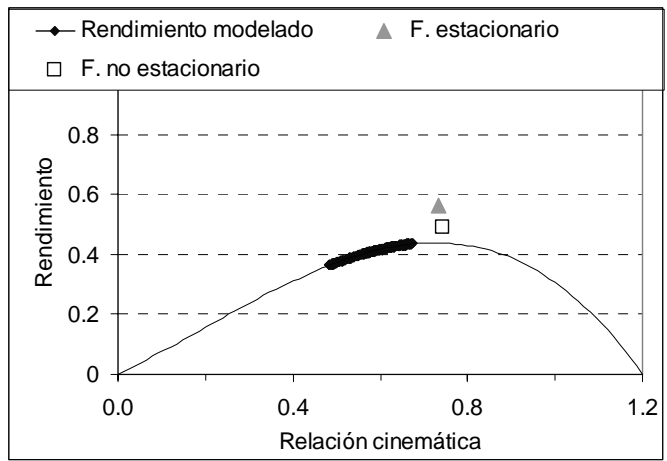

Punto 1: $100 \% 80000 \mathrm{rpm}$

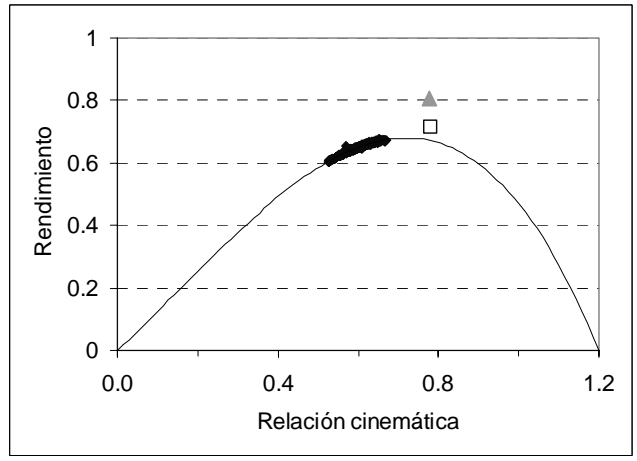

Punto 3: $50 \% 90000 \mathrm{rpm}$

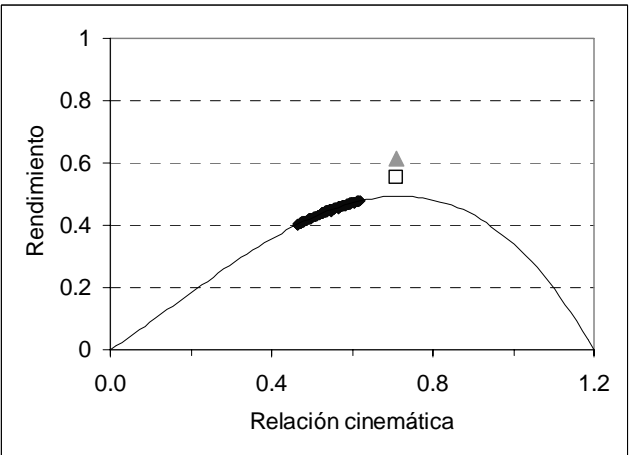

Punto 2: 20\% $100000 \mathrm{rpm}$

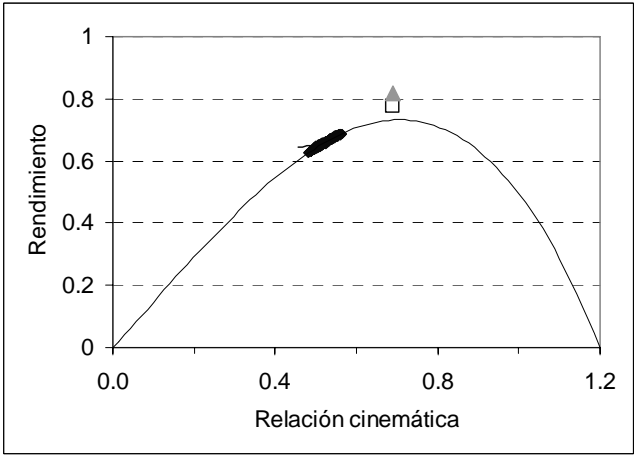

Punto 4: $100 \% 80000 \mathrm{rpm}$

Figura 5. 22: Rendimientos obtenidos de las medidas bajo condiciones de flujo estacionario, de flujo no estacionario y rendimientos instantáneos obtenidos para los puntos modelados en función de la relación cinemática..

En conclusión, se demuestra como combinando una instalación experimental y un modelo unidimensional de turbinas de geometría variable es posible profundizar en el estudio de las interacciones del flujo pulsante con el rendimiento de las TGV bajo diferentes condiciones de funcionamiento. Esta tarea se deja planteada como un trabajo futuro de la presente tesis. 


\subsection{Validación del modelo con ensayos en banco motor}

A continuación se presenta la caracterización de dos TGV diferentes, una de álabes fijos, perteneciente a un grupo de sobrealimentación de un motor de encendido por compresión de 2.0 litros de cilindrada y otra de álabes móviles, perteneciente a un grupo de sobrealimentación de un motor de encendido por compresión de 11.12 litros de cilindrada.

\subsubsection{Validación del modelo para TGV de álabes fijos}

Con el fin de pode validar el modelo se utilizaron los datos obtenidos de ensayar un turbogrupo de la marca Garret, formado por una turbina de geometría variable (VNT GT $15 \mathrm{XXP}$ ) y un compresor (A/R=0.42). El turbogrupo se acopló a un motor diesel de automoción de 2.01 de cilindrada, con intercooler y de inyección directa.

Como puede observarse en la figura 5. 23, la turbina de geometría variable que se va a utilizar para el presente trabajo está compuesta por un vástago móvil al que se le unen los álabes del estator y una bomba de vacío que controla la posición del vástago. El funcionamiento de la turbina viene determinado por una presión de referencia que define las condiciones de funcionamiento ideales para un par dado de régimen de giro y gasto de combustible. Detalles de este mecanismo pueden verse también en la figura 4. 7 .

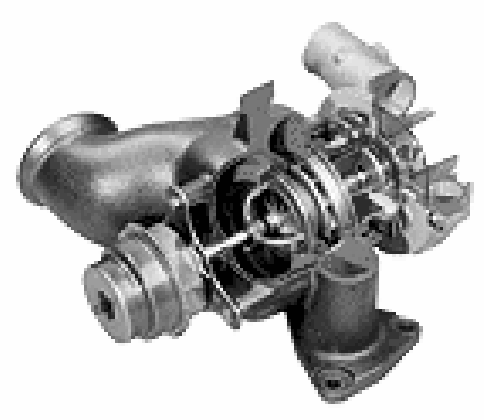

a

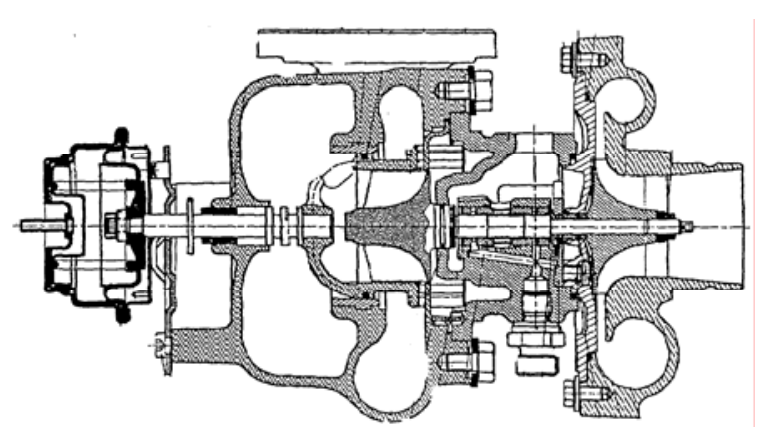

b

Figura 5. 23: a) Turbogrupo utilizado para realizar las medidas y validar el modelo. La turbina es de geometría variable y álabes fijos. b) Esquema del turbogrupo. 


\subsubsection{Caracterización de la TGV}

Antes de describir los ensayos realizados se va a realizar una revisión del funcionamiento de la TGV ensayada y del modelo dinámico que se implementó en el modelo de acción de ondas.

El modelado global del comportamiento de la TGV se puede dividir en cuatro submodelos diferentes, tal y como se muestra en la figura 5. 24. E1 último de estos submodelos es el que calcula el valor de las áreas efectivas de las toberas equivalentes al estator y al rotor, que se ha desarrollado en el capitulo anterior. Los otros tres modelos, desarrollados por Rodríguez [30] se explican brevemente a continuación.

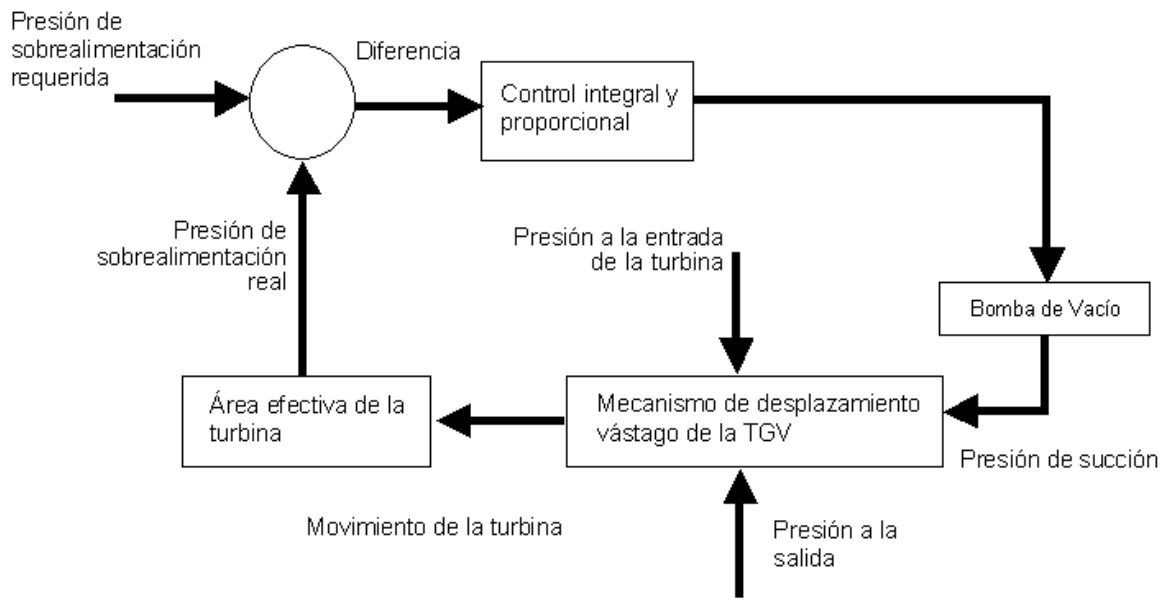

Figura 5. 24: Esquema del modelado de la turbina de geometría variable.

El primer submodelo corresponde a un regulador proporcional integral programado en la Unidad de Control Electrónico (ECU), que en función de la diferencia entre la presión de sobrealimentación requerida (que depende del régimen de giro del motor y de la cantidad de combustible) y la presión de sobrealimentación medida a la entrada del colector de admisión emite una señal que es la que controla la bomba de vacío. El segundo submodelo relaciona la señal obtenida y la presión de succión en la válvula provocada por la bomba de vacío mediante una función de transferencia.

La presión de succión, junto con la presión a la entrada de la turbina, la presión a la salida de la turbina, las fuerzas de rozamiento y los parámetros estáticos del muelle (constante del muelle y valor de la precarga) forman un sistema de fuerzas que determinan el desplazamiento del vástago de la TGV y la posición final del estator de la TGV. Este sistema de fuerzas constituye el tercer submodelo. 
Este modelado permite determinar la posición del estator y en consecuencia establecer la base para el submodelo desarrollado en el capítulo, con el que se determinan las propiedades fluidodinámicas de la turbina en función de la geometría de la misma, el desplazamiento del vástago y las condiciones termodinámicas del gas a la salida del rotor.

Una descripción más amplia de estos ensayos de caracterización y de los submodelos desarrollados para el modelado de la dinámica de la TGV puede encontrarse en la tesis doctoral de Rodríguez [30].

\subsubsection{Ensayos realizados}

Los ensayos se realizaron en una sala de ensayo de motores. La turbina de geometría variable trabajaba acoplada a un motor de encendido por compresión.

En la figura 5. 25 se observan los principales componentes de la instalación del banco de ensayos donde se realizaron las medidas, que se muestran en el Anexo I. Destacan los elementos característicos de la misma como el sistema de refrigeración del agua, aceite y combustible del motor, el sistema de control del freno y el sistema de adquisición de datos.

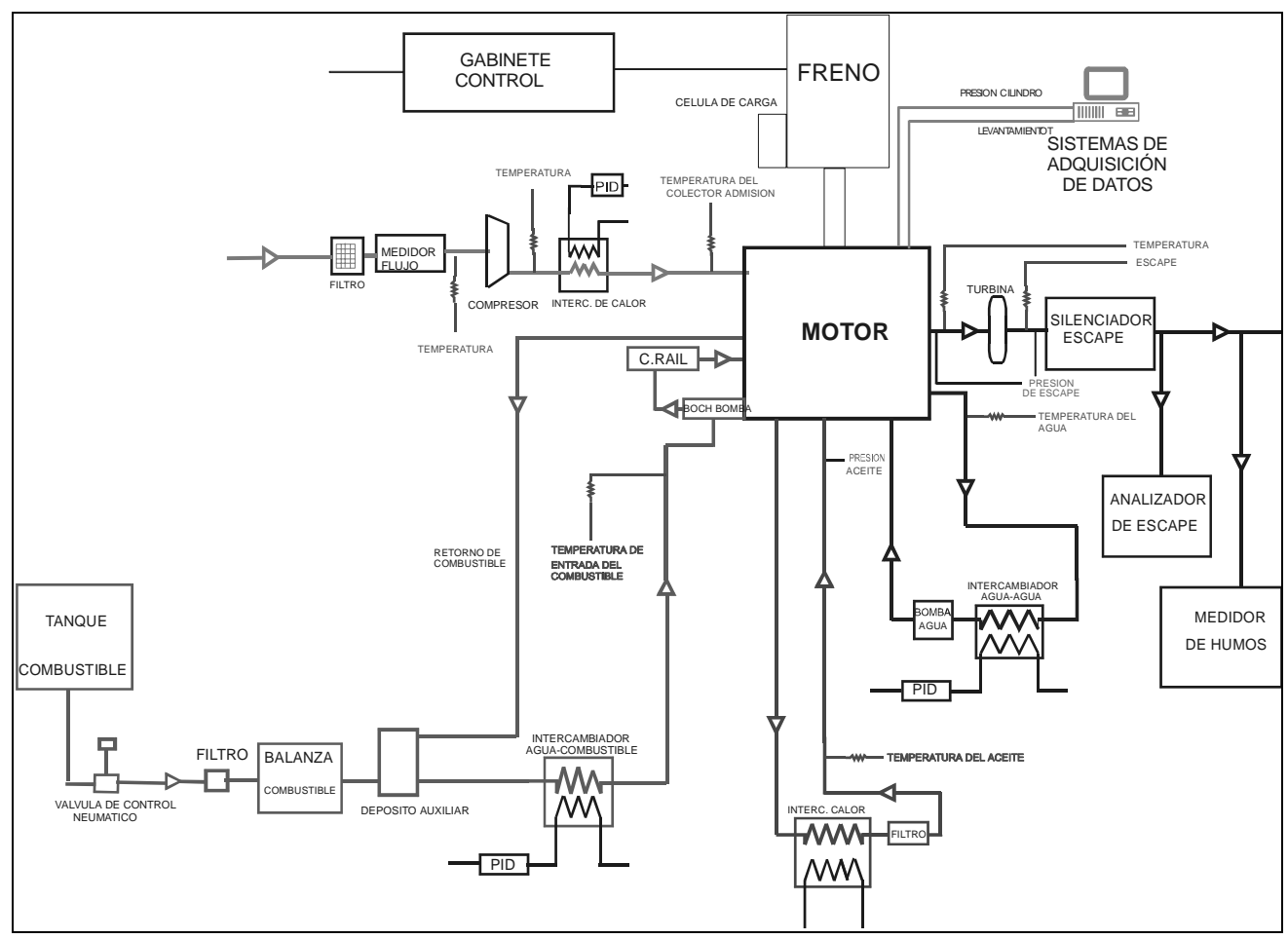

Figura 5. 25: Esquema del banco de ensayo. 
Otros de los elementos característicos del banco de ensayos, son el sistema de medida de aire y combustible, los elementos del sistema de escape, como son, el analizador de gases de escape y medidores de presión, con su correspondiente instrumentación para refrigerarlos y evitar la deriva térmica. Con respecto al sistema de control, destaca el control del freno con el cual se regula el régimen de giro del motor, lo que a su vez permite realizar transitorios de carga a régimen constante. Además de regular los PID que controlan la temperatura del agua, aceite y combustible de entrada al motor.

Por último el sistema de adquisición de datos es el encargado de almacenar la información suministrada por la instrumentación utilizada, entre las que se encuentran variables como temperatura y presión en diferentes puntos de interés.

Las principales características del motor son las que se muestran en la siguiente tabla:

\begin{tabular}{|c|c|}
\hline Tipo de inyección & Directa \\
Número de cilindros & 4 \\
Cilindrada total & $2.18 \mathrm{l}$ \\
Relación de compresión & $18: 1$ \\
Potencia máxima & $90 \mathrm{~kW}(4000 \mathrm{rpm})$ \\
Par máximo & $316 \mathrm{Nm}(2250 \mathrm{rpm})$ \\
Régimen de giro máximo & $4500 \mathrm{rpm}$ \\
Diámetro del cilindro & $85 \mathrm{~mm}$ \\
Carrera & $96 \mathrm{~mm}$ \\
Longitud de la biela & $152 \mathrm{~mm}$ \\
Volumen de la cámara de combustión & $26.7 \mathrm{~cm}$ \\
\hline
\end{tabular}

Tabla 5. 4: Características del motor.

Se realizaron dos tipos de ensayos por separado con características diferentes, aunque todos ellos se realizaron en la misma instalación y en todos ellos se realizaron las mismas medidas.

Al primero de los ensayos se le denominará ensayo patrón, en él se midieron las condiciones de funcionamiento de la turbina para determinados 
puntos de funcionamiento del motor, entre 1000 y $4000 \mathrm{rpm}$, para diferentes puntos de carga. Se midió la apertura de la turbina cuando el conjunto estaba estabilizado (sin forzarla a que fuera una apertura determinada) y el resto de los parámetros mencionados anterior mente.

El segundo de los ensayos fue el que se denominará ensayo a apertura constante. En este ensayo se fijó el desplazamiento del vástago que regula la posición del estator de la turbina, tomando los valores de $0,1,2,3,4,6$ y 10 $\mathrm{mm}$, y el régimen de giro del turbogrupo. Se midió cuando el resto de los parámetros estaban estabilizados.

En cada uno de los ensayos se midieron los parámetros más significativos en un banco de ensayo de motores, especialmente los relacionados con las condiciones de funcionamiento de la turbina, como son la presión y temperatura a la entrada y salida de la turbina, el gasto que pasa a través de la turbina y el desplazamiento del vástago, que está relacionado con la posición del estator de la misma.

\subsubsection{Resultados obtenidos en los ensayos}

A partir de la ecuación (4. 22) y utilizando los valores medidos en los ensayos a apertura de la TGV constante es posible calcular el grado de reacción para cada uno de los puntos de funcionamiento en los que se han tomado medidas.

A partir de los resultados obtenidos se observa que el grado de reacción varia entre 0.1 y 0.25 cuando la TGV está abierta (Desp TGV $=10$ ), lo que significa que el salto entálpico que se produce en el rotor es muy pequeño y la TGV es casi de acción. Al disminuir el incremento de velocidad relativa en el rotor, no hay reacción y eso justificaria su mal rendimiento. Los resultados son coherentes con las hipótesis del apartado 4.1 (figura 4. 10)

Para la TGV abierta se observa que a medida que aumenta el caudal trasegado disminuye el grado de reacción, es decir para un área efectiva de la tobera equivalente al estator constante si la cantidad de gases trasegados aumenta entonces aumenta la relación de expansión en el estator y aumenta el salto entálpico que se produce en el estator, lo que hace que el porcentaje del salto entálpico total sea mayor, por lo que el salto entálpico en el rotor disminuye y por lo tanto disminuye el grado de reacción.

Por otro lado, cuando la TGV está cerrada (Desp TGV0=0) el grado de reacción aumenta y el incremento del entalpía en el rotor aumenta. Además, como el gasto trasegado por la TGV es casi constante para las distintas relaciones de expansión (figura 3. 17 y figura 5. 12), en el caso de mínimas aperturas de la TGV, el grado de reacción se mantiene también prácticamente constante. 

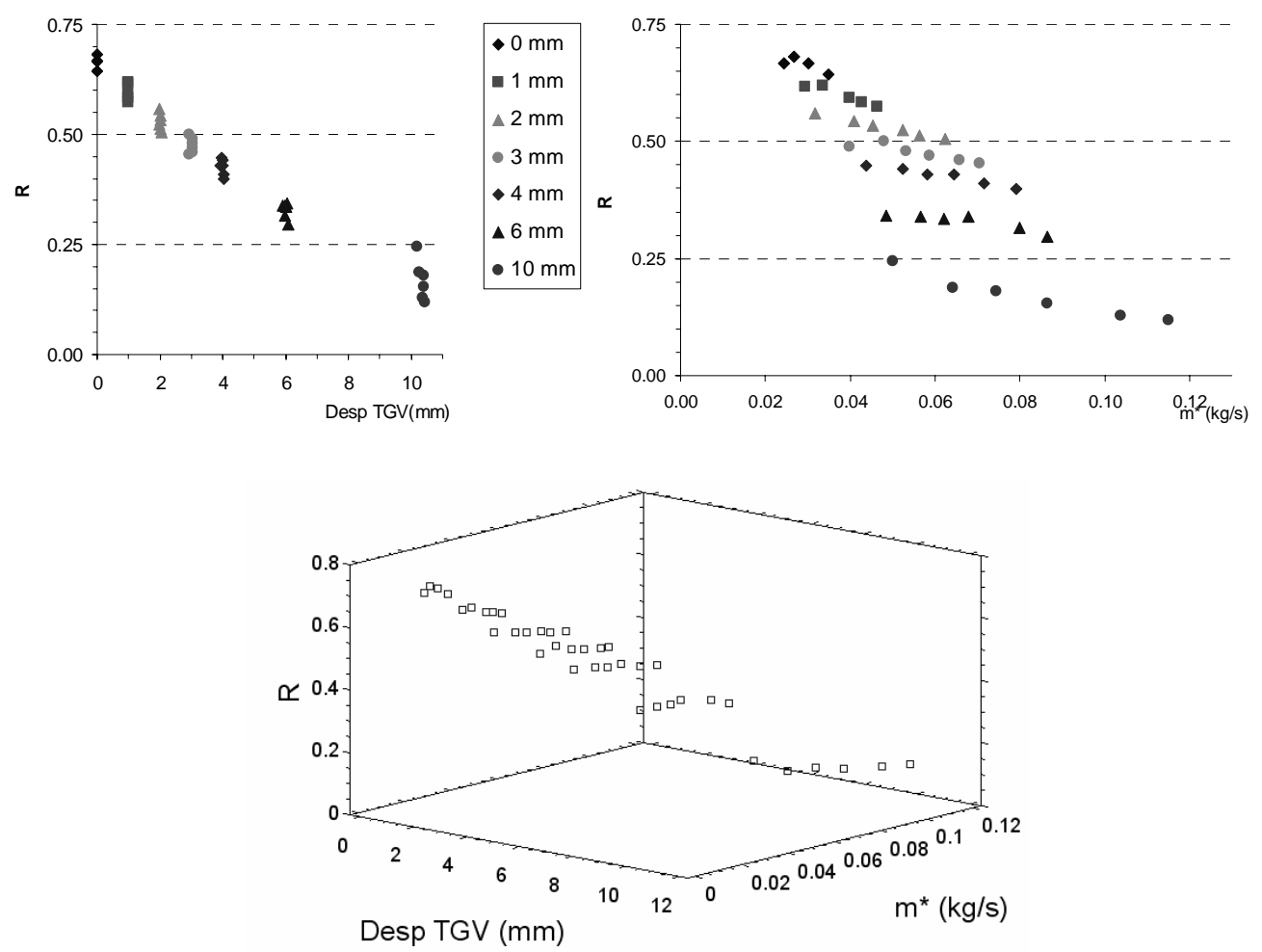

Figura 5. 26: Variación del grado de reacción con el desplazamiento del eje la turbina y con el gasto másico que pasa a través de ella. Gráfica en $3 D$ donde puede verse al mismo tiempo la variación del grado de reacción con las variables anteriores.

Los resultados obtenidos muestran una clara dependencia del grado de reacción con el desplazamiento del eje de la turbina, observándose que aumenta al cerrarse la turbina. También aparece una dependencia con el gasto másico que circula a través de la turbina, ya que disminuye al aumentar el gasto de gases de escape trasegado.

Una vez obtenido el grado de reacción para cada uno de los puntos de funcionamiento en que hemos tomado medidas, es posible calcular el área efectiva de las toberas equivalentes al estator $\mathrm{y}$ al rotor, utilizando las ecuaciones (4.33) y (4.34).

\subsubsection{Análisis de la dependencia de las áreas efectivas de las toberas equivalentes con diferentes parámetros.}

Para implementar el modelo de TGV en el modelado completo del motor se correlacionaron las áreas efectivas de las toberas equivalentes al estator y al rotor en función de variables conocidas por el modelo de motor. 
De modo que en función de unos pocos parámetros, para unas determinadas condiciones de funcionamiento el modelo pudiera calcular estas áreas efectivas y reproducir los saltos de presiones en el estator y el rotor, así como el trabajo realizado por la turbina y el rendimiento de la misma.

De este modo es muy sencillo implementar las ecuaciones obtenidas de las correlaciones en el modelo (programado en código C) y comparar los valores medidos en los ensayos con los resultados obtenidos del modelo.

Las correlaciones obtenidas para las áreas efectivas de las toberas equivalentes al estator y al rotor, a partir de las medidas obtenidas en los ensayos descritos a lo largo del presente apartado, son las siguientes. Para el estator:

$$
A_{e s t}=k_{1}-\frac{1}{e^{k_{2} \cdot\left(D e s p T G V-k_{3}\right)}}
$$

donde $A_{\text {est }}$ es el área efectiva de la tobera equivalente al rotor, en $\mathrm{mm}^{2}$, y DesTGV es el desplazamiento del vástago de la turbina en milímetros y las constantes valen:

$$
\begin{array}{ll}
k_{1}=415 \pm 8 & k_{3}=22 \pm 2 \\
k_{2}=0.257 \pm 0.018 & r^{2}=0.97
\end{array}
$$

Para el área efectiva de la tobera equivalente al rotor, en $\mathrm{mm}^{2}$, se obtiene:

$$
\begin{aligned}
& A_{\text {rot }}=k_{1} n^{*}+k_{2} \cdot \ln \left(k_{3} \cdot \dot{m}^{*}+k_{4}\right) \\
& \text { donde } n^{*}=\frac{n}{\sqrt{T_{10}}} \mathrm{y} \dot{m}^{*}=\frac{\dot{m} \sqrt{T_{10}}}{P_{10}}
\end{aligned}
$$

Donde $\dot{m}$ es el caudal de gases trasegados por la turbina (en $\mathrm{kg} / \mathrm{s}$ ), $\mathrm{n}$ el régimen de giro del turbogrupo (en rpm), y $\mathrm{T}_{01}$ (en $\mathrm{K}$ ) y $\mathrm{P}_{01}$ (en bar) los valores de la presión y temperatura de parada del gas a la entrada del rotor. Los valores de las constantes son los que se muestran en la siguiente tabla:

- $k_{1}=-0.116 \pm 0.006$

- $\quad k_{2}=2090 \pm 20$

- $k_{3}=0.40 \pm 0.06$
- $k_{4}=1.052 \pm 0.005$

- $r^{2}=0.98$ 
a
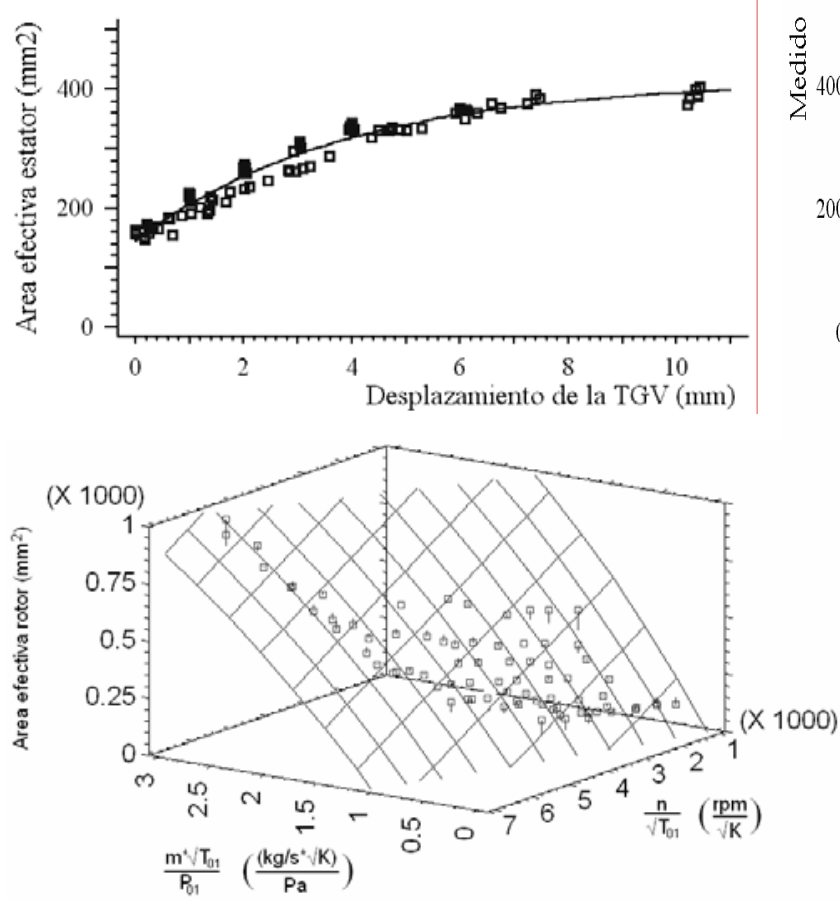

$\mathrm{C}$ b
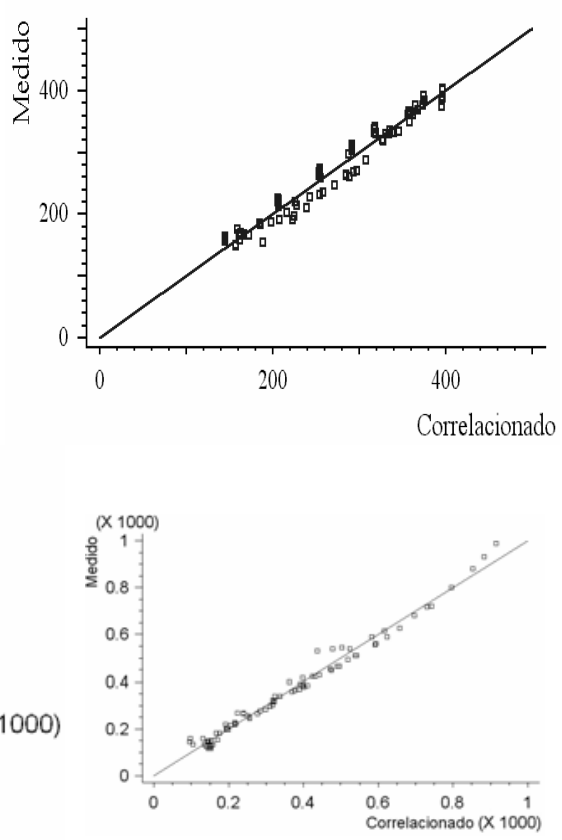

d

Figura 5. 27: a) Valores del área efectiva de la tobera equivalente al estator y curva obtenida a partir de la correlación. b) Comparación de los valores calculados con los obtenidos de la correlación para el área efectiva de la tobera equivalente al estator. c) Valores del área efectiva de la tobera equivalente al rotor y superficie obtenida a partir de la correlación. d) Comparación de los valores calculados con los obtenidos de la correlación para el área efectiva de la tobera equivalente al rotor.

Observamos una clara dependencia del área efectiva de la turbina equivalente al estator con el desplazamiento del eje de la turbina. Sin embargo, el área efectiva de la tobera equivalente al rotor muestra dependencia con el gasto másico que atraviesa la turbina y con el régimen de giro del turbogrupo corregidos con las condiciones parada del gas a la entrada del rotor.

Se observa es posible correlacionar el área efectiva de la tobera equivalente al rotor de la turbina en función del gasto y del régimen de giro corregidos con las condiciones del gas a la entrada del rotor. Se observa que el área efectiva de la tobera equivalente al rotor, para un régimen de giro determinado, aumenta al aumentar el caudal de gases trasegados. Por tanto, parece evidenciarse que el aumento de caudal y relación de expansión mejoran el aprovechamiento de la sección geométrica de paso del flujo por el rotor. Sin embargo, para un gasto determinado, el área efectiva de la tobera equivalente al rotor disminuye al aumentar el régimen de giro, esto es 
explicable pensando que al aumentar el régimen de giro aumentan las fuerzas centrífugas que se producen al girar el rotor y se dificulta el paso del gas de escape.

Una vez introducidas las correlaciones en el modelo de acción de ondas completo del motor los resultados obtenidos de las presiones instantáneas para los distintos casos son los que se muestran en las siguientes figuras.

Desde la figura 5. 28 a la figura 5.31 se muestra la comparación de los valores modelados de la presión instantánea a la entrada de la turbina (rojo), a la salida de la turbina (verde) y a la salida del colector de admisión (azul) con las presiones medidas (negro).
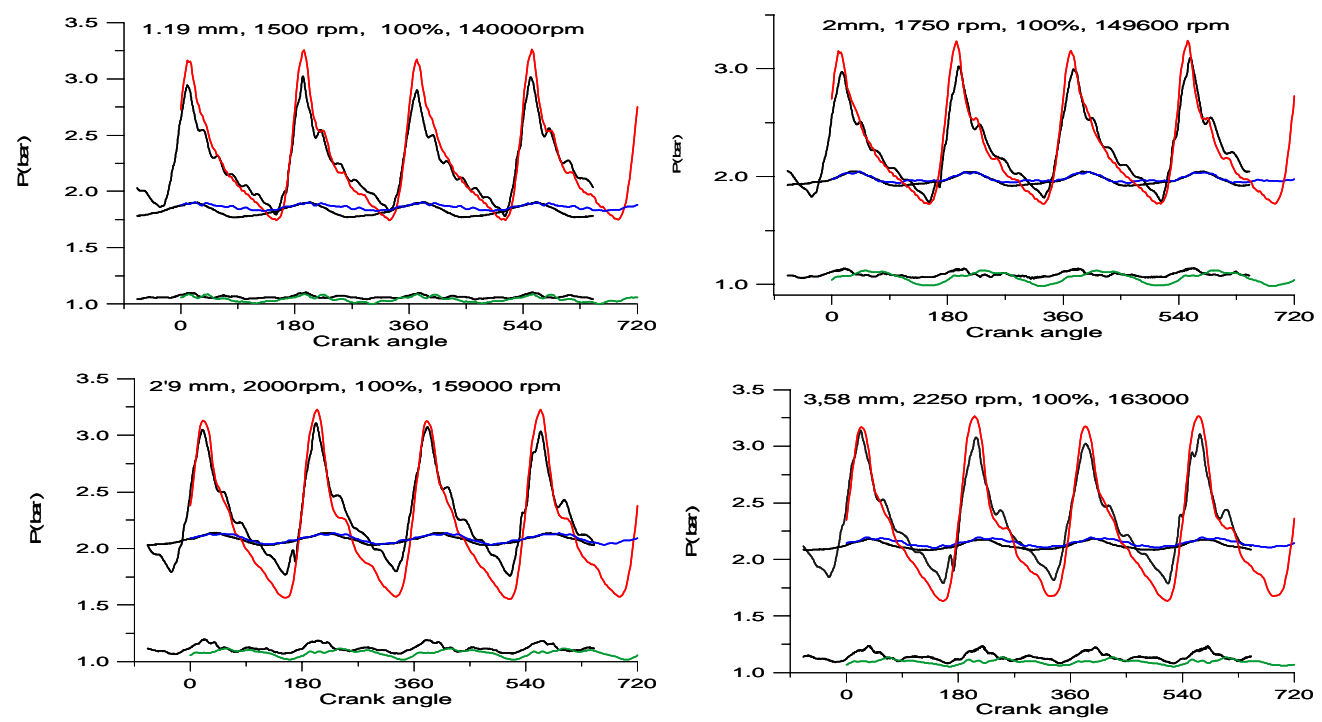

Figura 5. 28: Comparación, para diferentes puntos de plena carga del motor, medido-modelado de la presión a la entra de la turbina (rojo), a la salida de la misma (verde) y a la salida del intercooler (azul). En trazo negro se muestran los valores medidos. 

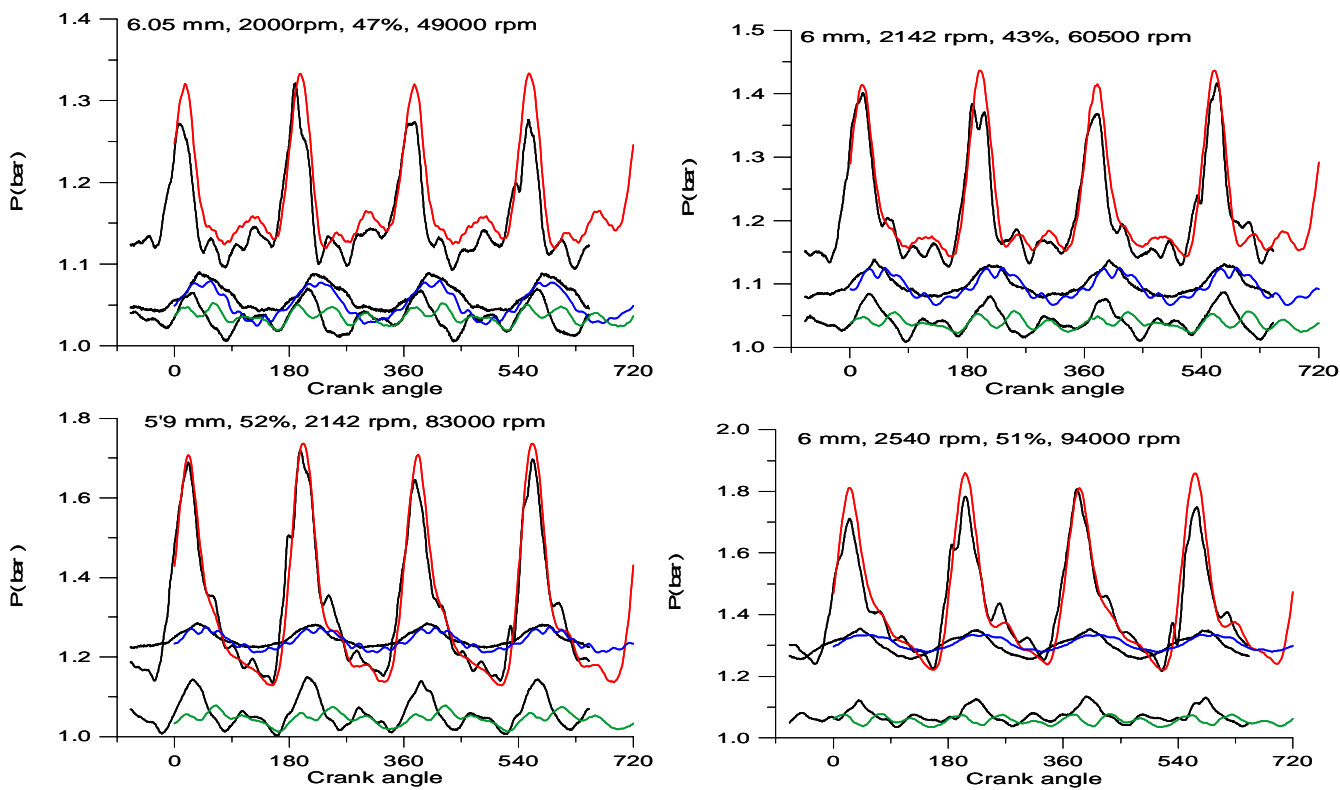

Figura 5. 29: Comparación, para diferentes puntos de la turbina abierta al 60\%, medido-modelado de la presión a la entra de la turbina (rojo), a la salida de la misma (verde) y a la salida del intercooler (azul). En trazo negro se muestran los valores medidos.
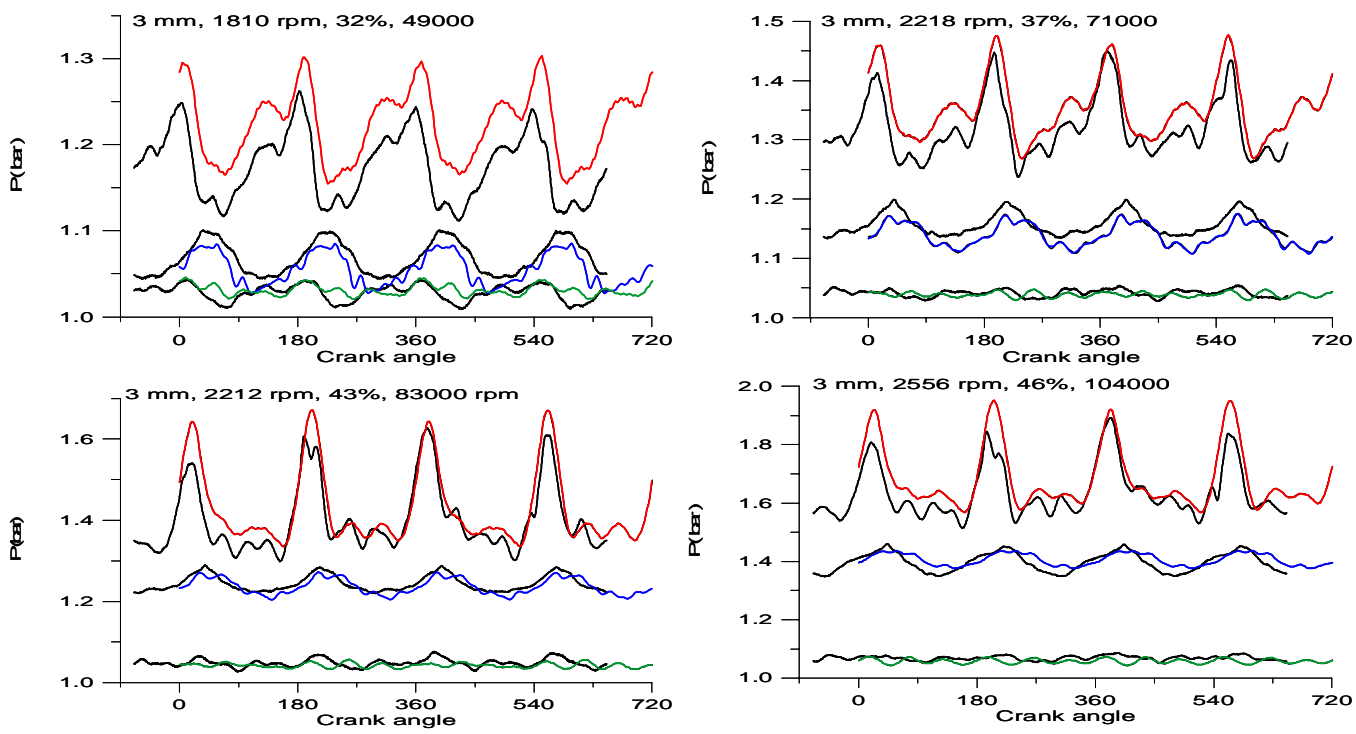

Figura 5. 30: Comparación, para diferentes puntos de la turbina abierta al 30\%, medido-modelado de la presión a la entra de la turbina (rojo), a la salida de la misma (verde) y a la salida del intercooler (azul). En trazo negro se muestran los valores medidos. 

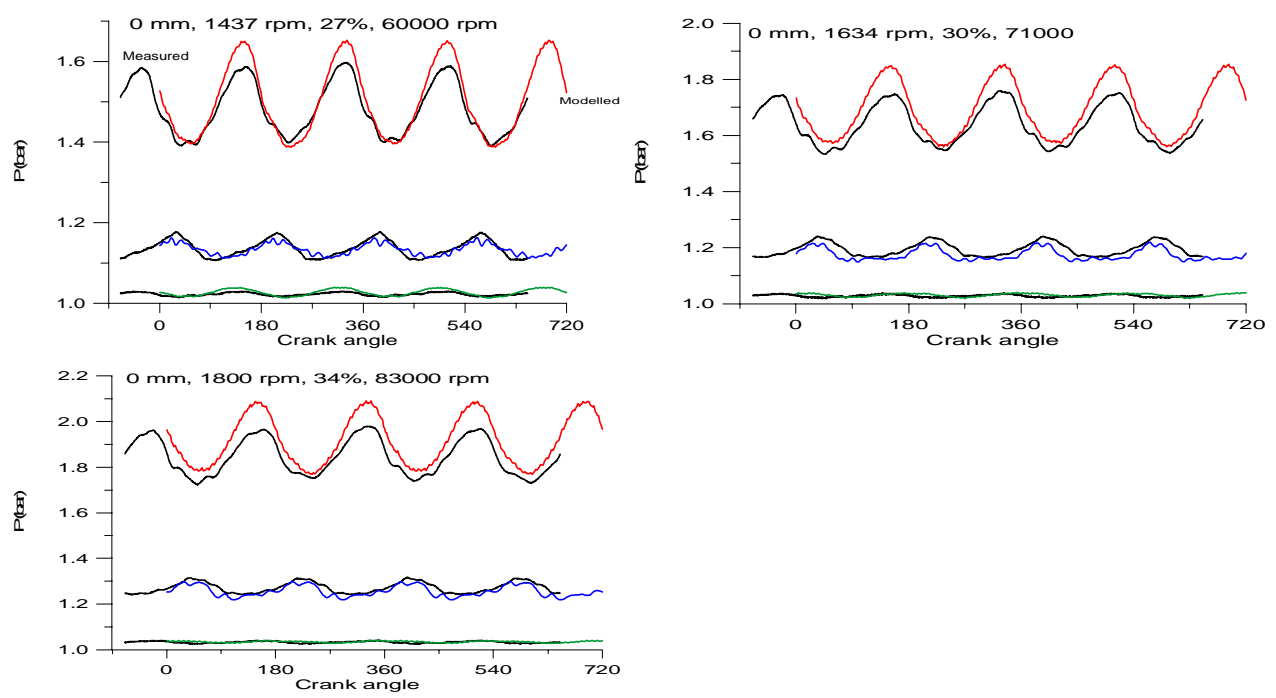

Figura 5. 31: Comparación, para diferentes de la turbina cerrda, medido-modelado de la presión a la entra de la turbina (rojo), a la salida de la misma (verde) y a la salida del intercooler (azul). En trazo negro se muestran los valores medidos.

A partir de las comparaciones medido-modelado observadas en las figuras anteriores se puede concluir que el modelo es capaz de reproducir el comportamiento fluidodinámico de la TGV, ajustándose los valores obtenidos a las medidas experimentales realizadas.

A la vista de los resultados obtenidos hay que destacar como se lamina el flujo a la salida de la turbina cuando está cerrada (figura 5. 31) en comparación con cuando está abierta al 60\% (figura 5. 29), lo que concuerda con las hipótesis realizadas en el apartado 4.1 (figura 4. 11).

\subsubsection{Validación del modelo para TGV de álabes móviles}

Con el fin de poder validar el modelo expuesto en el capítulo anterior se utilizaron los datos obtenidos de ensayar un turbogrupo de la marca KKK, formado por una turbina de geometria variable (K31-36.12 GVACD) y un compresor (K31-3767 OOAKB). El turbogrupo se acopló a un motor diesel 11.121 de cilindrada.

Antes de describir los ensayos realizados se va a realizar una revisión del funcionamiento de la TGV ensayada y del modelo dinámico que se implementó en el modelo de acción de ondas para completar el modelado de la turbina.

Como puede observarse en la figura 5. 32, la turbina de geometría variable que se va a utilizar para el presente trabajo está compuesta por un 
vástago móvil al que se le unen los álabes del estator y una bomba de vacío que controla la posición del vástago. El funcionamiento de la turbina viene determinado por una presión de referencia que define las condiciones de funcionamiento ideales para un par dado de régimen de giro y gasto de combustible.
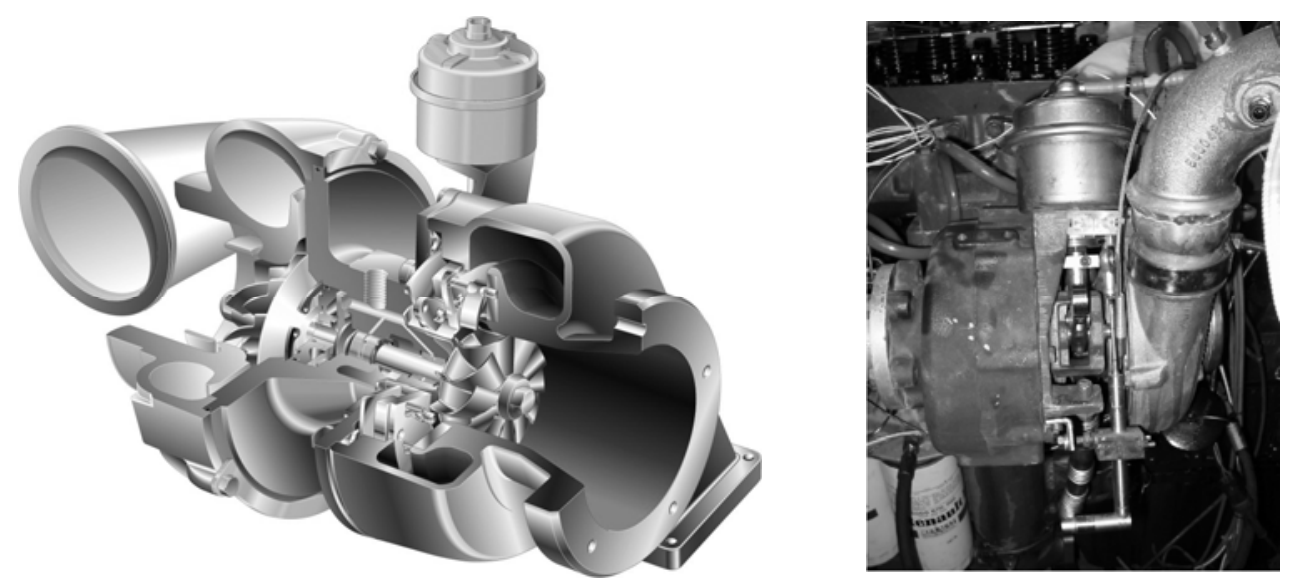

Figura 5. 32: Esquema y fotografía del turbogrupo de la marca KKK utilizado para realizar las medidas y validar el modelo de TGV.

\subsubsection{1 $\quad$ Caracterización de la TGV}

Como se ha descrito en la primera parte del capitulo, para la aplicación del modelo de la TGV es necesario conocer algunos parámetros geométricos de la misma, en cada uno de los puntos de funcionamiento en los que se quiera modelar la turbina. Es necesario por lo tanto caracterizar la turbina geométricamente asi como caracterizar y modelar el mecanismo que se utiliza para cambiar la posición de los álabes en el estator de la turbina.

En el caso de una TGV de álabes fijos el ángulo $\alpha_{1}$ se mantiene constante, pero en el caso de una TGV de álabes móviles es la variación de este ángulo la que provoca una variación en la sección de paso y es precisamente este ángulo el que necesitamos conocer para cada punto de funcionamiento.

La metodología seguida para determinar la relación entre el ángulo de los álabes, el desplazamiento del vástago y la señal PWM de la electroválvula es el que se presenta a continuación.

En primer lugar, se diseñó una pieza de PVC para sustituir la carcasa de la TGV (figura 5. 33), de manera que fuera posible mantener fija la posición relativa estator-rotor de la turbina y tener los álabes a la vista, para poder medir correctamente los ángulos que forman los mismos. Sustituyendo esta pieza por la carcasa de la turbina fue posible fotografiar la posición de 
los álabes al mismo tiempo que se medía la presión en el pulmón que mueve el vástago, el desplazamiento de éste y la señal de PWM de la electroválvula. En la figura 5. 34 se muestra un esquema del experimento diseñado para la caracterización del mecanismo de la turbina.

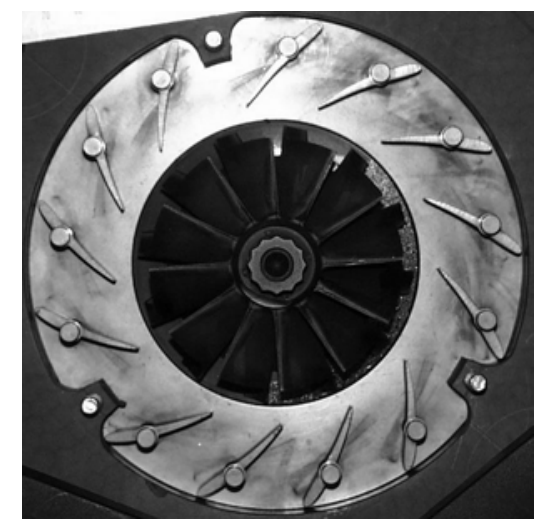

Figura 5. 33: Estator y rotor de la TGV, con la pieza de PVC construida para sustituir la carcasa y dejar los álabes a la vista.

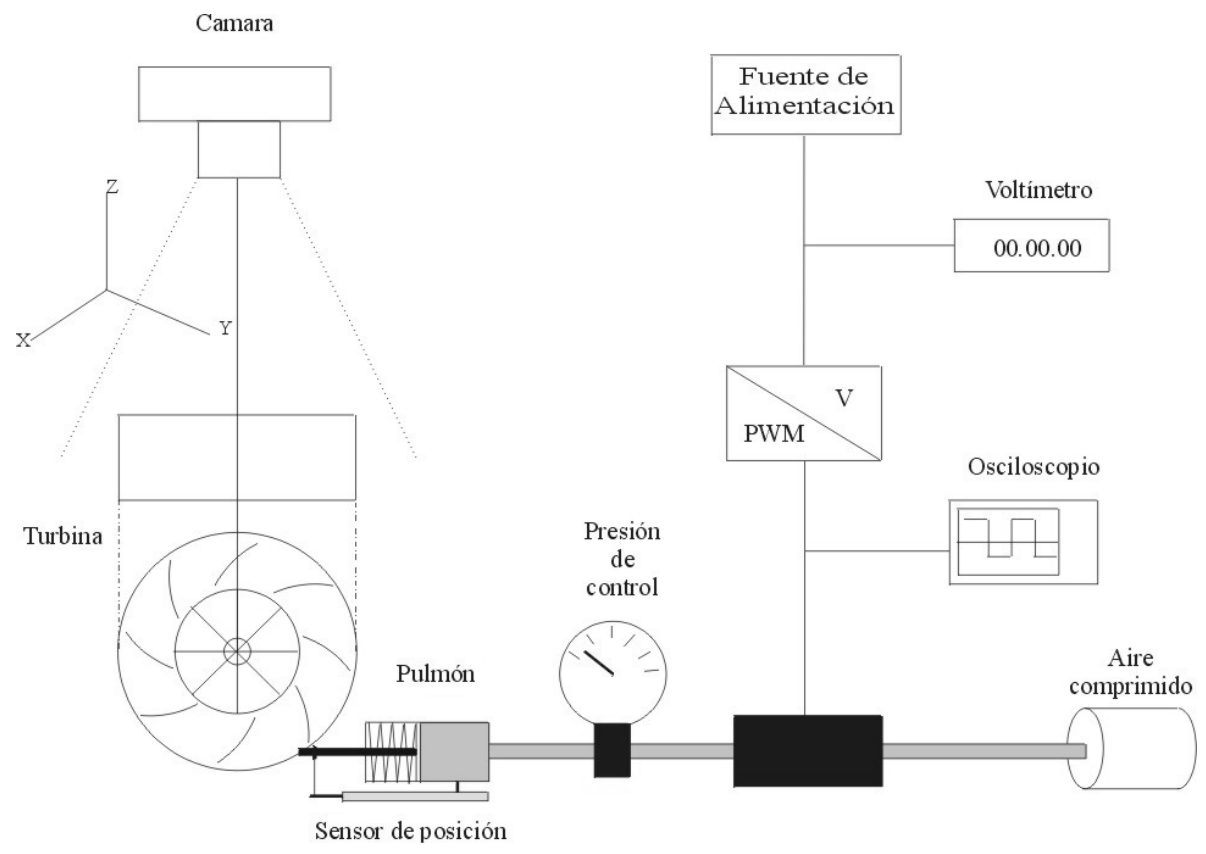

Figura 5. 34: Esquema del montaje diseñado para poder medir simultáneamente la posición de los álabes, el desplazamiento del vástago, la presión en el pulmón y la señal de PWM de la electroválvula.

En la figura 5. 35 se muestra un esquema del mecanismo de accionamiento de la TGV en el que se observa como aumentando la carga en 
el límite de la palanca (que es similar a aumentar la presión en el pulmón) el mecanismo tiene una especie de 'movimiento imposible' (la articulación debería seguir un movimiento circular y una trayectoria recta a la vez). Este movimiento es importante en la caracterización de la TGV como se verá al analizar los resultados obtenidos.

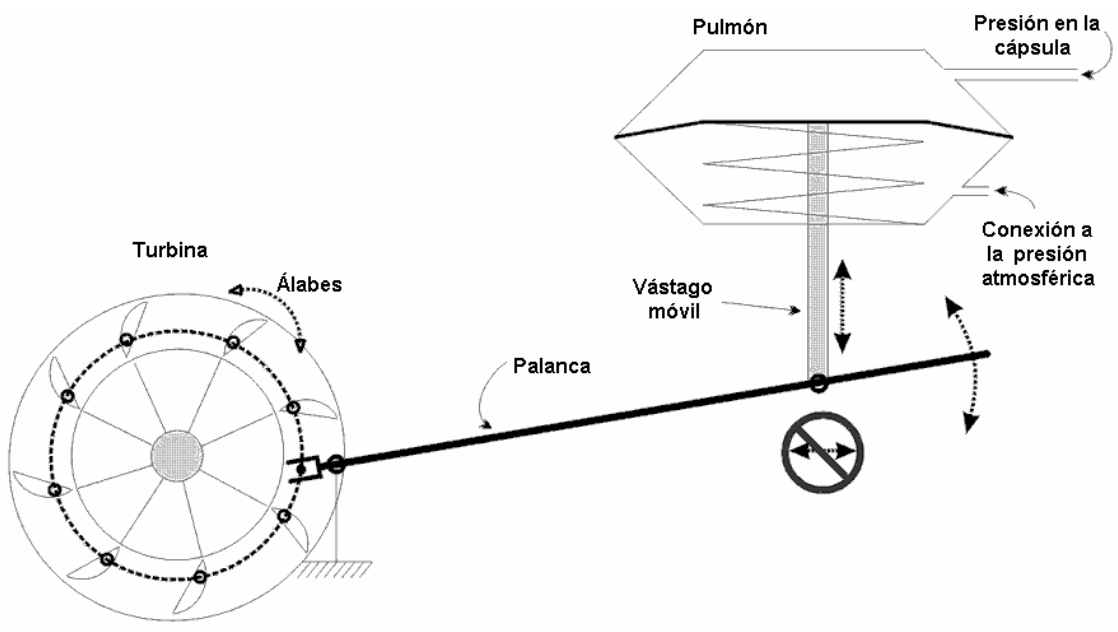

Figura 5. 35: Mecanismo de accionamiento de la TGV.

Para conocer el ángulo de los álabes se combinó la fotografía digital con el programa comercial AUTOCAD. En el caso de esta turbina, los álabes son curvados, por lo que fue necesario elegir un criterio que definiera su posición. Este criterio consistió en definir el ángulo de los álabes como el formado por dos lineas: la primera es la linea que va desde el centro del rotor de la turbina a la punta del álabe y la segunda es la bisectriz del ángulo formado por el borde de la punta del álabe. Un esquema de la medida de este ángulo para dos álabes en una determinada posición puede verse en la figura 5. 36 .

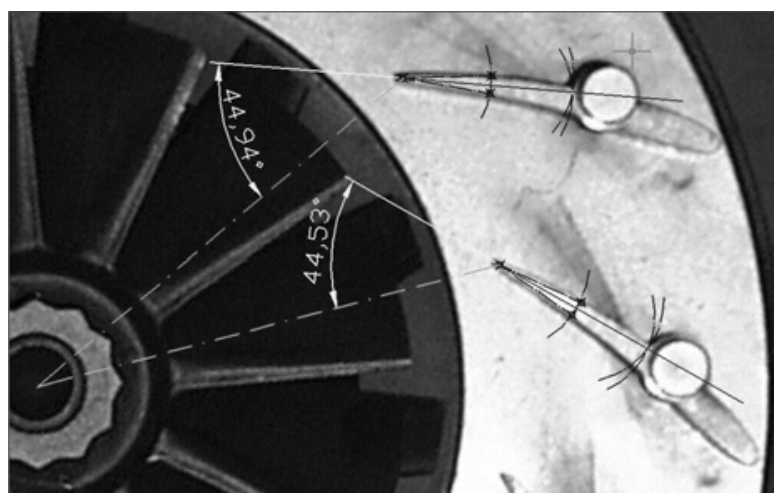

Figura 5. 36: Esquema del criterio utilizado para definir el ángulo de los álabes de esta turbina. 
Una vez realizadas estas medidas se obtuvieron tres importantes resultados. En primer lugar se observó que existian diferencias en el movimiento de los 13 álabes que se encuentran en el estator de la turbina. En la figura 5. 37 se muestra la dispersión obtenida para los 13 álabes, normalizados con el valor medio obtenido, para nueve ángulos medios diferentes. Como se observa en esta figura no todos los álabes se comportan de la misma forma, por ejemplo el álabe numerado como álabe 6 en todos los casos el ángulo que determina es menor que el valor medio. El caso contrario es del álabe 9, que siempre determina ángulos por encima del valor medio. Esta dispersión, que incluye el error de medida, puede afectar al comportamiento global de la turbina.

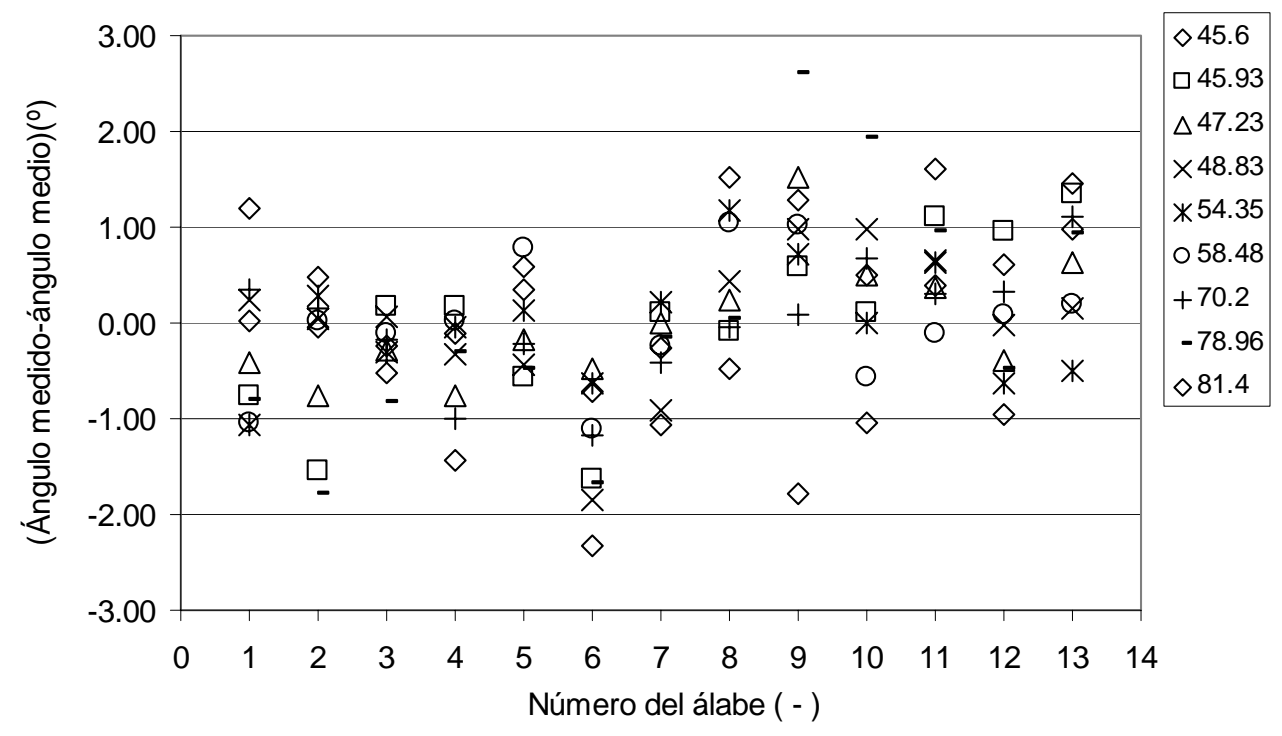

Figura 5. 37: Diferencia en grados del ángulo que forma cada álabe con el valor medio de los trece álabes.

En segundo lugar se observó que existía una relación lineal entre el valor medio del ángulo formado por los 13 álabes en cada posición con el desplazamiento del vástago (figura 5. 39). De este modo, una vez montada la turbina el motor, midiendo la posición del vástago era posible saber en que posición se encontraban los álabes del estator. 


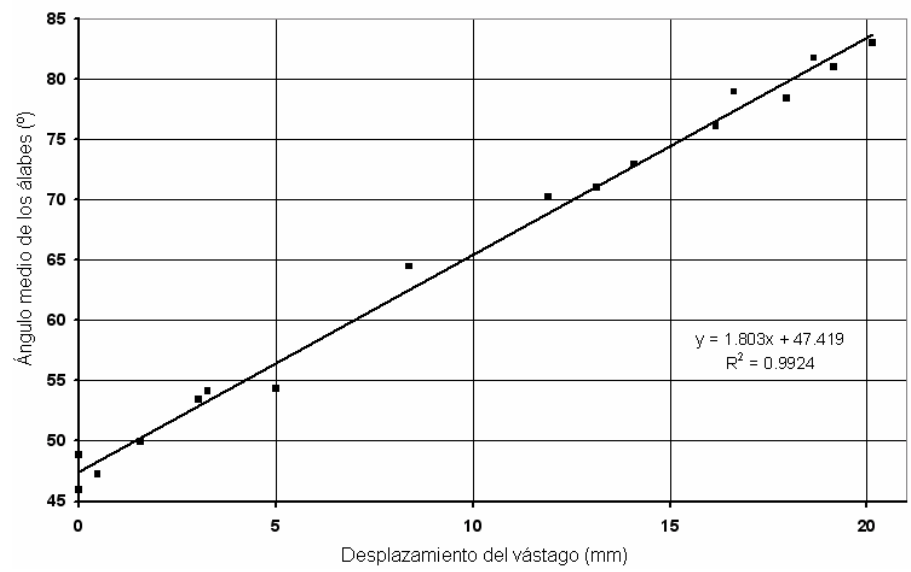

Figura 5. 38: Relación entre el ángulo medio de los álabes de la turbina con el desplazamiento del vástago móvil en cada posición.

Finalmente se observó que no ocurría lo mismo con la relación entre el desplazamiento del vástago y la presión en el pulmón. Se comprobó que el mecanismo tenía histéresis. Al aumentar la presión en el pulmón no se observaba ningún efecto hasta que llegada a 3.2 bar, punto en el que se desplazaba súbitamente el vástago. Una vez alcanzado el máximo desplazamiento (TGV cerrada), el camino seguido al disminuir la presión en el pulmón es diferente al mostrado en la subida, siendo en este caso mucho más continuo y con una pendiente más suavizada.

La TGV está completamente abierta cuando el desplazamiento del vástago es nulo y el ángulo $\alpha$ (figura 4. 12) toma valores alrededor de los $45^{\circ}$. Al cerrarse la TGV el desplazamiento del vástago alcanza los $20 \mathrm{~mm}$ y el ángulo de los álabes del estator llega casi hasta los $85^{\circ}$.

En la figura 5. 39 se muestran los resultados obtenidos al realizar el mismo ensayo con la pieza de PVC (Test 1) y con la carcasa original de la turbina (Test 2), para comprobar que no se introducian alteraciones en el mecanismo al realizar los ensayos descritos. 


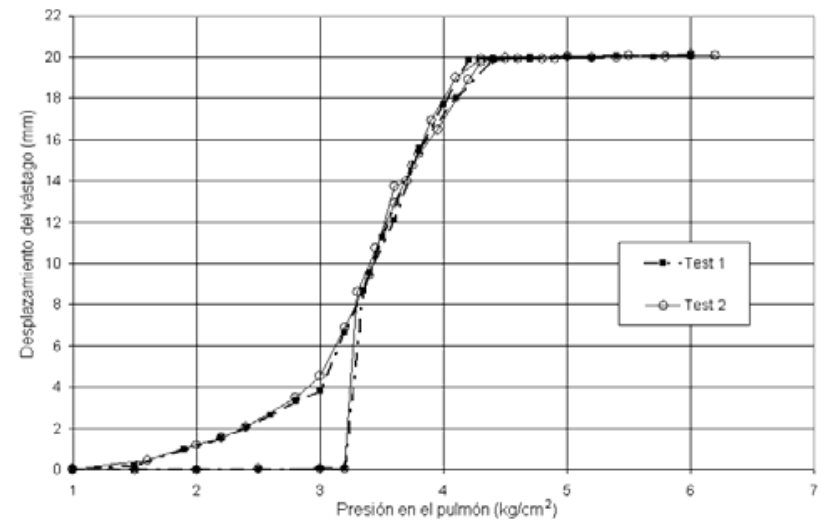

Figura 5. 39: Desplazamiento del vástago frente a la presión medida en el pulmón.

Este comportamiento del vástago perjudica la respuesta de la turbina, debido a que tarda más tiempo del necesario entre el momento en que la señal de PWM ordena cerrar la turbina y el momento en que empieza a cerrar y cuando el movimiento empieza la turbina se cierra directamente hasta un $40 \%$ de su punto máximo de cierre, sin puntos de transición. Este efecto dificulta la definición de los parámetros de control, ya que debido a la inicial ausencia de respuesta el sistema podría sobre oscilar.

En la figura 5. 40 se puede observar el planteamiento de dos experimentos, inicialmente propuestos para caracterizar la constante de precarga del muelle que se encuentra en el pulmón, relacionándola con la fuerza mínima necesaria para vencer inicialmente la carga del muelle, cuando este se encuentra en reposo. Durante la realización de los ensayos no se aumentó la presión en el pulmón.

Estos ensayos fueron llevados a cabo situando la carga en dos puntos diferentes, en primer lugar en el extremo del vástago y en segundo lugar en el punto de articulación del mismo, desacoplando la palanca del mecanismo. Como se observa en la gráfica de la figura 5. 41, el fenómeno de histéresis casi desapareció en el caso de aplicar la carga en el punto de articulación del vástago y se pudo calcular la precarga $\left(\mathrm{K}_{0}=95.15 \mathrm{~kg}\right)$ y la carga $(\mathrm{K}=4.46$ $\mathrm{kg} / \mathrm{mm}$ ). Este experimento confirma la hipótesis realizada de que la histéresis aparece por el 'movimiento imposible' que se ha descrito en párrafos anteriores. 

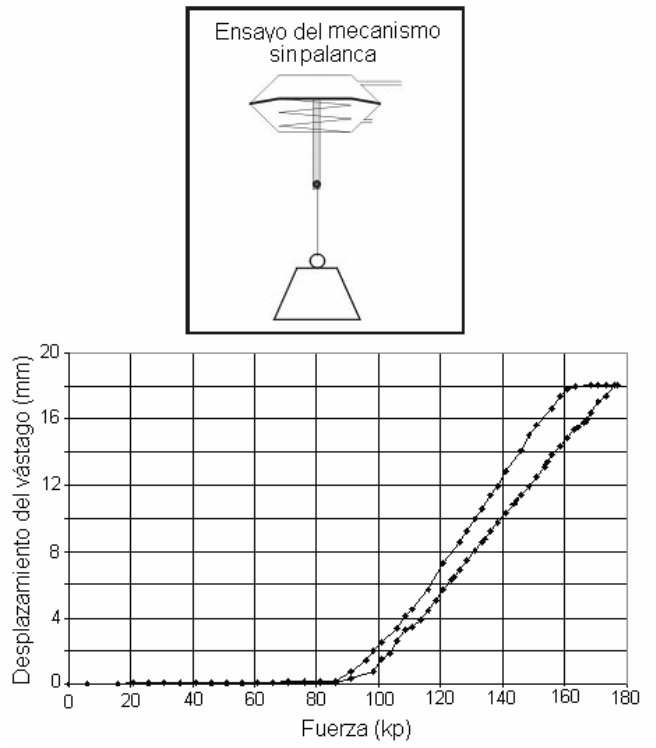
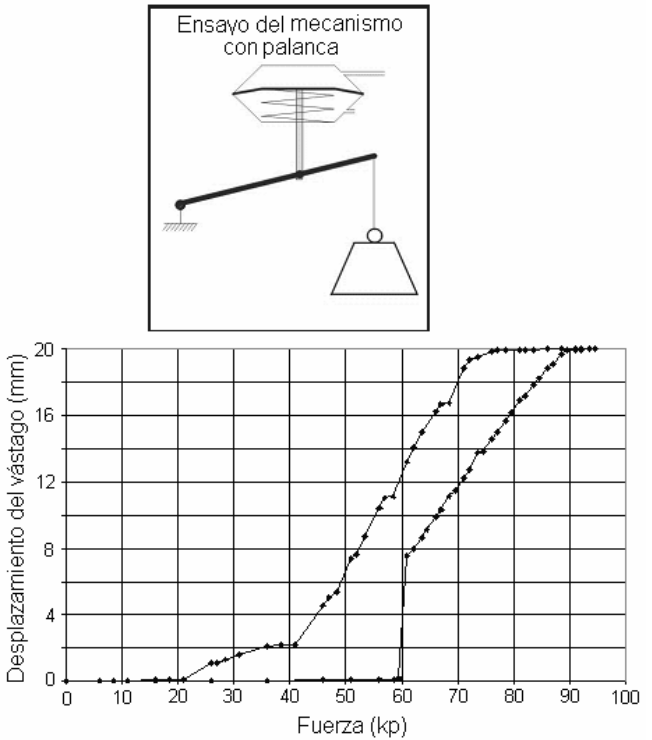

Figura 5. 40: Ensayos realizados con el mecanismo de accionamiento de la TGV.

En los resultados del ensayo realizado con palanca, en los que la carga para mover el vástago se sitúa en un extremo de la misma, puede observarse una histéresis similar a la observada en la figura 5. 39.

Por lo tanto, la razón de esta histéresis podría ser debida a la forma en que está concebido el mecanismo, ya que provoca que la palanca se deforme. Una vez que la palanca se ha doblado, la fuerza adicional desaparece y el mecanismo se desplaza normalmente.

En la figura 5. 41 se muestra la relación lineal que existe entre la presión en el pulmón y la señal de PWM.

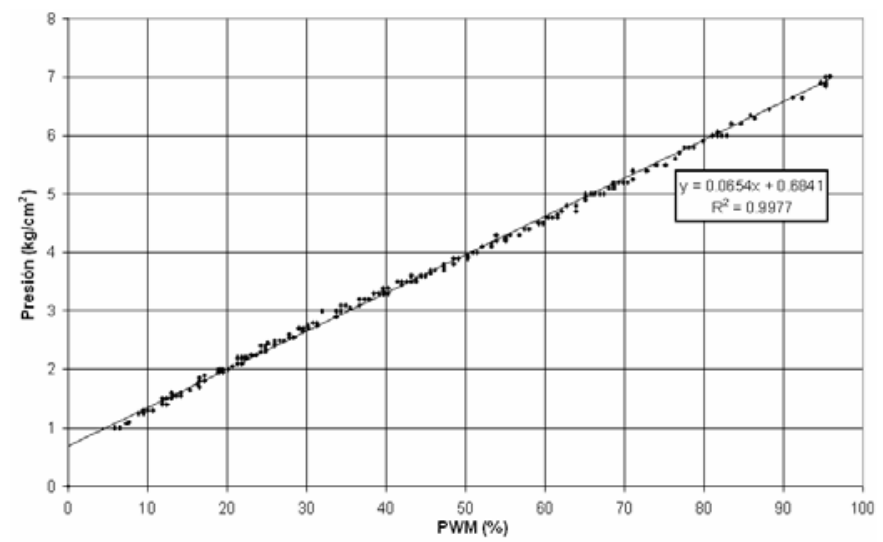

Figura 5. 41: Relación entre la presión en el pulmón y la señal de PWM. 
Después de todo el proceso de caracterización de la turbina, la información obtenida permitió relacionar la señal de PWM con el ángulo de los álabes, como puede observarse en la figura 5. 42. Esta información se introdujo directamente en el modelo de acción de ondas del motor, para controlar la turbina, debido a la dificultad que ofrecía el cálculo de los complejos efectos mecánicos que relacionan la presión en el pulmón de control con el desplazamiento del vástago.

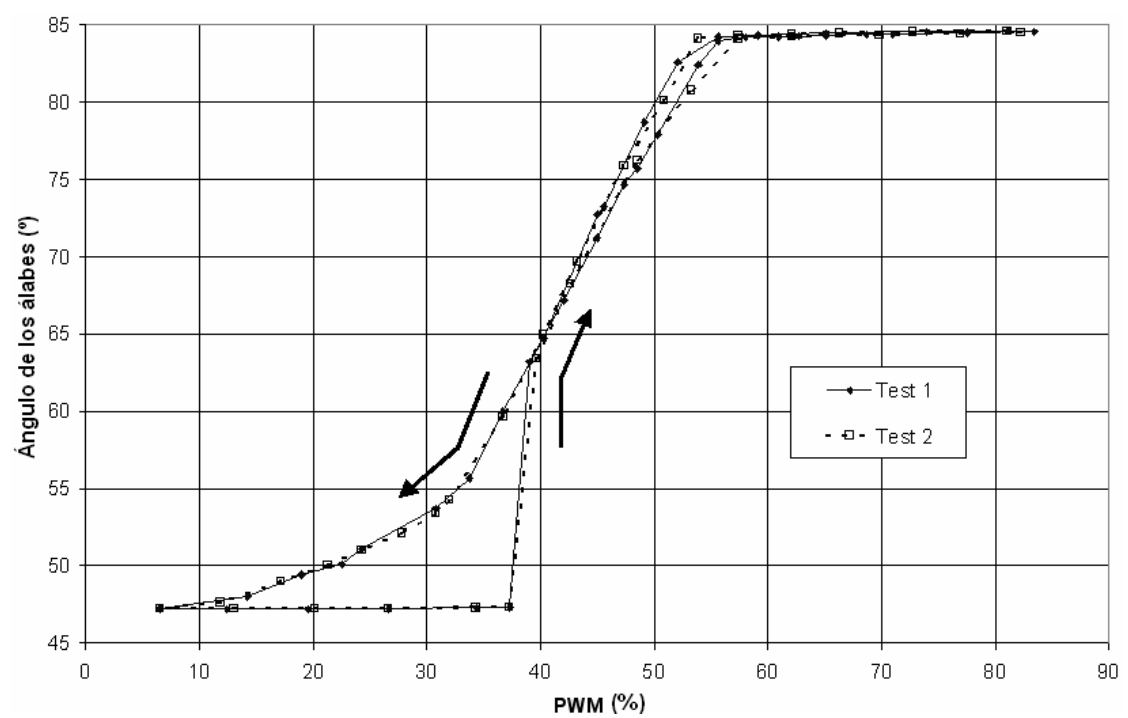

Figura 5. 42: Relación entre el ángulo medio de los álabes del estator y la señal de PWM.

Una vez acoplada la TGV al motor se realizaron otra serie de ensayos para verificar la existencia de este comportamiento con la histéresis mostrada en las figuras anteriores, obteniéndose en este caso que la histéresis se minimiza y la relación entre la presión en el pulmón de la TGV y el desplazamiento de la misma cambia, como se observa en la figura 5. 43. En este caso sólo se midió el desplazamiento del vástago y la presión en el pulmón de la TGV, ya que son los únicos parámetros mecánicos que se pueden medir cuando está la TGV trabajando acoplada al motor. 
Contribución a la caracterización experimental y modelado de TGV en grupos de sobrealimentación

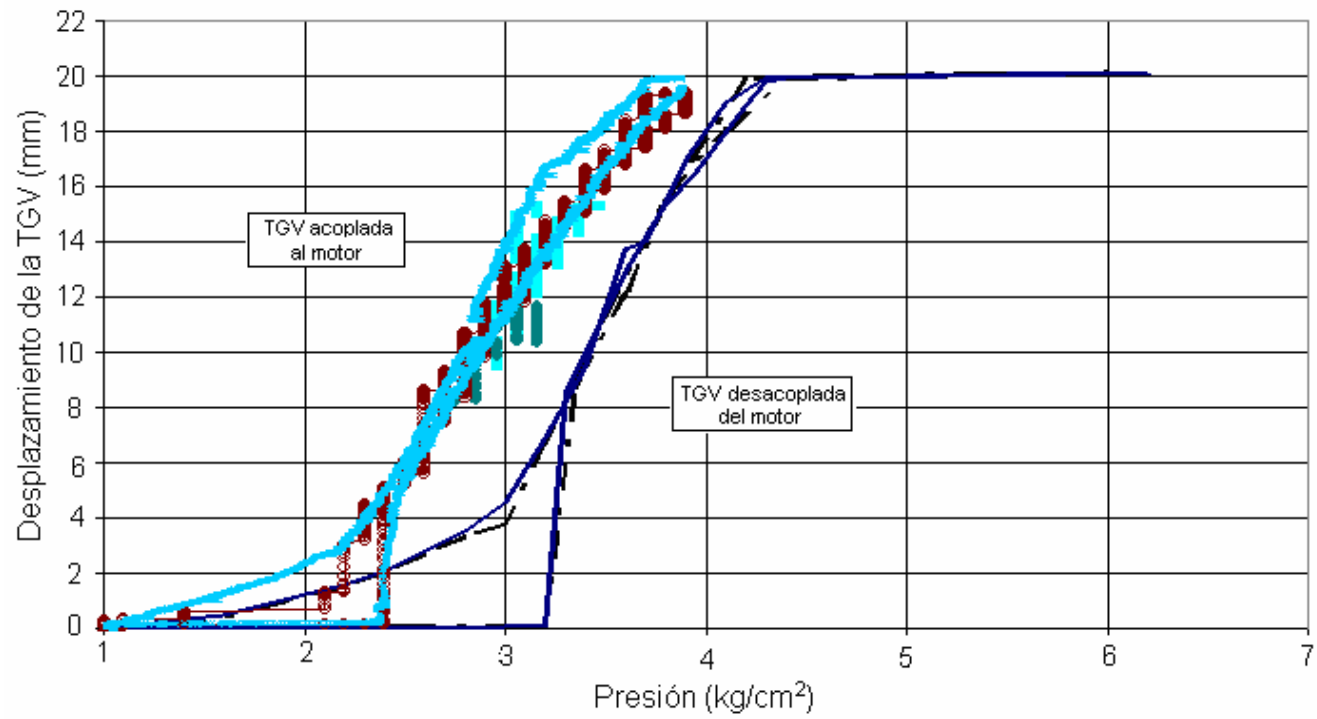

Figura 5. 43: Relación entre el desplazamiento y presión en el pulmón de la TGV.

Se observa que en el motor es necesaria una menor presión en el pulmón para abrir la TGV debido a los esfuerzos de presión de los gases de escape sobre los álabes del estator, por lo que la evolución que finalmente se implementó en el modelo es la que muestran los datos de la figura anterior en color marrón, que corresponde a la evolución media de los ensayos realizados con la TGV acoplada al motor.

\subsubsection{Ensayos realizados para la caracterización fluidodinámica de la TGV}

En este caso, el turbogrupo modelado estaba acoplado a un motor de encendido por compresión fabricado por el constructor francés RVI (Renault Véhicules Industrielles). En la tabla 5. 5 se muestran las características técnicas y geométricas de este motor, que pertenece a la serie MIDR62356EURO3, que el fabricante monta sobre una amplia gama de sus vehículos pesados (camiones, cabezas tractoras, autobuses y autocares). Se trata de un motor de 6 cilindros en linea, fuertemente sobrealimentado y con refrigeración de los gases de admisión. Posee 12 válvulas, rampa de balancines en cabeza y árbol de levas lateral.

El motor tiene una configuración convencional en los motores de transporte pesado por carretera, con una cilindrada unitaria de 1.85 litros y una relación carrera/diámetro de 1.24. El pistón es de aluminio, con la cámara de combustión labrada. La relación de diámetros entre cámara de combustión y el cilindro es de 0.67 , que junto con el bajo coeficiente de torbellino confiere a la cámara de combustión un carácter 'tranquilo', con movimientos de aire inducidos en la admisión y, durante la compresión, 
moderados, por lo que fundamentalmente el propio sistema de inyección es el encargado de la mezcla aire/combustible.

\begin{tabular}{|c|c|}
\hline Tipo de inyección & Directa \\
Número de cilindros & 6 \\
Volumen desplazado & $1.85 \mathrm{l}$ \\
Cilindrada total & $11.12 \mathrm{l}$ \\
Relación de compresión & $16.3: 1$ \\
Potencia máxima & $300 \mathrm{~kW}(1800 \mathrm{rpm})$ \\
Par máximo & $1500 \mathrm{Nm}(1500 \mathrm{rpm})$ \\
Régimen de giro máximo & $2000 \mathrm{rpm}$ \\
Diámetro del cilindro & $123 \mathrm{~mm}$ \\
Carrera & $156 \mathrm{~mm}$ \\
Longitud de la biela & $228 \mathrm{~mm}$ \\
Volumen de la cámara de combustión & $109.30 \mathrm{~cm}$ \\
Diámetro válvula de escape & $30.8 \mathrm{~mm}$ \\
Diámetro válvula de admisión & $34.5 \mathrm{~mm}$ \\
Coeficiente de torbellino medio & 1.23 \\
\hline
\end{tabular}

Tabla 5. 5: Características técnicas y geométricas del motor MIDR62356EURO3 de RVI.

Para la caracterización fluidodinámica de la TGV ser realizaron una serie de ensayos para cubrir todo el rango operativo del motor (desde 1000 a $1800 \mathrm{rpm}$ cada $200 \mathrm{rpm}$ y desde el $25 \%$ de carga hasta plena carga, aumentando cada 25\%), y esto para cada una de las seis aperturas seleccionadas de la TGV (0\%, 20\%, 40\%, 60\%, 80\% y 100\% de apertura), lo que hace un total de 120 puntos de ensayo (5 regimenes de giro del motor x 4 grados de carga x 6 posiciones de la TGV), como puede verse en la tabla 5. 6 .

No fue posible realizar todas las medidas descritas anteriormente por distintas limitaciones del motor y del turbogrupo. Se eligió, atendiendo a las especificaciones del fabricante del turbo, como limites de funcionamiento:

- Temperatura a la entrada de la turbina menor de $700^{\circ} \mathrm{C}$.

- Temperatura a la salida del compresor menor de $210^{\circ} \mathrm{C}$.

- Régimen de giro del turbogrupo menor de $112000 \mathrm{rpm}$. 
A partir de estas medidas se realizó un análisis similar al realizado en el caso de la turbina de álabes fijos. Los datos obtenidos en los ensayos se muestran en el Anexo I.

En primer lugar, tal y como se describe en el capitulo anterior se calcula el grado de reacción y a partir de éste valor, en función del ángulo límite se calculan las áreas efectivas de las toberas equivalentes al estator y al rotor.

Es necesario recordar en este punto que para turbinas de álabes móviles han de distinguirse dos situaciones: una de ellas cuando los álabes del estator dirigen el flujo a la entrada del rotor y el otro cuando se forma un volumen intermedio y los álabes del estator dejan de dirigir el flujo hacia el rotor, de manera que el ángulo de entrada al rotor viene dado por los álabes de este.

\begin{tabular}{|c|c|c|c|c|c|}
\hline \multicolumn{6}{|c|}{ Apertura TGV: $100 \%$} \\
\hline \multirow{2}{*}{$\begin{array}{c}\text { Carga } \\
\%\end{array}$} & \multicolumn{5}{|c|}{ Régimen de giro del motor } \\
\hline & 1800 & 1600 & 1400 & 1200 & 1000 \\
\hline 100 & TET & TET & TET & TET & TET \\
\hline 75 & & TET & TET & & \\
\hline 50 & & & & & \\
\hline 25 & & & & & \\
\hline
\end{tabular}

\begin{tabular}{|c|c|c|c|c|c|}
\hline \multicolumn{6}{|c|}{ Apertura TGV: $80 \%$} \\
\hline $\begin{array}{c}\text { Carga } \\
\%\end{array}$ & 1800 & 1600 & 1400 & 1200 & 1000 \\
\hline 100 & TET & TET & TET & TET & TET \\
\hline 75 & & & & & \\
\hline 50 & & & & & \\
\hline 25 & & & & & \\
\hline
\end{tabular}

\begin{tabular}{|c|c|c|c|c|c|}
\hline \multicolumn{5}{|c|}{ Apertura TGV: $60 \%$} \\
\hline $\begin{array}{c}\text { Carga } \\
\%\end{array}$ & 1800 & 1600 & 1400 & 1200 & 1000 \\
\hline 100 & & & & & \\
\hline 75 & & & & & \\
\hline 50 & & & & & \\
\hline 25 & & & & & \\
\hline
\end{tabular}

\begin{tabular}{|c|c|c|c|c|c|}
\hline \multicolumn{5}{|c|}{ Apertura TGV: 40\% } \\
\hline $\begin{array}{c}\text { Carga } \\
\%\end{array}$ & 1800 & 1600 & 1400 & 1200 & 1000 \\
\hline & & & & & \\
\hline 100 & & & & & \\
\hline 75 & & & & & \\
\hline 50 & & & & & \\
\hline 25 & & & & & \\
\hline
\end{tabular}

\begin{tabular}{|c|c|c|c|c|c|}
\hline \multicolumn{5}{|c|}{ Apertura TGV: $20 \%$} \\
\hline $\begin{array}{c}\text { Carga } \\
\%\end{array}$ & \multicolumn{5}{|c|}{ Régimen de giro del motor } \\
\hline & 1800 & 1600 & 1400 & 1200 & 1000 \\
\hline 100 & TSC-RT & & & & \\
\hline 75 & & & & & \\
\hline 50 & & & & & \\
\hline 25 & & & & & \\
\hline
\end{tabular}

\begin{tabular}{|c|c|c|c|c|c|}
\hline \multicolumn{7}{|c|}{ Apertura TGV: 0\% } \\
\hline \multirow{2}{*}{$\begin{array}{c}\text { Carga } \\
\%\end{array}$} & 1800 & 1600 & 1400 & 1200 & 1000 \\
\hline & TSC & TSC & & & \\
\hline 100 & TSégimen de giro del motor \\
\hline 75 & & & & & \\
\hline 50 & & & & & \\
\hline 25 & & & & & \\
\hline
\end{tabular}

Limitado por:

TET: Temperatura Entrada Turbina

TSC:Temperatura Salida Compresor

$\mathrm{RT}$ :Régimen del turbogrupo

Tabla 5. 6: Ensayos realizados para la caracterización de la TGV.

En el caso de esta turbina los álabes del estator dejan de dirigir el flujo cuando el ángulo $\alpha_{1}$ es mayor de $56^{\circ}$, como se muestra en la figura siguiente. Por lo tanto se tendrá:

- $\quad \mathrm{Si} \alpha_{1} \leq 56^{\circ} \rightarrow R=1-\frac{\operatorname{tg} \alpha_{1}}{2 \cdot u_{1}} \cdot \frac{\dot{m} R T_{2}}{A_{2} P_{2}}$

- $\quad$ Si $\alpha_{1}>56^{\circ} \rightarrow R=0.5$ 

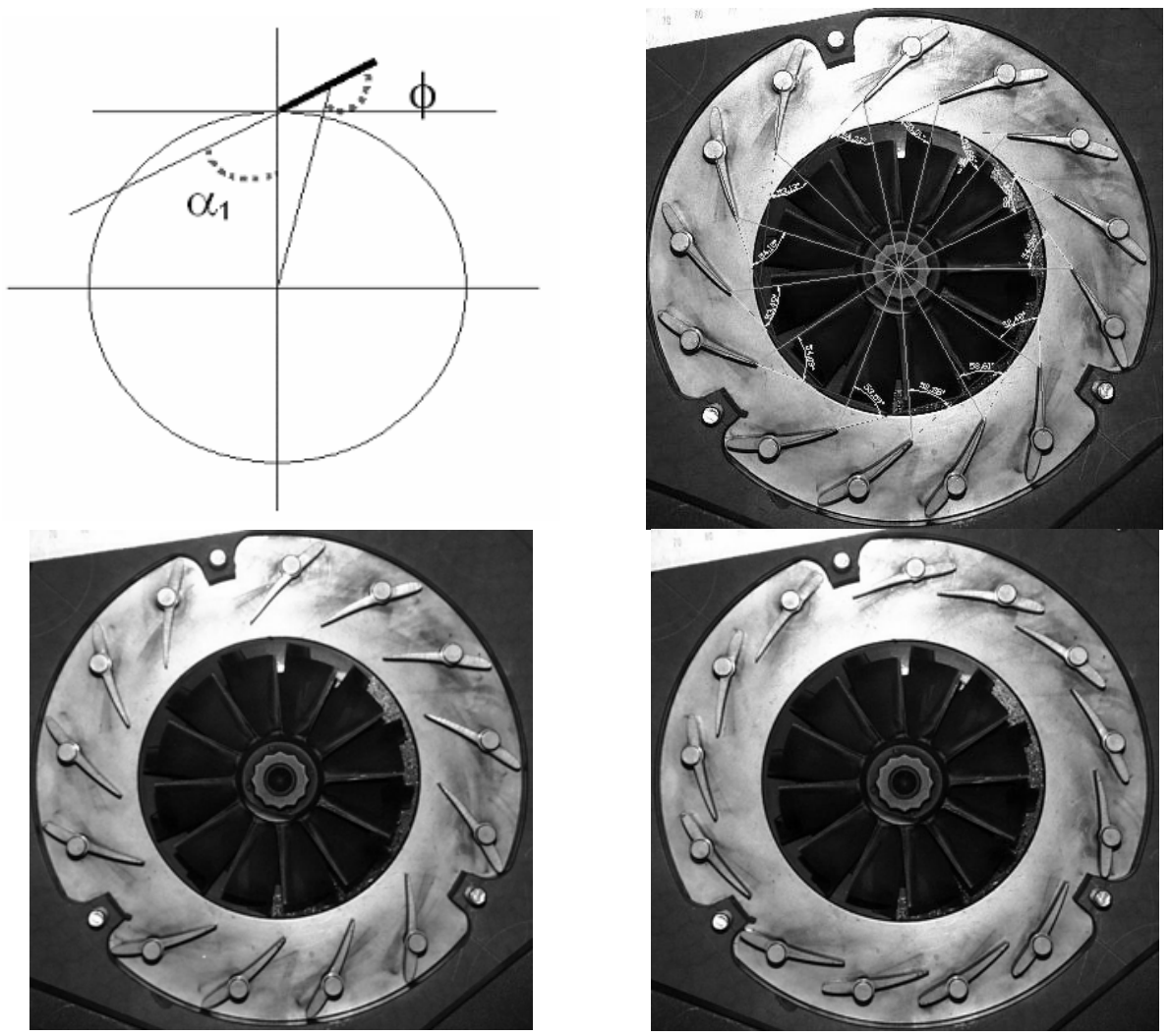

Figura 5. 44: En la parte superior de la figura se muestra un esquema del estator de la turbina donde se indica cual es el ángulo $\alpha_{1}$ y una fotografía de la turbina en la que la dirección de los álabes del estator es tangente a los álabes del rotor. En la parte de abajo hay dos imágenes que muestran la posición de los álabes del estator cuando la turbina está abierta (izquierda) y cuando está cerrada (derecha.)

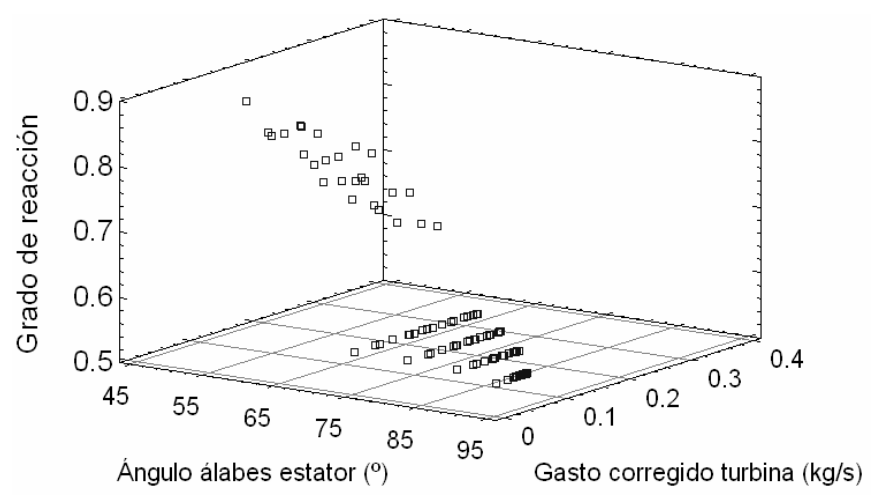

Figura 5. 45: Grado de reacción obtenido para los diferentes puntos de la TGV medidos, en función de la posición de los álabes del estator $\left(\alpha_{1}\right)$ y del gasto corregido trasegado por la misma. 
Una vez calculado el grado de reacción es posible calcular la presión intermedia entre el estator y el rotor, y correlacionarlas con variables operativas del sistema como en el caso anterior.

Para el caso del área efectiva de la tobera equivalente al estator, en $\mathrm{mm}^{2}$, se obtiene:

$$
A_{e s t}=k_{1}+e^{\left(k_{3}+k_{2} \cdot \alpha_{1}\right)}
$$

Donde $\alpha_{1}$ es el ángulo de los álabes que se muestra en la figura 5. 44, medido en grados y los valores de las constantes son los que se muestran en la siguiente tabla:
- $k 1=94+6$
- $k 3=9.72+0.05$
- $k 2=-0.0383+0.0009$
- $r^{2}=0.95$

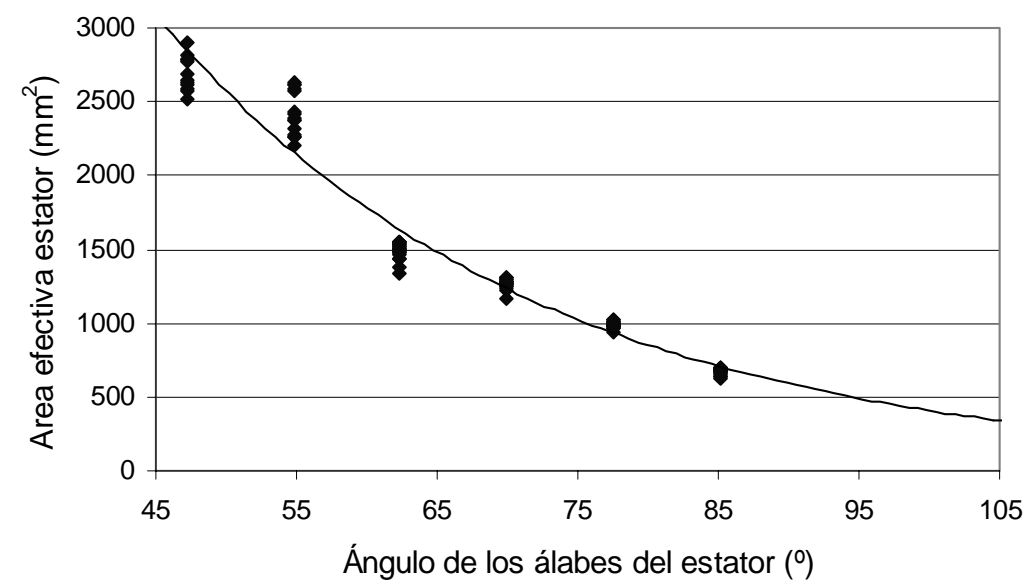

Figura 5. 46: Correlación obtenida del área efectiva de la tobera equivalente al estator en función del ángulo $\alpha_{1}$ de los álabes del estator.

Para el caso del área efectiva de la tobera equivalente al rotor la correlación obtenida es:

$$
\begin{aligned}
& A_{\text {rot }}=k_{1} n^{*}+k_{2} \cdot \ln \left(k_{3} \cdot \dot{m}^{*}+k_{4}\right) \\
& \text { donde } n^{*}=\frac{n}{\sqrt{T_{10}}} \mathrm{y} \dot{m}^{*}=\frac{\dot{m} \sqrt{T_{10}}}{P_{10}}
\end{aligned}
$$

Donde $\dot{m}$ es el caudal de gases trasegados por la turbina (en $\mathrm{kg} / \mathrm{s}$ ), $\mathrm{n}$ el régimen de giro del turbogrupo (en rpm), y $\mathrm{T}_{01}$ (en K) y $\mathrm{P}_{01}$ (en bar) los valores de la presión y temperatura de parada del gas a la entrada del rotor. Los valores de las constantes son los que se muestran en la siguiente tabla: 


$$
\begin{array}{ll}
- & k_{1}=-0.208 \pm 0.009 \\
- & k_{2}=2320 \pm 70 \\
- & k_{3}=0.265 \pm 0.014
\end{array}
$$

$$
\begin{aligned}
& k_{4}=1.13 \pm 0.06 \\
& r^{2}=0.94
\end{aligned}
$$

Es necesario destacar que se ha obtenido una correlación igual a la obtenida en el caso de un TGV de álabes fijos.
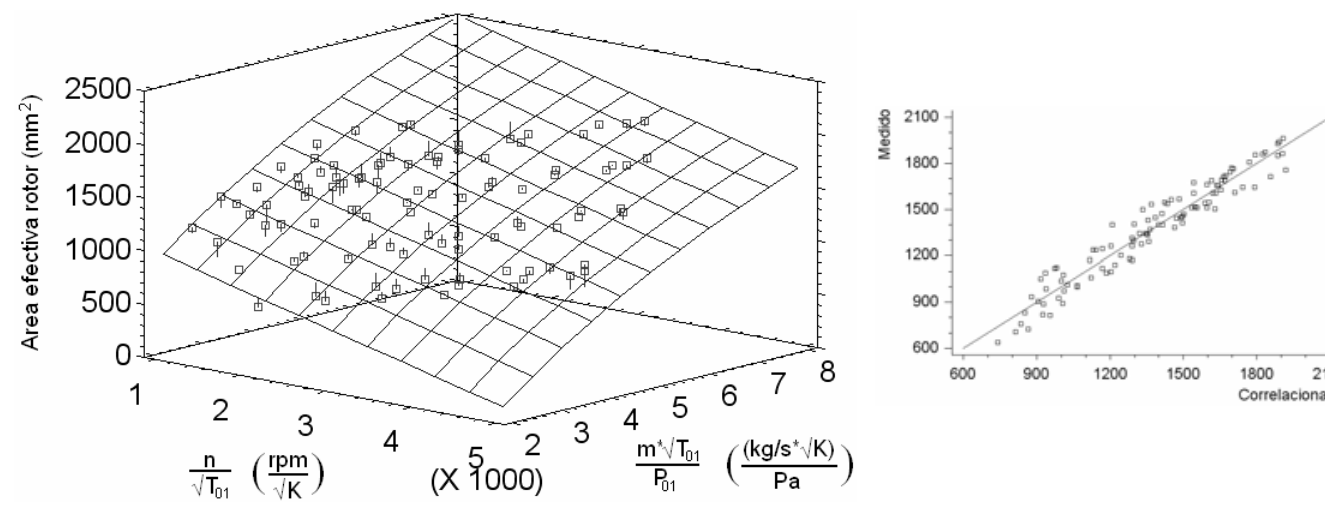

Figura 5. 47: Correlación obtenida del área efectiva de la tobera equivalente al rotor en función del gasto y del régimen corregidos con las condiciones del gas a la entrada del rotor.

A partir de los resultados obtenidos se observa para un gasto corregido determinado, el área efectiva de la tobera equivalente al rotor disminuye al aumentar el régimen de giro corregido, debido al aumento de las fuerzas centrifugas. Y como también ocurría en el caso de la TGV de álabes fijos para un determinado régimen de giro corregido, el área efectiva de la tobera equivalente al rotor aumenta al aumentar el gasto corregido.

Para completar el modelo global falta conocer el rendimiento de la turbina, que se introduce en el modelo a partir de una serie de curvas que relacionan la relación cinemática con el rendimiento isentrópico, para posiciones fijas de la turbina253[9]. Santos [30] desarrolla una metodología para determinar de una forma simple la curva de rendimiento estacionaria en función de la relación cinemática a partir de los datos suministrados por el fabricante.

La relación cinemática se define como la relación entre la velocidad periférica de los álabes a la entrada del rotor y la velocidad que tendrian los gases si se expandieran adiabática y reversiblemente desde las condiciones de parada a la entrada de la turbina hasta la salida de esta.

$$
\sigma=\frac{u}{c_{2 s}}=\frac{\frac{\pi D_{r} n}{60}}{\sqrt{2 c_{p} T_{00}\left(1-\left(p_{00} / p_{2}\right)^{1-\gamma / \gamma}\right)}}
$$


Siendo $\mathrm{n}$ el régimen de giro de la turbina en revoluciones por minuto y $D_{\mathrm{r}}$ el diámetro del rodete.

Tomando los valores del rendimiento obtenidos a partir de las medidas y expresándolos en función de la relación cinemática se obtienen, para cada apertura, los puntos que se muestran en la figura 5. 48, en la que se observa que todos los puntos medidos se encuentran en un área muy limitada. A partir de estos puntos y la metodología desarrollada por Santos [30] se obtienen las curvas de rendimiento en función de relación cinemática que se introducen en el modelo.

Una vez descritas las características geométricas y la dinámica de la turbina, así como el motor al que estaba acoplada la turbina y en que se han realizado las medidas, se va a pasar ahora a la validación del modelo propiamente dicha. 


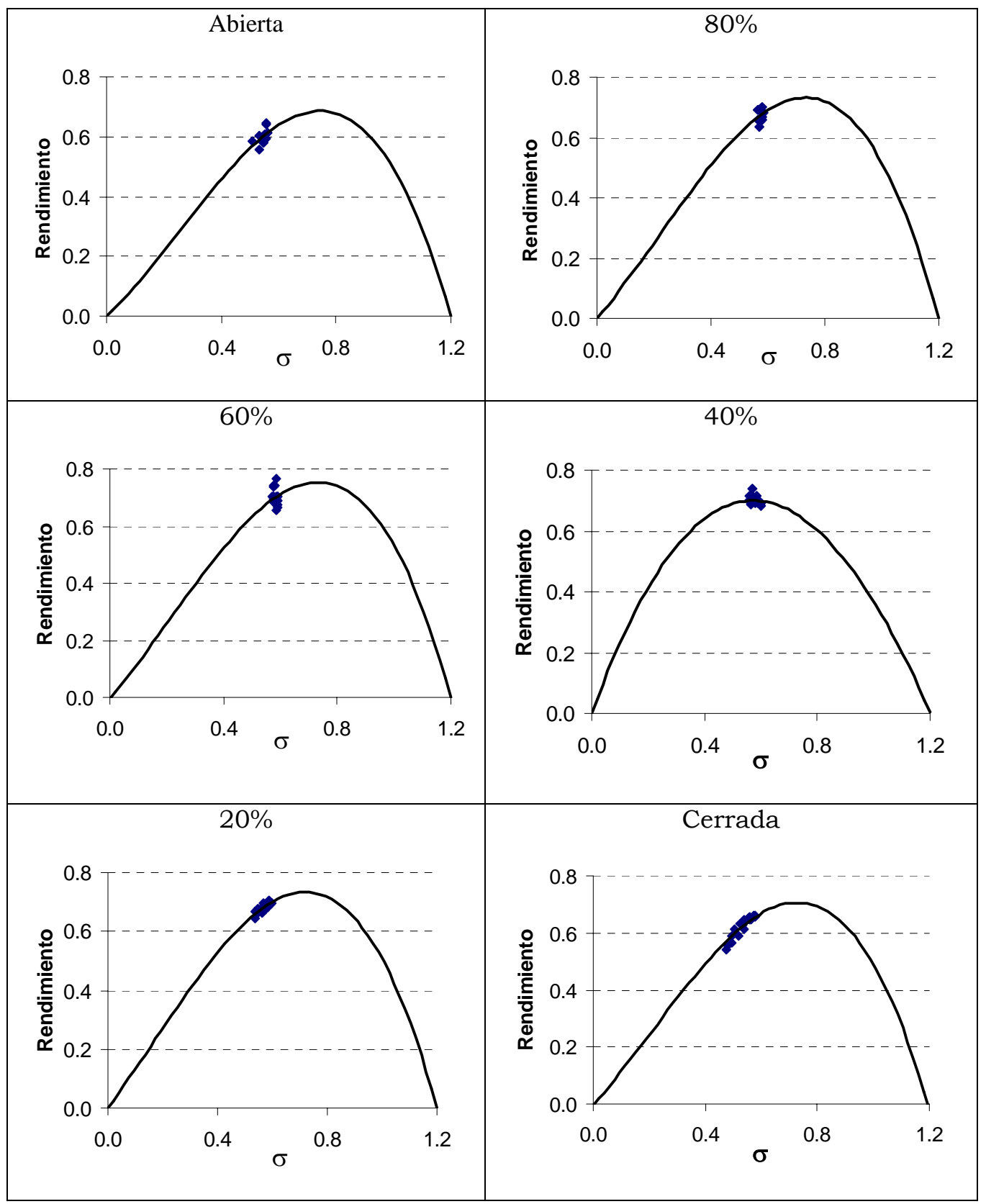

Figura 5. 48: Rendimiento de la turbina frente a la relación cinemática para las diferentes aperturas medidas. 


\subsubsection{Ensayos realizados para la validación del modelo}

Los ensayos para la validación del modelo de TGV para el caso de turbinas de álabes móviles se realizaron en una instalación diferente a la descrita en el caso de la validación del modelo para turbinas de álabes fijos.

Además en este caso los ensayos realizados para la validación son ensayos del tipo transitorios de carga, en los que el régimen de giro del motor se mantiene constante, pero el par efectivo evoluciona desde $\mathrm{O} \mathrm{Nm}$ hasta condiciones de plena carga. Estos ensayos siguen un ciclo conocido como ELR, correspondiente a los que se efectúan durante la homologación de motores para vehículos de transporte pesado.

El transitorio de carga se define en función del máximo régimen de giro del motor, siendo en este caso de 2000rpm. La normativa define tres regímenes de giro de referencia del motor, que son los más representativos de su funcionamiento, que son el $50 \%$, el $60 \%$ y el $70 \%$ del régimen máximo de funcionamiento. En el caso de este motor serán 1000, 1200 y $1400 \mathrm{rpm}$.

Por otro lado, la posición del acelerador del motor debe alcanzar el $100 \%$ en 0.2 segundos, en forma de rampa, como puede verse en la figura 5 . 49.

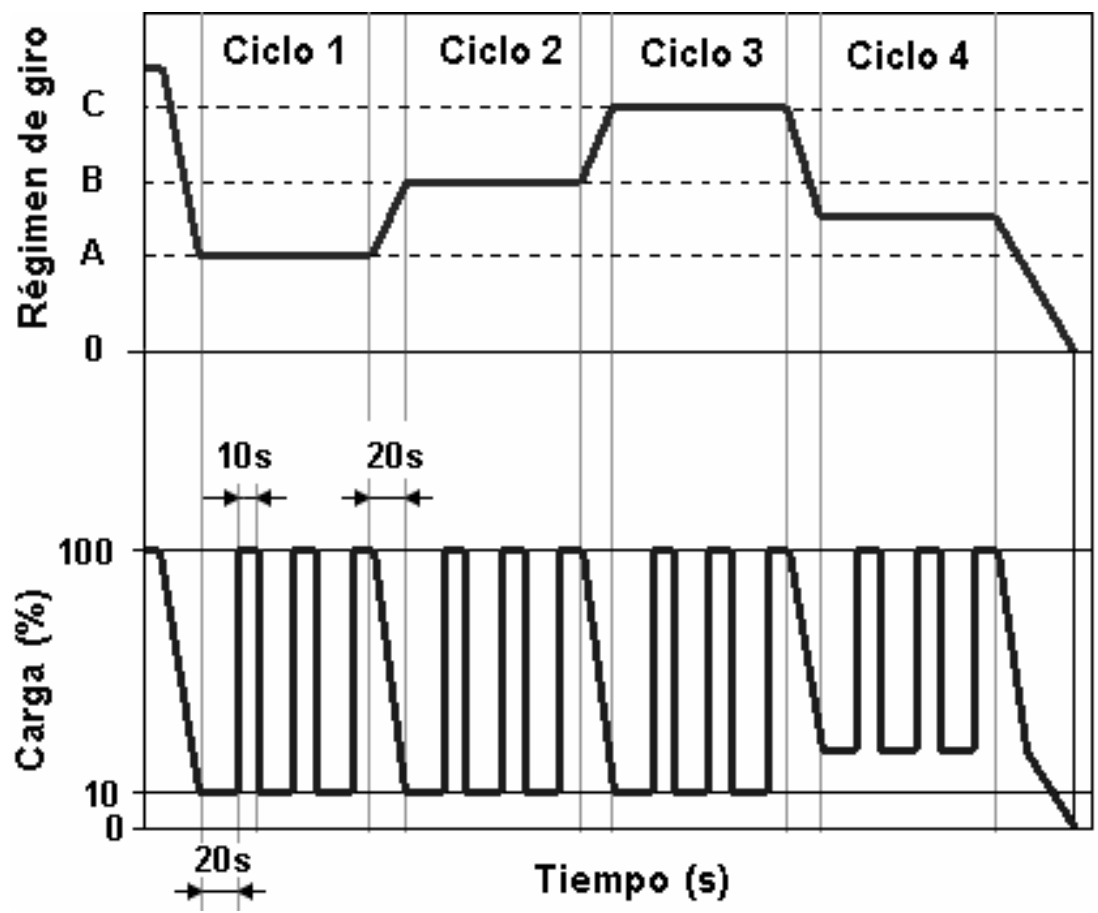

Figura 5. 49: Esquema de los transitorios de carga según el proceso normalizado por la ELR. 


\subsubsection{Comparación medido-modelado}

A continuación se puede ver el aspecto general de la aplicación de pretratamiento con la configuración del banco de ensayo de motores en la que se han realizado las medidas utilizadas para la validación que ahora se presenta.

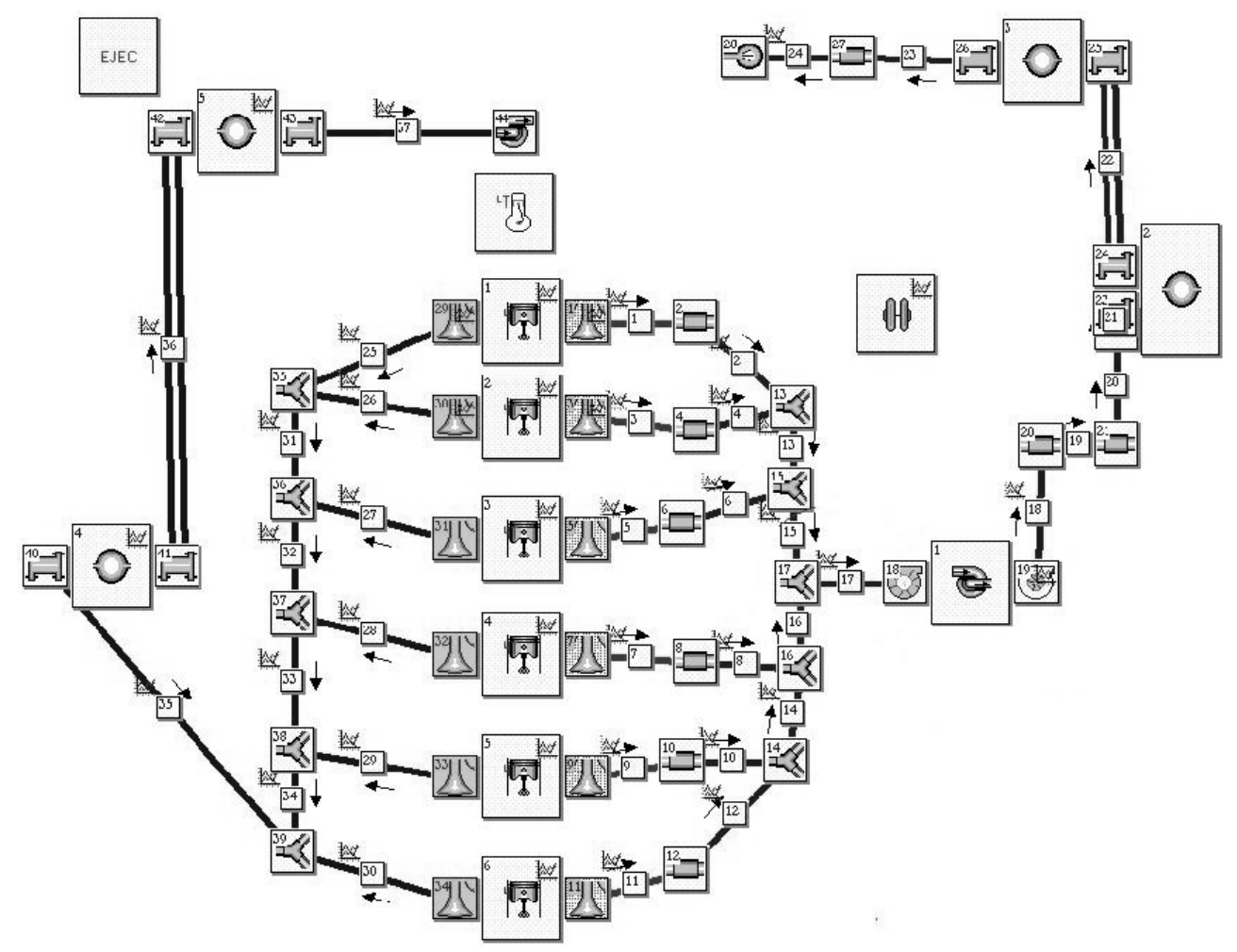

Figura 5. 50: Esquema de la instalación utilizada para validar el modelo de TGV.

Para cada uno de los regimenes de giro en los que sea ha realizado la comparación medido-modelado, se muestran dos gráficas, en la primera de ellas se comparan ocho variables importantes a la hora de caracterizar el comportamiento transitorio de un motor. Estas variables son: la presión de sobrealimentación, el régimen de giro del turbogrupo, el gasto másico de aire, el dosado relativo, la presión a la entrada y a la salida de la turbina, la cantidad de combustible inyectado y la posición de la turbina de geometría variable.

La validación del modelo se llevará a cabo comparando algunos parámetros calculados por el modelo completo de motor con resultados obtenidos en las medidas realizas durante los ensayos experimentales de transitorios de carga. La comparación aparece en las figura 5. 51 a la figura 
Contribución a la caracterización experimental y modelado de TGV en grupos de sobrealimentación

5. 53, mostrándose una buena aproximación entre los resultados medidos y los modelados.

Las diferencias observadas en los tres transitorios se deben fundamentalmente al modelado del mecanismo de la TGV que se ha realizado (figura 5. 43), debido a lo cual no se ha modelado el mecanismo de histéresis de la TGV.

El modelo funciona coherentemente con lo desplazamientos de la TGV que predice y cuando el desplazamiento medido coincide con el modelado el modelo funciona bien, reproduciendo perfectamente los valores medidos. Esto ocurre al comienzo del transitorio, en los tres casos, alrededor de los veinte primeros ciclos.

Se observa en los tres casos presentados que en el modelo abre antes la TGV, por lo que la presión en el escape no aumenta hasta los valores que se alcanzan en los ensayos (puede observarse gráfica de la esquina inferior izquierda de la figura 5. 51, de la figura 5. 52 y de la figura 5. 53). Es por ello que a la entrada de la turbina hay disponible menos energía en el modelado (el régimen de giro del turbogrupo modelado es menor que el régimen medido) y por lo tanto el compresor tiene menos energía disponible, lo que hace que no se alcancen las presiones en la admisión medidas, como se observa en la gráfica superior izquierda de las tres figuras.

Además, como experimentalmente la TGV permanece cerrada más tiempo, al abrir lo hace de una forma más brusca (recordemos que la regulación de la TGV es función de la presión en la admisión y es necesario que se abra más rápidamente para alcanzar los valores de consigna deseados y no tener valores excesivamente altos). Debido a esto la presión en el escape disminuye más bruscamente y la energía a la entrada de la turbina también, cosa que se observa fácilmente en la gráficas del régimen de giro, en las que a partir de este punto el régimen de giro del turbogrupo modelado es mayor que el medido, así como en las gráficas de la presión de escape, en las que la presión de escape modelada no llega a bajar hasta los valores medidos experimentalmente.

Cabe destacar como se observa en los tres casos que la presión a la entrada de la turbina reproduce las mismas tendencias que se observa en la posición de la turbina, tanto en el caso del modelo como de la medida.

Todo lo anterior valida el modelo propuesto en el capítulo 4 también en condiciones transitorias de motor. 

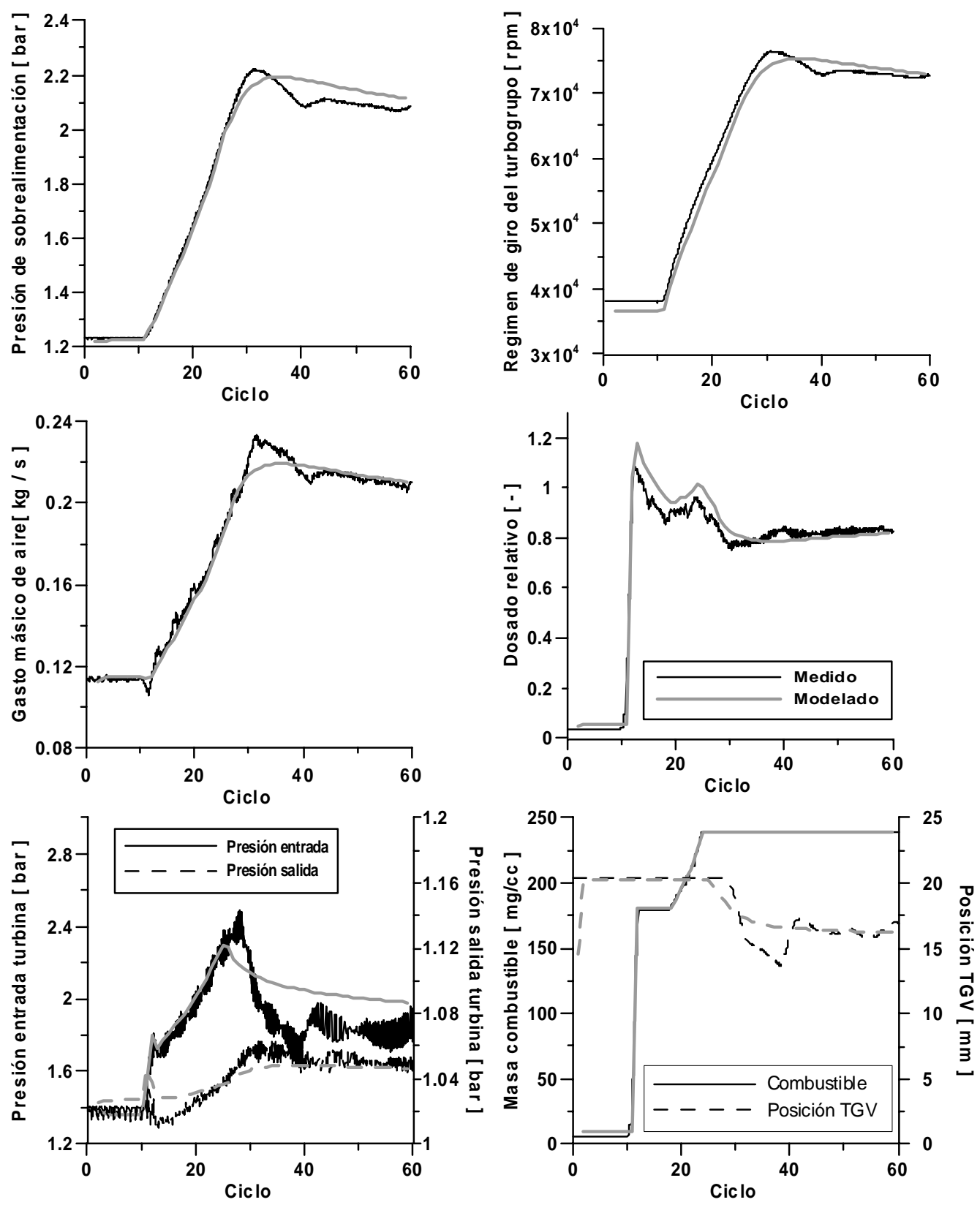

Figura 5. 51: Comparación de las variables medidas con las modeladas en los ensayos de 1000 rpm. 
Contribución a la caracterización experimental y modelado de TGV en grupos de sobrealimentación
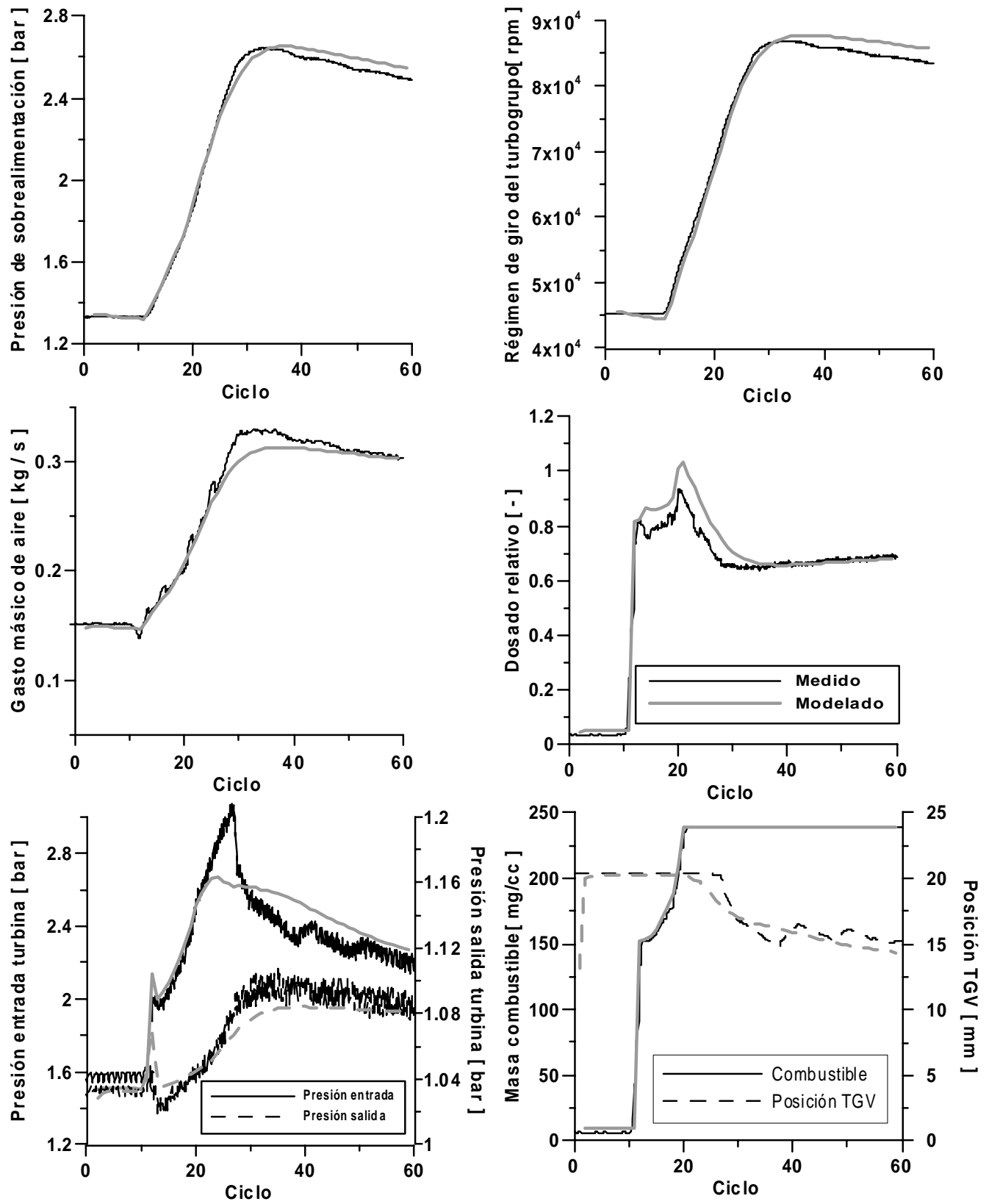

Figura 5. 52: Comparación de las variables medidas con las modeladas en los ensayos de $1200 \mathrm{rpm}$ 

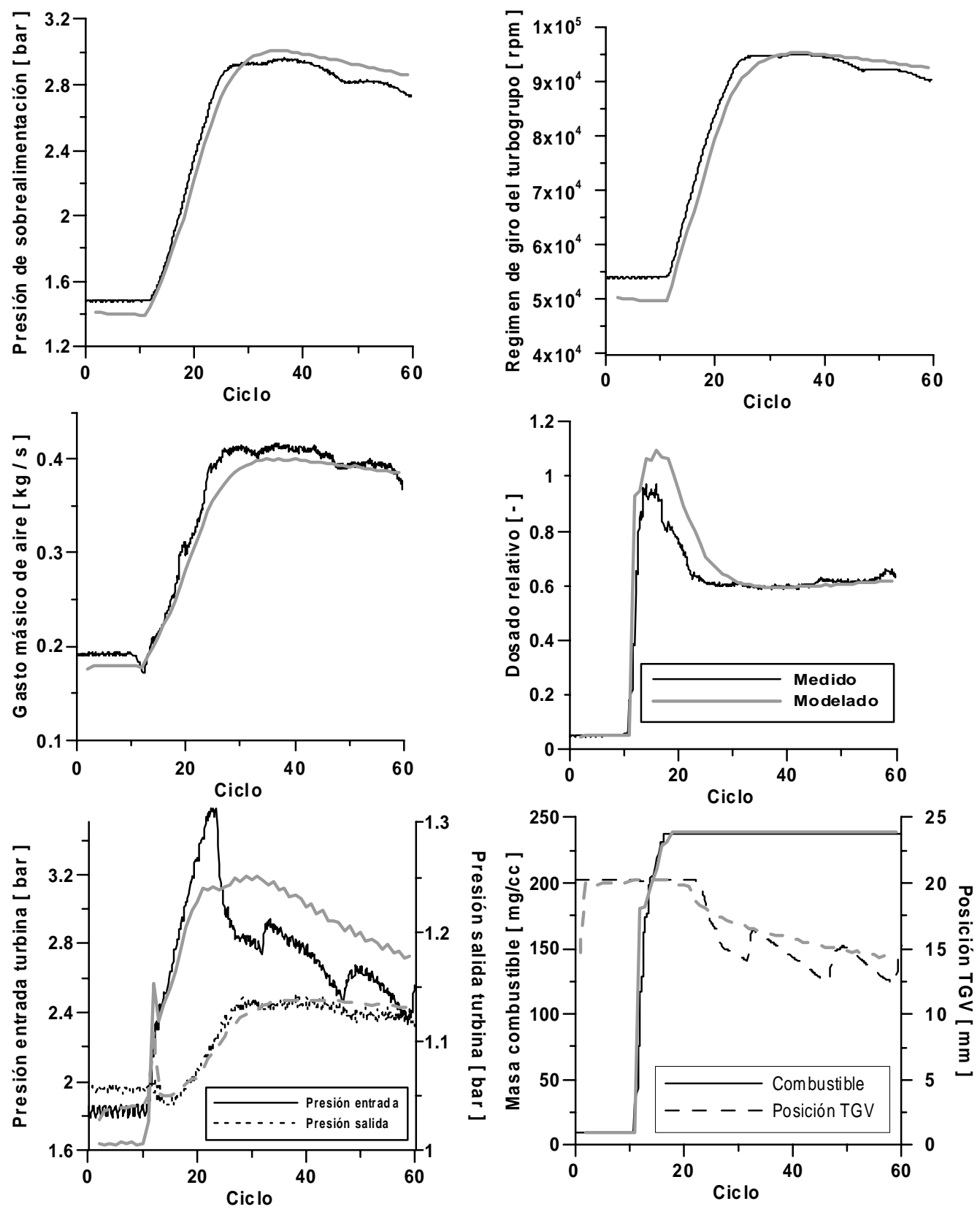

Figura 5. 53: Comparación de las variables medidas con las modeladas en los ensayos de 1400 rpm 
Un ejemplo de cómo se ajustan las presiones instantáneas se puede observar en la siguiente gráfica, donde se observa un perfecto ajuste entre las medidas realizadas y los valores modelados, tanto en la amplitud como en la fase de las ondas de presión.

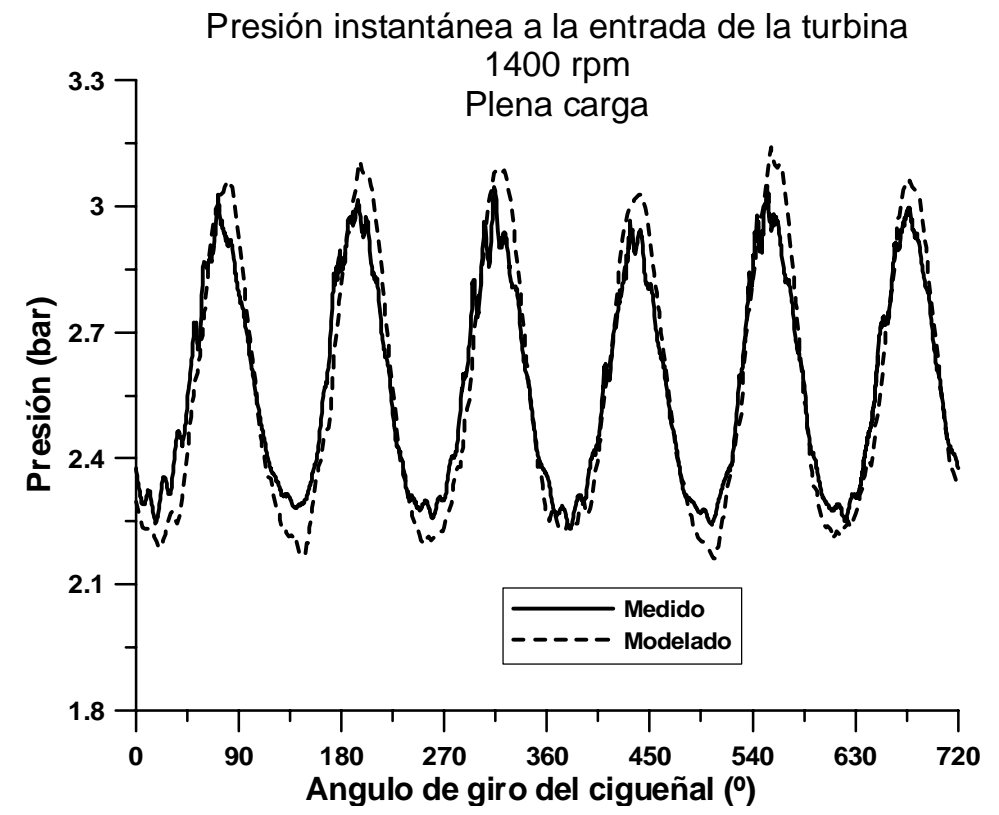

Figura 5. 54: Comparación medido-modelado de la presión instantánea a la entrada de la turbina, para medidas realizadas a plena carga y 1400 rpm. 


\subsection{Resumen}

A lo largo de este capítulo se ha elaborado una sintesis de los trabajos desarrollados a lo largo de la realización de la presente tesis doctoral, utilizando tanto el modelo unidimensional para turbinas de geometría variable propuesto, como las medidas realizadas en la instalación experimental, expresamente construida para el ensayo y estudio de turbogrupos y para la validación del modelo propuesto.

En la primera parte del capítulo se presenta el WAM, un modelo de acción de ondas unidimensional, no homoentrópico y no estacionario, en el que se ha incluido el modelo para turbinas de geometria variable expuesto en el capítulo 4 del presente trabajo. En este primer apartado se presenta el modelado de todos los puntos que forman una línea de isorégimen de un mapa de compresor, trabajando la TGV del turbogrupo bajo condiciones de flujo estacionario. A la vista de los resultados obtenidos es posible concluir que el modelo utilizado se ajusta perfectamente a las medidas realizadas en la instalación y es posible modelar el rendimiento instantáneo de la turbina, así pues, se demuestra como combinando la instalación experimental desarrollada y el modelos unidimensional propuesto es posible profundizar en el estudio de las interacciones del flujo pulsante con el rendimiento de la TGV bajo diferentes condiciones de funcionamiento.

Para finalizar el capítulo se muestra como el modelo completo de motor, con el submodelo de turbina de geometria variable, tanto en el caso de turbinas de álabes fijos, como en el caso de turbinas de álabes móviles, es capaz de reproducir con gran precisión el comportamiento de la turbina acoplada al motor.

En el caso de la turbina de geometría variable de álabes fijos acoplada a motor se realizó el modelado completo del conjunto para puntos estacionarios de motor. A partir de este estudio se obtienen las siguientes conclusiones:

o El grado de reacción de una turbina de geometría variable de álabes fijos tiene un elevado nivel de correlación, con el gasto trasegado por la turbina y la apertura de la misma.

o Una vez conocido el grado de reacción de la turbina en unas determinadas condiciones de funcionamiento es posible calcular las áreas efectivas de las toberas equivalentes al estator y al rotor de la turbina. Obteniéndose que en el caso de esta turbina el área efectiva del estator se correlaciona con la posición de la turbina y la del rotor el gasto másico y el régimen de giro de la turbina corregidos con las condiciones del gas a la entrada del rotor. 
- Al comparar las medidas y los valores obtenidos con el modelo de acción de ondas se obtiene un elevado grado de acuerdo, obteniéndose errores máximos en la presión a la entrada de la turbina de alrededor del $5 \%$.

En el caso de la turbina de geometría variable de álabes móviles acoplada a motor se realizó el modelado completo del conjunto para transitorios de carga de motor. A partir de este estudio se obtienen las siguientes conclusiones:

o Es posible correlacionar el área efectiva de la tobera equivalente al estator de la turbina en función de la posición de la turbina.

o Es posible correlacionar el área efectiva de la tobera equivalente al rotor de la turbina en función del gasto del régimen de giro corregidos con las condiciones del gas a la entrada del rotor. Se evidencia que el área efectiva de la tobera equivalente al rotor, para un régimen de giro determinado, aumenta al aumentar el caudal de gases trasegados y la relación de expansión. Sin embargo, para un gasto determinado, el área efectiva de la tobera equivalente al rotor disminuye al aumentar el régimen de giro, puesto que aumentan las fuerzas centrifugas que se producen al girar el rodete y se dificulta el paso de los gases de escape.

o Con estas dos correlaciones y conociendo la dinámica que gobierna la posición de la turbina es posible modelarla, tanto en condiciones estacionarias de motor como para reproducir los transitorios de carga de un motor diesel turboalimentado. 


\section{Anexo 1: TABLAS DE MEDIDAS}

En el presente anexo se incluyen los datos medidos obtenidos en los ensayos de caracterización de las TGV modeladas.

En primer lugar se muestran los resultados obtenidos en el llamado ensayo patrón (tabla a. 1 a tabla a. 4), a continuación se muestran los resultados de los ensayos de caracterización de la TGV de álabes fijos bajo condiciones de flujo no estacionario (tabla a. 5 a tabla a. 7). Finalmente se muestran los resultados de los ensayos de caracterización de la TGV de álabes móviles(tabla a. 8 a tabla a. 25).

\begin{tabular}{|c|c|c|c|c|c|c|c|c|c|c|c|c|c|c|c|}
\hline FECHA & HORA & CODIGO & REGIMEN & CARGA & PAR & POTENCIA & PME & P. ATM & T.AMB & T. COMB & T. AGUA & T.ACEITE & T_EN_COM & T_SA_COM & T_SAIN_E \\
\hline ddmmyy & hhmmss & & rpm & $\%$ & $\mathrm{Nm}$ & $\mathrm{KW}$ & bar & bar & Cel & Cel & Cel & Cel & Cel & Cel & Cel \\
\hline 23-jun-99 & 12:05:16 & c1001 & 1000 & 22.50 & 17.20 & 1.80 & 1.015 & 1.016 & 29.30 & 30.41 & 85.58 & 85.12 & 30.91 & 36.79 & 35.14 \\
\hline 23-jun-99 & 11:53:48 & $\mathrm{c} 1002$ & 1000 & 25.70 & 34.20 & 3.60 & 1.976 & 1.016 & 29.70 & 30.45 & 85.16 & 85.12 & 31.57 & 37.74 & 36.03 \\
\hline 23-jun-99 & 11:36:12 & c1004 & 1000 & 33.10 & 70.20 & 7.40 & 4.058 & 1.016 & 30.00 & 31.00 & 85.07 & 85.52 & 32.79 & 41.28 & 39.49 \\
\hline 23-jun-99 & 11:11:14 & $\mathrm{c} 1000$ & 1000 & 100.10 & 158.20 & 16.60 & 9.115 & 1.016 & 29.30 & 30.92 & 85.06 & 85.01 & 35.36 & 56.31 & 52.36 \\
\hline 23-jun-99 & $20: 30: 13$ & c1252 & 1250 & 29.80 & 34.80 & 4.50 & 1.973 & 1.015 & 29.50 & 26.87 & 85.03 & 82.15 & 29.67 & 37.14 & 35.35 \\
\hline 23-jun-99 & $17: 50: 29$ & C1253 & 1250 & 33.20 & 51.70 & 6.80 & 2.999 & 1.014 & 31.20 & 28.81 & 85.02 & 83.17 & 31.37 & 40.35 & 36.90 \\
\hline 23 -jun-99 & $20: 10: 48$ & c1254 & 1250 & 36.90 & 70.20 & 9.20 & 4.050 & 1.015 & 30.00 & 27.15 & 85.40 & 84.04 & 30.59 & 42.31 & 39.99 \\
\hline 23-jun-99 & $13: 05: 13$ & c1256 & 1250 & 43.80 & 105.10 & 13.80 & 6.064 & 1.016 & 30.00 & 31.55 & 85.07 & 83.89 & 31.60 & 52.80 & 48.85 \\
\hline 23-jun-99 & $19: 56: 13$ & c1258 & 1250 & 49.60 & 139.30 & 18.30 & 8.040 & 1.015 & 30.60 & 28.40 & 85.18 & 84.21 & 31.56 & 57.35 & 53.61 \\
\hline 23-jun-99 & $19: 44: 04$ & $\mathrm{c} 12510$ & 1250 & 54.50 & 174.10 & 22.80 & 10.035 & 1.015 & 31.30 & 28.83 & 85.07 & 82.93 & 33.34 & 70.19 & 59.85 \\
\hline 23-jun-99 & $12: 49: 29$ & c1250 & 1249 & 100.10 & 207.10 & 27.10 & 11.952 & 1.016 & 29.70 & 31.93 & 85.16 & 84.43 & 33.90 & 83.96 & 60.06 \\
\hline 24 -jun-99 & $11: 52: 08$ & c1504 & 1499 & 40.20 & 69.60 & 10.90 & 4.013 & 1.018 & 30.30 & 28.60 & 85.16 & 84.89 & 31.56 & 47.46 & 45.32 \\
\hline 24-jun-99 & $11: 37: 31$ & c1508 & 1499 & 50.00 & 138.90 & 21.70 & 7.970 & 1.017 & 30.70 & 29.88 & 85.15 & 85.78 & 33.58 & 68.30 & 59.80 \\
\hline 24 -jun-99 & $11: 21: 15$ & $\mathrm{c} 1512$ & 1499 & 59.10 & 210.30 & 33.00 & 12.130 & 1.017 & 30.70 & 30.15 & 85.22 & 84.90 & 35.52 & 91.78 & 60.00 \\
\hline 24 -jun-99 & 11:12:40 & c1500 & 1498 & 100.10 & 269.50 & 42.30 & 15.545 & 1.017 & 29.60 & 29.75 & 85.08 & 85.07 & 36.72 & 113.13 & 58.98 \\
\hline 25-jun-99 & $12: 47: 13$ & c1752 & 1750 & 34.70 & 34.60 & 6.30 & 1.992 & 1.016 & 30.70 & 28.95 & 85.29 & 85.20 & 31.46 & 42.01 & 40.61 \\
\hline 25 -jun-99 & $12: 32: 58$ & C1754 & 1750 & 42.00 & 68.90 & 12.60 & 3.958 & 1.016 & 30.70 & 28.95 & 85.04 & 85.25 & 32.61 & 52.63 & 49.914 \\
\hline 25 -jun-99 & $12: 21: 22$ & c1756 & 1750 & 47.50 & 104.20 & 19.10 & 6.018 & $\frac{1.010}{1.016}$ & $\begin{array}{l}30.10 \\
30.90\end{array}$ & $\frac{29.95}{29.00}$ & 85.19 & $\begin{array}{l}83.253 \\
84.44\end{array}$ & $\frac{32.01}{34.02}$ & 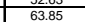 & $\begin{array}{l}49.94 \\
59.30\end{array}$ \\
\hline 25 -jun -99 & $12: 04: 52$ & $\begin{array}{l}\mathrm{c} 1758 \\
\mathrm{c} 1758\end{array}$ & 1750 & 51.40 & 138.90 & 25.40 & 8.004 & 1.016 & 31.10 & 30.79 & 85.18 & 84.18 & 34.30 & $\begin{array}{l}74.49 \\
74.9\end{array}$ & 59.29 \\
\hline 25-jun-99 & $\begin{array}{l}11: 54: 12 \\
\end{array}$ & c17510 & 1750 & 55.80 & 173.00 & 31.80 & 10.017 & 1.016 & 31.30 & 31.05 & 85.11 & 84.32 & 33.89 & $\begin{array}{l}83.46 \\
\end{array}$ & $\begin{array}{l}59.69 \\
\end{array}$ \\
\hline 25 -jun-99 & $11: 31: 31$ & c17512 & 1750 & 60.90 & 208.70 & 38.40 & 12.077 & 1.016 & 31.00 & 31.07 & 85.31 & 85.06 & 34.34 & $\begin{array}{l}07.40 \\
97.09\end{array}$ & $\begin{array}{l}0.00 \\
60.42\end{array}$ \\
\hline 25 -jun-99 & $11: 18: 12$ & c17514 & 1749 & 66.50 & 243.50 & 44.50 & 14.012 & 1.016 & 30.30 & 30.92 & 85.10 & 85.09 & 34.49 & 109.06 & 60.37 \\
\hline 24 -jun-99 & $12: 35: 01$ & c1750 & 1751 & 100.10 & 289.30 & 52.90 & 16.628 & 1.017 & 30.60 & 31.17 & 85.11 & 85.10 & 35.72 & 120.77 & 59.80 \\
\hline 23-jun-99 & $18: 37: 18$ & C2004 & 2000 & 43.60 & 68.80 & 14.40 & 3.964 & 1.014 & 30.40 & 30.01 & 85.14 & 83.48 & 32.90 & 59.59 & 55.91 \\
\hline 23-jun-99 & $18: 26: 35$ & $\begin{array}{l}\mathrm{c} 20007 \\
\end{array}$ & 2000 & 51.60 & 120.80 & 25.30 & 6.958 & 1.014 & 30.10 & 30.01 & 85.13 & 85.38 & 33.46 & 79.01 & 59.41 \\
\hline 23-jun-99 & $18: 47: 51$ & c2008 & 2001 & 53.60 & 139.40 & 29.20 & 8.040 & 1.014 & 30.30 & 31.93 & 85.23 & 86.62 & 33.31 & 85.88 & 60.06 \\
\hline 23-jun-99 & 19:02:09 & c2012 & 2000 & 61.90 & 207.50 & 43.50 & 11.979 & 1.014 & 30.60 & 32.31 & 85.16 & 84. & 33.47 & 99.77 & 59.83 \\
\hline 23-jun-99 & $19: 22: 51$ & c2000 & 2000 & 100.10 & 308.30 & 64.60 & 17.788 & 1.014 & 31.30 & 31.68 & 85.16 & 85.34 & 37.30 & 129.87 & 59.81 \\
\hline 01-jul-99 & $10: 04: 17$ & $\mathrm{c} 2252$ & 2250 & 38.900 & 35.300 & 8.400 & 2.057 & 1.018 & 29.600 & 30.920 & 85.380 & 84.550 & 31.690 & 54.200 & 50.950 \\
\hline 30-jun-99 & $\begin{array}{l}17: 04: 40 \\
\end{array}$ & c2254 & 2250 & 44.500 & 69.900 & 16.500 & 4.030 & 1.019 & 33.100 & 33.510 & 85.200 & 84.330 & 37.310 & 63.290 & 59.230 \\
\hline 30-jun-99 & $18: 51: 09$ & c22256 & 2250 & 48.700 & 103.900 & 24.600 & 6.009 & 1.018 & 34.000 & 33.620 & 85.230 & 86.050 & 39.610 & 73.770 & 59.500 \\
\hline 30-jun-99 & $16: 54: 30$ & c2258 & 2250 & 53.200 & 137.800 & 32.600 & 7.973 & 1.019 & 33.000 & 35.690 & 85.320 & 84.680 & 37.610 & 88.710 & 59.870 \\
\hline 30-jun-99 & $18: 42: 14$ & c22510 & 2250 & 58.900 & 174.400 & 41.100 & 10.048 & 1.018 & 34.200 & 36.130 & 85.080 & 83.880 & 38.740 & 96.900 & 59.500 \\
\hline 30 -jun -99 & $18: 30: 52$ & $\mathrm{c} 22514$ & 2250 & 68.700 & 242.100 & 57.200 & 13.999 & 1.018 & 34.200 & 36.020 & 84.990 & 84.410 & 39.080 & 117.680 & 59.810 \\
\hline $\begin{array}{l}30-\text { unn-99 } \\
30 \text {-jun }\end{array}$ & $\begin{array}{l}18.30: 52 \\
18: 20: 12\end{array}$ & $\frac{\square 22514}{\mathrm{c} 22516}$ & $\frac{250}{2250}$ & $\begin{array}{l}\text { 68.100 } \\
74.700\end{array}$ & $\frac{24.100}{278.200}$ & $\begin{array}{l}\frac{10.200}{65.300} \\
\end{array}$ & $\begin{array}{l}13.999 \\
15.975\end{array}$ & $\begin{array}{l}1.018 \\
1.018\end{array}$ & $\begin{array}{r}34.200 \\
33.900\end{array}$ & $\begin{array}{l}35.000 \\
35.580\end{array}$ & $\begin{array}{l}84.4900 \\
85.150\end{array}$ & $\begin{array}{l}84.450 \\
85.420\end{array}$ & $\begin{array}{l}39.080 \\
39.110\end{array}$ & $\begin{array}{l}11.080 \\
127.410\end{array}$ & $\begin{array}{l}\frac{59.810}{60.680} \\
\end{array}$ \\
\hline 25 -jun-99 & $13: 44:$ & 2250 & 2250 & 100.10 & 307.30 & 72.30 & 17.705 & 1.0 & 32.00 & 32.84 & 85.18 & 85. & 37.49 & 132.13 & 59.84 \\
\hline 23-jur & & $\mathrm{C} 2508$ & 2500 & 54 & 138 & 36 & 7.9 & 1. & & 38 & 85 & 83 & 33 & & 60.00 \\
\hline 23 -jun-99 & $16: 34: 06$ & $\mathrm{C} 2500$ & 2501 & $\frac{34.20}{100.10}$ & $\frac{130.00}{300.70}$ & $\frac{30 .}{79 .}$ & 17.4 & $\frac{1.0}{1.0}$ & 32 & $\frac{30}{37}$ & 85.19 & 87 & 37. & $\frac{94.52}{134.06}$ & $\begin{array}{l}64.09 \\
\end{array}$ \\
\hline $\begin{array}{l}2-3-j n \mid-99 \\
01-j u l-99\end{array}$ & $\begin{array}{l}10.3400 \\
11: 51: 50\end{array}$ & $\begin{array}{l}02500 \\
3002\end{array}$ & 3000 & $\frac{10.10}{41.600}$ & $\begin{array}{l}300.10 \\
36.500\end{array}$ & $\begin{array}{l}11.10 \\
11.500\end{array}$ & $\frac{1.4}{2.1}$ & $\frac{1.014}{1.018}$ & $\begin{array}{r}32.30 \\
31.700\end{array}$ & $\begin{array}{l}3.160 \\
34.930\end{array}$ & $\begin{array}{l}85.19 \\
85.080\end{array}$ & $\begin{array}{l}84.740 \\
84.74\end{array}$ & $\begin{array}{l}3.83 \\
33.050\end{array}$ & $\begin{array}{l}134.00 \\
60.230\end{array}$ & $\begin{array}{l}04.09 \\
58.500\end{array}$ \\
\hline 01-jul-99 & $11: 3$ & 3004 & 2999 & 46.000 & 69.300 & 21. & 3.9 & 1.018 & 31.800 & 34.900 & 85.070 & 84.760 & 33.640 & 69.770 & 59.890 \\
\hline $01-$ jul-99 & $11: 23: 44$ & 3006 & 2999 & 51.600 & 105.000 & 33.0 & 6.05 & 1.018 & 32.800 & 34.980 & 85.020 & 84.660 & 34.090 & 81.930 & 59.650 \\
\hline $01-$ jul-99 & $11: 06: 24$ & 3008 & 3000 & 57.600 & 138.800 & 43.600 & 8.011 & 1.018 & 32.800 & 39.300 & 85.140 & 84.360 & 35.040 & 95.420 & 59.600 \\
\hline $01-$ jul-99 & $10: 52: 38$ & 30010 & 3000 & 60.700 & 172.800 & 54.200 & 9.949 & 1.018 & 33.100 & 38.970 & 85.100 & 84.700 & 35.800 & 101.970 & 57.250 \\
\hline $01-$ jul-99 & $10: 34: 42$ & 30012 & 2999 & 66.900 & 208.000 & 65.200 & 11.976 & 1.018 & 33.600 & 38.770 & 85.070 & 84.960 & 37.040 & 112.770 & 59.720 \\
\hline $01-$-jul-99 & $10: 22: 36$ & 30014 & 300 & 73.30 & 240. & 75. & 13.8 & 1.0 & 31 & 37 & 85.120 & 87. & 36.940 & & 60.850 \\
\hline 30 -jun-99 & $13: 37: 30$ & $\mathrm{c} 30$ & 2999 & 100.100 & 277.200 & 87.0 & 15.9 & 1.020 & 33.8 & 37. & 85.06 & 89. & 39.270 & 134.000 & 66.780 \\
\hline 30-jun-99 & $13: 47: 42$ & c3500 & 3500 & 100.100 & 249.500 & 91. & 14. & $\begin{array}{l}.020 \\
1.020\end{array}$ & 38.800 & $\frac{15.900}{40.750}$ & $\begin{array}{l}85.000 \\
85.060\end{array}$ & $\begin{array}{l}95.000 \\
93.800\end{array}$ & $\begin{array}{l}39.270 \\
42.970\end{array}$ & $\begin{array}{l}1359.000 \\
139.990\end{array}$ & $\begin{array}{l}0.1100 \\
71.210\end{array}$ \\
\hline 01-jul-99 & $13: 11: 59$ & 40 & 4000 & 42.400 & 35.200 & 14. & 2.0 & 1.017 & 32.900 & 38.650 & 85.100 & 84.490 & 34.210 & 66.800 & 59.940 \\
\hline 23-jun-99 & $17: 20: 03$ & C4006 & 4000 & 55.10 & 104.60 & 43.50 & 5.993 & 1.014 & 34.80 & 40.17 & 85.13 & 86.40 & 35.14 & 96.51 & 57.30 \\
\hline $01-$ jul-99 & $12: 35: 41$ & 4008 & 4000 & 62.900 & 139.200 & 58.400 & 8.034 & 1.018 & 35.300 & 45.070 & 85.130 & 88.160 & 37.550 & 112.680 & 60.250 \\
\hline $01-$ jul-99 & $12: 21: 14$ & 40010 & 4000 & 70.900 & 173.800 & 72.600 & 9.993 & 1.018 & 32.700 & 43.070 & 85.330 & 91.000 & 36.650 & 124.360 & 66.470 \\
\hline 23-jun-99 & $17: 06: 47$ & C4000 & 4001 & 100.10 & 222.50 & 93.20 & 12.823 & 1.014 & 35.10 & 43.24 & 85.17 & 96.37 & 39.81 & 144.13 & 72.78 \\
\hline 01-jul-99 & $13: 25: 35$ & 4500 & 4500 & 100.100 & 173.500 & 81.900 & 10.018 & 1.017 & 36.200 & 45.330 & 84.980 & 97.670 & 41.110 & 142.270 & 77.940 \\
\hline
\end{tabular}

Tabla A. 1: Puntos medidos en el ensayo patrón(1). 
Contribución a la caracterización experimental y modelado de TGV en grupos de sobrealimentación

\begin{tabular}{|c|c|c|c|c|c|c|c|c|c|c|c|c|c|c|c|}
\hline CODIGO & TEN_TU & TSA_Cl1 & TSA_Cl2 & [SA_Cl3 & T_SA_Cl4 & T_SA_TU & T_EGR & POOIL & & & P_SA_COM & P_SIIABS & P_SA_IN & P_EN_TU & PSAA \\
\hline 001 & $\begin{array}{ll}\text { Cel } \\
16578\end{array}$ & $\begin{array}{ll}\text { Cel } \\
15136\end{array}$ & $\begin{array}{c}\text { Cel } \\
14130\end{array}$ & $\begin{array}{lll}\text { Cel } \\
1577\end{array}$ & $\begin{array}{l}\text { Cel } \\
14575\end{array}$ & Cel & $\begin{array}{ll}\mathrm{Cel} \\
\end{array}$ & Bar & bar & bar & \begin{tabular}{|l|l|} 
bar \\
10151
\end{tabular} & bar & bar & bar & bar \\
\hline & $\frac{103.18}{211.65}$ & & & & & & & & & & $\frac{1.051}{0.9750}$ & & & & \\
\hline & $\frac{215.83}{308.83}$ & 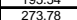 & $\frac{15.12}{253.53}$ & $\frac{20.34}{200.84}$ & $\frac{15.46}{25.64}$ & $\frac{15.94}{25.911}$ & $\frac{150.47}{144.67}$ & $\begin{array}{l}\frac{1.60}{1.60} \\
\end{array}$ & $\frac{0.000}{0.0000}$ & $\frac{1.016}{1.016}$ & $\frac{1.9108}{1.0188}$ & 1.062 & $\frac{0.036}{0.046}$ & $\frac{1.1527}{1.1527}$ & $\begin{array}{l}\frac{1.0055}{1.0082} \\
\end{array}$ \\
\hline 000 & 543.94 & 463.15 & 435.20 & 498.01 & & 446.88 & 27.95 & 1.50 & -0.0020 & & & & 0.175 & $\frac{1.1521}{1.3434}$ & \\
\hline & & 214.36 & 194.44 & 216.95 & 199.54 & 195.65 & 150.74 & 1.90 & 0.0010 & & & & & & \\
\hline $\begin{array}{l}\mathrm{C} 12253 \\
\mathrm{C}^{1254}\end{array}$ & \begin{tabular}{|l|}
274.08 \\
3230 \\
\end{tabular} & \begin{tabular}{|l}
255.97 \\
3013 \\
\end{tabular} & $\begin{array}{l}231.13 \\
27261 \\
\end{array}$ & $\begin{array}{l}262.49 \\
33038 \\
\end{array}$ & $\begin{aligned} 242.38 \\
28209\end{aligned}$ & $\begin{array}{l}231.09 \\
27329 \\
\end{array}$ & \begin{tabular}{|l}
156.65 \\
1629
\end{tabular} & $\begin{array}{l}1.80 \\
1.80\end{array}$ & $\begin{array}{l}0.0000 \\
0.00010\end{array}$ & 1.014 & \begin{tabular}{|l|l}
1.0491 \\
10829
\end{tabular} & 1.054 & $\begin{array}{l}0.040 \\
0.073\end{array}$ & $\begin{array}{l}1.1657 \\
1.2409\end{array}$ & $\begin{array}{l}1.0131 \\
1.157 \\
\end{array}$ \\
\hline$\frac{c 1254}{c 1256}$ & $\frac{324.30}{441498}$ & & & & 282.09 & $\begin{array}{l}273.29 \\
232.29\end{array}$ & \begin{tabular}{|l|}
162.92 \\
12747
\end{tabular} & $\begin{array}{l}1.80 \\
1.80\end{array}$ & -0.0010 & $\begin{array}{l}1.014 \\
1014\end{array}$ & \begin{tabular}{|l}
1.0829 \\
10244 \\
104
\end{tabular} & $\frac{1.088}{1.102}$ & 0.073 & $\frac{1.2408}{1.2023}$ & $\begin{array}{l}1.0157 \\
10207\end{array}$ \\
\hline$\frac{c 1256}{c 1258}$ & $\frac{144.98}{470.13}$ & \begin{tabular}{|l|}
366.10 \\
416.39
\end{tabular} & $\frac{349.85}{391.80}$ & $\frac{398.03}{438.98}$ & $\begin{array}{l}3550.09 \\
397.59\end{array}$ & $\begin{array}{l}344.23 \\
388.58 \\
\end{array}$ & $\frac{127.47}{27.43}$ & $\frac{1.80}{1.70}$ & $\begin{array}{l}-0.0020 \\
-0.0030\end{array}$ & $\frac{1.014}{1.012}$ & $\frac{1.1844}{1.2482}$ & $\frac{1.192}{1.247}$ & $\frac{0.176}{0.232}$ & $\frac{1.4232}{1.6155}$ & $\frac{1.0207}{1.0258}$ \\
\hline & & & & $\frac{514.78}{5148}$ & & $\frac{30.46}{444.42}$ & 20.16 & $\frac{1.70}{1.70}$ & $\frac{-0.0030}{-0.0030}$ & & $\frac{1.4619}{1.3619}$ & $\frac{1.361}{1.361}$ & $\frac{.346}{0.346}$ & $\frac{1.0153}{1.6423}$ & \\
\hline c1250 & 515.22 & 5552.19 & 541.26 & 596.02 & \begin{tabular}{|l}
542.78 \\
\end{tabular} & 515.80 & 29.01 & 1.70 & -0.0040 & 1.01 & 1.4968 & 1.494 & 0.478 & 1.8749 & 1.0204 \\
\hline & 250.88 & 328.95 & 298.85 & 332.28 & 308.88 & & & 2.20 & -0.0010 & & 1.1413 & 1.142 & 0.124 & 1.3653 & $\begin{array}{ll}1.0158 \\
\end{array}$ \\
\hline c1508 & $\begin{array}{r}364.31 \\
44374\end{array}$ & $\begin{array}{l}432.04 \\
55069\end{array}$ & 414.37 & $\begin{array}{r}454.92 \\
550.46\end{array}$ & \begin{tabular}{|l|}
416.67 \\
\end{tabular} & 393.10 & $\begin{array}{l}79.82 \\
3211 \\
2\end{array}$ & 2.20 & -0.0040 & 1.013 & 1.3753 & 1.367 & 0.350 & 1.6592 & 324 \\
\hline & $\begin{array}{l}\frac{443.74}{531.57} \\
\end{array}$ & $\frac{540.69}{627.15}$ & & $\frac{550.46}{645.95}$ & $\frac{511.26}{586.47}$ & $\frac{469.29}{55286}$ & $\frac{32.14}{33.64}$ & & $\frac{-0.0080}{-0.0100}$ & $\frac{1.009}{1007}$ & $\frac{1.6234}{1.8585}$ & 1.609 & $\frac{0.592}{0.816}$ & $\frac{2.1241}{2328}$ & $\frac{1.044}{10644}$ \\
\hline & $\frac{53.57}{27.97}$ & & & & 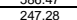 & & 192.76 & & $\frac{-0.0010}{-0.010}$ & & & . & $\frac{0.016}{0.066}$ & 告.250 & 1.064 \\
\hline & 375.49 & & 321.80 & & 334.65 & 314.42 & 219.04 & 2.60 & -0.0030 & 1.013 & 1.1950 & 1.199 & 0.183 & 1.4946 & $\frac{1.0050}{1.0262}$ \\
\hline 758 & $\begin{array}{l}478.32 \\
49.90\end{array}$ & $\begin{array}{l}434.78 \\
449.63\end{array}$ & 409.86 & 450.72 & 414.54 & 394.95 & 239.31 & 2.70 & $\begin{array}{l}-0.0040 \\
-00090\end{array}$ & 1012 & 1.3146 & 1.310 & 294 & $\begin{array}{l}1.5552 \\
1.9211\end{array}$ & 1.019 \\
\hline & $\begin{array}{l}4988.90 \\
5\end{array}$ & & & & & & & & & 1.008 & & & & & 1.047 \\
\hline 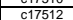 & 5 & $\begin{array}{l}40.50 \\
58074\end{array}$ & $\begin{array}{l}450.05 \\
51722\end{array}$ & $\begin{array}{l}40.04 \\
52224\end{array}$ & $\begin{array}{l}453.50 \\
49185\end{array}$ & 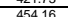 & 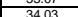 & 2.200 & -0.010 & 100 & 1.5000 & . & (1) & $\frac{1.0302}{20444}$ & $\frac{1.0424}{1.0645}$ \\
\hline & 596.48 & $\begin{array}{l}5000.14 \\
592.59 \\
\end{array}$ & $\frac{513.23}{543.73}$ & $\frac{26.24}{506.67}$ & $\begin{array}{l}541.05 \\
524.78 \\
\end{array}$ & $\begin{array}{l}454.40 \\
474.44 \\
\end{array}$ & & & & 1.000 & 1.8741 & & 0.835 & 2.3277 & $\frac{1.0645}{1.0589}$ \\
\hline & $\frac{551.78}{551.78}$ & $\frac{56.29}{660.29}$ & $\frac{245.65}{645.65}$ & 627.63 & $\begin{array}{l}574.18 \\
574.18\end{array}$ & 5 & $\begin{array}{l}53.4 .44 \\
35.76\end{array}$ & $\frac{2.50}{2.40}$ & $\begin{array}{l}-0.0160 \\
-0.0190 \\
\end{array}$ & $\begin{array}{l}1.000 \\
0.998\end{array}$ & $\frac{1.18741}{1.9975}$ & $\frac{1.651}{1.967}$ & $\begin{array}{l}0.859 \\
0.950\end{array}$ & $\frac{2.32471}{2.2606}$ & $\frac{1.0569}{1.0919}$ \\
\hline & 390.40 & 350.70 & & 385.9 & 357.10 & & 214.10 & 3.20 & $\frac{-0.0050}{-0.0050}$ & & & & & & 1.0182 \\
\hline & $\begin{array}{l}485.02 \\
477.62\end{array}$ & $\frac{440.15}{43911}$ & 422.79 & $\begin{array}{r}470.81 \\
457.65\end{array}$ & 439.77 & $\begin{array}{r}392.58 \\
329415\end{array}$ & 238.51 & 3.00 & -0.0090 & 1.005 & $\begin{array}{l}1.5213 \\
16155\end{array}$ & $\frac{1.511}{1.600}$ & 0.497 & $\frac{1.8931}{109123}$ & $\begin{array}{l}1.0347 \\
1.1452\end{array}$ \\
\hline 2012 & & & & $\begin{array}{l}-451.03 \\
55120\end{array}$ & & & 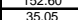 & $\frac{3.000}{300}$ & $\begin{array}{l}-.00140 \\
-0.000\end{array}$ & 0.095 & $178 \mathrm{P}$ & 1768 & & & $\begin{array}{l}1.0452 \\
10652\end{array}$ \\
\hline & 6 & 640.86 & $\begin{array}{l}65.64 \\
626.74\end{array}$ & 653.63 & 608.93 & 556.81 & 36.611 & 2.90 & $\begin{array}{l}-0.00900 \\
-0.0260\end{array}$ & 0.998 & 21101 & $\frac{1.1068}{2077}$ & 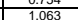 & & 1.0652 \\
\hline 2252 & $\begin{array}{l}292.260 \\
\end{array}$ & 232.200 & 236.390 & 299.040 & 6.610 & $\begin{array}{l}241.110 \\
\end{array}$ & 180.030 & 3.900 & -0.007 & 1.0 & 1.252 & 1.250 & 0.232 & 1.573 & .15326 \\
\hline c22254 & 391.460 & 298.880 & 321.080 & 399.340 & 387.120 & 324.180 & 216.260 & 3.800 & -0.007 & 1.012 & 1.319 & $\frac{1.31}{1.31}$ & 0.294 & 1.5645 & 1.0394 \\
\hline $2: 256$ & 482.860 & 426.150 & 409.750 & 472.50 & 444.920 & 398.470 & 272.83 & 3.700 & 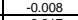 & 1.010 & 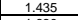 & & 0.4 & 65 & 485 \\
\hline & & $\begin{array}{l}\frac{436.090}{46800} \\
4\end{array}$ & $\begin{array}{l}435.5050 \\
456760\end{array}$ & 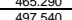 & & $\frac{351.100}{4 x^{2}}$ & & & & & $\frac{1.630}{1.732}$ & & 0.595 & & $\frac{1.073}{10069}$ \\
\hline$\frac{2514}{5214}$ & 512.800 & $\begin{array}{l}466.8400 \\
533.730\end{array}$ & $\begin{array}{l}455.650 \\
525.340\end{array}$ & $\begin{array}{l}\frac{49.5 .40}{566.410} \\
5\end{array}$ & $\begin{array}{l}420.4600 \\
538100\end{array}$ & $\begin{array}{l}4 \frac{435.620}{466.170} \\
\end{array}$ & $\begin{array}{l}40.150 \\
40.950\end{array}$ & $\frac{3.500}{3.500}$ & $\begin{array}{l}-0.02 \\
-0.02\end{array}$ & 0 & 1.1598 & & $\frac{0.094}{0.043}$ & & $\frac{1.0868}{11143}$ \\
\hline c22516 & $\begin{array}{l}636.150 \\
6\end{array}$ & 582.960 & & 614.870 & 580.560 & 508.830 & 42.020 & & & & 2.109 & & & & \\
\hline 2250 & 690.17 & 63586 & 624.88 & 660.29 & 617.94 & 55871 & 42.22 & 3.30 & -0.0340 & 0.981 & 2.1585 & $\frac{2.124}{2.124}$ & 1.109 & 2.319 & $\frac{1.1281}{1.1403}$ \\
\hline C2508 & & 426.09 & 426.36 & 464 & 442. & 382. & 86.91 & 4.3 & -0.0 & 0.9 & & 1.70 & 0.692 & & \\
\hline & 699.23 & $\frac{627.10}{274180}$ & $\frac{630.1}{2694}$ & $\frac{666.1}{3230}$ & $\frac{630}{310}$ & $\frac{56}{525}$ & $\frac{50.39}{32.970}$ & $\frac{3.80}{5.100}$ & $\begin{array}{l}-0.0440 \\
-00^{2}\end{array}$ & 0.970 & $\frac{2.2252}{16259}$ & & 1.157 & $\frac{2.3512}{15268}$ & . 1.1724 \\
\hline & $\frac{303}{374}$ & 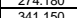 & $\frac{209}{337}$ & & & $\frac{25}{31}$ & & & & & & & & & \\
\hline & $\frac{329}{429}$ & 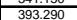 & 准 & $\frac{318}{418}$ & $\frac{300}{405}$ & & $\frac{02.7}{32.7}$ & $\frac{1.000}{5.000}$ & & & $\frac{1.5}{1.5}$ & & & & $\frac{1.10837}{1.042}$ \\
\hline 3008 & 46490 & 424120 & 42390 & . & 440580 & 300 & 33 & 5000 & -0 & 0.977 & 1770 & 169 & 0.464 & 20469 & $\frac{1.1042}{1.1302}$ \\
\hline 30010 & 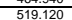 & \begin{tabular}{|l|l|}
457.760 \\
\end{tabular} & 465.230 & 508.890 & $\begin{array}{l}498.050 \\
\end{array}$ & $\frac{1426.730}{240}$ & 33.3 & 5.000 & -0.04 & 0.973 & 1.815 & 1.77 & 0.755 & 2.0975 & 1.1504 \\
\hline 3001 & \begin{tabular}{|l|l}
561.760 \\
\end{tabular} & \begin{tabular}{|l|l|}
513.180 \\
\end{tabular} & 522.690 & 540. & 521.130 & 459. & 33.640 & 5.00 & -0.9 & 0.9 & \begin{tabular}{|l}
1.949 \\
\end{tabular} & 1.90 & 0.8 & 2.2483 & 1.1664 \\
\hline$c 3000$ & 685 & 547. & 637010 & $\frac{587.6}{656.1}$ & 622 & 49 & 37. & 4501 & $\begin{array}{l}-0.059 \\
-0.694\end{array}$ & 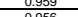 & 2221 & 215 & $\overline{113}$ & & \\
\hline & 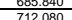 & $\frac{627}{651}$ & 657570 & - & $\frac{622}{664}$ & $\frac{56}{59}$ & $\frac{31.120}{38610}$ & 4.500 & $\begin{array}{l}-0.0044 \\
-0.083\end{array}$ & 0.9566 & & & & & \\
\hline & & & & & & & & & & & & & & & \\
\hline & $\frac{376.98}{476.98}$ & 429.34 & 428.91 & 473.83 & $\frac{074.57}{4745}$ & 394. & 30. & $\frac{2.30}{5.30}$ & & $\frac{5.9}{0.9}$ & $\frac{\pi .6}{16}$ & $\frac{1.5}{1.5}$ & & & \\
\hline 4008 & 530.970 & 490.560 & 491.590 & 524.260 & 503.820 & \begin{tabular}{|l|l|l}
439.6 \\
\end{tabular} & $\frac{36.8}{36.8}$ & 5.200 & -0.074 & 0.944 & 1.8 & 1.769 & 0.75 & 2.3607 & \\
\hline 0010 & $\begin{array}{l}506.530 \\
7\end{array}$ & 540.030 & 30 & $\begin{array}{l}598.1 \\
71.5\end{array}$ & 589.350 & $\begin{array}{l}502.160 \\
0.07\end{array}$ & $\begin{array}{l}35.490 \\
2772\end{array}$ & 5.000 & \begin{tabular}{|l|}
-0.086 \\
\end{tabular} & 932 & 99 & & 12 & $\frac{5695}{775}$ & 95 \\
\hline & & & & & & & & & & & & & & & 2 \\
\hline
\end{tabular}

Tabla A. 2: Puntos medidos en el ensayo patrón(2).

\begin{tabular}{|c|c|c|c|c|c|c|c|c|c|c|c|c|c|c|c|}
\hline CODIGO & M_AIRE & M_AIR_CC & AIRVS100 & G.COMB & CODIGO & FUEL_CC & G_VS100 & TGVDES & \begin{tabular}{|l|l|} 
EGR_DES \\
\end{tabular} & OPACID_1 & RPP_TURB & SWIRL & AVINYPI & AVINYPR & \begin{tabular}{|l|l|l|l|} 
DURI_PI \\
\end{tabular} \\
\hline & $\begin{array}{ll}\mathrm{Kghh} \\
3205\end{array}$ & $\begin{array}{ll}\mathrm{mg} / \mathrm{cc} \\
267000\end{array}$ & $\begin{array}{l}\text { mg/ciclo } \\
26600\end{array}$ & $\begin{array}{ll}\mathrm{kg} / \mathrm{h} \\
0.588\end{array}$ & & $\begin{array}{l}\mathrm{mg} / \mathrm{cc} \\
632\end{array}$ & $\frac{\mathrm{mm}^{2} 3}{8.85}$ & $\frac{\mathrm{mm}}{0.17}$ & $\frac{\mathrm{mm}}{576}$ & $\frac{1 \%}{145}$ & $\frac{\mathrm{rpm}}{1657}$ & & $\begin{array}{l}\text { grados } \\
1300\end{array}$ & $\begin{array}{l}\text { grados } \\
0.00\end{array}$ & $\begin{array}{l}\text { usec } \\
27500\end{array}$ \\
\hline$\frac{c 1001}{c 1002}$ & $\begin{array}{l}\frac{32.05}{33.56} \\
\end{array}$ & $\frac{267.000}{280.000}$ & $\begin{array}{l}226.00 \\
279.00 \\
\end{array}$ & $\frac{0.758}{1.086}$ & $\begin{array}{l}\mathrm{c} 1001 \\
\mathrm{c} 1002\end{array}$ & $\begin{array}{l}6.32 \\
9.05 \\
\end{array}$ & $\frac{8.85}{11.55}$ & 0.17 & $\frac{5.76}{5.42}$ & $\frac{1.45}{4.29}$ & $\frac{16557}{18682}$ & & $\frac{13.00}{13.08}$ & 0.00 & 275.00 \\
\hline c1004 & 51.57 & 430.000 & 444.00 & 1.848 & c1004 & 15.40 & 18.63 & & & & 36458 & & 14.08 & 0.18 & \\
\hline $\begin{array}{ll}c 1000 \\
c 1252\end{array}$ & 74.14 & \begin{tabular}{|l|l|}
618.000 \\
\end{tabular} & 587.00 & $\begin{array}{l}4.121 \\
1300\end{array}$ & $\begin{array}{c}c 1000 \\
1052\end{array}$ & $\begin{array}{r}34.33 \\
\end{array}$ & 44.90 & $\begin{array}{l}0.63 \\
025\end{array}$ & $\begin{array}{l}0.20 \\
5.47\end{array}$ & $\begin{array}{l}10.94 \\
6.73\end{array}$ & \begin{tabular}{|l|l|}
66881 \\
26796
\end{tabular} & & $\begin{array}{l}30.20 \\
1.43\end{array}$ & $\begin{array}{l}2.80 \\
0.47\end{array}$ & $\begin{array}{l}177.00 \\
2500\end{array}$ \\
\hline$\frac{c 1252}{C 1253}$ & $\frac{42.00}{51.97}$ & \begin{tabular}{|l|}
288.000 \\
346.000 \\
\end{tabular} & $\frac{278.00}{330.00}$ & $\frac{1.360}{1.810}$ & $\begin{array}{l}\mathrm{c} 1252 \\
\mathrm{C} 2253 \\
\end{array}$ & $\begin{array}{l}9.06 \\
12.06 \\
\end{array}$ & $\begin{array}{l}12.65 \\
15.82 \\
\end{array}$ & $\frac{0.25}{0.24}$ & $\frac{5.47}{4.61}$ & $\frac{6.73}{5.28}$ & $\begin{array}{l}26796 \\
35659\end{array}$ & & $\begin{array}{l}14.43 \\
15.00\end{array}$ & 0.47 & $\frac{258.00}{245.00}$ \\
\hline c1254 & $\frac{11.37}{62.67}$ & 418.000 & 405.00 & 2.299 & c1254 & 15.33 & $\begin{array}{l}\frac{15.82}{19.05} \\
\end{array}$ & 0.26 & $\begin{array}{l}4.61 \\
3.74 \\
\end{array}$ & $\begin{array}{l}5.88 \\
7.80\end{array}$ & 45864 & & $\frac{15.00}{16.55}$ & $\begin{array}{l}0.48 \\
0.47\end{array}$ & $\begin{array}{l}2455000 \\
255.00\end{array}$ \\
\hline & & & & & & & & & & & & & & & 216.00 \\
\hline c1258 & 98.50 & \begin{tabular}{|l|}
656.000 \\
\end{tabular} & $\begin{array}{l}637.00 \\
637.0\end{array}$ & 4.223 & c1258 & 28.14 & 38.20 & 0.68 & 0.00 & 1.51 & $\frac{17362}{77382}$ & & 27.10 & 2.25 & 169.00 \\
\hline $\mathrm{c} 12510$ & $\begin{array}{l}104.49 \\
\end{array}$ & \begin{tabular}{|l|l|}
697.000 \\
\end{tabular} & 670.00 & 5.364 & $\begin{array}{c}c 12510 \\
\end{array}$ & & 46.65 & 0.33 & 0.04 & 4.76 & 92611 & & 35.01 & 2.92 & 178.00 \\
\hline$\frac{c 1250}{c 1504}$ & $\frac{112.68}{73.94}$ & \begin{tabular}{|l|}
752.000 \\
410000
\end{tabular} & $\frac{715.00}{445000}$ & 6.810 & $\begin{array}{c}\mathrm{c} 1250 \\
c 1504\end{array}$ & $\begin{array}{l}45.42 \\
1591\end{array}$ & $\begin{array}{l}58.10 \\
19.97\end{array}$ & \begin{tabular}{|l|l|}
0.41 \\
0.31
\end{tabular} & $\begin{array}{l}0.29 \\
3.75\end{array}$ & $\frac{32.85}{5.38}$ & $\begin{array}{l}107415 \\
59238\end{array}$ & & $\begin{array}{l}43.60 \\
2.12\end{array}$ & $\begin{array}{l}3.00 \\
0.66\end{array}$ & $\begin{array}{l}216.00 \\
18000\end{array}$ \\
\hline & 73.94 & & & $\begin{array}{l}2.862 \\
5102 \\
\end{array}$ & & $\begin{array}{l}15.91 \\
236\end{array}$ & $\frac{19.97}{37.25}$ & \begin{tabular}{|l}
0.31 \\
0.74
\end{tabular} & $\frac{3.75}{.65}$ & $\frac{5.38}{3.394}$ & $\begin{array}{l}59238 \\
94412\end{array}$ & & $\frac{22.12}{33^{325}}$ & $\frac{0.66}{260}$ & $\begin{array}{l}180.00 \\
16600\end{array}$ \\
\hline$\frac{1506}{c 1512}$ & $\frac{124.17}{153.49}$ & $\frac{6900.000}{853.000}$ & $\frac{682.00}{825.00}$ & $\begin{array}{l}5.102 \\
7.486 \\
\end{array}$ & $\begin{array}{l}\mathrm{C} 1508 \mathrm{8} \\
\mathrm{c} 1512\end{array}$ & $\begin{array}{r}2.836 \\
41.62 \\
\end{array}$ & $\frac{37.25}{52.64}$ & $\frac{0.14}{0.84}$ & $\frac{0.65}{0.15}$ & $\frac{3.94}{3.14}$ & $\frac{94642}{120226}$ & & $\frac{30.35}{41.40}$ & $\frac{2.10}{4.00}$ & $\frac{166.00}{178.00}$ \\
\hline$c 1500$ & 171.83 & 956.000 & 908.00 & 10.090 & $\mathrm{c} 1500$ & 56.11 & 70.95 & 1.19 & $\begin{array}{l}0.15 \\
0.23 \\
\end{array}$ & $\frac{3.14}{15.20}$ & 139265 & & $\begin{array}{l}41.400 \\
45.00\end{array}$ & $\begin{array}{l}4.00 \\
4.01\end{array}$ & $\frac{170.00}{210.00}$ \\
\hline The & 63.48 & 302.000 & 299.00 & 2.072 & c1752 & $\begin{array}{l}9.87 \\
\end{array}$ & 13.39 & 0.32 & $\begin{array}{l}5.62 \\
\end{array}$ & $\begin{array}{l}4.70 \\
\end{array}$ & $\begin{array}{l}45332 \\
\end{array}$ & & 20.65 & 0.85 & $\begin{array}{l}165.00 \\
\end{array}$ \\
\hline & & & & & & & & & 4.12 & 5.60 & 70223 & & 26.01 & 0.85 & 164.00 \\
\hline 1756 & & & & $\begin{array}{l}4.828 \\
5.921 \\
\end{array}$ & $\begin{array}{l}\mathrm{c} 1776 \\
\mathrm{c} 1758\end{array}$ & $\frac{22.99}{2800}$ & $\begin{array}{l}29.97 \\
3647\end{array}$ & $\frac{0.85}{133}$ & $\frac{3.63}{1.74}$ & $\frac{16.00}{9.83}$ & $\frac{87268}{102280}$ & & $\begin{array}{l}30.75 \\
3380 \\
3380\end{array}$ & $\frac{1.07}{1.07}$ & $\frac{165.00}{1690}$ \\
\hline & $\frac{112.6}{179.16}$ & 853.000 & $\begin{array}{l}7854.00 \\
784.00\end{array}$ & $\frac{1.516}{7016}$ & $\frac{217510}{c 17510}$ & $\frac{2.42}{3.42}$ & $\frac{2.44}{44.44}$ & & 0.12 & $\frac{2.83}{3.83}$ & 1116165 & & $\frac{23.75}{38.75}$ & $\frac{2.3}{3.8}$ & $\frac{169.00}{16000}$ \\
\hline$\frac{217512}{c}$ & 194.93 & 929.000 & $\frac{184.00}{854.00}$ & 8.510 & c17512 & $\frac{0.54}{40.54}$ & 51.40 & $\frac{1.60}{1.42}$ & $\frac{0.17}{0.17}$ & 3.75 & $\frac{130058}{130058}$ & & $\frac{38.7}{41.5}$ & $\frac{3.86}{4.81}$ & $\frac{1600.00}{164.00}$ \\
\hline c17514 & 211.20 & 1006.000 & 922.00 & 9.822 & $c 17514$ & 46.79 & 58.82 & 1.36 & 0.21 & 3.36 & 141095 & & 42.80 & 5.60 & $\begin{array}{l}104.00 \\
192.00\end{array}$ \\
\hline 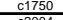 & 2222.21 & 1057.000 & 967.00 & 12.252 & c1775c & 58.3 & 73. & 2.05 & 0.24 & 20.70 & 149602 & & 45.0 & . & 20 \\
\hline & $\frac{121.55}{162.72}$ & $\frac{506.000}{678000}$ & 478.00 & $\begin{array}{l}4.009 \\
6078\end{array}$ & $\begin{array}{c}c 2004 \\
c^{2} 2007\end{array}$ & $\frac{16.71}{2532}$ & $\frac{2.1 .55}{21}$ & 0.61 & 3.72 & $\frac{1.93}{1.93}$ & 84669 & & 30.55 & $\frac{1.20}{1.20}$ & 5.00 \\
\hline & & T.0.000 & & & & & & 1.0 & & & 11050 & & & & \\
\hline c2012 & 229.61 & 957000 & 86000 & 9.395 & $\frac{16001}{c 0012}$ & 39.14 & 50.06 & $\frac{1.39}{211}$ & 0.16 & $\frac{2.40}{0.91}$ & 135799 & & $\frac{31.45}{4220}$ & $\frac{2.13}{562}$ & $\frac{160.00}{16300}$ \\
\hline$c 2000$ & 265.89 & 1108.000 & & 14.134 & $c^{22}$ & 58.89 & & $\frac{2.8}{2.8}$ & 0.25 & 6.02 & & & & & $\frac{105.00}{200.00}$ \\
\hline c2252 & $\begin{array}{l}143.7699 \\
\end{array}$ & 533.000 & 502.000 & 2.917 & c2252 & 10.806 & 14.350 & $\frac{2.000}{1.190}$ & 3.430 & 5.750 & 80933 & & 27.250 & 1.690 & 165 \\
\hline$c 2254$ & 153.016 & 567.000 & 527.000 & 4.471 & $\mathrm{c} 2254$ & 16.557 & 22.210 & 1.750 & 4.170 & 6.640 & 89927 & & 33.600 & 1.080 & 160 \\
\hline $2 \frac{1256}{259}$ & $\begin{array}{l}163.313 \\
230012\end{array}$ & \begin{tabular}{|l|}
605.000 \\
\end{tabular} & $\begin{array}{l}561.000 \\
746000\end{array}$ & $\begin{array}{l}6.115 \\
7571 \\
757\end{array}$ & & $\begin{array}{l}22.648 \\
28.041 \\
\end{array}$ & & $\begin{array}{l}2.010 \\
250\end{array}$ & $\begin{array}{l}4.550 \\
1320\end{array}$ & $\frac{11.060}{2320}$ & $\begin{array}{l}102454 \\
123879 \\
\end{array}$ & & $\begin{array}{l}37.030 \\
3820\end{array}$ & $\begin{array}{l}1.880 \\
2970\end{array}$ & 160 \\
\hline & $\begin{array}{l}253.001 \\
251.149\end{array}$ & $\frac{886.000}{930.000}$ & $\frac{746.000}{824.000}$ & $\frac{1.511}{9.041}$ & $\begin{array}{l}\frac{c 2258}{c 22510} \\
\end{array}$ & $\frac{28.041}{33.484}$ & $\frac{35.51 / 0}{44.820}$ & $\frac{2.450}{2.830}$ & $\frac{1.320}{0.070}$ & & $\frac{123807}{133179}$ & & $\frac{38.620}{41.100}$ & $\frac{2.970}{5.360}$ & $\begin{array}{l}160 \\
163\end{array}$ \\
\hline c222514 & 282.715 & 1047.000 & & & 222514 & & & & 0.0 .160 & & 151782 & & & $\frac{1.300}{7800}$ & $\frac{163}{206}$ \\
\hline c252516 & 206155 & 1097000 & 19.10000 & 14046 & c22516 & 52.014 & 65.200 & $\frac{3.230}{3.230}$ & $\frac{.100}{0.20}$ & 1300 & $\begin{array}{l}15182 \\
159169 \\
\end{array}$ & & 44550 & 850 & $\frac{206}{215}$ \\
\hline 224 & 302.02 & \begin{tabular}{|l|l|l}
1119.000 \\
\end{tabular} & 1020.00 & 15.725 & 2250 & 58.24 & $\begin{array}{l}.2 .80 \\
72.80 \\
\end{array}$ & 3.58 & 0.27 & 5.60 & 162 & & 45.00 & 8.90 & 218.00 \\
\hline C2508 & 267.84 & \begin{tabular}{|l|l|}
893.000 \\
\end{tabular} & 800.00 & 8.524 & $\begin{array}{l}\mathrm{C} 2508 \\
\end{array}$ & 28.41 & 35.40 & 2.65 & 0.79 & 1.35 & 133438 & & 40.73 & 3.75 & 167.00 \\
\hline C2500 & $\begin{array}{l}344.99 \\
2479041\end{array}$ & \begin{tabular}{|l|l|l}
1136.000 \\
699000
\end{tabular} & \begin{tabular}{|l}
1065.00 \\
6200000
\end{tabular} & $\begin{array}{l}17.082 \\
4330 \\
\end{array}$ & $\begin{array}{l}\text { C2500 } \\
3302\end{array}$ & $\begin{array}{r}56.93 \\
12035 \\
\end{array}$ & $\begin{array}{l}71.00 \\
16000\end{array}$ & $\frac{4.37}{4500}$ & $\frac{0.30}{-0.210}$ & $\frac{8.62}{2180}$ & $\frac{166478}{95814}$ & & $\frac{45.00}{36230}$ & $\frac{10.99}{3.750}$ & $\frac{183.00}{165}$ \\
\hline & & & & & & & & & & & & & & & 165 \\
\hline $\begin{array}{l}\frac{3044}{3006} \\
3006\end{array}$ & $\begin{array}{l}2599353 \\
29376\end{array}$ & \begin{tabular}{|l|}
830.000 \\
\end{tabular} & $\frac{6150000}{757000}$ & $\begin{array}{l}6.160 \\
801\end{array}$ & 3004 & $\frac{17.153}{22789}$ & 30.000 & $\frac{4.150}{4680}$ & $\frac{-0.140}{-0.070}$ & $\frac{2.540}{2050}$ & $\begin{array}{l}106365 \\
123685\end{array}$ & & $\begin{array}{l}\frac{36.50}{39900} \\
39\end{array}$ & $\frac{3.230}{7.400}$ & $\frac{168}{1779}$ \\
\hline 0008 & $\begin{array}{l}2950.010 \\
3301 \\
\end{array}$ & \begin{tabular}{|l}
518.000 \\
9
\end{tabular} & \begin{tabular}{|l}
835.000 \\
\end{tabular} & $\begin{array}{l}.021 \\
10.162 \\
\end{array}$ & 3008 & $\begin{array}{l}28.129 \\
2826\end{array}$ & 39.3 & $\begin{array}{l}4.0000 \\
4.360\end{array}$ & -0.020 & 2.5600 & $\begin{array}{l}1150000 \\
138124 \\
\end{array}$ & & $\frac{35.7000}{42.700}$ & $\frac{1.400}{10.190}$ & 183 \\
\hline 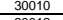 & 344.505 & \begin{tabular}{|l|l|}
957.000 \\
\end{tabular} & 872.000 & 12.20 & 30010 & 33. & 43.5 & 4.8. & 0.040 & 2.340 & 14 & & & 11.600 & 185 \\
\hline$\frac{3012}{30214}$ & $\begin{array}{r}3655.592 \\
659\end{array}$ & 1016 & & 14.368 & & 39.920 & & & 0.100 & 2.840 & 153 & & & & 83 \\
\hline 30014 & $\begin{array}{l}3487.639 \\
\end{array}$ & 1017 & 1043 & $\begin{array}{l}16.524 \\
19291\end{array}$ & 3014 & $\begin{array}{l}45.8391 \\
55360\end{array}$ & (58. & S.3.300 & $\begin{array}{l}0.150 \\
.020\end{array}$ & $\frac{4.660}{9.60}$ & $\begin{array}{l}1022455 \\
11950\end{array}$ & & (46.3500 & $\begin{array}{l}13.860 \\
1.307\end{array}$ & 78 \\
\hline & $\frac{453}{453}$ & 1086 & 1054,000 & 21 & & & & & & 22100 & 17 & & 40. & & \\
\hline & 311 & $\frac{1049.0}{649.0}$ & 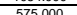 & 6 & 4002 & 12746 & 16400 & 6.25 & 0 & 2760 & 108 & & 0000 & & \\
\hline C4006 & 390.68 & 814.00 & 757.00 & 11.65 & 640 & 24.28 & 32. & 6.12 & 0 & 1.58 & $\begin{array}{l}142949 \\
1429\end{array}$ & & 0.00 & 16.45 & 0.00 \\
\hline 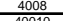 & & & & $14.7 \mathrm{C}$ & 40 & & 40. & & & & & & & 20.00 & \\
\hline $\begin{array}{l}401010 \\
6400\end{array}$ & $\begin{array}{r}463.6066 \\
\end{array}$ & 966.0000 & 925.000 & $\begin{array}{l}17.970 \\
1.978\end{array}$ & 400100 & $\begin{array}{l}37.435 \\
457\end{array}$ & 48.66 & 6.75 & 0.120 & $\frac{19.830}{1983}$ & 169 & & 0.000 & 22.800 & 0 \\
\hline 4500 & $\begin{array}{l}550.01 \\
509.496 \\
\end{array}$ & \begin{tabular}{|l|}
1053.000 \\
944.000
\end{tabular} & \begin{tabular}{|l}
910.000 \\
\end{tabular} & $\begin{array}{l}20.011 \\
21.829 \\
\end{array}$ & 4500 & $\begin{array}{l}40.427 \\
40.427\end{array}$ & $\begin{array}{l}01.01 \\
51.400\end{array}$ & $\begin{array}{l}7.40 \\
7.480\end{array}$ & $\begin{array}{l}0.31 \\
0.200\end{array}$ & $\begin{array}{r}31.87 \\
29.450\end{array}$ & 180499 & & $\begin{array}{l}0.00 \\
0.000\end{array}$ & 24.000 & 0 \\
\hline
\end{tabular}

Tabla A. 3: Puntos medidos en el ensayo patrón(3). 
Capitulo 5

Validación del nuevo modelo de TGV propuesto

\begin{tabular}{|c|c|c|c|c|c|c|c|c|c|c|c|c|c|c|c|c|c|c|}
\hline & & & & & & & & & $F A$ & $A_{-F}$ & $A_{-} F$ & $A F=H B$ & & IHC & & EGR HBA & 02 COEGR & DESFAS \\
\hline & $\begin{array}{l}\text { usec } \\
56000\end{array}$ & $\frac{\mathrm{kg} / \mathrm{m} 3}{1.13}$ & $\frac{\text { bar }}{31900}$ & $\frac{\mathrm{kg} / \mathrm{m} 3}{1.156}$ & $\%$ & $\%$ & $\%$ & $\%$ & & & & & $\%$ & $\frac{p p m}{140}$ & $\mathrm{ppm}$ & $\%$ & $\%$ & $\begin{array}{l}\text { grados } \\
\end{array}$ \\
\hline$\frac{c 1001}{c 1002}$ & $\begin{array}{l}\frac{560.00}{655.00} \\
6\end{array}$ & .169 & \begin{tabular}{|l|}
319.00 \\
327.00
\end{tabular} & $\begin{array}{l}1.156 \\
1.155\end{array}$ & 0.0204 & $\frac{0.420}{0.440}$ & $\begin{array}{l}4.850 \\
6.700\end{array}$ & $\frac{0.044}{0.048}$ & & $\begin{array}{l}0.343 \\
0.469 \\
\end{array}$ & $\begin{array}{l}30.90 \\
30\end{array}$ & 11.900 & $\begin{array}{l}4.3 .300 \\
1.740\end{array}$ & $\frac{44.270}{47.010}$ & $\frac{105.200}{96.800}$ & $\begin{array}{r}38.070 \\
34.790 \\
\end{array}$ & $\frac{1.870}{2.350}$ & \\
\hline & 825.00 & $\frac{1.169}{1.168}$ & & 1.184 & 0.335 & & & \begin{tabular}{|l|l|}
0.024 \\
\end{tabular} & & 0.0 .520 & 27.90 & 26.700 & $\frac{11.140}{9.820}$ & $\frac{47.010}{25.340}$ & $\begin{array}{l}95.8000 \\
259.950\end{array}$ & 13.870 & $\frac{1.140}{1.140}$ & \\
\hline$\frac{000}{200}$ & 1250.00 & 1.171 & 497.00 & 1.275 & 0.338 & 0.881 & 12.460 & \begin{tabular}{|l|l|} 
\\
\end{tabular} & 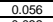 & 0.806 & \begin{tabular}{|l|l|}
17.992 \\
\end{tabular} & 16.900 & 3.290 & 11.940 & 1105.870 & 0.080 & 0.040 & \\
\hline C1253 & 68500 & 1161 & $\begin{array}{l}376.50 \\
386.00\end{array}$ & $\begin{array}{l}1.169 \\
1.185 \\
\end{array}$ & 0 & $\begin{array}{l}0.436 \\
0.532\end{array}$ & \begin{tabular}{|l|l|}
6.670 \\
7470
\end{tabular} & 0.039 & 035 & $\begin{array}{l}0.469 \\
0.559\end{array}$ & \begin{tabular}{|l|}
30.889 \\
287721 \\
\end{tabular} & \begin{tabular}{l|l|l} 
& 32.100 \\
28700 &
\end{tabular} & 0660 & $\begin{array}{l}39.160 \\
3.680 \\
\end{array}$ & $\begin{array}{l}990.000 \\
129210 \\
\end{array}$ & $\begin{array}{l}37.340 \\
28100\end{array}$ & 2120 & \\
\hline & & & & & & & & & & $\frac{0.505}{0.532}$ & 28.721 & $\frac{28.800}{26.600}$ & & $\frac{3.0 .680}{20.000}$ & $\frac{129.1210}{215.630}$ & $\frac{28.100}{17.960}$ & $\frac{2.120}{1.480}$ & \\
\hline & 910.00 & & $\frac{817.00}{417.00}$ & 1.290 & 0.347 & 0.795 & (1) & $\frac{0.01}{0.01}$ & & 0.571 & & 些4.000 & 6000 & $\frac{2.000}{13.110}$ & 4 & $\frac{1.300}{6.840}$ & $\begin{array}{l}\frac{1.400}{0.640} \\
0.04\end{array}$ & 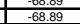 \\
\hline & & & $\begin{array}{l}494.00 \\
\end{array}$ & & 0.364 & & & & & & & & 450 & & & & & -68.89 \\
\hline 2510 & $\frac{1120.00}{12500}$ & $\frac{1.162}{1.169}$ & $\frac{627.50}{760}$ & $\frac{1.425}{1.563}$ & $\begin{array}{l}0.357 \\
0.235 \\
235\end{array}$ & 0.889 & $\frac{1.610}{2090}$ & $\frac{0.04}{0.75}$ & & .744 & $\frac{19.44}{10.5}$ & 18.600 & 670 & 7.850 & $\begin{array}{c}1493.520 \\
\end{array}$ & 0.080 & 0.040 & $\begin{array}{l}-68.89 \\
6899\end{array}$ \\
\hline$\frac{01504}{c 1504}$ & $\begin{array}{l}12500.00 \\
700.00\end{array}$ & 69 & 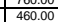 & $\frac{1.563}{1.250}$ & . & 0.074 & $\frac{7.810}{7810}$ & $\frac{0.102}{0.029}$ & & & & & & $\frac{10.540}{10340}$ & & & 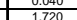 & $\begin{array}{l}-68.89 \\
-69.49\end{array}$ \\
\hline & & 1.167 & 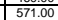 & & & & & & & & & & .340 & Dits & 871.29 & & & - -69.49 \\
\hline c1512 & $\begin{array}{l}1080.00 \\
1080\end{array}$ & 1.167 & 782.00 & 1.684 & 0.371 & 0.922 & 10.590 & 0.158 & 049 & 707 & 0.50 & 14.500 & 0.010 & 8.290 & 1421.010 & 0.010 & 0.040 & $\begin{array}{l}-659.49 \\
-69.49 \\
\end{array}$ \\
\hline 750 & 1440.00 & $\begin{array}{l}1.171 \\
1.165 \\
\end{array}$ & 900.00 & 1.924 & $\begin{array}{l}0.353 \\
0.257\end{array}$ & $\begin{array}{l}0.903 \\
0.577\end{array}$ & $\frac{12.830}{6.800}$ & $\begin{array}{l}.482 \\
0.062\end{array}$ & 0.055 & 8.851 & $\frac{17.1}{30 .}$ & $\frac{6.50}{6.501}$ & $\begin{array}{l}2.720 \\
.1672\end{array}$ & 9.210 & 1208.720 & 0.010 & 0.040 & -69 \\
\hline & & & & & & & & & & & & & & & & & & \\
\hline 1.1756 & $\frac{590.00}{7900.00}$ & 掹1655 & 555.50 & $\frac{1.254}{1.374}$ & $\frac{0.343}{0.333}$ & $\frac{0.058}{0.708}$ & 9.410 & $\frac{0.033}{0.023}$ & & $\frac{503}{663}$ & & $\frac{1.2940}{2.940}$ & $\frac{0.9040}{8.940}$ & 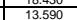 & $\frac{140.90}{2420}$ & $\frac{2.480}{21.1800}$ & . & $\begin{array}{l}-69.1 \\
-69.1 \\
\end{array}$ \\
\hline c1758 & 850.00 & 1.164 & $\frac{642.00}{660}$ & 1.516 & 0.361 & 0.864 & 8.87 & 0.021 & 0 & 568 & 20.5 & 24.340 & 650 & 8.790 & 424.94 & 9.8 & 00 & -69. \\
\hline & 945.00 & & & & & 0.954 & & 0.018 & & & & & 8600 & & & & 0.040 & 69 \\
\hline$\frac{1512}{7554}$ & 111000 & $\frac{1.164}{1167}$ & $\begin{array}{l}8495900 \\
94900\end{array}$ & $\begin{array}{l}\frac{1.1969}{1.935} \\
\end{array}$ & 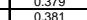 & $\begin{array}{l}0.944 \\
0.945\end{array}$ & $\begin{array}{l}\frac{10.0000}{10730} \\
\end{array}$ & 0.035 & 047 & $\frac{674}{674}$ & 50 & $\frac{1.5900}{20240}$ & 0.010 & $\begin{array}{l}\frac{6.8500}{9400} \\
940\end{array}$ & $\frac{1285.2 .2}{15006}$ & 0.100 & $\frac{0.040}{0.040}$ & -69.1.1. \\
\hline & 4500 & 1.168 & 100000 & 2.059 & 0.363 & & $\begin{array}{l}1.0 .130 \\
12.470\end{array}$ & 0.469 & & 194 & & & 3290 & 9110 & $\frac{150.6}{14045}$ & & 040 & $\begin{array}{l}-69.15 \\
-69.15\end{array}$ \\
\hline 2004 & 675.00 & & $\frac{100.50}{619.50}$ & 1.364 & & & $17+7$ & 0 & & & & & & 1.00 & & & & - \\
\hline & 68 & 65 & 742.00 & 1.583 & $\sqrt{3.350}$ & 0.779 & & 0.02 & & & 26.7 & 5.3 & 9.110 & 14.370 & 281.4 & 19.170 & 660 & -69.1 \\
\hline 2012 & $\begin{array}{l}730.00 \\
934.00\end{array}$ & $\frac{1.164}{1.164}$ & $\begin{array}{l}775.30 \\
950.50\end{array}$ & $\begin{array}{l}1.674 \\
1.851 \\
\end{array}$ & 0.0 .364 & 0.8989 & \begin{tabular}{|l|}
7.840 \\
9.220
\end{tabular} & \begin{tabular}{|l|}
0.025 \\
0.021 \\
\end{tabular} & \begin{tabular}{|l|l|}
0.041 \\
\end{tabular} & 0.593 & 24.440 & 23.300 & $\frac{10.130}{8.020}$ & $\frac{10.990}{10.600}$ & $\begin{array}{l}464.910 \\
1220.370\end{array}$ & $\frac{8.520}{0.080}$ & $\frac{0.700}{0.040}$ & -69.18 \\
\hline c22000 & 1335.00 & 1.161 & 1100.00 & 2.175 & 0. & 80 & 11.95 & \begin{tabular}{|l|l}
0.18 \\
\end{tabular} & & & & & 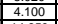 & 8.320 & 1516.1 & $\pi$ & 40 & -69.1 \\
\hline & 43 & & $\frac{605}{675}$ & & & & & $\begin{array}{l}0.06 \\
\end{array}$ & & & & & 4.650 & 25.840 & $\frac{1.25 .2}{125.2}$ & & $\frac{1.130}{1.130}$ & -68.9 \\
\hline$\frac{c 2544}{c 2256}$ & $\begin{array}{l}530 \\
605\end{array}$ & $\begin{array}{l}1.11100 \\
1.155\end{array}$ & $\begin{array}{l}113 \\
799\end{array}$ & $\begin{array}{l}1.376 \\
1.488\end{array}$ & $\begin{array}{l}0.310 \\
0.338\end{array}$ & $\begin{array}{l}0.748 \\
0.739\end{array}$ & $\begin{array}{l}6.720 \\
8.570\end{array}$ & \begin{tabular}{|l|}
0.063 \\
0.040
\end{tabular} & \begin{tabular}{|l|l|}
0.029 \\
0.037
\end{tabular} & $\frac{0.424}{0.543}$ & $\frac{34.223}{26706}$ & $\begin{array}{l}32.0900 \\
25.290\end{array}$ & $\frac{11.920}{9.190}$ & $\frac{20.950}{11.730}$ & $\frac{158.050}{199.650}$ & $\begin{array}{l}\frac{21.350}{19.030} \\
\end{array}$ & $\frac{1.460}{1.660}$ & $\begin{array}{l}-68.910 \\
-68.910\end{array}$ \\
\hline$c 2258$ & & & & & & & & & & & & & & & & & & 10 \\
\hline$\overline{c 22510}$ & 775 & 1.154 & $\begin{array}{l}953 \\
9\end{array}$ & 1.794 & 382 & 0.943 & 8.280 & 0.021 & $\overline{03}$ & & 27.7 & 26.270 & 6.65 & 7.100 & 790.31 & 80 & 040 & $\begin{array}{c}-68.910 \\
\end{array}$ \\
\hline$\frac{c 252514}{c}$ & $\begin{array}{l}979 \\
1085 \\
\end{array}$ & $\frac{1.155}{1.156}$ & $\frac{1121}{1173}$ & $\begin{array}{l}2.053 \\
2.160\end{array}$ & 0.3949 & $\begin{array}{l}0.928 \\
0.923\end{array}$ & $\begin{array}{l}9.760 \\
10.900 \\
\end{array}$ & \begin{tabular}{|l|}
0.024 \\
0.038 \\
\end{tabular} & $\begin{array}{l}043 \\
047\end{array}$ & $\frac{0.688}{0.688}$ & \begin{tabular}{|l|}
23.179 \\
21.085 \\
\end{tabular} & $\frac{22.200}{20.050}$ & $\frac{7.370}{5.890}$ & $\begin{array}{l}9.330 \\
12.080\end{array}$ & $\begin{array}{l}\frac{13660.000}{1510.480} \\
\end{array}$ & $\begin{array}{l}0.090 \\
0.090\end{array}$ & $\frac{0.040}{0.040}$ & $\begin{array}{l}-68.910 \\
-68.910 \\
\end{array}$ \\
\hline 2250 & $\begin{array}{l}1250.00 \\
61000\end{array}$ & $\frac{1.159}{1.15}$ & \begin{tabular}{|l|l|}
1200.00 \\
\end{tabular} & $\begin{array}{l}2.223 \\
1.795\end{array}$ & $\begin{array}{l}0.387 \\
0.359\end{array}$ & $\begin{array}{l}0.915 \\
.010\end{array}$ & 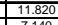 & $\begin{array}{l}0.082 \\
0.027 \\
\end{array}$ & & 0.15 & $\frac{19.2}{131.2}$ & $\frac{18.3}{30.3}$ & 年 & $\begin{array}{l}13.170 \\
3.62\end{array}$ & 1555.6 & 0.080 & 0.040 & -68. \\
\hline 2508 & & & & & & & & & & & & & & & & & & \\
\hline 3002 & $\frac{10400}{400}$ & $\frac{1.156}{1.164}$ & 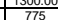 & $\frac{2.243}{1.311}$ & 0.0 .39 & $\frac{0.9}{0.9}$ & $\frac{1.11}{3.870}$ & $\frac{0.09}{0.13}$ & & & $\frac{11.97}{572.2}$ & 童. & 5 & $\frac{1.5000}{45.300}$ & & 0.030 & $\frac{0.050}{0.040}$ & $\frac{-69.15}{-69.120}$ \\
\hline & 48 & & 868 & & & & & & & & & & & & & & & \\
\hline 3006 & 550 & \begin{tabular}{|l|l}
1.159 \\
\end{tabular} & $\begin{array}{l}982 \\
\end{array}$ & 1.588 & 0.338 & 0.953 & 6.250 & 0.039 & \begin{tabular}{|l|l|}
0.027 \\
\end{tabular} & 0. & 36.506 & 34.400 & 12.450 & 11.260 & 4055.05 & 0.070 & 0.040 & -69.120 \\
\hline$\frac{3008}{30010}$ & $\begin{array}{l}5900 \\
628\end{array}$ & $\begin{array}{l}1.1 .159 \\
1.58\end{array}$ & $\frac{1100}{1158}$ & $\begin{array}{l}1.772 \\
1.870\end{array}$ & $\begin{array}{l}0.361 \\
0.374\end{array}$ & $\begin{array}{l}0.942 \\
0.930\end{array}$ & $\begin{array}{l}7.010 \\
7.970\end{array}$ & \begin{tabular}{|l|}
0.025 \\
0.019 \\
\end{tabular} & \begin{tabular}{|l|}
0.035 \\
0.35
\end{tabular} & 0.5 & $\frac{32.514}{28.234}$ & $\frac{30.7}{27.1}$ & $\frac{11.380}{9.970}$ & $\begin{array}{l}8.300 \\
6.990\end{array}$ & $\begin{array}{l}6999.920 \\
943.970\end{array}$ & $\begin{array}{l}0.080 \\
0.080\end{array}$ & $\begin{array}{l}0.040 \\
0.040\end{array}$ & $\begin{array}{l}-69.120 \\
-6.9120 \\
\end{array}$ \\
\hline 30012 & 0 & & & & & & & & & & & & & & & & 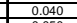 & \\
\hline 30014 & 880 & 1.166 & 132 & 2.133 & 0.385 & 0.918 & 9.43 & & & & 23.4 & & 7.790 & 8.92 & 1401 & 0.0 & 0.050 & -69.120 \\
\hline c35 & & 1.140 & 135 & 2.115 & 0.356 & 0.92 & 10.5 & $\frac{0.05}{0.06}$ & & & & & & & & & 0.060 & \\
\hline 40 & 44 & 15 & & & & & & & & & & & & & & & & \\
\hline C400 & 553 & 1.147 & 125 & 1.673 & 0. & 0.88 & 6.5 & 0.011 & 030 & & 33.5 & & 960 & 8.6 & & & 540 & \\
\hline & & & & . 1.849 & 0.33 & & 7.590 & & & & & & & & & & & \\
\hline & & & & 1.98 & & & & 0 & & & & & & & & & & 69.370 \\
\hline 4500 & 810 & 1.146 & 1350 & $\begin{array}{l}1.973 \\
\end{array}$ & 0.315 & & & & & & & & & 140 & & 0.240 & & \\
\hline
\end{tabular}

Tabla A. 4: Puntos medidos en el ensayo patrón(4).

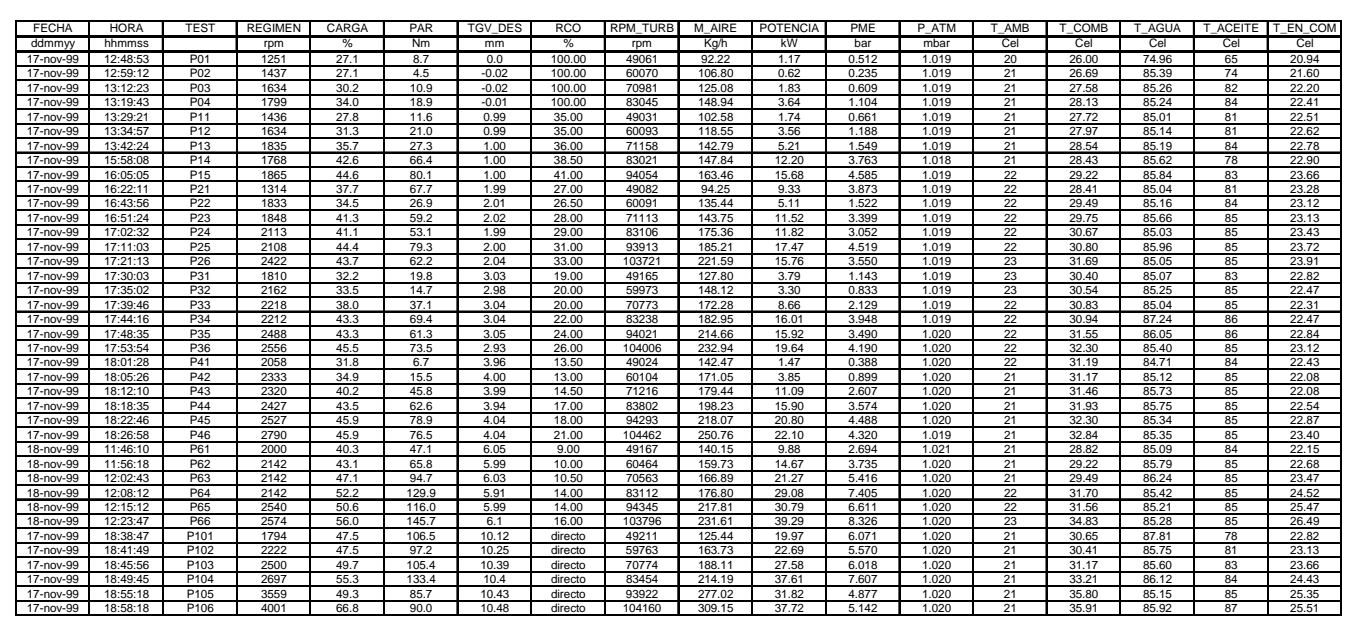

Tabla A. 5: Puntos medidos para la caracterización de la TGV de álabes fijos(1). 
Contribución a la caracterización experimental y modelado de TGV en grupos de sobrealimentación

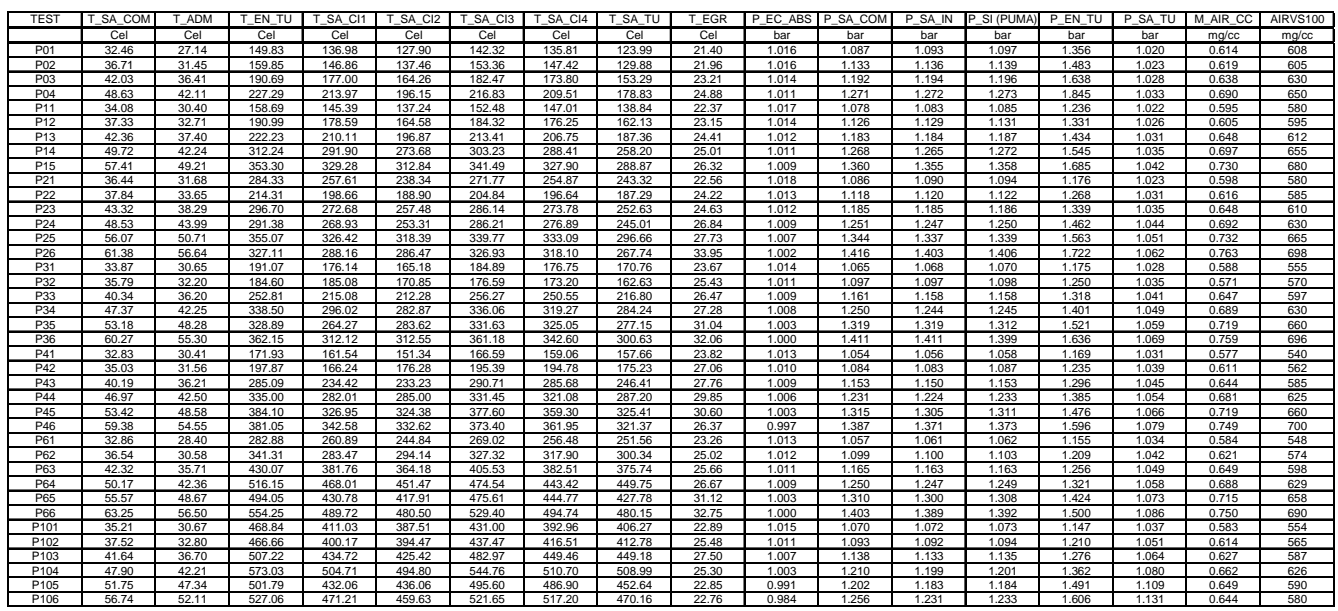

Tabla A. 6: Puntos medidos para la caracterización de la TGV de álabes fijos(2).

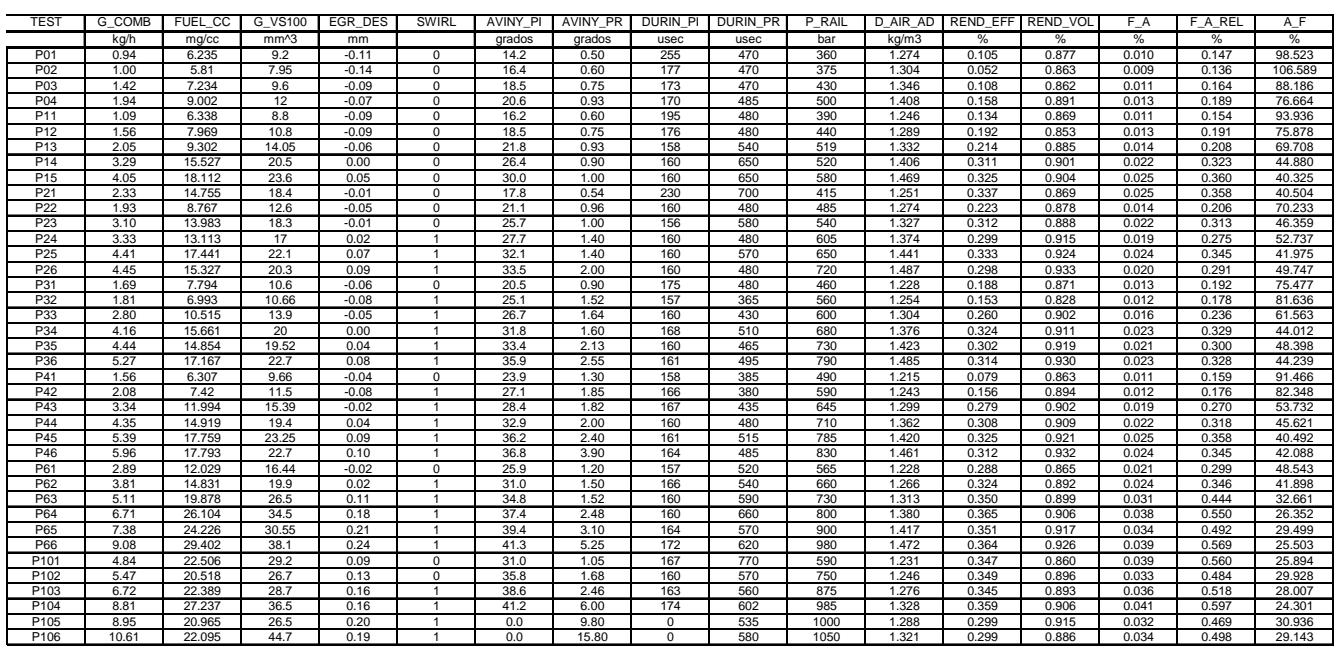

Tabla A. 7: Puntos medidos para la caracterización de la TGV de álabes fijos(3). 


\begin{tabular}{|c|c|c|c|c|c|c|c|c|c|c|c|c|}
\hline DATE & TIME & TEST & P_ATMOSF & T_AIR & PHI & SPEED & ALPHA & TORQUE & TORQUISO & POTISO & PMEISO & COSPISO \\
\hline ddmmyy & hhmmss & 100\%ар0mm & mbar & Cel & $\%$ & rpm & $\%$ & $\mathrm{Nm}$ & $\mathrm{Nm}$ & kW & Jbar & $g / k W h$ \\
\hline 03-jul-02 & $16: 45: 01$ & C750* & 1009 & 37.22 & 39.2 & 1800 & 79.1 & 825.2 & 860.365 & 162.127 & 9.8288 & 231.428 \\
\hline 03-jul-02 & $16: 51: 55$ & C500 & 1009 & 37.75 & 38.2 & 1800 & 78.9 & 791.1 & 823.171 & 155.17 & 9.4039 & 231.633 \\
\hline 03-jul-02 & $17: 23: 28$ & C250 & 1009 & 37.79 & 35.4 & 1800 & 37.5 & 392.9 & 402.384 & 75.817 & 4.5968 & 247.958 \\
\hline 03-jul-02 & $17: 16: 17$ & Cp500 & 1009 & 37.65 & 37.5 & 1600 & 58.6 & 851.8 & 898.415 & 150.6 & 10.2635 & 219.466 \\
\hline $03-j u l-02$ & $17: 09: 10$ & Сp250 & 1009 & 37.21 & 38.1 & 1600 & 37.9 & 433.2 & 443.438 & 74.34 & 5.0658 & 229.586 \\
\hline 03-jul-02 & $18: 07: 53$ & Bp500 & 1009 & 36.29 & 39 & 1400 & 58.5 & 904.4 & 961.846 & 140.956 & 10.9881 & 216.287 \\
\hline 03-jul-02 & $17: 45: 23$ & Bp250 & 1009 & 36.35 & 39.1 & 1400 & 37.4 & 451.6 & 461.633 & 67.656 & 5.2737 & 221.536 \\
\hline 03 -jul-02 & $18: 24: 31$ & A750* & 1009 & 36.14 & 40.4 & 1200 & 68.7 & 1096.8 & 1153.569 & 144.958 & 13.1783 & 181.926 \\
\hline 03-jul-02 & $18: 21: 17$ & A500 & 1009 & 35.95 & 40.6 & 1200 & 59.5 & 935.2 & 990.71 & 124.532 & 11.3178 & 211.758 \\
\hline 03-jul-02 & $18: 14: 21$ & A250 & 1009 & 35.93 & 38.9 & 1200 & 37.7 & 466.5 & 476.523 & 59.94 & 5.4438 & 214.51 \\
\hline 03-jul-02 & $18: 52: 45$ & Ap750* & 1009 & 36.21 & 41.1 & 1000 & 70.7 & 1065.3 & 1163.236 & 121.731 & 13.2888 & 223.47 \\
\hline $03-$ jul-02 & $18: 46: 48$ & Ap500 & 1009 & 36 & 41.4 & 1000 & 56.5 & 898 & 950.44 & 99.497 & 10.8578 & 205.027 \\
\hline 03-jul-02 & $18: 33: 15$ & Ap250 & 1009 & 35.46 & 41.3 & 1000 & 36.3 & 466 & 475.711 & 49.647 & 5.4345 & 210.979 \\
\hline
\end{tabular}

Tabla A. 8: Puntos medidos para la caracterización de la TGV de álabes móviles(1).

\begin{tabular}{|c|c|c|c|c|c|c|c|c|c|c|c|c|c|c|}
\hline TEST & RENEFISO & ECOMP & T_SCOMP & TT_SINC & T_ETURB & T_STURB & T_MUR_et & TTWO & T_EWINC & T_SWINC & TT_FUEL & T_OIL & P_OIL & P_EC_AB \\
\hline 100\%ар0mm & $\%$ & Cel & Cel & Cel & Cel & Cel & Cel & Cel & Cel & Cel & Cel & Cel & Bar & bar \\
\hline C750* & 37.214 & 40.59 & 81.49 & 40.02 & 683.52 & 632.91 & 567 & 85.23 & 31.87 & 46.39 & 44.02 & 98.5 & 5.1 & 0.995 \\
\hline$C 500$ & 37.181 & 41.09 & 79.89 & 39.96 & 668.34 & 619.64 & 555 & 85.1 & 32.24 & 46.33 & 44.24 & 98.3 & 5.1 & 0.996 \\
\hline $\mathrm{C} 250$ & 34.733 & 39.8 & 58.69 & 39.53 & 447.77 & 420.44 & 375 & 84.14 & 32.25 & 46.08 & 43.33 & 95 & 5.3 & 1 \\
\hline Cp500 & 39.243 & 39.79 & 69.66 & 40.38 & 671.7 & 620.67 & 521 & 86.41 & 31.97 & 46.94 & 43.06 & 97.6 & 5 & 1 \\
\hline Cp250 & 37.513 & 38.78 & 54.15 & 39.29 & 420.09 & 392.49 & 328 & 84.82 & 32.11 & 45.24 & 42.9 & 94.14 & 5.2 & 1.001 \\
\hline Bp500 & 39.82 & 38.69 & 62.89 & 35.02 & 670.53 & 620.75 & 515 & 85.84 & 31.29 & 39.59 & 41.42 & 94.96 & 4.9 & 1.001 \\
\hline Bp250 & 38.876 & 37.45 & 47.72 & 33.8 & 406.09 & 375.67 & 296 & 85.36 & 31.63 & 36.81 & 41.79 & 92.04 & 5.1 & 1.004 \\
\hline A750* & 47.34 & 38.87 & 72.67 & 38.66 & 697.7 & 653.13 & 522 & 86.41 & 31.02 & 45.32 & 40.86 & 96.26 & 4.5 & 1.002 \\
\hline A500 & 40.671 & 38.52 & 65.66 & 37.58 & 625.63 & 585.1 & 470 & 85.98 & 31.07 & 43.38 & 40.86 & 95.25 & 4.6 & 1.003 \\
\hline A250 & 40.149 & 38.36 & 47.53 & 36.69 & 389.77 & 375.73 & 328 & 83.26 & 31.34 & 41.46 & 41.24 & 91.99 & 4.8 & 1.005 \\
\hline Ap750* & 38.54 & 38.37 & 65.72 & 36.83 & 698.85 & 669.05 & 496 & 85.88 & 31.12 & 42.82 & 43.4 & 95.83 & 3.6 & 1.005 \\
\hline Ap500 & 42.006 & 37.9 & 57.49 & 36.37 & 561.8 & 530.1 & 412 & 85.35 & 31 & 41.95 & 43.16 & 94.9 & 3.7 & 1.006 \\
\hline \begin{tabular}{|l|l} 
Ap250 \\
\end{tabular} & 40.821 & 37.31 & 46.87 & 37.42 & 340.38 & 319.42 & 264 & 84.14 & 31.02 & 43.39 & 41.96 & 91.3 & 4 & 1.006 \\
\hline
\end{tabular}

Tabla A. 9: Puntos medidos para la caracterización de la TGV de álabes móviles(2).

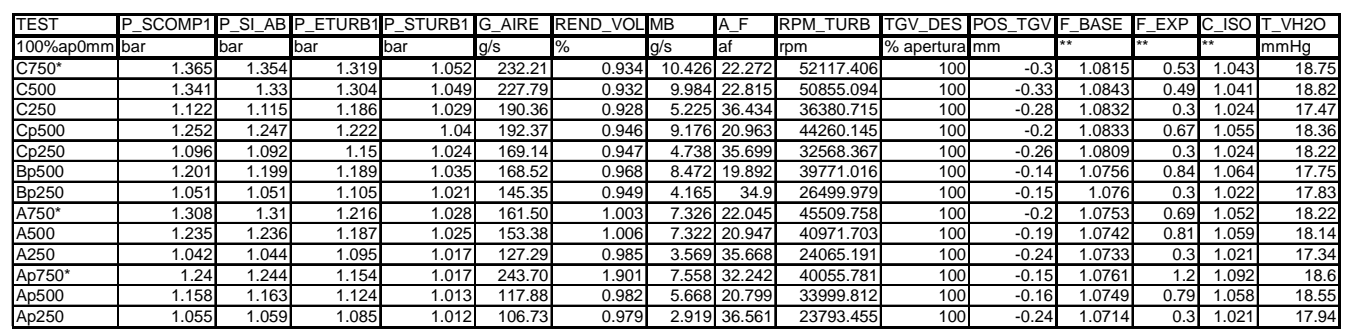

Tabla A. 10: Puntos medidos para la caracterización de la TGV de álabes móviles(3).

\begin{tabular}{|c|c|c|c|c|c|c|c|c|c|c|c|c|}
\hline DATE & TIME & TEST & P_ATMOSF & T_AIR & $\mathrm{PHI}$ & SPEED & ALPHA & TTORQUE & TORQUISO & POTISO & PMEISO & COSPISO \\
\hline ddmmyy & hhmmss & $80 \% a 406 \mathrm{~mm}$ & mbar & Cel & $\%$ & rpm & $\%$ & $\mathrm{Nm}$ & $\mathrm{Nm}$ & $\mathrm{kW}$ & bar & $g / k W h$ \\
\hline 04-jul-02 & 11:58:47 & C25408 & 1019 & 31.4 & 49.5 & 1800 & 38.6 & 399.1 & 404.045 & 76.149 & 4.6158 & 245.661 \\
\hline 04-jul-02 & 11:51:55 & c50408 & 1019 & 31.65 & 47.7 & 1800 & 56 & 790.8 & 800.884 & 151.012 & 9.1493 & 226.557 \\
\hline 04-jul-02 & $12: 08: 46$ & c75408 & 1019 & 32.31 & 44.3 & 1800 & 76.1 & 1185.9 & 1212.055 & 228.412 & 13.8465 & 226.517 \\
\hline 04-jul-02 & $12: 24: 18$ & сp25408 & 1019 & 31.23 & 49.6 & 1600 & 38.9 & 436.9 & 442.181 & 74.413 & 5.0515 & 228.266 \\
\hline 04-jul-02 & $12: 31: 16$ & cp50408 & 1019 & 31.51 & 48 & 1600 & 56.9 & 851.9 & 865.782 & 144.954 & 9.8907 & 213.442 \\
\hline 04-jul-02 & $12: 37: 04$ & сp75408 & 1019 & 32.02 & 44.9 & 1600 & 76.9 & 1275.7 & 1314.998 & 220.682 & 15.0225 & 210.755 \\
\hline 04-jul-02 & $12: 44: 30$ & bp25408 & 1019 & 31.58 & 45.8 & 1400 & 38.2 & 456.3 & 461.994 & 67.738 & 5.2778 & 219.894 \\
\hline 04-jul-02 & $12: 52: 43$ & bp50408 & 1019 & 31.74 & 45 & 1400 & 57.1 & 898.4 & 921.088 & 134.896 & 10.5225 & 211.921 \\
\hline 04-jul-02 & 13:01:24 & bp $75^{*} 408$ & 1019 & 32.37 & 42.8 & 1400 & 71.3 & 1204.4 & 1252.048 & 183.722 & 14.3034 & 209.223 \\
\hline 04-jul-02 & 13:09:13 & a25408 & 1019 & 31.12 & 45.4 & 1200 & 38.3 & 467.1 & 472.501 & 59.356 & 5.3978 & 214.8 \\
\hline $04-j u l-02$ & $13: 14: 12$ & a50408 & 1019 & 31.22 & 45.6 & 1200 & 58.6 & 937.2 & 960.517 & 120.636 & 10.9729 & 208.162 \\
\hline 04-jul-02 & 13:19:50 & $a 75^{\star} 408$ & 1019 & 31.67 & 45.1 & 1200 & 75.8 & 1297.7 & 1355.346 & 170.346 & 15.4834 & 209.915 \\
\hline 04-jul-02 & $13: 28: 29$ & ap25408 & 1019 & 30.84 & 48.3 & 1000 & 36.6 & 456.2 & 461.378 & 48.493 & 5.2708 & 214.404 \\
\hline 04-jul-02 & $13: 35: 03$ & ap50408 & 1019 & 31.01 & 50.5 & 1000 & 55.9 & 903.3 & 926.675 & 96.899 & 10.5863 & 202.483 \\
\hline 04-jul-02 & $13: 39: 37$ & $\operatorname{ap} 75^{*} 408$ & 1019 & 31.24 & 50.2 & 1000 & 77.1 & 1233.1 & 1294.701 & 135.675 & 14.7906 & 220.759 \\
\hline
\end{tabular}

Tabla A. 11: Puntos medidos para la caracterización de la TGV de álabes móviles(4). 
Contribución a la caracterización experimental y modelado de TGV en grupos de sobrealimentación

\begin{tabular}{|c|c|c|c|c|c|c|c|c|c|c|c|c|c|c|}
\hline TEST & RENEFISO & T_ECOMP & T_SCOMP & SINC & T_ETURB & T_STURB & T_MUR_et & TWO & T_EWINC & T_SWINC & T_FUEL & T_OIL & P_OIL & P_EC_AB \\
\hline $80 \% a 406 \mathrm{~mm}$ & $\%$ & Cel & Cel & Cel & Cel & Cel & Cel & Cel & Cel & Cel & Cel & Cel & Bar & bar \\
\hline C25408 & 35.058 & 32.1 & 57.56 & 38.26 & 411.29 & 375.22 & 335 & 84.3 & 26.63 & 47.76 & 39.36 & 94.33 & 5.3 & 1.009 \\
\hline \begin{tabular}{|l|} 
c50408 \\
\end{tabular} & 38.015 & 32.81 & 84.36 & 40.16 & 575.92 & 515.97 & 479 & 85.6 & 26.15 & 49.25 & 39.89 & 97.41 & 5.1 & 1.003 \\
\hline \begin{tabular}{|l|}
$c 75408$ \\
\end{tabular} & 38.021 & 34.13 & 118.15 & 41.49 & 689.61 & 607 & 590 & 86.01 & 26.82 & 48.28 & 40.67 & 99.6 & 5 & 0.992 \\
\hline \begin{tabular}{|l|} 
cp25408 \\
\end{tabular} & 37.73 & 31.68 & 52.18 & 35.7 & 388.96 & 354.72 & 303 & 84.9 & 27.52 & 42.4 & 39.4 & 93.6 & 5.2 & 1.011 \\
\hline \begin{tabular}{|c|} 
cp50408 \\
\end{tabular} & 40.35 & 32.52 & 73.63 & 39.18 & 575.74 & 521.13 & 460 & 86.13 & 27.71 & 47.56 & 39.59 & 96.81 & 5 & 1.007 \\
\hline \begin{tabular}{|c|} 
cp75408 \\
\end{tabular} & 40.865 & 34.03 & 102.42 & 41.22 & 697.89 & 625.05 & 581 & 86.16 & 27.64 & 49.47 & 40.18 & 99.21 & 4.9 & 1.001 \\
\hline bp25408 & 39.166 & 32.66 & 47.88 & 36.45 & 390.06 & 364.11 & 321 & 83.52 & 28.15 & 44.91 & 39.49 & 92.9 & 5 & 1.013 \\
\hline bp50408 & 40.64 & 33.13 & 65.27 & 37.33 & 606.34 & 556.66 & 483 & 85.73 & 28.15 & 45.02 & 39.1 & 96.25 & 4.9 & 1.011 \\
\hline bp75*408 & 41.164 & 34.91 & 84.93 & 40.6 & 699.68 & 636.77 & 576 & 85.56 & 28.03 & 49.41 & 39.5 & 98.22 & 4.8 & 1.008 \\
\hline a25408 & 40.095 & 33.03 & 44.75 & 36.44 & 370.84 & 351.02 & 304 & 83.6 & 28.17 & 44.77 & 38.35 & 91.83 & 4.9 & 1.015 \\
\hline a50408 & 41.374 & 32.81 & 64.72 & 35.48 & 570.78 & 524.58 & 426 & 86.2 & 28 & 42.59 & 37.8 & 94.43 & 4.7 & 1.013 \\
\hline \begin{tabular}{|l|}
$75 * 408$ \\
\end{tabular} & 41.028 & 34.03 & 83.25 & 39.08 & 697.89 & 640.07 & 551 & 86.3 & 27.99 & 48.58 & 37.99 & 97.15 & 4.4 & 1.011 \\
\hline ap25408 & 40.169 & 32.48 & 43.82 & 36.77 & 327.92 & 306.4 & 264 & 84.13 & 28.06 & 45.4 & 39.15 & 91.28 & 4.1 & 1.016 \\
\hline ap50408 & 42.534 & 32.48 & 55.81 & 34.61 & 516.18 & 479.78 & 376 & 85.82 & 27.84 & 41.87 & 39.71 & 94.21 & 3.8 & 1.015 \\
\hline $\mathrm{ap}^{2} 5^{\star} 408$ & 39.013 & 33.43 & 73.04 & 35.33 & 687.36 & 645.97 & 510 & 86.53 & 27.95 & 43.41 & 39.96 & 96.42 & 3.6 & 1.014 \\
\hline
\end{tabular}

Tabla A. 12: Puntos medidos para la caracterización de la TGV de álabes móviles(5).

\begin{tabular}{|c|c|c|c|c|c|c|c|c|c|c|c|c|c|c|c|}
\hline TEST & P_SCOMP1 & P_SI_AB & P_ETURB1 & IP_STURB1 & G_AIRE & REND_VOL & MB & A_F & RPM_TURB & TGV_DES & POS_TGV & F_BASE & EEXP & C_ISO & - $\mathrm{VH} 2 \mathrm{O}$ \\
\hline $80 \%$ a406mm & bar & bar & bar & bar & $\mathrm{g} / \mathrm{s}$ & $\%$ & $\mathrm{~g} / \mathrm{s}$ & af & rpm & $\%$ apertura & $\mathrm{mm}$ & ** & ** & ** & $\mathrm{mmHg}$ \\
\hline $\begin{array}{ll}\mathrm{c} 25408 \\
\end{array}$ & 1.214 & 1.203 & 1.256 & 1.045 & 207.653 & 0.934 & 5.198 & 39.952 & 41567.805 & 80 & 3.97 & 1.0422 & 0.3 & 1.012 & 17.16 \\
\hline \begin{tabular}{|l|}
$c 50408$ \\
\end{tabular} & 1.514 & 1.501 & 1.439 & 1.068 & 259.895 & 0.943 & 9.501 & 27.355 & 58023.875 & 80 & 4.02 & 1.0431 & 0.3 & 1.013 & 16.78 \\
\hline \begin{tabular}{|l|} 
c75408 \\
\end{tabular} & 1.925 & 1.914 & 1.734 & 1.112 & 330.801 & 0.946 & 14.375 & 23.013 & 73581.68 & 80 & 4.02 & 1.0459 & 0.49 & 1.022 & 16.17 \\
\hline cp25408 & 1.167 & 1.161 & 1.206 & 1.04 & 181.45 & 0.944 & 4.698 & 38.626 & 37041.926 & 80 & 4.02 & 1.0412 & 0.3 & 1.012 & 17.04 \\
\hline $\begin{array}{l}\text { cp50408 } \\
\end{array}$ & 1.398 & 1.391 & 1.329 & 1.056 & 218.294 & 0.959 & 8.601 & 25.381 & 51380.16 & 80 & 4.06 & 1.0423 & 0.39 & 1.016 & 16.75 \\
\hline \begin{tabular}{|c|} 
cp754088 \\
\end{tabular} & 1.73 & 1.723 & 1.525 & 1.085 & 269.171 & 0.961 & 12.899 & 20.867 & 65657.227 & 80 & 4.05 & 1.0444 & 0.7 & 1.031 & 16.13 \\
\hline bp25408 & 1.116 & 1.114 & 1.154 & 1.036 & 154.123 & 0.957 & 4.138 & 37.242 & 31391.682 & 80 & 3.96 & 1.042 & 0.3 & 1.012 & 16.05 \\
\hline bp50408 & 1.301 & 1.298 & 1.251 & 1.052 & 181.636 & 0.971 & 7.951 & 22.844 & 44977.797 & 80 & 4.01 & 1.0427 & 0.6 & 1.025 & 15.89 \\
\hline $\begin{array}{ll}\text { bp } 75 * 408 \\
\end{array}$ & 1.505 & 1.502 & 1.356 & 1.062 & 210.533 & 0.983 & 10.669 & 19.733 & 55552.008 & 80 & 3.98 & 1.0457 & 0.87 & 1.04 & 15.67 \\
\hline \begin{tabular}{|l|}
$\mathrm{a} 25408$ \\
\end{tabular} & 1.084 & 1.084 & 1.125 & 1.033 & 132.137 & 0.984 & 3.543 & 37.293 & 26978.553 & 80 & 3.92 & 1.0391 & 0.3 & 1.012 & 15.49 \\
\hline \begin{tabular}{|l|} 
a50408 \\
\end{tabular} & 1.307 & 1.306 & 1.235 & 1.04 & 163.007 & 1.004 & 6.98 & 23.355 & 44197.688 & 80 & 4.01 & 1.0398 & 0.63 & 1.025 & 15.66 \\
\hline$a 75^{\star} 408$ & 1.501 & 1.502 & 1.318 & 1.048 & 184.738 & 1.002 & 9.933 & 18.599 & 54107.793 & 80 & 4 & 1.0423 & 1.05 & 1.044 & 15.88 \\
\hline ap25408 & 1.087 & 1.09 & 1.111 & 1.027 & 110.373 & 0.982 & 2.878 & 38.35 & 25800.477 & 80 & 3.94 & 1.0384 & 0.3 & 1.011 & 16.22 \\
\hline ap50408 & 1.214 & 1.217 & 1.164 & 1.029 & 126.203 & 0.999 & 5.458 & 23.121 & 36953.41 & 80 & 4.02 & 1.0402 & 0.65 & 1.026 & 17.12 \\
\hline $\mid \frac{1}{a p 75 * 408}$ & 1.386 & 1.389 & 1.231 & 1.035 & 145.782 & 1.013 & 8.316 & 17.53 & 47512.016 & 80 & 4.04 & 1.0415 & 1.2 & 1.05 & 17.26 \\
\hline
\end{tabular}

Tabla A. 13: Puntos medidos para la caracterización de la TGV de álabes móviles(6).

\begin{tabular}{|c|c|c|c|c|c|c|c|c|c|c|c|c|}
\hline DATE & TIME & TEST & P_ATMOSF & T_AIR & $\mathrm{PHI}$ & SPEED & ALPHA & TORQUE & TORQUISO & POTISO & PMEISO & COSPISO \\
\hline ddmmyy & hhmmss & text & mbar & Cel & $\%$ & rpm & $\%$ & $\mathrm{Nm}$ & $\mathrm{Nm}$ & $\mathrm{kW}$ & bar & $\mathrm{g} / \mathrm{kWh}$ \\
\hline 04-jul-02 & 15:52:07 & C25815 & 1019 & 29.78 & 59.3 & 1800 & 38.8 & 398.5 & 402.69 & 76.04 & 4.6003 & 244.273 \\
\hline 04-jul-02 & $15: 56: 39$ & C50815 & 1019 & 30.55 & 57.1 & 1800 & 55.2 & 794.3 & 803.553 & 151.535 & 9.1798 & 220.584 \\
\hline 04-jul-02 & $16: 00: 51$ & C75815 & 1019 & 31.1 & 55.8 & 1800 & 74.8 & 1189.6 & 1204.521 & 226.928 & 13.7604 & 221.035 \\
\hline 04-jul-02 & 16:09:56 & C100**815 & 1019 & 32.05 & 53.4 & 1800 & 99.1 & 1416.1 & 1436.033 & 270.603 & 16.4052 & 228.085 \\
\hline 04-jul-02 & $17: 35: 23$ & $\mathrm{c} 100 * 81$ & 1019 & 32.07 & 55.7 & 1800 & 99.2 & 1519.9 & 1541.717 & 290.518 & 17.6125 & 236.022 \\
\hline 04-jul-02 & $16: 15: 08$ & cp25815 & 1019 & 31.47 & 55.2 & 1600 & 33.5 & 426.6 & 432.209 & 72.165 & 4.9375 & 223.861 \\
\hline 04-jul-02 & $16: 21: 46$ & cp50815 & 1019 & 31.49 & 55.1 & 1600 & 49.6 & 861.2 & 872.553 & 145.921 & 9.968 & 210.131 \\
\hline 04-jul-02 & $16: 26: 31$ & cp75815 & 1019 & 31.75 & 54.2 & 1600 & 65.7 & 1278.9 & 1301.258 & 217.793 & 14.8655 & 203.761 \\
\hline 04-jul-02 & $16: 30: 14$ & cp100815 & 1019 & 31.96 & 54 & 1600 & 84.9 & 1699.3 & 1737.65 & 290.947 & 19.8509 & 208.132 \\
\hline 04-jul-02 & $16: 35: 24$ & bp25815 & 1019 & 31.5 & 54.6 & 1400 & 34.1 & 458.8 & 464.878 & 68.089 & 5.3107 & 216.943 \\
\hline 04-jul-02 & $16: 40: 13$ & bp50815 & 1019 & 31.58 & 55.5 & 1400 & 50.5 & 910.9 & 926.558 & 135.872 & 10.585 & 206.108 \\
\hline 04-jul-02 & $16: 43: 42$ & bp75815 & 1019 & 31.73 & 54.6 & 1400 & 68.4 & 1363.4 & 1404.135 & 205.879 & 16.0408 & 199.837 \\
\hline 04-jul-02 & $16: 47: 43$ & bp100815 & 1019 & 32.13 & 54.1 & 1400 & 83.6 & 1711.1 & 1771.009 & 259.726 & 20.2319 & 200.822 \\
\hline 04-jul-02 & $16: 53: 42$ & a25815 & 1019 & 31.15 & 56.3 & 1200 & 33.9 & 453.5 & 459.216 & 57.676 & 5.2461 & 212.835 \\
\hline 04-jul-02 & $16: 57: 06$ & a50815 & 1019 & 31.25 & 55.8 & 1200 & 52.9 & 967.5 & 989.464 & 124.405 & 11.3036 & 204.483 \\
\hline 04-jul-02 & $17: 02: 16$ & a75815 & 1019 & 31.68 & 55.3 & 1200 & 70.4 & 1392.3 & 1446.556 & 181.755 & 16.5254 & 199.924 \\
\hline 04-jul-02 & $17: 05: 29$ & $a 100 * 815$ & 1019 & 31.72 & 55.1 & 1200 & 78.6 & 1590.4 & 1660.035 & 208.618 & 18.9642 & 198.947 \\
\hline 04-jul-02 & $17: 14: 02$ & ap25815 & 1019 & 30.7 & 59.1 & 1000 & 32.7 & 459.2 & 4464.757 & 48.546 & 5.3094 & 212.774 \\
\hline 04-jul-02 & $17: 20: 36$ & ap50815 & 1019 & 30.58 & 59.1 & 1000 & 49.8 & 895.7 & 915.395 & 95.935 & 10.4574 & 199.894 \\
\hline 04-jul-02 & $17: 25: 04$ & ap75815 & 1019 & 31.05 & 58.8 & 1000 & 74.1 & 1351.9 & 1419.055 & 148.606 & 16.2112 & 211.183 \\
\hline 04-jul-02 & $17: 28: 45$ & $\operatorname{ap} 100 * 81$ & 1019 & 31.31 & 57.9 & 1000 & 79.8 & 1454.3 & 1532.357 & 160.591 & 17.5056 & 212.583 \\
\hline
\end{tabular}

* = Se sobrepasa la temperatura máxima a la entrada de la turbina $\left(700^{\circ} \mathrm{C}\right)$. Por tanto medimos el punto con mayor carga

que nos deja la dicha temperatura. $Y$ de esta manera el punto siguiente de mayor carga (100\%) no se realiza.

** = Las cartografias, aunque no limitan, no inyectan más. Se recomienda aumentar la duración de la inyección principal.

Para que la Turbina tenga más energia y cambie su posición de funcionamiento.

Tabla A. 14: Puntos medidos para la caracterización de la TGV de álabes móviles(7). 


\begin{tabular}{|c|c|c|c|c|c|c|c|c|c|c|c|c|c|c|}
\hline TEST & RENEFISO & T_ECOMP & T_SCOMP & T_SINC & T_ETURB & T_STURB & T_MUR_et & TWO & T_EWINC & T_SWINC & T_FUEL & T_OIL & P_OIL & $P \_C C A B$ \\
\hline text & $\%$ & Cel & Cel & Cel & Cel & Cel & Cel & Cel & Cel & Cel & Cel & Cel & Bar & bar \\
\hline C25815 & 35.257 & 30.53 & 65.59 & 35.31 & 376.29 & 328.91 & 296 & 86.07 & 26.12 & 42.57 & 36.75 & 93.51 & 5.3 & 1.007 \\
\hline \begin{tabular}{|l|}
$\mathrm{C} 50815$ \\
\end{tabular} & 39.044 & 31.53 & 99.99 & 40.81 & 507.53 & 430.55 & 417 & 86.75 & 25.86 & 48.23 & 37.95 & 96.66 & 5.1 & 0.998 \\
\hline \begin{tabular}{|l|}
$\mathrm{C} 75815$ \\
\end{tabular} & 38.964 & 32.66 & 138.95 & 42.35 & 599.78 & 497.1 & 515 & 86.75 & 25.9 & 47.28 & 38.58 & 98.89 & 5 & 0.982 \\
\hline $\mathrm{C} 100^{\star *} 815$ & 37.76 & 34.68 & 165.85 & 42.75 & 665.47 & 545.51 & 590 & 85.76 & 26.47 & 50.7 & 39.5 & 100.3 & 4.9 & 0.97 \\
\hline c100*81 & 36.49 & 34.57 & 180.83 & 50.94 & 712.77 & 578.99 & 632 & 88.43 & 28.16 & 59.58 & 40.75 & 102 & 4.9 & 0.963 \\
\hline \begin{tabular}{|l|} 
cp25815 \\
\end{tabular} & 38.472 & 34.16 & 62.15 & 34.35 & 363.76 & 335.34 & 336 & 81.94 & 27.1 & 41.33 & 38.68 & 93.99 & 5.1 & 1.01 \\
\hline \begin{tabular}{|l|} 
cp50815 \\
\end{tabular} & 40.986 & 33.18 & 90.56 & 41.01 & 520.27 & 454.08 & 428 & 85.58 & 26.97 & 48.15 & 38.28 & 95.98 & 5.1 & 1.004 \\
\hline \begin{tabular}{|l|} 
cp75815 \\
\end{tabular} & 42.267 & 33.6 & 120.49 & 41.61 & 599.34 & 512.31 & 503 & 86.34 & 26.94 & 47.76 & 38.6 & 98.09 & 4.9 & 0.995 \\
\hline cp100815 & 41.38 & 34.34 & 156.56 & 42.42 & 679.31 & 566 & 586 & 86.8 & 27.05 & 50.03 & 39.35 & 99.94 & 4.8 & 0.981 \\
\hline bp25815 & 39.699 & 34.02 & 55.82 & 35.14 & 369.82 & 344.78 & 336 & 82.13 & 27.53 & 42.91 & 38.55 & 93.41 & 5 & 1.012 \\
\hline bp50815 & 41.786 & 33.35 & 77.93 & 37.55 & 546.32 & 487.62 & 433 & 85.58 & 27.66 & 45.34 & 37.88 & 95.18 & 4.9 & 1.009 \\
\hline bp75815 & 43.097 & 33.82 & 106.24 & 41.95 & 643.44 & 562.66 & 525 & 86.87 & 27.38 & 49.5 & 38.13 & 97.58 & 4.8 & 1.003 \\
\hline bp100815 & 42.886 & 34.71 & 134.43 & 42.38 & 699.59 & 602.64 & 595 & 86.36 & 27.49 & 48.66 & 38.56 & 99.16 & 4.7 & 0.996 \\
\hline a25815 & 40.465 & 33.79 & 49.62 & 35.88 & 354.07 & 335.51 & 317 & 82.19 & 27.95 & 44.86 & 37.98 & 92.09 & 4.8 & 1.014 \\
\hline a50815 & 42.118 & 33.06 & 72.97 & 35.92 & 545.71 & 492.2 & 411 & 85.59 & 27.96 & 43.53 & 37.55 & 93.86 & 4.7 & 1.011 \\
\hline a75815 & 43.078 & 33.9 & 97.4 & 41.02 & 658.63 & 588 & 530 & 86.59 & 27.79 & 50.01 & 37.76 & 97.11 & 4.4 & 1.008 \\
\hline $2 \mathrm{a} 100 * 815$ & 43.29 & 34.56 & 109.83 & 40.83 & 697.22 & 618.61 & 574 & 86.28 & 27.83 & 49.15 & 38.04 & 98.11 & 4.3 & 1.007 \\
\hline ap25815 & 40.477 & 32.55 & 45.98 & 35.64 & 322.3 & 300.42 & 264 & 83.88 & 28.09 & 43.79 & 39.04 & 91.28 & 4 & 1.016 \\
\hline ap50815 & 43.085 & 32.17 & 59.24 & 34.1 & 490.75 & 453.12 & 367 & 85.63 & 28.02 & 40.67 & 39.51 & 94.07 & 3.8 & 1.015 \\
\hline ap75815 & 40.782 & 32.89 & 84.21 & 35.67 & 661.84 & 605.57 & 499 & 86.9 & 27.98 & 43.42 & 39.8 & 96.56 & 3.6 & 1.013 \\
\hline \begin{tabular}{|l|}
$\mathrm{ap} 100 * 81$ \\
\end{tabular} & 40.513 & 33.94 & 92.48 & 38.88 & 701.39 & 644.5 & 549 & 86.2 & 28.21 & 48.69 & 40.15 & 97.6 & 3.5 & 1.012 \\
\hline
\end{tabular}

Tabla A. 15: Puntos medidos para la caracterización de la TGV de álabes móviles(8).

\begin{tabular}{|c|c|c|c|c|c|c|c|c|c|c|c|c|c|c|c|}
\hline TEST & P_SCOMP1 & P_SI_AB & 3 P_ETURB1 & P_STURB1 & G_AIRE & |REND_VOL & MB & A_F & RPM_TURB & TGV_DES & POS_TGV & F_BASE & F_EXP & C_ISO & T_VH2O \\
\hline text & bar & bar & bar & bar & $\mathrm{g} / \mathrm{s}$ & $\%$ & $g / s$ & af & rpm & $\%$ apertura & $\mathrm{mm}$ & ** & ** & ** & $\mathrm{mmHg}$ \\
\hline \begin{tabular}{|l|}
$\mathrm{C} 25815$ \\
\end{tabular} & 1.329 & 1.315 & 1.367 & 1.049 & 227.074 & 0.926 & 5.15 & 44.095 & 48412.906 & 80 & 8.11 & 1.0355 & 0.3 & 1.011 & 18.76 \\
\hline \begin{tabular}{|l|} 
C50815 \\
\end{tabular} & 1.731 & 1.716 & 1.654 & 1.077 & \begin{tabular}{l|l|}
296.087 \\
\end{tabular} & 0.942 & 9.281 & 31.903 & 66504.023 & 80 & 8.11 & 1.0395 & 0.3 & 1.012 & 18.85 \\
\hline \begin{tabular}{|l|} 
C75815 \\
\end{tabular} & 2.248 & 2.236 & 2.088 & 1.127 & 388.564 & 0.953 & 13.941 & 27.872 & 82850.68 & 80 & 8.07 & 1.0425 & 0.3 & 1.013 & 19.03 \\
\hline $\mathrm{C} 100^{* \star 815}$ & 2.606 & 2.597 & 2.424 & 1.173 & 442.389 & 0.936 & 17.149 & 25.796 & 92229.281 & 80 & 7.98 & 1.0476 & 0.3 & 1.014 & 19.22 \\
\hline \begin{tabular}{|c|}
$\mathrm{c} 100 * 81$ \\
\end{tabular} & 2.848 & 2.828 & 2.63 & 1.203 & 465.961 & 0.928 & 19.052 & 24.457 & 97382.375 & 80 & 8.02 & 1.0485 & 0.3 & 1.014 & 20.05 \\
\hline \begin{tabular}{|l|} 
ср25815 \\
\end{tabular} & 1.247 & 1.241 & 1.284 & 1.041 & 195.684 & 0.948 & 4.503 & 43.454 & 42808.754 & 80 & 7.9 & 1.0446 & 0.3 & 1.013 & 19.21 \\
\hline cp50815 & 1.594 & 1.586 & 1.501 & 1.061 & 250.653 & 0.971 & 8.533 & 29.374 & 60322.379 & 80 & 8.04 & 1.0447 & 0.3 & 1.013 & 19.21 \\
\hline \begin{tabular}{|c|} 
cp75815 \\
\end{tabular} & 1.983 & 1.976 & 1.772 & 1.091 & 314.358 & 0.979 & 12.341 & 25.473 & 73994.812 & 80 & 8.07 & 1.046 & 0.38 & 1.017 & 19.18 \\
\hline \begin{tabular}{|c|} 
cp100815 \\
\end{tabular} & 2.499 & 2.496 & 2.178 & 1.143 & 393.268 & 0.972 & 16.832 & 23.364 & 87902.727 & 80 & 8.1 & 1.0473 & 0.48 & 1.023 & 19.34 \\
\hline bp25815 & 1.186 & 1.184 & 1.215 & 1.035 & 165.3 & 0.961 & 4.108 & 40.235 & 37334.5 & 80 & 7.96 & 1.0446 & 0.3 & 1.013 & 19.04 \\
\hline bp50815 & 1.446 & 1.443 & 1.362 & 1.052 & 204.827 & 0.986 & 7.777 & 26.338 & 52734.082 & 80 & 8.04 & 1.0454 & 0.38 & 1.017 & 19.44 \\
\hline \begin{tabular}{|l|} 
bp75815 \\
\end{tabular} & 1.793 & 1.792 & 1.566 & 1.073 & 252.377 & 0.992 & 11.426 & 22.087 & 66606.875 & 80 & 8.07 & 1.046 & 0.65 & 1.03 & 19.28 \\
\hline bp100815 & 2.164 & 2.166 & 1.807 & 1.101 & 306.828 & 0.999 & 14.483 & 21.186 & 77954.125 & 80 & 8.06 & 1.0484 & 0.73 & 1.035 & 19.56 \\
\hline \begin{tabular}{|l|}
$\mathrm{a} 25815$ \\
\end{tabular} & 1.126 & 1.127 & 1.161 & 1.031 & 138.513 & 0.99 & 3.412 & 40.601 & 31217.049 & 80 & 7.96 & 1.043 & 0.3 & 1.013 & 19.25 \\
\hline a50815 & 1.401 & 1.402 & 1.31 & 1.041 & 175.197 & 1.007 & 7.062 & 24.808 & 49421.258 & 80 & 8.05 & 1.0435 & 0.53 & 1.023 & 19.2 \\
\hline a75815 & 1.671 & 1.674 & 1.443 & 1.053 & 208.114 & 1.019 & 10.095 & 20.616 & 61154.152 & 80 & 8.07 & 1.046 & 0.85 & 1.039 & 19.49 \\
\hline \begin{tabular}{|l|}
$\mathrm{a} 100 * 815$ \\
\end{tabular} & 1.814 & 1.818 & 1.518 & 1.061 & 225.864 & 1.017 & 11.53 & 19.59 & 66321.477 & 80 & 8.06 & 1.0461 & 0.95 & 1.044 & 19.45 \\
\hline ap25815 & 1.108 & 1.112 & 1.132 & 1.026 & 113.782 & 0.989 & 2.876 & 39.563 & 28190.289 & 80 & 8.01 & 1.0411 & 0.3 & 1.012 & 19.69 \\
\hline ap50815 & 1.253 & 1.257 & 1.202 & 1.029 & 132.575 & 1.014 & 5.322 & 24.913 & 39757.223 & 80 & 8.09 & 1.0404 & 0.55 & 1.022 & 19.57 \\
\hline \begin{tabular}{|l|} 
ap75815 \\
\end{tabular} & 1.512 & 1.518 & 1.317 & 1.037 & 161.574 & 1.029 & 8.714 & 18.542 & 53686.367 & 80 & 8.13 & 1.0432 & 1.15 & 1.05 & 19.99 \\
\hline ap100*81 & 1.589 & 1.594 & 1.35 & 1.04 & 168.158 & 1.03 & 9.479 & 17.74 & 56985.07 & 80 & 8.1 & 1.0445 & 1.2 & 1.054 & 19.97 \\
\hline
\end{tabular}

Tabla A. 16: Puntos medidos para la caracterización de la TGV de álabes móviles(9).

\begin{tabular}{|c|c|c|c|c|c|c|c|c|c|c|c|c|}
\hline DATE & TIME & TEST & P_ATMOSF & T_AIR & Humeda & SPEED & Pos acele & ITORQUE & TORQUISO & POTISO & PMEISO & COSPISO \\
\hline ddmmyy & hhmmss & 40\%ap12.23n & mbar & Cel & $\%$ & $\mathrm{rpm}$ & $\%$ & $\mathrm{Nm}$ & $\mathrm{Nm}$ & kW & bar & $\mathrm{g} / \mathrm{kWh}$ \\
\hline $05-j u l-02$ & $12: 19: 47$ & C25122 & 1027 & 29.87 & 54.5 & 1800 & 38.1 & 399.2 & 402.611 & 75.828 & 4.5994 & 245.103 \\
\hline 05-jul-02 & 12:23:30 & c50122 & 1027 & 30.66 & 53.3 & 1800 & 54 & 799.3 & 807.153 & 152.191 & 9.2209 & 219.035 \\
\hline 05-jul-02 & 12:28:04 & c75122 & 1027 & 31.46 & 50.9 & 1800 & 71.9 & 1181.7 & 1194.725 & 225.165 & 13.6485 & 219.889 \\
\hline 05-jul-02 & $12: 31: 42$ & c100*122 & 1027 & 31.96 & 48.4 & 1800 & 83.5 & 1314.2 & 1329.499 & 250.528 & 15.1881 & 221.73 \\
\hline 05-jul-02 & $12: 35: 14$ & cp25122 & 1027 & 31.89 & 50 & 1600 & 38.3 & 427.5 & 432.538 & 72.309 & 4.9413 & 226.144 \\
\hline 05-jul-02 & 12:39:18 & cp50122 & 1027 & 31.81 & 49.8 & 1600 & 53.7 & 851.7 & 861.486 & 144.254 & 9.8416 & 205.037 \\
\hline 05-jul-02 & 12:43:51 & сp75122 & 1027 & 32.21 & 48.2 & 1600 & 71.2 & 1282.1 & 1297.63 & 217.34 & 14.8241 & 199.948 \\
\hline 05 -jul-02 & $12: 48: 24$ & сp100122 & 1027 & 32.87 & 45.2 & 1600 & 88.8 & 1699.7 & 1721.692 & 288.715 & 19.6685 & 201.338 \\
\hline 05-jul-02 & 12:53:38 & bp25122 & 1027 & 32.47 & 47.5 & 1401 & 38.1 & 452.3 & 457.911 & 67.2 & 5.2312 & 216.686 \\
\hline 05-jul-02 & $12: 57: 29$ & bp50122 & 1027 & 32.17 & 47.5 & 1401 & 54.8 & 902.5 & 913.238 & 134.027 & 10.4328 & 200.089 \\
\hline 05-jul-02 & $13: 00: 43$ & bp75122 & 1027 & 32.62 & 46.7 & 1401 & 72.7 & 1351.7 & 1372.534 & 201.435 & 15.6798 & 194.841 \\
\hline 05 -jul-02 & $13: 03: 25$ & bp100122 & 1027 & 32.81 & 45.4 & 1401 & 90.1 & 1799.7 & 1836.113 & 269.257 & 20.9757 & 191.633 \\
\hline 05 -jul-02 & $13: 18: 04$ & a25122 & 1027 & 32.23 & 48.8 & 1200 & 38.5 & 466.4 & 472.108 & 59.271 & 5.3933 & 213.387 \\
\hline $05-j u l-02$ & $13: 14: 07$ & a50122 & 1027 & 32.67 & 46.5 & 1200 & 55.9 & 927.3 & 939.856 & 118.178 & 10.7369 & 200.419 \\
\hline 05-jul-02 & 13:10:41 & a75122 & 1027 & 33.09 & 44.6 & 1200 & 74.5 & 1393.8 & 1430.231 & 179.717 & 16.3389 & 193.249 \\
\hline 05-jul-02 & $13: 07: 35$ & a100122 & 1027 & 32.9 & 44.7 & 1200 & 92.5 & 1859.5 & 1920.535 & 241.45 & 21.9401 & 189.76 \\
\hline $05-j u l-02$ & $13: 20: 32$ & ap25122 & 1027 & 31.93 & 49.8 & 1000 & 37 & 455.7 & 461.066 & 48.287 & 5.2672 & 212.774 \\
\hline 05-jul-02 & 13:23:48 & ap50122 & 1027 & 31.83 & 49.8 & 1000 & 54.9 & 906.1 & 923.311 & 96.659 & 10.5479 & 199.516 \\
\hline 05-jul-02 & $13: 28: 48$ & ap75122 & 1027 & 31.73 & 48.8 & 1000 & 77 & 1356.8 & 1404.684 & 147.213 & 16.0471 & 202.334 \\
\hline 05-jul-02 & $13: 33: 27$ & ap100122 & 1027 & 32.41 & 46.4 & 1000 & 96.3 & 1803.4 & 1890.326 & 198.221 & 21.595 & 202.535 \\
\hline 09-jul-02 & $10: 35: 48$ & $\mathrm{C} 100 * 1223$ & 1012 & 32.03 & 45.6 & 1800 & 99.7 & 1456.2 & 1477.594 & 278.473 & 16.88 & 228.655 \\
\hline
\end{tabular}

Tabla A. 17: Puntos medidos para la caracterización de la TGV de álabes móviles(10). 
Contribución a la caracterización experimental y modelado de TGV en grupos de sobrealimentación

\begin{tabular}{|c|c|c|c|c|c|c|c|c|c|c|c|c|c|c|}
\hline TEST & RENEFISO & TT ECOMP & T SCOMP & TT SINTe & T ETURB & TT STURB & T Pared et & Twater & TIEWINC & T SWINC & TT FUEL & T OIL & P_OIL & PEC AB \\
\hline 40\%ар12.23n & $\%$ & Cel & Cel & Cel & Cel & Cel & Cel & Cel & Cel & Cel & Cel & Cel & Bar & bar \\
\hline $\mathrm{C25122}$ & 35.138 & 30.91 & 78.98 & 40.09 & 354.35 & 293.08 & 283 & 87.02 & 25.5 & 47.37 & 36.27 & 92.62 & 5.3 & 1.012 \\
\hline \begin{tabular}{|l|}
$\mathrm{c} 50122$ \\
\end{tabular} & 39.32 & 31.57 & 119.44 & 41.89 & 460.06 & 361.85 & 377 & 87.17 & 25.32 & 47.56 & 38.43 & 96.05 & 5.1 & 0.999 \\
\hline \begin{tabular}{|l|} 
c75122 \\
\end{tabular} & 39.167 & 32.47 & 162.54 & 42.09 & 544.36 & 418.33 & 468 & 87.08 & 25.4 & 49.62 & 39.17 & 98.51 & 5 & 0.979 \\
\hline $\begin{array}{l}\mathrm{c} 100 * 122 \\
\end{array}$ & 38.842 & 33.33 & 177.79 & 43.29 & 578.66 & 441.88 & 506 & 86.29 & 25.63 & 51.93 & 39.6 & 99.33 & 4.9 & 0.972 \\
\hline \begin{tabular}{|l|} 
cp25122 \\
\end{tabular} & 38.084 & 33.77 & 73.53 & 34.54 & 344.81 & 303.37 & 322 & 82.12 & 26.06 & 41.08 & 38.89 & 94.26 & 5.1 & 1.016 \\
\hline \begin{tabular}{|l|} 
cp50122 \\
\end{tabular} & 42.004 & 33.35 & 104.77 & 40.48 & 459.92 & 377.48 & 378 & 84.96 & 25.94 & 46.62 & 38.29 & 95.33 & 5 & 1.008 \\
\hline \begin{tabular}{|l|} 
cp75122 \\
\end{tabular} & 43.073 & 33.75 & 142.06 & 40.67 & 534.02 & 425.76 & 451 & 86.33 & 26.07 & 48.67 & 38.59 & 97.67 & 4.9 & 0.996 \\
\hline \begin{tabular}{|c|} 
cp100122 \\
\end{tabular} & 42.776 & 34.66 & 177.24 & 42.62 & 600.11 & 466.01 & 521 & 86.44 & 26.25 & 51.97 & 39.76 & 99.62 & 4.8 & 0.98 \\
\hline bp25122 & 39.746 & 34.55 & 64.68 & 34.91 & 343.6 & 307.22 & 304 & 82.19 & 26.81 & 41.55 & 38.69 & 93.09 & 5 & 1.019 \\
\hline \begin{tabular}{|l|} 
bp50122 \\
\end{tabular} & 43.043 & 33.87 & 91.72 & 38.31 & 478.1 & 405.17 & 376 & 85.28 & 26.85 & 46.01 & 38.02 & 94.56 & 4.9 & 1.014 \\
\hline bp75122 & 44.202 & 34.25 & 124.54 & 42.03 & 559.33 & 460.69 & 457 & 86.8 & 26.6 & 48.47 & 38.18 & 96.9 & 4.8 & 1.006 \\
\hline bp100122 & 44.942 & 34.76 & 155.2 & 42.44 & 611.54 & 489.72 & 517 & 87.17 & 26.56 & 48.39 & 39.18 & 98.89 & 4.7 & 0.997 \\
\hline a25122 & 40.361 & 34.39 & 56.83 & 37.54 & 348.77 & 319.4 & 302 & 82.82 & 27.33 & 46.97 & 38.07 & 92.2 & 4.8 & 1.022 \\
\hline a50122 & 42.972 & 35.4 & 84.47 & 37.93 & 502.57 & 448.1 & 427 & 83.38 & 27.1 & 46.72 & 38.15 & 95.39 & 4.5 & 1.018 \\
\hline a75122 & 44.566 & 35.83 & 113.96 & 38.17 & 590.32 & 509.81 & 502 & 84.58 & 26.85 & 45.41 & 38.74 & 97.92 & 4.2 & 1.014 \\
\hline \begin{tabular}{|l|}
$\mathrm{a} 100122$ \\
\end{tabular} & 45.386 & 35.61 & 139.86 & 39.74 & 643.5 & 537.42 & 542 & 85.95 & 26.69 & 45.47 & 39.6 & 99.26 & 4.1 & 1.008 \\
\hline \begin{tabular}{|l|} 
ap25122 \\
\end{tabular} & 40.477 & 33.78 & 50.37 & 36.45 & 319.67 & 294.6 & 266 & 83.61 & 27.32 & 45.36 & 38.69 & 91.37 & 4 & 1.023 \\
\hline \begin{tabular}{|l|} 
ap50122 \\
\end{tabular} & 43.167 & 33.37 & 65.13 & 35.25 & 474.86 & 426.53 & 343 & 85.73 & 27.21 & 42.59 & 39.38 & 93.36 & 3.8 & 1.022 \\
\hline \begin{tabular}{|l|} 
ap751222 \\
\end{tabular} & 42.566 & 33.91 & 92.32 & 37.56 & 616.65 & 547.74 & 479 & 86.46 & 27.12 & 46.25 & 39.89 & 96.58 & 3.5 & 1.02 \\
\hline \begin{tabular}{|l|} 
ap100122 \\
\end{tabular} & 42.523 & 34.98 & 121.08 & 41.63 & 702.08 & 612.42 & 567 & 86.73 & 26.94 & 50.28 & 40.46 & 99.06 & 3.3 & 1.017 \\
\hline C100*1223 & 37.666 & 34.51 & 196.69 & 43.97 & 633.59 & 484.79 & 559 & 85.58 & 24.94 & 54.17 & 39.17 & 100.02 & 4.9 & 0.946 \\
\hline
\end{tabular}

Tabla A. 18: Puntos medidos para la caracterización de la TGV de álabes móviles(11).

\begin{tabular}{|c|c|c|c|c|c|c|c|c|c|c|c|c|c|c|c|}
\hline TEST & P_SCOMP1 & $\bar{P}$ _SI_AB & P_ETURB1 & STURB1 & G_AIRE & REND_VOL & M fuel & 1/Dosa & dRPM_TURB & TGV_DES & POS_TGV & BASE & F_EXP & C_ISO & $\mathrm{VH} 2 \mathrm{O}$ \\
\hline $40 \%$ ap12.23n & bar & bar & bar & bar & $\mathrm{g} / \mathrm{s}$ & $\%$ & $\mathrm{~g} / \mathrm{s}$ & af & rpm & $\%$ & $\mathrm{~mm}$ & $\star \star$ & ** & $t_{-}$ & $\mathrm{mmHg}$ \\
\hline C25122 & 1.479 & 1.478 & 1.551 & 1.054 & 248.334 & 0.915 & 5.167 & 48.06 & 56023.496 & 40 & 12.17 & 1.0287 & 0.3 & 1.009 & 17.32 \\
\hline \begin{tabular}{|l|}
$\mathrm{c} 50122$ \\
\end{tabular} & 1.995 & 1.996 & 1.994 & 1.086 & 338.443 & 0.929 & 9.257 & 36.562 & 75203.797 & 40 & 12.18 & 1.0331 & 0.3 & 1.01 & 17.73 \\
\hline \begin{tabular}{|l|}
$\mathrm{c} 75122$ \\
\end{tabular} & 2.608 & 2.61 & 2.592 & 1.142 & 436.118 & 0.916 & 13.756 & 31.705 & 91704.586 & 40 & 12.16 & 1.0372 & 0.3 & 1.011 & 17.7 \\
\hline \begin{tabular}{|l|}
$\mathrm{c} 100 * 122$ \\
\end{tabular} & 2.819 & 2.821 & 2.812 & 1.166 & 463.576 & 0.904 & 15.436 & 30.032 & 96792.641 & 40 & 12.12 & 1.0394 & 0.3 & 1.012 & 17.31 \\
\hline \begin{tabular}{|l|} 
cp25122 \\
\end{tabular} & 1.37 & 1.374 & 1.427 & 1.046 & 213.367 & 0.935 & 4.552 & 46.877 & 50073.656 & 40 & 12.03 & 1.0395 & 0.3 & 1.012 & 17.84 \\
\hline cp50122 & 1.774 & 1.778 & 1.732 & 1.066 & 276.051 & 0.953 & 8.221 & 33.578 & 67141.414 & 40 & 12.1 & 1.039 & 0.3 & 1.012 & 17.67 \\
\hline \begin{tabular}{|l|} 
cp75122 \\
\end{tabular} & 2.287 & 2.293 & 2.16 & 1.1 & 362.224 & 0.97 & 12.076 & 29.994 & 82514.094 & 40 & 12.15 & 1.0409 & 0.3 & 1.012 & 17.49 \\
\hline \begin{tabular}{|c|} 
cp100122 \\
\end{tabular} & 2.816 & 2.827 & 2.649 & 1.148 & 432.151 & 0.944 & 16.134 & 26.785 & 95179.195 & 40 & 12.19 & 1.0438 & 0.3 & 1.013 & 17.03 \\
\hline bp25122 & 1.271 & 1.281 & 1.317 & 1.037 & 176.443 & 0.948 & 4.044 & 43.635 & 43480.332 & 40 & \begin{tabular}{l|}
12.1 \\
12.07
\end{tabular} & 1.0422 & 0.3 & 1.012 & 17.51 \\
\hline bp50122 & 1.605 & 1.614 & 1.541 & 1.053 & 225.843 & 0.973 & 7.447 & 30.327 & 59807.484 & 40 & 12.14 & 1.0403 & 0.3 & 1.012 & 17.21 \\
\hline bp75122 & 2.031 & 2.042 & 1.846 & 1.078 & 285.264 & 0.983 & 10.899 & 26.173 & 74227.68 & 40 & 12.17 & 1.0428 & 0.37 & 1.015 & 17.34 \\
\hline bp100122 & 2.472 & 2.487 & 2.185 & 1.107 & 349.427 & 0.991 & 14.337 & 24.373 & 85829.688 & 40 & 12.17 & 1.0434 & 0.47 & 1.02 & 17.05 \\
\hline a25122 & 1.191 & 1.204 & 1.23 & 1.029 & 145.647 & 0.981 & 3.516 & 41.424 & 36865.789 & 40 & 12.09 & 1.0412 & 0.3 & 1.012 & 17.73 \\
\hline \begin{tabular}{|l|} 
a50122 \\
\end{tabular} & 1.487 & 1.501 & 1.412 & 1.037 & 184.781 & 0.999 & 6.576 & 28.101 & 53977.457 & 40 & 12.08 & 1.043 & 0.32 & 1.014 & 17.32 \\
\hline \begin{tabular}{|l|} 
a75122 \\
\end{tabular} & 1.837 & 1.852 & 1.634 & 1.056 & 229.675 & 1.007 & 9.649 & 23.802 & 67463.555 & 40 & 12.1 & 1.0448 & 0.59 & 1.026 & 17 \\
\hline $\begin{array}{l}\mathrm{a} 100122 \\
\end{array}$ & 2.201 & 2.218 & 1.857 & 1.076 & 273.554 & 1.006 & 12.725 & 21.498 & 77994.422 & 40 & 12.14 & 1.0438 & 0.75 & 1.033 & 16.88 \\
\hline ap25122 & 1.132 & 1.148 & 1.169 & 1.024 & 115.811 & 0.977 & 2.854 & 40.579 & 30902.639 & 40 & 12.13 & 1.0397 & 0.3 & 1.012 & 17.79 \\
\hline ap50122 & 1.302 & 1.319 & 1.258 & 1.028 & 137.755 & 1.008 & 5.358 & 25.71 & 43207.379 & 40 & 12.19 & 1.0391 & 0.49 & 1.019 & 17.68 \\
\hline ap75122 & 1.585 & 1.602 & 1.415 & 1.037 & 167.974 & 1.019 & 8.27 & 20.312 & 57067.844 & 40 & 12.23 & 1.0381 & 0.93 & 1.035 & 17.26 \\
\hline ap100122 & 1.915 & 1.933 & 1.563 & 1.051 & 202.474 & 1.032 & 11.136 & 18.181 & 68782.273 & 40 & 12.22 & 1.0414 & 1.16 & 1.048 & 17.02 \\
\hline $\mathrm{C} 100 * 1223$ & 3.056 & 3.049 & 3.064 & 1.193 & 490.59 & 0.887 & 17.69 & 27.733 & 102721.797 & 40 & 12 & 1.0498 & 0.3 & 1.015 & 16.4 \\
\hline
\end{tabular}

Tabla A. 19: Puntos medidos para la caracterización de la TGV de álabes móviles(12).

\begin{tabular}{|c|c|c|c|c|c|c|c|c|c|c|c|c|}
\hline DATE & TIME & TTEST & P_ATMOSF & T_AIR & $\mathrm{PHI}$ & SPEED & ALPHA & TORQUE & TORQUISO & POTISO & PMEISO & COSPISO \\
\hline ddmmyy & hhmmss & $20 \% a 16.30 \mathrm{~m}$ & mbar & Cel & $\%$ & rpm & $\%$ & $\mathrm{Nm}$ & $\mathrm{Nm}$ & $\mathrm{kW}$ & bar & $\mathrm{g} / \mathrm{kWh}$ \\
\hline 09-jul-02 & $11: 49: 35$ & C251630 & 1012 & 32.5 & 45.3 & 1800 & 37.8 & 394.4 & 400.49 & 75.418 & 4.5752 & 250.69 \\
\hline 09-jul-02 & $11: 56: 43$ & C501630 & 1012 & 33.24 & 42 & 1800 & 53.7 & 796.7 & 809.736 & 152.638 & 9.2504 & 221.155 \\
\hline 09-jul-02 & $12: 02: 18$ & C751630 & 1012 & 33.87 & 39 & 1800 & 72.5 & 1186.9 & 1207.334 & 227.587 & 13.7925 & 224.45 \\
\hline 09-jul-02 & 12:11:14 & Cp251630 & 1012 & 33.72 & 42 & 1600 & 37.9 & 436.8 & 444.35 & 74.215 & 5.0762 & 226.321 \\
\hline 09-jul-02 & $12: 15: 23$ & Cp501630 & 1012 & 34.11 & 41.1 & 1600 & 53.2 & 857 & 872.332 & 146.282 & 9.9655 & 203.092 \\
\hline 09-jul-02 & $12: 20: 20$ & Cp751630 & 1012 & 33.96 & 40.2 & 1600 & 70.4 & 1279.7 & 1302.081 & 218.039 & 14.8749 & 199.143 \\
\hline 09-jul-02 & $12: 26: 18$ & Сp1001630* & 1012 & 34.78 & 37.3 & 1600 & 88.5 & 1693.9 & 1725.363 & 288.919 & 19.7105 & 201.964 \\
\hline 09-jul-02 & 12:32:30 & Bp251630 & 1011 & 33.97 & 39.4 & 1400 & 37.6 & 452.6 & 460.533 & 67.437 & 5.2611 & 216.596 \\
\hline 09-jul-02 & $12: 37: 18$ & Bp501630 & 1011 & 34.42 & 39 & 1400 & 53.6 & 903.4 & 919.979 & 134.787 & 10.5098 & 195.707 \\
\hline 09-jul-02 & $12: 41: 21$ & Bp751630 & 1011 & 34.82 & 37.9 & 1400 & 71 & 1350.3 & 1375.881 & 201.749 & 15.718 & 190.52 \\
\hline 09-jul-02 & $12: 46: 44$ & Bp1001630 & 1011 & 35.17 & 41 & 1400 & 88.8 & 1799.4 & 1835.238 & 268.998 & 20.9657 & 189.784 \\
\hline 09-jul-02 & $13: 32: 12$ & A251630 & 1011 & 31.92 & 53.3 & 1200 & 38.1 & 463.7 & 470.859 & 59.109 & 5.3791 & 212.346 \\
\hline 09-jul-02 & $13: 29: 10$ & A501630 & 1011 & 31.99 & 53.3 & 1200 & 54.9 & 935.8 & 950.46 & 119.521 & 10.858 & 195 \\
\hline 09-jul-02 & $13: 26: 15$ & A751630 & 1011 & 32.39 & 52.7 & 1200 & 72.4 & 1386.1 & 1408.695 & 177.099 & 16.0929 & 190.352 \\
\hline 09-jul-02 & $13: 22: 55$ & A1001630 & 1011 & 32.39 & 52.4 & 1200 & 90.2 & 1861.3 & 1902.089 & 239.007 & 21.7294 & 186.263 \\
\hline 09-jul-02 & $13: 10: 38$ & Ap251630 & 1011 & 33.3 & 47.5 & 1000 & 36.8 & 463 & 471.031 & 49.482 & 5.381 & 211.909 \\
\hline 09-jul-02 & $13: 13: 42$ & Ap501630 & 1011 & 33.05 & 49.2 & 1000 & 53.6 & 905 & 921.835 & 96.359 & 10.531 & 195.978 \\
\hline 09-jul-02 & $13: 17: 40$ & Ap751630 & 1011 & 32.81 & 51.1 & 1000 & 72.7 & 1351.5 & 1398.486 & 146.438 & 15.9763 & 190.825 \\
\hline 09-jul-02 & $13: 19: 42$ & Ap1001630 & 1011 & 32.59 & 52.1 & 1000 & 90.7 & 1809.6 & 1889.081 & 197.969 & 21.5808 & 188.379 \\
\hline
\end{tabular}

= Se alcanza Temperatura máxima a la salida del compresor $\left(210^{\circ} \mathrm{C}\right)$ en los puntos C100 y Cp100.

Tabla A. 20: Puntos medidos para la caracterización de la TGV de álabes móviles(13). 


\begin{tabular}{|c|c|c|c|c|c|c|c|c|c|c|c|c|c|c|}
\hline TEST & RENEFISO & T ECOMP & T SCOMP & T_SINC & \begin{tabular}{|l|}
$T$ ETURB \\
\end{tabular} & T_STURB & T_MUR_et & TWO & T_EWINC & T_SWINC & T_FUEL & T_OIL & $\mathrm{P}$ OIL & $P \_C A B$ \\
\hline $20 \%$ a16.30mi & $\%$ & Cel & Cel & Cel & Cel & Cel & Cel & Cel & Cel & Cel & Cel & Cel & Bar & bar \\
\hline C251630 & 34.355 & 33.41 & 104.43 & 40.09 & 330.94 & 245.32 & 268 & 85.47 & 25.17 & 47.69 & 37.26 & 93.69 & 5.3 & 0.991 \\
\hline C501630 & 38.943 & 34.47 & 152.18 & 40.44 & 428.14 & 299.44 & 363 & 85.88 & 25.22 & 47.26 & 38.7 & 96.96 & 5.1 & 0.974 \\
\hline \begin{tabular}{|l|} 
C751630 \\
\end{tabular} & 38.371 & 35.19 & 201.14 & 45.02 & 527.07 & 361.21 & 455 & 86.37 & 25.36 & 53.98 & 39.5 & 99.04 & 5 & 0.948 \\
\hline Cp251630 & 38.054 & 35.61 & 1.78 & 8.04 & 325.66 & 5.23 & 270 & 83.25 & 26.33 & 45.54 & 38.43 & 93.24 & 5.1 & 0.998 \\
\hline \begin{tabular}{|l} 
Cp501630 \\
\end{tabular} & 42.407 & 35.6 & 131.61 & 41.84 & 422.1 & 310.33 & 343 & 85.93 & 26.1 & 47.1 & 38.39 & 95.38 & 5 & 0.987 \\
\hline Cp751630 & 3.248 & 35.92 & 73.63 & 41.3 & 492.88 & 349.8 & 416 & 86.45 & 26.13 & 50.32 & 38.9 & 97.78 & 4.9 & 0.971 \\
\hline Cp1001630* & 42.643 & 37.02 & 212.72 & 47.01 & 570.66 & 398.19 & 495 & 85.96 & 26.4 & 58.68 & 40.4 & 99.85 & 4.8 & 0.953 \\
\hline Bp251630 & 39.763 & 36.46 & 79.9 & 37.07 & 324.67 & 268.4 & 271 & 82.55 & 27.14 & 43.81 & 38.7 & 92.61 & 5 & 1.002 \\
\hline Bp501630 & 44.007 & 36.44 & 116.38 & 41.42 & 431.69 & 333.72 & 343 & 85.54 & 26.85 & 47.94 & 38.19 & 94.62 & 4.9 & 0.995 \\
\hline Bp751630 & 45.205 & 37.08 & 154.54 & 41.94 & 496.04 & 367.79 & 408 & 86.63 & 26.73 & 46.66 & 38.48 & 96.76 & 4.8 & 0.984 \\
\hline Bp1001630 & 45.38 & 38.03 & 189.84 & 41.84 & 552.45 & 399.07 & 473 & 86.19 & 26.85 & 48.77 & 39.99 & 99.12 & 4.6 & 0.971 \\
\hline \begin{tabular}{|l|} 
A251630 \\
\end{tabular} & 40.559 & 5.77 & 69.17 & 37.69 & 332.15 & 289.68 & 281 & 82.58 & 28.03 & 46.53 & 38.6 & 92.37 & 4.8 & 1.005 \\
\hline A501630 & 44.166 & 36.53 & 104.5 & 38.59 & 453.83 & 373.16 & 376 & 83.55 & 27.83 & 46.3 & 38.7 & 95.2 & 4.5 & \\
\hline A751630 & 45.245 & 37.02 & 137.78 & 39.15 & 521.71 & 412.37 & 434 & 84.74 & 27.66 & 47.63 & 39.26 & 97.33 & 4.2 & 0.994 \\
\hline A1001630 & 46.238 & 37.05 & 167.75 & 42.63 & 571.51 & 434.47 & 478 & 86.4 & 27.48 & 50.43 & 40.49 & 99.14 & 4.1 & 0.986 \\
\hline \begin{tabular}{|l|} 
Ap251630 \\
\end{tabular} & 40.642 & 36.89 & 60.94 & 36.38 & 320.38 & 290.23 & 278 & 82.53 & 27.89 & 45.09 & 39.81 & 92.33 & 3.9 & 1.007 \\
\hline \begin{tabular}{|l|} 
Ap501630 \\
\end{tabular} & 43.946 & 36.71 & 79.43 & 36.57 & 447.49 & 384.27 & 325 & 85.05 & 27.95 & 44.23 & 40.06 & 93.33 & 3.8 & 1.006 \\
\hline \begin{tabular}{|l|l} 
Ap751630 \\
\end{tabular} & 45.133 & 36.7 & 109.11 & 40.04 & 551.12 & 460.94 & 419 & 86.43 & 27.67 & 49.02 & 40.48 & 96.04 & 3.6 & 1.003 \\
\hline Ap1001630 & 45.719 & 36.88 & 137.95 & 41.9 & 612.16 & 495.78 & 475 & 87.25 & 27.49 & 49.8 & 40.68 & 97.66 & 3.4 & 0.999 \\
\hline
\end{tabular}

Tabla A. 21: Puntos medidos para la caracterización de la TGV de álabes móviles(14).

\begin{tabular}{|c|c|c|c|c|c|c|c|c|c|c|c|c|c|c|c|}
\hline TEST & P_SCOMP1 & P_SI_AB & P_ETURB1 & P_STURB1 & G_AlRE & REND_VOL & MB & A_F & RPM_TURB & TGV_DES & POS_TGV & BASE & EXP & C_ISO & $\mathrm{VH} 2 \mathrm{O}$ \\
\hline $20 \% \mathrm{a} 16.30 \mathrm{~m}$ & bar & bar & bar & bar & $\mathrm{g} / \mathrm{s}$ & $\%$ & $\mathrm{~g} / \mathrm{s}$ & af & rpm & $\%$ & $\mathrm{~mm}$ & ** & ** & ** & $\mathrm{mmHg}$ \\
\hline 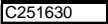 & 1.756 & 1.746 & 2.004 & 1.067 & 287.787 & 0.897 & 5.257 & 54.742 & 67484.109 & 20 & 16.28 & 1.0526 & 0.3 & 1.015 & 16.71 \\
\hline \begin{tabular}{|l|}
$\mathrm{C501630}$ \\
\end{tabular} & 2.419 & 2.405 & 2.71 & 1.107 & 391.011 & 0.886 & 9.376 & 41.702 & 86663.945 & 20 & 16.28 & 1.0558 & 0.3 & 1.016 & 16.15 \\
\hline \begin{tabular}{|l}
$\mathrm{C} 751630$ \\
\end{tabular} & 3.141 & 3.141 & 3.561 & 1.162 & 482.282 & 0.849 & 14.188 & 33.992 & 103390.766 & 20 & 16.27 & 1.0585 & 0.3 & 1.017 & 15.53 \\
\hline \begin{tabular}{|l|} 
Cp251630 \\
\end{tabular} & 564 & 1.563 & 1.73 & 1.05 & 234.105 & 0.912 & 4.68 & 50.018 & 59480.137 & 20 & 16.21 & 1.0588 & 0.3 & 1.017 & 16.6 \\
\hline \begin{tabular}{|l|}
$\mathrm{Cp} 501630$ \\
\end{tabular} & 995 & 2.097 & 2.242 & 1.101 & 312.035 & 0.917 & 8.246 & 37.841 & 77342.891 & 20 & 16.27 & 1.0608 & 0.3 & 1.018 & 16.58 \\
\hline \begin{tabular}{|c|} 
Cp751630 \\
\end{tabular} & 726 & 2.73 & 2.894 & 1.115 & 408.38 & 0.92 & 12.067 & 33.843 & 92846.133 & 20 & 16.31 & 1.0595 & 0.3 & 1.017 & 16.09 \\
\hline \begin{tabular}{|l|l|} 
Cp10030* \\
\end{tabular} & 3.329 & 3.335 & .549 & 1.161 & 468.605 & 0.88 & 16.218 & 28.893 & 105359.445 & 20 & 16.3 & 1.0633 & 0.3 & 1.019 & 15.63 \\
\hline $\mathrm{Bp2}$ & 415 & .417 & 1.535 & 1.04 & 190.004 & 0.93 & 4.063 & 46.767 & 9.156 & 20 & 16.18 & 1.06 & 0.3 & 1.018 & 15.76 \\
\hline Bp50 & 1.871 & 1.875 & 1.93 & 1.058 & 253.17 & 0.95 & 7.332 & 34.529 & 31.359 & 20 & 16.27 & 1.0626 & 0.3 & 1.018 & 16.02 \\
\hline \begin{tabular}{|l|} 
Bp751630 \\
\end{tabular} & 2.55 & 2.406 & 2.424 & 1.085 & 328.952 & \begin{tabular}{l|}
0.963 \\
\end{tabular} & 10.677 & 30.809 & 84389.367 & 20 & 16.29 & 1.0645 & 0.3 & 1.019 & 15.92 \\
\hline \begin{tabular}{|l} 
Bp1 \\
\end{tabular} & 2.944 & 2.951 & 951 & 1.12 & 401.473 & 0.958 & 14.184 & 28.304 & 96477.789 & 20 & 16.33 & 1.068 & 0.3 & 1.02 & 17.53 \\
\hline \begin{tabular}{|l|}
$A 251630$ \\
\end{tabular} & 1.299 & 1.302 & 381 & 1.032 & 153.233 & 0.954 & 3.49 & 43.911 & 44396.914 & 20 & 16.21 & 1.0527 & 0.3 & 1.016 & 19.03 \\
\hline \begin{tabular}{|l|} 
A501630 \\
\end{tabular} & 1.698 & 1.703 & 1.705 & 1.045 & 205.811 & 0.982 & 6.47 & 31.808 & 62932.91 & 20 & 16.21 & 1.0531 & 0.3 & 1.016 & 19.11 \\
\hline A75 & 6 & 2.136 & .065 & 1.064 & 257.315 & 0.981 & 9.36 & 27.491 & 76508.594 & 20 & 16.24 & 1.0554 & 0.3 & 1.016 & 19.33 \\
\hline (A & 81 & 2.588 & 428 & 1.085 & 311.652 & 0.992 & 12.368 & 25.197 & 87486.305 & 20 & 16.27 & 1.0553 & 0.4 & 1.022 & 19.2 \\
\hline \begin{tabular}{|l|} 
Ap251630 \\
\end{tabular} & 1.194 & 1.202 & 1.258 & 1.019 & 118.8 & 0.957 & 2.904 & 40.909 & 36708.207 & 20 & 16.22 & 1.0591 & 0.3 & 1.017 & 18.32 \\
\hline Ap50 & 1.408 & 1.415 & 1.409 & 1.025 & 145.59 & 0.997 & 5.255 & 27.704 & 9676.07 & 20 & 16.26 & 1.0582 & 0.33 & 1.019 & 18.7 \\
\hline & & 1.746 & 1.626 & 1.037 & 179.993 & 1.01 & 7.766 & 23.176 & & 2 & 16.3 & 1.0575 & 0.61 & 1.035 & 19.18 \\
\hline Ap1001630 & 2.109 & 2.113 & 1.902 & 1.05 & 218.254 & 1.019 & 10.352 & 21.084 & 74893.023 & 20 & 16.35 & 1.0564 & 0.78 & 1.044 & 19.31 \\
\hline
\end{tabular}

Tabla A. 22: Puntos medidos para la caracterización de la TGV de álabes móviles(15).

\begin{tabular}{|c|c|c|c|c|c|c|c|c|c|c|c|c|}
\hline DATE & TIME & TEST & P_ATMOSF & T_AIR & PHI & SPEED & ALPHA & TORQUE & TORQUISO & POTISO & PMEISO & COSPISO \\
\hline ddmmyy & hhmmss & 0\%a20.38mm & mbar & Cel & $\%$ & $\mathrm{rpm}$ & $\%$ & $\mathrm{Nm}$ & $\mathrm{Nm}$ & $\mathrm{kW}$ & bar & $g / k W h$ \\
\hline 09-jul-02 & 16:08:50 & C252038 & 1009 & 33.02 & 48.4 & 1800 & 40.6 & 399.7 & 406.65 & 76.844 & 4.6456 & 287.484 \\
\hline 09-jul-02 & 16:19:06 & c502038 & 1009 & 33.71 & 46.1 & 1800 & 53.6 & 702.4 & 715.309 & 134.838 & 8.1717 & 254.539 \\
\hline 09-jul-02 & 16:23:04 & c752038* & 1009 & 34.06 & 45 & 1800 & 58.5 & 803.8 & 818.94 & 154.301 & 9.3555 & 250.723 \\
\hline 09-jul-02 & 16:31:21 & ср252038 & 1009 & 33.62 & 47.3 & 1600 & 39 & 425.1 & 432.93 & 72.561 & 4.9458 & 247.865 \\
\hline 09-jul-02 & $16: 37: 46$ & cp502038 & 1009 & 33.83 & 46 & 1600 & 55.1 & 851.7 & 867.501 & 145.319 & 9.9103 & 216.908 \\
\hline 09-jul-02 & 16:41:58 & cp752038 & 1009 & 34.25 & 44.2 & 1600 & 74.6 & 1276.7 & 1301.111 & 218.076 & 14.8638 & 216.618 \\
\hline 09-jul-02 & 17:04:25 & bp252038 & 1009 & 34.13 & 43.1 & 1400 & 38.2 & 450.8 & 459.249 & 67.275 & 5.2464 & 228.133 \\
\hline 09-jul-02 & 17:08:55 & bp502038 & 1009 & 34.65 & 42.2 & 1400 & 54.8 & 905.9 & 923.657 & 135.46 & 10.5518 & 202.888 \\
\hline 09-jul-02 & 17:13:38 & bp752038 & 1009 & 35.05 & 39.2 & 1400 & 73.4 & 1353.6 & 1380.554 & 202.417 & 15.7714 & 199.605 \\
\hline 09-jul-02 & 17:18:01 & bp1002038* & 1009 & 35.04 & 39.9 & 1400 & 79.7 & 1495.3 & 1525.227 & 223.726 & 17.4241 & 201.684 \\
\hline 09-jul-02 & $17: 25: 03$ & a252038 & 1008 & 34.31 & 43.5 & 1200 & 38.7 & 472 & 481.165 & 60.433 & 5.4968 & 217.654 \\
\hline 09-jul-02 & $17: 30: 32$ & a502038 & 1008 & 34.78 & 41 & 1200 & 55.7 & 937.5 & 956.15 & 120.154 & 10.923 & 198.7 \\
\hline 09-jul-02 & $17: 34: 28$ & a752038 & 1008 & 34.82 & 41.4 & 1200 & 74 & 1402.7 & 1430.8 & 179.882 & 16.3454 & 194.202 \\
\hline 09-jul-02 & 17:40:08 & a1002038 & 1008 & 35.22 & 39.5 & 1200 & 91.6 & 1855.3 & 1893.318 & 237.772 & 21.6292 & 192.154 \\
\hline 09-jul-02 & $17: 48: 10$ & ap252038 & 1008 & 34.3 & 42.5 & 1000 & 37.1 & 453.9 & 462.611 & 48.443 & 5.2848 & 215.311 \\
\hline 09-jul-02 & 17:52:30 & ap502038 & 1008 & 34.38 & 42.1 & 1000 & 54.4 & 904.5 & 921.996 & 96.561 & 10.5328 & 197.316 \\
\hline 09-jul-02 & $17: 57: 22$ & ap752038 & 1008 & 34.77 & 41.5 & 1000 & 73.3 & 1355.5 & 1389.519 & 145.365 & 15.8738 & 192.816 \\
\hline 09-jul-02 & 18:03:52 & ap1002038 & 1008 & 35.11 & 39.1 & 1000 & 90 & 1799 & 1860.304 & 194.611 & 21.252 & 188.645 \\
\hline
\end{tabular}

= Máxima Temperatura salida compresor $\left(210^{\circ} \mathrm{C}\right)$. En C75, C100, Cp100, Bp100

Tabla A. 23: Puntos medidos para la caracterización de la TGV de álabes móviles(16). 
Contribución a la caracterización experimental y modelado de TGV en grupos de sobrealimentación

\begin{tabular}{|c|c|c|c|c|c|c|c|c|c|c|c|c|c|c|}
\hline TEST & RENEFISO & T_ECOMP & T_SCOMP & T_SINC & TETURB & TI_STURB & T_MUR_et & TWO & TTEWINC & T_SWINC & T FUEL & T_OIL & $\mathrm{P}$ POIL & $P E C A B$ \\
\hline $0 \%$ a20.38mm & $\%$ & Cel & Cel & Cel & Cel & Cel & Cel & Cel & Cel & Cel & Cel & Cel & Bar & bar \\
\hline C252038 & 29.958 & 33.98 & 147.17 & 40.41 & 345.16 & 211.53 & 287 & 87.57 & 26.22 & 49.65 & 37.04 & 92.95 & 5.2 & 0.977 \\
\hline \begin{tabular}{|l|} 
c502038 \\
\end{tabular} & 33.835 & 34.77 & 188.77 & 41.89 & 420.22 & 250.75 & 359 & 85.83 & 26.44 & 47.86 & 39.73 & 97.37 & 5 & 0.958 \\
\hline c752038* & 34.35 & 34.99 & 202.8 & 44.19 & 448.56 & 266.31 & 382 & 85.76 & 26.78 & 51.65 & 40.12 & 97.99 & 5 & 0.951 \\
\hline 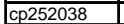 & 34.746 & 34.96 & 120.81 & 38.73 & 323.36 & 216.99 & 267 & 84.35 & 27.3 & 46.17 & 39.2 & 93.81 & 5.1 & 0.991 \\
\hline \begin{tabular}{|c|}
$\operatorname{cp} 502038$ \\
\end{tabular} & 39.706 & 35.23 & 169.12 & 40.86 & 417.44 & 263 & 352 & 85.83 & 27.26 & 49.5 & 39.37 & 96.57 & 5 & 0.976 \\
\hline \begin{tabular}{|l}
$\operatorname{cp} 752038$ \\
\end{tabular} & 39.759 & 35.51 & 220.04 & 46.23 & 508.01 & 309.66 & 430 & 86.49 & 27.39 & 54.77 & 39.77 & 98.45 & 4.8 & 0.954 \\
\hline bp252038 & 37.752 & 35.41 & 101.82 & 40 & 320.43 & 233.2 & 256 & 85.09 & 27.94 & 47.81 & 39.15 & 93.21 & 5 & 0.998 \\
\hline \begin{tabular}{|l|} 
bp502038 \\
\end{tabular} & 42.449 & 35.99 & 146.7 & 41.77 & 425.35 & 290.13 & 344 & 86.47 & 27.82 & 46.65 & 39.1 & 95.76 & 4.8 & 0.99 \\
\hline bp752038 & 43.147 & 36.77 & 194.02 & 42.02 & 499.89 & 325.79 & 418 & 86.5 & 27.79 & 49.89 & 39.42 & 97.72 & 4.7 & 0.977 \\
\hline bp1002038* & 42.703 & 37.32 & 211.83 & 43.63 & 526.93 & 341.06 & 451 & 85.97 & 27.99 & 51.93 & 39.7 & 98.42 & 4.6 & 0.971 \\
\hline \begin{tabular}{|l|} 
a252038 \\
\end{tabular} & 39.569 & 36.61 & 88.43 & 37.01 & 329.1 & 259.59 & 269 & 83.34 & 28.64 & 44.2 & 38.7 & 92.26 & 4.8 & 1.002 \\
\hline \begin{tabular}{|l|} 
a502038 \\
\end{tabular} & 43.344 & 36.75 & 128.61 & 41.05 & 453.1 & 337.18 & 362 & 85.91 & 28.38 & 48.61 & 38.48 & 94.92 & 4.5 & 0.997 \\
\hline a752038 & 44.348 & 37.39 & 170.78 & 41.7 & 528.07 & 375.24 & 432 & 86.68 & 28.32 & 48.19 & 38.7 & 96.99 & 4.2 & 0.99 \\
\hline \begin{tabular}{|l|}
$\mathrm{a} 1002038$ \\
\end{tabular} & 44.821 & 38.32 & 207.41 & 42.39 & 580.83 & 400.15 & 492 & 86.28 & 28.48 & 51.8 & 40.58 & 99.69 & 3.9 & 0.983 \\
\hline \begin{tabular}{|l|} 
ap252038 \\
\end{tabular} & 40 & 37.04 & 72.11 & 35.35 & 318.87 & 269.09 & 259 & 83.21 & 29.23 & 42.14 & 40.41 & 91.62 & 4 & 1.005 \\
\hline ap502038 & 43.648 & 36.56 & 100.07 & 37.88 & 456.56 & 364.8 & 340 & 85.91 & 29.21 & 46.03 & 40.84 & 93.77 & 3.8 & 1.003 \\
\hline ap752038 & 44.667 & 37.26 & 136.79 & 41.91 & 551.46 & 428.43 & 435 & 86.67 & 28.77 & 50.53 & 41.33 & 96.87 & 3.5 & 1 \\
\hline ap1002038 & 45.654 & 38.65 & 171.05 & 41.02 & 603.35 & 454.19 & 500 & 85.99 & 28.81 & 47.73 & 41.98 & 99.79 & 3.2 & 0.996 \\
\hline
\end{tabular}

Tabla A. 24: Puntos medidos para la caracterización de la TGV de álabes móviles(17).

\begin{tabular}{|c|c|c|c|c|c|c|c|c|c|c|c|c|c|c|c|}
\hline TEST & P_scomP1 & P_SI_AB & P_ETURB1 & TURB1 & AIRE & REND_VOL & $\overline{\mathrm{MB}}$ & A_F & RPM_TURB & TGV_DES & OS_TGV & $\mathrm{SE}$ & $\overline{E X P}$ & C_ISO & I_VHZC \\
\hline $0 \% \mathrm{a} 20.38 \mathrm{~mm}$ & bar & bar & bar & bar & $\mathrm{g} / \mathrm{s}$ & $\%$ & $\mathrm{~g} / \mathrm{s}$ & af & $\mathrm{rpm}$ & $\%$ & $\mathrm{~mm}$ & ** & ** & ** & $\mathrm{mmHg}$ \\
\hline C252038 & 2.354 & 2.348 & 3.378 & 1.129 & 361.788 & 0.84 & 6.12 & 59.112 & 84372.086 & 0 & 20.34 & 1.0592 & 0.3 & 1.017 & 18.39 \\
\hline $\begin{array}{l}\mathrm{C502038} \\
\end{array}$ & 2.991 & 2.992 & 4.369 & 1.166 & 443.752 & 0.812 & 9.533 & 46.548 & 98927.539 & 0 & 20.27 & 1.0626 & 0.3 & 1.018 & 18.19 \\
\hline $\begin{array}{l}\mathrm{c} 752038^{*} \\
\end{array}$ & 3.205 & 3.208 & 4.695 & 1.173 & 467.769 & 0.805 & 10.752 & 43.507 & 103310.93 & 0 & 20.26 & 1.0643 & 0.3 & 1.019 & 18.09 \\
\hline \begin{tabular}{|l|} 
cp252038 \\
\end{tabular} & 1.953 & 1.954 & 2.643 & 1.089 & 273.66 & 0.854 & 4.994 & 54.802 & 72396.414 & 0 & 20.24 & 1.0625 & 0.3 & 1.018 & 18.57 \\
\hline \begin{tabular}{|l|} 
cp502038 \\
\end{tabular} & 2.667 & 2.671 & 3.575 & 1.127 & 364.851 & 0.839 & 8.758 & 41.661 & 90274.758 & 0 & 20.28 & 1.0633 & 0.3 & 1.019 & 18.28 \\
\hline \begin{tabular}{|l|}
$\operatorname{cp} 752038$ \\
\end{tabular} & 3.508 & 3.518 & 4.749 & 1.164 & 456.968 & 0.811 & 13.118 & 34.835 & 106894.875 & 0 & 20.34 & 1.0652 & 0.3 & 1.019 & 17.96 \\
\hline bp252038 & 1.688 & 1.694 & 2.149 & 1.058 & 210.331 & 0.869 & 4.266 & 49.299 & 62650.207 & 0 & 20.28 & 1.064 & 0.3 & 1.019 & 17.4 \\
\hline bp502038 & 2.274 & 2.283 & 2.839 & 1.09 & 276.506 & 0.852 & 7.632 & 36.23 & 80213.633 & 0 & 20.32 & 1.0668 & 0.3 & 1.02 & 17.55 \\
\hline \begin{tabular}{|l|} 
bp752038 \\
\end{tabular} & 3.005 & 3.014 & 3.728 & 1.121 & 362.532 & 0.847 & 11.22 & 32.31 & 96134.977 & 0 & 20.3 & 1.068 & 0.3 & 1.02 & 16.68 \\
\hline bp1002038* & 3.284 & 3.296 & 4.093 & 1.132 & 389.319 & 0.836 & 12.529 & 31.073 & 101537.367 & 0 & 20.31 & 1.0683 & 0.3 & 1.02 & 16.94 \\
\hline \begin{tabular}{|l|} 
a252038 \\
\end{tabular} & 1.497 & 1.503 & 1.809 & 1.036 & 163.203 & 0.878 & 3.656 & 44.645 & 54161.672 & 0 & 20.18 & 1.066 & 0.3 & 1.019 & 17.74 \\
\hline a502038 & 1.97 & 1.978 & 2.311 & 1.058 & 209.83 & 0.869 & 6.631 & 31.645 & 71138.141 & 0 & 20.25 & 1.0679 & 0.3 & 1.02 & 17.16 \\
\hline a752038 & 2.53 & 2.541 & 2.927 & 1.085 & 266.541 & 0.861 & 9.701 & 27.476 & 85894.047 & 0 & 20.26 & 1.0683 & 0.3 & 1.02 & 17.38 \\
\hline \begin{tabular}{|l|}
$\mathrm{a} 1002038$ \\
\end{tabular} & 3.073 & 3.087 & 3.547 & 1.105 & 318.025 & 0.848 & 12.701 & 25.039 & 97057.773 & 0 & 20.2 & 1.0699 & 0.3 & 1.02 & 16.94 \\
\hline \begin{tabular}{|l|} 
ap252038 \\
\end{tabular} & 1.307 & 1.315 & 1.511 & 1.022 & 118.661 & 0.871 & 2.897 & 40.957 & 43661.344 & 0 & 20.18 & 1.0656 & 0.3 & 1.019 & 17.34 \\
\hline \begin{tabular}{|l|} 
ap502038 \\
\end{tabular} & 1.603 & 1.612 & 1.804 & 1.03 & 145.798 & 0.88 & 5.292 & 27.553 & 57719.695 & 0 & 20.28 & 1.0659 & 0.3 & 1.019 & 17.23 \\
\hline \begin{tabular}{|l|} 
ap752038 \\
\end{tabular} & 2.007 & 2.017 & 2.197 & 1.045 & 181.911 & 0.889 & 7.795 & 23.337 & 71822.812 & 0 & 20.32 & 1.068 & 0.38 & 1.025 & 17.37 \\
\hline ap1002038 & 2.418 & 2.433 & 2.635 & 1.062 & 221.664 & 0.896 & 10.206 & 21.719 & 83099.688 & 0 & 20.27 & 1.0691 & 0.5 & 1.034 & 16.66 \\
\hline
\end{tabular}

Tabla A. 25: Puntos medidos para la caracterización de la TGV de álabes móviles(18). 


\section{Bibliografia}

[1] Arnau, F.J. (2003) Aportaciones al cálculo numérico para el modelado del flujo compresible unidimensional en conductos de M.C.I.A. Tesis Doctoral. Universidad Politécnica de Valencia.

[2] Benajes, J., Bermúdez, V. y Galindo, J. (1994) Efecto de la geometría del intercooler en las prestaciones de motores de automoción. XI Congreso Nacional de Ingeniería Mecánica. Anales de Ingeniería Mecánica, Año 10, Vol. 2.

[3] Benajes, J., Luján, J.M., Bermúdez, V. and Serrano, J. R. (2002) Modelling of Turbocharged Diesel Engines in Transient Operation. Part 1: Insight into the Relevant Physical Phenomena. I.Mech.E Part D. Vol 216.

[4] Benajes, J., Reyes, E., Bermúdez, V. and Serrano, J. R. (1998) Predesign Criteria for Exhaust Manifolds in I.C. Automotive Engines. SAE Paper 980783.

[5] Benajes, J., Reyes, E., Galindo, J. and Peidró, J. (1997) Predesign Model for Intake Manifolds in Internal Combustión Engines. SAE Paper 970055.

[6] Benajes, J., Reyes, E., and Luján, J.M. (1996) Modeling study of the scavenging process in a turbocharged Diesel engine with modified valve operation. Proceedings of the I.MechE. Part C: Journal of Mechanical Engineering Science. Vol 210, pp 383-393.

[7] Benson, R.S. (1982) The Termodynnamics and Gas Dynamics of Internal Combustión Engines. Oxford University Press. New York. ISBN 0-19856210-1, pp 73-76.

[8] Corberán, J.M. (1984) Contribución al Modelado del Proceso de Renovación de la Carga en Motores de Combustión Interna Alternativos. Tesis Doctoral. Universidad Politécnica de Valencia.

[9] Dale, A. and Watson, N. (1986) Vaneless radial turbocharger turbine under unsteady flow conditions. Instn.Mech.Engrs.Conference Turbocharging and Turbocharguers, pp 65-76. Londres.

[10] Desantes, J.M, Benajes, J., Luján, J.M and Fremod, E. (1995) Production of internal EGR in turbocharged diesel engines by jeans of intake valve pre-lift and exhaust valve post-lift. Procedings of the $5^{\text {th }}$ Int. EAEC Congress. Strasbourg. 
[11] Desantes, J.M., Chust, M.D. y Llorens; J. (1993) Análisis comparativo de métodos numéricos para la resolución del flujo no estacionario en colectores de motores de combustión interna alternativos. II Congreso de Métodos Numéricos en Ingeniería. F. Ambarina y M. Casteleiro (Eds.) OSEMNI.

[12] Galindo, J. (1998) Caracterización experimental y modelado de uniones direccionales de colectores de escape de motores de combustión interna alternativos. Tesis doctoral. Universidad Politécnica de Valencia.

[13] Galindo, J., Serrano, J.R., Climent, H. And Arnau, F.J. (2001) New one-dimensional fluid-dynamic model for automotive intercoolers. $8^{\text {th }}$ European Automotive Congress (EAEC-FISITA) Conference A proceeding, pp 347-365. Bratislava.

[14] Luján, J.M., (1993) Proyecto de desarrollo y optimización de un modelos de cálculo asistido por ordenador para el grupo de sobrealimentación en motores de combustión interna alternativos. Proyecto final de carrera dirigido por el Dr. D. Jesús Benajes Calvo. E.T.S. Ingenieros Industriales. Universidad Politécnica de Valencia.

[15] Luján, J.M., (1998) Recirculación interna de gases de combustión en mootres diesel sobrealimentados. Tesis doctoral. Universidad Politécnica de Valencia.

[16] Payri, F., Benajes, J. and Chust, M.D. (1991) Programme pour étude assistée par ordinateur de systémes d'admision et d'echappement de moteurs. Entropie. 162, 17-23.

[17] Payri, F., Benajes, J. and Galindo, J. (1995) One-dimensional fluiddynamic model for catalytic converters in automotive engines. SAE Technical paper 950785.

[18] Payri, F., Benajes, J., Galindo, J. and Serrano J.R. (2002) Modelling of Turbocharged Diesel Engines in Transient Operation. Part 2: Wave Action Models for Calculating the Transient Operation in a High Speed Direct Injection Engine. I.Mech.E Part D. Vol 216.

[19] Payri, F., Benajes, J. and Luján, J.M. (1994) Modelo de cálculo para el waste-gate de grupos de sobrealimentación en motores térmicos. XI Congreso Nacional de Ingeniería Mecánica. Anales de Ingeniería Mecánica. Año 10, Vol 2. 
[20] Payri, F., Benajes, J. and Reyes, M. (1996) Modelling of supercharger turbines in internal combustion engines. Intenational Journal of Mechanical Science. Vol 38, N8-9, pp 835-869.

[21] Payri, F., Corberán, J.M. and Boada, F. (1986) Modifications to the method of characteristics for the analysis of the gas exchange process in internal combustion engines. 105/86 @ImechE. Proc Instn Mech Engrs. Vol 200, pp 259-266. No D4.

[22] Payri, F., Desantes, J.M. and Corberán, J.M. (1988) A Quasy-Steady model on gas exchange process, some results. Motor Sympo'88. Praga.

[23] Payri, F., Desantes, J.M. y Tinaut, F. (1984) Solución a la condición de contorno de la unión cilindro-conducto de los MCIA. Anales de la Ingeniería Mecánica. Año2, nº1.

[24] Payri, F., Galindo, J. Serrano, J.R. and Cervelló, C. (2000) Variable Geometry Turbine Modelling and Control for Turbocharged Diesel Engine Transient Operation. THIESEL2000 Thermofluidynamic Processes in Diesel Engines. Conference Proceedings, pp 173-189.

[25] Payri, F., Llorens, J., Chust, M.D. (1993) Modelo Matemático para el Cálculo de la Aerodinámica Interna de Motores Alternativos. I Congreso Iberoamericano de Ingeniería Mecánica. Madrid.

[26] Payri, F., Reyes, E. and Galindo, J. (2001) Analysis and Modelling of the Fluid-Dynamic Effects in Branched Exhaust junctions of I.C.E. Trans. ASME, Int. J. Gas Turbine Power 123(1), pp 197-203.

[27] Payri, F., Reyes, E. and Serrano, J.R. (1999) A model for load transient of turbocharged diesel engines. SAE Technical Paper 199901-0225.

[28] Requejo, I. (1987) Contribución al modelado de los grupos de turbosobrealimentación de MCIA. Tesis Doctoral, Universidad Politécnica de Barcelona (1987)

[29] Reyes, M. (1993) Contribución al modelado del proceso de transferencia de calor en colectores de escape de motores alternativos. Tesis doctoral, Universidad Politécnica de Valencia.

[30] Rodriguez, A.A. (2001) Síntesis de la Respuesta Transitoria en Motores Diesel de Inyección Directa Turboalimentados. Tesis Doctoral, Universidad Politécnica de Valencia. 
[31] Santos, R.J. (1999) Estudio del aprovechamiento de la energía de los gases de escape en motores diesel. Tesis Doctoral, Universidad Politécnica de Valencia.

[32] Serrano, J.R. (1999) Análisis y Modelado del Transitorio de Carga en M.E.C. Turboalimentados. Tesis Doctoral, Universidad Politécnica de Valencia.

[33] Serrano, J.R, Arnau, F.J. y Cervelló, C. (2000) Nuevo modelo para turbinas de geometría variable. XIV Congreso Nacional de Ingeniería Mecánica. Anales de Ingeniería Mecánica. Año 13, vol 3.

[34] Vera, F. (2004) Efecto de la recirculación del gas de escape en el proceso de renovación de la carga en motores turbo-sobrealimentados. Tesis Doctoral, Universidad Politécnica de Valencia.

[35] Winterbone, D.E., Nikpour, B. and Frost, H. (1991) A contribution to the understanding of turbocharger turbine performance in pulsating flow. I.Mech.E. C443/011, pp 19-30.

[36] Winterbone, D.E., Pearson, R.J. (1998) Turbocharger turbine performance under unsteady flow - a review of experimental results and proposed models. I.Mech.E. C554/031/98.

[37] Winterbone, D.E., Pearson, R.J. and Zhao, Y. (1991) Numerical Simulation of Intake and Exhaust Flow in a high-Speed Multi-Cylinder Petrol Engine Using the Lax-Wendroff Method I.Mech.E. C430/038.

[38] Winterbone, D.E., ans Shitomi, M. (1990) The Accuracy of Calculating Wave Action in Engine Intake Manifolds. SAE Technical Paper 900677.

[39] Yeo, J.H. and Baines, N.C. (1990) Pulsating flow behaviour in a twinentry vaneless radial-inflow turbine. I.Mech.E. Conference on Turbocharging and Turbocharguers, C405/004, pp.113-122. Londres. 


\section{Capitulo 6: Conclusiones y trabajos futuros}

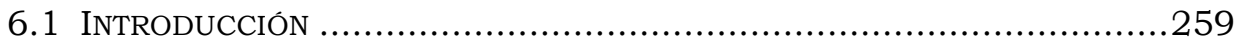

6.2 NUEVA INSTALACIÓN PARA LA CARACTERIZACIÓN DE TURBOGRUPOS .......260

6.2.1 Conclusiones acerca del ensayo de un turbogrupo...............................261

6.2.2 Comportamiento del compresor en bombeo.........................................263

6.3 NUEVO MODELO UNIDIMENSIONAL PARA TURBINAS DE GEOMETRÍA VARIABLE 265

6.3.1 Modelado de la instalación .......................................................................266

6.3.2 Validación del modelo en ensayos de motor ..........................................267

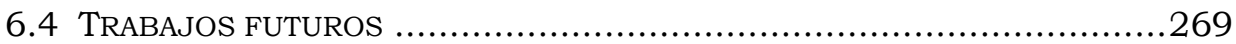





\subsection{Introducción}

Este último capítulo tiene como objetivo realizar una síntesis de todas las conclusiones obtenidas de la labor investigadora llevada cabo durante los últimos años y que han dado como fruto la presente tesis doctoral, enfocada al desarrollo de una instalación para el estudio de turbogrupos de sobrealimentación y su aplicación al desarrollo de un modelo para turbinas de geometria variable.

Las conclusiones se han dividido dependiendo de cada uno de los temas abordados en el presente trabajo. Así, en primer lugar se van a exponer las conclusiones obtenidas al revisar la instalación diseñada y construida para la caracterización de turbogrupos, así como la validez de los métodos utilizados para la realización de las medidas y las posibles mejoras que podrian desarrollarse.

A continuación se recogerán las conclusiones más destacables en lo referente al nuevo modelo para turbinas de geometría variable desarrollado y sobre los resultados obtenidos al aplicar dicho modelo para turbinas montadas en el banco de ensayos descrito y para turbinas instaladas en banco motor bajo diferentes condiciones de funcionamiento. 


\subsection{Nueva instalación para la caracterización de turbogrupos}

Después de realizar una revisión de las instalaciones destinadas al ensayo de turbogrupos presentes en la bibliografia se ha intentado aprovechar las mejores características de cada una, para llegar construir una instalación completa, versátil y fiable.

En comparación con el resto de instalaciones presentes en la bibliografia hay que destacar que es la única en la que se pueden reproducir las condiciones de funcionamiento en las que trabajan las turbinas cuando se encuentran acopladas a motores. Por una parte, al utilizar gas de escape para mover la turbina se mantienen las características termodinámicas del gas. De este modo, al realizar ensayos bajo condiciones de flujo estacionario y bajo condiciones de flujo no estacionario, las propiedades termodinámicas del gas de ensayo se mantienen constantes.

Por otro lado, el utilizar un motor de combustión interna alternativo como generador de pulsos hace que la forma de éstos reproduzca la forma de los que se encuentra una turbina al trabajar acoplada a un motor, cosa que no es posible obtener mediante el uso de válvulas rotativas.

El mayor inconveniente que presenta la instalación es la posibilidad de la existencia de fugas, por lo que se hace necesario revisar la instalación antes de cada ensayo, para garantizar que las medidas realizadas son correctas.

Así pues se ha diseñado y montado una instalación experimental para caracterizar turbogrupos. Se ha comprobado que funciona correctamente y cumple los requisitos necesarios para utilizarla para realizar los ensayos. Como se habia propuesto desde el inicio, se ha construido una instalación versátil, que permite ensayar turbogrupos de muy diferentes dimensiones cambiando su configuración de una forma rápida y sencilla, siendo posible caracterizar desde turbogrupos de pequeños motores de automoción hasta grandes turbogrupos destinados a sobrealimentar grandes motores de transporte pesado.

Las diferentes configuraciones del banco permiten ensayar turbinas bajo diferentes condiciones de flujo. Ha de recordarse que interponiendo un depósito entre el colector de escape y la entrada a la turbina es posible realizar ensayos de turbina bajo condiciones de flujo estacionario y retirando este depósito es posible realizar ensayos bajo condiciones de flujo no estacionario, siendo posible además variar el nivel de pulsación.

Cabe destacar el circuito cerrado de aire del compresor del turbogrupo, cuyo fin es variar la densidad del aire que trasiega éste y ampliar el rango de ensayo de la turbina. Si la presión a la entrada del compresor 
aumenta, el gasto de aire que trasiega el compresor aumenta, aumentando también el trabajo realizado por él para mantener la relación de compresión, de modo que el régimen de giro del turbogrupo disminuye, siendo posible de esta forma aumentar el caudal de gases de escape que trasiega la turbina para recuperar el régimen de giro del turbogrupo y de este modo aumentar la relación de expansión. $\mathrm{Si}$, por el contrario, se disminuye la presión a la entrada del compresor, el gasto de aire que éste trasiega disminuye, disminuyendo también el trabajo realizado por el compresor para mantener la relación de compresión, de modo que el régimen de giro del turbogrupo aumenta. Entonces, para recuperar el régimen de giro inicial es posible disminuir el caudal de gases que trasiega la turbina, de modo que se disminuye también la relación de expansión.

Con este circuito se ha conseguido un sistema para aumentar el rango de ensayo de la turbina cuando se encuentra acoplada a un compresor, que consiste en aumentar o disminuir la cantidad de aire que éste trasiega aumentando o disminuyendo su densidad.

Simultáneamente a la construcción de la instalación se ha desarrollado un software de control y adquisición de datos que permite controlar la instalación de una forma rápida y sencilla. Este conjunto de programas informáticos, denominado Samaruc, ha sido enteramente elaborado por técnicos del Departamento de Máquinas y Motores Térmicos. Aunque todavía no permite una automatización completa de la sala, si que es muy importante el desarrollo de los PID que se utilizan para la realización de los ensayos, ya que se controlan las variables importantes para los ensayos, de forma rápida y precisa. Además este tipo de regulación permite seleccionar con exactitud los puntos que se pretende ensayar, consiguiendo, no sólo la obtención del mapa con los puntos que se consideran de interés, sino también la repetitividad de los ensayos.

Cabe destacar que la instrumentación de la sala es adecuada para las necesidades de la instalación, puesto que se dispone de todas las medidas necesarias para el control de la instalación, la obtención de los mapas característicos de los turbogrupos y el control de los ensayos. Éstas han demostrado ser precisas y fiables a lo largo de numerosos ensayos.

\subsubsection{Conclusiones acerca del ensayo de un turbogrupo}

A lo largo del documento se ha analizado la forma de realizar los ensayos de un turbocompresor.

Se han revisado las variables operativas del turbogrupo, esto es, aquellas variables de la instalación que al variar van a hacer que varie a su vez el punto de funcionamiento de la turbina o el compresor que se esté ensayando. Además se ha realizado una revisión en la que se relacionan las variaciones de las variables operativas de la instalación con las variables 
Contribución a la caracterización experimental y modelado de TGV en grupos de sobrealimentación

operativas del turbogrupo, de forma que se ha obtenido una relación entre cada una de ellas y el punto de funcionamiento de la turbina y el compresor.

También se ha desarrollado una metodología para alcanzar un determinado punto de funcionamiento, esto es, el proceso para llegar al punto de medida deseado. Para ello se han distinguido dos casos, las medidas de los puntos de funcionamiento del compresor y las medidas de los puntos de funcionamiento de la turbina.

- Evaluación de las medidas experimentales obtenidas en la instalación

Una vez alcanzado el punto de operación deseado, se ha revisado la metodologia para realizar la medida, analizándose la normativa existente sobre la realización de medidas para la caracterización de turbogrupos. Se han descrito tanto la situación de los captadores de medida de gasto másico de aire, de presión y temperatura como la instrumentación utilizada para la realización de dichas medidas.

También se ha realizado una revisión del tratamiento que se aplica sobre las medidas para poder obtener los mapas de funcionamiento del turbogrupo, la normalización de las medidas a partir de la normativa existente, la obtención de la variables termodinámicas de funcionamiento del turbogrupo, así como un método para discriminar los puntos de bombeo del compresor frente a los puntos de funcionamiento estable.

Se ha realizado una revisión sobre la incertidumbre en las medidas realizadas $\mathrm{y}$ en los resultados obtenidos, obteniéndose que la instrumentación utilizada es la adecuada para una instalación de estas características.

Las mayores incertidumbres se obtienen, como se ha visto en el capítulo 3, para los rendimientos del compresor y la turbina a los regímenes de giro mínimos, resultado muy razonable porque son los resultados que mayor número de medidas experimentales requieren y a bajo régimen es cuando se presentan menores relaciones de compresión y expansión, y por lo tanto menores saltos entálpicos, de modo que los errores relativos son más grandes.

\section{- $\quad$ Mapas del compresor y la turbina}

A lo largo del documento, se ha descrito un procedimiento de ensayo tanto para la caracterización del comportamiento del compresor como para la caracterización de la turbina. En el procedimiento de ensayo establecido para el compresor se ha determinado la forma de obtener el punto de bombeo, de gasto minimo, y el de choque para cada régimen de giro. 
Siguiendo este procedimiento es posible obtener el mapa de funcionamiento de cualquier compresor centrífugo que forme parte de un turbogrupo destinado a la sobrealimentación de pequeños motores diesel de automoción o grandes motores utilizados en los vehículos de transporte pesado.

En los mapas de compresor que se muestran puede observarse como las curvas de régimen constante son de la forma esperada para un compresor centrífugo. Los rendimientos calculados para los diferentes puntos son, como debe suceder en un compresor centrífugo, máximos en la zona central del mapa, disminuyendo para gastos próximos a bombeo o a choque.

En cuanto a la turbina, se muestra como ejemplo el mapa obtenido para una turbina de geometría variable, obtenido para diferentes aperturas de los álabes del estator. En los mapas se comprueba que el flujo evoluciona en la turbina, en lo que se refiere a relación de expansión y gasto másico, según la forma propia de la ecuación de la tobera. La curva gasto másico-relación de expansión, que presenta la misma forma para todas las aperturas, queda desplazada hacia menores relaciones de expansión y mayores gastos másicos a medida que aumenta la apertura de los álabes del estator. La variación del gasto con la relación de expansión es más significativa para regímenes de giro bajos. En cambio la variación de la apertura de la turbina tiene una gran influencia sobre la cantidad de gasto trasegado. El aumento de la relación de expansión influye muy significativamente, en todas las aperturas del estator, sobre el régimen de giro alcanzado.

Se comprueba que para todos los regimenes los rendimientos obtenidos con el estator de la turbina totalmente abierto son menores que con cualquier otro grado de apertura. Los rendimientos obtenidos para la turbina cerrada son los siguientes más bajos, aunque el nivel es más próximo al de las curvas correspondientes al resto de aperturas que al de las de apertura total. Las aperturas intermedias presentan rendimientos similares entre sí, siendo los mayores rendimientos alcanzados los máximos de las curvas de apertura del $40 \%$.

\subsubsection{Comportamiento del compresor en bombeo}

Para la detección del bombeo se ha desarrollado una metodología basada en el análisis en frecuencia de las señales del compresor medidas instantáneamente. Para ello se han analizado diferentes variables y se ha llegado a la conclusión de que la presión a la salida del compresor es la más útil a la hora de realizar el análisis para discriminar si un punto de funcionamiento del compresor es un punto de funcionamiento estable o si se encuentra en la zona de bombeo.

Cuando el compresor entra en la zona de bombeo, el espectro de la señal de la medida de la presión instantánea muestra picos de amplitud en la 
zona de bajas frecuencias, que no aparecen cuando el compresor trabaja en la zona de funcionamiento estable. El pico de máxima amplitud, que indica la existencia del fenómeno de bombeo, se encuentra en frecuencias que van desde los 5 a los $15 \mathrm{~Hz}$, dependiendo del tamaño del compresor, de la instalación y de las condiciones de funcionamiento.

Se ha comprobado en la instalación que la frecuencia a la que aparece el bombeo varia con el volumen que hay aguas abajo del compresor. Si este volumen se reduce, la frecuencia a la que aparece el bombeo aumenta.

Es posible concluir que el bombeo se manifiesta en unas oscilaciones de gran amplitud y baja frecuencia en las variables instantáneas medidas en el compresor. Por tanto, es posible detectar el bombeo realizando la transformada de Fourier de una de las variables instantáneas medidas y representando su espectro a bajas frecuencias durante los ensayos o en el tratamiento a posteriori de las medidas. Los puntos en los que dicho espectro presente un pico de una amplitud a una frecuencia baja serán considerados puntos de bombeo. 


\subsection{Nuevo modelo unidimensional para turbinas de geometria variable}

Otra de las aportaciones del presente trabajo ha sido el desarrollo de un nuevo modelo unidimensional para turbinas de geometría variable. Este modelo, esta basado en un modelo anterior para turbinas de geometría fija que sustituye la turbina por dos toberas ideales, que reproducen las caídas de presión que se producen en el estator y en el rotor, que descargan a un volumen intermedio, que reproduce la acumulación de masa en el sistema.

El modelo presentado sigue la siguiente estructura, en primer lugar se calcula el grado de reacción de la turbina en las condiciones de funcionamiento deseadas.

Se ha propuesto una metodología para el cálculo del grado de reacción de turbinas de geometría variable, a partir de parámetros geométricos y de las condiciones de los gases a la salida de la turbina o a partir de las variables corregidas de los mapas proporcionados por el fabricante

Una vez obtenido el grado de reacción, y teniendo en cuenta el tipo, la posición de los álabes del estator de la TGV que se esté modelando y las condiciones de trabajo, es posible calcular el salto de presiones que se produce en el estator y el salto de presiones que se produce en el rotor. Una vez conocidos estos saltos de presión es posible calcular las áreas efectivas de las toberas equivalentes que representan al estator y al rotor de la turbina.

Para la validación de este modelo de turbina de geometría variable, ha sido introducido en un modelo más amplio de motor (WAM), este es un modelo de acción de ondas unidimensional, no homoentrópico y no estacionario, en el que se ha incluido el modelo para turbinas de geometría variable propuesto a lo largo del presente trabajo.

Este modelo completo se ha validado en el banco de ensayo realizando para ello el modelado de todos los puntos que forman una línea de isorégimen de un mapa de compresor, trabajando la TGV del turbogrupo bajo condiciones de flujo continuo. A la vista de los resultados obtenidos, que se muestran en el capítulo 5, es posible concluir que el modelo utilizado se ajusta perfectamente a las medidas realizadas en la instalación.

En la segunda parte de la validación del modelo en el banco de ensayo se utiliza el modelo para estudiar el comportamiento de otra TGV bajo condiciones de flujo no estacionario, ajustándose los valores medios de las variables medidas en la instalación y los valores instantáneos de la presión a la entrada de la turbina. 


\subsubsection{Modelado de la instalación}

Con la ayuda del modelo completo WAM ha sido posible modelar la instalación desarrollada para caracterizar turbogrupos. La utilidad del modelado radica en la posibilidad de obtener valores de variables dificiles o imposibles de medir, como las temperaturas instantáneas. La temperatura de entrada a la turbina interesa para estimar las pérdidas de calor y el rendimiento de la turbina. Su evolución instantánea presenta importantes oscilaciones respecto al valor medio, especialmente en caso de ensayos con flujo no estacionario, que no pueden ser medidas. Sin embargo, modelando el ensayo en el modelo de acción de ondas se puede estimar esta evolución satisfactoriamente si el ajuste de las variables medidas de las que se dispone es correcto, tanto en valores medios como instantáneos.

En los modelados realizados se ha comprobado que el modelo es capaz de reproducir correctamente los ensayos realizados. Las variables modeladas, medias e instantáneas, se ajustan con precisión a las medidas. Por tanto, se puede concluir que las temperaturas instantáneas modeladas y los rendimientos modelados son correctos.

En conclusión, el modelo reproduce bien los ensayos del banco de turbos y los resultados obtenidos en él son útiles para el análisis del turbogrupo, especialmente de la turbina, completando la información obtenida en los ensayos en el banco.

Además, la validación del modelo permite concluir que es útil para la preparación de ensayos, modelando previamente los cambios que se vayan a efectuar en los mismos para predecir las tendencias y orden de magnitud de las modificaciones obtenidas.

Es posible concluir que combinando una instalación experimental y un modelo unidimensional de turbinas de geometria variable ha sido posible obtener el rendimiento de una TGV trabajando bajo condiciones de flujo no estacionario, mostrando así el potencial que tienen las dos herramientas al combinarlas. 


\subsubsection{Validación del modelo en ensayos de motor}

Para finalizar la validación se muestra como el modelo completo de motor, con el submodelo de turbina de geometría variable, tanto en el caso de turbinas de álabes fijos, como en el caso de turbinas de álabes móviles, es capaz de reproducir con gran precisión el comportamiento global del motor y el de la turbina.

En el caso de la turbina de geometría variable de álabes fijos acoplada a motor se realizó el modelado completo del conjunto para puntos estacionarios de motor. A partir de este estudio se obtuvo que el grado de reacción de una TGV de álabes fijos tiene un elevado nivel de correlación con el gasto trasegado por la turbina y la apertura de la misma.

Una vez conocido el grado de reacción de la turbina en unas determinadas condiciones de funcionamiento es posible calcular las áreas efectivas de las toberas equivalentes al estator y al rotor de la turbina. Obteniéndose que en el caso de esta turbina el área efectiva del estator se correlaciona con la posición de la turbina y la del rotor con el gasto másico y el régimen de giro de la turbina corregidos los dos con las condiciones de parada del gas a la entrada del rotor.

Se evidencia que el área efectiva de la tobera equivalente al rotor, para un régimen de giro determinado, aumenta al aumentar el caudal de gases trasegados. Sin embargo, para un gasto determinado, el área efectiva de la tobera equivalente al rotor disminuye al aumentar el régimen de giro, puesto que aumentan las fuerzas centrifugas que se producen al girar el rodete y se dificulta el paso de los gases de escape.

Al comparar las medidas y los valores obtenidos con el modelo de acción de ondas se obtiene un elevado grado de acuerdo, obteniéndose errores máximos en la presión a la entrada de la turbina de alrededor del $5 \%$.

En el caso de la TGV de álabes móviles acoplada a motor se realizó el modelado completo del conjunto para transitorios de carga de motor. A partir de este estudio se obtuvo que también es posible correlacionar el área efectiva de la tobera equivalente al estator de la turbina en función de la posición de la turbina. Por otro lado, igual que en el caso anterior, es posible obtener una buena correlación para el la del rotor con el gasto másico y el régimen de giro de la turbina corregidos los dos con las condiciones del gas a la entrada del rotor. Se obtuvieron las mismas tendencias comentadas para la TGV de álabes fijos, esto es aumenta el área efectiva de la tobera equivalente al rotor al aumentar el caudal de gases trasegados, para un régimen de giro dado, y disminuye al aumentar el régimen de giro, para un gasto determinado, 
Contribución a la caracterización experimental y modelado de TGV en grupos de sobrealimentación

Con estas dos correlaciones y conociendo la dinámica que gobierna la posición de la turbina es posible modelarla, de modo que es posible reproducir los transitorios de carga de un motor diesel turboalimentado. 


\subsection{Trabajos futuros}

Las principales herramientas obtenidas a lo largo de este proceso de investigación abren un amplio abanico de posibilidades a la hora de desarrollar trabajos futuros, dirigidos en dos direcciones fundamentales que son la mejora y explotación de la instalación experimental, construida como una herramienta fundamental para la obtención de medidas experimentales, y la mejora de modelo de turbina de geometria variable presentado, de tal forma que tenga en cuenta las dimensiones de la turbina.

- Explotación de la instalación

Sobre el control de la instalación, se está analizando la posibilidad de automatizarla en mayor medida, aprovechando toda la metodología desarrollada para la realización de los ensayos de turbinas y compresores que se muestra a largo del capítulo 3, de manera que un regulador establezca las líneas de régimen que se van ensayando, determinando los valores de consigna de régimen y gasto o relación de compresión/expansión en los PID de los que actualmente se dispone.

Se pretende llegar a diseñar un regulador que detecte que las condiciones de bombeo han sido alcanzadas y determine el comienzo del ensayo de la siguiente línea de régimen en el caso de ensayos para un compresor o el comienzo de una determinada línea de régimen en el caso de los ensayos de turbinas.

Para diseñar un regulador que sea capaz de discriminar los puntos de funcionamiento estable del compresor de los puntos de funcionamiento en la zona de bombeo cabe destacar la conveniencia de la ampliación del estudio de estos últimos con datos de un mayor número de compresores, destinado a establecer criterios de identificación aplicables a cualquier compresor.

En este sentido queda abierto el campo para trabajos futuros sobre el comportamiento en bombeo de los turbocompresores. Puesto que el paso de condiciones de funcionamiento estables a condiciones de bombeo es brusco la detección del repentino aumento de la amplitud a una determinada frecuencia del espectro no presenta dificultad. Sin embargo, queda por comprobar si diferentes compresores llevan asociadas frecuencias características de bombeo muy diferentes o si esta frecuencia se mantiene en el mismo rango en cualquier compresor ensayado, aunque ya se observa en los espectros de los compresores estudiados hasta el momento una dependencia de esta frecuencia respecto del régimen de giro del turbogrupo, la variación entre la correspondiente al régimen máximo y la de régimen mínimo (entre 5 y $15 \mathrm{~Hz}$ ) es tan pequeña que no implica ningún inconveniente en la búsqueda del pico propio del bombeo en el espectro durante los ensayos. 
Obtenida la relación entra la frecuencia de bombeo, el volumen encerrado aguas abajo del compresor y el régimen de giro del turbogrupo, sería interesante también desarrollar un filtro, fácilmente programable en las ECU, para la detección del bombeo del compresor en vehículos. De este modo, en el caso de que el compresor de un vehículo entre en la zona de bombeo, la ECU podría tener programadas las consiguientes acciones de control necesarias para volver a la zona de funcionamiento estable.

Por otro lado, se está desarrollando la posibilidad de mejorar el sistema de colectores de escape y de admisión, para poder cambiar la configuración de éstos cuando se requiera más rápidamente, mediante la implementación de un sistema con válvulas, de esta forma se evitaría el desmontaje y posterior montaje del escape, actuando sobre las válvulas, con el consecuente ahorro en tiempo, materiales y mano de obra en el cambio de unas configuraciones a otras.

También se está estudiando la posibilidad de montar un sistema de lubricación independiente para el turbogrupo, de modo que sea posible estudiar las pérdidas de aceite que puedan producirse en éste por diversas causas y realizar el balance energético del turbogrupo.

A lo largo del documento se ha comentado varias veces la dificultad que se tiene para realizar correctamente las medidas de la temperatura de los gases de escape. Es por ello que se está estudiando la forma de mejorar estas medidas con las herramientas de que se dispone, para lo cual se están planteando estudios que permitan determinar las posibles diferencias existentes entre la temperatura de los gases y la medida obtenida con los termopares. Estos estudios plantean la utilización de un modelo de transmisión de calor aplicado a un tubo que trasiegue diferentes caudales de gas de escape, en el que se realicen medidas de la temperatura de gas en diferentes puntos, con termopares situados tanto en el sentido del flujo como perpendicular a él, con diferentes grados de inmersión.

Se está estudiando también la posibilidad de realizar medidas de la velocidad del flujo a lo largo del caracol, a la entrada y a la salida del rotor de la turbina. Esto podría realizarse si se utilizara la instalación con cilindros trabajando en arrastre, dopando el aire y haciendo accesos ópticos en la turbina, para poder realizar medidas con láser.

- Mejora del modelo de turbina de geometría variable

Se está evaluando la opción de realizar un modelo unidimensional, que no sólo tenga en cuenta la longitud de la voluta de la turbina sino que en lugar de utilizar una tobera equivalente para el estator utilice tantas como álabes hay en el estator. 
La finalidad de tener en cuenta cada una de las toberas formadas por los álabes del estator es poder calcular la velocidad de salida del gas de escape de los mismos.

De este modo, conocida la geometría de los álabes y su posición, así como la velocidad del gas de escape a salida del estator y por otro lado conociendo la velocidad de giro del turbogrupo será posible calcular la velocidad relativa de los gases en el estator, completando así los triángulos de velocidades de la turbina. Conocidos éstos se podrá modelar de una forma más fisica la tobera del rotor.

- Aplicaciones del modelado tridimensional

Debido a los avances computacionales de los últimos tiempos, ya es posible realizar un modelado tridimensional de una TGV, en el que se reproduzca la geometría de la voluta, del estator y el rotor de la turbina.

Debido a la dificultad experimental que presenta la medida de las condiciones existentes en el volumen intermedio entre el estator y el rotor de la turbina y con el objetivo de conocer en cierta medida como se comportan los gases de escape al atravesar los álabes del estator de la turbina, se está comenzando a realizar cálculos 3D mediante la utilización de programas comerciales para poder validar las hipótesis realizadas en el capitulo anterior.

Elegidas unas determinadas condiciones de funcionamiento de la TGV se pretende realizar simulaciones 3D para obtener la presión intermedia entre el estator y el rotor de la turbina, valor que resulta imposible medir, y comprarlo con el valor obtenido a partir del modelo unidimensional expuesto en el capítulo 4.

- Profundización en los efectos del flujo pulsante sobre las prestaciones de la turbomáquina.

A la vista de los resultados obtenidos al combinar las medidas obtenidas con la instalación experimental y el modelo unidimensional de TGV descritos en el documento, es posible profundizar en el estudio de los efectos del flujo pulsante sobre el rendimiento de las TGV bajo diferentes condiciones de funcionamiento. 